Departamento de Ingeniería Química Industrial y Medio Ambiente,

\title{
ANÁLISIS DE SOSTENIBILIDAD DEL CICLO DE VIDA DE UNA CONFIGURACIÓN INNOVADORA DE TECNOLOGÍA TERMOSOLAR
}

Tesis Doctoral

\author{
Autora: \\ Blanca Corona Bellostas \\ Ingeniera Técnica en Diseño Industrial \\ Máster en Ingeniería Ambiental
}

Director de tesis:

Guillermo San Miguel Alfaro

Doctor en Ingeniería Civil y Ambiental 

A la memoria de mi padre, 

"Detrás,

más atrás de los siglos y las máscaras,

detrás de los espejos, más atrás

aún,

¿oís?

No mata el tiempo.

Nos crea."

Gonzalo Corona 



\section{Agradecimientos}

La realización de esta tesis doctoral no habría sido posible sin el apoyo, asesoramiento y ayuda de muchas personas con las que he tenido el placer de trabajar y convivir durante estos cuatro años.

En el ámbito académico, me gustaría agradecer en primer lugar a mi director de tesis Guillermo San Miguel. Gracias por brindarme la oportunidad de realizar esta tesis, por darme la libertad de profundizar en las líneas de investigación que más me interesaban y a la vez respaldarme y asesorarme. Por criticar y elogiar cuando era preciso, y por empujarme a publicar cada artículo de investigación.

A mis compañeros del grupo de investigación (Paco, Maripaz, Diego, Alberto, Estela y el grupo de Jesús Fernández) quiero agradecer su paciencia, ánimos y sugerencias al escuchar todas las dudas que he estado expresando en voz alta durante este periodo; especialmente gracias a Diego Ruiz por compartir conmigo su sabiduría y experiencia en ACV. También me gustaría agradecer a Eduardo Cerrajero, por su disponibilidad y amabilidad para responder todas mis preguntas sobre HYSOL y la tecnología termosolar. Sus conocimientos y punto de vista se han tenido muy en cuenta en los aspectos más técnicos de esta tesis.

Quiero agradecer a Yolanda Lechón y a todo el grupo de la unidad de Análisis de Sistemas Energéticos del CIEMAT por acogerme durante unos meses y tratarme como a una más del equipo. Especialmente gracias a Cristina de la Rúa por enseñarme y guiarme en el mundo del análisis Input Output; realizar esta estancia y aprender de ella ha sido una de las experiencias más valiosas de mi doctorado.

I wish to thank Stig Irving Olsen for giving me the opportunity to visit the wonderful Quantitative Sustainability Assessment Unit of the Technical University of Denmark, and Kossara Bozhilova-Kisheva for her advice on the consecution and development of Social-LCA, as well as her kindness during my stay in Copenhagen. I also want to thank Devinder Mahajan and his group for his attention and gentleness during my stay in the Advanced Energy Research and Technology Center of the Stony Brook University (Nueva York).

Gracias también a mi familia activista de Ingeniería Sin Fronteras, por enriquecer mi perspectiva de la vida y de la sostenibilidad con interminables debates sobre las repercusiones sociales y medioambientales de las actividades humanas. 
En el ámbito personal, quiero agradecer a las amigas y amigos que forman parte de mi vida desde hace años por todas las veces que me han acompañado en las aventuras y desventuras, y también por las veces que me han escuchado y ayudado a levantarme aunque fuera en la distancia. Gracias también a las personas que he conocido durante estos años en Madrid, porque con sus ánimos, conversaciones y buenos ratos han conseguido que esta ciudad sea un lugar acogedor donde vivir. Gracias a Alberto por acompañarme con su cariño y apoyo durante la mayor parte de esta etapa.

Por último, gracias a mi familia por constituir una parte muy importante de mi vida. Gracias a mi hermana por cuidar de mí y por mostrarme el camino a seguir. Gracias a Pep por su afecto y sus consejos sobre la vida y la investigación. Gracias a mi madre por creer en mí, por escuchar sin juzgar, por estar siempre disponible, por enseñarme a esforzarme y a tener esperanza... gracias en definitiva por ser mi mayor apoyo. 


\section{Resumen}

Contar con herramientas para cuantificar la sostenibilidad de productos y servicios es fundamental para que la actividad humana se desarrolle de forma beneficiosa para la sociedad y el medioambiente. Por ello, el Análisis de Sostenibilidad del Ciclo de Vida (ASCV) está actualmente desarrollándose como una herramienta holística que permite evaluar de forma conjunta los impactos ambientales, económicos y sociales de un producto o servicio a lo largo de su ciclo de vida completo.

La producción de electricidad es una de las actividades humanas con mayor repercusión en el desarrollo sostenible, y su consumo resulta vital para satisfacer gran parte de nuestras necesidades humanas. La inestabilidad actual en el suministro de combustibles fósiles, junto con la demanda creciente de electricidad y el avance del cambio climático antropogénico, refuerzan la necesidad y preocupación humana por abastecerse urgentemente de fuentes de energía limpias y asequibles. En este contexto nace HYSOL (Innovative Configuration of a Fully Renewable Hybrid CSP Plant, no 308912), un proyecto europeo del séptimo programa marco encaminado a desarrollar una tecnología híbrida de producción de electricidad mediante energía solar térmica y combustibles gaseosos biomásicos.

Esta tesis doctoral se realiza en el marco del proyecto HYSOL, cuantificando su impacto ambiental mediante la metodología de Análisis de Ciclo de Vida, y expandiendo esta cuantificación a las áreas de economía y sociedad con el objetivo de obtener un análisis de sostenibilidad completo.

Para la consecución del ASCV llevado a cabo en esta tesis se han realizado las siguientes actividades:

- Se ha estudiado el estado del arte actual de la metodología de ASCV para recopilar las recomendaciones y lecciones aprendidas hasta la fecha por la comunidad científica. Dichas lecciones se han integrado en el marco metodológico propuesto en esta tesis para la evaluación de la sostenibilidad de la tecnología HYSOL.

- En la evaluación del área ambiental, se ha realizado un Análisis de Ciclo de Vida para determinar y comparar el impacto ambiental potencial de la tecnología HYSOL en sus dos escenarios principales (HYSOL BIO para la operación con biometano y HYSOL GN para la operación con gas natural). Los resultados también se han comparado con el impacto ambiental de la tecnología termosolar convencional en España. Además se ha 
aplicado el enfoque consecuencial para determinar las consecuencias ambientales de introducir electricidad de la planta HYSOL en el mercado eléctrico español.

- Para evaluar el área económica se ha realizado un análisis de Costes de Ciclo de Vida considerando costes internos y externos de los escenarios HYSOL BIO y HYSOL GN así como de la termosolar convencional. Además, se ha realizado un análisis Input Output Multi-regional para estimar los efectos socio-económicos de los escenarios HYSOL BIO, HYSOL GN, y termosolar convencional. También se ha profundizado en el desarrollo del análisis Input Output para estimar el efecto neto de incluir la tecnología HYSOL en el mercado eléctrico español.

- Para evaluar el área social, se ha avanzado en el desarrollo de la metodología de Análisis de Ciclo de Vida Social proponiendo un nuevo método de caracterización para evaluar el comportamiento social del ciclo de vida de la tecnología HYSOL en España. También se ha llevado a cabo un análisis de riesgos sociales del ciclo de vida de la tecnología HYSOL y termosolar convencional utilizando la Social Hotspots Database.

- Por último, se han integrado los resultados obtenidos mediante el análisis de las tres áreas de la sostenibilidad (medioambiente, economía y sociedad) en un sistema de preguntas y respuestas que representan la sostenibilidad del sistema analizado. Además, se han confeccionado unos diagramas visuales que facilitan la interpretación de los resultados y la toma de decisiones.

Los resultados han revelado que la aplicación del ASCV a una tecnología innovadora como HYSOL puede proporcionar una base cuantitativa, científica, apta y eficaz para la toma de decisiones sostenible respecto al desarrollo de la tecnología y del sector de la electricidad.

El análisis indica que la tecnología HYSOL presenta diferencias significativas de sostenibilidad cuando se utiliza biometano o gas natural como combustible de hibridación. La operación con biometano presenta mejor sostenibilidad ambiental y social que el gas natural, aunque la sostenibilidad económica del escenario con biometano es inferior que la del gas natural a nivel empresa y superior a nivel nacional.

La mejor eficiencia de conversión de energía térmica que presenta la tecnología HYSOL respecto a la tecnología cilindro-parabólica o torre convencionales producen una mejora ambiental, económica y social. Este resultado indica que la innovación tecnológica conseguida mediante el proyecto HYSOL está bien encaminada a mejorar la sostenibilidad de la tecnología termosolar y del sector eléctrico español. 


\begin{abstract}
The use of specific tools to quantify the sustainability of products and services is essential in order to develop human activities in a profitable way for the society and the environment. To this purpose, Life Cycle Sustainability Assessment (LCSA) is being developed as a holistic tool to evaluate environmental, economic and social impacts of one product or service throughout their full life cycle.

Electricity generation is one of the human activities with highest repercussion on sustainable development, while electricity consumption is vital to meet most of our necessities. The current instability of fossil fuels' supply, the increasing electricity demand and the advance of anthropogenic climate change, reinforce the human necessity for clean and affordable energy sources. In this context emerge HYSOL (Innovative Configuration of a Fully Renewable Hybrid CSP Plant, no 308912), an European project within the seventh framework program aiming at developing a hybrid electricity generation technology using solar thermal energy and biomass gaseous fuels.
\end{abstract}

This doctoral thesis is carried out in the framework of the HYSOL project, quantifying its environmental impact using Life Cycle Assessment (LCA) and expanding this quantification to the economic and social areas in order to obtain a full sustainability assessment.

The following activities have been carried out for the consecution of the HYSOL LCSA:

- The LCSA state of art was explored in order to compile the recommendations and lessons learned by the scientific community up to date. Such lessons were integrated into the methodological framework proposed in this thesis.

- In the environmental area, a LCA was performed in order to determine and compare the potential environmental impact of the HYSOL technology in two main scenarios (HYSOL BIO for the power plant operation with biomethane, and HYSOL GN for the operation with natural gas). The results were also compared with the environmental impact of the conventional solar thermal technology in Spain. The consequential life cycle approach was also applied in order to determine the environmental consequences of introducing HYSOL electricity into the Spanish electricity market.

- In the economic area, a Life Cycle Cost Analysis was performed in order to estimate the internal and external costs of the HYSOL BIO, HYSOL GN and conventional solar thermal power plants. A Multiregional Input Output Analysis was also performed 
to estimate the socio-economic effects of HYSOL BIO, HYSOL GN and conventional solar thermal technology. This analysis was extended to also considerate the net effects of introducing HYSOL technology in the Spanish electricity market.

- In the social area, a Social Life Cycle Assessment was applied, and a new characterization method was proposed in order to evaluate the social performance of the HYSOL technology life cycle in Spain. A social risk assessment of the HYSOL technology and conventional solar thermal technology was also performed using the Social Hotspots Database.

- The obtained results in the three areas (environment, economy and society) were integrated by a "questions and answers" layout, representing the sustainability of the analyzed system. Visual diagrams representing the sustainability of the analyzed scenarios were also provided in order to facilitate the interpretation of results and the decision making process.

The results revealed that the application of LCSA to an innovative technology such as HYSOL can provide a quantitative, scientific, suitable and effective base for a sustainable decision making process regarding the technology development and the electricity sector.

The analysis indicates that the HYSOL technology presents significant sustainability differences when the power plant uses biomethane or natural gas as hybridization fuel. The operation with biomethane presents better environmental and social sustainability than the operation with natural gas, although the biomethane economic sustainability is lower than the natural gas at a company level and higher at a national level.

The better thermal energy conversion efficiency achieved by the HYSOL technology with respect to the conventional solar thermal technology generates an environmental, economic and social improvement. These results indicate that the technologic innovation developed by the HYSOL project is well aimed to improve the sustainability of solar thermal energy and the Spanish electricity sector. 


\section{ÍNDICE GENERAL}

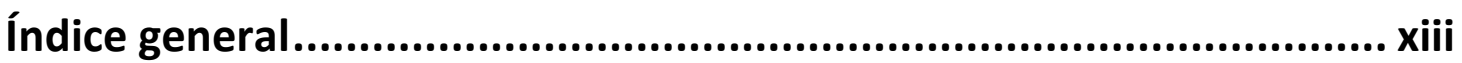

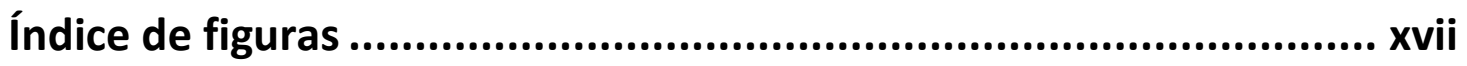

Índice de tablas ........................................................................ xxii

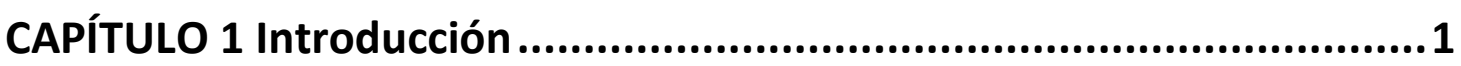

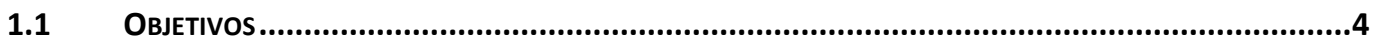

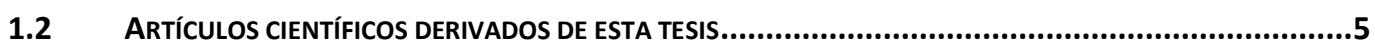

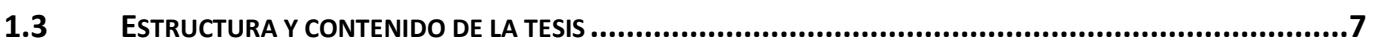

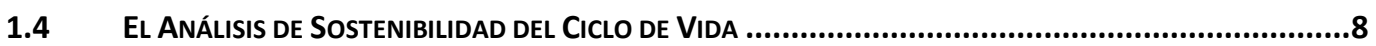

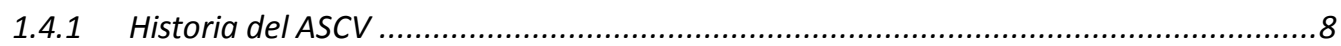

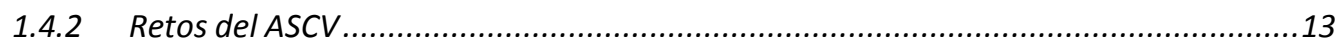

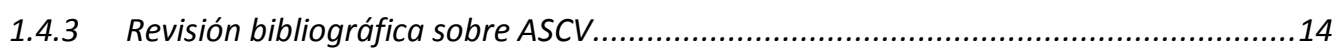

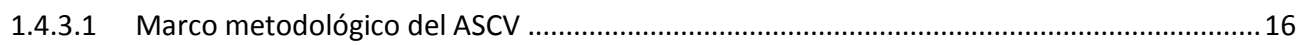

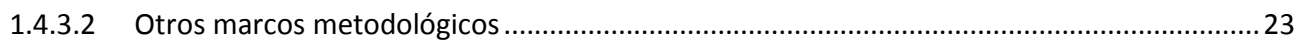

1.4.3.3 Metodologías para cada pilar de la sostenibilidad. .........................................................24

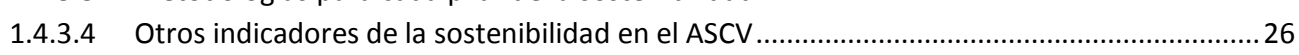

1.4.3.5 Agregación, ponderación e interpretación de resultados ...............................................27

1.4.3.6 Conclusiones de la revisión sobre ASCV ..........................................................................29

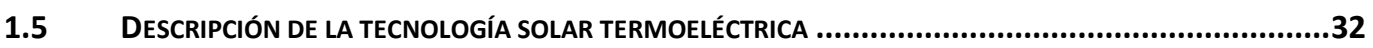

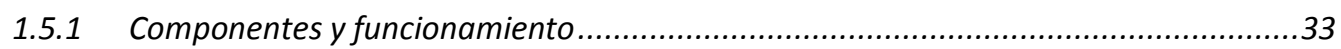

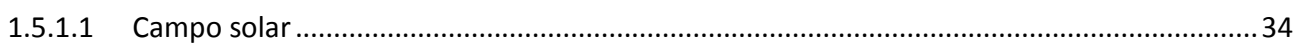

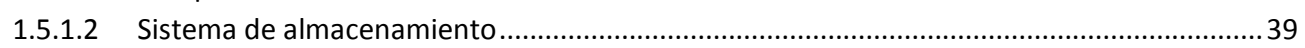

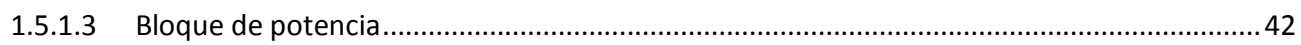

1.5.1.4 Otras instalaciones de una planta termosolar ...................................................................43

1.5.2 La hibridación en la tecnología termosolar..................................................45

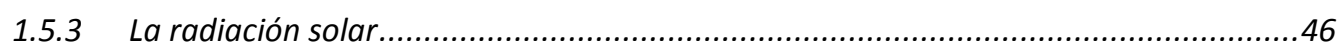

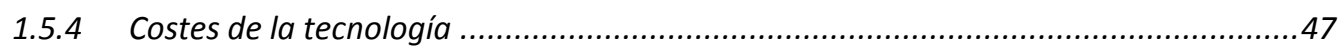

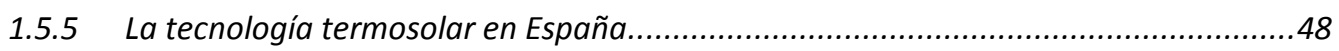

1.5.5.1 Las plantas termosolares y el mercado eléctrico español ....................................................51

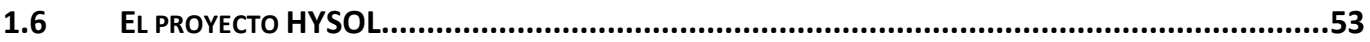

\section{CAPÍTULO 2 Metodología del Análisis de Sostenibilidad de Ciclo de Vida de la tecnología HYSOL .................................................................... 55}

2.1 DEFINICIÓN DE OBJETIVO Y ALCANCE..........................................................................57

2.1.1 Definición del sistema de estudio ..................................................................57

2.1.2 Enunciación de escenarios de análisis ...............................................................58

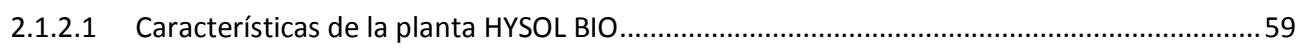

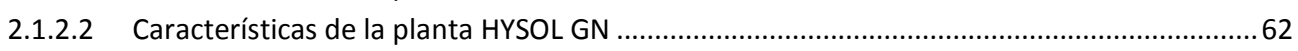

2.1.2.3 Características principales de la planta TERMOSOLAR CCP .....................................................62

2.1.3 Definición de sub-preguntas y herramientas de análisis ........................................64 
CAPÍTULO 3 Análisis del área ambiental ..........................................69

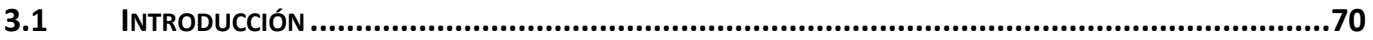

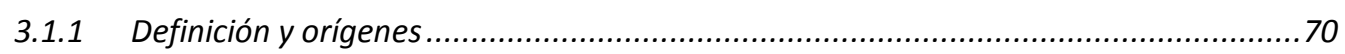

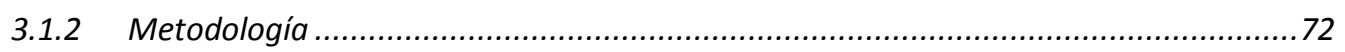

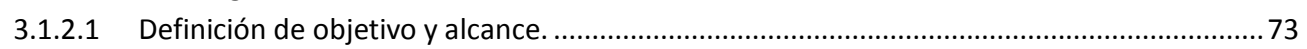

3.1.2.2 Análisis de Inventario de Ciclo de Vida (AICV) ........................................................................ 74

3.1.2.3 Evaluación del Impacto ambiental de Ciclo de Vida (EICV) .................................................77

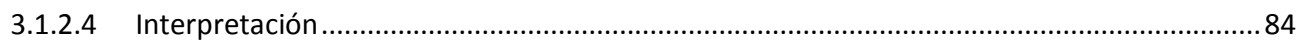

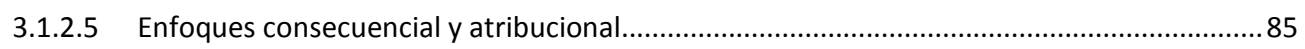

3.1.3 Revisión de estudios de ACV-A sobre centrales termosolares..................................86

3.2 ANÁlISIS DE CICLO DE VIDA AMBIENTAL DE LA TECNOLOGÍA HYSOL .............................................94

3.2.1 Definición del objetivo y del alcance .................................................................94

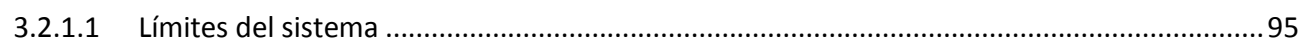

3.2.1.2 Metodología para la Evaluación del Impacto de Ciclo de Vida.............................................97

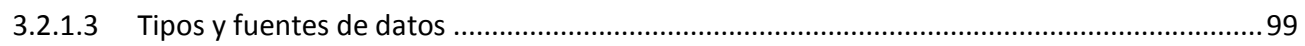

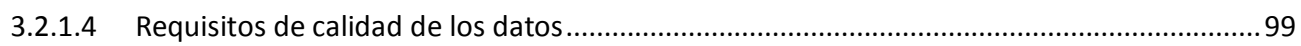

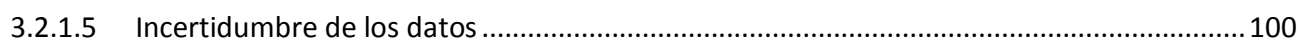

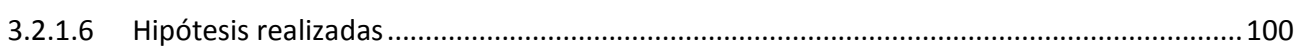

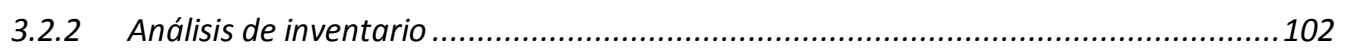

3.2.2.1 Fase de extracción de materias primas y fabricación de componentes ............................... 102

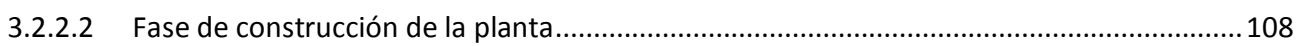

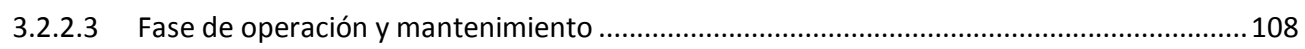

3.2.2.4 Fase de desmantelamiento y gestión de residuos ........................................................... 109

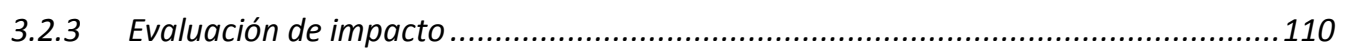

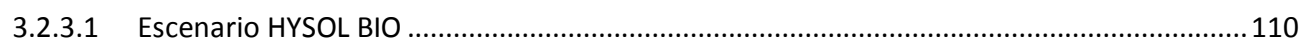

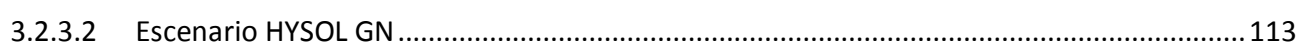

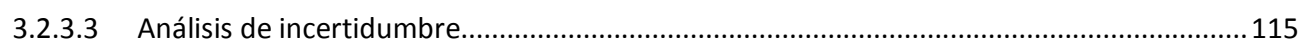

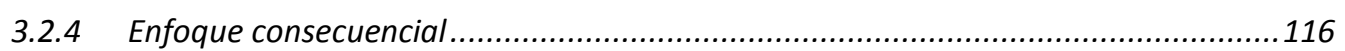

3.2.4.1 Elección de la tecnología marginal ................................................................................... 117

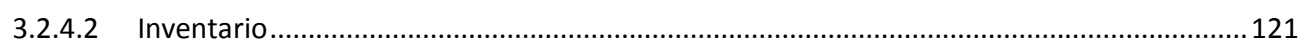

3.2.4.3 Evaluación de impacto ambiental consecuencial ............................................................. 121

3.2.5 Interpretación ......................................................................................... 126

3.3 ANÁLISIS DE CICLO DE VIDA AMBIENTAL DE DISTINTAS TECNOLOGÍAS TERMOSOLARES .......................130

3.3.1 ACV-A de la tecnología termosolar cilindro-parabólica ........................................130

3.3.1.1 Definición del objetivo y del alcance ................................................................................... 130

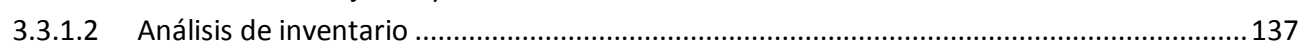

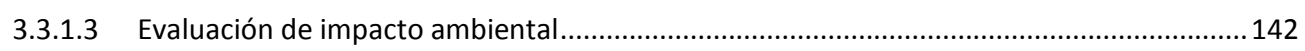

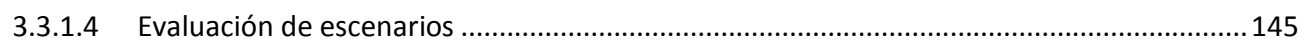

3.3.1.5 Análisis de sensibilidad del gas natural ...................................................................... 152

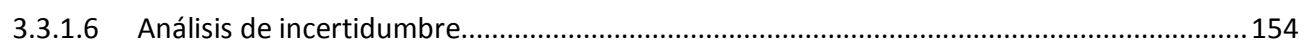

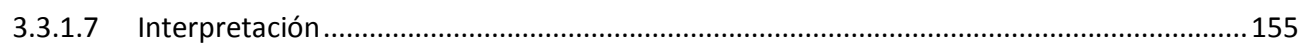

3.3.2 ACV-A de la tecnología termosolar de torre ..................................................... 158

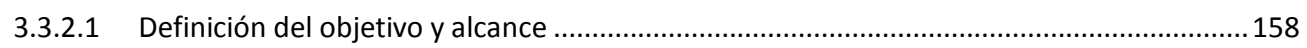

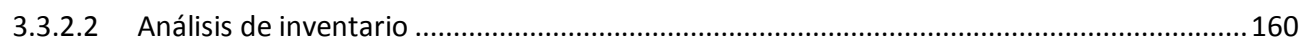

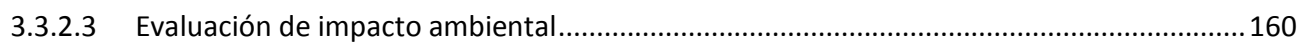

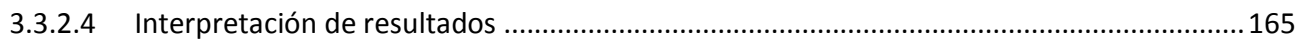

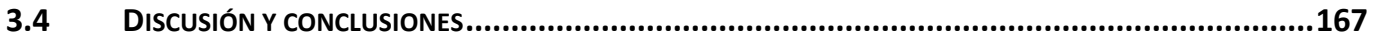




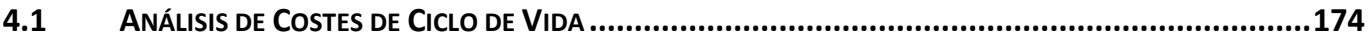

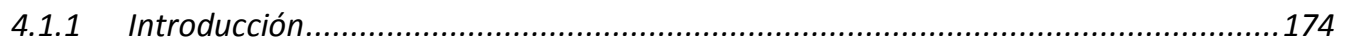

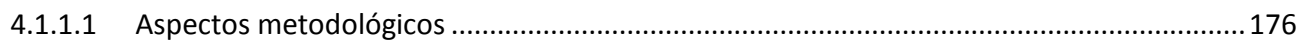

4.1.1.2 Cálculo monetario de externalidades................................................................................. 179

4.1.1.3 Revisión de estudios de Costes de Ciclo de Vida................................................................ 183

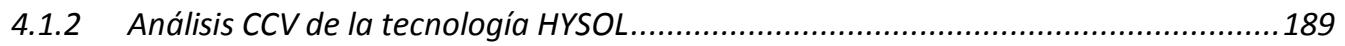

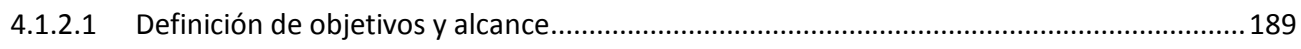

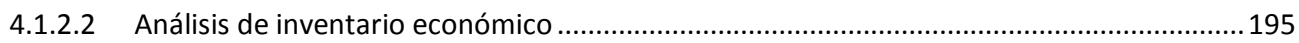

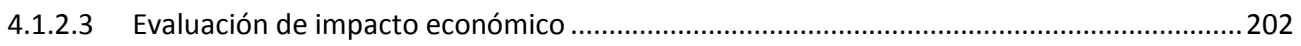

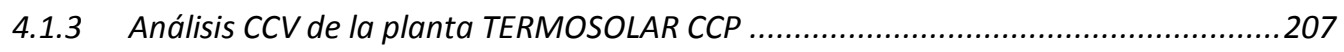

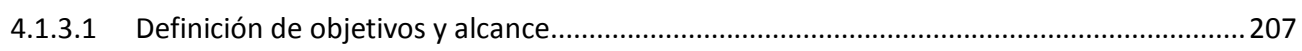

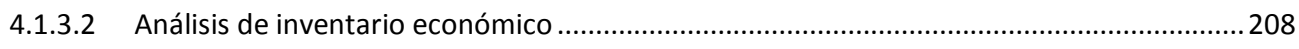

4.1.3.3 Evaluación de impacto económico ........................................................................................... 211

4.1.4 Interpretación y discusión de resultados...........................................................215

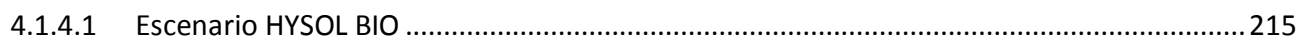

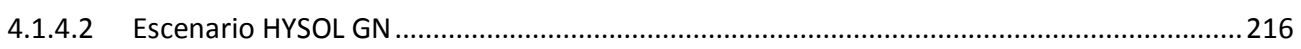

4.1.4.3 Comparación de escenarios HYSOL con TERMOSOLAR CCP .................................................2 216

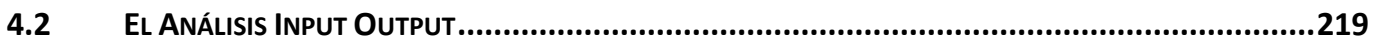

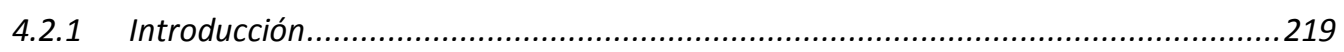

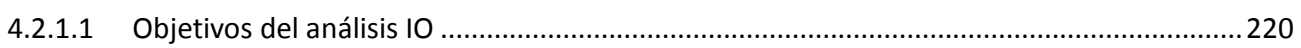

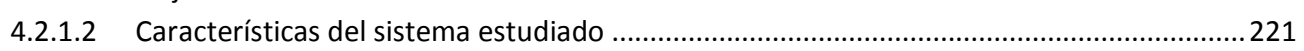

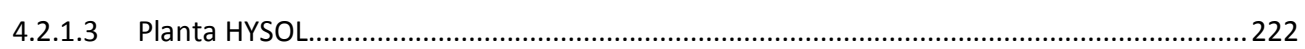

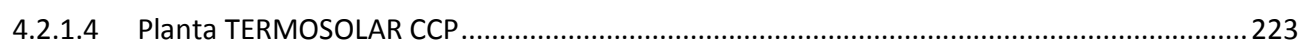

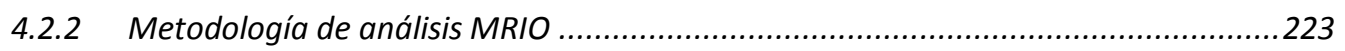

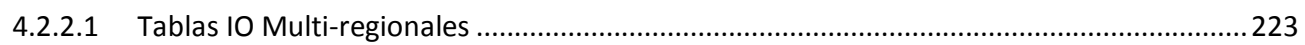

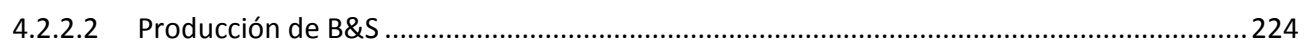

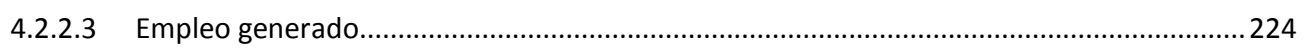

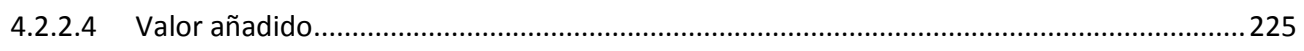

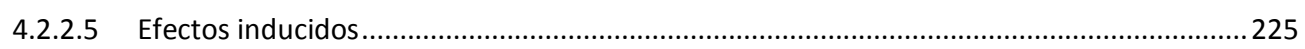

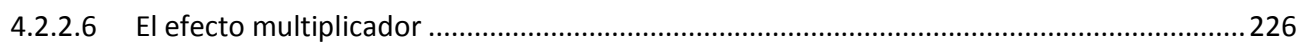

4.2.2.7 Metodología consecuencial para el cálculo de los efectos netos ........................................227

4.2.3 Resultados del análisis MRIO aplicado a la planta HYSOL ......................................230

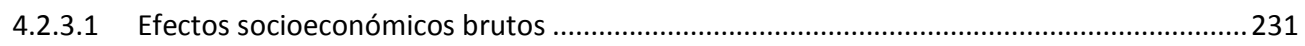

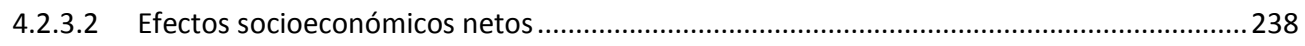

4.2.4 Resultados del análisis MRIO aplicado a la planta TERMOSOLAR CCP ....................242

4.2.4.1 Efectos socioeconómicos brutos de la planta TERMOSOLAR CCP .........................................2 242

4.2.4.2 Efectos socioeconómicos netos de la planta TERMOSOLAR CCP .......................................245

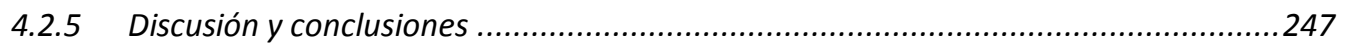

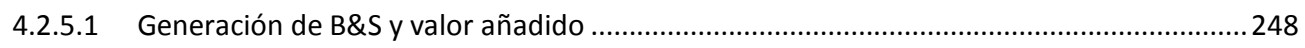

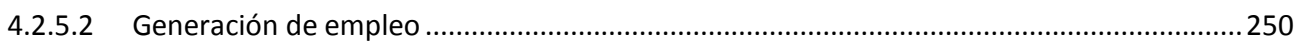

CAPÍTULO 5 Análisis del área social ................................................ 251

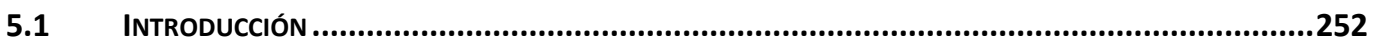

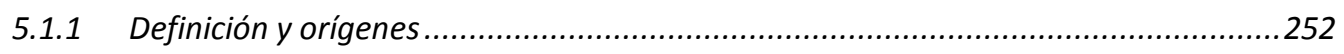

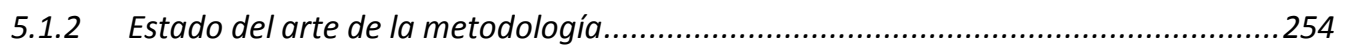

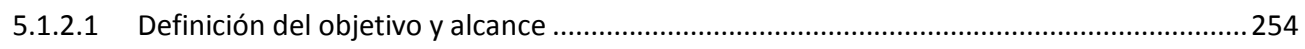

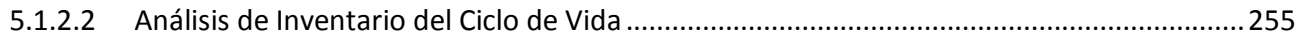

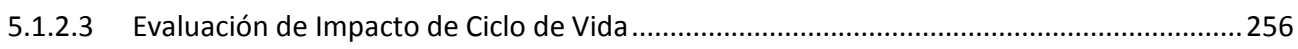

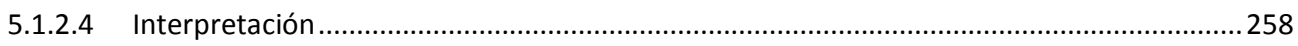




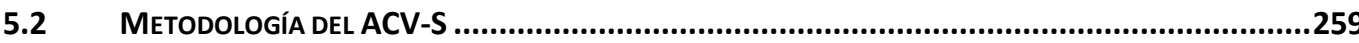

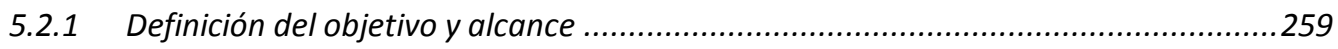

5.2.2 Análisis de inventario ...................................................................................262

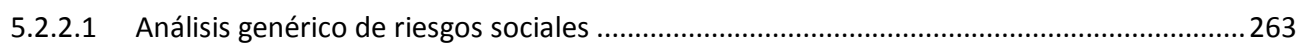

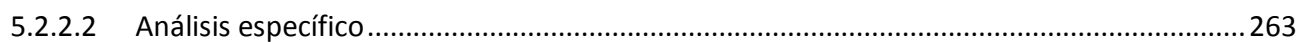

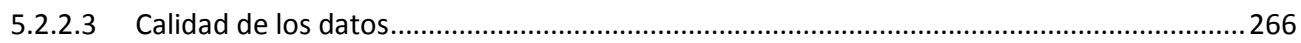

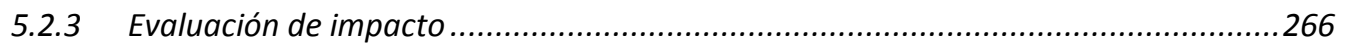

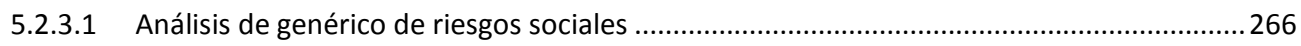

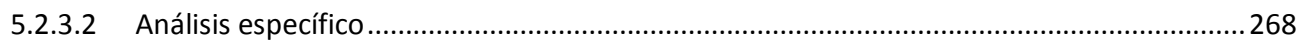

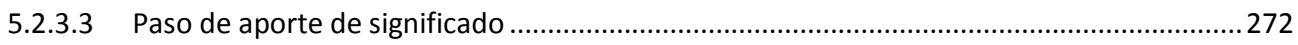

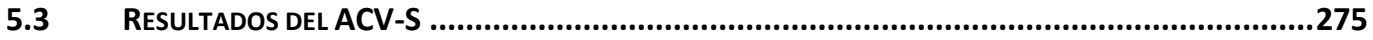

5.3.1 Análisis genérico de riesgos sociales................................................................275

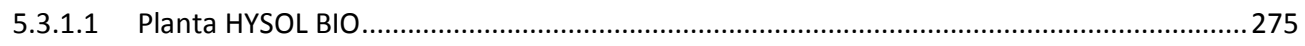

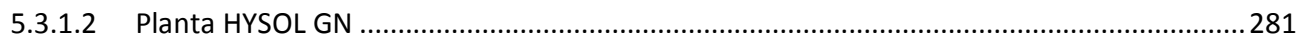

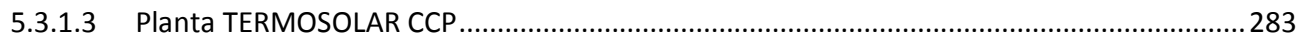

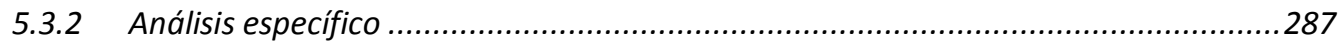

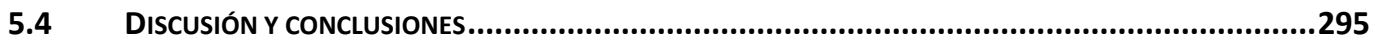

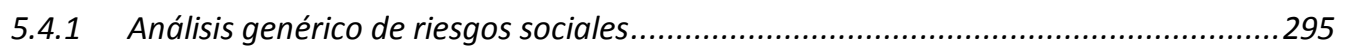

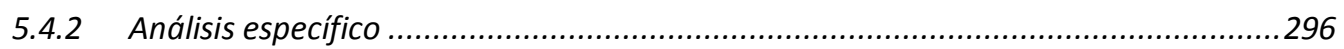

\section{CAPÍTULO 6 Integración e interpretación de resultados del Análisis de} Sostenibilidad del Ciclo de Vida.................................................... 299

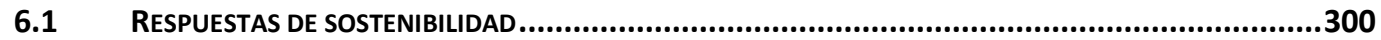

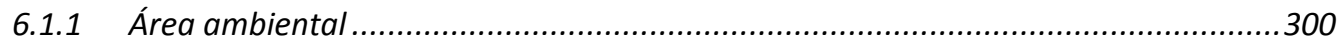

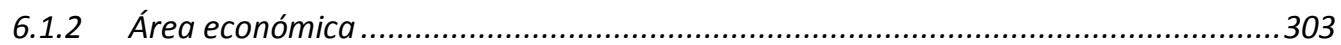

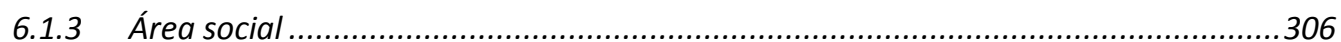

6.2 ALCANCE DEL ESTUDIO Y DECISIONES METODOLÓGICAS ...........................................................309

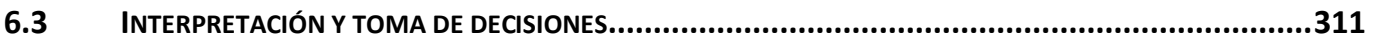

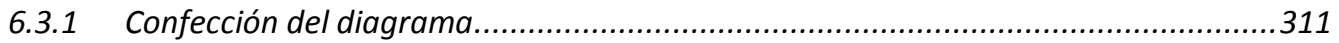

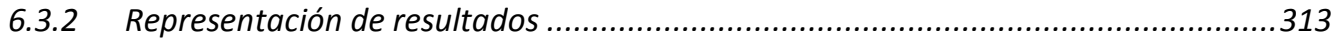

Conclusiones y líneas futuras de investigación.................................. 318

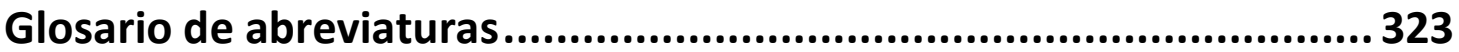

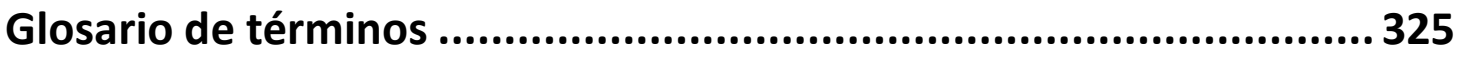

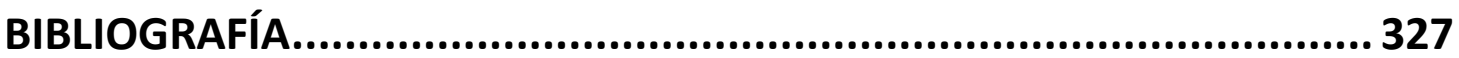

ANEXO I: Tablas de inventario para el ACV-A................................... 349

ANEXO II: Tablas de inventario económico .................................... 376

ANEXO III: Tablas de inventario y caracterización para el ACV-S........ 385 


\section{ÍNDICE DE FIGURAS}

Figura 1 Los tres pilares del desarrollo sostenible. .1

Figura 2 Herramientas de análisis principales para las tres áreas de la sostenibilidad.

Figura 3 Principales iniciativas internacionales para el desarrollo de un análisis de sostenibilidad de productos y servicios bajo enfoque de ciclo de vida

Figura 4 Esquema de los enfoques para realizar un ASCV...

Figura 5 Número de publicaciones sobre ASCV por tema y año publicadas...............................15

Figura 6 El Panel de Sostenibilidad de Ciclo de Vida según Finkbeiner et al. (2010) ..................28

Figura 7 Distribución de las publicaciones revisadas en función del método escogido de

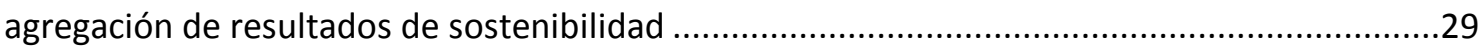

Figura 8 Las diferentes tecnologías de la energía solar térmica de concentración (IDAE 2011).33

Figura 9 Imagen del campo de colectores cilindro-parabólicos de la planta Andasol 1 desarrollada

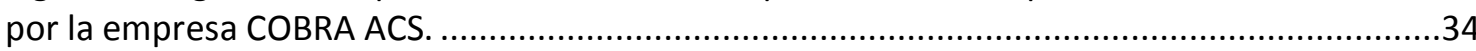

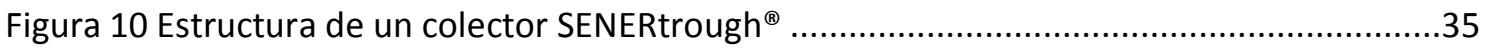

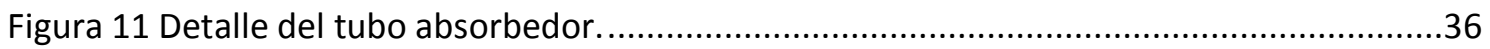

Figura 12 Fotografía de la planta solar termoeléctrica con tecnología de torre Gemasolar, de

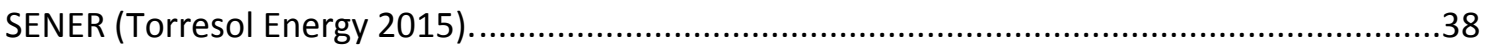

Figura 13 Esquema de un receptor externo tubular (izquierda) y un receptor de cavidad

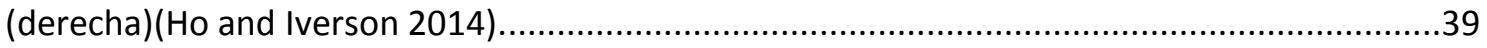

Figura 14 Relación entre las horas de almacenamiento térmico, el factor de capacidad y el múltiplo solar en una planta cilindro-parabólica de 100 MW (IRENA 2012) ..............................41

Figura 15 Diagrama de una planta solar termoeléctrica con tecnología cilindro-parabólica .....42

Figura 16 Mapa mundial de radiación solar directa.

Figura 17 La planta de torre Solúcar PS10, la primera planta termosolar explotada comercialmente en Europa.

Figura 18 Configuración de la planta demostrativa HYSOL, con tecnología cilindro-parabólica 54

Figura $19 \mathrm{El}$ nuevo intercambiador de calor entre sales y gases de escape, junto al simulador de gases de escape, instalados en la planta demostrativa del proyecto HYSOL. .54

Figura 20 Esquema de las fases del Análisis de Sostenibilidad de Ciclo de Vida propuesto en esta tesis.......

Figura 21 Escenarios analizados en el Análisis de Sostenibilidad de Ciclo de Vida de la tecnología HYSOL 
Figura 23 Área ambiental de la sostenibilidad

Figura 24 Diagrama de las etapas cubiertas por el ciclo de vida de una planta de producción eléctrica.

Figura 25 Etapas de un ACV-A, según la norma ISO 14040 (AENOR 2006) . .73

Figura 26 Árbol de procesos principales del ciclo de vida de la central. . .95

Figura 27 Procedencia del gas natural en España según CORES, en el año 2012 (CORES 2013)

Figura 28 Contribución relativa de cada fase del ciclo de vida a los impactos ambientales caracterizados de la planta HYSOL BIO.

Figura 29 Contribución relativa de los sistemas de la fase de fabricación a los impactos ambientales caracterizados de la planta HYSOL BIO

Figura 30 Impactos de normalización asociados al ciclo de vida de la planta HYSOL BIO por categoría y fase.

Figura 31 Perfil normalizado asociado al ciclo de vida de la planta HYSOL GN.

Figura 32 Resultados de caracterización (por MWh) para la planta HYSOL BIO representando la incertidumbre con barras de error ( $95 \%$ de intervalo de confianza). 116

Figura 33 Contribución relativa de cada fase del ciclo de vida a los impactos ambientales caracterizados de la planta HYSOL BIO, según el enfoque consecuencial.

Figura 34 Contribución relativa de los sistemas de la planta HYSOL a los impactos de la fase E\&F según el enfoque consecuencial

Figura 35 Impactos de normalización asociados al ciclo de vida de la planta HYSOL según el enfoque consecuencial.

Figura 36 Comparación del perfil normalizado de punto medio de la planta HYSOL BIO y el escenario alternativo (HYSOL con gas natural) bajo los enfoques atribucional y consecuencial

Figura 37 Comparación del perfil ponderado de punto final de la planta HYSOL BIO y el escenario alternativo (HYSOL con gas natural) bajo los enfoques atribucional y consecuencial.

Figura 38 Árbol de procesos principales del ciclo de vida de la planta termosolar cilindroparabólica.....

Figura 39 Contribución relativa de cada fase del ciclo de vida a los impactos ambientales caracterizados de una planta termosolar cilindro-parabólica base (con tecnología cilindroparabólica y operación en modo sólo solar)

Figura 40 Contribución relativa de cada sistema de la planta termosolar cilindro-parabólica a los impactos ambientales asociados con la fase de E\&F del ciclo de vida.

Figura 41 Perfil normalizado del impacto ambiental de la central termosolar cilindro-parabólica operando en modo solo solar (escenario base)

Figura 42 Perfil normalizado del impacto ambiental de la central termosolar cilindro-parabólica con refrigeración en seco 
Figura 43 Perfil normalizado del impacto ambiental de la central termosolar cilindro-parabólica con un $15 \%$ de electricidad producida por gas natural (TERMOSOLAR CCP).

Figura 44 Perfil normalizado del impacto ambiental de la central termosolar cilindro-parabólica con un $15 \%$ de electricidad producida por biometano.

Figura 45 Perfil normalizado del impacto ambiental de la central termosolar cilindro-parabólica con un $15 \%$ de electricidad producida por biomasa (astillas de chopo)..... 151

Figura 46 Relación entre el impacto caracterizado y el porcentaje de hibridación con gas natural para las distintas categorías de impacto

Figura 47 Resultados de caracterización (por MWh) para la planta termosolar cilindroparabólica representando la incertidumbre con barras de error (95\% de intervalo de confianza) 155

Figura 48 Comparación de impactos normalizados entre los distintos escenarios planteados para la tecnología termosolar cilindro-parabólica. 158

Figura 49 Configuración de la central termosolar de torre analizada 159

Figura 50 Contribución relativa de cada fase del ciclo de vida a los impactos ambientales caracterizados de una planta termosolar torre (modo sólo solar) 161

Figura 51 Contribución relativa de cada sistema de la planta termosolar de torre a los impactos ambientales asociados con la fase de E\&F del ciclo de vida. 162

Figura 52 Perfil normalizado del impacto ambiental de la central termosolar de torre (modo solo solar) 163

Figura 53 Perfil normalizado del impacto ambiental de la central termosolar torre hibridada con gas natural. 164

Figura 54 Comparación de los resultados normalizados entre los distintos escenarios planteados para la tecnología termosolar torre. 166

Figura 55 Perfil de ponderación de los escenarios planteados en el área ambiental: planta HYSOL $\mathrm{BIO}$, planta HYSOL GN, termosolar convencional en 6 escenarios, termosolar de torre en modo sólo solar, y termosolar de torre hibridada con gas natural.

Figura 56 Área económica de la sostenibilidad 173

Figura 57 Ejemplo de la metodología "Enfoque de camino de impacto" aplicada en ExternE, siguiendo el ejemplo de la contaminación aérea. (Bickel and Friedrich 2004)..... 181

Figura 58 Diagrama de ciclo de vida de la planta HYSOL incluyendo materiales, energía y flujos económicos de entrada y salida 190

Figura 59 Comparación de costes internos de ciclo de vida de la planta HYSOL y la planta TERMOSOLAR CCP, por fases

Figura 60 Efectos económicos brutos, netos y desplazados producidos por la planta HYSOL BIO por unidad funcional 240

Figura 61 Empleo generado bruto, neto y desplazado por la planta HYSOL BIO por unidad funcional 240

Figura 62 Efectos económicos brutos, netos y desplazados producidos por la planta HYSOL GN por unidad funcional 
Figura 63 Empleo generado bruto, neto y desplazado por la planta HYSOL GN por unidad funcional

Figura 64 Generación de B\&S y de valor añadido brutos en todos los escenarios considerados (resultados globales que incluyen los efectos en España y en el resto del mundo) 248

Figura 65 Generación de B\&S y de valor añadido netos en todos los escenarios considerados a nivel global y a nivel nacional (sólo España)

Figura 66 Generación de empleo bruto y neto en todos los escenarios considerados a nivel global $y$ a nivel nacional

Figura 67 Área social de la sostenibilidad. 251

Figura 68 Los dos tipos de enfoque para la evaluación de impacto social de ciclo de vida .256

Figura 69 Diagrama de la categoría de impacto Derechos laborales y trabajo digno..... 257

Figura 70 Los 22 temas sociales y cinco categorías de la Social Hotspots Database (Benoit-Norris et al. 2013) 267

Figura 71 Categorías de impacto y subcategorías consideradas en el análisis específico .269

Figura 72 Diagrama de flujo para el paso de aporte de significado .273

Figura 73 Resultados de caracterización por fases del análisis de hotspots de la planta HYSOL BIO 275

Figura 74 Resultados ponderados del análisis de hotspots sociales de la planta HYSOL BIO por categoría y fase de ciclo de vida. 276

Figura 75 Resultados de caracterización del análisis de hotspots de la fase E\&F de la planta HYSOL, por sistemas de componentes 278

Figura 76 Resultados de caracterización por fases del análisis de hotspots de la planta HYSOL GN

Figura 77 Resultados ponderados del análisis de hotspots sociales de la planta HYSOL GN por categoría y fase de ciclo de vida......

Figura 78 Resultados de caracterización por fases del análisis de hotspots de la planta TERMOSOLAR CCP. 284

Figura 79 Resultados ponderados del análisis de hotspots sociales de la planta TERMOSOLAR CCP por categoría y fase de ciclo de vida 284

Figura 80 Resultados de caracterización del análisis de hotspots de la fase E\&F de la planta TERMOSOLAR CCP, por sistemas de componentes 286

Figura 81 Caracterización de subcategorías para las categorías de impacto social analizadas 288

Figura 82 Comparación del riesgo social ponderado de la planta HYSOL y la TERMOSOLAR CCP por fases del ciclo de vida 296

Figura 83 Herramientas de análisis utilizadas para las tres áreas de la sostenibilidad..... 299

Figura 84 Esquema de diagrama de resultados y código de colores para una alternativa 312 
Figura 85 Jerarquía para un Proceso Analítico Jerárquico de toma de decisiones respecto a la alternativa más sostenible

Figura 86 Diagramas de sostenibilidad para la toma de decisiones sobre la tecnología más sostenible (HYSOL con biometano, HYSOL GN, o TERMOSOLAR CCP)... 


\section{ÍNDICE DE TABLAS}

Tabla 1 Resumen de los casos de estudio que implementan el ASCV .19

Tabla 2 Características de la planta HYSOL y electricidad vertida a la red. .61

Tabla 3 Características de la central del escenario TERMOSOLAR CCP, según datos propios ....63

Tabla 4 Preguntas de sostenibilidad y asignación de herramientas de análisis ...........................65

Tabla 5 Principales bases de datos a nivel internacional o europeo .........................................75

Tabla 6 Matriz Pedigree, (Manual Introduction to LCA, SimaPro 7) .........................................76

Tabla 7 Valor básico de incertidumbre (Manual Introduction to LCA, SimaPro 7) .....................77

Tabla 8 Los cinco métodos más utilizados actualmente por la comunidad científica europea ..79

Tabla 9 Características de las centrales termosolares según los análisis encontrados en la literatura científica.....

Tabla 10 Resultados caracterizados de los ACV-A de centrales termosolares con tecnología cilindro-parabólica según la literatura científica

Tabla 11 Resultados caracterizados de los ACV-A de centrales termosolares con tecnología de torre según la literatura científica .93

Tabla 12 Datasets y cantidades incluidas en el proceso "Acero galvanizado" $(1 \mathrm{~kg})$ 103

Tabla 13 Datasets y cantidades incluidas en el proceso "Industrial paint (anticorrosive and fireproof)" (1 kg) 103

Tabla 14 Procesos contenidos en el dataset "Circulation pump, 600 kW Alemania" .106

Tabla 15 Contenido del proceso correspondiente a la fabricación de $1 \mathrm{~kg}$ de nitrato potásico, procedente de mina de caliche.....

Tabla 16 Escenario de tratamiento de residuos generados tras el desmantelamiento de la central termosolar. 109

Tabla 17 Impactos caracterizados en diferentes fases del ciclo de vida de la planta HYSOL BIO

Tabla 18 Impactos caracterizados por fases del ciclo de vida de la planta HYSOL GN

Tabla 19 Resultados de Monte Carlo para los impactos ambientales caracterizados de la planta HYSOL BIO (95\% de intervalo de confianza).....

Tabla 20 Mix de tecnología marginal por tramos mensuales, calculado para las 24 horas del día 120

Tabla 21 Cobertura de la demanda de electricidad por tecnologías, media del año 2014 120

Tabla 22 Impactos consecuenciales caracterizados por diferentes fases del ciclo de vida de la planta HYSOL BIO 
Tabla 23 Impactos consecuenciales caracterizados por diferentes fases del ciclo de vida de la planta HYSOL GN

Tabla 24 Características de la central de la planta termosolar cilindro-parabólica base (50 MW,

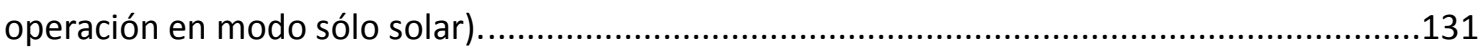

Tabla 25 Principales características que difieren en los distintos escenarios analizados ..........136

Tabla 26 Consumo de gas natural y producción de electricidad para distintos porcentajes de hibridación de la planta TERMOSOLAR CCP

Tabla 27 Emisiones difusas de los herbicidas, calculadas mediante la herramienta PestLCI 2.0

Tabla 28 Impactos caracterizados en diferentes fases del ciclo de vida de la planta termosolar convencional base (con tecnología cilindro-parabólica y operación en modo sólo solar)........142

Tabla 29 Impactos caracterizados en diferentes fases del ciclo de vida de la planta termosolar cilindro-parabólica con refrigeración en seco 146

Tabla 30 Impactos caracterizados en diferentes fases del ciclo de vida de la planta termosolar cilindro-parabólica con un $15 \%$ de electricidad producida por gas natural (TERMOSOLAR CCP)

Tabla 31 Impactos caracterizados en diferentes fases del ciclo de vida de la planta termosolar cilindro-parabólica con un $15 \%$ de electricidad producida por biometano

Tabla 32 Impactos caracterizados en diferentes fases del ciclo de vida de la planta termosolar cilindro-parabólica con un $15 \%$ de electricidad producida por biomasa (astillas de chopo) ...150

Tabla 33 Impactos caracterizados del ciclo de vida de una planta termosolar CCP hibridada en un $15 \%$ con astillas de chopo considerando distintas distancias de transporte de la biomasa

Tabla 34 Impactos caracterizados del ciclo de vida de una planta termosolar cilindro-parabólica considerando distintos porcentajes de hibridación con gas natural (0-55 \%) . 153

Tabla 35 Impactos ponderados de punto final del ciclo de vida de una planta termosolar cilindroparabólica considerando distintos porcentajes de hibridación con gas natural (0-55 \%)........154

Tabla 36 Resultados de Monte Carlo para los impactos ambientales caracterizados de la planta termosolar cilindroparabólica (95\% de intervalo de confianza) .154

Tabla 37 Comparación de los resultados caracterizados entre los distintos escenarios planteados para la tecnología termosolar cilindro-parabólica.

Tabla 38 Características principales de la tecnología termosolar torre, en modo solo solar y en el escenario de hibridación con gas natural.

Tabla 39 Impactos caracterizados en diferentes fases del ciclo de vida de la planta termosolar de torre (modo sólo solar)

Tabla 40 Impactos caracterizados en diferentes fases del ciclo de vida de la planta termosolar de torre hibridada con gas natural

Tabla 41 Comparación de los resultados caracterizados entre los distintos escenarios planteados para la tecnología termosolar torre 166 
Tabla 42 Resultados de caracterización para los escenarios planteados en el área ambiental: planta HYSOL BIO, planta HYSOL GN, termosolar cilindro-parabólica en 6 escenarios, termosolar de torre en modo sólo solar, y termosolar de torre hibridada con gas natural. También incluye el modelado consecuencial de los escenarios para la planta HYSOL .......................................170

Tabla 43 Subcategorías pertenecientes a la categoría de costes internos ..............................194

Tabla 44 Subcategorías pertenecientes a la categoría de costes externos...............................194

Tabla 45 Costes de daño marginales para las emisiones de gases de efecto invernadero en diferentes períodos, según el proyecto CASES (CASES project 2008) y convertidos a $€_{2013 . . . . .195}$

Tabla 46 Inventario de costes para la producción de biometano .............................................197

Tabla 47 Costes asociados con la compra y transporte de componentes de la planta HYSOL (fase E\&F). 199

Tabla 48 Costes de construcción e ingeniería civil de la planta HYSOL (fase C) ........................199

Tabla 49 Costes de operación y mantenimiento de la planta HYSOL (fase O\&M) .....................200

Tabla 50 Costes de desmantelamiento de la planta HYSOL (fase D\&D) ..................................200

Tabla 51 Costes del ciclo de vida de la producción de biometano por unidad energética (MJ) 202

Tabla 52 Costes internos por unidad funcional (€2015/MWh) de la planta HYSOL BIO (todos los valores descontados hasta el presente) 203

Tabla 53 Costes externos $\left(€_{2015} / \mathrm{MWh}\right.$ ) de la planta HYSOL BIO (todos los valores descontados hasta el presente) 204

Tabla 54 Costes internos por unidad funcional (€2015/MWh) de la planta HYSOL GN (todos los valores descontados hasta el presente) 205

Tabla 55 Costes externos ( $€_{2015} / \mathrm{MWh}$ ) de la planta HYSOL GN (todos los valores descontados hasta el presente) 206

Tabla 56 Costes asociados con la compra y transporte de componentes de la planta TERMOSOLAR CCP (fase E\&F). 209

Tabla 57 Costes de construcción e ingeniería civil de la planta TERMOSOLAR CCP (fase C) .....210 Tabla 58 Costes de operación y mantenimiento de la planta TERMOSOLAR CCP (fase O\&M) .210 Tabla 59 Costes de desmantelamiento de la planta TERMOSOLAR CCP (fase D\&D) 210

Tabla 60 Costes internos por unidad funcional (€2015/MWh) de la planta TERMOSOLAR CCP (todos los valores descontados hasta el presente)

Tabla 61 Costes externos $\left(€_{2015} / \mathrm{MWh}\right.$ ) de la planta convencional (15\% gas natural, todos los valores descontados hasta el presente)

Tabla 62 Producción de electricidad, retribución obtenida, costes internos y costes externos de la central TERMOSOLAR CCP con distintos porcentajes de gas natural (en $€_{2015}$ )....... 214

Tabla 63 Comparación de costes externos ( $€_{2015} / \mathrm{MWh}$ ) entre la planta HYSOL BIO, la planta HYSOL GN, y la planta TERMOSOLAR CCP 
Tabla 64 Características y costes (valor presente) del ciclo de vida de las tecnologías marginales, en $€_{2011}$

Tabla 65 Impacto del ciclo de vida de las 145 plantas de biometano sobre la producción de B\&S (en €2011).

Tabla 66 Valor añadido producido por el ciclo de vida delas 145 plantas de biometano (en €2011)

Tabla 67 Empleo generado durante el ciclo de vida de las 145 plantas de biometano

Tabla 68 Impacto del ciclo de vida de la planta HYSOL BIO sobre la producción de B\&S (en €2011)

Tabla 69 Valor añadido producido por el ciclo de vida de la planta HYSOL BIO (en €2011) .....234

Tabla 70 Empleo generado durante el ciclo de vida de la planta HYSOL BIO 234

Tabla 71 Beneficios socioeconómicos globales generados durante el ciclo de vida de la planta HYSOL BIO, por unidad funcional 235

Tabla 72 Contribución de las regiones económicas y los países más relevantes en la cadena de valor a la generación de B\&S (más de un $1 \%$ ), valor añadido y empleo de la planta HYSOL BIO

Tabla 73 Impacto del ciclo de vida de la planta HYSOL GN sobre la producción de B\&S (en €2011)

Tabla 74 Valor añadido producido por el ciclo de vida de una planta HYSOL GN (en €2011)...237

Tabla 75 Empleo generado durante el ciclo de vida de la planta HYSOL GN

Tabla 76 Beneficios socioeconómicos globales generados durante el ciclo de vida de la planta HYSOL GN, por unidad funcional. 238

Tabla 77 Resultados LEC para cada tecnología marginal y su porcentaje de participación en el mix de tecnologías marginales. 238

Tabla 78 Efectos socioeconómicos de la demanda de electricidad por parte del mix de tecnologías marginales.

Tabla 79 Efectos socioeconómicos netos del ciclo de vida de la planta HYSOL BIO a nivel nacional e internacional

Tabla 80 Efectos socioeconómicos netos del ciclo de vida de la planta HYSOL GN a nivel nacional e internacional......

Tabla 81 Producción de B\&S durante el ciclo de vida de una planta TERMOSOLAR CCP

Tabla 82 Contribución de los países más relevantes en la cadena de valor de la planta TERMOSOLAR CCP (más del $1 \%$ de la generación de B\&S) a los sectores económicos más relevantes (más de $3 \%$ de contribución a B\&S)

Tabla 83 Valor añadido producido por el ciclo de vida de una planta TERMOSOLAR CCP 244

Tabla 84 Empleo generado durante el ciclo de vida de una planta TERMOSOLAR CCP .244

Tabla 85 Beneficios socioeconómicos brutos generados por España durante el ciclo de vida de la planta TERMOSOLAR CCP, por unidad funcional. 245 
Tabla 86 Resultados LEC para cada tecnología marginal y su porcentaje de participación en el mix de tecnologías marginales.

Tabla 87 Efectos socioeconómicos de la demanda de electricidad por parte del mix de

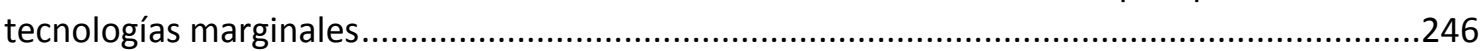

Tabla 88 Efectos socioeconómicos netos del ciclo de vida de una planta TERMOSOLAR CCP a

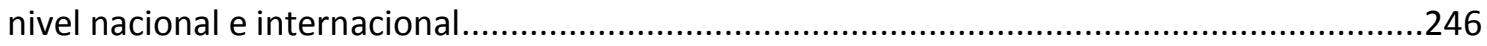

Tabla 89 Beneficios económicos brutos, netos y desplazados de la planta TERMOSOLAR CCP por unidad funcional

Tabla 90 Indicadores de inventario para cada subcategoría considerados en el ACV-S de la planta bajo estudio .264

Tabla 91 Clasificación de las subcategorías descritas por la guía en la categoría de impacto de Derechos laborales y trabajo digno. 269

Tabla 92 Clasificación de las subcategorías descritas por la guía en la categoría de impacto de Salud y seguridad 270

Tabla 93 Clasificación de las subcategorías descritas por la guía en la categoría de impacto de Patrimonio cultural 271

Tabla 94 Clasificación de las subcategorías descritas por la guía en la categoría de impacto de Relaciones justas 271

Tabla 95 Clasificación de las subcategorías descritas por la guía en la categoría de impacto Sostenibilidad socio-económica.

Tabla 96 Sectores económicos que contribuyen con más de $1 \%$ al riesgo social ponderado del ciclo de vida de la planta HYSOL BIO 276

Tabla 97 Sectores económicos que contribuyen a más de un 2\% del riesgo social ponderado en los sistemas de la fase E\&F de la planta HYSOL.

Tabla 98 Sectores económicos que contribuyen con más de $1 \%$ al riesgo social ponderado del ciclo de vida de la planta HYSOL GN

Tabla 99 Sectores económicos que contribuyen con más de $1 \%$ al riesgo social ponderado del ciclo de vida de la planta TERMOSOLAR CCP. 285

Tabla 100 Sectores económicos que contribuyen a más de un $2 \%$ del riesgo social ponderado en los sistemas de la fase E\&F de la planta TERMOSOLAR CCP.

Tabla 101 Resultados de asignación de cargas y comportamiento social del ciclo de vida de la planta HYSOL 292

Tabla 102 Resultados de asignación de cargas y comportamiento social del ciclo de vida de la planta TERMOSOLAR CCP.....

Tabla 103 Asignación de cargas y comportamiento social de la planta HYSOL según las categorías de actores

Tabla 104 Asignación de cargas y comportamiento social de la planta TERMOSOLAR CCP según las categorías de actores 
Tabla 105 Impacto ambiental potencial de la tecnología HYSOL en los cuatro indicadores principales

Tabla 106 Impacto ambiental potencial de la tecnología HYSOL en las categorías de punto medio

Tabla 107 Valores absolutos y variaciones porcentuales de cada criterio de sostenibilidad para cada alternativa.

Tabla 108 Tabla de inventario de la fabricación y transporte del sistema campo solar de una planta HYSOL de torre de $100 \mathrm{MW}$ 349

Tabla 109 Tabla de inventario de la fabricación del sistema receptor central de una planta HYSOL de torre de $100 \mathrm{MW}$. 350

Tabla 110 Tabla de inventario de la fabricación y transporte del sistema de almacenamiento térmico de una planta HYSOL de torre de $100 \mathrm{MW}$ 351

Tabla 111 Tabla de inventario de la fabricación y transporte del sistema del bloque de potencia de una planta HYSOL de torre de $100 \mathrm{MW}$. 353

Tabla 112 Sistema de instalaciones de una planta HYSOL de torre de $100 \mathrm{MW}$ 356

Tabla 113 Tabla de inventario de la construcción de una planta HYSOL de torre de 100 MW.356 Tabla 114 Tabla de inventario de la operación y mantenimiento de una planta HYSOL de torre de $100 \mathrm{MW}$..... 360

Tabla 115 Tabla de inventario del desmantelamiento de una planta HYSOL de torre de $100 \mathrm{MW}$ 360

Tabla 116 Tabla de inventario de la fabricación y transporte del sistema circuito HTF de una planta cilindro-parabólica de $50 \mathrm{MW}$ (escenario TERMOSOLAR CCP). 361

Tabla 117 Tabla de inventario de la fabricación y transporte del sistema campo solar de una planta cilindro-parabólica de $50 \mathrm{MW}$ (escenario TERMOSOLAR CCP) 362

Tabla 118 Tabla de inventario de la fabricación y transporte del sistema de almacenamiento térmico de una planta cilindro-parabólica de $50 \mathrm{MW}$ (escenario TERMOSOLAR CCP). 365

Tabla 119 Tabla de inventario de la fabricación y transporte del sistema del bloque de potencia de una planta cilindro-parabólica de $50 \mathrm{MW}$ (escenario TERMOSOLAR CCP). 366

Tabla 120 Inventario de la fabricación y transporte de las instalaciones auxiliares de una planta cilindro-parabólica de $50 \mathrm{MW}$ (escenario TERMOSOLAR CCP) 367

Tabla 121 Tabla de inventario de la construcción de una planta cilindro-parabólica de $50 \mathrm{MW}$ (escenario TERMOSOLAR CCP)..... 368

Tabla 122 Tabla de inventario de la operación y mantenimiento de una planta cilindro-parabólica de $50 \mathrm{MW}$ en modo sólo solar 371

Tabla 123 Tabla de inventario del desmantelamiento de una planta cilindro-parabólica de 50 MW (escenario TERMOSOLAR CCP) ..... 372

Tabla 124 Inventario de pretratamiento del suelo para la plantación de chopo. 373 
Tabla 125 Inventario de fertilizantes aplicados durante la fase de pretratemiento del suelo en la plantación de chopo.

Tabla 126 Inventario de la fase de cultivo del chopo, por GJ de biomasa cosechada 374

Tabla 127 Inventario para la fase de cosechado del chopo, por GJ de biomasa cosechada ......374

Tabla 128 Inventario para el cosechado de astillas del chopo, por GJ cosechado. .375

Tabla 129 Inventario económico de la fase de inversión inicial de la planta HYSOL (descontado al año de comienzo del proyecto) 376

Tabla 130 Inventario económico de la fase de operación y mantenimiento de la planta HYSOL (descontado al año de comienzo del proyecto) 378

Tabla 131 Inventario económico de la fase de desmantelamiento y disposición de residuos de la planta HYSOL (descontado al año de comienzo del proyecto) 379

Tabla 132 Inventario económico de la fase de inversión inicial de la planta TERMOSOLAR CCP descontado al año de comienzo del proyecto). 379

Tabla 133 Inventario económico de la fase de operación y mantenimiento de la planta TERMOSOLAR CCP (descontado al año de comienzo del proyecto) 381

Tabla 134 Inventario económico de la fase de desmantelamiento y disposición de residuos de la planta TERMOSOLAR CCP (descontado al año de comienzo del proyecto) 382

Tabla 135 Euros por kilogramo de emisión al aire en España, según lo calculado por el proyecto CASES para una altura de emisión desconocida (CASES project 2008) 383

Tabla 136 Euros por kilogramo de radionucleótidos emitidos al aire y agua, según lo calculado por el proyecto CASES (CASES project 2008) 384

Tabla 137 Inventario para el análisis de hotspots sociales de la fase E\&F de la planta HYSOL.385

Tabla 138 Inventario para el análisis de hotspots sociales de la fase de Construcción de la planta HYSOL. 386

Tabla 139 Inventario para el análisis de hotspots sociales de la fase de Operación y Mantenimiento de la planta HYSOL 386

Tabla 140 Inventario para el análisis de hotspots sociales de la fase de Desmantelamiento y Disposición de residuos de la planta HYSOL 386

Tabla 141 Inventario para el análisis de hotspots sociales de la fase E\&F de la planta TERMOSOLAR CCP. 387

Tabla 142 Inventario para el análisis de hotspots sociales de la fase de Construcción de la planta TERMOSOLAR CCP. 388

Tabla 143 Inventario para el análisis de hotspots sociales de la fase de Operación y Mantenimiento de la planta TERMOSOLAR CCP 388

Tabla 144 Inventario para el análisis de hotspots sociales de la fase de Desmantelamiento y Disposición de residuos de la planta TERMOSOLAR CCP... 388

Tabla 145 Inventario y caracterización para las fases de Construcción y Desmantelamiento de la planta HYSOL. 389 
Tabla 146 Inventario y caracterización para la fase de Operación y Mantenimiento de la planta HYSOL.....

Tabla 147 Paso de aporte de significado: Resultados de las categorías de impacto y subcategorías del análisis específico de la planta HYSOL 



\section{CAPÍTULO 1 Introducción}

La problemática social, ambiental y económica va creciendo cada día, tanto sus causas y efectos como la conciencia social de que es necesario actuar sobre ello. Afortunadamente, esta conciencia se extiende a lo largo del mundo, y las autoridades van tomando decisiones y encaminando sus políticas hacia un desarrollo más sostenible mediante organismos internacionales como el PNUMA (Programa de las Naciones Unidas para el Medio Ambiente) o el Panel Intergubernamental del Cambio Climático (IPCC, del inglés Intergovernmental Panel on Climate Change).

El desarrollo sostenible se entiende actualmente como aquel que permite "satisfacer las necesidades de la generación actual sin sacrificar la capacidad de las futuras generaciones de satisfacer sus propias necesidades", y debe apoyarse en tres grandes pilares: sociedad, economía y medioambiente. Esta definición de sostenibilidad fue mundialmente conocida en 1987 gracias al informe Brundtland (Brundtland 1987) realizado por la ex-primera ministra de Noruega Gro Harlem Brundtland para la ONU (Organización de Naciones Unidas). Este informe analiza, critica y replantea las políticas internacionales de desarrollo, manifestando que el desarrollo económico mundial se está alcanzando bajo un coste medioambiental y social demasiado alto. Por ello, para conseguir un desarrollo sostenible, las actividades humanas deben plantearse de forma que la interacción entre las áreas de sociedad, economía y medioambiente sea viable, equitativa y saludable (ver Figura 1).

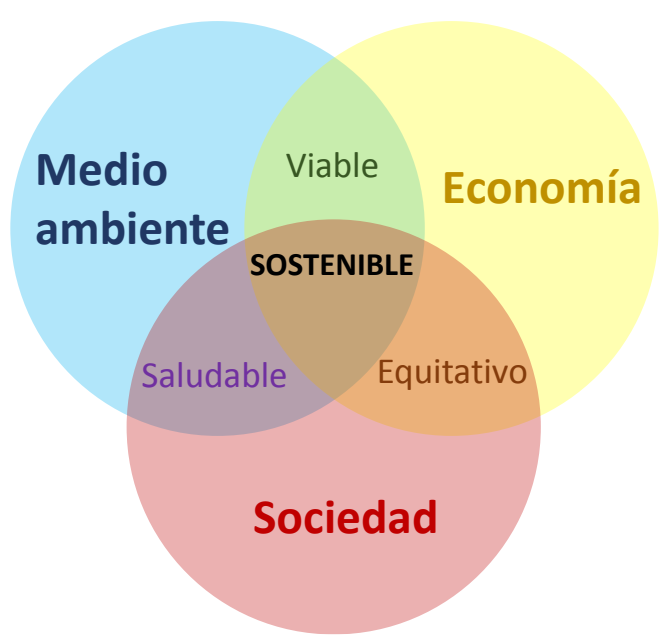

Figura 1 Los tres pilares del desarrollo sostenible 
Contar con herramientas para cuantificar la sostenibilidad de productos y servicios es fundamental para que la actividad humana se desarrolle de forma sostenible. En las últimas décadas los esfuerzos para medir la sostenibilidad de productos y servicios han estado muy enfocados a herramientas de evaluación de impacto ambiental. La Comisión Europea identificó en su Política de Productos Integrada (COM, 2003) al Análisis de Ciclo de Vida (ACV) como la mejor metodología disponible para el análisis y comparación de impactos ambientales potenciales de productos. Se denomina ACV al estudio consistente en determinar el impacto ambiental que produce un sistema o producto durante todas las fases de su ciclo de vida (extracción de materiales, transporte, fabricación de componentes, construcción, desmantelamiento, gestión de residuos). Este enfoque de ciclo de vida se está desarrollando y ampliando a las otras áreas de la sostenibilidad (economía y sociedad), especialmente desde la declaración internacional del PNUMA en Malmö en el año 2000 (Declaration 2000, UNEP/SETAC 2015) donde se animaba encarecidamente a que todos los organismos persiguieran una economía basada en el ciclo de vida. El enfoque de ciclo de vida aplicado a las áreas economía y sociedad ha tomado forma principalmente en las siguientes herramientas de análisis: Costes de Ciclo de Vida (CCV) y Análisis de Ciclo de Vida Social (ACV-S). Mientras que el CCV empezó a aplicarse hace décadas, el ACV-S está todavía en los inicios de su desarrollo metodológico.

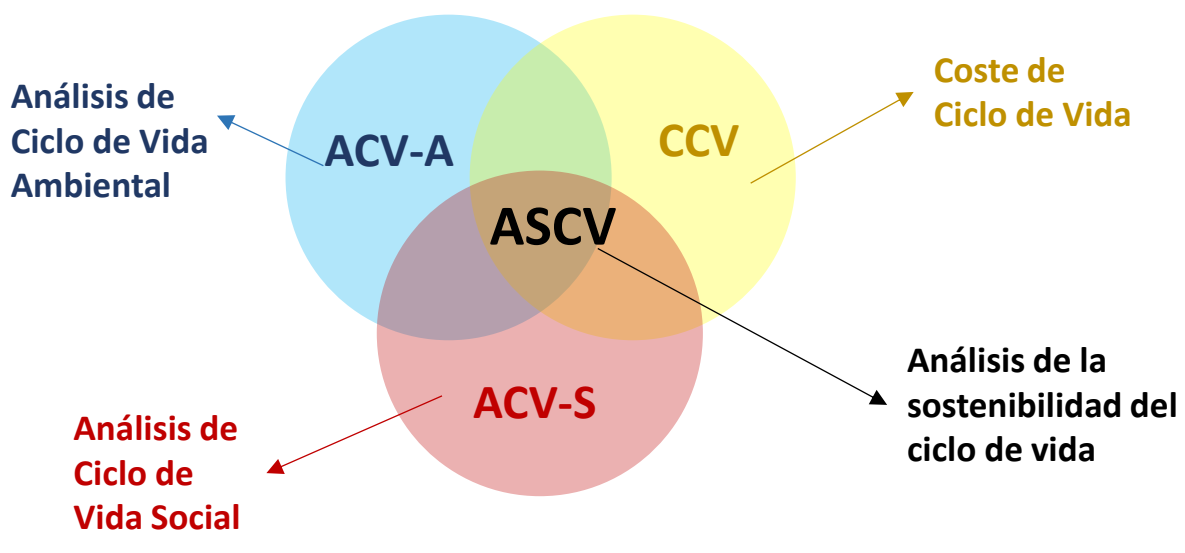

Figura 2 Herramientas de análisis principales para las tres áreas de la sostenibilidad

La necesidad de un mundo más sostenible junto con el desarrollo de metodologías ACV ha propiciado el interés por desarrollar una metodología holística encaminada a integrar los tres factores de la sostenibilidad: el Análisis de la Sostenibilidad del Ciclo de Vida (ASCV). El objetivo de esta nueva metodología es evaluar los impactos ambientales, económicos y sociales de un producto o servicio a lo largo de su ciclo de vida completo, siguiendo los marcos metodológicos de las ISO 14040 y 14044, y combinando principalmente, aunque no exclusivamente, tres herramientas de análisis (ver Figura 2): el ACV Ambiental (ACV-A), el análisis CCV, y el ACV-S. 
La producción de electricidad es una de las actividades humanas con mayor repercusión en el desarrollo sostenible, ya que la sociedad actual depende de su consumo para realizar muchas de las actividades diarias, especialmente en los países con alto nivel de desarrollo. Además, en las últimas décadas se ha comprobado una relación directa entre el desarrollo económico y el aumento del consumo energético (EIA 2014). La dependencia energética ha propiciado que el consumo de electricidad mundial se haya multiplicado por cuatro durante los últimos 30 años (IEA 2015). El aumento progresivo de la demanda de electricidad implica un mayor consumo de recursos para su producción, especialmente de combustibles fósiles (en base a carbón, petróleo y gas natural) que en el año 2013 producían el 67\% de la electricidad mundial (IEA 2015). Esta situación hace que la producción eléctrica y térmica represente aproximadamente el $25 \%$ de las emisiones mundiales directas de Gases de Efecto Invernadero (GEI) (IPCC 2015), convirtiéndose en uno de los sectores con mayor responsabilidad en la lucha contra el cambio climático.

El cambio climático antropogénico (causado por los GEI) y sus efectos adversos sobre el planeta es uno de los problemas ambientales más acuciantes de nuestra sociedad. Durante los últimos 21 años se ha celebrado anualmente la Conferencia de las Partes (COP, del inglés, Conference Of Parts), cumbre de las Naciones Unidas donde todos los países deben comprometerse a bajar sus emisiones GEI con el objetivo de mantener el aumento de la temperatura global por debajo de $2{ }^{\circ} \mathrm{C}$ (en comparación con los niveles preindustriales). Las estimaciones de la Agencia Internacional de la Energía (IEA, del inglés, International Energy Agency) indican que los esfuerzos internacionales en desarrollo e instalación de tecnologías renovables lograrán que los recursos renovables (sol, viento y agua) sean la principal fuente de producción de electricidad en el año 2030 (IEA 2015). Sin embargo, sus proyecciones indican que ese logro no será suficiente para conseguir el objetivo de la COP, requiriendo una mayor implantación de tecnologías renovables y eficiencia energética.

La inestabilidad actual en el suministro de combustibles fósiles, junto con la demanda creciente de electricidad y el avance del cambio climático antropogénico, refuerzan la necesidad y preocupación humana por abastecerse urgentemente de fuentes de energía limpias y asequibles. En este contexto nace HYSOL (Innovative Configuration of a Fully Renewable Hybrid CSP Plant, no 308912), un proyecto europeo del séptimo programa marco encaminado a desarrollar una tecnología híbrida de producción de electricidad mediante energía solar térmica y combustibles gaseosos biomásicos. El desarrollo de esta nueva tecnología persigue superar una de las mayores desventajas de la generación de electricidad renovable: la producción a demanda, independientemente de las condiciones meteorológicas. 
El desarrollo de nuevas tecnologías de producción de electricidad renovable como HYSOL debe estar acompañado de análisis de sostenibilidad, no sólo para sustentar de forma cuantitativa su potencial mejora ambiental, social y económica, sino también para contribuir a la mejora de la sostenibilidad desde la fase de diseño.

Esta tesis forma parte del proyecto HYSOL, cuantificando su impacto ambiental mediante la metodología de ACV, y expandiendo esta cuantificación a las áreas de economía y sociedad con el objetivo de obtener un análisis de sostenibilidad completo.

\subsection{OBJETIVOS}

El objetivo principal de esta tesis es contribuir al desarrollo de la metodología ASCV evaluando el impacto potencial de sostenibilidad de una tecnología innovadora de producción eléctrica (la tecnología desarrollada en el proyecto HYSOL).

Actualmente existen distintas herramientas para analizar los tres pilares de la sostenibilidad, y ha habido varios esfuerzos internacionales por integrarlas en un análisis de sostenibilidad. Sin embargo, la comunidad científica evidencia la necesidad de desarrollar estas herramientas y su integración con mayor profundidad a nivel conceptual y metodológico (Cinelli et al. 2013). Todavía se precisa desarrollo en el paso de la teoría a la práctica (Neugebauer et al. 2015), y los métodos actuales son tan complejos que resultan difíciles de aplicar y comprender por la industria (Finkbeiner et al. 2010, Pesonen and Horn 2013). Por ello, la metodología presentada en esta tesis, basándose en los avances metodológicos hasta la fecha de la comunidad científica, pretende profundizar en concepto y métodos, contribuyendo al acervo actual del ASCV con un caso de estudio completo y unos resultados sencillos y fáciles de comprender.

Los objetivos secundarios de la tesis son:

- Cuantificar el impacto ambiental potencial del ciclo de vida de la tecnología HYSOL, en sus dos escenarios principales: hibridación con biometano o hibridación con gas natural

- Comparar el impacto ambiental potencial de la tecnología HYSOL con la tecnología termosolar convencional.

- Aplicar y desarrollar la herramienta CCV para estimar los costes de ciclo de vida internos y externos de la tecnología HYSOL, así como su rentabilidad e impacto macroeconómico.

- Aplicar y desarrollar la herramienta ACV-S para estimar el impacto social potencial de la tecnología HYSOL, incluyendo el empleo generado. 
- Proporcionar un resultado de ASCV que facilite la toma de decisiones sostenible respecto al desarrollo e implantación de la tecnología HYSOL.

\subsection{ARTí́CULOS CIENTífICOS DERIVADOS DE ESTA TESIS}

En el marco de esta tesis doctoral se han publicado varios artículos de investigación en revistas internacionales y se han presentado parte de los resultados en congresos internacionales. Esta sección presenta una lista de dichas publicaciones.

\section{Publicaciones en revistas internacionales de investigación (indexadas por el JCR):}

1. Corona B, Cerrajero E, López D, San Miguel G (2016) Full environmental life cycle cost analysis of concentrating solar power technology: Contribution of externalities to overall energy costs. Sol Energy., 758-768. doi: 10.1016/j.solener.2016.06.059

2. Corona, B., Escudero, L., Quéméré Goulven, Luque-Heredia, I., \& San Miguel, G. (2016). Energy and environmental life cycle assessment of a high concentration photovoltaic power plant in Morocco. The International Journal of Life Cycle Assessment, 1-10. doi:10.1007/s11367-016-1157-y

3. Corona B, de la Rúa C, San Miguel G (2016) Socio-economic and environmental effects of concentrated solar power in Spain: A multiregional input output analysis. Solar Energy Mater Solar Cells, 156, 112-121. DOI: 10.1016/j.solmat.2016.03.014

4. Corona B, Ruiz D, San Miguel G (2016) Life Cycle Assessment of a HYSOL Concentrated Solar Power Plant: Analyzing the Effect of Geographic Location. Energies 9(6), 413. doi:10.3390/en9060413

5. Corona, B., \& San Miguel, G. (2015). Environmental analysis of a concentrated solar power (CSP) plant hybridised with different fossil and renewable fuels. Fuel, 145, 63-69. doi:10.1016/j.fuel.2014.12.068

6. Corona, B., San Miguel, G., \& Cerrajero, E. (2014). Life cycle assessment of concentrated solar power (CSP) and the influence of hybridising with natural gas. The International Journal of Life Cycle Assessment, 19(6), 1264-1275. doi: 10.1007/s11367-014-0728-z

7. San Miguel, G., \& Corona, B. (2014). Hybridizing concentrated solar power (CSP) with biogas and biomethane as an alternative to natural gas: Analysis of environmental performance using LCA. Renewable Energy, 66, 580-587. doi:10.1016/j.renene.2013.12.023

8. San Miguel, G., Corona, B., Ruiz, D., Landholm, D., Laina, R., Tolosana, E., H. Sixto, I. Cañellas (2015). Environmental, energy and economic analysis of a biomass supply chain based on a 
poplar short rotation coppice in Spain. Journal of Cleaner Production, 94, 93-101. doi:10.1016/j.jclepro.2015.01.070

\section{Publicaciones en otras revistas internacionales de investigación:}

9. Corona, B., López, A., \& San Miguel, G. (2016). Socio-economic effects of a HYSOL CSP plant located in different countries: An input output analysis. Procedia Computer Science, 83, $1150-1156$.

10.Corona, B., Ruiz, D., \& San Miguel, G. (2016). Environmental Assessment of a HYSOL CSP Plant Compared to a Conventional Tower CSP Plant. Procedia Computer Science, 83, 1110-1117.

\section{Capítulos en libros:}

11. San Miguel, G., Corona, B., Servert, J., López, D., Cerrajero, E., Gutierrez, F., et al. (2015). Technical and environmental analysis of parabolic trough concentrating solar power (CSP) technologies. Environment, energy and climate change II (pp. 33-53) Springer.

\section{Presentaciones en congresos:}

12. Corona, B., \& San Miguel, G.,(2013). Life cycle assessment of a hybrid concentrated solar power plant: Comparison between different fossil and renewable fuels. Proceedings of the Energy and Environment Knowledge Week, Toledo, 20-22th of November.

13. Corona, B., \& San Miguel, G. (2013). Environmental assessment of Concentrating Solar Power (CSP) technology: assessment of LCA methodology. Proceedings of the 13th International Conference on Environmental Science \& Technology, Athens, 20-22th of November.

14. San Miguel, G., \& Corona, B. (2013). Environmental performance of a concentrating solar power (CSP) plant operating with biogas. Proceedings of the 22nd European Biomass Conference and Exhibition, Copenhagen, 5-7th of June.

\section{Artículos enviados a revistas de investigación (todavía no publicados)}

Corona, B., Bozhilova-Kisheva, K.P., Olsen, S.I., San Miguel, G. (2016) Social Life Cycle Assessment of a Concentrated Solar Power plant in Spain: a methodological proposal. Actualmente en el proceso de revisión por la revista Journal of Industrial Ecology (enviado el 14 de abril, aceptado bajo revisión el 1 de agosto).

San Miguel, G., Corona, B. (2016) Economic viability of concentrating solar power under different regulatory frameworks: Spain as a case study. Actualmente en el proceso de revision por la revista Renewable \& Sustainable Energy Reviews (enviado el 29 de junio). 


\subsection{ESTRUCTURA Y CONTENIDO DE LA TESIS}

Esta tesis sigue una estructura particular diseñada para describir el desarrollo metodológico y los resultados obtenidos de la forma más clara posible. El Capítulo 1 (Introducción) incluye los objetivos de esta tesis y expone el estado del arte del ASCV junto con los aspectos más relevantes de la tecnología termosolar y su situación en España. El Capítulo 2 define la metodología ASCV aplicada en esta tesis, incluyendo el primer paso para la realización del ASCV: Definición del objetivo y alcance. Los Capítulos 3, 4 y 5 presentan la introducción, metodología, desarrollo, análisis y resultados para cada área de la sostenibilidad (medioambiente, economía y sociedad respectivamente). Cada uno de estos capítulos sigue una estructura donde se define en primer lugar la metodología en cuestión y sus orígenes, en segundo lugar se describe su aplicación al caso de estudio, y finalmente se discuten los resultados. El Capítulo 6 recopila los resultados y discusión de los tres capítulos anteriores para responder a las preguntas de sostenibilidad fijadas en el Capítulo 2, proporcionando el resultado final para el ASCV de la tecnología HYSOL. Por último, se presentan las conclusiones de la tesis y las líneas futuras de investigación. Además, esta tesis contiene un glosario de abreviaturas y definiciones al final de la misma. 


\subsection{EL ANÁLISIS DE SOSTENIBILIDAD DEL CICLO DE VIDA}

En la Conferencia de las Naciones Unidas sobre Medioambiente y Desarrollo de Rio de Janeiro en 1992 se estableció la sostenibilidad como el principal objetivo político para el desarrollo futuro de la humanidad (United Nations 1992). En su última conferencia del año 2015 (United Nations 2015) los anteriormente llamados Objetivos Del Milenio, pasaron a denominarse Objetivos de Desarrollo Sostenible, al entenderse que los esfuerzos internacionales deben ir encaminados a conseguir la sostenibilidad social, ambiental y económica.

Actualmente, la situación global de crisis económica, ambiental y social ha alcanzado tal magnitud que son necesarias herramientas que nos permitan contabilizar y fomentar la sostenibilidad de las actividades humanas. En la busca del análisis de sostenibilidad, el progreso en el desarrollo de metodologías de análisis de ciclo de vida ha derivado hacia la herramienta de análisis ASCV, que permite integrar los tres pilares de la sostenibilidad bajo el enfoque de ciclo de vida y siguiendo el marco metodológico de las normas ISO 14040 y 14044 . El principal objetivo de esta herramienta es ayudar a tomar la decisión más sostenible (Traverso et al. 2012).

\subsubsection{Historia del ASCV}

Según Nzila et al (2012) y Klöpffer (2008), los inicios del ASCV se remontan al desarrollo en 1987 del Análisis de portfolio de producto ("Product Line Analysis", hoy extendido a "Product Portfolio Analysis" por el proyecto PROSA (Grießhammer et al. 2007)), al ser uno de los primeros enfoques en considerar las tres dimensiones de la sostenibilidad mediante un enfoque de ciclo de vida. La metodología propuesta y desarrollada estaba muy enfocada a la visión de producto y empresa, proveyendo un marco integrado para el análisis de cada aspecto de la sostenibilidad por separado, y de la sostenibilidad como un todo.

Posteriormente, a mediados de los 90, O’Brien et al. (1996) proponían el “Análisis de ciclo de vida social y ambiental "(traducido del inglés, Social and Environmental Life Cycle Assessment), refiriéndose al modelo de tres anillos o círculos de la sostenibilidad junto con el enfoque de ciclo de vida. A partir de entonces surgieron varios proyectos nacionales e internacionales (mostrados en la Figura 3), destinados al desarrollo de metodologías que, sin ser la integración de las tres técnicas ACV-A, CCV y ASCV, se basaban en el estudio del ciclo de vida del sistema/producto. 
El Proyecto COMPASS (Kuhndt and Liedtke 1999) es una iniciativa que busca ayudar a las empresas y sectores a aumentar su sostenibilidad en los aspectos económicos, sociales y ambientales. El método desarrollado consiste en cinco pasos: la descripción del comportamiento de la empresa en los tres aspectos, la "visualización" de los objetivos a cumplir mediante el método a aplicar (satisfacción del cliente, protección de la salud...), el análisis de la situación de la empresa, la inclusión de los resultados de los pasos anteriores en la toma de decisiones y la comunicación del plan propuesto hacia el exterior.

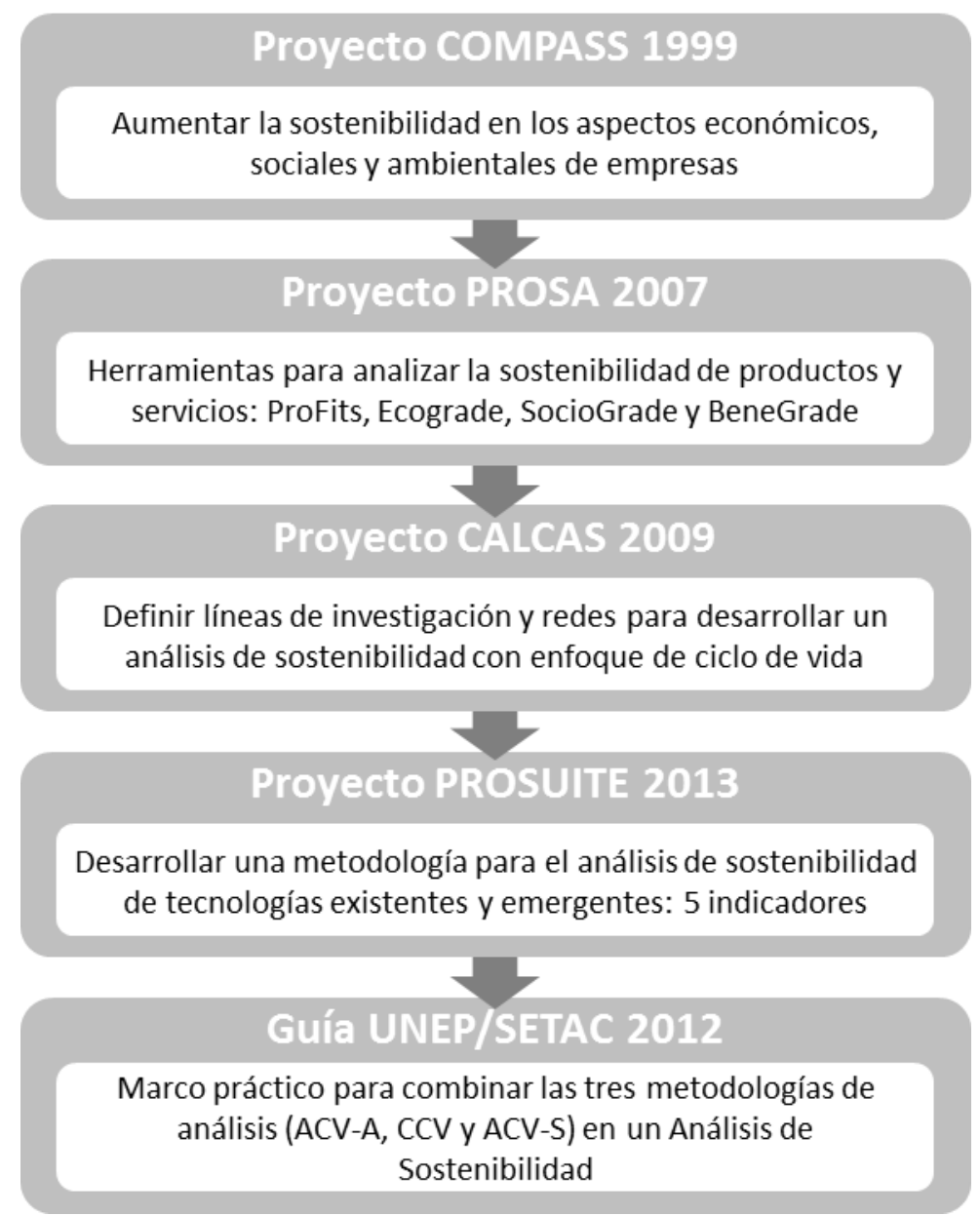

Figura 3 Principales iniciativas internacionales para el desarrollo de un análisis de sostenibilidad de productos y servicios bajo enfoque de ciclo de vida

El proyecto PROSA (Product Sustainability Assessment) (Grießhammer et al. 2007, Zamagni et al. 2009), financiado por el Ministerio de Investigación Alemán (BMBF), tenía como objetivo el desarrollo de una metodología de análisis de sostenibilidad de productos y servicios. Esta metodología se apoya en las herramientas de análisis de mercado de productos (Product Portfolio Analysis), ACV-A, CCV, ACV-S y análisis de utilidad. La herramienta ACV-S propuesta en el proyecto se complementa con en el desarrollo paralelo de la iniciativa UNEP-SETAC sobre ACV-S. El proyecto desarrolla las herramientas ProFitS (para la sostenibilidad), Ecograde 
CAPÍTULO 1: Introducción

(aspectos medioambientales), SocioGrade (aspectos sociales) y BeneGrade (aspectos de utilidad).

CALCAS (Coordination Action for innovation in Life Cycle Analysis for Sustainability), es un Proyecto paneuropeo, financiado por el Sexto Programa Marco de la Comisión Europea (ENEA, 2009)(Zamagni et al. 2009). El objetivo principal de este proyecto es definir las líneas de investigación y redes de trabajo para un análisis de sostenibilidad basado en el enfoque de ciclo de vida. Comenzando desde la complejidad del objeto de estudio (la multidisciplinariedad del concepto de sostenibilidad, las diferentes naturalezas de la elección de los sujetos implicados, y el rol de los sistemas de gobierno) se desarrollan tres líneas principales de actividad: (1) el análisis del presente y la perspectiva en las necesidades de los distintos usuarios (legisladores, negociantes, ciudadanos, investigadores y desarrolladores), (2) la revisión crítica de las herramientas de análisis y su base científica para individualizar diferentes vías de integración, y (3) el análisis de los mecanismos que unen sistemas de gobierno y decisiones sostenibles.

La propuesta del proyecto CALCAS pretende ser un marco único y unitario capaz de incorporar conocimientos desde todos los dominios relevantes para el desarrollo sostenible, permitiendo conectar los análisis a nivel micro (cuando es posible implementar un modelo muy detallado, como en el ACV-A) con niveles macro, donde se encuentran la mayoría de las cuestiones inherentes a la sostenibilidad (Zamagni et al. 2009). En este proyecto se identifica a la metodología ASCV como un desarrollo de la metodología del ACV tanto en profundidad como en ampliación de conceptos (social, económico). Proponen un método de trabajo consistente en tres fases: un análisis "semántico" (en el que se define la pregunta a responder y las decisiones a tomar), un análisis "sintáctico" (en el que se identifican los métodos de análisis disponibles e idóneos para responder las preguntas planteadas) y un análisis "operacional" (donde se aplican los métodos seleccionadas y se verifican los resultados). Entre los 28 métodos de análisis posibles para la profundización del ACV, y por lo tanto, la consecución de un ASCV, se encuentran el CCV, el cálculo de externalidades mediante ExternE, el análisis Input Output (IO) y el ACV-S (Schepelmann et al. 2008).

El proyecto PROSUITE (2009-2013), financiado por la Comisión Europea, tiene como objetivo desarrollar una metodología para el análisis de sostenibilidad de tecnologías existentes y emergentes. En su informe principal (Blok et al. 2013) se revisan los distintos enfoques de análisis de sostenibilidad expuestos hasta la fecha, sin embargo, se considera que ninguno es aplicable de forma genérica a todos los aspectos de la sostenibilidad de una tecnología. Proponen un nuevo marco de sostenibilidad basado en el enfoque de ciclo de vida. Argumentan 
que analizar por separado los tres pilares (por ejemplo mediante LCA-A, CCV y ACV-S) puede llevar a error, ya que en muchas ocasiones los límites entre los tres pilares se confunden, y los indicadores de unos y otros se solapan. Por ello, proponen un enfoque que consiste en las siguientes categorías de impacto (con indicadores específicos):

Además de estos proyectos, el PNUMA publicó en el año 2012 una guía para la aplicación de la metodología de Análisis de Sostenibilidad de Tecnologías (Sustainability Assessment of Technologies, SAT) (UNEP 2012). El enfoque de esta metodología es realizar un análisis de la situación para encontrar la mejor tecnología disponible en cada caso. Si bien se nombra el enfoque de ciclo de vida y la consideración de los aspectos ambientales, económicos y sociales, la metodología no aporta avances relevantes en el análisis de estos aspectos, si no que se centra en el marco metodológico a seguir para la toma de decisiones en la elección de una tecnología adecuada a cada situación.

Paralelamente al desarrollo del proyecto PROSUITE, la iniciativa de la UNEP/SETAC abordó el análisis de sostenibilidad como una integración de las tres técnicas ACV-A, CCV y ACV-S. La principal publicación que describe esta metodología es un informe titulado "Hacia el Análisis de Sostenibilidad de Ciclo de Vida: tomando decisiones informadas sobre productos (Towards a Life Cycle Sustainability Assessment. Making informed choices on products)" (Ciroth et al. 2011). Este informe proporciona un marco práctico para combinar las tres metodologías de análisis (ACV, CCV y ACV-S). También contiene 8 estudios de caso con la implementación de estas metodologías.

A pesar del desarrollo de todos estos proyectos, la mayoría de las publicaciones recientes sobre ASCV se refieren a la publicación de Klöpffer (2008) y al proyecto CALCAS (Zamagni et al. 2009) como inicio del desarrollo del ASCV. Klöpffer describía en su primera publicación sobre ASCV el estado del arte de la metodología, indicando dos enfoques para el marco metodológico del ASCV:

- Un "nuevo ACV", entendido como la expansión del ACV-A con las metodologías del CCV y el ACV-S como categorías de impacto adicionales.

- La suma de ACV-A, CCV y ACV-S con unos límites del sistema similares y con resultados independientes.

Estos dos enfoques, mostrados en la Figura 4, derivan en lo que se ha diferenciado por varios autores (Sala et al. 2013, Zamagni et al. 2013) como el ASCV Análisis (del inglés, Analysis) y el ASCV Evaluación (del inglés, Assessment). El ASCV Análisis amplía el alcance del ACV "convencional" para cubrir no sólo impactos ambientales sino todas las dimensiones de la 
sostenibilidad (personas, planeta y prosperidad). También amplía el alcance desde el nivel de producto (escala micro) al nivel de sector económico (escala meso) o incluso de economía global (escala macro). Por ello, prefieren utilizar el término "marco" en lugar de metodología, ya que el ASCV es un marco multidisciplinar integrador de varios modelos, y no un modelo en sí mismo (Guinee et al. 2010). Este enfoque es el desarrollado por el proyecto CALCAS.

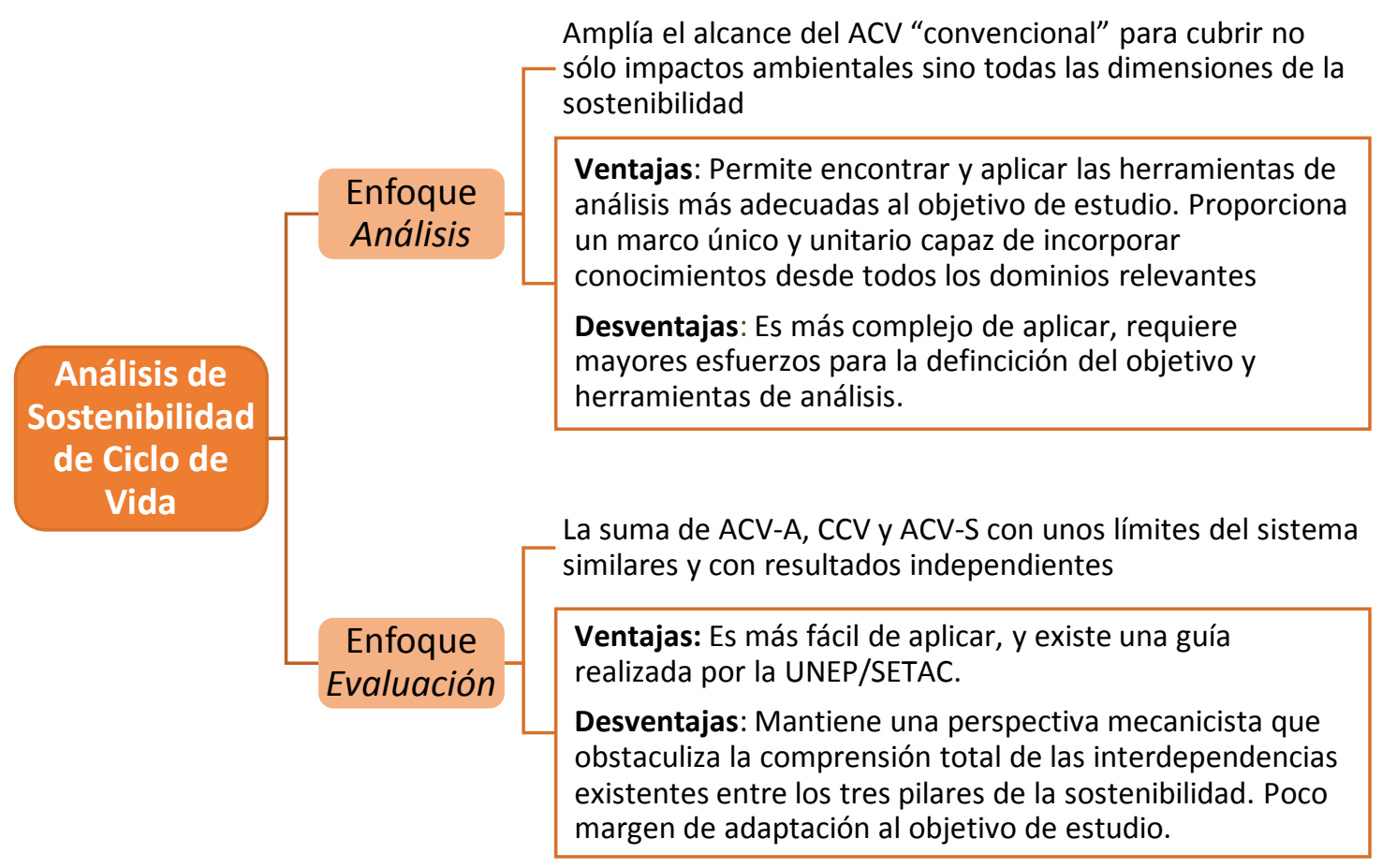

Figura 4 Esquema de los enfoques para realizar un ASCV

El segundo enfoque propuesto por Klöpffer, denominado en esta tesis ASCV Evaluación, fue presentado en la Conferencia de Naciones Unidas sobre el Desarrollo Sostenible (Rio+20) en el año 2012 por la iniciativa UNEP/SETAC (Valdivia et al. 2013), y se corresponde con el informe "Hacia el Análisis de Sostenibilidad de Ciclo de Vida: tomando decisiones informadas sobre productos"(Ciroth et al. 2011). En la actualidad, el ASCV Evaluación es el enfoque más desarrollado, pero ha sido criticado por mantener una perspectiva mecanicista que obstaculiza la comprensión total de las interdependencias existentes entre los tres pilares de la sostenibilidad (Zamagni et al. 2013).

A finales del año 2012 hubo en Copenhague un taller en el marco del simposio "SETAC Europe 18th LCA Case Study" en el que se pusieron en común las experiencias y conocimientos de la comunidad científica sobre el ASCV (Cinelli et al. 2013). Las conclusiones del taller evidenciaban que, a pesar del desarrollo metodológico existente para el análisis de cada pilar de la sostenibilidad, existe una necesidad manifiesta de estudiar el tema en profundidad a un nivel tanto conceptual como metodológico. Se observó una falta de estudios que comprobaran la 
efectividad del método y se resaltó la importancia de la comunicación de resultados. También se puso de manifiesto la variedad de enfoques existentes para el marco del ASCV, sumando a las dos opciones principales propuestas por Klöpffer otros enfoques como el desarrollado por el proyecto PROSUITE (Blok et al. 2013).

La revista Internacional Journal of Life Cycle Assessment lanzó una llamada en el año 2012 animando a los investigadores en el área del ACV y la sostenibilidad a responder preguntas relacionadas con el estado incipiente de la metodología de ASCV (Zamagni 2012). Esta llamada y la urgencia hacia un desarrollo sostenible, propiciaron que la publicación de casos de estudio y propuestas metodológicas aumentaran exponencialmente en los últimos 3 años. Los temas detectados como importantes se englobaban en tres perspectivas (Zamagni et al. 2013): (1) Concepto (ontología, epistemología y metodología de ASCV), (2) Práctica (casos de estudio y aplicaciones de la metodología de ASCV), y (3) Dirección futura (cómo seguir desarrollando la metodología). La mayor parte de los estudios publicados tras el primer año de la llamada se incluyeron en el área del concepto, exponiendo algunos de ellos la utilidad del enfoque de ciclo de vida para la evaluación de la sostenibilidad (Sala et al. 2013). Varios autores subrayaron la necesidad de encuadrar las herramientas de ASCV en su contexto de uso u objetivo del análisis. En el área de la práctica, tres estudios fueron publicados en relación a la integración de las metodologías de ACV y CCV (Heijungs et al. 2012, L. Simões et al. 2013, Wood and Hertwich 2013), mientras que un estudio abordó la respuesta sobre cómo incluir también los resultados del ACV-S y evaluar las relaciones entre las tres metodologías, utilizando el análisis multi-criterio y la curva de Pareto (Ostermeyer et al. 2013). Actualmente, la comunidad científica identifica al ASCV como una metodología en desarrollo, y demanda más casos de estudio y debates que den respuesta a todas las cuestiones metodológicas por resolver.

\subsubsection{Retos del ASCV}

Ya que el ASCV está todavía en sus inicios, muchas cuestiones metodológicas importantes siguen siendo una incógnita y están sujetas a debate. Estas cuestiones varían desde conceptos estructurales del marco ASCV (enfoques generales, metodologías para cada pilar de la sostenibilidad, la comunicación de resultados, etc.), hasta soluciones prácticas que permitan abordar las diferencias de límites del sistema y escalas (micro, meso y macro) entre cada pilar, el uso coherente del descuento para impactos futuros, o el tratamiento de la incertidumbre.

Numerosos estudios de ASCV han sido publicados en los últimos 3 años, intentando responder a algunas de las cuestiones por resolver en torno al Concepto, Práctica y Dirección 
futura del ASCV. La respuesta de los investigadores ha sido variada, presentándose distintas soluciones para el mismo problema, lo que genera confusión a la hora de establecer una guía metodológica para nuevos practicantes.

Para llevar a cabo el análisis de sostenibilidad contenido en esta tesis, se ha realizado una revisión exhaustiva de los casos de estudio llevados a cabo desde los inicios de la metodología ASCV hasta Agosto del 2015. Mediante esta revisión se pretende dar una visión global de cómo la comunidad científica está respondiendo a las cuestiones metodológicas más importantes.

Considerando el estado de desarrollo actual, las cuestiones metodológicas bajo estudio son: el marco metodológico general para la práctica del ASCV, la elección de metodologías de ciclo de vida para cada pilar de la sostenibilidad, el método de agregación, evaluación e interpretación de resultados del ASCV y otros indicadores a tener en cuenta en un análisis de sostenibilidad. Se ha distinguido entre "marco general" y "metodología para agregación, evaluación e interpretación de resultados" ya que se ha observado en la revisión bibliográfica preliminar que estas dos cuestiones no van necesariamente unidas.

\subsubsection{Revisión bibliográfica sobre ASCV}

La búsqueda bibliográfica se ha realizado mediante el motor de búsqueda de la Web Of Science (WOS), desde la Universidad Politécnica de Madrid, en Septiembre del año 2015. Para la primera búsqueda se utilizaron las palabras "Life Cycle Sustainability Assessment" como tema, obteniéndose 61 resultados, incluyendo artículos publicados en revistas de revisión por pares (53), actas de conferencias (8) y libros (0 resultados). De estos resultados, 9 publicaciones no recogían contenido importante sobre ASCV (o sólo lo nombraban) por lo que no fueron revisadas en profundidad. Además, se descartaron dos estudios por escasez de contenido. En la segunda búsqueda se utilizaron las palabras "Life Cycle Sustainability Analysis", obteniendo como resultado 7 estudios, de los cuales, dos se habían obtenido previamente en la búsqueda anterior. No se han realizado búsquedas con otros términos como "sustainability assessment" o "LCSA" al buscarse explícitamente estudios que versaran sobre la metodología de ASCV. Junto a los estudios encontrados mediante la búsqueda en WOS, también se han consultado los informes principales de 5 proyectos o iniciativas internacionales relacionadas con el ASCV (descritos en la sección 1.4.1 de este capítulo).

Debido al estado de desarrollo de la metodología ASCV, los principales aspectos a revisar en las publicaciones son: Marcos generales propuestos para llevar a cabo un ASCV, metodologías empleadas para analizar cada pilar de la sostenibilidad, inclusión de otros indicadores de la 
sostenibilidad, y metodologías para la agregación, ponderación e interpretación de resultados. La Figura 5 describe de forma gráfica el número de publicaciones sobre ASCV por tema y año de publicación.

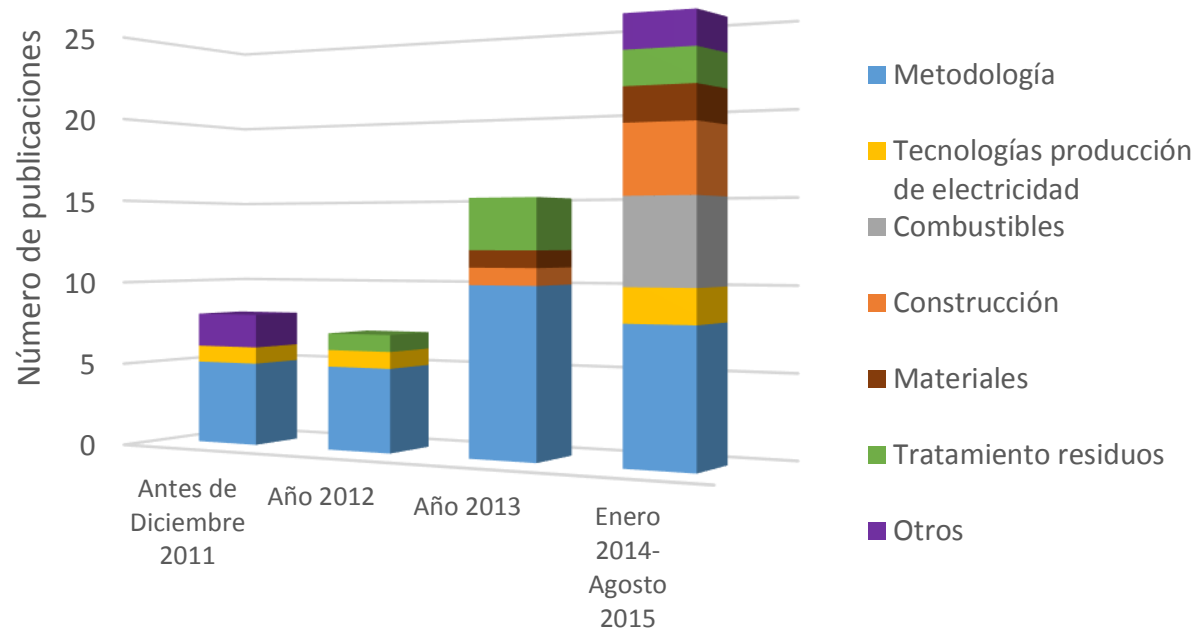

Figura 5 Número de publicaciones sobre ASCV por tema y año

De las 55 publicaciones revisadas cuyo tema principal es el ASCV (sin contar informes de proyectos), 28 publicaciones corresponden sólo a cuestiones metodológicas, mientras que 27 publicaciones describen también casos de estudio ${ }^{1}$. En la Tabla 1 se muestra un resumen de los casos de estudio revisados, incluyendo información sobre el marco metodológico, técnicas de análisis, y métodos de agregación y evaluación de impactos aplicados en cada caso. El $13 \%$ de los artículos fueron publicados en el año 2012, el 28 \% en el año 2013 y el 37 \% en el año 2014 y la primera mitad del 2015. Entre los casos de estudio revisados, sólo el 30 \% de ellos (8 estudios) llevan a cabo todos los pasos de la metodología (análisis de los tres pilares de la sostenibilidad, más agregación/ponderación e interpretación final de resultados), mientras que el resto de casos están incompletos. Los productos o sistemas analizados por los casos de estudio corresponden a los siguientes sectores: producción de energía (4 publicaciones sobre tecnologías de producción eléctrica y 5 publicaciones sobre combustibles), construcción (3 publicaciones sobre edificios y 2 sobre pavimentos), fabricación de materiales ( 3 publicaciones),

\footnotetext{
${ }^{1}$ No se han considerado como casos de estudio las publicaciones cuyo objetivo principal es un desarrollo metodológico concreto, a pesar de que aporten un ejercicio aplicado.
} 
CAPÍTULO 1: Introducción

tratamiento de residuos (6 publicaciones), sector agrícola ( 2 publicaciones), y otros (2 publicaciones, sobre vehículos y envases).

\subsubsection{Marco metodológico del ASCV}

\subsection{Marco para el enfoque ASCV Evaluación}

La mayor parte de los casos de estudio encontrados (el $48 \%, 13$ estudios) toman el marco metodológico propuesto por las guías de la UNEP/SETAC (Ciroth et al. 2011), que se corresponde con el llamado ASCV Evaluación. Nueve de estos estudios aportan como referencias a los principales desarrolladores de este método (Finkbeiner, Traverso, la guía UNEP/SETAC y Klöpffer), mientras que los 4 casos de estudio restantes aplican el marco metodológico ASCV Evaluación sin nombrar ninguna de las referencias principales (incluso uno de ellos referencia a las publicaciones que defienden el ASCV Análisis).

La propuesta de la iniciativa UNEP/SETAC se basa en seguir las mismas fases metodológicas de las normas ISO 14040 para cada una de las tres metodologías (ACV-A, CCV, ACV-S), como sigue:

1. En la primera fase, "Definición de objetivo y alcance", se debe prestar especial atención a que las tres metodologías (ACV-A, CCV y S-ACV) tengan un objetivo, alcance y unidad funcional comunes. Se recomienda que haya continuidad en los límites del sistema al aplicar cada metodología, pero con flexibilidad, ya que un proceso puede tener relevancia para una de las técnicas, pero ser irrelevante para otra (por ejemplo, la Investigación y Desarrollo en el CCV o en el ACV-A). Por lo tanto, lo importante es establecer los criterios de corte adecuados para cada herramienta.

2. En la fase de "Análisis de Inventario de Ciclo de Vida" se hace hincapié en mantener la consistencia en las tres áreas (medioambiente, economía y sociedad), recogiendo información cuantitativa, cualitativa y semi-cuantitativa.

3. En la fase de "Evaluación de Impacto de Ciclo de VIda", se recomienda la clasificación y caracterización según los estándares y criterios correspondientes a cada técnica, y no se recomienda la agregación/ponderación de resultados de las tres áreas, debido al estado inicial de la metodología y a la diferente naturaleza de cada resultado. Es por ello que la mayoría de los estudios han centrado sus esfuerzos en desarrollar marcos para la integración de resultados de las tres áreas (esto se explica con mayor profundidad en el apartado 1.4.3.5 de este capítulo).

En base a estas guías, distintos autores han hecho aportaciones para la consecución del ASCV. Pesonen and Horn (Pesonen and Horn 2013) ponen de manifiesto el gran esfuerzo 
necesario para realizar un ASCV, tanto por la variedad de información necesaria como por la elección de la metodología adecuada. Por ello, proponen un marco metodológico para el ASCV Evaluación que ayude a minimizar los esfuerzos de la fase de inventario y evaluación de impacto a la vez que se facilita la visualización de los resultados. Este método está especialmente enfocado a ofrecer una herramienta sencilla al mundo corporativo. La herramienta se llama "Sustainability SWOT" (DAFO de sostenibilidad) y combina dos métodos: la matriz de estrategia DAFO (Debilidades, Amenazas, Fortalezas y Oportunidades) con el ACV. En la práctica, la herramienta se estructura en 4 fases: (1) Identificación de las etapas del ciclo de vida, (2) Identificación de los impactos en sostenibilidad (en los 3 pilares) ahora y en el futuro, (3) Interpretación de los impactos, (4) Compilación del DAFO de sostenibilidad, donde se visualizan los resultados.

\subsection{Marco para el enfoque ASCV Análisis}

El $7 \%$ ( 2 casos) de los casos de estudio revisados utilizan o proponen el marco ASCV Análisis desarrollado por el proyecto CALCAS. Como se indica en la sección 1.4.1, dicho proyecto representa los primeros esfuerzos centrados en establecer un marco de referencia para la puesta en práctica de la metodología del ASCV Análisis. En la práctica, el marco propuesto toma la estructura metodológica del ACV según las ISO 14040, pero combinando la fase de inventario y evaluación de impactos en una sola fase: "modelado". Especial atención debe prestarse en utilizar las técnicas de análisis adecuadas durante el modelado, incluyendo modelos técnicos, físicos, ambientales, micro y meso-macro económicos, culturales, políticos, éticos y sociales (Heijungs et al. 2010).

Van der Giesen et al. (2013) profundiza en los resultados del proyecto CALCAS, y propone un marco metodológico considerando también las conclusiones de casos de estudio de ASCV publicados hasta la fecha. Este marco está especialmente pensado para nuevas tecnologías, y consiste en cinco pasos:

1. Descripción del sistema: Describir el sistema de forma amplia proporciona una base sólida para abordar las etapas encaminadas a la evaluación de sostenibilidad del ciclo de vida de una tecnología. Aporta ideas para realizar la pregunta correcta e identificar los actores relevantes del ciclo de vida. Desde el punto de vida de la ecología industrial, se recomienda examinar el sistema a través de un enfoque ascendente con actores no directamente implicados para identificar posibles impactos o puntos de atención que probablemente no se traten pero son relevantes en una visión más amplia. 
CAPÍTULO 1: Introducción

2. Definición de escenarios: Definir escenarios de posible desarrollo en la tecnología o servicio prestado.

3. Indicadores y herramientas: Encontrar las herramientas adecuadas para cuantificar los indicadores identificados.

4. Aplicación de herramientas (incluyendo recogida de inventarios).

5. Interpretación de resultados.

Hu et al. (2013) profundizan en el marco metodológico propuesto por el proyecto CALCAS, proporcionando cinco pasos operacionales para la puesta en práctica del ASCV, muy similares a los propuestos por van der Giesen et al.: (1) Definición amplia del sistema, (2) Definición de escenarios, (3) Definición de sub-preguntas para herramientas individuales (4) aplicación de herramientas y (5) interpretación de resultados en un marco ASCV. La diferencia más notable con los cinco pasos de van der Giesen et al. es que este método pone especial énfasis en las preguntas para la elección de las herramientas de análisis (paso 3).

Stefanova et al. (2014) también profundiza en el marco metodológico iniciado por CALCAS, proponiendo los siguientes pasos para la consecución de la fase de "definición de objetivos y alcance": (1) definición de objetivos a nivel macro, (2) mapa tecnológico y (3) descripción del contexto (técnico, social, económico y ambiental). 
Tabla 1 Resumen de los casos de estudio que implementan el ASCV

\begin{tabular}{|c|c|c|c|c|c|c|}
\hline Producto & Publicación & $\begin{array}{l}\text { Enfoque/ } \\
\text { Marco del } \\
\text { análisis }\end{array}$ & $\begin{array}{l}\text { Área ambiental } \\
\text { (Herramienta e indicadores) }\end{array}$ & $\begin{array}{l}\text { Área económica } \\
\text { (Herramienta e } \\
\text { indicadores) }\end{array}$ & $\begin{array}{l}\text { Área social (Herramienta e } \\
\text { indicadores) }\end{array}$ & $\begin{array}{l}\text { Metodología de } \\
\text { agregación y } \\
\text { ponderación }\end{array}$ \\
\hline $\begin{array}{l}\text { Bioetanol ( } 3 \\
\text { alternativas) }\end{array}$ & (Ren et al. 2015) & $\begin{array}{l}\text { ASCV } \\
\text { Evaluación }\end{array}$ & ACV-A (ReCiPe Midpoint) & $\begin{array}{l}\text { CCV. Coste de ciclo de } \\
\text { vida (coste de } \\
\text { producción). }\end{array}$ & $\begin{array}{l}\text { ACV-S. (UNEP/SETAC). } \\
\text { Condiciones laborales, } \\
\text { Repercusión socio-económica }\end{array}$ & $\begin{array}{l}\text { Método MCDM que } \\
\text { combina el PAJ y el } \\
\text { método VIKOR para } \\
\text { priorizar alternativas. }\end{array}$ \\
\hline $\begin{array}{l}\text { Electricidad de origen } \\
\text { nuclear }\end{array}$ & $\begin{array}{l}\text { (Stamford 2012, } \\
\text { Stamford and } \\
\text { Azapagic 2011, } \\
\text { Stamford and } \\
\text { Azapagic 2014) }\end{array}$ & $\begin{array}{l}\text { Marco propio } \\
\text { (una selección } \\
\text { de } \\
\text { indicadores) }\end{array}$ & ACV-A (CML 2001) & $\begin{array}{l}\text { Análisis tecno- } \\
\text { económico. (Cuestiones } \\
\text { técnicas, Coste Nivelado } \\
\text { de la energía, incentivos } \\
\text { financieros, variabilidad } \\
\text { de costes) }\end{array}$ & $\begin{array}{l}\text { Ocho categorías (Empleo, } \\
\text { Impactos en salud humana, } \\
\text { Riesgos de accidentes, } \\
\text { Impactos en la comunidad } \\
\text { local, Derechos humanos, } \\
\text { Seguridad energética, } \\
\text { Proliferación nuclear, equidad } \\
\text { intergeneracional) }\end{array}$ & No contemplado. \\
\hline $\begin{array}{l}\text { Módulos } \\
\text { fotovoltaicos }\end{array}$ & $\begin{array}{l}\text { (Traverso et al. } \\
\text { 2012) }\end{array}$ & $\begin{array}{l}\text { ASCV } \\
\text { Evaluación }\end{array}$ & ACV-A (Eco-indicador 99) & $\begin{array}{l}\text { CCV. Costes totales } \\
\text { (células, materiales, } \\
\text { equipos, electricidad, } \\
\text { fuerza laboral) }\end{array}$ & $\begin{array}{l}\text { ACV-S. (UNEP/SETAC). } \\
\text { Categoría Trabajadores }\end{array}$ & $\begin{array}{l}\text { Panel de sostenibilidad } \\
\text { de ciclo de vida. Sin } \\
\text { ponderación }\end{array}$ \\
\hline $\begin{array}{l}\text { Producción de biogás } \\
\text { ( } 3 \text { alternativas) }\end{array}$ & $\begin{array}{l}\text { (Nzila et al. } \\
\text { 2012) }\end{array}$ & $\begin{array}{l}\text { Análisis de } \\
\text { Sostenibilidad } \\
\text { multi-criterio }\end{array}$ & $\begin{array}{l}\text { ACV-A (Agotamiento de } \\
\text { recursos, Cambio climático, } \\
\text { Demanda de energía) }\end{array}$ & $\begin{array}{l}\text { Coste de inversión, coste } \\
\text { laboral, autonomía } \\
\text { energética. }\end{array}$ & No contemplado. & $\begin{array}{l}\text { MCDM. Diagrama de } \\
\text { araña, sin ponderación. }\end{array}$ \\
\hline $\begin{array}{l}\text { Doce tecnologías de } \\
\text { producción de } \\
\text { hidrógeno }\end{array}$ & $\begin{array}{l}\text { (Manzardo et al. } \\
\text { 2012) }\end{array}$ & $\begin{array}{l}\text { ASCV } \\
\text { Evaluación }\end{array}$ & ACV-A (no realizado) & CCV (no realizado) & ACV-S (no realizado) & $\begin{array}{l}\text { Un nuevo método MCDM } \\
\text { desarrollado para el } \\
\text { estudio }\end{array}$ \\
\hline $\begin{array}{l}\text { Producción de } \\
\text { hidrógeno }\end{array}$ & $\begin{array}{l}\text { (Stefanova et al. } \\
\text { 2014) }\end{array}$ & ASCV Análisis & $\begin{array}{l}\text { Sin caso de estudio (solo } \\
\text { alcance) }\end{array}$ & No contemplado & No contemplado & No contemplado \\
\hline
\end{tabular}




\begin{tabular}{|c|c|c|c|c|c|c|}
\hline Producto & Publicación & $\begin{array}{l}\text { Enfoque/ } \\
\text { Marco del } \\
\text { análisis }\end{array}$ & $\begin{array}{l}\text { Área ambiental } \\
\text { (Herramienta e indicadores) }\end{array}$ & $\begin{array}{l}\text { Área económica } \\
\text { (Herramienta e } \\
\text { indicadores) }\end{array}$ & $\begin{array}{l}\text { Área social (Herramienta e } \\
\text { indicadores) }\end{array}$ & $\begin{array}{l}\text { Metodología de } \\
\text { agregación y } \\
\text { ponderación }\end{array}$ \\
\hline $\begin{array}{l}\text { Seis combustibles } \\
\text { para transporte }\end{array}$ & $\begin{array}{l}\text { (Zhou et al. } \\
\text { 2007) }\end{array}$ & No indicado & $\begin{array}{l}\text { ACV-A (Potencial de } \\
\text { Calentamiento Global) }\end{array}$ & $\begin{array}{l}\text { CCV: coste total de ciclo } \\
\text { de vida para el } \\
\text { consumidor }\end{array}$ & No contemplado & $\begin{array}{l}\text { MCDM. Varios esquemas } \\
\text { de ponderación. }\end{array}$ \\
\hline $\begin{array}{l}\text { Tecnología solar } \\
\text { fotovoltaica }\end{array}$ & $\begin{array}{l}\text { (Yu and Halog } \\
\text { 2015) }\end{array}$ & $\begin{array}{l}\text { ASCV } \\
\text { Evaluación }\end{array}$ & $\begin{array}{l}\text { ACV-A (CML } 2000+\text { Tiempo } \\
\text { de retorno energético) }\end{array}$ & $\begin{array}{l}\text { CCV. LEC, coste de } \\
\text { electricidad al año, VAN, } \\
\text { flujos de caja }\end{array}$ & $\begin{array}{l}\text { ACV-S. UNEP/SETAC } \\
\text { guidelines. Different } \\
\text { stakeholders, qualitative } \\
\text { information. }\end{array}$ & $\begin{array}{l}\text { Diagrama radial } \\
\text { triangular (Panel de } \\
\text { sostenibilidad) }\end{array}$ \\
\hline $\begin{array}{l}\text { Reutilización de } \\
\text { residuos de equipos } \\
\text { electrónicos y } \\
\text { eléctricos. }\end{array}$ & $\begin{array}{l}\text { (Lu et al. 2014) } \\
\text { Comunicación } \\
\text { en congreso. }\end{array}$ & $\begin{array}{l}\text { No indicado. } \\
\text { ¿ASCV } \\
\text { Evaluación? }\end{array}$ & ACV-A. Eco-indicador 99 & $\begin{array}{l}\text { CCV. Coste de ciclo de } \\
\text { vida }\end{array}$ & $\begin{array}{l}\text { ACV-S.UNEP/SETAC. Salud } \\
\text { humana, salarios y creación de } \\
\text { empleo }\end{array}$ & No contemplado \\
\hline $\begin{array}{l}\text { Tratamiento de } \\
\text { residuos sólidos } \\
\text { municipales. }\end{array}$ & $\begin{array}{l}\text { (Menikpura et } \\
\text { al. 2012) }\end{array}$ & $\begin{array}{l}\text { No indicado. } \\
\text { ¿ASCV } \\
\text { Evaluación? }\end{array}$ & ACV-A (Eco-indicador 99) & $\begin{array}{l}\text { CCV. Coste de ciclo de } \\
\text { vida }\end{array}$ & $\begin{array}{l}\text { Daño a la salud humana } \\
\text { (DALY) y bienestar } \\
\text { comunitario (por empleo) }\end{array}$ & No contemplado \\
\hline $\begin{array}{l}\text { Disposal scenarios for } \\
\text { used PET bottles }\end{array}$ & $\begin{array}{l}\text { (Foolmaun and } \\
\text { Ramjeawon } \\
\text { 2013) }\end{array}$ & $\begin{array}{l}\text { ASCV } \\
\text { Evaluación }\end{array}$ & ACV-A. Eco-Indicator 99 & $\begin{array}{l}\text { CCV. Coste de ciclo de } \\
\text { vida y VAN }\end{array}$ & $\begin{array}{l}\text { ACV-S. UNEP/SETAC. } \\
\text { Categorías: trabajadores, } \\
\text { sociedad, comunidad local }\end{array}$ & $\begin{array}{l}\text { PAJ, usando el vector } \\
\text { Eigen }\end{array}$ \\
\hline $\begin{array}{l}\text { Sistemas de colección } \\
\text { de aceite usado. }\end{array}$ & $\begin{array}{l}\text { (Vinyes et al. } \\
\text { 2013) }\end{array}$ & $\begin{array}{l}\text { ASCV } \\
\text { Evaluación }\end{array}$ & ACV-A. (CML-2001) & $\begin{array}{l}\text { CCV. Coste de ciclo de } \\
\text { vida interno y externo. }\end{array}$ & $\begin{array}{l}\text { ACV-S. UNEP/SETAC. } \\
\text { Trabajadores y empleo local }\end{array}$ & $\begin{array}{l}\text { Diagrama triangular: } \\
\text { puntuación en relación a } \\
\text { otras alternativas }\end{array}$ \\
\hline $\begin{array}{l}\text { Reciclado de } \\
\text { hormigón }\end{array}$ & (Hu et al. 2013) & ASCV Análisis & ACV-A. No realizado & $\begin{array}{l}\text { CCV. Coste de ciclo de } \\
\text { vida. No realizado }\end{array}$ & $\begin{array}{l}\text { ACV-S UNEP/SETAC. No } \\
\text { realizado }\end{array}$ & MCDA. No realizado \\
\hline $\begin{array}{l}\text { Reciclado de vidrio en } \\
\text { automoción }\end{array}$ & $\begin{array}{l}\text { (Hoogmartens et } \\
\text { al. 2014) }\end{array}$ & $\begin{array}{l}\text { ASCV } \\
\text { Evaluación }\end{array}$ & ACV-A. & $\begin{array}{l}\text { Análisis Coste-Beneficio o } \\
\text { e-CCV }\end{array}$ & CCV o ACV-S (no realizado) & No contemplado \\
\hline Edificios residenciales & $\begin{array}{l}\text { (Hossaini et al. } \\
\text { 2015) }\end{array}$ & $\begin{array}{l}\text { ASCV } \\
\text { Evaluación }\end{array}$ & $\begin{array}{l}\text { ACV-A. Herramienta de la US } \\
\text { EPA y revisión bibliográfica }\end{array}$ & CCV. Con VAN & $\begin{array}{l}\text { Análisis de temas sociales } \\
\text { importantes según la revisión }\end{array}$ & MCDM: PAJ \\
\hline
\end{tabular}




\begin{tabular}{|c|c|c|c|c|c|c|}
\hline Producto & Publicación & $\begin{array}{l}\text { Enfoque/ } \\
\text { Marco del } \\
\text { análisis }\end{array}$ & $\begin{array}{l}\text { Área ambiental } \\
\text { (Herramienta e indicadores) }\end{array}$ & $\begin{array}{l}\text { Área económica } \\
\text { (Herramienta e } \\
\text { indicadores) }\end{array}$ & $\begin{array}{l}\text { Área social (Herramienta e } \\
\text { indicadores) }\end{array}$ & $\begin{array}{l}\text { Metodología de } \\
\text { agregación y } \\
\text { ponderación }\end{array}$ \\
\hline $\begin{array}{l}\text { Renovación de } \\
\text { edificios }\end{array}$ & $\begin{array}{l}\text { (Ostermeyer et } \\
\text { al. 2013) }\end{array}$ & No indicado & ACV-A. Recipe, CED & $\begin{array}{l}\text { CCV. Coste de ciclo de } \\
\text { vida }\end{array}$ & ACV-S (no realizado) & Aproximación de Pareto \\
\hline $\begin{array}{l}\text { Edificios comerciales } \\
\text { y residenciales de } \\
\text { EEUU }\end{array}$ & $\begin{array}{l}\text { (Onat et al. } \\
\text { 2014) }\end{array}$ & $\begin{array}{l}\text { Análisis } 10 \\
\text { híbrido con } \\
\text { ACV }\end{array}$ & $\begin{array}{l}\text { ACV-A híbrido basado en IO. } \\
\text { GEI, consumo de energía, } \\
\text { huella hídrica, generación de } \\
\text { residuos y otros indicadores } \\
\text { ecológicos }\end{array}$ & $\begin{array}{l}\text { IO. Importaciones, } \\
\text { beneficio empresarial, } \\
\text { PIB }\end{array}$ & $\begin{array}{l}\text { IO. Ingresos, impuestos, } \\
\text { heridas }\end{array}$ & Diagrama de araña. \\
\hline $\begin{array}{l}\text { Cuatro alternativas } \\
\text { para pavimentos }\end{array}$ & $\begin{array}{l}\text { (Kucukvar et al. } \\
\text { 2014, Kucukvar } \\
\text { et al. 2014) }\end{array}$ & $\begin{array}{l}\text { Análisis IO } \\
\text { híbrido con } \\
\text { ACV }\end{array}$ & $\begin{array}{l}\text { IO. GEI, consumo de energía, } \\
\text { huella hídrica, generación de } \\
\text { residuos y otros indicadores } \\
\text { ecológicos }\end{array}$ & $\begin{array}{l}\text { IO. Importaciones, } \\
\text { beneficio empresarial }\end{array}$ & $\begin{array}{l}\text { IO. Ingresos, impuestos, } \\
\text { heridas }\end{array}$ & $\begin{array}{l}\text { MCDM: Distintos } \\
\text { esquemas de } \\
\text { ponderación. Conjuntos } \\
\text { difusos y TOPSIS } \\
\text { (Tecnique for Order of } \\
\text { Preference by Similarity } \\
\text { to Ideal Solution). }\end{array}$ \\
\hline $\begin{array}{l}\text { Tres tipos de } \\
\text { producción de acero }\end{array}$ & $\begin{array}{l}\text { (Burchart-Korol } \\
\text { 2013) }\end{array}$ & $\begin{array}{l}\text { ASCV } \\
\text { Evaluación }\end{array}$ & ACV-A (Huella de carbono) & CCV (no realizado) & $\begin{array}{l}\text { ACV-S (no realizado) } \\
\text { Estimación de empleo } \\
\text { generado }\end{array}$ & No contemplado \\
\hline $\begin{array}{l}\text { Procesos de } \\
\text { fabricación }\end{array}$ & $\begin{array}{l}\text { (Peukert et al. } \\
\text { 2015) }\end{array}$ & $\begin{array}{l}\text { "Tiered } \\
\text { approach" }\end{array}$ & ACV-A (Huella de carbono) & Costes de fabricación & Salarios justos & No contemplado \\
\hline $\begin{array}{l}\text { Materiales para } \\
\text { tuberías de } \\
\text { alcantarillas }\end{array}$ & $\begin{array}{l}\text { (Akhtar et al. } \\
\text { 2015) }\end{array}$ & $\begin{array}{l}\text { No indicado. } \\
\text { Parece ASCV } \\
\text { Evaluación. }\end{array}$ & $\begin{array}{l}\text { ACV-A (Consumo energía, } \\
\text { recursos, huella de carbon, } \\
\text { acidificación y formación de } \\
\text { smog) }\end{array}$ & $\begin{array}{l}\text { CCV. Coste de ciclo de } \\
\text { vida. }\end{array}$ & No contemplado & $\begin{array}{l}\text { Dos marcos: PAJ y } \\
\text { usando un solo indicador } \\
\text { (emergía). }\end{array}$ \\
\hline $\begin{array}{l}\text { Plantaciones de } \\
\text { manglares }\end{array}$ & $\begin{array}{l}\text { (Moriizumi et al. } \\
\text { 2010) }\end{array}$ & No indicado. & ACV-A (Carbon footprint) & Flujo de caja acumulado. & $\begin{array}{l}\text { Empleo creado Amount of } \\
\text { employment created }\end{array}$ & $\begin{array}{l}\text { MCMD propuesto (no } \\
\text { realizado) }\end{array}$ \\
\hline
\end{tabular}




\begin{tabular}{|c|c|c|c|c|c|c|}
\hline $\begin{array}{l}\text { Transporte y } \\
\text { producción de } \\
\text { fertilizantes }\end{array}$ & $\begin{array}{l}\text { (Martínez- } \\
\text { Blanco et al. } \\
\text { 2014) }\end{array}$ & $\begin{array}{l}\text { ASCV } \\
\text { Evaluación }\end{array}$ & $\begin{array}{l}\text { ACV-A. } 10 \text { categorías de } \\
\text { punto medio }\end{array}$ & $\begin{array}{l}\text { CCV. Coste de ciclo de } \\
\text { vida }\end{array}$ & ACV-S. UNEP/SETAC & $\begin{array}{l}\text { Panel de Ciclo de Vida de } \\
\text { la Sostenibilidad }\end{array}$ \\
\hline $\begin{array}{l}\text { Vehículos de } \\
\text { pasajeros }\end{array}$ & $\begin{array}{l}\text { (Onat et al. } \\
\text { 2014) }\end{array}$ & $\begin{array}{l}\text { Input Output } \\
\text { híbrido con } \\
\text { ACV-A }\end{array}$ & $\begin{array}{l}\text { Huella de carbon, consume } \\
\text { de agua, consume de } \\
\text { energía, generación de } \\
\text { residuos peligrosos, } \\
\text { formación de partículas + } \\
\text { otros indicadores ecológicos }\end{array}$ & $\begin{array}{l}\text { IO excedente bruto de } \\
\text { operación, PIB, } \\
\text { importaciones e } \\
\text { impuestos }\end{array}$ & $\begin{array}{l}\text { IO. Ingresos, accidents, } \\
\text { creación de empleo, salud } \\
\text { humana. }\end{array}$ & Diagrama de araña \\
\hline Embajaje & $\begin{array}{l}\text { (Dobon et al. } \\
\text { 2011) }\end{array}$ & Marco propio & ACV-A & $\begin{array}{l}\text { CCV (costs internos y } \\
\text { externos) }\end{array}$ & Valoración contingente (WTP) & No contemplado \\
\hline
\end{tabular}

*PAJ= Proceso Analítico jerárquico. MCDM= Métodos de toma de análisis multi-criterio (del inglés, Multi Criteria Decision Making). IO= Input Output. CED= Demanda acumulada de energía, del inglés, Cumulative Energy Demand 
Otro aspecto importante de este enfoque es definir el nivel requerido de análisis que proporcionará los resultados más ajustados al objetivo o pregunta principal. El proyecto CALCAS identificó tres niveles de análisis de sostenibilidad, con características y necesidades específicas (Zamagni et al. 2009):

- Sistemas micro; contemplan el sistema producto. Presentan efectos limitados en el espacio, tiempo y mercado. Un ejemplo de este nivel sería la comparación entre el impacto ambiental de un cultivo de maíz o uno de jatrofa para la producción de bioetanol. Sus características principales son: baja variabilidad, baja complejidad, baja incertidumbre, y buen conocimiento de los datos y modelos. Principales necesidades: normalización, simplicidad, análisis de detalle.

- Sistemas meso; contemplan los efectos relevantes del sistema producto sobre otros sistemas en el tiempo y el espacio. Un ejemplo en este nivel podría ser la estimación impacto ambiental de introducir el bioetanol como principal combustible para el transporte. Sus características principales son: baja variabilidad, alta complejidad, incertidumbre media, y disponibilidad de suficientes modelos fiables y datos; principales necesidades: confiabilidad, prevalencia de métodos analíticos sobre procedimientos y cuantitativos vs cualitativos, participación de partes interesadas, efectos rebote, análisis de sensibilidad.

-Sistemas macro; contemplan los efectos relevantes del sistema producto sobre toda la economía. Un ejemplo de este nivel podría ser la estimación del impacto ambiental derivado del cambio de uso del suelo de productos alimentarios a combustibles. Presentan baja reversibilidad, alta penetración y capacidad de difusión en todos los ámbitos y efectos relevantes en todos los niveles. Se caracterizan por: alta variabilidad, alta complejidad, alta incertidumbre, y muchas carencias de conocimientos y datos; principales necesidades: integrar todas las posibilidades, interacciones y mecanismos considerados, participación de expertos, combinación de métodos analíticos y procedimientos, enfoque heurístico para la mejora del aprendizaje de los sistemas, y sistema de "actualización".

\subsubsection{Otros marcos metodológicos}

Entre los 27 casos de estudio encontrados mediante la revisión bibliográfica, hay varios estudios que presentan un marco metodológico diferente a los dos expuestos anteriormente. El $15 \%$ (4 casos) utilizan el análisis Input Output como marco general y el 30 \% (8 estudios) proponen su propio marco metodológico (o uno diferente a los anteriores). Cabe mencionar que los cuatro estudios de Input Output publicados comparten un mismo autor (Murat Kucukvar). 
El análisis Input Output (IO) aplicado al ASCV consiste en integrar indicadores sociales y ambientales en un marco Input Output, mediante las tablas simétricas 10 que describen las relaciones económicas entre los sectores de la economía de una región. Este enfoque proporciona un análisis a nivel meso o macro económico, al tener en cuenta todos los impactos indirectos en la cadena de valor del ciclo de vida (Onat et al. 2014).

Otros autores (Neugebauer et al. 2015, Peukert et al. 2015) defienden la aplicación de un marco metodológico denominado "Tiered approach". Este enfoque proporciona una jerarquía de indicadores para llevar a cabo el análisis de sostenibilidad mediante tres pasos. En el primer paso, se propone analizar los indicadores más importantes en los tres pilares de la sostenibilidad, para posteriormente aumentar el número y complejidad de indicadores en el segundo y tercer paso del análisis. El objetivo de este enfoque es apoyar la aplicación práctica y el desarrollo del marco metodológico mediante una implementación paso a paso de los indicadores de sostenibilidad.

Junto a estos enfoques, también se encuentra el enfoque del proyecto PROSUITE, explicado en la sección 1.4.1 de este capítulo, y que consiste en un análisis con 5 categorías de impacto: Salud humana, bienestar humano, prosperidad, medioambiente natural y recursos agotables. Sin embargo, ningún caso de estudio revisado aplica este enfoque.

\subsubsection{Metodologías para cada pilar de la sostenibilidad.}

El proyecto CALCAS propone 28 posibles métodos de análisis para la profundización del ACV, y por lo tanto, la consecución de un ASCV (Schepelmann et al. 2008). Sin embargo, el 63\% de los casos de estudio revisados sólo utilizan (o proponen, en el caso de los ASCV incompletos) las metodologías de ACV, CCV y ACV-S para el análisis de cada pilar de la sostenibilidad, mientras que el resto de los estudios aplican o proponen otra combinación. Cabe mencionar que en tres estudios no se estudia ni se nombra el pilar social, pero sí se analizan indicadores técnicos (como la exergía, la eficiencia, o el Tiempo de Retorno Energético). A continuación, se describe los métodos elegidos por cada caso de estudio.

\subsubsection{1 Área ambiental}

El hecho de que la metodología de ACV "convencional" comenzara su desarrollo hace décadas y esté estandarizada a nivel internacional, ha propiciado que prácticamente todos los casos de estudio la utilicen para analizar el pilar ambiental. Sólo cuatro estudios (15\%) utilizan la metodología de análisis híbrida Input Output (IO)-ACV. El uso de la metodología híbrida IOACV asegura unos mismos objetivos y alcance del estudio para los tres pilares de la 
sostenibilidad. También facilita y agiliza el análisis, al compartir el mismo inventario en los tres pilares.

Aparte de estos 4 estudios que aplican la metodología IO-ACV, la principal diferencia metodológica de los casos de estudio revisados es la elección de las categorías de impacto ambiental, que en algunos casos se limitan a la huella de carbono, y en otros aplican métodos de evaluación con resultados para más de 15 categorías de impacto.

\subsubsection{2 Área económica}

Existe cierta discrepancia entre los investigadores en torno a la metodología apropiada para el pilar económico de la sostenibilidad. Jorgensen et al. (2010) indicaban que la metodología de CCV no debería tenerse en cuenta en los análisis de sostenibilidad, ya que sus resultados solo son relevantes para la "sostenibilidad de la empresa". Además, siguiendo la definición de sostenibilidad según el informe Brundtland, los beneficios privados de una empresa no son de relevancia para la "sostenibilidad de la sociedad mundial". Klöpffer, respondía a esta afirmación, indicando que incluir el CCV en un análisis de sostenibilidad es relevante dependiendo del caso. Por ejemplo, el CCV informa sobre microeconomía y flujos monetarios reales, que resulta relevante en un análisis de sostenibilidad a escala micro.

En la línea con estos argumentos, Wood y Hertwich (2013) analizan los indicadores correspondientes al pilar económico que deberían incluirse en un ASCV. Defienden que aunque el CCV es un indicador útil para los análisis económicos, falla en representar la dimensión total de la sostenibilidad económica. Además, podría resultar contradictorio ya que mientras el usuario o productor intentará minimizar todos los costes de ciclo de vida y aumentar el beneficio privado, la sociedad preferirá maximizar el salario recibido por los trabajadores y minimizar el beneficio privado de las empresas. El pilar económico de la sostenibilidad debería incluir una perspectiva de bienestar económico global que no está generalmente representada por el CCV. Por ello, Wood y Hertwich proponen ampliar el análisis para incluir otros indicadores representativos de la sostenibilidad a un nivel global, como son el valor añadido (con todos sus componentes: coste laboral, impuestos, beneficios), la productividad del trabajo y capital, el comercio internacional (medido mediante importaciones), la innovación, y los requerimientos estructurales del sistema de producción (medidos mediante los enlaces entre sectores). Para el cálculo de estos indicadores, se recomiendo utilizar la metodología de análisis Input-Output.

A pesar de estas apreciaciones, muchos autores siguen confiando únicamente en la metodología CCV para analizar el pilar económico. De los casos de estudio revisados, el $55 \%$ (15 estudios) aplican el CCV como método para evaluar el pilar económico, de los cuales, 4 
estudios referencian el código práctico de Hunkeler et al. (Hunkeler et al. 2008, Swarr et al. 2011). El 11\% (3 estudios) proponen la metodología de CCV pero no la aplican. En cuando a los demás casos de estudio, el $15 \%$ (4 estudios) utilizan la metodología IO, el 7 \% (2 estudios) analizan únicamente alguna categoría de costes (de fabricación, laboral o de inversión), 2 estudios realizan un análisis tecno-económico en el que tienen en cuenta indicadores específicos de la tecnología estudiada, y un estudio aplica el Flujo de Caja Acumulado.

\subsubsection{3 Área social}

Debido al estado inicial de la metodología ACV-S, se observa gran variabilidad en los indicadores escogidos para analizar el pilar social. Mientras que el $40 \%$ de los estudios revisados (11 estudios) proponen la herramienta de ACV-S desarrollada por la UNEP-SETAC para el análisis del pilar social, sólo 7 de estos estudios la aplican. Además, la mayoría de ellos analizan solamente alguna categoría de impacto y de actores, siendo los trabajadores el actor más analizado. Esto se debe a que a pesar de que la metodología empieza a extenderse y aplicarse por la comunidad científica, todavía surgen dudas y existen cuestiones metodológicas por resolver. El $15 \%$ de los estudios analizan el pilar social mediante indicadores de empleo, ingresos, impuestos y salud humana obtenidos mediante tablas Input Output. El $11 \%$ (3 estudios) analizan indicadores sociales específicos que son relevantes para la tecnología o producto estudiado sin seguir una metodología concreta. Dos estudios analizan el empleo generado y el salario percibido, otro estudio analiza la salud humana y los ingresos, y el resto de estudios (10 estudios) no proporciona información sobre ningún indicador social.

\subsubsection{Otros indicadores de la sostenibilidad en el ASCV}

Hay una serie de mecanismos socio-culturales, institucionales y políticos que no se suelen incluir en los análisis ACV actuales. Por ejemplo, algunas tecnologías podrían no aceptarse por toda la sociedad, como la tecnología nuclear o los transgénicos. Esos mecanismos que resultarían de interés en un análisis de sostenibilidad pueden resultar difícil de integrar en el marco del ASCV. Según Heijungs et al. (2010), la inclusión de estos mecanismos puede verse favorecida por la integración de los distintos actores de la sociedad en la definición de objetivos y alcance, así como en la interpretación de resultados. La inclusión de estos mecanismos se vería más facilitada en un contexto de ASCV Análisis y menos en uno de ASCV Evaluación, ya que el primero pone énfasis en la elección de metodologías que respondan a las cuestiones de sostenibilidad definidas por el alcance y objetivos del estudio.

En esta línea, Pizzirani et al. (2014) profundizan en la pertinencia de incluir la cultura en los ASCV, al detectar su poca presencia en los casos de estudio hasta la fecha. Shneider et al. (2014) 
y Sonnemann et al. (2015) defienden la importancia de incluir la criticidad de recursos (criticality of resources) en los pilares económicos y sociales del ASCV. Coinciden en que la ampliación del ACV al ASCV proporciona una buena oportunidad para incluir los impactos de la criticidad de recursos que, por su naturaleza social y geo-política, suelen quedar fuera del marco metodológico de un ACV.

\subsubsection{Agregación, ponderación e interpretación de resultados}

En los tres principales enfoques metodológicos más aplicados y propuestos para la consecución del ASCV (Assessment, Analysis e Input Output), existe el debate de cómo agregar, evaluar y/o interpretar los impactos de las tres áreas de la sostenibilidad. Es difícil cuantificar la importancia que tiene un área respecto a la otra, pero en ocasiones resulta necesario cuando estamos evaluando dos alternativas que presentan mejoras en áreas diferentes ( $p$ ej. Tomar la decisión de elegir una alternativa que presenta buenos resultados económicos u otra alternativa que presenta mejores resultados en el área del impacto ambiental). La ponderación introduce el juicio subjetivo, ya que alguien puede dar más importancia al área social mientras que otra persona se la da al área ambiental, y ninguno de las dos tiene por qué estar equivocada. Los juicios subjetivos nos alejan de los resultados científicos y objetivos. Sin embargo, ignorar o negar que la ponderación ocurre en la toma de decisiones del mundo real no es un enfoque plausible en el desarrollo de esquemas de evaluación de alternativas (Finkbeiner et al. 2010). Por ello, varios autores se han centrado en el desarrollo de metodologías de agregación y ponderación de impactos, siendo el análisis multi-criterio la metodología preferida.

El análisis multi-criterio para la toma de decisiones (MCDM, del inglés, Multi-Criteria Decision Making) es un tipo de métodos que facilitan encontrar la mejor alternativa, dado un número de alternativas y criterios a tener en cuenta (Triantaphyllou 2013). Por lo tanto, se puede utilizar un método MCDM que ayude en la toma de decisiones respecto a la mejor alternativa considerando criterios ambientales, económicos y sociales. Por lo general, los métodos MCDM combinan métodos de Análisis Multi-Criterio con Métodos de Ponderación, que ayudan a determinar la importancia relativa de los distintos criterios. Wang et al (2009) realizan una revisión de los métodos MCDM aplicados a la sostenibilidad de sistemas de producción energética. Según su revisión, el Proceso Analítico Jerárquico (PAJ) y la Metodología de Conjuntos Difusos son los métodos de análisis multi-criterio más utilizados para la toma de decisiones sobre sostenibilidad energética, aunque se recomienda aplicar distintos métodos MCDM para obtener resultados más racionales. El PAJ es preferido por su aplicación simple, mientras que los conjuntos difusos son especialmente interesantes para decisiones basadas en criterios cualitativos e información vaga o imprecisa (Wang et al. 2009). 
Algunos autores han desarrollado métodos de MCDM adaptados a la evaluación e interpretación del ASCV. Una de las primeras propuestas fue publicada por Finkbeiner et al. (2010), quienes profundizaron en el primer esquema propuesto por Klöepffer (ASCV $=$ ACV + CCV + ACV-S), describiendo dos posibles métodos para la evaluación de resultados basados en el análisis multi-criterio: el "Triángulo de ciclo de vida sostenible" y el "Panel de Sostenibilidad de Ciclo de Vida". Ambas herramientas proporcionan una forma transparente de ponderar los resultados de forma cuantitativa. La primera se propone para facilitar la ponderación de resultados cuando hay tres dimensiones (como en la sostenibilidad) y fue desarrollada inicialmente por Hofstetter et al. (1999) como una forma de ponderar impactos ambientales. El panel de ciclo de vida sostenible fue propuesto por Traverso et al. (2012) en base a la herramienta y software llamado "Panel de sostenibilidad" (traducido del inglés, The Dashboard of Sustainability) desarrollada por un grupo de investigación de la Joint Research Center (Hardi and Semple 2000, Jesinghaus 2000). El Panel de Sostenibilidad de Ciclo de Vida (mostrado en la Figura 6) se presenta como una herramienta para evaluar y comparar distintas alternativas mediante factores económicos, sociales y ambientales. Presenta dos características principales: su capacidad de presentar resultados por cada indicador o agregados mediante un índice, y la visualización gráfica de dichos resultados (mediante un cartograma).
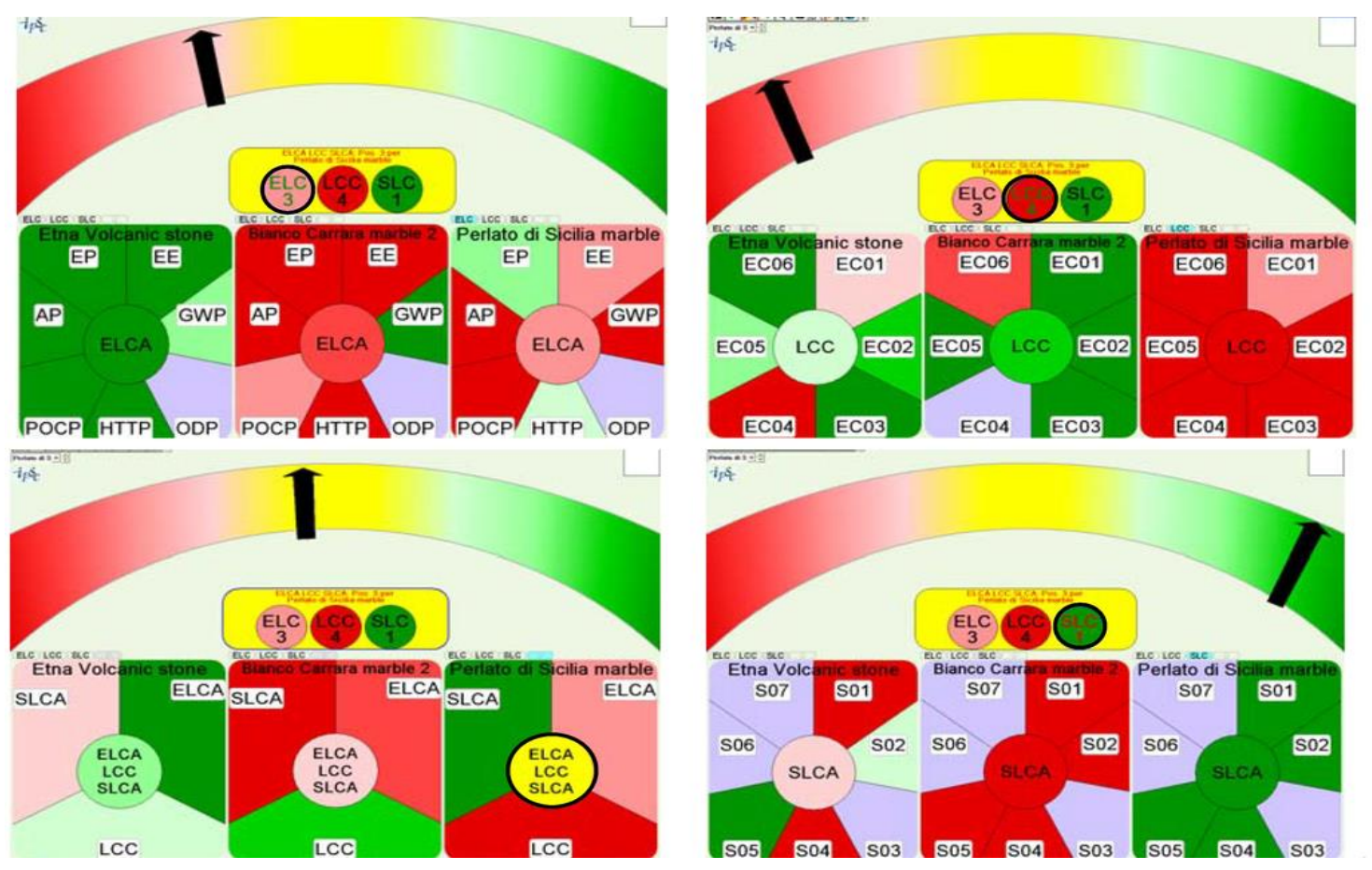

Figura 6 El Panel de Sostenibilidad de Ciclo de Vida según Finkbeiner et al. (2010)

Halog y Manik (2011) proponen una metodología que combina distintos métodos usados por los ecologistas industriales y los economistas biofísicos. Ya que los métodos MCDM aplicados al ACV son estáticos en el tiempo (no proporcionan proyecciones o tendencias futuras), estos 
autores proponen complementar con otros métodos como los Modelos Basados en Agentes y Dinámicas de Sistemas para modelar las interrelaciones dinámicas entre las variables a lo largo del tiempo.

Vinyes et al. (2013) utilizan la metodología de ASCV para analizar la sostenibilidad de distintos métodos de recolección de aceite usado (en escuelas, puerta a puerta, o en centros urbanos específicos). En su estudio utiliza una combinación de las metodologías de ACV, CCV y ACV-S, aplicando una evaluación multi-criterio para abordar la balanza de indicadores y su ponderación final. Para ello, lista los resultados de todos los indicadores obtenidos mediante las tres metodologías. A cada indicador le asigna un porcentaje, siendo $100 \%$ el de mayor valor, y $0 \%$ el de menor. Establece una diferencia entre indicadores con efectos negativos y positivos (para el indicador final de sostenibilidad), asignándoles un valor del 1 al 5, para luego sumarlos y obtener la puntuación de cada análisis (ACV, CCV, ACV-S). Finalmente obtiene un factor de sostenibilidad para cada opción analizada (asignándole un 1 a la opción más sostenible, y calculando los valores de las otras opciones en relación al valor más sostenible).

Según la revisión de estudios ASCV y lo dispuesto en la Figura 7, el 33 \% (9 estudios) de los estudios revisados no aplican ningún método de agregación de resultados, y se limitan a discutir el impacto en cada pilar de sostenibilidad para las alternativas estudiadas; el $19 \%$ (5 estudios) no agregan los resultados pero utilizan un diagrama radial (de araña o en triángulo) para la visualización de resultados; el 15 \% (4 estudios) utilizan un método de Análisis Multicriterio de tipo PAJ; el 7\% (2 estudios) aplican el Panel y Triángulo de Sostenibilidad de Ciclo de Vida (Life Cycle Sustainability Dashboard); y el resto de estudios (7 estudios) aplican un método de análisis multicriterio de toma de decisiones adaptado al caso en cuestión y distinto a los anteriores. Esta información está recopilada en la Tabla 1.

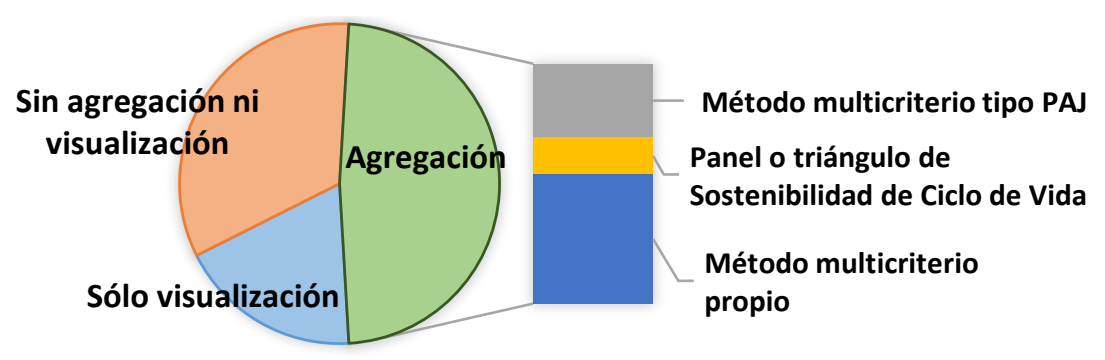

Figura 7 Distribución de las publicaciones revisadas en función del método escogido de agregación de resultados de sostenibilidad

\subsubsection{Conclusiones de la revisión sobre ASCV}

La metodología de ASCV está suscitando gran interés entre la comunidad científica, aumentando exponencialmente el número de publicaciones en los últimos 4 años. Debido a su 
estado inicial de desarrollo hay una gran cantidad de publicaciones encaminadas a la descripción y definición del marco metodológico, aunque también se están aplicando y publicando casos de estudios en productos y servicios muy variados. Según la revisión de casos de estudio realizada, hay más casos en el sector energético, especialmente combustibles, pero también en el sector de la construcción y del tratamiento de residuos.

La revisión de publicaciones sobre desarrollo metodológico indica que hay dos tipos de enfoque para la realización del ASCV: el ASCV Análisis y el ASCV Evaluación. Muchos argumentos se encuentran a favor del enfoque del análisis, ya que es más completo y permite aplicar las herramientas de evaluación más apropiadas para el sistema analizado, sin embargo, la mayor parte de estudios aplica el llamado enfoque evaluación (un 48\% de los casos aplica el evaluación versus un $7 \%$ de los casos que aplica el análisis). Esto puede ser debido a que el enfoque evaluación es más fácil de implementar, y las metodologías por separado constituyen un análisis que tiene valor por sí mismo. Además, las guías aportadas por la UNEP-SETAC que recogen el enfoque evaluación son más accesibles y están más difundidas. Sin embargo, varios autores coinciden en que analizar los tres pilares por separado puede descuidar los impactos transfronterizos o las interrelaciones entre las distintas partes del estudio (Heijungs et al. 2010, van der Giesen et al. 2013), además, el uso del enfoque análisis favorece la inclusión de otros indicadores de la sostenibilidad como la cultura y la criticidad de recursos. Otro enfoque metodológico presente en los casos de estudio (en un 15\%) es el análisis híbrido ACV-Input Output, cuya principal ventaja reside en que su aplicación es relativamente sencilla y supone un ahorro del tiempo invertido (las tres áreas de la sostenibilidad presentan el mismo inventario). Además facilita la aplicación de un enfoque a nivel macro, especialmente en el análisis del pilar económico. Sin embargo, sus posibilidades están muy limitadas al número de sectores que contenga la matriz 10 y a los vectores ambientales y sociales disponibles.

Según la revisión de los casos de estudio, las metodologías de análisis preferidas para el ASCV son el ACV, CCV y ACV-S. Mientras que el ACV se aplica prácticamente en todos los casos de estudio, el CCV y el ACV-S se aplican sólo en el $55 \%$ y $26 \%$ de los estudios revisados respectivamente. Esto es debido principalmente al menor estado de desarrollo del CCV y ACV$\mathrm{S}$, y a la diversidad de métodos de evaluación económica fuera del ámbito del ACV. En cuanto al pilar económico, cabe resaltar que la idoneidad de utilizar el CCV como única metodología para el pilar económico resulta insuficiente para varios expertos (Jorgensen et al. 2013, Wood and Hertwich 2013). 
La cuestión metodológica con más variabilidad en los casos de estudio revisados es el método de agregación, evaluación e interpretación de resultados de sostenibilidad. La mitad de los estudios no agregan los resultados o utilizan un diagrama radial para visualizar los mismos (un 33 y un 15\% respectivamente). El resto de casos de estudio utilizan un método de evaluación multi-criterio, siendo el PAJ el más aplicado.

Sólo el 30\% de los estudios analizados llevan a cabo todos los pasos de la metodología (análisis de los tres pilares de sostenibilidad más agregación y/o ponderación de impactos para la toma de decisiones). Esto es señal de que muchas preguntas rodean hoy a la teoría y práctica del ASCV y el desarrollo metodológico actual todavía no está lo suficiente maduro como para responder a todas ellas. Por lo tanto, son necesarios más casos de estudio que sirvan de base comparativa para, en un futuro, desarrollar estándares que permitan realizar análisis de sostenibilidad con enfoque de ciclo de vida y una base metodológica común. 


\subsection{DESCRIPCIÓN DE LA TECNOLOGÍA SOLAR TERMOELÉCTRICA}

Se han publicado varios trabajos que describen las características técnicas de las plantas termosolares: Lovegrove et al. (2012), Rodríquez Trouwborst (2010), García Garrido (2009), CIEMAT (2009), Fenercom (2012), IRENA $(2012,2014)$ y IDAE (2011). A continuación se detallan las características y los componentes de esta tecnología según la información publicada en dichos trabajos.

La tecnología solar termoeléctrica (abreviada en esta tesis como tecnología termosolar) permite el aprovechamiento de la radiación solar para la generación de energía eléctrica. Los rayos solares se concentran mediante espejos en un receptor que calienta un fluido caloportador. La energía térmica almacenada en el fluido caloportador es transformada en electricidad mediante un ciclo termodinámico convencional. En la mayoría de plantas el ciclo termodinámico es de tipo Rankine, aunque también se utilizan de tipo Stirling, Brayton y ciclos combinados. El diseño del campo solar (compuesto por reflectores y receptor), así como los parámetros termodinámicos, difieren según el tipo de tecnología de concentración. Como se muestra en la Figura 8, actualmente hay cuatro tecnologías principales de concentración solar aplicadas a la producción de energía solar termoeléctrica:

- Tecnología de colectores cilindro-parabólicos: se basa en unos colectores solares conformados por espejos con forma clilindro parabólica que reflejan la radiación sobre un tubo receptor situado en la línea focal. Dicho tubo absorbedor contiene el fluido caloportador (comúnmente aceite sintético), que es transportado mediante un sistema de tuberías hasta el bloque de potencia.

- Tecnología de captadores lineales Fresnel: consiste en la utilización de una serie de espejos lineales que pueden rotar alrededor de su eje para dirigir los rayos reflejados hacia un receptor lineal situado por encima de ellos, que puede ser único o doble. Estos captadores se están proponiendo para la generación directa de vapor a baja temperatura (que circula por el tubo absorbedor). El principal atractivo de esta tecnología reside en su excelente aprovechamiento del terreno y bajo coste potencial.

- Tecnología de torre o de receptor central: consiste en un campo de espejos planos o heliostatos que, gracias a un sistema de seguimiento solar mediante dos ejes, reflejan la radiación sobre un intercambiador de calor situado en la parte superior de una torre central. Existen varias tecnologías posibles para el receptor, cuyo principal fluido caloportador son sales fundidas. 
- Tecnología de disco parabólico: consiste en un conjunto de espejos de forma discoparabólica que siguen al sol mediante dos ejes de giro y en cuyo foco se dispone el receptor solar en el que se calienta el fluido. El fluido es calentado hasta $750^{\circ} \mathrm{C}$ para generar electricidad, actualmente se utilizan principalmente motores Stirling.

Las plantas con tecnología de torre y de generadores disco-parabólicos son sistemas de alta temperatura, y están menos extendidas a nivel comercial que las centrales de colectores cilindro-parabólicos, generalmente clasificadas como media temperatura debido a las limitaciones térmicas del aceite térmico utilizado como fluido de trabajo.

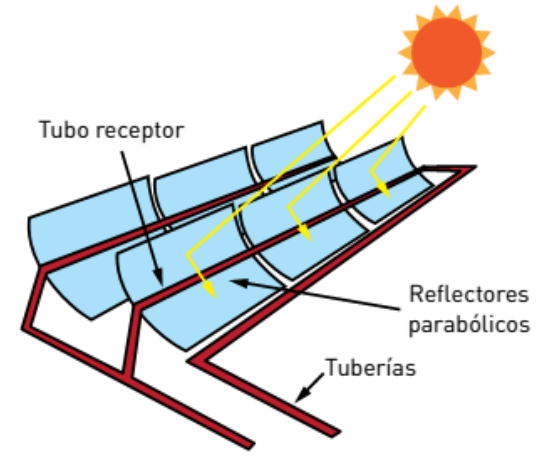
Cilindros parabólicos
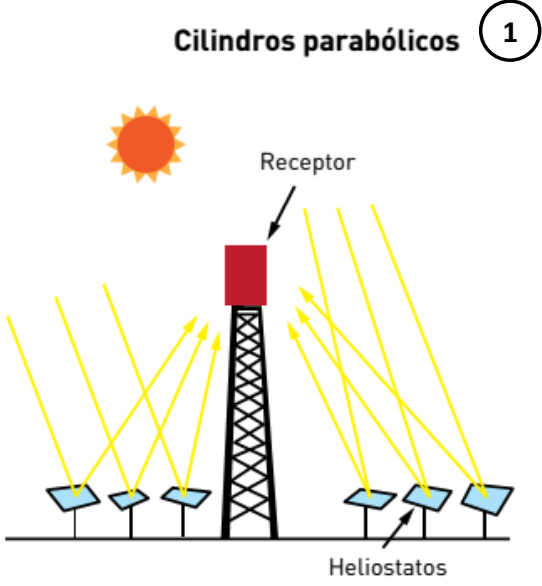

Receptor central

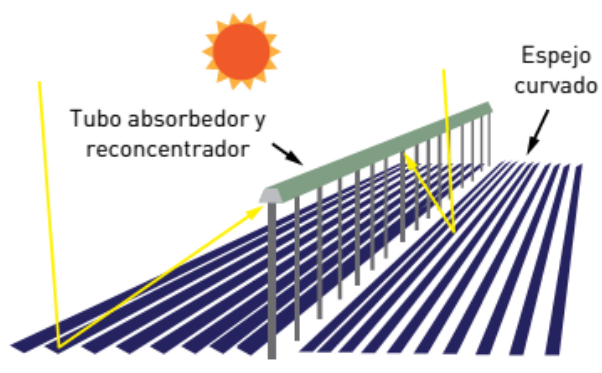

Lineal de Fresnel 2

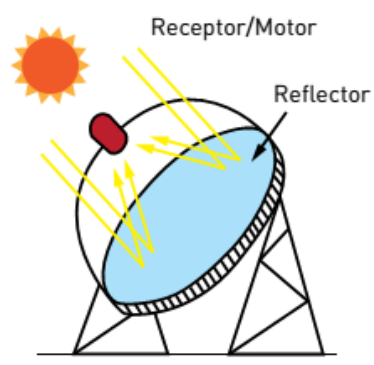

Disco parabólico (4)

Figura 8 Las diferentes tecnologías de la energía solar térmica de concentración (IDAE 2011)

En esta tesis nos centraremos en las tecnologías de colectores cilindro-parabólicos y de torre, ya que son las más desarrolladas y de interés para el proyecto HYSOL. En las siguientes secciones se detallan las partes y características básicas de estas tecnologías.

\subsubsection{Componentes y funcionamiento}

Esta sección contiene información sobre los componentes de las plantas con tecnología cilindro-parabólica y tecnología de torre, así como su funcionamiento básico. 


\subsubsection{Campo solar}

El campo solar es el sistema de componentes encargado de concentrar y reflejar la radiación solar con el objetivo de aprovechar la energía térmica del sol. Los principales componentes del campo solar son los espejos reflectores y el receptor o absorbedor por el que circula el fluido HTF (fluido caloportador, del inglés, Heat Transfer Fluid). A continuación se describen las principales características del campo solar de las dos tecnologías estudiadas.

\subsection{Tecnología de colectores cilindro-parabólicos.}

Los colectores cilindro-parabólicos de una central típica de $50 \mathrm{MW}$ de potencia instalada, miden aproximadamente $150 \mathrm{~m}$ de largo y tienen una apertura de entre 5 y 6 metros de ancho. Los colectores se organizan en lazos de cuatro unidades conectadas en serie, permitiendo que el fluido HTF circule por los tubos absorbedores desde la entrada hasta la salida de cada fila. EI número de lazos de colectores varía en función de la potencia de la planta y de si ésta consta de almacenamiento térmico. La Figura 9 muestra una vista aérea del campo solar de una central termosolar instalada en España (Andasol 1) de $50 \mathrm{MW}$ de potencia y 7,5 horas de almacenamiento térmico, que consta de 624 lazos de colectores.

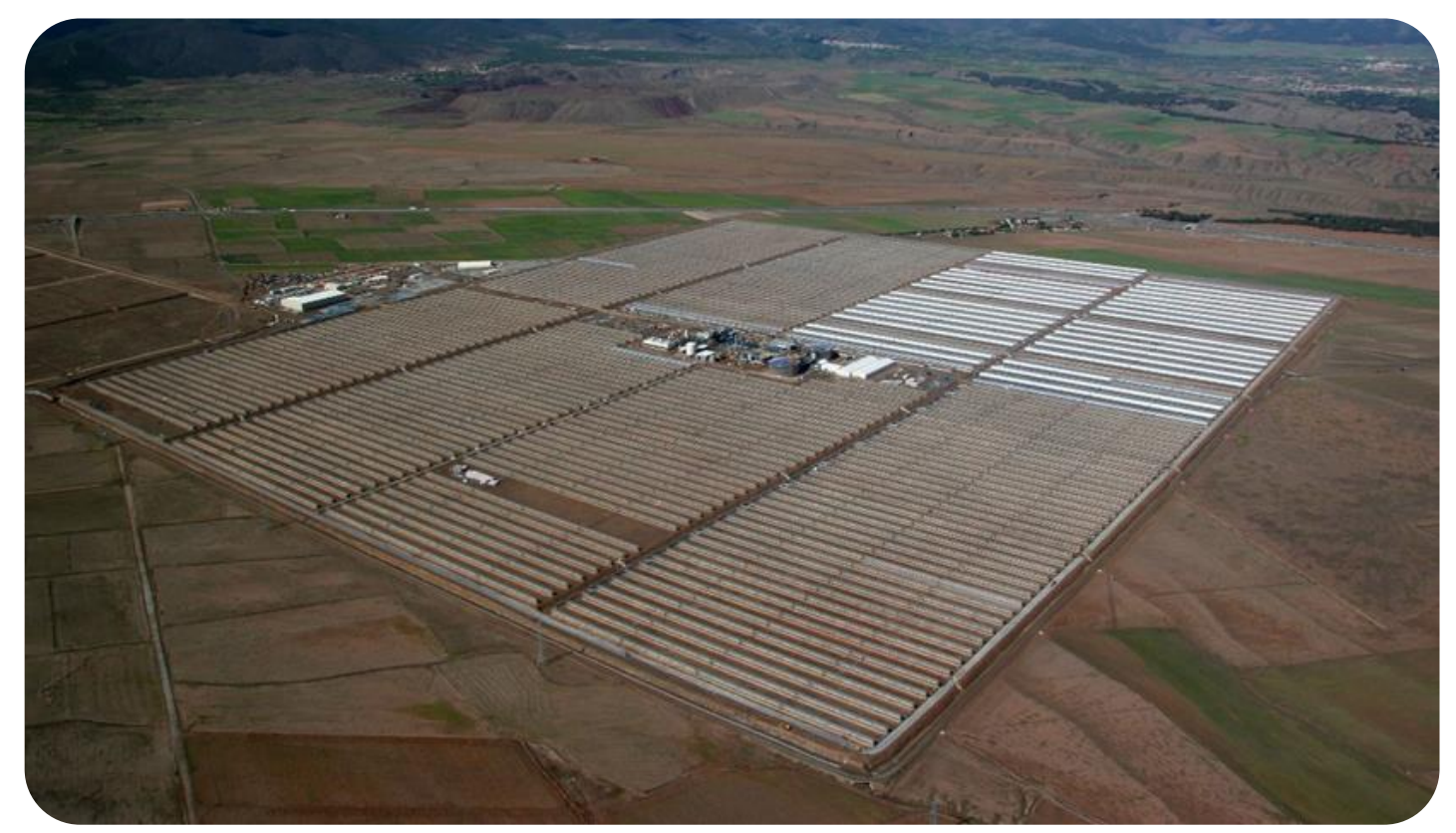

Figura 9 Imagen del campo de colectores cilindro-parabólicos de la planta Andasol 1 desarrollada por la empresa COBRA ACS

De BSMPS - Trabajo propio, GFDL, https://commons. wikimedia.org/w/index.php?curid=8801773

Cada colector contiene los siguientes componentes principales: cimentación y estructura de soporte, reflector cilindro-parabólico, tubo absorbedor y sistema de seguimiento solar. 
- Cimentación y estructura soporte: La cimentación soporta los colectores y los fija al suelo de forma que la estructura soporte las cargas de peso y viento. La estructura del colector es metálica, da rigidez al conjunto de los elementos y sujeta el espejo y tubo absorbente. Adopta diferentes configuraciones según el tipo de colector. En el caso de los colectores SENERtrough ${ }^{\circledR}$ (Figura 10 ) la estructura se basa en un tubo axial que soporta los perfiles metálicos a los que van sujetos los espejos.

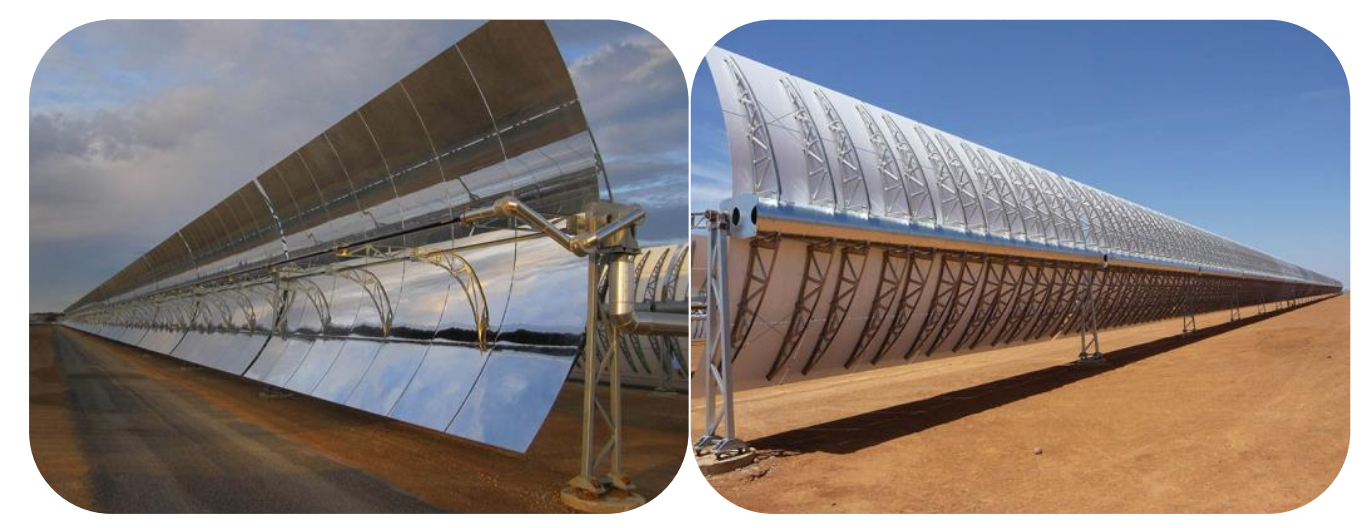

Figura 10 Estructura de un colector SENERtrough ${ }^{\circledR}$

Fuente: SENER, http://www.sener.es/revista-sener/es/n44/al_da_energa_y_procesos.html

- Reflector cilindro-parabólico: Su misión es reflejar la radiación solar incidente y concentrarla en el tubo absorbedor situada en la línea focal de la parábola que forma su perfil. Para reflejar adecuadamente la radiación solar se utilizan películas de plata sobre un soporte vidrioso que aporta rigidez. En estos casos, es común que el vidrio tenga una fina película de plata protegida por una película de cobre y otra de pintura epoxi. Los espejos así configurados pueden tener una reflectividad solar del orden del 93,5 \% (recién instalados). Requieren de limpiezas periódicas para no perder su reflectividad.

- Tubo absorbedor o receptor: Es el elemnto encargado de convertir la radiación solar concentrada en energía térmica. Como se observa en la Figura 11, el tubo absorbedor está compuesto por dos tubos concéntricos: uno interior metálico por el que circula el HTF y otro exterior fabricado con cristal de alta transmitancia. El tubo metálico lleva un recubrimiento selectivo (normalmente compuestos de material cermet) que consigue una elevada absorción de la radiación solar (94\%) y una baja emisión en el espectro infrarrojo (15\%). Entre ambos tubos existe una cámara de vacío (mantenida mediante piezas denominadas getters) que evita la degradación del recubrimiento. El tubo de cristal exterior protege el tubo interior y reduce las pérdidas térmicas por 
convección. Ambos tubos están sellados mediante una soldadura vidrio-metal y un fuelle metálico que compensa la diferente dilatación térmica.

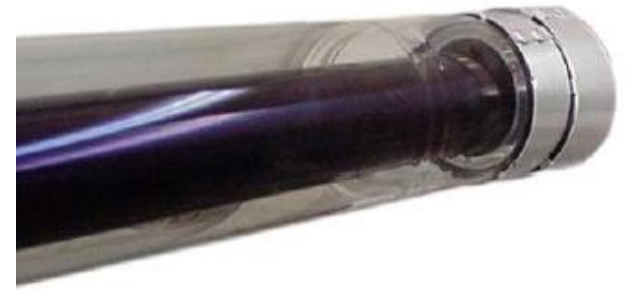

Figura 11 Detalle del tubo absorbedor.

- Sistema de seguimiento solar: Consiste en un mecanismo que cambia la orientación del colector para absorber la máxima radiación posible. El eje de giro suele orientarse en configuraciones Norte-Sur o Este-Oeste, y es controlado mediante un dispositivo electrónico que realiza un seguimiento directo con sensores solares (fotocélulas). Cada colector lleva su controlador local y una unidad hidráulica de accionamiento compuesta por dos pistones. Todos los controladores locales están comunicados con un controlador supervisor de campo situado en la sala central de control de la central.

El circuito HTF permite transportar la energía térmica absorbida por el HTF al ciclo termodinámico. Está compuesto por los siguientes elementos:

- Fluido HTF: El fluido más utilizado es el aceite sintético Therminol ${ }^{\circledR}$ VP-1 (mezcla eutéctica compuesta por un $73,5 \%$ en peso de bifenilo y un $26,5 \%$ de óxido de difenilo). Este aceite trabaja bien a temperaturas inferiores a $400{ }^{\circ} \mathrm{C}$, aunque su punto de congelación es de $12{ }^{\circ} \mathrm{C}$ lo que obliga a mantener la temperatura del circuito por encima de dicho valor. Nuevas centrales también están implementando sales fundidas como fluido caloportador; el uso de sales podría evitar problemas actuales de los aceites relacionados con la degradación del fluido y los escapes de aceite.

- Bombas de circulación: Para una central con $50 \mathrm{MW}$ de potencia instalada suelen instalarse tres bombas horizontales multietapa de aproximadamente $2600 \mathrm{~kW}$ de potencia.

- Tanques de expansión: tanques de acero que homogenizan del aceite tras haber cedido su calor en el tren de generación de vapor, además de como apoyo para casos de vaciado del campo solar.

- $\quad$ Tanques de rebose: Tanques de acero a presión situados a nivel del suelo que recogen el fluido que rebosa de los tanques de expansión junto con el fluido limpio procedente del sistema de regeneración del aceite. Son los que configuran los llamados sistemas de merma (tres tanques) y recuperación (dos tanques). 
- Tanques de almacenamiento y de nitrógeno: almacenan el fluido térmico no utilizado y el nitrógeno que se utiliza en el sistema para presurizaciones.

- Aero-refrigerador y aerocondensador: Enfrían mediante aire el fluido y condensan los vapores del sistema para el proceso de regeneración del fluido térmico.

El fluido circula desde los tanques de expansión y rebose hasta el campo solar, donde las bombas de circulación regulan el caudal. El fluido entra al campo solar con una temperatura aproximada de $290^{\circ} \mathrm{C}$, y aumenta $100^{\circ} \mathrm{C}$ de temperatura durante su recorrido. La energía térmica recogida es transferida al ciclo de agua-vapor mediante el sistema de generación de vapor (descrito en el bloque de potencia, sección 1.5.1.3 de este capítulo).

\subsection{Tecnología de torre}

La principal ventaja de la tecnología de torre respecto a la cilindro-parabólica es que toda la radiación es concentrada en un receptor central, evitando la necesidad de redes de transporte de energía térmica en el campo solar, y aumentando la eficiencia y la temperatura del calor recolectado. La desventaja es que la cantidad de radiación solar recolectada por área es menor, y los espejos precisan ser colocados con suficiente espacio como para evitar sombras y bloqueos del sol.

- Los heliostatos

Los heliostatos son los espejos encargados de concentrar la radiación solar en el receptor central. Normalmente los heliostatos se componen de espejos planos de unos 4-6 mm de espesor, llamados facetas, colocados con una ligera inclinación para superponer sus imágenes en el receptor. Los heliostatos así configurados pueden tener una reflectividad de $92 \%$, y consiguen concentrar en el receptor el 97 \% de la radiación que reciben (Fenercom 2012). La superficie de los heliostatos suele ser de unos 100-150 $\mathrm{m}^{2}$, aunque los hay más pequeños cuando la instalación es de baja potencia.

Los espejos son montados sobre un soporte móvil diseñado para seguir y reflejar la luz solar en el receptor central de forma eficiente. El sistema de seguimiento solar más común en los heliostatos es el sistema de dos ejes elevación-acimut. Alternativamente, pueden incorporar un tercer eje de rotación (respecto al centro del heliostato) para evitar pérdidas.

La limpieza de heliostatos es muy importante para obtener una alta eficiencia. Si los espejos son enjuagados y restregados de la forma adecuada, las pérdidas medias de reflectividad pueden estar limitadas a un $6 \%$, mientras que si se añade un ciclo adicional de limpiezas ligeras entre lavados, las pérdidas pueden bajar hasta un 3,5\% (Lovegrove and Stein 2012). 
Hay dos configuraciones principales para el campo solar: el campo norte (los heliostatos se sitúan al norte de la torre, concentrando la luz en una sola cara del receptor) y el campo circular (donde los heliostatos se sitúan en torno a la torre, que no se encuentra en el centro del campo si no desplazada hacia el sur). Sin embargo, se ha comprobado empíricamente que la disposición circular escalonada es la mejor solución (Lovegrove and Stein 2012). El tamaño del campo solar se incrementa con la potencia instalada, lo que lleva a incrementar la distancia entre el receptor y los espejos situados en las afueras del campo solar. Una mayor distancia entre heliostatos y receptores resulta en mayores pérdidas ópticas debido a absorción atmosférica, mayor desviación angular debido a imperfecciones en los espejos, y errores en el seguimiento solar de los espejos.

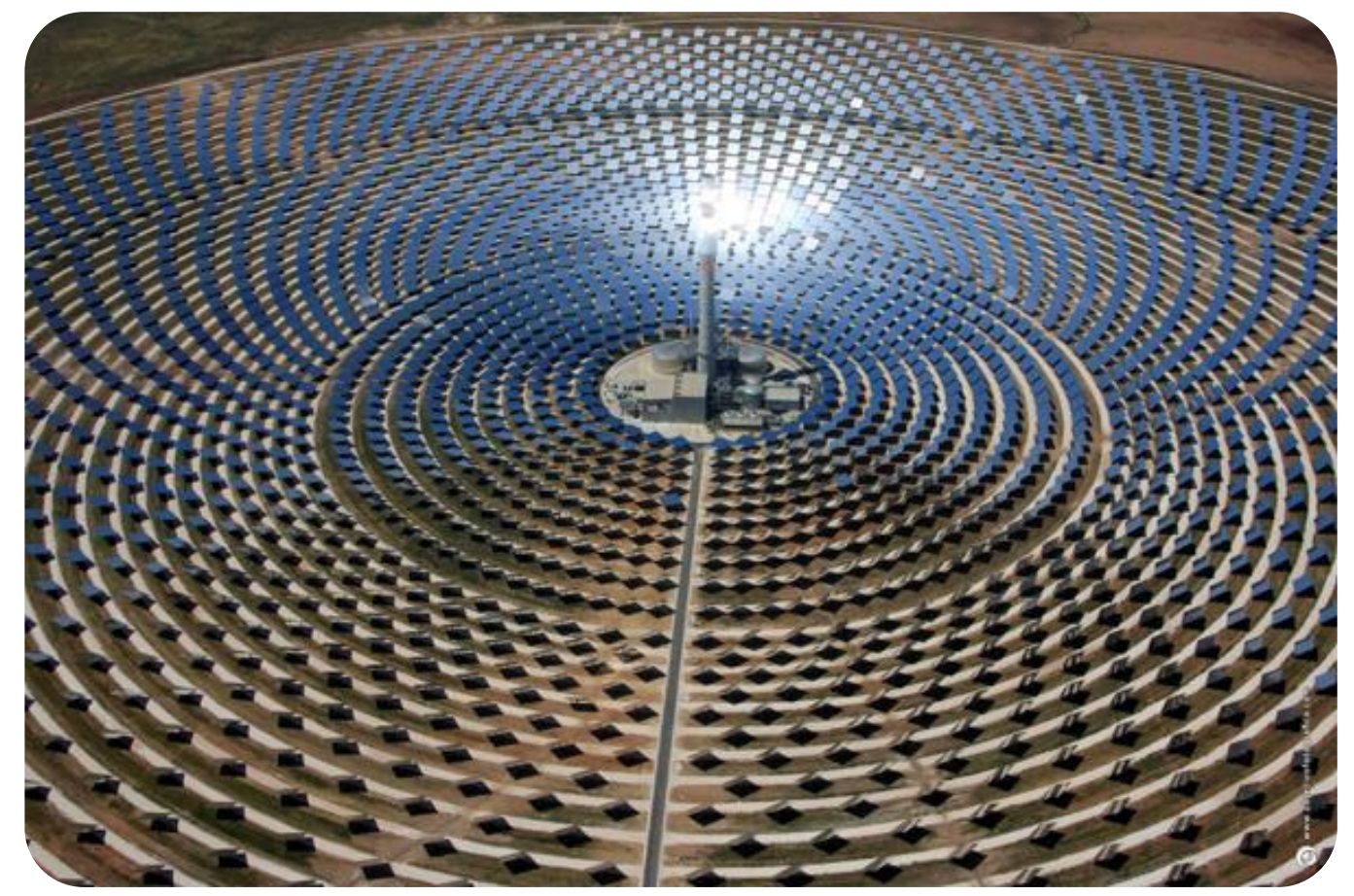

Figura 12 Fotografía de la planta solar termoeléctrica con tecnología de torre Gemasolar, de SENER (Torresol Energy 2015)

- $\quad$ El receptor central

El receptor central se sitúa en una torre cuya altura varía en función de las características del campo solar y la ubicación seleccionada. Es el encargado de concentrar la radiación reflejada en los heliostatos en calor, y transferirlo a un fluido térmico que puede ser agua, aire o sales inorgánicas. En el caso de utilizar sales, el calor obtenido se transfiere a vapor mediante un ciclo agua-vapor de tipo Rankine, al igual que en la tecnología cilindro-parabólica.

Los dos tipos de receptor central más utilizados son el de cilindro externo, y el receptor de cavidad. El primero está diseñado para recibir la radiación de un campo solar dispuesto en forma 
de campo circular. Su principal ventaja es que la torre precisa de menos altura, y por lo tanto se disminuyen los costes; su desventaja es que la superficie está expuesta al exterior, por lo tanto se pierde algo de radiación térmica. El receptor de cavidad consiste en una carcasa aislada con una gran apertura (o cavidad) para recoger la luz solar. Esta apertura puede ser vertical u horizontal, dependiendo de la disposición de los heliostatos. La principal ventaja es que al estar aislada presenta menos pérdidas; la desventaja es que sólo se aprovecha eficientemente la luz proveniente de los heliostatos localizados en el cono definido por la normal a la apertura del receptor, por lo tanto la torre debe ser más alta para aumentar el cono. El principal problema que presentan los receptores centrales es su material, ya que debe ser capaz de soportar irradiancias incidentes del orden de $650 \mathrm{~kW} / \mathrm{m}^{2}$ (Fenercom 2012).
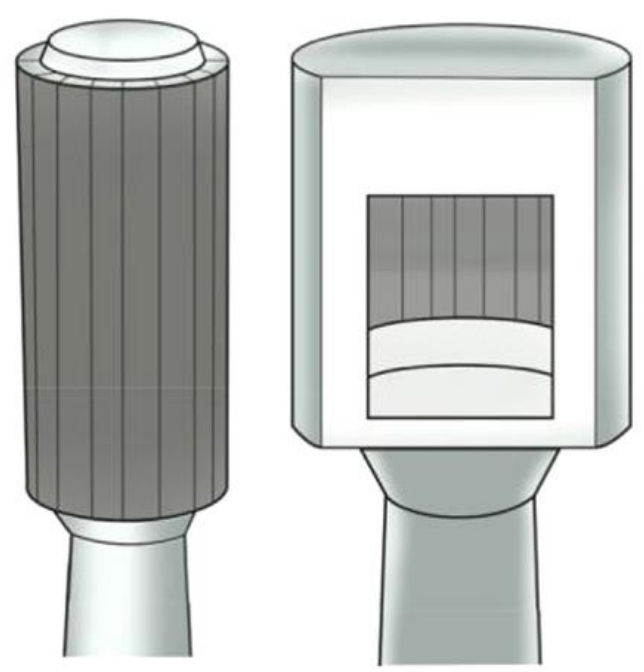

Figura 13 Esquema de un receptor externo tubular (izquierda) y un receptor de cavidad (derecha)(Ho and Iverson 2014)

La utilización de sales orgánicas como HTF en este tipo de plantas permite alcanzar altas temperaturas y disminuir la sensibilidad al paso de nubes. En estos casos, las sales se mantienen a $290^{\circ} \mathrm{C}$ en el tanque de almacenamiento de sales frías (para evitar su congelación) y pueden alcanzar hasta los $1000^{\circ} \mathrm{C}$ a su paso por el receptor (aunque la temperatura más común a su paso por el receptor es en torno a $600^{\circ} \mathrm{C}$ ).

\subsubsection{Sistema de almacenamiento}

La dependencia de la radiación solar para la producción de electricidad en la tecnología termosolar hace que la mayoría de plantas termosolares en España no superen las 2.400 horas anuales de operación equivalentes en plena carga (IDAE 2011). Para incrementar las horas de operación existen dos opciones que pueden implementarse de forma aislada o conjunta, la 
hibridación con un combustible (fósil o renovable) y el almacenamiento térmico de energía utilizando un medio con alta capacidad térmica.

Los sistemas de almacenamiento térmico (TES, del inglés, Thermal Energy Storage) permiten aprovechar el exceso de energía térmica recogido por el campo solar para producir de forma continua y prevenir los riesgos derivados de las oscilaciones de la radiación solar. Son de gran utilidad durante las horas nocturnas, para producir durante los periodos transitorios de sombra debido al paso de nubes y también para facilitar el proceso de arranque. Gracias a estos sistemas se puede producir energía en periodos de baja radiación, a costa de campos solares de mayor tamaño. La relación entre el tamaño del campo solar y la potencia del ciclo termodinámico se define mediante el múltiplo solar, que representa el cociente entre la potencia térmica generada por el campo solar y la potencia térmica demandada por el bloque de potencia en condiciones normales (IDAE 2011). El múltiplo solar óptimo es aquel que maximiza la producción eléctrica por unidad de superficie de espejo. En plantas con TES superior a 6 horas, los múltiplos solares suelen ser superiores a 2.0.

Debido a la necesidad de un mayor campo solar, los TES incrementan los costes de la tecnología, pero permiten mayores factores de $\operatorname{capacidad}^{2}$ y reducen la variabilidad de producción diaria, especialmente en los días de invierno, cuando el recurso solar es menos estable. La Figura 14 muestra la relación entre las horas de almacenamiento térmico, el factor de capacidad y el múltiplo solar en una planta cilindro-parabólica de $100 \mathrm{MW}$ de potencia instalada en regiones con buen recurso solar. Como se observa en la figura, la producción eléctrica aumenta considerablemente en aquellas plantas que presentan un múltiplo solar superior a 2 junto con un almacenamiento térmico de 6 horas o superior.

La tecnología actual de almacenamiento térmico más madura es la de tanques de sales fundidas, encontrándose otros tipos de almacenamiento como el almacenamiento sólido con hormigón (Oró et al., 2012). La composición de las sales más utilizada es una mezcla eutéctica de nitrato de potasio ( $40 \%$ ) y nitrato de sodio (60\%) aunque también se pueden utilizar sales ternarias que incorporan además nitrito de sodio (u otros compuestos).

\footnotetext{
${ }^{2}$ El factor de capacidad de una planta de producción eléctrica es el cociente entre la energía final que genera la planta y la que hubiera producido si estuviera funcionando durante las 8760 horas del año.
} 


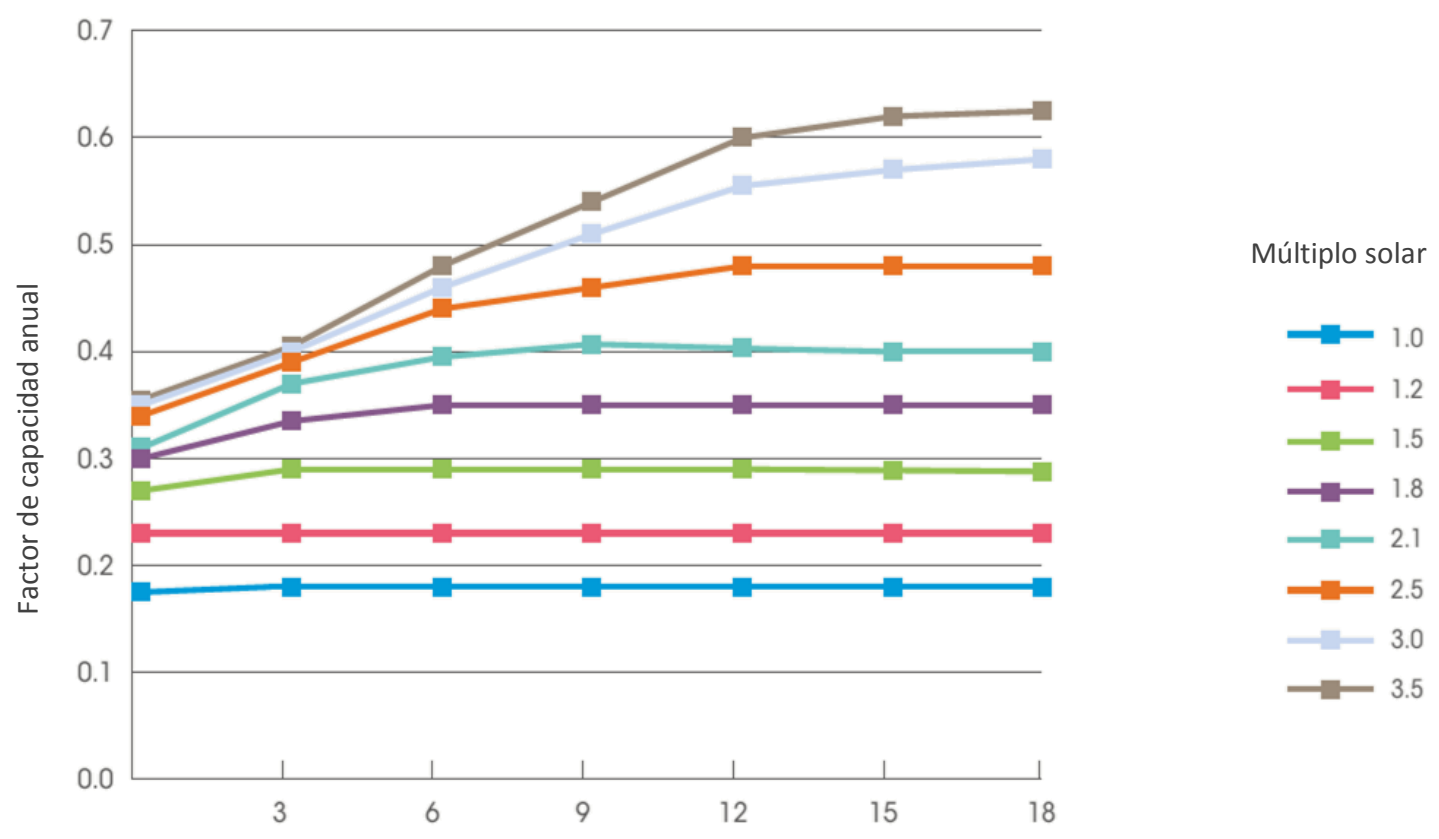

Horas de almacenamiento térmico

Figura 14 Relación entre las horas de almacenamiento térmico, el factor de capacidad y el múltiplo solar en una planta cilindro-parabólica de 100 MW (IRENA 2012)

En el caso de las centrales cilindro-parabólicas, la opción más utilizada es el almacenamiento térmico en forma de calor sensible con sales fundidas. El procedimiento consiste en utilizar el calor sobrante durante las horas de luz para calentar las sales (a través de un cambiador de calor que conecta el HTF con el tanque de sales térmicas). Cuando el ciclo de potencia requiere mayor energía térmica que la proporcionada por el campo solar, se hace recircular el flujo de sales térmicas hacia el cambiador de calor para recalentar el aceite.

El sistema se compone de dos tanques, uno frío con una temperatura mínima de aproximadamente $290{ }^{\circ} \mathrm{C}$ para evitar la solidificación de las sales y otro caliente (a aproximadamente $390^{\circ} \mathrm{C}$ ) que se calienta con el HTF. Los tanques disponen de resistencias eléctricas en las zonas central e inferiores del tanque con el objetivo de que las sales no alcancen la temperatura de congelación (aproximadamente $220^{\circ} \mathrm{C}$ ). Cada tanque dispone de bombas de almacenamiento de sales de eje horizontal.

El conjunto de intercambiadores de calor están dispuestos en serie desde el tanque frío al caliente, de tal manera que el HTF circula por los tubos mientras que las sales fundidas circulan por la carcasa. También consta de un sistema de drenajes compuesto por un una bomba de drenaje y un depósito situado a 2 metros bajo el suelo que recoge los drenajes de las tuberías e intercambiadores. 
En el caso de las centrales de torre, se sigue un sistema similar, pero sin la necesidad de intercambiadores de calor entre aceite y sales ya que las sales son el HTF utilizado. En estas plantas se almacenan las sales a temperaturas superiores $\left(565^{\circ} \mathrm{C}\right.$ en el tanque de sales caliente) ya que no existe la restricción de temperatura de los aceites sintéticos $\left(400^{\circ} \mathrm{C}\right)$.

\subsubsection{Bloque de potencia}

El bloque de potencia es el sistema encargado de transformar la energía térmica en energía eléctrica. El ciclo termodinámico más común en esta tecnología es un ciclo de turbina de vapor tipo Rankine, donde se transfiere la energía térmica del HTF al vapor mediante intercambiadores de calor. La Figura 15 muestra el diagrama de una planta solar termoeléctrica con tecnología cilindro-parabólica, donde se observan los colectores, el TES y el bloque de potencia (ciclo Rankine). El bloque de potencia de este tipo de plantas consta de dos sistemas: el sistema de generación de vapor (que contiene el tren de generación de vapor) y el sistema de generación eléctrica. En el tren de generación de vapor se utiliza la energía térmica contenida en el HTF para producir vapor sobrecalentado, mientras que el sistema de generación eléctrica es el encargado de convertir la energía térmica del vapor en energía eléctrica.

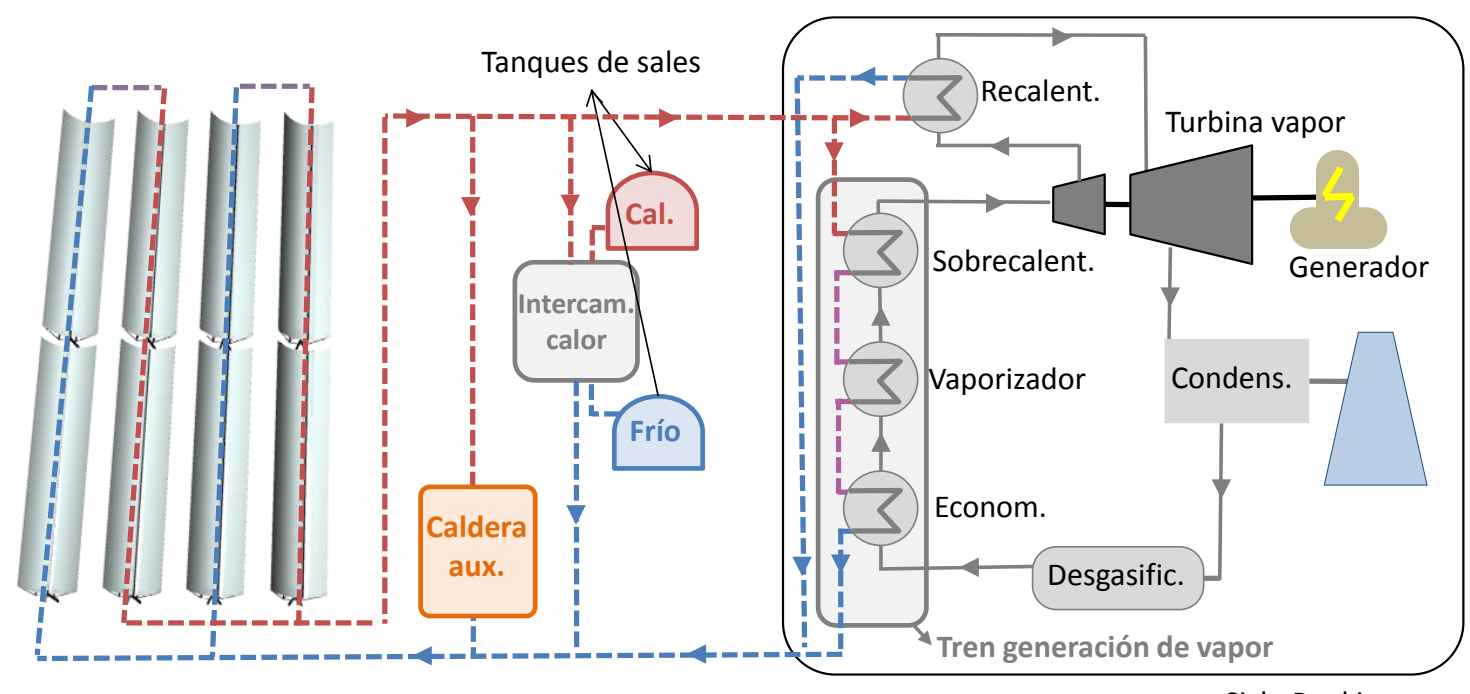

Ciclo Rankine

Figura 15 Diagrama de una planta solar termoeléctrica con tecnología cilindro-parabólica

En el tren de generación de vapor, el agua del circuito es presurizada (entre los 50 y los 100 bar de presión) mediante una bomba centrífuga multietapa y conducida al economizador, donde es precalentada hasta el punto de ebullición. En el vaporizador y sobrecalentador, se produce vapor y se sobrecalienta hasta los $380^{\circ} \mathrm{C}$ (en una central típica cilindro-parabólica). El vapor generado es entonces conducido hasta la turbina de vapor, perteneciente al sistema de generación eléctrica. El ciclo Rankine obtiene mayores eficiencias de conversión de energía 
térmica a eléctrica cuanto mayor sea la temperatura y la presión del vapor a la entrada de la turbina.

El tren de generación de vapor también consta de un recalentamiento intermedio (mediante un recalentador), en el que el vapor (extraído de la turbina de alta presión) obtiene un valor térmico similar al obtenido a la salida del sobrecalentador, a menor presión. Este vapor es introducido de nuevo en la turbina de baja presión.

Las plantas termosolares suelen incorporar una caldera auxiliar (mostrada en la Figura 15) operada generalmente con gas natural, para mejorar la estabilidad del sistema, facilitar la puesta en marcha y evitar la congelación del HTF. La energía auxiliar necesaria dependerá del tamaño del campo solar y del TES, de la naturaleza del HTF, de la radiación solar recibida y de la temperatura ambiente. Para las condiciones típicas del sur de España, esta cantidad en una planta cilindro-parabólica típica varía entre 100.000 y 130.000 MJ/MW/año.

Los principales componentes del sistema de generación eléctrica son el turbogenerador, el condensador y sistema de condensado, el sistema de refrigeración (en húmedo o en seco), y otros como sellos o lubricación de la turbina.

La turbina, donde se convierte la energía potencial del vapor en energía mecánica rotativa, obtiene un rendimiento que oscila entre el $27 \%$ y el $40 \%$, dependiendo de la carga a la que esté la planta. El generador es el encargado de transformar la energía mecánica en energía eléctrica.

El vapor, tras ceder su calor en la turbina de vapor, debe ser condensado con la ayuda del sistema de refrigeración. El sistema de refrigeración más usado por su eficiencia y precio son las torres evaporativas de agua fría. Sin embargo, debido a la escasez de agua en lugares con alta radiación, también se implantan sistemas de refrigeración con grandes aerocondensadores, que transfieren el calor de condensación al aire ambiental.

\subsubsection{Otras instalaciones de una planta termosolar}

Además del campo solar, el sistema de almacenamiento y el bloque de potencia, las plantas termosolares tienen otras instalaciones que son necesarias para el correcto funcionamiento: el edificio de control, el sistema eléctrico, la planta de tratamiento de aguas, e instalaciones auxiliares como caminos, carreteras y aparcamientos.

\subsection{Edificio de control}

En la parte central de la planta se encuentra el edifico de control, donde funciona el sistema de adquisición de datos y control que interrelaciona al operador con los diferentes sistemas de 
la planta. Este edificio puede clasificarse como edificio de oficinas, ya que no tiene otros requerimientos especiales.

\subsection{Planta de tratamiento de aguas}

La calidad del agua disponible en la zona de ubicación de la planta es importante para determinar el volumen de agua requerido y las instalaciones de tratamiento de agua necesarias. La regulación ambiental limita el volumen de abastecimiento y vertido, así como la concentración de los contaminantes. El volumen de agua requerido para la operación de las planta termosolares es muy diferente dependiendo del sistema de refrigeración. El sistema de refrigeración por aire no precisa de agua, mientras que las torres de refrigeración húmedas precisan grandes cantidades. El volumen de agua necesario para el segundo caso depende de los siguientes factores:

- El número de horas de operación y el calor que precisa ser disipado mediante el sistema de condensación (un bloque de potencia más eficiente requerirá un volumen de refrigeración inferior).

- Los límites ambientales para la concentración de contaminantes en las aguas residuales del sistema de refrigeración.

- La calidad del agua de partida y de vertido permitido determina el número de ciclos de concentración de la torre de refrigeración. El número de ciclos debe ser el mínimo cociente entre el límite de vertido de un contaminante y el contenido en el agua de aporte para dicho contaminante. El agua de refrigeración de una torre admite varios ciclos de recirculación hasta el momento en que los contaminantes en la balsa alcanzan el límite permitido (debido a la evaporación del agua durante el proceso de refrigeración) y se procede a la purga. Normalmente se admiten entre 3 y 4 ciclos.

Además, también se necesita agua para el circuito de vapor y para la limpieza de los espejos. Tanto para operar la turbina de vapor como para refrigerar el ciclo termodinámico se requiere agua desmineralizada en condiciones adecuadas. El proceso es el siguiente:

- Ablandamiento: Cuando el agua proviene de un río o caudal de agua dulce ha de eliminarse la dureza de la misma (si viene de agua de mar el proceso es la desalación), generalmente mediante ósmosis inversa.

- Afino: proceso final de ajuste del agua de alimentación que consiste normalmente en una desionización. 
Las aguas sobrantes de purgas son llevadas a una balsa común en la que se homogenizan y se controla sus parámetros contaminantes antes de verterlas al medio receptor. Previamente cada vertido ha de haber sido analizado.

\subsection{Sistema eléctrico}

Además, también es necesario un sistema de alta tensión en el que la energía eléctrica generada se transporta a la red eléctrica. Este sistema precisa de transformadores para igualar la tensión eléctrica de la electricidad generada (unos 10000 V) a la de la red (132000, 220000 o 400000 V), además de protecciones eléctricas, la red de tierras y los equipos de medida.

\subsubsection{La hibridación en la tecnología termosolar}

La estrategia de combinar la radiación solar con otros combustibles para la producción de electricidad mediante tecnología termosolar se denomina hibridación. Según lo indicado en la sección 1.5.1.3 de este capítulo, la tecnología termosolar incorpora una caldera auxiliar (operada generalmente con gas natural) para mejorar la estabilidad del sistema, facilitar la puesta en marcha del ciclo termodinámico y evitar la congelación del HTF. La cantidad de energía térmica obtenida mediante esta caldera puede incrementarse para extender las horas de operación de la planta, y por lo tanto, aumentar su producción eléctrica total. El combustible más usado es el gas natural, debido a su bajo coste, combustión limpia y respuesta rápida, aunque también se han utilizado otros combustibles como fueloil, carbón y biomasa (Deign 2012, Lovegrove and Pye 2012, Servert et al. 2011).

La hibridación con combustibles fósiles puede mejorar de forma significativa la gestionabilidad ${ }^{3}$ y rentabilidad de una planta termosolar, por lo que la mayor parte de las plantas instaladas en España producen entre un $12 \%$ y un $15 \%$ de la electricidad mediante la combustión de gas natural. Comparando con el almacenamiento térmico, la hibridación con gas natural requiere menos inversión económica pero implica mayores costes de operación.

La principal desventaja del uso de gas natural en las plantas termosolares deriva de la baja eficiencia del ciclo termodinámico (normalmente entre 30 y $35 \%$ ) comparada con la obtenida por las plantas modernas de ciclo combinado (entre 50 y $55 \%$ ). Además, el impacto ambiental

\footnotetext{
${ }^{3}$ Habilidad de la planta de proveer electricidad bajo demanda a cualquier hora del día sin desperdiciar energía primaria (Servert et al. 2015).
} 
de las plantas hibridadas con combustibles fósiles es mayor que aquellas funcionando en modo sólo solar (Lechon et al. 2008, Viebahn et al. 2008), especialmente en lo que se refiere a huella de carbono.

\subsubsection{La radiación solar}

La tecnología termosolar requiere de grandes cantidades de radiación solar directa (DNI, del inglés, Direct Normal Irradiation) para que la producción de electricidad sea rentable. La radiación solar directa es aquella que llega en línea recta desde la posición del sol hasta el lugar donde se recibe. Se distingue de la radiación solar difusa en que la segunda llega de todas las direcciones debido a la dispersión realizada por las partículas y moléculas en la atmosfera. La radiación solar está muy distribuida por el territorio mundial en comparación con otras fuentes de energía (como los combustibles fósiles), aunque determinadas zonas son más atractivas para la tecnología debido a sus mayores niveles de DNI. Normalmente, las plantas termosolares suelen instalarse en ubicaciones con una DNI promedio anual mayor a $1.750 \mathrm{kWh} / \mathrm{m}^{2}$ (IDAE 2011).

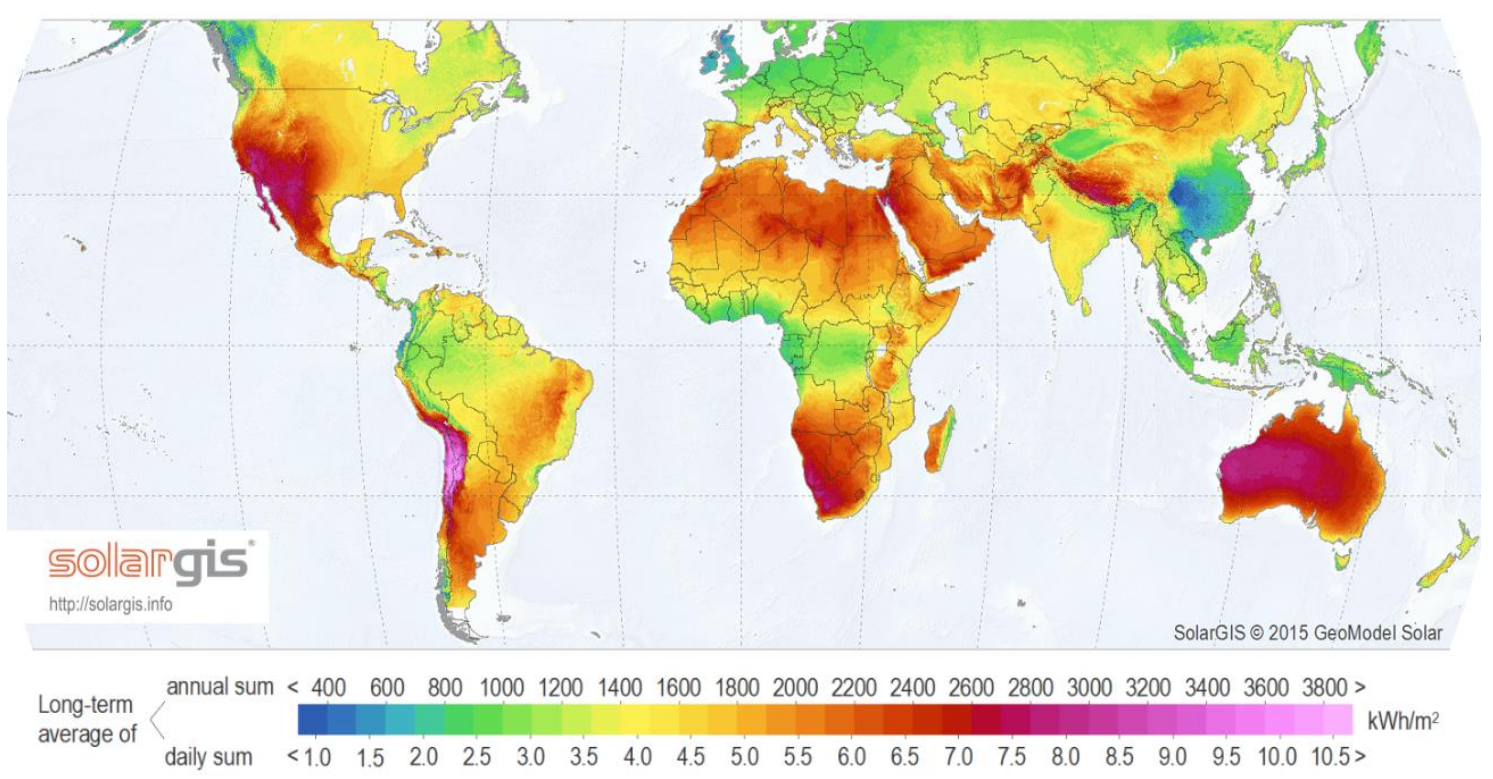

Figura 16 Mapa mundial de radiación solar directa

Fuente: Solargis http://solargis.info/doc/_pics/freemaps/1000px/dni/SolarGIS-Solar-map-DNI-Worldmap-en.png

Actualmente, se puede determinar el nivel de radiación solar directa en cualquier lugar de la Tierra con un margen de error en torno al 5 \% (Fenercom 2012). En la Figura 16 se muestra un mapa mundial con información sobre DNI para cada país. Se puede observar que las zonas con mayor radiación y potencial para la tecnología termosolar son el norte y sur de África, 
Australia, el suroeste de Sudamérica, el noroeste de Norteamérica, el sur de Europa, y algunas zonas del centro de Asia. Los lugares con mayor radiación directa pueden alcanzar valores de DNI superiores a los $3.600 \mathrm{kWh} / \mathrm{m}^{2}$ de promedio anual.

\subsubsection{Costes de la tecnología}

La tecnología cilindro-parabólica es la más madura y extendida de las tecnologías termosolares, concentrando en torno al 85 \% de la potencia instalada a finales del año 2014 (IRENA 2014). Esta situación de desarrollo propicia que la mayor parte de experiencia tecnológica e información económica disponible se refiera a la tecnología cilindro-parabólica. El coste nivelado de la electricidad ${ }^{4}$ (LEC, del inglés, Levelized Electricity Cost) para plantas cilindroparabólicas con almacenamiento varía entre $0,20 \$ / \mathrm{kWh}$ y $0,36 \$ / \mathrm{kWh}$, considerando una vida útil de 25 años y una tasa de descuento de 7,5\% (IRENA 2014). Para la tecnología de torre apenas hay información de LEC en plantas comerciales, aunque algunas estimaciones apuntan a un rango similar a la cilindro-parabólica (IRENA 2014). El valor de LEC en la tecnología termosolar depende principalmente de los costes de inversión y de la disponibilidad del recurso solar.

El coste de inversión de una planta termosolar varía considerablemente dependiendo de si consta de almacenamiento térmico. El coste de inversión de las plantas cilindro-parabólicas sin almacenamiento en los países de la OCDE (Organización para la Cooperación y el Desarrollo Económicos) varía entre 4600 y $8000 \$ / \mathrm{kW}$, mientras que en aquellas con almacenamiento de entre 4 y 8 horas varía típicamente entre 6800 y 12800 \$/kW (IRENA 2014). Los costes de Operación y Mantenimiento (O\&M) de plantas termosolares construidas recientemente no están disponibles públicamente, sin embargo, estimaciones ingenieriles de enfoque bottom up (del inglés, de abajo a arriba) indican que los costes de O\&M pueden variar entre 0,02 y 0,04 $\$ / k W h(I R E N A$ 2014).

Debido al estado incipiente de desarrollo de la tecnología termosolar, se espera una bajada de costes considerable para los próximos años. La reducción de costes de inversión en plantas cilindro-parabólicas para el año 2025 podría rondar entre el 20 y $45 \%$, mientras que para la tecnología de torre esta reducción podría alcanzar el 28 \% (IRENA 2014). Sin embargo, un enfoque más interesante para el abaratamiento del LEC sería aprovechar la bajada de costes de

\footnotetext{
${ }^{4}$ Precio constante de la electricidad producida por una tecnología considerando todos los costes del ciclo de vida.
} 
inversión para aumentar el factor de capacidad desde el $48 \%$ al 72 \% (en tecnología de torre) mediante el incremento del almacenamiento térmico y el tamaño del campo solar. Este aumento del factor de capacidad podría darse especialmente en plantas con tecnología de torre ya que pueden lograr mayores temperaturas de operación (gracias al uso de sales como HTF) que derivan en una mayor eficiencia del ciclo termodinámico y un menor coste económico de almacenamiento. De esta forma, la LEC de la tecnología de torre en 2025 podría variar entre los $0,11 \$ / \mathrm{kWh}$ y los $0,16 \$ / \mathrm{kWh}$ (IRENA 2014).

\subsubsection{La tecnología termosolar en España}

Con 2.362 MW de potencia termosolar instalada y 50 plantas de producción eléctrica (entre 1,4 y $50 \mathrm{MW}$ de potencia por planta), España es actualmente el país líder en tecnología termosolar, concentrando el 47,8 \% de la potencia instalada mundial (Protermosolar 2016). Estados Unidos es el siguiente país con mayor potencia instalada (1.710 MW en el año 2015), presentando el $34,6 \%$ de la cuota mundial.

El importante papel que ha jugado España en el desarrollo y comercialización de la tecnología termosolar ha sido resultado del marco regulatorio favorable que hubo en el país durante la primera década del 2000, cuando las instalaciones de energía renovable percibían altos incentivos a la producción. Esta situación propició una alta tasa de desarrollo y un aumento de plantas de energías renovables, ocasionando la instalación de $2.300 \mathrm{MW}$ de tecnología termosolar entre 2007 y 2013.

La promoción de energías renovables en Europa comenzó con la publicación del Libro Blanco Energía para el Futuro: Fuentes Renovables de Energía (EC 1997). En respuesta a este documento, España promulgó la Ley 54/1997, de 27 de noviembre, del Sector Eléctrico, estableciendo un Régimen Especial (RE) para tecnologías de producción eléctrica que requirieran consideraciones especiales. Este régimen era aplicable a plantas con potencias instaladas inferiores a $50 \mathrm{MW}$ que se basaran en fuentes de energía renovables, residuos o tecnologías de cogeneración. La Ley se desarrolló bajo sucesivos Reales Decretos (2818/1998, $1955 / 2000841 / 2002,436 / 2004,2351 / 2004,661 / 2007,1565 / 2010$ y $1614 / 2010$ ), que establecían distintos regímenes de subsidios específicos para aquellas tecnologías enmarcadas por el RE. Los subsidios podían percibirse de dos formas según la preferencia del productor: una tarifa regulada o una prima adicional al precio retribuido por el mercado eléctrico convencional.

Durante el Real Decreto 136/2004 los inversores empezaron a aventurarse en la instalación de plantas termosolares, obteniendo como subsidio una tarifa regulada de $21,6216 \mathrm{c} € / \mathrm{kWh}$ o 
una prima de 18,73872 c£/kWh. Además, el Real Decreto 2351/2004 permitía que las plantas termosolares utilizaran combustibles auxiliares para incrementar la generación de electricidad percibiendo el mismo subsidio para toda la electricidad producida. La cantidad de electricidad adicional producida por este combustible estaba limitada a un 12 \% cuando percibía la tarifa regulada, y a un $15 \%$ cuando percibía la prima.

La primera planta termosolar comercial en Europa, llamada PS10 (Figura 17), se aprobó en España durante el año 2004, y entró en operación en el año 2007. Dicha planta estaba basada en tecnología de torre, y contaba con una potencia instalada de $11 \mathrm{MW}$ y un almacenamiento térmico de 0,5 horas. A esta planta le siguió Andasol, una planta cilindro-parabólica de $50 \mathrm{MW}$ y 7,5 horas de almacenamiento que entró en operación en el año 2008.

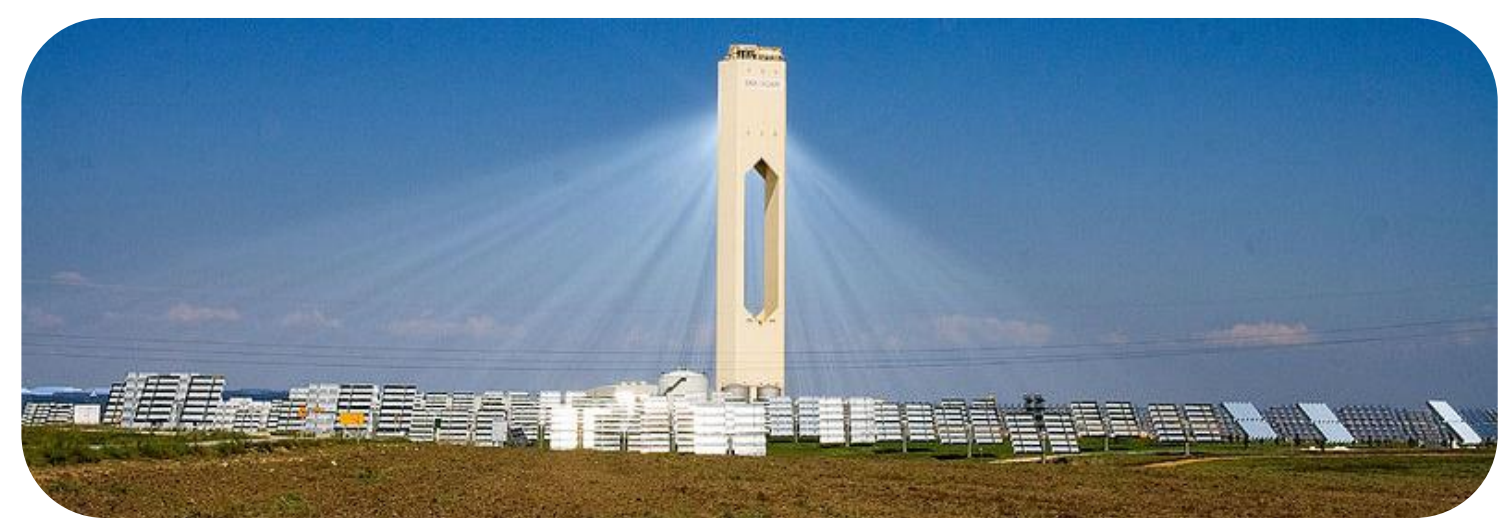

Figura 17 La planta de torre Solúcar PS10, la primera planta termosolar explotada comercialmente en Europa

Fuente: Afloresm 2007 http://flickr.com/photos/74424373@N00/1448540890

El gobierno español fijó mediante el Plan de Energías Renovables 2005-2010 un objetivo ambicioso para el desarrollo de la tecnología termosolar: instalar $500 \mathrm{MW}$ de potencia termosolar para la generación de 1298 GWh/año (IDAE 2005). Este objetivo impulsó la promulgación del Real Decreto 661/2007 que fijó una remuneración mayor para las plantas termosolares: una tarifa regulada de $26,9375 \mathrm{c} € / \mathrm{kWh}$ y una prima de $25,4000 \mathrm{c} € / \mathrm{kWh}$. En ambos casos los incentivos percibidos se actualizaban anualmente según el IPC (Índice de Precios de Consumo) y se reducían un $20 \%$ tras 25 años de operación de la planta. Esta situación provocó una expansión del mercado solar en España, llevando a la instalación de 6 plantas termosolares en el año 2009 (173,5 MW de potencia), 9 plantas en el 2010 (450 MW), 11 en el 2011 (520 MW) y 18 plantas en el año 2012 (905 MW) (NREL 2014).

El siguiente Plan de Energías Renovables (2010-2020) fijó objetivos aún más ambiciosos para la tecnología termosolar: 3001 MW de potencia instalada y 8287 GWh/año de producción 
eléctrica para el año 2015, y 4800 MW de potencia con 14,378 GWh/año de producción para el 2020. Sin embargo, el aumento del precio de la electricidad por las nuevas instalaciones de energías renovables, junto con la crisis económica y la mala gestión política, provocaron el aumento del déficit tarifario, una deuda pública con las compañías eléctricas que alcanzó en el año 2013 los 30 millones de euros. Con el objetivo de reducir este déficit, España actuó desde el año 2010 hasta hoy regulando el sistema retributivo de las energías renovables y disminuyendo los parámetros retributivos de todas las energías renovables.

El Real Decreto 1565/2010 redujo los incentivos a la termosolar un $15 \%$ respecto al Real Decreto 661/2007. El siguiente Real Decreto 1614/2010 fijó un límite para la cantidad de electricidad susceptible de remuneración extra y eliminó la opción de retribución por prima. Además, el Real Decreto 14/2010 estableció un peaje de 0,5 €/MWh a los productores de electricidad por el transporte y distribución mediante la red eléctrica.

El gobierno que comenzó su legislatura en 2011 promulgó con carácter de urgencia el Real Decreto Ley $1 / 2012$, por el que se suspendía el registro de nuevas instalaciones de energías renovables susceptibles de incentivos. Mediante la ley 15/2012 se introdujo un nuevo impuesto a la producción de electricidad de $7 \%$ sobre los beneficios brutos, y se retiraron los incentivos a la electricidad producida por combustibles fósiles en plantas termosolares.

El Real Decreto Ley 9/2013 introdujo los principios del nuevo sistema retributivo para las plantas de energía renovable, cogeneración y residuos. Estos principios se desarrollaron mediante el Real Decreto 413/2014 y la Orden Ministerial IET/1045/2014, imponiendo un nuevo sistema retributivo con carácter retroactivo, basado en una "rentabilidad razonable" a la inversión igual a 7,398 \%. Este nuevo sistema retributivo, vigente hasta la fecha, se compone de tres parámetros: el retorno a la inversión, el retorno a la operación y el precio de venta según el mercado eléctrico. Los valores de los dos primeros parámetros están definidos para 895 tipos diferentes de instalaciones de energías renovables en función de los correspondientes costes de inversión y explotación según el Ministerio de Energía y Turismo.

Este nuevo régimen retributivo es mucho menos favorable económicamente para las energías renovables que los anteriores, por lo que la Asociación de Empresas de Energías Renovables-APPA en España ha apelado al Tribunal Supremo Español, por la inseguridad legal y financiera derivada de estas medidas retroactivas (APPA 2014). La imposibilidad de registrar nuevas plantas de energías renovables bajo un régimen retributivo favorable, junto con la disminución de los incentivos y la inseguridad jurídica en España, han generado que el sector de 
las energías renovables se haya estancado, provocando la huida de inversores nacionales e internacionales.

\subsubsection{Las plantas termosolares y el mercado eléctrico español}

A pesar de que la instalación de nuevas plantas termosolares se estancó en el año 2013, la cuota de contribución de la tecnología termosolar a la cobertura de la demanda eléctrica en España se consolidó en el año 2015 en un 2\%, con una producción eléctrica anual de 5.113 GWh, superior en $89 \mathrm{GWh}$ al registro del año 2014. Entre los meses de mayo y septiembre (de mayor radiación solar), se cubrieron demandas diarias acumuladas por encima del 5\%.

Las plantas termosolares tienen su pico de generación de electricidad durante las horas centrales del día, al ser el momento con mayor recurso solar. Además, las plantas con almacenamiento térmico e hibridación con otros combustibles pueden prolongar su producción durante las horas del día con menor recurso solar (principalmente durante la noche). Cuanto mayor sea la capacidad del TES y la hibridación, mayor adaptabilidad tienen las plantas para ajustar su perfil de producción a la curva de demanda presentada en el mercado diario.

El actual mercado eléctrico español está regulado por el Operador del Mercado Ibérico Español (OMIE), una empresa regulada por el Convenio Internacional de Santiago, relativo a la constitución de un mercado ibérico de la energía eléctrica entre el Reino de España y la República de Portugal, y sujeta a la regulación sectorial eléctrica en España (OMIE 2016).

El OMIE provee que el precio de la electricidad se fije diariamente (todos los días del año, a las 12:00 horas), para las veinticuatro horas del día siguiente, mediante el denominado Mercado Diario. El precio y el volumen de energía en una hora determinada se establecen por el cruce entre la oferta y la demanda de electricidad.

Una vez obtenidos los resultados del Mercado Diario (gobernados por la libre contratación entre agentes compradores y vendedores), éstos se remiten al Operador del Sistema para el ajuste y validación de su viabilidad técnica. Este proceso se denomina gestión de las restricciones técnicas del sistema y asegura que los resultados del mercado sean técnicamente factibles en la red de transporte. En este proceso los resultados del mercado diario sufren pequeñas variaciones, del orden del $4 \%$ ó 5 \% de la energía, dando lugar a un Programa Diario Viable.

Tras el mercado diario, los agentes pueden volver a comprar y vender electricidad en el mercado intradiario, es decir en distintas sesiones de contratación unas horas antes del tiempo real. Los mercados intradiarios permiten a los agentes compradores y vendedores reajustar sus compromisos (de compra y venta respectivamente) hasta cuatro horas antes del tiempo real. A 
CAPÍTULO 1: Introducción

partir de ese momento, existen otros mercados gestionados por el Operador del Sistema en el que se asegura en todo momento el equilibrio de la producción y el consumo. Estos mercados incluyen los Mercados a plazo (donde se gestionan los contratos de futuros), los mercados no organizados (contratos bilaterales entre los sujetos del mercado), los servicios complementarios (regulación secundaria, terciaria y control de tensión) y la gestión de desvíos (resolución de desvíos entre generación y consumo) (Fenercom 2012). 


\subsection{EL PROYECTO HYSOL}

La tecnología termosolar tiene un gran potencial de desarrollo y de adaptabilidad al mercado eléctrico por su capacidad de desacoplar la generación de electricidad del recurso solar mediante el uso de almacenamiento y de la hibridación con otros combustibles. Con el objetivo de aumentar la eficiencia y firmeza de la tecnología termosolar nace HYSOL, un proyecto europeo financiado por la Comisión Europea bajo el Séptimo Programa Marco (№ 308912). La iniciativa, en la que participan nueve empresas y centro de investigación europeos (entre los que se encuentra la Universidad Politécnica de Madrid) está liderada por COBRA T\&I del grupo ACS y tiene un presupuesto superior a los 9 millones de euros destinado al desarrollo, construcción, operación y optimización de una planta a escala preindustrial en el complejo termosolar de Ciudad Real. Las actividades del proyecto comenzaron en el año 2013 y terminaron en Julio de 2016.

HYSOL (del inglés, Innovative Configuration of a Fully Renewable Hybrid CSP Plant) está basado en la hibridación de la tecnología termosolar con un combustible gaseoso mediante la integración en el bloque de potencia de una turbina de gas aeroderivativa y un intercambiador de calor entre las sales térmicas y los gases de escape de la turbina. El nuevo diseño del bloque de potencia mejora no sólo la eficiencia del ciclo térmico de la planta, sino también la firmeza y gestionabilidad en el suministro de electricidad, dos de los principales objetivos en el desarrollo de la tecnología termosolar. Esta configuración se puede adaptar tanto a la tecnología cilindroparabólica como a la de torre.

Además, el proyecto HYSOL está diseñado para utilizar combustibles biomásicos en la turbina de gas (biogás, singas o biometano), permitiendo la producción de electricidad $100 \%$ renovable. El combustible puede ser producido directamente en la ubicación de la planta termosolar o también en otras partes del territorio, requiriendo en el segundo caso la depuración del mismo y la integración en la red de gas natural nacional.

La Figura 18 describe la configuración de la planta desarrollada por el proyecto HYSOL (con tecnología cilindro-parabólica). Según se observa en la figura, la planta HYSOL consta de un ciclo termodinámico similar a la tecnología termosolar convencional (donde el campo solar produce energía térmica que es almacenada en un TES de sales fundidas y transformada en electricidad mediante un ciclo de vapor Rankine), pero añade un ciclo Brayton con una turbina aeroderivativa y un nuevo intercambiador de calor (HRS, del inglés, Heat Recovery System). 


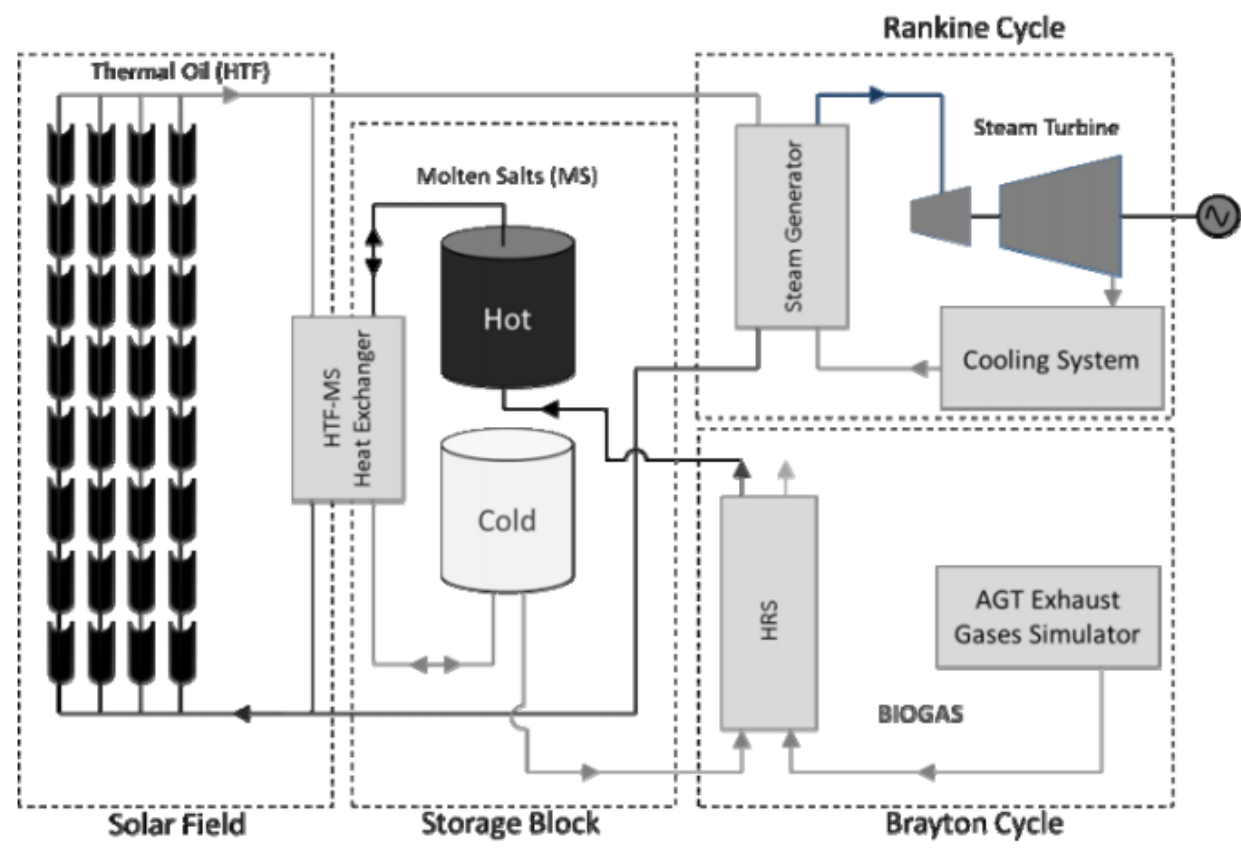

Figura 18 Configuración de la planta demostrativa HYSOL, con tecnología cilindro-parabólica

En la planta demostrativa desarrollada por el proyecto, el gas de escape de la turbina de gas será suministrado por un simulador de gases de escape con capacidad de emular las condiciones de trabajo de distintos tipos de turbinas. El HRS será capaz de aumentar la temperatura de las sales desde los $292^{\circ} \mathrm{C}$ a los $550^{\circ} \mathrm{C}$. El calor excedente de los gases tras su paso por el intercambiador (en torno a $290^{\circ} \mathrm{C}$ ) se reutiliza para optimizar el funcionamiento de la planta.

La Figura 19 muestra el nuevo intercambiador de calor y el simulador de gases de escape que se han instalado en la planta demostrativa construida en el complejo termosolar de Manchasol I y II (propiedad de ACS).

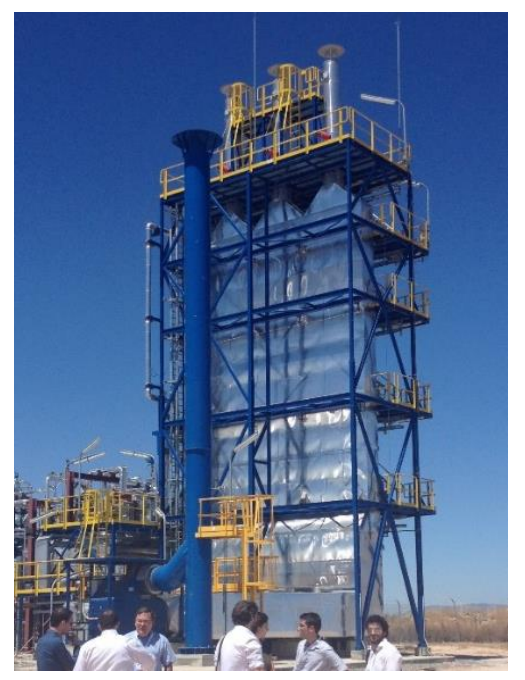

Figura 19 El nuevo intercambiador de calor entre sales y gases de escape, junto al simulador de gases de escape, instalados en la planta demostrativa del proyecto $\mathrm{HYSOL}$ 


\section{CAPÍTULO 2 \\ Metodología del Análisis de Sostenibilidad de Ciclo de Vida de la tecnología HYSOL}

Según la revisión bibliográfica descrita en la sección 1.4.3 del Capítulo 1 de esta tesis, hay dos marcos metodológicos principales para la realización de un Análisis de Sostenibilidad del Ciclo de Vida (ASCV): el marco denominado ASCV análisis o el denominado ASCV evaluación. El primero supone la realización de un sólo análisis completo en todas sus dimensiones de sostenibilidad, mientras que el segundo es la combinación de las herramientas Análisis de Ciclo de Vida Ambiental (ACV-A), Análisis de Costes de Ciclo de Vida (CCV) y Análisis de Ciclo de Vida Social (ACV-S) con un mismo alcance y objetivo. Para este estudio se ha escogido el enfoque del ASCV Análisis, ya que es más completo y flexible a la hora de adaptar las técnicas de análisis disponibles a la naturaleza del caso de estudio.

La principal base para el desarrollo metodológico del ASCV de esta tesis son las normas ISO 14040 y 14044, ya que deben ser la base para cualquier análisis de ciclo de vida. Además, se ha implementado el marco operacional para la puesta en práctica del ASCV propuesto por Hu et al. (2013), que se fundamenta en el desarrollo metodológico del proyecto CALCAS (Heijungs et al. 2009, Zamagni et al. 2009). El marco aplicado se compone de las siguientes tres fases mostradas en la Figura 20: (1) Definición del objetivo y alcance, (2) Modelado: Aplicación de herramientas, y (3) Interpretación de resultados.

\section{Definición de objetivo y alcance}
1.1 Definición del sistema
1.2 Enunciación de escenarios de análisis
1.3 Definición de sub- preguntas de sostenibilidad y herramientas de análisis

\section{Modelado}

2.1 Área ambiental

2.2 Área económica

2.3 Área social
3. Interpretación de resultados

3.1 Respuestas de sostenibilidad

3.2 Interpretación y toma de decisiones. 
CAPÍTULO 2: Metodología de ASCV de la tecnología HYSOL

Como se observa en el esquema de la Figura 20, la primera fase consta de tres pasos: (1.1) Definición amplia del sistema de estudio, donde se describe el sistema a analizar y su principal objetivo, (1.2) Enunciación de escenarios de análisis, donde se consideran y definen los distintos escenarios de análisis que servirán de base comparativa y (1.3) Definición de sub-preguntas de sostenibilidad, donde se descompone la pregunta principal de sostenibilidad en preguntas más concretas. La segunda fase del ASCV, Modelado, es la fase que mayor tiempo y recursos requiere, y corresponde a la aplicación de las herramientas de análisis que proporcionan resultados cuantitativos en las distintas áreas de sostenibilidad (medioambiente, economía y sociedad). Por último, la fase de Interpretación de resultados consta de dos pasos: (3.1) la cuantificación de la sostenibilidad del sistema analizado mediante la respuesta de las subpreguntas de sostenibilidad, y (3.2) la interpretación y toma de decisiones respecto al escenario o alternativa más sostenible.

En las siguientes secciones se describen las tres fases del análisis aplicadas a la tecnología HYSOL. 


\subsection{DEFINICIÓN DE OBJETIVO Y ALCANCE}

\subsubsection{Definición del sistema de estudio}

Este paso consiste en describir el sistema en estudio de la forma más amplia posible, con el fin de identificar el problema y las decisiones en juego, las principales interrelaciones (sinergias, conflictos, compensaciones, etc.) entre los objetos, procesos y actores, y entre los ámbitos ambientales, económicos y sociales. La mayor parte de esta información ha sido definida en las secciones 1.4 y 1.5 del Capítulo 1 de esta tesis, donde se describen la tecnología termosolar, el proyecto HYSOL, el mercado eléctrico español, y las sinergias entre ellos.

La metodología desarrollada en esta tesis, y los resultados de la misma, están encaminados a facilitar la toma de decisiones para la promoción de tecnologías de producción eléctrica (o de otro tipo de productos) en un entorno de gestión pública.

El objetivo principal del ASCV de la tecnología HYSOL es responder a la siguiente pregunta: ¿En qué medida puede la nueva tecnología HYSOL mejorar la sostenibilidad (ambiental, social y económica) de la producción eléctrica en el mercado eléctrico español? La respuesta a esta pregunta implica considerar no sólo el nivel de proyecto/producto o micro, en el que se describe la sostenibilidad de un sistema aislado, sino también su efecto en el sector, es decir, en el mercado eléctrico español. Para ello es necesario acudir también al nivel de análisis meso, en el que se consideran los efectos más relevantes en otros sistemas afectados por el sistema de estudio.

El objetivo secundario de este análisis es favorecer la toma de decisiones a la hora de escoger la opción más sostenible entre los distintos escenarios tecnológicos planteados (ver siguiente sección). Con este fin, los resultados deben ofrecer una guía para determinar qué alternativa debería promoverse en mayor grado para mejorar la sostenibilidad de la producción eléctrica.

El análisis de esta tesis considera el enfoque BAU (del inglés, Business As Usual), en el que se asume que la situación económica y política actual en un futuro próximo se mantiene en el tiempo y no cambia de forma apreciable. 


\subsubsection{Enunciación de escenarios de análisis}

La definición de escenarios es el segundo paso en la definición del objetivo y alcance de un ASCV, y forma la base para la modelización de la sostenibilidad. Durante este paso se consideran y definen los distintos escenarios de análisis que servirán de base comparativa.

Según lo definido por el proyecto HYSOL, la tecnología desarrollada es capaz de entregar energía gestionable y firme durante todo el año sin importar las condiciones meteorológicas. Esta gestionabilidad se consigue principalmente gracias a la producción adicional de electricidad mediante una turbina de gas, que puede quemar biometano o gas natural. En el primer caso, la electricidad producida es $100 \%$ renovable además de gestionable y firme. Aunque la tecnología termosolar convencional5 también es capaz de producir electricidad mediante un combustible auxiliar, la tecnología HYSOL presenta un avance en términos de eficiencia energética y capacidad de adaptación a la demanda eléctrica.

Para analizar e incluir estas particularidades en el análisis de sostenibilidad, se ha decidido establecer los siguientes escenarios principales de comparación: la tecnología HYSOL utilizando biometano, denominada en esta tesis HYSOL BIO; la tecnología HYSOL utilizando gas natural, denominada en esta tesis HYSOL GN, y la tecnología termosolar convencional según el desarrollo tecnológico previo a HYSOL, denominada en esta tesis TERMOSOLAR CCP (Colectores CilindroParabólicos). Dichos escenarios se muestran en el diagrama de la Figura 21. El escenario de la tecnología HYSOL GN se considera como un escenario probable en regiones donde los recursos naturales para la producción de biogás son escasos, ya que la cantidad de biometano requerida por año (3,40 x 109 MJ/año) excede la capacidad de las instalaciones de biogás instaladas hasta la fecha.

\footnotetext{
${ }^{5}$ En esta tesis se considera como convencional a la configuración de plantas termosolares más común según el desarrollo de la tecnología previo a HYSOL. Se ha escogido este término por diferenciación con la tecnología HYSOL. Sin embargo, cabe destacar que la tecnología termosolar es reciente y está en continuo desarrollo, por lo que ninguna de sus configuraciones podría considerarse convencional en el sentido estricto de la palabra.
} 


\section{Tecnología HYSOL: Torre, $180 \mathrm{MW}$

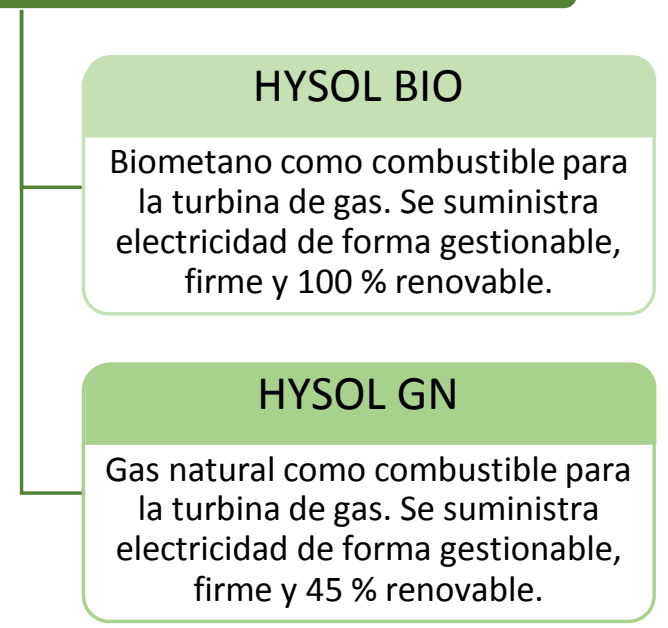

Figura 21 Escenarios analizados en el Análisis de Sostenibilidad de Ciclo de Vida de la tecnología HYSOL

Además, en el capítulo de análisis del área ambiental (Capítulo 3) también se han estudiado otras alternativas y escenarios adicionales que resultan interesantes desde el punto de vista del impacto ambiental. Estos escenarios incluyen el uso de otros combustibles o modos de operación (biomasa sólida, modo sólo solar, distintos porcentajes de gas natural) y el efecto de dos tipos distintos de refrigeración para el ciclo de vapor (en húmedo o en seco). En estos casos, la definición y características de los correspondientes escenarios se describen en el apartado correspondiente del Capítulo 3.

En las siguientes secciones se describen las características específicas de las plantas analizadas para cada escenario.

\subsubsection{Características de la planta HYSOL BIO}

La planta de referencia analizada se considera representativa de la tecnología HYSOL, y se asume que está ubicada en Talarrubias, Badajoz. Esta planta todavía no existe, ya que la tecnología HYSOL aún no se ha construido a escala comercial (hasta ahora sólo se ha construido a escala pre-industrial). Los detalles sobre las especificaciones y configuración de la planta están descritos en la Figura 22 y la Tabla 2. La planta de estudio presenta una configuración de ciclo combinado (Rankine y Brayton) con una turbina de vapor de $100 \mathrm{MW}$ y una turbina de gas de $80 \mathrm{MWe}$. El campo solar (número 1 en Figura 22) se basa en la tecnología de torre y consiste en 9151 heliostatos con diseño circular. La radiación solar reflejada por los heliostatos se dirige a un receptor central externo (2) aumentando la energía térmica contenida en un fluido HTF. Este fluido consiste en sales binarias fundidas, compuestas por nitrato sódico y potásico, y cumplen 
dos objetivos: transportar el calor en el sistema de generación de vapor y almacenar energía térmica mediante un sistema TES. Este sistema de almacenamiento consta de dos tanques con configuración indirecta (3) y tiene una capacidad de 14 horas diarias, que son utilizadas para aumentar la producción de electricidad así como su gestionabilidad. La energía térmica recogida por el HTF se utiliza posteriormente para conducir el ciclo termodinámico Rankine (4) basado en tecnología de refrigeración mediante aire (que reduce el consumo de agua a costa de rendimientos de generación de electricidad más bajos y más altos costes económicos). La turbina de gas aeroderivativa (5) consume biometano (o alternativamente gas natural) como combustible auxiliar y se utiliza para apoyar la generación de electricidad cuando el almacenamiento térmico se ha agotado, o para aumentar la producción en horas pico. Los gases de escape de la turbina de gas son conducidos al HRS, donde el HTF es recalentado (6), mejorando la gestionabilidad y la eficiencia de utilización del combustible.

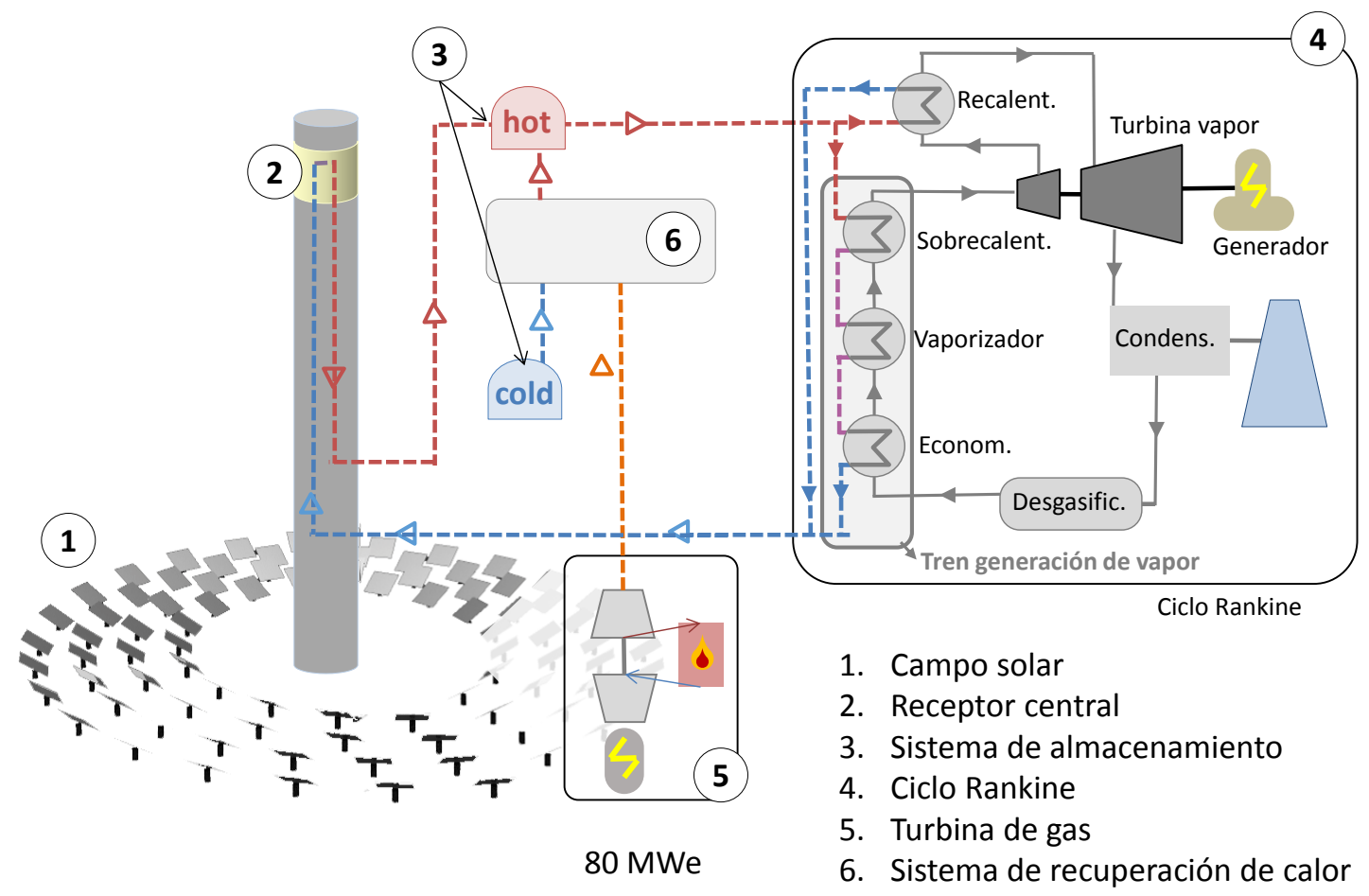

Figura 22 Configuración de la planta HSYOL

Los principales detalles técnicos de la planta HYSOL están descritos en la Tabla 2. La electricidad producida por la planta ha sido proporcionada y calculada por IDie ${ }^{6}$ en base a las características de la planta y a la curva de la demanda de electricidad española. La generación

\footnotetext{
${ }^{6}$ IDie es una empresa de investigación y desarrollo especializada en energías renovables que participa en el desarrollo técnico del proyecto HYSOL.
} 
de electricidad bruta de la planta HYSOL analizada asciende a 938.046 MWh/año. La electricidad neta, es decir, la electricidad bruta menos el autoconsumo para actividades de operación y mantenimiento, asciende a 847.248 MWh/año. Finalmente, la electricidad vertida a la red, que incluye las pérdidas de eficiencia debido a indisponibilidad de red y a la reducción anual por la degradación de componentes (0,2 \% anual), asciende a 799.437 MWh/año. Este último dato es el que se ha considerado como producción final para los cálculos por unidad funcional del ASCV.

Tabla 2 Características de la planta HYSOL y electricidad vertida a la red

\begin{tabular}{ll}
\hline Características de la planta & Cantidad \\
\hline Potencia Instalada, MW & 180 \\
Radiación Directa Normal (DNI), KWh/m²/año & 2.086 \\
Heliostatos, unidades & 9.151 \\
Apertura, $\mathrm{m}^{2}$ & 1.321 .174 \\
Área del campo solar, ha & 837,7 \\
Lavados de heliostatos al año, $\mathrm{n}$ - & 63 \\
Múltiplo solar & 2,35 \\
Potencia térmica del receptor, MWt & 689,4 \\
Horas de almacenamiento térmico, $\mathrm{h}$ & 14 \\
Sales térmicas, t & 31.464 \\
Altura de la torre, m & 201 \\
Generación bruta anual de electricidad, MWh/año & 928.620 \\
Generación neta anual de electricidad, MWh/año & 847.248 \\
Electricidad vertida anualmente a red, MWh/yr & 797.423 \\
Vida útil de la central, años & 25 \\
Eficiencia del ciclo térmico, gas- electricidad (\%) & 52 \\
Horas equivalentes a plena carga, $\mathrm{h} / \mathrm{año}$ & 4.707 \\
Fracción solar, \% & 45 \\
Consumo de gas anual, MJ/año & $3,40 \times 10^{9}$ \\
\hline
\end{tabular}

El combustible auxiliar de la planta HYSOL BIO es biometano, obtenido tras la depuración de biogás, y producido en las proximidades de la planta o en cualquier lugar del territorio nacional. La producción de biometano se ha incluido en el estudio considerando los siguientes procesos: transporte y pretratamiento de residuos biológicos, fermentación de la materia orgánica (producción de biogás), y procesos de depuración del biogás hasta el grado de biometano. También incluye los impactos de la infraestructura en cuanto a la fabricación de equipos y la construcción de la planta.

Las instalaciones de biogás de pequeña escala (escala granja) suelen producir del orden de 10.000-100.000 Nm³/año, que resulta insuficiente para proveer de gas de mantenimiento a una planta termosolar de tamaño típico en España (50 MW) funcionando en modo solo solar (San Miguel and Corona 2013). Las instalaciones centralizadas de gran escala tienen una capacidad de generación de biometano típica entre 1 y $5 \times 10^{6} \mathrm{Nm}^{3} /$ año, mientras que algunas plantas que 
CAPÍTULO 2: Metodología de ASCV de la tecnología HYSOL

operan en lugares específicos del norte de Europa pueden producir hasta $25 \times 10^{6} \mathrm{Nm}^{3}$ /año (AEBIOM 2009). Ya que las necesidades de gas de la planta HYSOL $\left(9,48 \times 10^{7} \mathrm{Nm}^{3} / a n ̃ o\right)$ son mucho mayores que la producción de una planta centralizada a gran escala, esta tesis supone que hay numerosas plantas de producción de biometano - situadas en distintas ubicaciones del territorio nacional- que proporcionan biometano a la red de gas natural para transportarlo hasta la planta HYSOL.

Este estudio considera que el biometano se obtiene de residuos biológicos consistentes en una mezcla de lodos de depuradora, residuos agroalimentarios y estiércol de ganado vacuno y porcino. La planta de biometano media supuesta en el análisis consume 26.000 t/año de residuos biológicos para la producción de $1,3 \times 10^{6} \mathrm{Nm}^{3} /$ año de biogás por fermentación anaerobia termofílica. El proceso de digestión en la planta de producción de biogás se divide en dos fases: una primera digestión en condiciones termófilas (alrededor de $55^{\circ} \mathrm{C}$ ) y una posterior digestión en condiciones mesófilas (alrededor de $39^{\circ} \mathrm{C}$ ), con un tiempo de retención hidráulico de 30 días. La vida útil de las plantas de biometano es 20 años. Los datos utilizados para modelar esta planta son datos reales obtenidos de una planta de producción de biogas en Asturias.

\subsubsection{Características de la planta HYSOL GN}

La planta HYSOL GN, operando con gas natural, presenta la misma configuración y características que la planta HYSOL BIO (Figura 22 y Tabla 2). La única diferencia es que el combustible quemado en la turbina de gas es gas natural, obtenido de la red de gas natural española.

\subsubsection{Características principales de la planta TERMOSOLAR CCP}

El escenario comparativo principal contempla como tecnología convencional una planta termosolar con tecnología cilindro-parabólica de $50 \mathrm{MW}$ de potencia instalada en Talarrubias, Badajoz. Las características principales de la central se encuentran descritas en la Tabla 3. La configuración de la central se corresponde con lo representado en la Figura 15 del Capítulo 1 de esta tesis. El campo solar consiste en 624 colectores cilindro-parabólicos de tipo SENERtrough, organizados en 156 lazos proporcionando una apertura solar de $510120 \mathrm{~m}^{2}$. La central utiliza aceite sintético como HTF y cuenta con un sistema de almacenamiento térmico por sales fundidas de 7,5 horas. La transformación de energía térmica a electricidad se realiza mediante un ciclo de vapor Rankine, con una eficiencia térmica de $37 \%$. Se asume que el $15 \%$ de la electricidad producida proviene de la combustión de gas natural en una caldera auxiliar,

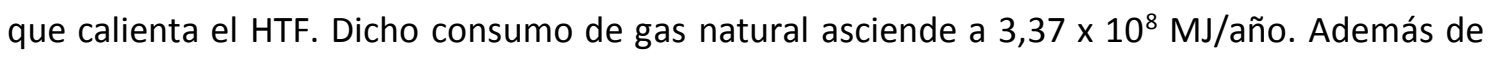
este consumo de gas para producción adicional de electricidad, la planta consume $6,80 \times 10^{6}$ 
MJ al año de gas natural para operaciones de puesta en marcha y para el mantenimiento de la temperatura de las sales fundidas y el aceite térmico.

Tabla 3 Características de la central del escenario TERMOSOLAR CCP, según datos propios

\begin{tabular}{ll}
\hline Características de la planta & Cantidad \\
\hline Potencia Instalada, MW & 50 \\
Radiación Directa Normal, kWh/m²/año & 2.086 \\
Apertura, $\mathrm{m}^{2}$ & 510.120 \\
No de colectores & 624 \\
Tipo de colectores & SENERTROUGH \\
Área ocupada por la central, ha & 200 \\
Horas de almacenamiento térmico, h & 7,5 \\
Electricidad bruta generada al año, MWh/año & 219,319 \\
Electricidad neta generada al año, MWh/año & 206,946 \\
Electricidad vertida a red anualmente, MWh/año & 194,677 \\
Vida útil de la central, años & 25 \\
Eficiencia térmica del ciclo Rankine & $35 \%$ \\
Eficiencia neta solar-eléctrica & $16,5 \%$ \\
Horas equivalentes a plena carga, h/año & 3.673 \\
Fracción solar, \% & $85 \%$ \\
Consumo de gas natural para producción de electricidad, MJ/año & $3,37 \times 10^{8}$ \\
Consumo de gas natural durante la fase O\&M, MJ/año & $6,80 \times 10^{6}$ \\
\hline
\end{tabular}

La electricidad anual producida se ha calculado mediante el software de modelado de centrales de energías renovables SAM (System Advisor Model), desarrollado por NREL (National Renewable Energy Laboratory. Golden, CO. 2015). Los cálculos se han realizado teniendo en cuenta la meteorología de un año típico en la ubicación de la planta. La central genera anualmente 219,319 MWh de electricidad bruta. El 5,6 \% de esta electricidad se auto-consume durante la operación de la central (consumo parasitario), por lo que la electricidad neta producida es 206,946 MWh/año. Parte de la electricidad necesaria para la operación de la central proviene de la red eléctrica española, sin embargo, se considera como autoconsumo a efectos de compra-venta de electricidad por lo que se resta de la producción total (no hay gasto económico en electricidad pero se vende menos electricidad al mercado eléctrico). Se asume que un $4 \%$ de la electricidad neta generada se pierde por ajustes de salida de electricidad asociados a la disponibilidad del sistema, y restricciones de red. Además, también se considera una reducción de la producción del $0,2 \%$ anual debido a la degradación de equipos. Considerando los autoconsumos, los ajustes de salida y la degradación de equipos, la electricidad vendida por la central es 194,677 MWh/año (de media), que equivale a 3673 horas anuales equivalentes a plena carga. 


\subsubsection{Definición de sub-preguntas y herramientas de análisis}

Tal y como se indica en la sección 2.1.1 de este capítulo, el objetivo principal del análisis de sostenibilidad planteado en esta tesis es responder a la siguiente pregunta: ¿En qué medida puede la nueva tecnología HYSOL mejorar la sostenibilidad (ambiental, social y económica) de la producción eléctrica en el mercado eléctrico español? La respuesta a esta pregunta debe abordarse desde distintas disciplinas, y su alcance es tan amplio que es difícil de responder sin ayudarse de sub-preguntas de sostenibilidad más concretas. Definir las preguntas de sostenibilidad adecuadas es el principal desafío para la puesta en práctica del ASCV. Para ello se ha seguido el enfoque metodológico propuesto por Hu et al.(2013) basado en el proyecto CALCAS, donde el tercer paso para la determinación del objetivo y alcance (Definición de subpreguntas y herramientas de análisis) consiste en formular preguntas adicionales que puedan ser contestadas por las herramientas analíticas existentes.

Las preguntas y respuestas de sostenibilidad conectan el problema real con el ejercicio abstracto de modelado y simulación. La naturaleza y contenido de las preguntas ayudan a escoger el nivel de análisis y la herramienta aplicada para responderlas. Las respuestas sirven para traducir los resultados e información disponible en conclusiones y recomendaciones (Heijungs et al. 2009).

Las respuestas a las sub-preguntas de sostenibilidad planteadas en este análisis deben facilitar el conocer la sostenibilidad de la tecnología HYSOL cuando se integra en el mercado español. La respuesta a la pregunta principal conlleva una cuantificación de la sostenibilidad, ya que se desea conocer en qué medida se mejora la sostenibilidad. Por ello, es necesario cuantificar los resultados en cada área y así obtener indicadores que nos muestren la magnitud del cambio producido por la tecnología HYSOL. Por lo tanto, todas las herramientas aplicadas deberán proporcionar una cuantificación del impacto producido.

Para este análisis, se han planteado tres o cuatro sub-preguntas para cada área de la sostenibilidad con el objetivo de responder a la pregunta principal del análisis. La Tabla 4 muestra las distintas sub-preguntas junto con el nivel de la pregunta (micro, meso o macro) y las herramientas de análisis que proporcionan las respuestas. 
Pregunta principal: ¿En qué medida puede la nueva tecnología HYSOL mejorar la sostenibilidad (ambiental, social y económica) de la producción eléctrica en el mercado eléctrico español?

\begin{tabular}{|c|c|c|}
\hline Área ambiental & $\begin{array}{l}\text { Nivel de la } \\
\text { pregunta }\end{array}$ & $\begin{array}{l}\text { Metodología a } \\
\text { aplicar }\end{array}$ \\
\hline ¿Cuál es el impacto ambiental potencial de la tecnología HYSOL? & Micro & $\begin{array}{l}\text { ACV-Ambiental } \\
\text { atribucional }\end{array}$ \\
\hline $\begin{array}{l}\text { ¿Es el impacto ambiental del ciclo de vida de la tecnología HYSOL } \\
\text { inferior al de la tecnología termosolar convencional? }\end{array}$ & Micro & $\begin{array}{l}\text { ACV-Ambiental } \\
\text { atribucional }\end{array}$ \\
\hline $\begin{array}{l}\text { ¿Cuánto se reduce el impacto ambiental del sector eléctrico al } \\
\text { proveer de electricidad HYSOL al mercado eléctrico español? }\end{array}$ & Meso & $\begin{array}{l}\text { ACV-Ambiental } \\
\text { consecuencial }\end{array}$ \\
\hline \multicolumn{3}{|l|}{ Área económica } \\
\hline ¿Cuál es el coste del ciclo de vida de la tecnología HYSOL? & Micro & $\mathrm{CCV}$ \\
\hline $\begin{array}{l}\text { ¿Disminuyen los costes de ciclo de vida por unidad funcional de la } \\
\text { tecnología HYSOL respecto a los de la termosolar convencional? }\end{array}$ & Micro & $\mathrm{CCV}$ \\
\hline $\begin{array}{l}\text { ¿Qué efecto tiene el ciclo de vida de la tecnología HYSOL en la } \\
\text { generación de B\&S, y valor añadido? }\end{array}$ & Micro & Análisis 10 \\
\hline $\begin{array}{l}\text { ¿Aumenta la generación de B\&S y el valor añadido cuando se } \\
\text { introduce la tecnología HYSOL en el mercado eléctrico español? }\end{array}$ & $\begin{array}{l}\text { Meso/Econo } \\
\text { mía global }\end{array}$ & $\begin{array}{l}\text { Análisis } 10 \text { con } \\
\text { enfoque } \\
\text { consecuencial }\end{array}$ \\
\hline \multicolumn{3}{|l|}{ Área social } \\
\hline $\begin{array}{l}\text { ¿Aumenta el empleo generado en España por la introducción de la } \\
\text { tecnología HYSOL en el mercado eléctrico español? }\end{array}$ & $\begin{array}{l}\text { Meso/Econo } \\
\text { mía global }\end{array}$ & $\begin{array}{l}\text { Análisis IO con } \\
\text { enfoque } \\
\text { consecuencial }\end{array}$ \\
\hline $\begin{array}{l}\text { ¿Cuál es el riesgo de que ocurran problemas sociales en la cadena } \\
\text { de valor de la tecnología HYSOL? }\end{array}$ & Micro & ACV-Social \\
\hline $\begin{array}{l}\text { ¿Cómo afecta el ciclo de vida de la tecnología HYSOL en los } \\
\text { derechos laborales, salud y seguridad, herencia cultural y natural, } \\
\text { justicia y sostenibilidad socio-económica de los trabajadores, la } \\
\text { comunidad local, la sociedad y los actores de la cadena de valor? }\end{array}$ & Micro & ACV-Social \\
\hline $\begin{array}{l}\text { ¿Mejoran las condiciones sociales en España debido al ciclo de vida } \\
\text { de la tecnología HYSOL? }\end{array}$ & Micro & ACV-Social \\
\hline
\end{tabular}


CAPÍTULO 2: Metodología de ASCV de la tecnología HYSOL

La principal herramienta escogida para evaluar el área ambiental ha sido el ACV-Ambiental (ACV-A), ya que es la metodología de análisis más madura y, según la revisión bibliográfica realizada para esta tesis (sección 1.4.3 del Capítulo 1), es la más comúnmente utilizada en el ASCV. Esta metodología tiene dos enfoques mayoritarios: Atribucional y Consecuencial (para más información sobre la diferencia entre ambos enfoques, ver Sección 3.1.2.5 del Capítulo 3). Debido al nivel de análisis requerido por las preguntas de sostenibilidad en el área ambiental (micro y meso), se ha decidido aplicar ambos enfoques.

El área económica también presenta preguntas que se encuadran en dos niveles distintos (micro y meso). El CCV sólo es aplicable para responder preguntas de nivel micro, sin embargo, la metodología IO permite abarcar niveles meso o incluso macro. Por ello, se ha decidido aplicar ambas metodologías para responder adecuadamente a las preguntas del área económica. Además, este análisis plantea aplicar el análisis IO Multi-regional con enfoque consecuencial (para más información, consultar la sección 4.2.2.7 del Capítulo 4). Mediante este enfoque se pueden calcular los efectos netos producidos por la tecnología, es decir, incluir no sólo los efectos brutos que produce el sistema, sino también los efectos netos producidos al sustituir otras tecnologías en el mercado eléctrico español (siguiendo un enfoque meso, análogo a la metodología consecuencial en ACV-A).

Por último, el área social contiene dos enfoques: el socio-económico y el social. El primero tiene en cuenta la creación de empleo según el cálculo de la metodología IO, mientras que el segundo pretende responder a preguntas de índole social relacionadas con el bienestar humano. Es por ello que las metodologías propuestas son el análisis 10 con enfoque consecuencial y el ACV-Social (ACV-S). Ya que el empleo generado se calcula mediante una herramienta aplicada en el área económica, los resultados de empleo se describen en el capítulo 4 (correspondiente al área económica). Sin embargo, los resultados finales se interpretan en el área social. 


\subsection{MODELADO: APLICACIÓN DE HERRAMIENTAS}

En la fase de modelado se utilizan las herramientas analíticas escogidas en el paso anterior para producir resultados que respondan a las preguntas de sostenibilidad fijadas.

Según las preguntas definidas en el paso anterior, las herramietnas idóneas a aplicar para la consecución de este análisis, son el ACV-A (atribucional), ACV-A (consecuencial), CCV, Análisis IO, y ACV-S. En los próximos capítulos 3, 4 y 5 se muestran los estudios realizados para cada área o pilar de la sostenibilidad, describiendo la metodología de análisis, el inventario, las suposiciones metodológicas y las sinergias entre las distintas tecnologías analizadas. Los indicadores obtenidos por cada herramienta servirán como criterios para la toma de decisiones final.

\subsection{INTERPRETACIÓN DE RESULTADOS Y TOMA DE DECISIONES}

Este es el último paso en el que se interpretan los resultados obtenidos mediante la aplicación de las herramientas y se responden a las preguntas de sostenibilidad planteadas. Dichas respuestas representan la medida en que la tecnología HYSOL aumenta (o disminuye) la sostenibilidad de la producción de electricidad en España.

Los resultados deben representarse junto con una discusión sobre el alcance del estudio y las principales decisiones metodológicas tomadas que afectan a los resultados finales.

Además, este último paso debe facilitar la elección del escenario más sostenible. Para ello, la toma de decisiones debe basarse en criterios debidamente documentados y calculados para cada alternativa propuesta. Dichos criterios se obtienen mediante la aplicación de las herramientas en los capítulos 3, 4 y 5 de esta tesis, y se describen mediante las respuestas de sostenibilidad. Presentar estos resultados de forma clara y directa para la toma de decisiones es un reto en el $\mathrm{ASCV}$, por lo que se recomienda acompañarlo con una representación gráfica de los resultados de los criterios para cada alternativa (Ciroth et al. 2011). Según la revisión bibliográfica sobre agregación e interpretación de resultados de ASCV realizada para esta tesis (sección 1.4.3.5 del Capítulo 1), la representación gráfica más utilizada es un diagrama circular o radial donde se representan la idoneidad de una alternativa u otra mediante escalas numéricas y/o de colores. Por lo tanto, para este análisis se van a elaborar diagramas circulares para cada alternativa, utilizando una escala de colores que represente la mejor elección según cada criterio. 
CAPÍTULO 2: Metodología de ASCV de la tecnología HYSOL

Los criterios escogidos para representar la sostenibilidad en cada área y servir de fundamento en la toma de decisiones son los siguientes:

- Área ambiental: huella de carbono, indicador de punto final, estrés hídrico, Tiempo de Retorno Energético (TRE).

- Área económica: coste interno de ciclo de vida, balance de costes e ingresos, porcentaje de valor añadido y efecto multiplicador.

- Área social: Intensidad laboral, riesgo de problemas sociales en la cadena de valor, y puntos de comportamiento social de la empresa (en las categorías de Derechos laborales y trabajo digno, Salud y seguridad, Patrimonio cultural y natural, Relaciones justas, y Sostenibilidad socio-económica).

Estos criterios se han escogido por representar los principales y más representativos indicadores obtenidos mediante las herramientas de análisis ACV-A, CCV, IO y ACV-S de la tecnología HYSOL.

La mayor parte de los procesos de toma de decisiones suelen tener lugar en el ámbito de la gestión pública o de la empresa. Este análisis está planteado desde una perspectiva del bien público, y no del bien privado de una empresa particular. Por lo tanto, debe ofrecer una guía para escoger qué alternativa debería promoverse en mayor grado para mejorar la sostenibilidad de la producción eléctrica, contribuyendo al bien de la sociedad en su conjunto.

Una vez que se han presentado los resultados para cada alternativa, escoger la opción más sostenible es inmediato si una alternativa presenta mejores resultados ( $\mathrm{y} / \mathrm{o}$ similares) en todos los criterios, sin embargo, en la mayor parte de los casos unos criterios presentan mejores resultados que otros. En estos casos, la toma de decisiones puede facilitarse aplicando un método multi-criterio para la toma de decisiones (MCDM, del inglés, Multi-Criteria Decision Making) donde la elección de los participantes sea tal que represente lo máximo posible al grupo de personas afectadas por la decisión final (o a los propios tomadores de decisiones). Este análisis ofrece toda la información necesaria para realizar un proceso MCDM final de toma de decisiones.

La interpretación del ASCV de la tecnología HYSOL y la guía para la toma de decisiones se encuentra en el Capítulo 6 de esta tesis. 


\section{CAPÍTULO 3 Análisis del área ambiental}

Este capítulo recoge el estado del arte, metodología, análisis y resultados para el área ambiental del Análisis de Sostenibilidad de Ciclo de Vida (ASCV) de la tecnología HYSOL (Figura 23). Este capítulo incluye seis secciones. Las tres primeras secciones presentan: la definición y orígenes del Análisis de Ciclo de Vida Ambiental (ACV-A), los aspectos metodológicos más importantes para su consecución y una revisión bibliográfica de resultados del ACV-A aplicado a la tecnología termosolar. La cuarta sección presenta el ACV-A de la tecnología HYSOL, incluyendo los dos escenarios propuestos en la definición del objetivo y alcance del ASCV (HYSOL BIO y HYSOL GN), según los dos tipos de modelado principales (atribucional y consecuencial). La quinta sección está planteada con fines comparativos, y contiene el ACV-A de dos tecnologías de concentración solar (cilindro-parabólica y de torre), incluyendo la planta definida como CONVENCIONAL CCP según la definición del objetivo y alcance del ASCV. Por último, la sexta sección presenta la discusión, comparación y conclusiones de los principales resultados obtenidos para el área ambiental.

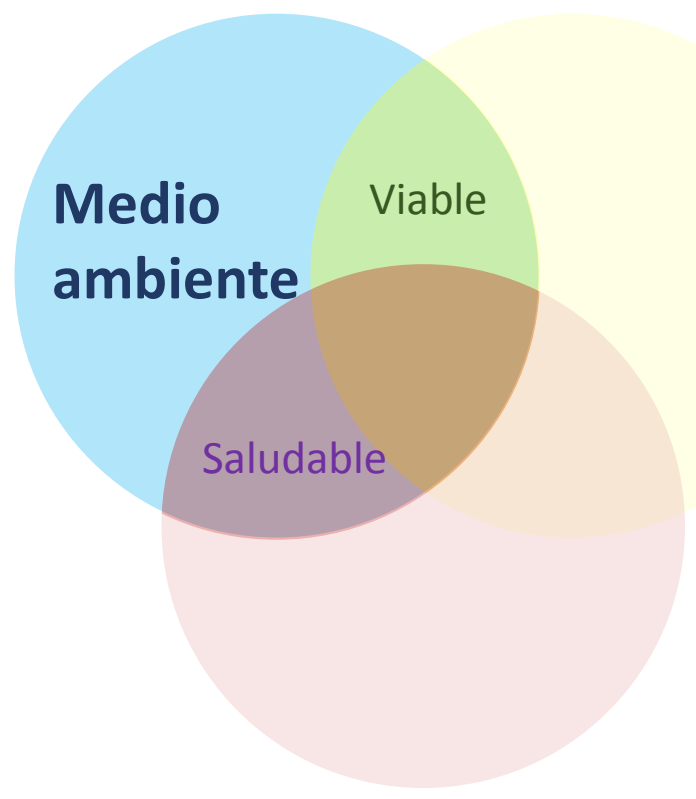

Figura 23 Área ambiental de la sostenibilidad 


\subsection{INTRODUCCIÓN}

\subsubsection{Definición y orígenes}

El Análisis de Ciclo de Vida (ACV) ambiental es una herramienta destinada a calcular los impactos ambientales de todo el ciclo de vida de un producto o sistema, desde la extracción de materias primas para su fabricación, hasta la disposición de los residuos generados (Guinée et al. 2006). En la Figura 24 se observa un diagrama con las etapas del ciclo de vida de una planta solar termoeléctrica. En dicha figura se puede apreciar que el ciclo de vida tiene un carácter circular: cuando los residuos se reciclan vuelven a introducirse en el sistema a través de la utilización de materiales reciclados (o energía obtenida) en la fabricación de componentes.

En los inicios de la metodología ACV sólo se contemplaba la estimación de impactos ambientales, por lo que no se distinguía entre ambiental, social o económico. En la actualidad, la metodología de ACV se ha extendido para aplicarse a las tres áreas, por lo que en esta tesis se va a considerar el término ACV-Ambiental (ACV-A) para distinguir el ACV aplicado únicamente al área ambiental.

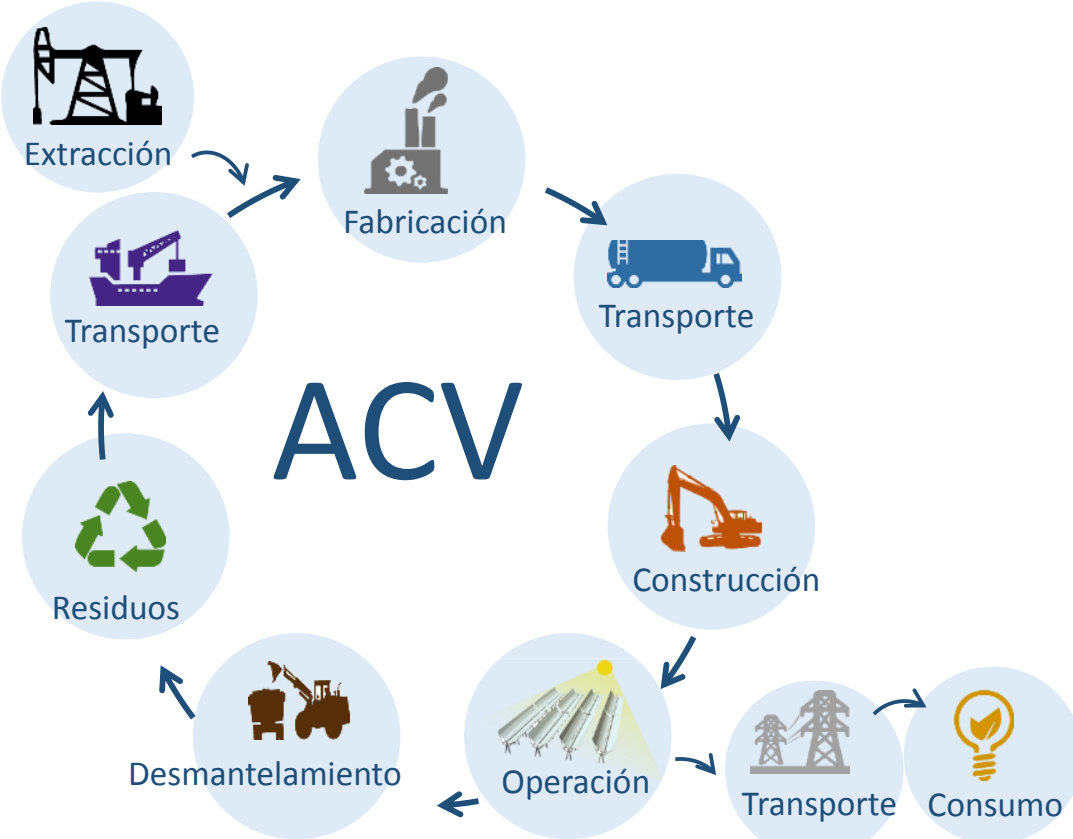

Figura 24 Diagrama de las etapas cubiertas por el ciclo de vida de una planta de producción eléctrica

Los orígenes de la metodología de ACV-A se remontan a los años 60 y 70, época en la que se publicaron los primeros estudios enfocados a algunas etapas concretas del ciclo de vida de productos. El término "Ánalisis de Ciclo de Vida" (en inglés "Life Cycle Assessment") comenzó a usarse en los años 90 para referirse a aquellos análisis de impacto ambiental que contemplaban el 
ciclo de vida de los productos o servicios. En 1993 tuvo lugar la formulación del primer código internacional de ACV-A: "Guidelines for Life-Cycle Assessment: a code of practice" (SETAC 1993), que fue tomado como base para las primeras normas internacionales sobre metodología ACV-A. Estas normas comenzaron a desarrollarse en 1994 por la ISO (Organización Internacional de Normalización, del inglés, International Organisation for Standardisation) dando lugar a diferentes series de normas que se han ido actualizando con el tiempo. En primer lugar se redactaron las normas ISO 14040:1998, ISO 14041:1999, ISO 14042:2001 e ISO 14043:2001 (aprobadas a nivel europeo y nacional), que en el año 2006 fueron sustituidas por las siguientes normas vigentes en la actualidad:

- UNE-EN ISO 14040:2006 Gestión ambiental. Análisis del ciclo de vida. Principios y marco de referencia. En esta norma se establecen principios fundamentales que se deberían utilizar como orientación para tomar decisiones relacionadas tanto con la planificación como con la realización de un ACV-A.

- UNE-EN ISO 14044:2006 Gestión ambiental. Análisis del ciclo de vida. Requisitos y directrices. Esta norma describe los principios y el marco de referencia para el análisis del ciclo de vida.

En el año 2002, el UNEP (Programa de las Naciones Unidas para el Medioambiente, del inglés, United Nations Environmental Program) y la Sociedad de Química y Toxicidad Ambiental (SETAC, del inglés Society of Environmental Toxicology and Chemistry), pusieron en marcha la "Iniciativa de Ciclo de Vida". Esta iniciativa se concibe como respuesta a la llamada de la Declaración de Malmö (Declaration 2000) a que todos los gobiernos del mundo a desarrollar una economía de ciclo de vida. El objetivo de la iniciativa es "facilitar la generación y adopción de enfoques basados en la ciencia del ciclo de vida e información de los productos por parte del gobierno, los negocios y la práctica de la sociedad civil en todo el mundo, como base para la producción y consumo sostenibles" (UNEP/SETAC 2015).

La otra gran iniciativa internacional sobre ACV-A comenzó sus inicios en el año 2003, con la Comunicación de Política de Productos Integrada de la Comisión Europea COM (2003)302 (Commision of the European Communities 2003) que establecía el ACV-A como la mejor metodología disponible de análisis de impactos ambientales potenciales de productos. Con el objetivo de cubrir la necesidad de información y metodologías consistentes y consensuadas para el ACV-A, se creó la Plataforma Europea de Análisis de Ciclo de Vida (JRC 2016). La plataforma está liderada por el Joint Research Centre de la Comisión Europea, y es el responsable de la Base de datos Internacional de Ciclo de Vida (ILCD, del inglés, International Life Cycle Database). 
El ACV también se ha tomado como base metodológica para la estandarización de etiquetas y declaraciones ambientales de producto, según las normas ISO 14020, ISO 14021, ISO 14024 e ISO 14025. Estas normas establecen tres tipos de etiquetado: ecoetiquetas (tipo I), Autodeclaraciones ambientales (tipo II) y Declaraciones Ambientales de Producto (tipo III). Las tres etiquetas están basadas en el enfoque de ciclo de vida, aunque las Declaraciones Ambientales de Producto (DAP) son las únicas que proporcionan una compilación verificable de datos ambientales cuantificados bajo las categorías y parámetros especificados en las normas ISO 14040, y siguiendo unas Reglas de Categoría de Productos (RCP). Las RCP son conjuntos de reglas que definen los requisitos que debe cumplir el ACV de un producto/servicio para obtener una DAP. Estas reglas permiten la transparencia y la comparabilidad entre diferentes DAP basadas en una misma categoría de producto (EPD 2016).

Actualmente la metodología se encuentra en un estado de desarrollo avanzado, en el que durante los últimos 15 años se han publicado más de 6000 documentos en bases de datos internacionales, principalmente artículos de revistas (74 \%), pero también comunicaciones en congresos y libros (Hou et al. 2015). Además, también se han registrado más de 550 DAP oficiales, pertenecientes a productos de 150 empresas en 28 países (EPD 2016).

\subsubsection{Metodología}

El ACV-A consiste en la evaluación ambiental de todas las entradas y salidas de flujos elementales que comprenden el ciclo de vida de un sistema o producto. Un flujo elemental, según la norma ISO 14040 es "Materia o energía que entra al sistema bajo estudio, que ha sido extraído del medioambiente sin una transformación previa por el ser humano, o materia o energía que sale del sistema bajo estudio, que es liberado al medioambiente sin una transformación posterior por el ser humano". Esta evaluación se lleva a cabo mediante las siguientes fases:

1. Definición de objetivo y alcance.

2. Análisis de inventario

3. Evaluación del impacto

4. Interpretación

El ACV es una técnica iterativa, donde cada fase utiliza resultados de otras fases y su iteración contribuye a la integración y coherencia de los resultados. El esquema del marco metodológico puede verse en la Figura 25. 


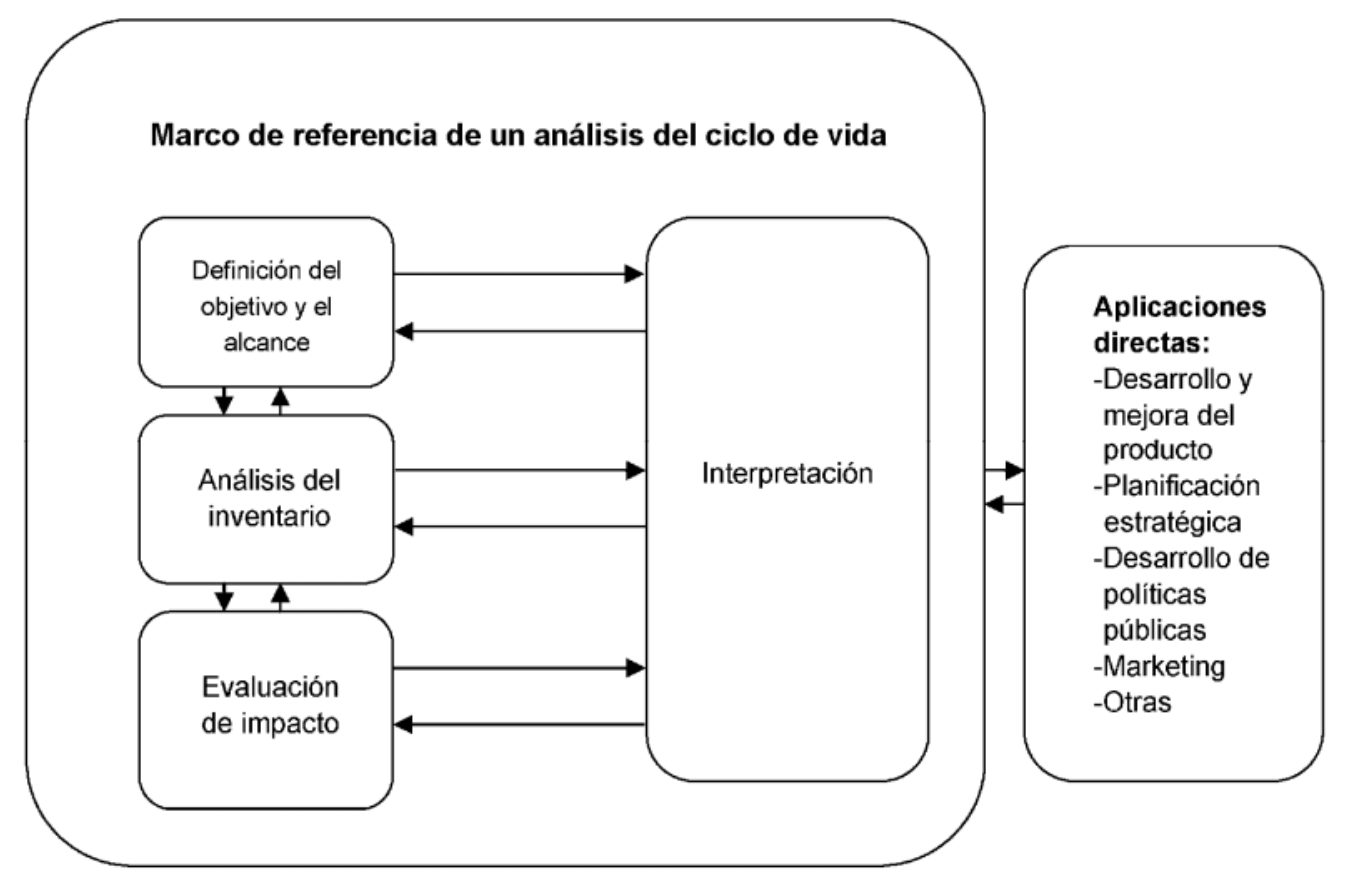

Figura 25 Etapas de un ACV-A, según la norma ISO 14040 (AENOR 2006)

A continuación se resumen las principales cuestiones a tener en cuenta al llevar a cabo cada fase del análisis (según las normas ISO).

\subsubsection{Definición de objetivo y alcance.}

El objetivo de un ACV-A debe abarcar las razones por las que se realiza el estudio, así como su aplicación, el público previsto y si los resultados van a utilizarse para aseveraciones comparativas públicas. Los dos objetivos más comunes son la evaluación de impactos de un sistema/producto para determinar su magnitud y detectar posibles puntos de mejora ambiental, y la comparación entre sistemas/productos para la toma de decisiones basada en criterios ambientales.

El alcance debe definir la profundidad, la amplitud y el nivel de detalle que va a seguir el estudio. El alcance debe ser compatible y coherente con el objetivo del estudio. El alcance puede tener que ajustarse a lo largo del estudio debido a la naturaleza iterativa del análisis.

En la definición del alcance deben especificarse las siguientes cuestiones: las características del sistema o producto estudiado, las funciones de dicho producto, los límites del sistema, los procedimientos de asignación de cargas ambientales, las categorías de impacto y metodologías de evaluación de impacto seleccionadas, los requisitos de calidad de datos, las suposiciones, la revisión crítica (si la hay) y el tipo/formato del informe requerido.

En esta fase se define también la unidad funcional, es decir, aquella que define la cuantificación de las funciones o características de desempeño del producto. Un sistema puede tener varias 
funciones posibles; las seleccionadas dependerán del objetivo y alcance del estudio. Por ejemplo, la mayoría de sistemas de producción eléctrica tendrán como unidad funcional $1 \mathrm{MWh}$ (o kWh), ya que su principal función es la producción de electricidad. Sin embargo, es posible que mediante el mismo sistema también se satisfagan otras funciones, como la de generar calor (MJ) en un proceso de cogeneración. En ese caso, habrá de determinarse cuál es la función principal a estudiar según el objetivo del estudio.

La unidad funcional es necesaria para asegurar una base común en la comparación de resultados de ACV-A, especialmente cuando se comparan dos sistemas diferentes. De esta manera, si se han seguido los mismos principios y suposiciones para evaluar dos sistemas de producción eléctrica diferente, podrá compararse de forma coherente el impacto ambiental de cada una respecto a la producción de $1 \mathrm{MWh}$.

\subsubsection{Análisis de Inventario de Ciclo de Vida (AICV)}

Consiste en la recopilación y evaluación de las entradas y salidas de materia y energía que tienen lugar en el ciclo de vida de un producto o servicio.

La recopilación de datos suele agruparse en procesos unitarios. El proceso unitario es, según la ISO 14040, "el elemento más pequeño considerado en el análisis del inventario del ciclo de vida para el cual se cuantifican datos de entrada y salida". Tras la recopilación, suele ser necesaria una serie de cálculos destinados a la validación de los datos, determinar su relación con los procesos unitarios, y reflejar su relación con la unidad funcional.

También debe considerarse la asignación de cargas a realizar cuando el sistema bajo estudio incluye productos múltiples. Las distintas entradas y salidas deben asignarse a los distintos procedimientos de forma transparente y con criterios específicos. La norma dice que siempre que sea posible debe evitarse la asignación ampliando el sistema del producto para incluir las funciones adicionales relacionadas con los co-productos (productos adicionales generados mediante el mismo sistema, al mismo tiempo). En caso de que esto no sea posible, se sugiere utilizar reglas físicas (masa, volumen) o criterios económicos.

Los datos de inventario pueden ser primarios o secundarios, dependiendo de la importancia relativa de los procesos que describen. Los datos primarios corresponden a aquellos procesos inherentes a la tecnología, descritos en cada fase del inventario (como las eficiencias de la central, la cantidad de materiales de cada componente o el gasto de combustible por la central) y que han sido obtenidos mediante medidas o estudios empíricos/teóricos. Los datos secundarios corresponden a aquellos procesos aguas arriba a la fabricación de la planta, que son comunes a 
muchos otros procesos de la tecnosfera (como la fabricación de materiales y de vehículos de transporte, la provisión de combustibles fósiles, etc.) y que provienen de bases de datos públicas o privadas, literatura y estadísticas.

La fase AICV se ve facilitada por la existencia de bases de datos internacionales que recopilan información de inventario de numerosos procesos unitarios presentes en la actividad productiva global. Las principales bases de datos europeas o internacionales a disposición de los practicantes de ACV-A (de manera pública o privada) se describen brevemente en la Tabla 5. Otras bases de datos confeccionadas a nivel nacional no se han incluido en dicha tabla ya que son representativas de otros países diferentes a España.

Tabla 5 Principales bases de datos a nivel internacional o europeo

\begin{tabular}{|c|c|c|}
\hline $\begin{array}{l}\text { Nombre de la } \\
\text { base de datos }\end{array}$ & Desarrollador & Características \\
\hline Ecoinvent & ecoinvent & $\begin{array}{l}\text { Contiene datos de inventario de diversos sectores como la } \\
\text { producción de energía, transporte, materiales de construcción, } \\
\text { producción de químicos, producción de metales, frutas y verduras, } \\
\text { etc. La base de datos consta de más de } 10.000 \text { datasets } \\
\text { interrelacionadas; cada una de ellas describe un inventario de ciclo } \\
\text { de vida a nivel de proceso. Contempla varios enfoques de } \\
\text { modelado: asignación con reciclado, asignación por defecto y } \\
\text { consecuencial. www.ecoinvent.org }\end{array}$ \\
\hline GaBi & $\mathrm{GaBi}$ & $\begin{array}{l}\text { Es, junto a ecoinvent, una de las bases de datos más utilizadas. Se } \\
\text { basa principalmente en la recolección de datos primarios en } \\
\text { diversos sectores desde la agricultura hasta la electrónica, textiles } \\
\text { o servicios. Contiene más de } 6000 \text { datasets. www.gabi- } \\
\text { software.com }\end{array}$ \\
\hline $\begin{array}{l}\text { European Life } \\
\text { Cycle Data }\end{array}$ & $\begin{array}{l}\text { Joint Research } \\
\text { Centre }\end{array}$ & $\begin{array}{l}\text { Comprende datos representativos de la Unión Europea para } \\
\text { inventarios de materiales clave, materiales energéticos, transporte } \\
\text { y gestión de residuos. El enfoque se pone en la aplicabilidad, } \\
\text { consistencia y calidad de los datos. Los respectivos conjuntos de } \\
\text { datos son oficialmente proporcionados y aprobados por la } \\
\text { Asociación Industrial que corresponda. } \\
\text { http://eplca.jrc.ec.europa.eu/ELCD3/ }\end{array}$ \\
\hline $\begin{array}{l}\text { EU and Danish } \\
\text { Input Output } \\
\text { library }\end{array}$ & $\begin{array}{l}2.0 \text { consultants } \\
\text { as part of project } \\
\text { FORWAST (EU } \\
\text { FP6) }\end{array}$ & $\begin{array}{l}\text { Consiste en una tabla danesa de } 133 \text { sectores económicos y una } \\
\text { tabla europea (EU27) con } 142 \text { sectores. http://lca- } \\
\text { net.com/services-and-solutions/input-output-databases-life-cycle- } \\
\text { assessment/ }\end{array}$ \\
\hline
\end{tabular}

\subsection{Incertidumbre de los datos}

Cualquier análisis numérico debería ir acompañado de información sobre la incertidumbre asociada con los datos de partida. Esta información permite una interpretación de los resultados más transparente y precisa. 
La incertidumbre de los datos de la base de datos de Ecolnvent viene determinada por el cuadrado de la desviación estándar geométrica (con un $95 \%$ de intervalo de confianza). Para aquellos datos que supongan más del $1 \%$ del impacto ambiental total, se aplicará el mismo método de evaluación de incertidumbre que en la base de datos de ecoinvent, determinado mediante la matriz Pedigree (Tabla 6).

Tabla 6 Matriz Pedigree, (Manual Introduction to LCA, SimaPro 7)

\begin{tabular}{|c|c|c|c|c|c|c|}
\hline \multicolumn{2}{|c|}{ Score: } & \multirow{2}{*}{$\begin{array}{l}1 \\
\text { Verified data } \\
\text { based on } \\
\text { measurements }\end{array}$} & \multirow{2}{*}{\begin{tabular}{|l}
2 \\
Verified data partly \\
based on \\
assumptions OR \\
non-verified data \\
based on \\
measurements
\end{tabular}} & \multirow{2}{*}{\begin{tabular}{|l|}
3 \\
Non-verified data \\
partly based on \\
qualified estimates
\end{tabular}} & \multirow[b]{2}{*}{$\begin{array}{l}4 \\
\text { Qualified estimate } \\
\text { (e.g. by industrial } \\
\text { expert); data } \\
\text { derived from } \\
\text { theoretical } \\
\text { information } \\
\text { (stoichiometry, } \\
\text { enthalpy, etc.) }\end{array}$} & \multirow{2}{*}{\begin{tabular}{|l|}
5 \\
Non-qualified estimate \\
\end{tabular}} \\
\hline \multirow{2}{*}{\multicolumn{2}{|c|}{ 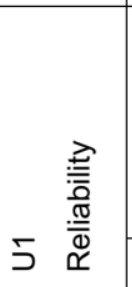 }} & & & & & \\
\hline & & 1.00 & 1.05 & 1.10 & 1.20 & 1.50 \\
\hline \multirow[b]{2}{*}{$\stackrel{\Im}{\supset}$} & \multirow{2}{*}{ 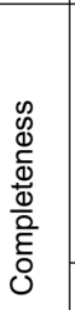 } & $\begin{array}{l}\text { Representative } \\
\text { data from all sites } \\
\text { relevant for the } \\
\text { market considered } \\
\text { over an adequate } \\
\text { period to even out } \\
\text { normal fluctuations }\end{array}$ & $\begin{array}{l}\text { Representative } \\
\text { data from }>50 \% \text { of } \\
\text { the sites relevant } \\
\text { for the market } \\
\text { considered over an } \\
\text { adequate period to } \\
\text { even out normal } \\
\text { fluctuations }\end{array}$ & $\begin{array}{l}\text { Representative } \\
\text { data from only } \\
\text { some sites } \\
(<<50 \%) \text { relevant } \\
\text { for the market } \\
\text { considered OR } \\
>50 \% \text { of sites but } \\
\text { from shorter } \\
\text { periods }\end{array}$ & $\begin{array}{l}\text { Representative } \\
\text { data from only one } \\
\text { site relevant for } \\
\text { the market } \\
\text { considered OR } \\
\text { some sites but } \\
\text { from shorter } \\
\text { periods }\end{array}$ & $\begin{array}{l}\text { Representativeness } \\
\text { unknown or data from } \\
\text { a small number of sites } \\
\text { AND from shorter } \\
\text { periods }\end{array}$ \\
\hline & & 1.00 & 1.02 & 1.05 & 1.10 & 1.20 \\
\hline & \multirow{2}{*}{ 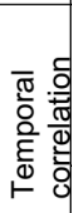 } & $\begin{array}{l}\text { Less than } 3 \text { years } \\
\text { of difference to our } \\
\text { reference year } \\
(2000)\end{array}$ & $\begin{array}{l}\text { Less than } 6 \text { years } \\
\text { of difference to our } \\
\text { reference year } \\
(2000)\end{array}$ & $\begin{array}{l}\text { Less than } 10 \text { years } \\
\text { of difference to our } \\
\text { reference year } \\
(2000)\end{array}$ & $\begin{array}{l}\text { Less than } 15 \\
\text { years of difference } \\
\text { to our reference } \\
\text { year }(2000)\end{array}$ & $\begin{array}{l}\text { Age of data unknown } \\
\text { or more than } 15 \text { years } \\
\text { of difference to our } \\
\text { reference year (2000) }\end{array}$ \\
\hline & & 1.00 & 1.03 & 1.10 & 1.20 & 1.50 \\
\hline \multirow[b]{2}{*}{$\stackrel{\unlhd}{\supset}$} & \multirow{2}{*}{ 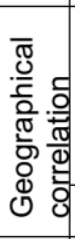 } & $\begin{array}{l}\text { Data from area } \\
\text { under study }\end{array}$ & $\begin{array}{l}\text { Average data from } \\
\text { larger area in } \\
\text { which the area } \\
\text { under study is } \\
\text { included }\end{array}$ & $\begin{array}{l}\text { Data from smaller } \\
\text { area than area } \\
\text { under study, or } \\
\text { from similar area }\end{array}$ & & $\begin{array}{l}\text { Data from unknown } \\
\text { OR distinctly different } \\
\text { area (north America } \\
\text { instead of middle east, } \\
\text { OECD-Europe instead } \\
\text { of Russia) }\end{array}$ \\
\hline & & 1.00 & 1.01 & 1.02 & & 1.10 \\
\hline \multirow[t]{2}{*}{ 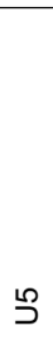 } & \multirow[t]{2}{*}{ 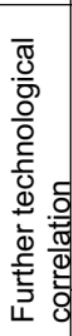 } & $\begin{array}{l}\text { Data from } \\
\text { enterprises, } \\
\text { processes and } \\
\text { materials under } \\
\text { study (i.e. identical } \\
\text { technology) } \\
\\
\end{array}$ & & $\begin{array}{l}\text { Data on related } \\
\text { processes or } \\
\text { materials but same } \\
\text { technology, OR } \\
\text { Data from } \\
\text { processes and } \\
\text { materials under } \\
\text { study but from } \\
\text { different } \\
\text { technology }\end{array}$ & $\begin{array}{l}\text { Data on related } \\
\text { processes or } \\
\text { materials but } \\
\text { different } \\
\text { technology, OR } \\
\text { data on laboratory } \\
\text { scale processes } \\
\text { and same } \\
\text { technology }\end{array}$ & $\begin{array}{l}\text { Data on related } \\
\text { processes or materials } \\
\text { but on laboratory scale } \\
\text { of different technology }\end{array}$ \\
\hline & & 1.00 & & 1.20 & 1.50 & 2.00 \\
\hline \multirow[b]{2}{*}{$\stackrel{\varrho}{\supset}$} & \multirow{2}{*}{$\begin{array}{l}\frac{D}{N} \\
\frac{N}{D} \\
\frac{0}{0} \\
\frac{D}{\mathbb{N}} \\
\omega\end{array}$} & $\begin{array}{l}>100, \text { continuous } \\
\text { measurement, } \\
\text { balance of } \\
\text { purchased } \\
\text { products }\end{array}$ & $>20$ & $\begin{array}{l}>10, \text { aggregated } \\
\text { figure in } \\
\text { environmental } \\
\text { report }\end{array}$ & $>=3$ & unknown \\
\hline & & 1.00 & 1.02 & 1.05 & 1.10 & 1.20 \\
\hline
\end{tabular}

En función de la calidad de los datos (definida por categorías en la tabla 3.2) se obtienen distintos valores de U1-U6. Estos factores se introducen en la Ecuación (1) (Manual Introduction to LCA, SimaPro 7) para obtener el valor del cuadrado de la desviación geométrica estándar asociado a dicho dato. 


$$
\operatorname{SDg} 95=\sigma g 2=e^{\sqrt{\left[\ln \left(U_{1}\right)\right]^{2}+\left[\ln \left(U_{2}\right)\right]^{2}+\left[\ln \left(U_{3}\right)\right]^{2}+\left[\ln \left(U_{4}\right)\right]^{2}+\left[\ln \left(U_{5}\right)\right]^{2}+\left[\ln \left(U_{6}\right)\right]^{2}+\left[\ln \left(U_{b}\right)\right]^{2}}}
$$

El valor de Ub representa el valor básico de incertidumbre inherente a los distintos materiales y procesos. La Tabla 7 presenta los valores de Ub que se asignan a los distintos tipos de datasets.

Tabla 7 Valor básico de incertidumbre (Manual Introduction to LCA, SimaPro 7)

\begin{tabular}{|c|c|c|c|}
\hline Input / output group & Ub & Input / output group & Ub \\
\hline Demand of: & & Emission to air of: & \\
\hline thermal energy & 1.05 & $\mathrm{CO}_{2}$ & 1.05 \\
\hline electricity & 1.05 & $\mathrm{SO}_{2}$ & 1.05 \\
\hline semi-finished products & 1.05 & $\begin{array}{l}\text { combustion: NOX, NMVOC total, methane, N2O and } \\
\mathrm{NH}_{3}\end{array}$ & 1.50 \\
\hline working materials & 1.05 & Combustion: $\mathrm{CO}$ & 5.00 \\
\hline transport services & 2.00 & Combustion: individual hydrocarbons, TSM & 1.50 \\
\hline waste treatment services & 1.05 & Combustion: PM10 & 2.00 \\
\hline Infrastructure & 3.00 & Combustion: PM2.5 & 3.00 \\
\hline Resources: & & combustion: polycyclic aromatic hydrocarbons (PAH) & 3.00 \\
\hline primary energy carriers & 1.05 & Combustion: heavy metals & 5.00 \\
\hline metals, salts & 1.05 & process emissions: individual VOCs & 2.00 \\
\hline land use, occupation & 1.50 & process emissions: $\mathrm{CO}_{2}$ & 1.05 \\
\hline land use, transformation & 2.00 & process emissions: TSM & 1.50 \\
\hline Waste heat: & & process emissions: PM10 & 2.00 \\
\hline emission to air, water, and soil & 1.05 & process emissions: PM2.5 & 3.00 \\
\hline Emission to water of: & & from agriculture: $\mathrm{CH}_{4}, \mathrm{NH}_{3}$ & 1.20 \\
\hline BOD, COD, DOC, TOC & 1.50 & from agriculture: N2O, NOX & 1.40 \\
\hline $\begin{array}{l}\text { Inorganic compounds }\left(\mathrm{NH}_{4}, \mathrm{PO}_{4}, \mathrm{NO}_{3}, \mathrm{Cl}, \mathrm{Na}\right. \\
\text { etc.) }\end{array}$ & 1.50 & Radio nuclides (e.g., Radon-222) & 3.00 \\
\hline individual hydrocarbons, PAH & 3.00 & process emissions: other inorganic emissions & 1.50 \\
\hline heavy metals & 5.00 & Emission to soil of: & \\
\hline from agriculture: $\mathrm{NO}_{3}, \mathrm{PO}_{4}$ & 1.50 & oil, hydrocarbon total & 1.50 \\
\hline from agriculture: heavy metals & 1.80 & Pesticides & 1.20 \\
\hline from agriculture: pesticides & 1.50 & heavy metals & 1.50 \\
\hline Radio nuclides & 3.00 & Radio nuclides & 3.00 \\
\hline
\end{tabular}

\subsubsection{Evaluación del Impacto ambiental de Ciclo de Vida (EICV)}

Esta fase es la encargada de conocer y evaluar la magnitud de los impactos ambientales potenciales del ciclo de vida de un producto/servicio. Principalmente consiste en la asociación de los datos de inventario recopilados en la fase AICV con los indicadores de las categorías de impacto ambiental escogidas en la definición de objetivo y alcance.

Esta fase consta de cuatro pasos principales: (1) clasificación, (2) caracterización, (3) normalización y (4) ponderación. Sólo las dos primeras son necesarias y obligatorias según las normas ISO, mientras que la normalización y la ponderación son opcionales. La clasificación consiste en la asociación de las distintas salidas del sistema (resultados del análisis de inventario) con las categorías de impacto. Mediante la caracterización se calculan los indicadores de impacto de las categorías seleccionadas. Este cálculo se consigue mediante la asignación de factores de impacto relativos a cada elemento del inventario en función de su potencial ambiental para cada categoría. 
Por ejemplo, la categoría de impacto Cambio Climático (o Calentamiento Global) se caracteriza utilizando el GWP (Potencial de calentamiento global, del inglés, Global Warming Potential) y presenta como indicador el $\mathrm{kg}$ de $\mathrm{CO}_{2}$ equivalente (eq.). Este paso se lleva a cabo con la ayuda de modelos o métodos de caracterización desarrollados generalmente a nivel internacional, como es el caso del modelo del IPCC (Panel Intergubernamental sobre Cambio Climático) para la categoría de Cambio Climático.

Tras la caracterización puede realizarse una normalización, paso que consiste en el cálculo de la magnitud relativa de los resultados caracterizados en relación a un escenario de referencia. Mediante este paso se pretende dotar de significado relativo a los resultados para cada categoría de impacto, por lo que es necesario comparar dichos resultados con un escenario de referencia que muestre, por ejemplo, los niveles existentes de contaminación- y así conocer cómo de alto o bajo es un impacto respecto a dichos niveles.

La normalización es también el paso previo a la agrupación y/o ponderación, donde los resultados de cada categoría de impacto se agregan en función de su naturaleza, y en el caso de la ponderación, también se les da un peso relativo basado en juicios de valor. La ponderación no tiene una base científica, se basa en preferencias políticas, globales, empresariales o personales.

Las normas ISO 14040 y 14044 también indican la necesidad de completar la fase de EICV con análisis adicionales de la calidad de datos. Estos análisis pueden ser de la gravedad (identificando datos que contribuyen mayoritariamente al resultado de cada indicador), de la incertidumbre (cómo de confiable es un resultado en base a la incertidumbre agregada de los datos de partida), y de la sensibilidad (cómo afectan al resultado los cambios en los datos y las decisiones metodológicas).

\subsection{Métodos de evaluación de impacto}

La comunidad científica ha ido desarrollando distintos métodos de caracterización, normalización y ponderación que se utilizan a nivel internacional. Dichos métodos pueden clasificarse en métodos de punto medio (en inglés, midpoint) o punto final (en inglés, endpoint). Los primeros proporcionan resultados para impactos de punto medio, es decir, el impacto potencial representado por el indicador de caracterización de cada categoría. Sin embargo, los métodos de punto final proporcionan el impacto en términos del daño producido a un área de protección concreta, por ejemplo: salud humana, biodiversidad o recursos. Los primeros llevan asociada menor incertidumbre, ya que precisan de menos cálculos y suposiciones para llegar al indicador de categoría (normalmente sólo proporcionan resultados caracterizados, y en algún caso 
normalizados), mientras que los segundos son más inciertos (incluyen agrupación y ponderación) pero son más fáciles de interpretar.

Actualmente existen más de 50 métodos de evaluación disponibles en Europa (Bueno et al. 2015). Algunos de ellos -como el CML 2001 o el IPCC 2013- son métodos de punto medio, otros como el Eco-Indicador 99 o el EPS 2000-son métodos de punto final mientras que otros -como el ReCiPe 2008 o el Impact 2002- combinan los dos enfoques. Algunos de los métodos de evaluación desarrollados sólo contemplan una categoría de impacto ambiental ( $p$ ej. el IPCC 2013 sólo analiza cambio climático) mientras que otros analizan hasta 18 categorías diferentes ( $p$ ej. ReCiPe 2008). Además, también difieren en su cobertura geográfica, ya que algunos de los métodos desarrollados en Europa son específicos de determinadas regiones, mientras que otros permiten la normalización a nivel europeo o internacional.

No existen guías oficiales que ayuden a los practicantes de ACV-A a escoger entre distintos modelos de evaluación de impacto (Bueno et al. 2015), aunque el International Reference Life Cycle Data System (ILCD) propone mediante el manual ILCD Handbook (Wolf et al. 2012) un método de evaluación a nivel Europeo que combina distintos métodos para cada categoría de impacto. Sin embargo, esta guía sólo está disponible para los impactos de punto medio.

En la Tabla 8 se muestran los modelos de caracterización, normalización y ponderación más utilizados actualmente por la comunidad científica europea (Bueno et al. 2015).

Tabla 8 Los cinco métodos de evaluación de impacto de ACVutilizados de forma más habitual por la comunidad científica europea

\begin{tabular}{|c|c|c|c|}
\hline $\begin{array}{l}\text { Métodos de } \\
\text { evaluación }\end{array}$ & Enfoque & \multicolumn{2}{|l|}{ Categorías de impacto } \\
\hline $\begin{array}{l}\text { EDIP 97/2003 } \\
\text { (Hauschild and } \\
\text { Potting 2004) }\end{array}$ & Punto medio & \multicolumn{2}{|c|}{$\begin{array}{l}\text { Calentamiento global, Destrucción de la capa de ozono, } \\
\text { Acidificación, Eutrofización terrestre, Eutrofización acuática (N- } \\
\text { eq y P-eq), Ozono troposférico (humanos y vegetación), } \\
\text { Toxicidad humana (vía aire, agua y suelo), Ecotoxicidad (acuática } \\
\text { aguda, acuática grave, y terrestre), Recursos y Residuos. }\end{array}$} \\
\hline $\begin{array}{l}\text { CML } 2001 \text { (Leiden } \\
\text { University 2015) }\end{array}$ & Punto medio & \multicolumn{2}{|c|}{$\begin{array}{l}\text { Destrucción abiótica, Agotamiento de combustibles fósiles, } \\
\text { Calentamiento global, Destrucción de la capa de ozono, } \\
\text { Toxicidad humana, Ecotoxicidad (agua dulce, marina y terrestre), } \\
\text { Oxidación fotoquímica, Acidificación y Eutrofización. }\end{array}$} \\
\hline $\begin{array}{l}\text { Impact }+2002 \text { (Jolliet } \\
\text { et al. 2003) }\end{array}$ & $\begin{array}{l}\text { Punto medio y } \\
\text { final }\end{array}$ & $\begin{array}{l}\text { Carcinógenos, No-carcinógenos, } \\
\text { Compuestos inorgánicos (respirables y no } \\
\text { respirables), Radiación ionizante, } \\
\text { Destrucción de la capa de ozono, } \\
\text { Ecotoxicidad acuática, Acidificación } \\
\text { (terrestre y acuática), Ocupación de } \\
\text { tierras, Eutrofización acuática, } \\
\text { Calentamiento global, Energías no } \\
\text { renovables y Extracción de minerales. }\end{array}$ & $\begin{array}{l}\text { Salud humana, } \\
\text { Calidad de los } \\
\text { ecosistemas, } \\
\text { disponibilidad de } \\
\text { recursos, Cambio } \\
\text { climático }\end{array}$ \\
\hline
\end{tabular}




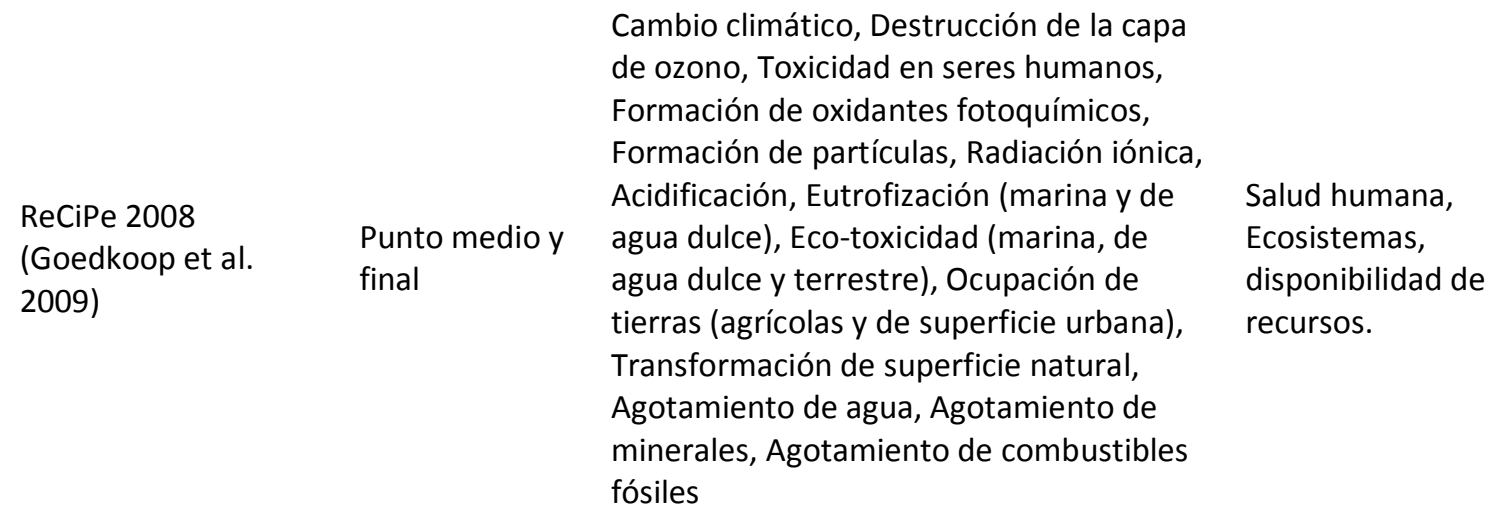

ILCD recommended practices (Wolf et al. Punto medio Cambio climático, Destrucción de la capa de ozono, Toxicidad en seres humanos (cancerígena y no cancerígena), Formación de oxidantes fotoquímicos, Formación de partículas, Radiación 2012) iónica ( $\mathrm{HH}$ y E), Acidificación, Eutrofización (marina, de agua dulce y terrestre), Eco-toxicidad de agua dulce, Uso de tierras, Agotamiento de agua, Agotamiento de minerales y combustibles fósiles

\subsection{Categorías de impacto ambiental}

Como se ha indicado en la sección anterior, hay diversos métodos de evaluación ambiental que consideran distintas categorías de impacto y modelos de caracterización. Aunque hay variaciones en la cobertura de impactos de los distintos métodos, la mayoría de ellos analizan al menos una de las siguientes categorías: cambio climático (o calentamiento global), acidificación, eutrofización, toxicidad, destrucción de la capa de ozono, formación de oxidantes fotoquímicos, uso de la tierra, consumo de agua y consumo de energía. A continuación se explica brevemente el impacto ambiental que representan dichas categorías.

- Cambio climático (o calentamiento global)

El cambio climático es, según la Convención Marco de las Naciones Unidas sobre el Cambio Climático (CMNUCC), un cambio del clima atribuido directa o indirectamente a actividades humanas que alteran la composición de la atmósfera mundial, y que viene a añadirse a la variabilidad natural del clima observada durante periodos de tiempo comparables (IPCC 1995).

El cambio climático puede producir un rango muy amplio de impactos en los ecosistemas y en la sociedad humana. En los últimos decenios, los cambios del clima han causado impactos en los sistemas naturales y humanos en todos los continentes. Los efectos observados incluyen la disminución en cantidad y calidad de los recursos hídricos, disminución del rendimiento de los cultivos, y cambios en el comportamiento de muchas especies terrestres, dulceacuícolas y marinas (IPCC 2015). 
La incertidumbre en la estimación de los impactos futuros por el cambio climático es muy alta, pero se espera que si la temperatura del planeta aumenta más de $2^{\circ} \mathrm{C}$ respecto a niveles preindustriales, habrá un riesgo alto o muy alto de que se produzcan los siguientes efectos sobre el planeta (IPCC 2015):

- Cambios abruptos e irreversibles en la sostenibilidad de los ecosistemas y las culturas.

- Aumento de episodios meteorológicos extremos (olas de calor, inundaciones, sequías, huracanes, etc.).

- Incremento de las desigualdades debido a los mayores riesgos y vulnerabilidad en las comunidades más desfavorecidas (sea cual sea el nivel de desarrollo de los países donde se encuentran).

Las estimaciones del impacto del cambio climático según el IPCC (en los que se basan la mayoría de métodos de evaluación de impacto de ciclo de vida) tienen en cuenta la influencia ejercida por el aumento antropogénico de los Gases de Efecto Invernadero (GEI). Todos los GEI tienen una propiedad común que sirve de base para su caracterización dentro de la categoría de cambio climático: su capacidad de absorber radiación infrarroja y con ello calentar la atmósfera. Esta capacidad se representa por el Potencial de Calentamiento Global (GWP, del inglés, Global Warming Potential). El GWP de una sustancia se define como el ratio entre el incremento de absorción infrarroja que causa $1 \mathrm{~kg}$ de dicha sustancia respecto al que causa $1 \mathrm{~kg}$ de dióxido de carbono $\left(\mathrm{CO}_{2}\right)$. Como los GEI presentan distintos tiempos de residencia en la atmósfera, los GWP se calculan para distintos horizontes temporales (20 años, 100 años, o 500 años).

El impacto de punto medio en cambio climático se mide en $\mathrm{kg} \mathrm{CO}_{2}$ eq, representando el aumento de la temperatura global debido a la radiación infrarroja. La huella de carbono de un producto o servicio equivale al impacto de punto medio en la categoría de cambio climático, es decir, representa las emisiones $\mathrm{GEI}$ (medidas en $\mathrm{kg} \mathrm{CO}_{2}$ eq) que son emitidas por el ciclo de vida del elemento estudiado.

\section{- Acidificación}

La acidificación es la alteración de la composición química del suelo y agua que disminuye su capacidad neutralizante. Las sustancias acidificadoras (principalmente $\mathrm{SO}_{2}, \mathrm{NO}_{\mathrm{x}}, \mathrm{HCl}$ y $\mathrm{NH}_{3}$ ) producen un rango amplio de impactos en el suelo, aguas superficiales, aguas subterráneas, organismos (muerte de plantas y especies animales), y deterioro de edificios. El factor de caracterización de dichas sustancias se llama Potencial de Acidificación (PA), y se calcula de distintas formas dependiendo del método de evaluación. Por ejemplo, el PA para la acidificación terrestre 
en el método ReCiPe se calcula considerando la persistencia en el ambiente de la sustancia acidificadora según modelos de deposición atmosférica y de acidificación dinámica del suelo (Goedkoop et al. 2009). El impacto de punto medio en acidificación suele expresarse mediante kg $\mathrm{SO}_{2}$ equivalentes.

\section{- Eutrofización}

La eutrofización acuática se define como el enriquecimiento en nutrientes de un entorno acuático que produce un cambio en el equilibrio de especies del entorno. La eutrofización en aguas interiores por el resultado de la actividad humana es uno de los principales factores que determina la calidad ecológica del agua. El alcance a largo plazo que tienen estos nutrientes tanto por aire como por ríos implica que, tanto las aguas interiores como las marinas, son susceptibles de este impacto ambiental (Goedkoop et al. 2009). La caracterización de eutrofización acuática en un ACV generalmente considera los nutrientes que limitan el crecimiento de biomasa acuática (principalmente fitoplancton y lentejas de agua). Simplificando, estos nutrientes son fósforo para entornos de agua dulce y nitrógeno para los de agua salada. El factor de caracterización de sustancias eutrofizadoras se llama Potencial de Eutrofización (PE), y se calcula de distintas formas dependiendo del método de evaluación. Por ejemplo, el PE en el método ReCiPe se calcula considerando el incremento marginal de concentración de cada nutriente en el medio acuático debido a un incremento marginal de su emisión (al aire, suelo u agua). En dicho método, el impacto de punto medio en eutrofización de agua dulce y marina se mide en $\mathrm{kg} P$ eq y $\mathrm{kg} \mathrm{N}$ eq respectivamente.

\section{- Toxicidad}

La toxicidad es una de las categorías de impacto del ACV que más variedad de métodos de caracterización presenta. Las principales dificultades a la hora de caracterizar la toxicidad son la diversidad de sustancias tóxicas emitidas, la variabilidad e incertidumbre de impactos causados tanto en la salud humana como en los ecosistemas, y la facilidad de dispersión del contaminante. Para representar esta diversidad de impactos, la categoría de toxicidad suele dividirse en toxicidad humana, eco-toxicidad acuática (en medios marinos y/o dulces) y eco-toxicidad terrestre. Los distintos métodos de evaluación de impacto utilizan diferentes aproximaciones para la caracterización de impactos en toxicidad, considerando diferentes modelos de dispersión, persistencia, exposición y efectos tóxicos. El modelo de caracterización ReCiPe utiliza el modelo de toxicidad según USES-LCA (Uniform System for the Evaluation of Substances for LCA). En los factores de caracterización de punto medio, este modelo considera la persistencia ambiental del 
contaminante y el factor tóxico (efecto) en el medio o especie que lo recibe. La sustancia utilizada como referencia (en ReCiPe 2008) es el químico 1,4-Diclorobenceno.

- Destrucción de la capa de ozono

La capa de ozono estratosférica contiene ozono que está continuamente formándose y destruyéndose por la acción de la luz solar y de las reacciones químicas en la estratosfera. La destrucción de la capa de ozono tiene lugar cuando el ratio de destrucción aumenta debido a emisiones fugitivas antropogénicas que persisten en la atmósfera. Los efectos de la disminución de la capa de ozono incluyen el aumento del riesgo de cáncer de piel y cataratas, el envejecimiento prematuro, la supresión del sistema inmunitario, y otros daños en los ecosistemas terrestres y acuáticos (Goedkoop et al. 2009). Las sustancias antropogénicas dañinas para la capa de ozono son sustancias químicas recalcitrantes que contienen átomos de cloro o bromo, como los clorofluorocarbonos (CFC). El Potencial de Destrucción de Ozono (ODP, del inglés, Ozone Depletion Potential) se define como la capacidad destructora de las sustancias dañinas para la capa de ozono. Se suele utilizar como referencia la sustancia CFC-11 (triclorofluorometano), que tiene asignado un ODP igual a 1.0 .

- Impactos en salud humana por partículas y ozono troposférico

Las partículas con diámetros inferiores a $10 \mu \mathrm{m}\left(\mathrm{PM}_{10}\right)$ producen daños en los seres humanos al ser capaces de alcanzar la parte alta de las vías respiratorias y pulmones. La $\mathrm{PM}_{10}$ secundaria se forma a partir de emisiones de dióxido de azufre $\left(\mathrm{SO}_{2}\right)$, amoníaco $\left(\mathrm{NH}_{3}\right)$ y óxidos de nitrógeno entre otros. Según los estudios de la OMS (Organización Mundial para la Salud), las partículas que producen mayor mortalidad por su exposición en humanos son aquellas inferiores a 2,5 $\mu \mathrm{m}\left(\mathrm{PM}_{2,5}\right)$, mientras que las partículas de diámetros entre $2,5 \mu \mathrm{m}$ y $10 \mu \mathrm{m}$ tienen efectos más visibles en la morbilidad respiratoria (WHO 2006). La PM puede ser antropogénica o provenir de fuentes naturales, pero los estudios de ACV se centran en las emisiones antropogénicas.

El ozono troposférico se forma como resultado de reacciones fotoquímicas entre el NOx y los NMVOC (compuestos orgánicos volátiles no metánicos, del inglés, Non Methane Volatile Organic Compounds). El ozono es dañino para la salud humana ya que produce inflamación en las vías respiratorias y daños en los pulmones.

Las dos categorías de punto medio que representan estos impactos son Formación de oxidantes fotoquímicos y Formación de partículas. El método ReCiPe considera como potencial de formación de partículas la fracción de ingesta de partículas por cantidad de sustancia emitida y se expresa en $\mathrm{PM}_{10}$ equivalente. El potencial de formación de oxidantes fotoquímicos considera el 
aumento de la concentración de ozono debido a la emisión de determinadas sustancias, y se expresa mediante los NMVOC equivalentes.

- Consumo de agua

El agua dulce es un recurso vital para la vida en el planeta, por lo que su libre disponibilidad es esencial para el desarrollo humano y de los ecosistemas. Algunas regiones del planeta tienen mayor disponibilidad de agua que otras, por lo que la magnitud de impacto por consumo de agua dependerá de la región donde se produzca dicho consumo. Ya que es muy difícil estimar el impacto que puede tener en los seres humanos y los ecosistemas la falta de agua dulce, la mayoría de métodos de evaluación de impacto se centran en cuantificar el consumo de agua durante el ciclo de vida. El método publicado por Pfister et al. (2009) obtiene los factores de caracterización usando el ratio de consumo de agua dulce anual respecto a la disponibilidad hidrológica en la región de consumo. Estos factores de caracterización se llaman Índice de Estrés Hídrico (WSI, del inglés, Water Stress Index), y representan la parte de agua de uso consuntivo que impide el consumo de agua dulce a otros usuarios ( $\mathrm{m}^{3}$ impedidos $/ \mathrm{m}^{3}$ consumidos). El índice WSI varía ente el 0,01 y el 1, y se calcula utilizando una función logística (curva en forma de S) que se basa en los umbrales de estrés hídrico según la OCDE. Este método sólo tiene en cuenta el uso consuntivo del agua para los procesos del ciclo de vida, y no considera todos los impactos ambientales potenciales significativos para el agua.

- Consumo de energía

La estimación del consumo de energía en el ACV persigue cuantificar el consumo de energía tanto directa como indirecta del ciclo de vida de un producto o servicio. La demanda acumulada de energía (CED, del inglés, Cumulative Energy Demand) representa el consumo de energía primaria tanto de fuentes fósiles (considerando el Poder Calorífico Superior en el caso de ecoinvent) como renovables. En las fuentes renovables, se considera energía como primaria la recolectada por la tecnología justo antes de su transformación en energía eléctrica (salvo para la fotovoltaica, que se considera la energía eléctrica producida) (Hischier et al. 2010).

\subsubsection{Interpretación}

Consiste en el análisis final de los resultados de las fases AICV y EICV en relación con el objetivo y alcance definidos. En esta fase se realizan las conclusiones y recomendaciones del estudio. La interpretación debe reflejar que los resultados están basados en un enfoque relativo y potencial, sin ser una predicción real de los efectos en las áreas de protección (salud, recursos, biodiversidad). 
Además, debe indicar las limitaciones del estudio, por ejemplo, si no incluye márgenes de seguridad, riesgos ni información sobre umbrales recomendados.

\subsubsection{Enfoques consecuencial y atribucional}

Mientras que el ACV-A se ha establecido como una de las principales metodologías para tomar en cuenta impactos ambientales (desde la creación de la norma ISO 14040 en 1998), la comunidad científica ha ido desarrollando nuevos enfoques metodológicos enmarcados en las normas ISO. Éstos implican no sólo la aplicación del ACV a otros pilares de la sostenibilidad (como la economía y la sociedad mediante los Costes de Ciclo de Vida y Análisis del Ciclo de Vida Social), sino también el refinamiento de la metodología según el objetivo del estudio.

Desde los inicios del ACV-A, el enfoque metodológico más utilizado ha sido el hoy denominado "modelado atribucional". Dicho enfoque o modelado vincula las actividades que ocurren dentro del ciclo de vida del sistema producto, atribuyendo las entradas y salidas a la unidad funcional. Nos da una evaluación del comportamiento ambiental de un sistema en aislado, que es útil para encontrar la etapa más contaminante del proceso o vida, o para el cálculo de la huella ambiental. Sin embargo, este enfoque no considera los efectos ambientales indirectos que se producen al integrar el sistema bajo estudio en una economía y entorno complejo donde interacciona con otros sistemas. Nuevos enfoques metodológicos, como el análisis consecuencial, permiten integrar en el ACV-A las consecuencias de los cambios introducidos en el mercado o entorno del sistema.

La primera vez que el término consecuencial se aplicó a un enfoque de modelado de ACV-A fue en un taller en 2001 (Curran et al. 2005, Weidema et al. 2009), refiriéndose a un modelo que intentaba describir las consecuencias de una decisión. En el enfoque de modelado consecuencial las actividades están incluidas en el sistema del producto en la medida en que se espera que cambien como consecuencia de un cambio en la demanda de la unidad funcional (Sonnemann and Vigon 2011). Este enfoque tiene en cuenta los cambios en el mercado derivados de la demanda de una unidad funcional del producto modelado, por lo tanto, es útil para evaluar el impacto de las decisiones en un contexto o mercado determinado. Por ejemplo, se puede aplicar para evaluar el impacto y consecuencias de nuevas estrategias o sistemas a gran escala, como ocurre con las políticas energéticas (Dandres et al. 2011). También es aconsejable para elegir entre dos productos diferentes o promover una tecnología en lugar de otras.

A continuación se muestran algunos casos en los que el modelado atribucional sería preferible al consecuencial: 
- Estudios a nivel social en los que se estudia todo el impacto ambiental de las actividades humanas, para encontrar áreas de mejora. Sin embargo, una vez que se han detectado, la mejor manera de analizar los cambios propuestos sería el modelo consecuencial.

- Estudios de fiscalización ambiental, para determinar quién debe pagar más impuestos en el ciclo de vida de un sistema ya que contamina más.

- Estudios en los que se busca evitar malas prácticas o recompensar buenas prácticas. Mientras que un modelo consecuencial puede responder la pregunta de si la actividad deplorable (por ejemplo, esclavitud) cambia como consecuencia de comprar el producto, no puede decir cuánto de la actividad deplorable hay en mi producto, ya que el sistema de un producto consecuencial no existe, ocurre. Por lo tanto, para este fin es mejor aplicar un modelo atribucional.

El modelado consecuencial es más complejo que el modelado atribucional, ya que los impactos ambientales no están limitados a las entradas y salidas de una cadena de valor, sino que también dependen del contexto político y del mercado.

El ACV-Consecuencial (ACV-C) identifica y caracteriza (en términos de impactos ambientales evitados o añadidos) todos los cambios inducidos en los procesos afectados del ciclo de vida. Para ello, el ACV-C se sirve de información marginal ${ }^{7}$ en lugar de información media de mercado. Considerar los efectos del mercado al introducir unidades marginales de un producto implica considerar el desplazamiento de otros productos. Dicho desplazamiento ocurre cuando al proveer un producto se evita la producción de otro producto alternativo en el mercado. En el modelado consecuencial, los flujos que ocurrirían por la producción del producto desplazado (impactos y/o beneficicos) se restan del sistema de producto estudiado, ya que dicho desplazamiento resulta en una menor producción del producto alternativo.

\subsubsection{Revisión de estudios de ACV-A sobre centrales termosolares.}

Tras realizar una revisión bibliográfica con las palabras "life cycle assessment" y "concentrated solar power" en diversos motores de búsqueda (WOK, ScienceDirect y Google Scholar) se han encontrado más de 20 estudios de ACV-A de la tecnología termosolar. A continuación se citan los estudios que se han considerado más relevantes, por aparecer en revistas de investigación

\footnotetext{
${ }^{7}$ Entendida como la producción de una unidad adicional.
} 
indexadas y aportar resultados sólidos del impacto ambiental de la generación de electricidad con tecnología termosolar.

Weinrebe et al. (1998) fue el primero en analizar el efecto ambiental de la hibridación con gas natural en una planta termosolar de tecnología de torre y otra de cilindro-parabólica utilizando la metodología de ACV-A. Diez años después, Lechón et al. (2008) analizan dos centrales termosolares en España, una de receptor central y otra de colectores cilindro parabólicos. Piemonte et al. (2011) analizan el ciclo de vida de una pequeña central termosolar con almacenamiento térmico comparado con el de una central térmica de petróleo y gas natural. Burkhardt et al. (2011) comparan los resultados de aplicar el ACV-A a distintas opciones de diseño en una planta termosolar de colectores cilindro parabólicos. También aportan resultados del tiempo de retorno energético (TRE). Oró et al. (2012) aportan el ACV-A de tres sistemas diferentes de almacenamiento de energía térmica en una central termosolar: almacenamiento mediante hormigón y dos variantes de sales fundidas. Klein et al. (2013) analizan el efecto invernadero, el consumo de agua y el terreno ocupado para una planta termosolar de tecnología cilindro-parabólica con distintos tipos de apoyo a la producción (almacenamiento térmico por sales o gas natural) y dos tipos de refrigeración distintos. Desideri et al. (2013) comparan el impacto ambiental de una planta termosolar de colectores cilindro parabólicos con el de una planta fotovoltaica de alta concentración. Whitaker et al. (2013) analizan el ciclo de vida de una planta termosolar con tecnología de torre ubicada en Arizona, EEUU. En su estudio analizan distintas alternativas de diseño, que incluye utilizar como soporte energético la electricidad o el gas natural, el uso de sales sintéticas o minadas, y un sistema de almacenamiento térmico mediante dos tanques o mediante un sistema termoclino. Ehtiwesh et al. (2016) analizan el ciclo de vida ambiental y exergético de plantas termosolares de $50 \mathrm{MW}$ con tecnología cilindro-parabólica.

En la Tabla 9 Por regla general, las referencias consultadas constatan el menor impacto ambiental que supone este tipo de tecnologías en comparación con otro tipo de tecnologías de producción de electricidad más convencionales basadas en la quema de combustibles fósiles. Las categorías de impacto ambiental con mayor impacto son acidificación, calentamiento global, toxicidad en seres humanos, eutrofización, y ecotoxicidad acuática y terrestre. Esto es debido principalmente a los siguientes procesos: consumo de materiales y recursos en la fabricación de los componentes, uso del aceite sintético, consumo de energía y combustibles fósiles a lo largo de todo el ciclo de vida, consumo de agua en la fase de operación y utilización del terreno para la instalación y el campo de colectores. 
Según la bibliografía, la huella de carbono de las plantas termosolares con tecnología cilindroparabólica presenta un rango de entre 17 y 317 kg CO2 eq/MWh. Si consideramos una operación en modo solar, el rango de resultados disminuye a $17-73 \mathrm{~kg} \mathrm{CO} 2 \mathrm{eq} / \mathrm{MWh}$. El consumo de agua de estas plantas se encuentra en un rango de 1,1-7,1 m3/MWh; la toxicidad humana presenta 90,2 Kg 1,4 DB/MWh; la eutrofización 6-45 g PO43-/MWh; la acidificación 98-590 g SO2 eq/MWh y el TRE $1-2$ años.

En cuanto a las plantas termosolares con tecnología de torre, la huella de carbono presenta un rango de entre 23 y $42 \mathrm{~kg} \mathrm{CO} 2$ eq/MWh para centrales en modo sólo solar, y 203 - 245 kg CO2 eq/MWh para centrales con un $15 \%$ de hibridación con gas natural. El consumo de agua de estas plantas presenta 1,2 - 1,5 m3/MWh; la toxicidad humana presenta $88,3 \mathrm{Kg} 1,4 \mathrm{DB} / \mathrm{MWh}$; la eutrofización 6 - 49,6 g PO43-/MWh; la acidificación 101 - 590 g SO2 eq/MWh y el TRE 12,2 - 16 meses.

Según los resultados consultados, se han detectado varios parámetros que afectan al impacto ambiental de la tecnología. El principal factor que más variación produce es el uso de gas natural para el apoyo a la producción eléctrica. Un 15 \% de hibridación puede aumentar hasta 10 veces el impacto en cambio climático de una planta operando en modo sólo solar. Los mayores valores de cambio climático para la tecnología cilindro-parabólica operando en modo sólo solar (60 - $73 \mathrm{~kg}$ $\mathrm{CO} 2 \mathrm{eq} / \mathrm{MWh}$ ) (Klein and Rubin 2013) vienen dados por un consumo mayor de gas natural para mantenimiento de la central. Las categorías de eutrofización y acidificación también ven aumentado su impacto por el uso de gas natural, aunque en menor medida. En cuanto al consumo de agua, ésta es mucho menor cuando el sistema de refrigeración es en seco (por aire), ya que la refrigeración en húmedo consume mucha agua. Las plantas también presentan distintos datos de vida útil ( 25 y 30 años) y/o radiación directa (DNI, del inglés, Direct Normal Irradiation). El aumento de la vida útil y/o la radiación directa implica que la planta funciona durante más de tiempo y/o recoge más energía solar, produciendo más electricidad y disminuyendo el impacto por unidad funcional. La variación de resultados también puede deberse a diferencias metodológicas, ya que no todos los estudios utilizan el mismo método de evaluación de impacto. 
Tabla 9 se muestra el resumen de las características principales de dichos estudios mientras que la Tabla 10 y la Tabla 11 muestran los resultados comparados. Algunos datos están incompletos debido a que no todos los estudios analizaban las mismas categorías. Por regla general, las referencias consultadas constatan el menor impacto ambiental que supone este tipo de tecnologías en comparación con otro tipo de tecnologías de producción de electricidad más convencionales basadas en la quema de combustibles fósiles. Las categorías de impacto ambiental con mayor impacto son acidificación, calentamiento global, toxicidad en seres humanos, eutrofización, y ecotoxicidad acuática y terrestre. Esto es debido principalmente a los siguientes procesos: consumo de materiales y recursos en la fabricación de los componentes, uso del aceite sintético, consumo de energía y combustibles fósiles a lo largo de todo el ciclo de vida, consumo de agua en la fase de operación y utilización del terreno para la instalación y el campo de colectores.

Según la bibliografía, la huella de carbono de las plantas termosolares con tecnología cilindroparabólica presenta un rango de entre 17 y 317 kg CO 2 eq/MWh. Si consideramos una operación en modo solar, el rango de resultados disminuye a $17-73 \mathrm{~kg} \mathrm{CO}$ eq/MWh. El consumo de agua de estas plantas se encuentra en un rango de 1,1-7,1 $\mathrm{m}^{3} / \mathrm{MWh}$; la toxicidad humana presenta 90,2 $\mathrm{Kg}$ 1,4 DB/MWh; la eutrofización $6-45 \mathrm{~g} \mathrm{PO}_{4}{ }^{3-} / \mathrm{MWh}$; la acidificación $98-590$ g SO 2 eq/MWh y el TRE $1-2$ años.

En cuanto a las plantas termosolares con tecnología de torre, la huella de carbono presenta un rango de entre 23 y $42 \mathrm{~kg} \mathrm{CO}$ eq/MWh para centrales en modo sólo solar, y $203-245 \mathrm{~kg} \mathrm{CO}$ eq/MWh para centrales con un $15 \%$ de hibridación con gas natural. El consumo de agua de estas plantas presenta $1,2-1,5 \mathrm{~m}^{3} / \mathrm{MWh}$; la toxicidad humana presenta $88,3 \mathrm{Kg} 1,4 \mathrm{DB} / \mathrm{MWh}$; la eutrofización 6 - 49,6 g PO${ }_{4}^{3-} / \mathrm{MWh}$; la acidificación $101-590$ g SO${ }_{2}$ eq/MWh y el TRE 12,2 - 16 meses.

Según los resultados consultados, se han detectado varios parámetros que afectan al impacto ambiental de la tecnología. El principal factor que más variación produce es el uso de gas natural para el apoyo a la producción eléctrica. Un $15 \%$ de hibridación puede aumentar hasta 10 veces el impacto en cambio climático de una planta operando en modo sólo solar. Los mayores valores de cambio climático para la tecnología cilindro-parabólica operando en modo sólo solar $(60-73 \mathrm{~kg}$ $\mathrm{CO}_{2}$ eq/MWh) (Klein and Rubin 2013) vienen dados por un consumo mayor de gas natural para mantenimiento de la central. Las categorías de eutrofización y acidificación también ven aumentado su impacto por el uso de gas natural, aunque en menor medida. En cuanto al consumo de agua, ésta es mucho menor cuando el sistema de refrigeración es en seco (por aire), ya que la refrigeración en húmedo consume mucha agua. Las plantas también presentan distintos datos de 
vida útil (25 y 30 años) y/o radiación directa (DNI, del inglés, Direct Normal Irradiation). El aumento de la vida útil y/o la radiación directa implica que la planta funciona durante más de tiempo y/o recoge más energía solar, produciendo más electricidad y disminuyendo el impacto por unidad funcional. La variación de resultados también puede deberse a diferencias metodológicas, ya que no todos los estudios utilizan el mismo método de evaluación de impacto. 
Tabla 9 Características de las centrales termosolares según los análisis encontrados en la literatura científica

\begin{tabular}{|c|c|c|c|c|c|}
\hline & Características principales & Fases ACV-A estudiadas & Categorías analizadas & $\begin{array}{l}\text { Categorías mayor } \\
\text { impacto }\end{array}$ & $\begin{array}{l}\text { Fases mayor } \\
\text { impacto }\end{array}$ \\
\hline Weinrebe et al., 1998 & $\begin{array}{l}\text { Torre, } 80 \mathrm{MW} \text {. Sin } \\
\text { almacenamiento. } 15 \% \text { gas } \\
\text { natural. Almacenamiento } 1 \mathrm{~h} \text {. } \\
\text { DRY COOLING. Vida útil= } 30 \text { años }\end{array}$ & $\begin{array}{l}\text { C, O\&M, } \\
\text { Desmantelamiento }\end{array}$ & $\begin{array}{l}\text { Efecto invernadero, } \\
\text { acidificación, eutrofización } \\
\left(\mathrm{PO}_{4}^{3-}\right)\end{array}$ & $\begin{array}{l}\text { No se comparan } \\
\text { entre sí }\end{array}$ & No se indica \\
\hline Weinrebe et al., 1998 & $\begin{array}{l}\text { Cilindro-parabólica, } 80 \text { MW. } 15 \\
\text { \% gas natural. Sin } \\
\text { almacenamiento. DRY COOLING. } \\
30 \text { años }\end{array}$ & $\begin{array}{l}\text { C, O\&M, } \\
\text { Desmantelamiento }\end{array}$ & $\begin{array}{l}\text { Efecto invernadero, } \\
\text { acidificación, eutrofización } \\
\left(\mathrm{PO}_{4}{ }^{3-}\right)\end{array}$ & $\begin{array}{l}\text { No se comparan } \\
\text { entre sí }\end{array}$ & Gas natural \\
\hline Lechon et al., 2008 & $\begin{array}{l}\text { Torre, } 17 \text { MW. Híbrida } 15 \% \text { gas } \\
\text { natural. Almacenamiento sales } \\
\text { 16h. Vida útil=25 años. } 1997 \\
\mathrm{kWh} / \mathrm{m}^{2} / \text { año. }\end{array}$ & $E \& F, C, O \& M, D \& D$ & CML (10 categorías) & $\begin{array}{l}\text { Acidificación, } \\
\text { cambio climático, } \\
\text { ecotoxicidad } \\
\text { terrestre y marina. }\end{array}$ & $E \& F, O \& M$ \\
\hline Lechon et al., 2008 & $\begin{array}{l}\text { Cilindro-parabólica, } 50 \text { MW. } \\
\text { Híbrida } 15 \% \text { gas natural. } \\
\text { Almacenamiento sales 7,5h. Vida } \\
\text { útil=25 años. } 2016 \mathrm{kWh} / \mathrm{m}^{2} / \text { año. }\end{array}$ & $E \& F, C, O \& M, D \& D$ & CML (10 categorías) & $\begin{array}{l}\text { Acidificación, } \\
\text { cambio climático, } \\
\text { ecotoxicidad } \\
\text { terrestre y marina. }\end{array}$ & $E \& F, O \& M$ \\
\hline Piemonte et al, 2010 & $\begin{array}{l}\text { Cilindro-parabólica, 0,4MWe-300 } \\
\text { días/año. Back-up: biomasa. Vida } \\
\text { útil=20 años. }\end{array}$ & $E \& F, C, D \& D$ & $\begin{array}{l}\text { Cambio climático, } \\
\text { destrucción capa de ozono, } \\
\text { toxicidad humana, } \\
\text { acidificación, eutrofización }\end{array}$ & Sin normalización & $\begin{array}{l}\text { E\&F. Acero de } \\
\text { construcción. }\end{array}$ \\
\hline Burkhardt et al., 2011 & $\begin{array}{l}\text { Cilindro-parabólica, } 103 \mathrm{MW} \text {. Con } \\
\text { almacenamiento sales. Vida útil= } \\
30 \text { años }\end{array}$ & $E \& F, C, O \& M, D \& D$ & $\begin{array}{l}\text { Cambio climático, Consumo } \\
\text { de agua, CED y TRE }\end{array}$ & Sin normalización & $E \& F, O \& M$ \\
\hline Klein et al., 2013 & $\begin{array}{l}\text { Cilindro-parabólica, } 100 \text { MW. } \\
\text { Vida útil= } 30 \text { años. } 2920 \\
\text { kWh/m2/año. }\end{array}$ & $E \& F, C, O \& M, D \& D$ & $\begin{array}{l}\text { Cambio climático. Consumo } \\
\text { de agua }\end{array}$ & Sin normalización & Gas natural \\
\hline Desideri et al., 2013 & $\begin{array}{l}\text { Cilindro-parabólica, } 2 \mathrm{MW} \text {. Sin } \\
\text { soporte energético. Vida útil= } 30 \\
\text { años. } 1700 \mathrm{kWh} / \mathrm{m} 2 / \text { año. }\end{array}$ & $E \& F, C, O \& M, D \& D$ & $\begin{array}{l}\text { Eco-indicator } 99 \text { (Salud } \\
\text { humana, calidad } \\
\text { ecosistemas, recursos) }\end{array}$ & Recursos & --- \\
\hline
\end{tabular}




\begin{tabular}{llll} 
Withaker et al., 2013 & $\begin{array}{l}\text { Torre, } 106 \mathrm{MW} \text {. Con soporte } \\
\text { energético básico. Vida útil=30 } \\
\text { años. } 2600 \mathrm{kWh} / \mathrm{m} 2 / \mathrm{año.}\end{array}$ & E\&F, C, O\&M, D\&D & $\begin{array}{l}\text { Cambio climático, Consumo } \\
\text { de agua, CED y TRE }\end{array}$ \\
\hline Ehtiwesh et al., 2016 & $\begin{array}{l}\text { Cilindro-parabólica, } 50 \mathrm{MW} \text {. } \\
\text { Almacenamiento 7,5h. Vida útil= } \\
25 \text { años. }\end{array}$ & E\&F, C, O\&M, D\&D & $\begin{array}{l}\text { Eco-indicator 99 (Salud } \\
\text { humana, calidad } \\
\text { ecosistemas, recursos). } \\
\text { Cumulative Exergy demand }\end{array}$ \\
\hline
\end{tabular}

*E\&F= Fase de Extracción de materias primas y Fabricación de componentes. O\&M= Fase de Operación y Mantenimiento. C= Fase de construcción. D\&D= Fase de Desmantelamiento y Disposición de residuos.

Tabla 10 Resultados caracterizados de los ACV-A de centrales termosolares con tecnología cilindro-parabólica según la literatura científica

\begin{tabular}{|c|c|c|c|c|c|c|c|}
\hline & $\begin{array}{c}\text { Cambio climático } \\
\text { ( } \mathrm{Kg} \mathrm{CO} 2 \\
\text { eq/MWh) }\end{array}$ & $\begin{array}{l}\text { Toxicidad } \\
\text { humana } \\
\text { (Kg 1,4 } \\
\text { DB/MWh) }\end{array}$ & $\begin{array}{l}\text { Eutrofización } \\
\qquad \mathrm{g} \mathrm{PO}_{4}^{3-} \\
\text { /MWh) }\end{array}$ & $\begin{array}{l}\text { Acidificación } \\
\text { (g SO} 2 \\
\text { eq/MWh) }\end{array}$ & $\begin{array}{c}\text { Ecotoxicidad } \\
\text { marina } \\
\text { (Kg 1-4DB/MWh) }\end{array}$ & $\begin{array}{c}\text { Consumo de } \\
\text { agua } \\
\text { (m³/MWh) }\end{array}$ & $\begin{array}{c}\text { TRE } \\
\text { (años) }\end{array}$ \\
\hline Weinrebe et al., 1998 (sólo solar) & 17 & --- & 6 & 98 & --- & --- & --- \\
\hline Weinrebe et al., 1998 (híbrida) & 234 & --- & 40 & 370 & --- & --- & --- \\
\hline Lechón et al., 2008 & 185 & 90,2 & 45 & 590 & 111600 & --- & 1 \\
\hline $\begin{array}{l}\text { Burkhardt et al., 2011. (refrigeración } \\
\text { húmeda) }\end{array}$ & 26 & --- & --- & --- & --- & 4,7 & 1 \\
\hline $\begin{array}{l}\text { Burkhardt et al., 2011. (refrigeración por } \\
\text { aire) }\end{array}$ & 28 & --- & --- & --- & --- & 1,1 & 1,1 \\
\hline Klein et al., 2013, TES, wet cooling & $60-73$ & --- & --- & --- & --- & 7,1 & --- \\
\hline Klein et al., 2013, Natural gas, dry cooling & $127-317$ & --- & --- & --- & --- & 1,5 & --- \\
\hline Desideri et al., 2013 & 22,6 & --- & --- & --- & --- & --- & 2 \\
\hline Ehtiwesh et al., 2016 & --- & --- & --- & --- & --- & --- & --- \\
\hline
\end{tabular}


Tabla 11 Resultados caracterizados de los ACV-A de centrales termosolares con tecnología de torre según la literatura científica

\begin{tabular}{|c|c|c|c|c|c|c|c|}
\hline & $\begin{array}{l}\text { Cambio } \\
\text { climático } \\
\left(\mathrm{Kg} \mathrm{CO}_{2}\right. \\
\text { eq/MWh) }\end{array}$ & $\begin{array}{l}\text { Toxicidad } \\
\text { humana } \\
\text { (Kg 1- } \\
\text { 4DB/MWh) }\end{array}$ & $\begin{array}{c}\text { Eutrofización (g } \\
\mathrm{PO}_{4}{ }^{3-} / \mathrm{MWh} \text { ) }\end{array}$ & $\begin{array}{l}\text { Acidificación (g } \\
\mathrm{SO}_{2} \mathrm{eq} / \mathrm{MWh} \text { ) }\end{array}$ & $\begin{array}{c}\text { Ecotoxicidad } \\
\text { marina } \\
\text { (Kg 1-4DB/MWh) }\end{array}$ & $\begin{array}{c}\text { Consumo de } \\
\text { agua } \\
\text { (m³/MWh) }\end{array}$ & $\begin{array}{c}\text { TRE } \\
\text { (meses) }\end{array}$ \\
\hline Weinrebe et al., 1998 (sólo solar) & 23 & --- & 6 & 101 & --- & --- & --- \\
\hline $\begin{array}{l}\text { Weinrebe et al., } 1998 \text { (híbrida } 15 \\
\% \text { ) }\end{array}$ & 245 & --- & 40 & 390 & --- & --- & --- \\
\hline Lechón et al., 2008 (híbrida 15 \%) & 203 & 88,3 & 49,6 & 590,1 & 114,7 & --- & 12,2 \\
\hline Whitaker et al., 2013 & $32-42$ & --- & --- & --- & --- & $1,2-1,5$ & $13-16$ \\
\hline
\end{tabular}




\subsection{ANÁLISIS DE CICLO DE VIDA AMBIENTAL DE LA TECNOLOGÍA HYSOL}

\subsubsection{Definición del objetivo y del alcance}

El objetivo principal de este análisis es obtener el impacto ambiental del ciclo de vida la tecnología HYSOL. Los objetivos secundarios, basados en lo dispuesto en la definición de subpreguntas del ASCV planteado en esta tesis, son:

1. Determinar si el impacto del ciclo de vida de la tecnología HYSOL (BIO y GN) es inferior al de la tecnología TERMOSOLAR CCP.

2. Encontrar los puntos del ciclo de vida que presentan mayores impactos ambientales.

3. Comparar el impacto del ciclo de vida de la tecnología HYSOL con el de otras tecnologías de concentración solar.

4. Determinar el impacto del ciclo de vida de la tecnología HYSOL dentro del mercado eléctrico español, incluyendo el impacto evitado al sustituir las tecnologías marginales.

5. Encontrar qué impactos ambientales se reducen más al proveer de electricidad HYSOL al mercado eléctrico español.

Para ello, se van a aplicar dos metodologías principales dentro de la rama del ACV-A: el análisis atribucional (que responde a las preguntas 1-3 del análisis de sostenibilidad planteadas en la sección 0 del Capítulo 2) y el análisis consecuencial (que responde a las preguntas 4-5).

El estudio principal va a seguir un enfoque atribucional, y contará con un apartado adicional describiendo el enfoque consecuencial. Este estudio consta de un escenario base con la planta HYSOL BIO (que opera con biometano según lo establecido en el Capítulo 2 de esta tesis), y un escenario alternativo HYSOL GN que contempla el uso de gas natural como combustible auxiliar (en lugar de biometano). Dicho escenario alternativo denominado HYSOL GN se considera como un escenario probable en países donde los recursos naturales para la producción de biometano son escasos, ya que la cantidad de biometano requerida por año (3,40 x $\left.10^{9} \mathrm{MJ} / \mathrm{año}\right)$ excede la capacidad de la mayoría de las instalaciones de biogás instaladas hasta la fecha. Las instalaciones de biogás de pequeña escala (escala granja) suelen producen del orden de 10.000-100.000 $\mathrm{Nm}^{3} /$ año, que resulta insuficiente incluso para proveer de gas de mantenimiento a una planta termosolar cilindro-parabólica de $50 \mathrm{MW}$ funcionando en modo solo solar (San Miguel and Corona 2013). 
La planta de referencia HYSOL BIO y la planta del escenario HYSOL GN presentan las mismas características, producción eléctrica y configuración (descritas en la sección 2.1.2.1 del Capítulo 2), ya que se considera el mismo poder calorífico para el biometano y el gas natural $(\mathrm{PCl}=35,9$ $\left.\mathrm{MJ} / \mathrm{Nm}^{3}\right)$.

\subsubsection{Límites del sistema}

En el siguiente diagrama de flujo (Figura 26), se muestra el árbol de procesos simplificado del ciclo de vida de la planta, junto con sus entradas principales. En él están contempladas las fases de Extracción de materias primas y Fabricación de materiales/elementos (E\&F), Construcción de la planta (C), Operación y Mantenimiento (O\&M), Desmantelamiento y Disposición de los residuos (D\&D).

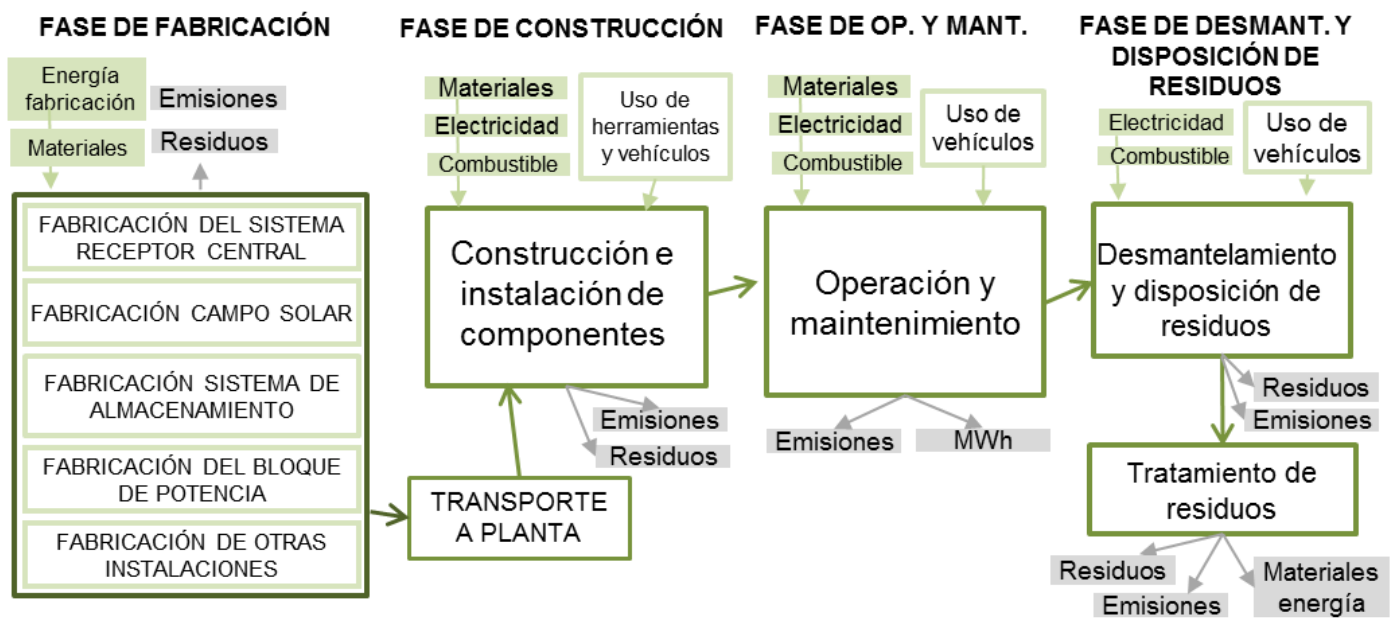

Figura 26 Árbol de procesos principales del ciclo de vida de la central

Al ser una instalación cuya principal fuente de energía es el sol, la mayor parte de materiales y recursos minerales consumidos se concentran en la primera fase (E\&F). Esta primera fase se ha dividido en cinco bloques, cada uno dedicado a la fabricación de los componentes de los principales sistemas de la instalación. La extracción de materias primas y fabricación de materiales de la fase E\&F se han modelado como procesos aguas arriba, según lo dispuesto por la base de datos ecoinvent 3.1, mientras que la fabricación de componentes de la central y su transporte a planta se han modelado como procesos del sistema. Los elementos principales de cada bloque o sistema se detallan a continuación:

- Sistema receptor central, con todos los elementos contenidos en la torre central. Esto incluye la torre, el receptor, tuberías y bombas de circulación.

- Campo solar, compuesto por los colectores solares (espejos y estructura), el sistema de seguimiento solar, válvulas y el camión de limpieza de colectores. 
- Sistema de almacenamiento térmico, contiene el conjunto de tuberías, bombas, intercambiadores de calor entre sales y vapor de agua, tanques, y las sales de nitrato.

- Bloque de potencia, con los componentes típicos de un ciclo de vapor Rankine (caldera auxiliar, calentadores, precalentadores, turbina de vapor y generador, desgasificador, condensador, torres de refrigeración y bombas de circulación) y el del ciclo Brayton (turbina de gas y tuberías). Este bloque también contiene el HRS propio de la tecnología HYSOL.

- Instalaciones, que incluye carreteras, edificios y el sistema de tratamiento de aguas.

La fase C contempla los impactos derivados del uso de herramientas y maquinaria de construcción, incluyendo los consumibles utilizados. Además, también considera la obra civil de la construcción de la central, que incluye estructuras metálicas de cada sistema y cimientos.

La fase O\&M incluye el consumo de electricidad, combustible, agua, materiales y componentes de repuesto y su transporte a planta. Quedan fuera del estudio los impactos de posibles accidentes o fugas ocasionados durante la fase de operación. Esta fase incluye todos los impactos del ciclo de vida del biometano en el caso de la planta HYSOL BIO, y del gas natural en el caso del escenario HYSOL GN.

En el caso del biometano, los residuos biológicos se clasifican en tres categorías: agroalimentaria (residuos de matadero y comida caducada), lodo de aguas residuales (de aguas residuales municipales y de la industria lechera) y estiércol (de ganado vacuno y porcino). La asignación de impactos para estos residuos sigue el principio de "quien contamina paga" por el cual los residuos de ciclos de vida anteriores deben considerarse libres de cualquier impacto ambiental. Además, el digestato sólido y líquido obtenido en el proceso de digestión se devuelve al ambiente en la forma de fertilizante gratuito para agricultores locales. Como este digestato no tiene valor económico, se ha considerado como un residuo de la producción del biometano. Las cargas asociadas con el transporte y aplicación del digestato como fertilizante no se han incluido en el alcance del estudio.

La digestión anaeróbica de estiércol de cerdo y vaca es una técnica mejorada de gestión de residuos con respecto al tratamiento convencional (almacenamiento en un tanque al descubierto antes de la aplicación al campo como fertilizante). Por lo tanto, se ha considerado que el tratamiento mediante biodigestión evita las emisiones de $\mathrm{CH}_{4}$ y $\mathrm{N}_{2} \mathrm{O}$ asociadas al tratamiento convencional (sólo la fracción de emisiones correspondiente al estiércol de cerdo/vaca, descrita por Giuntoli et al (2014)). Dichas emisiones se han sustraído del impacto del ciclo de vida del biometano. 
En el desmantelamiento de la planta HYSOL se consideran los materiales y combustibles utilizados en la maquinaria de demolición, mientras que en la gestión de residuos se plantea un escenario de reciclaje, detallado en la sección de análisis de inventario.

\subsubsection{Metodología para la Evaluación del Impacto de Ciclo de Vida.}

Se ha escogido como principal método de evaluación de impacto el ReCiPe perspectiva $H$ v.1.12, creado en el año 2008 por RIVM (Instituto Holandés de Salud Pública y Medioambiente), CML, PRé Consultants y la Universidad de Radboud (Holanda) (Goedkoop et al. 2009). Además, también se han escogido los métodos CED 1.09 (Hischier et al. 2010) (Cumulative Energy Demand, publicado por ecoinvent v.2 e implementado por Pré Consultants) para el consumo de energía y Pfister et al. (2009) para el consumo de agua.

La principal razón para escoger el método ReCiPe es que proporciona resultados tanto de punto medio como de punto final. Además, permite utilizar sets de normalización correspondientes a Europa y al resto del mundo, lo que resulta imprescindible para normalizar el impacto de la central si se ubica en otras partes del mundo.

En el trabajo final de máster previo a esta tesis se determinaron las siguientes categorías de punto medio como las más relevantes para la central de estudio y la comunidad científica:

- Cambio climático: Su factor de caracterización es el potencial de calentamiento global, y se mide en $\mathrm{kg}$ de $\mathrm{CO}_{2}$ equivalentes.

- Toxicidad en seres humanos: Representa la toxicidad, persistencia y acumulación de sustancias químicas en la cadena de alimentación humana. Se mide en kg 1,4diclorobenceno eq.

- Formación de partículas: Representa la fracción captada de partículas por el ser

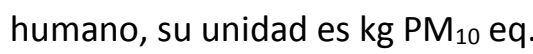

- Acidificación: Representa la persistencia y deposición de sustancias acidificadoras en el suelo, medida en $\mathrm{kg} \mathrm{SO}_{2}$ eq

- Eutrofización de agua dulce: Representa la persistencia ambiental de emisiones de nutrientes que contienen fósforo. Su unidad es el kg P eq.

- Ecotoxicidad de agua dulce: Representa la toxicidad, persistencia y acumulación de sustancias químicas en el agua dulce. Se mide en kg 1,4-dichlorobenzeen eq.

- Ecotoxicidad marina: Representa la toxicidad, persistencia y acumulación de sustancias químicas en el mar. Se mide en kg 1,4-dichlorobenzeen eq.

Las categorías de punto final consideradas son: 
- Daño a la salud humana: expresada como el número de años de vida perdidos y vividos en condiciones de vida disminuidas. Se contabilizan como Años de Vida Ajustado por Discapacidad (DALY, Disability Adjusted Life Years).

- Daño a los ecosistemas: la pérdida de especies en un área determinada, durante un periodo de tiempo determinada. Medida en especies-año.

- Daño a la disponibilidad de recursos: Mide el consumo de recursos, expresándolo mediante el incremento del precio de los mismos, medido en dólares \$.

La categoría de agotamiento de agua según el método ReCiPe no representa adecuadamente la escasez de agua derivada por el ciclo de vida de la tecnología, ya que sólo contabiliza el consumo de agua sin considerar la disponibilidad de agua del lugar de estudio. La norma ISO 14046:2014 dice que el análisis de huella hídrica debe presentarse con un calificativo, i.e. huella de escasez hídrica. Por lo tanto, se ha utilizado en lugar de ReCiPe el método publicado por Pfister et al. (2009). Este método obtiene los factores de caracterización usando el ratio de consumo de agua dulce anual respecto a la disponibilidad hidrológica. Estos factores de caracterización se llaman Índice de Estrés Hídrico (WSI, del inglés, Water Stress Index), y representan la parte de agua de uso consuntivo que impide el consumo de agua dulce a otros usuarios ( $\mathrm{m}^{3}$ impedidos $/ \mathrm{m}^{3}$ consumidos). Este método sólo tiene en cuenta el uso consuntivo del agua para los procesos del ciclo de vida, y no considera todos los impactos ambientales potenciales significativos para el agua, que son analizados mediante otras categorías de ecotoxicidad y eutrofización. Además, se ha decidido considerar sólo el consumo directo de agua por la planta, ya que la implementación del método en SimaPro todavía no tiene depurada la aplicación de índices a los distintos flujos de agua. Para ello, se han aplicado los índices de estrés regionales publicados por Pfister er al. (2009), según lo indicado en Google Earth (Pfister et al. 2012), al consumo directo de agua en la fase de O\&M.

La CED de un sistema es la suma de toda la energía primaria utilizada a lo largo del ciclo de vida del sistema. Este indicador se ha determinado para distintos escenarios usando el método CED v 1.09. Además, también se ha calculado el Tiempo de Retorno Energético (TRE), que se define como el periodo de tiempo requerido para que un sistema de producción de energía haya generado tanta energía como la consumida durante su ciclo de vida (CED).

EI TRE de la tecnología a ha sido calculado a partir de la Ecuación (2) (Lechon et al., 2008), donde: 


$$
T R E=\frac{C E D_{c}}{\left(\frac{E_{n e t}}{g}-C E D_{o}\right)}
$$

CEDc es la demanda acumulada de energía primaria para la construcción de la central, en MJ

CEDo es la demanda anual acumulada de energía primaria para la operación y mantenimiento de la central, en MJ/año

Enet : electricidad neta producida al año, en MJ/año

$g$ : rendimiento medio de la conversión de energía primaria en electricidad a nivel nacional. Este valor se ha calculado como $44,3 \%$ utilizando el ratio de energía primaria por energía final en la provisión de electricidad en España durante el año 2011 (MINETUR 2012).

\subsubsection{Tipos y fuentes de datos}

A continuación se describen brevemente las fuentes principales de datos primarios y secundarios:

- Datos primarios: La principal fuente de datos es la consulta a ingenieros especialistas involucrados en el diseño y construcción de la central analizada, de las empresas de ingeniería COBRA t\&i e IDie (participantes del proyecto HYSOL). Para aquellos datos de funcionamiento de la central no proporcionados por los ingenieros se ha utilizado el software de energías renovables SAM desarrollado por NREL (National Renewable Energy Laboratory. Golden, CO. 2015). Aquellos datos de inventario de componentes no proporcionados por los ingenieros se han estimado mediante la consulta bibliográfica de análisis de sistemas similares (indicados en la fase de inventario).

- Datos secundarios: Para los datos de procesos generales, se utilizará principalmente la base de datos Ecolnvent 3. Además, para aquellos componentes tecnológicos de los que no se disponga inventario de materiales, se consultará la base de datos EU\& DK Input Output database desarrollada por 2.0 LCA consultants como parte del proyecto FORWAST (Proyecto FORWAST 2011).

La fuente de cada dato de inventario se especifica en la sección Análisis de Inventario.

\subsubsection{Requisitos de calidad de los datos}

Se han considerado los siguientes requisitos para la recogida de información:

-La antigüedad de los datos debe ser menor a 15 años (por lo tanto, deben estar tomados después del año 2000). 
-Los datos deben provenir de tecnologías similares o iguales a la de la central en estudio.

-En el caso de tomar datos de análisis de ciclo de vida ya realizados, estos deberán haber sido publicados en revistas de investigación indexadas y reconocidas científicamente.

\subsubsection{Incertidumbre de los datos}

En este estudio se va a considerar la incertidumbre asociada con los datos de inventario para actividades y procesos unitarios. No se va a considerar la incertidumbre derivada del método de evaluación de impacto ya que el software SimaPro no permite incluir la incertidumbre asociada a cada factor de caracterización o normalización. Tampoco se va a considerar la incertidumbre asociada a los errores fortuitos ni a las elecciones metodológicas durante el modelado.

La incertidumbre de los datos contenidos en la base de datos ecoinvent viene determinada por indicadores de calidad de datos (DQI, del inglés, Data Quality Indicators), que asumen una distribución log-normal representada por el cuadrado de la desviación estándar geométrica (95 $\%$ de intervalo de confianza). Para mantener la coherencia y por su versatilidad, se han calculado Ios DQI correspondientes a cada dato primario utilizando la matriz Pedigree (descrita en sección 3.1.2.1).

El análisis de Monte Carlo es una forma cuantitativa de procesar la información y establecer un rango de incertidumbre en los resultados. SimaPro lleva a cabo este análisis de la siguiente manera: Asigna un valor aleatorio a los datos dentro del rango de incertidumbre asociado (medido por los DQI), y ejecuta el cálculo almacenando los resultados. Este proceso se vuelve a repetir tomando diferentes valores aleatorios dentro del rango hasta un número determinado de veces (p. ej. 1000) obteniendo el mismo número de resultados diferentes. Estos resultados forman parte de la distribución de incertidumbre de los resultados.

Para determinar la incertidumbre de los resultados de este estudio se ejecutará un análisis de Monte Carlo.

\subsubsection{Hipótesis realizadas}

Las principales hipótesis asumidas en el inventario de materiales y flujos de energía son:

- Gas Natural: Las cargas asociadas a la producción y distribución del gas natural se han obtenido de la base de datos ecoinvent 3, leídos por SimaPRO 8, considerando un poder calorífico de $35,9 \mathrm{MJ} / \mathrm{Nm}^{3}$. El gas natural ha sido adaptado según el origen de las importaciones durante el año 2012. Se han tomado de referencia los porcentajes de importaciones por países publicados por CORES (CORES 2013), según se describe en la Figura 27. 


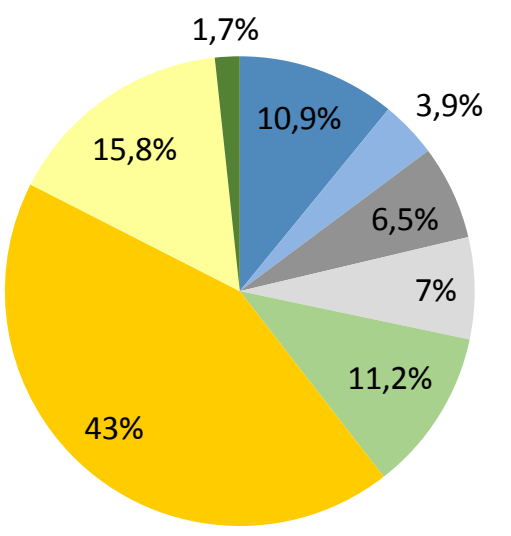

EUROPA $14,8 \%$
\begin{tabular}{|ll|}
\hline Noruega & Otros (Europa) \\
\hline AMÉRICA DEL SUR $13,5 \%$ & \\
\hline Perú & Trinidad y Tobago \\
\hline ÁFRICA 54,2 \% & Argelia \\
\hline Qatar & \\
Nigeria & Egipto \\
\hline
\end{tabular}

Figura 27 Procedencia del gas natural en España según CORES, en el año 2012 (CORES 2013)

No se han encontrado datasets relativas a gas natural procedente de Perú, de Trinidad y Tobago, de Egipto ni de Qatar, por lo que se ha considerado que los porcentajes de dichos países equivalen a gas natural de origen argelino. El porcentaje de "Otros, Europa" se considera que proviene de los Países Bajos.

- Electricidad: Para el consumo directo de electricidad se considerará el mix eléctrico medio español calculado a partir de datos suministrados por Red Eléctrica Española (REE) para el año 2013 (REE 2014): 20,5 \% nuclear, 19,1 \% eólica, 18,9 \% carbón, 14,8 \% hidroeléctrica, 11,8 \% gas natural (ciclos combinados), 3,0 \% solar fotovoltaica, 2,5 \% petróleo, 1,9 \% cogeneración, 1,6 \% solar térmica y $5,9 \%$ otras fuentes no renovables.

- Transporte: Para el transporte de componentes de la central, se ha considerado la tipología de transporte de acuerdo a su naturaleza (por mar o carretera y distintos tonelajes dependiendo del peso), según las cargas ambientales previstas por la base de datos ecoinvent 3. Se considera que el transporte por carretera cumple la normativa Euro IV.

- Gestión de residuos: Este estudio considera un sistema de ciclo cerrado en el que los componentes están fabricados con materiales primarios (especialmente en el caso de los metales), y el reciclaje de dichos materiales supone la producción de material secundario. Dicho material secundario se considera que sustituye al material primario de tal forma que la carga ambiental asociada al material primario equivalente se sustrae del impacto ambiental de la fase D\&D del ciclo de vida. Para los residuos correspondientes al desmantelamiento de la planta se ha aplicado un escenario de gestión de los residuos basado en la situación media española, media europea y datos estimados mundiales. Dichos escenarios contemplan tres vías de gestión de residuos (reciclaje, incineración y depósito en vertedero controlado) que se han aplicado 
CAPÍTULO 3: Análisis del área ambiental

según lo establecido por el tratamiento de residuos estándar en la base de datos ecoinvent 3, implementada en SimaPRO por Pre Consultants.

A lo largo del Análisis de Inventario se explican otras hipótesis y limitaciones aplicadas en la realización del estudio.

\subsubsection{Análisis de inventario}

Este inventario fue suministrado por las empresas IDie y COBRA t\&i. Ecolnvent v.3 se utilizó para obtener datos ambientales genéricos de la información y antecedentes sobre los siguientes elementos: procesamiento de materias primas, la fabricación de materiales para componentes de la planta, actividades de construcción, operación y mantenimiento de la planta termosolar y procesos de transporte. Debido a la falta de datos de inventario específicos relacionados con la tecnología de torre, algunos datos se obtuvieron de fuentes bibliográficas de estudios similares. Todos los supuestos y fuentes de datos se detallan en esta sección.

En las siguientes secciones se encuentran los principales supuestos y decisiones para los procesos que tienen lugar durante las fases del ciclo de vida principal del sistema bajo estudio.

\subsubsection{Fase de extracción de materias primas y fabricación de componentes}

La información de inventario relativa a los componentes de la central se ha organizado en los siguientes subsistemas: campo solar, sistema receptor, sistema de almacenamiento, bloque de potencia, grupo Brayton, y otras instalaciones.

La información de inventario sobre materiales y cantidades de los componentes así como datasets incertidumbre asociadas para cada subsistema de la planta se encuentra en el Anexo I. Algunos procesos de la base de datos ecoinvent se han modificado para reflejar de una forma más precisa el consumo energético del país de origen. Como la mayoría de componentes de la planta se fabrican en España, se ha sustituido el mix eléctrico original del dataset (por lo general, el europeo) por el mix español determinado en las hipótesis (sección 3.2.1.6), manteniendo la misma cantidad de consumo eléctrico. También se ha sustituido el consumo de gas natural (cuando el proceso requería su consumo) para el mix español del año 2012 (según sección 3.2.1.6). Por último, se ha modificado el origen del consumo de agua, adaptándolo al origen español. Estos datasets modificados han sido identificados con un asterisco $\left({ }^{*}\right)$ en las tablas de inventario. 
Se ha introducido información sobre la incertidumbre de los datos a cada entrada de inventario. La mayor parte se ha añadido como índices de calidad de datos (DQI, del inglés, Data Quality Index), según lo dispuesto en la sección 3.1.2.2 de este capítulo.

En las siguientes secciones se aporta información adicional sobre suposiciones y detalles de algunos materiales modelados en esta fase.

\subsection{El acero galvanizado}

Las bases de datos no contienen ningún dataset que represente la producción de acero galvanizado, por lo que se ha creado un nuevo dataset de acero mediante la aproximación de datos. Para ello, se ha asumido que el proceso de galvanizado consiste en cubrir acero de refuerzo con zinc y se ha utilizado la dataset "Zinc coat, pieces $\{R E R\} \mid$ zinc coating, pieces | Alloc Def, $U^{\prime \prime}$ asumiendo que cada tonelada de pieza a galvanizar presenta una superficie de $60 \mathrm{~m} 2$ (según información de la propia dataset). Las cantidades de materiales presentes en el nuevo proceso se muestran en la Tabla 12.

Tabla 12 Datasets y cantidades incluidas en el proceso "Acero galvanizado" (1 kg)

\begin{tabular}{llll} 
Dataset & Cantidad & Ud. & DS2 \\
\hline Zinc coat, pieces $\{$ RER\}| zinc coating, pieces | Alloc Def, U & 0,06 & $\mathrm{~m}^{2}$ & 1,06 \\
\hline Reinforcing steel $\{E S\} \mid$ market | Alloc Def, U & 1 & $\mathrm{~kg}$ & 1,03
\end{tabular}

\subsection{La pintura industrial}

Las bases de datos no contienen ningún dataset que represente la producción de pintura ignífuga y anticorrosiva de uso industrial, por lo que se ha hecho una aproximación. Para ello, se ha asumido que la pintura se compone de una pintura alquídica blanca junto con resina epoxy, asumiendo una proporción de $30 \%$ de pintura y $70 \%$ de resina. Se supone una cobertura de la pintura de $0,2 \mathrm{~kg} / \mathrm{m}^{2}$. Las cantidades de materiales presentes en el nuevo proceso se muestran en la Tabla 13.

Tabla 13 Datasets y cantidades incluidas en el proceso "Industrial paint (anticorrosive and fireproof)" (1 kg)

\begin{tabular}{llcc} 
Dataset & Cantidad & Ud. & DS2 \\
\hline $\begin{array}{l}\text { Alkyd paint, white, without solvent, in } 60 \% \text { solution state }\{\text { RoW\}| } \\
\text { alkyd paint production, white, solvent-based, product in } 60 \%\end{array}$ & 0,06 & $\mathrm{~m}^{2}$ & 1,06 \\
$\begin{array}{l}\text { solution state | Alloc Def, U } \\
\text { Epoxy resin, liquid }\{\text { RoW\}| production | Alloc Def, U }\end{array}$ & 1 & $\mathrm{~kg}$ & 1,03 \\
\hline $\begin{array}{l}\text { Transport, freight, lorry 7.5-16 metric ton, EURO4 \{RER\}| } \\
\text { transport, freight, lorry 7.5-16 metric ton, EURO4 | Alloc Def, U }\end{array}$ & 200 & $\mathrm{kgkm}$ & 1,37 \\
\hline
\end{tabular}


A continuación se describe el inventario y decisiones tomadas para la fabricación de los componentes de la planta (las tablas de inventario detallado se encuentran en el Anexo I).

\subsection{Campo solar}

El campo solar está compuesto por los heliostatos y el camión de limpieza de colectores. A continuación se detallan aspectos del inventario que han requerido modificar datasets de las bases de datos disponibles en SimaPro.

- Heliostatos

El inventario para un heliostato (hay 9151 heliostatos en total) incluye los impactos de fabricación de los materiales de los espejo, la estructura soporte (pedestal) y accionamiento, los cables eléctricos, y la caja de control. También incluye el transporte de todos los componentes asumiendo una distancia media de $200 \mathrm{~km}$.

El dataset asociado a los espejos ha sido modificado para reflejar el método de fabricación utilizado para este producto. Se asume que los reflectores consisten en vidrios planos de 2 milímetros, que tras un lavado con agua desmineralizada, se les aplica una solución de nitrato de plata y agentes reductores mediante pistolas pulverizadoras. Por último, se aplica una capa protectora de cobre secada con calentadores radiantes y cubierta con una capa de espuma epoxi para dar resistencia (Ernst \&Young and Fraunhofer Institute 2010). Según la información disponible en la base de datos de ecoinvent, el dataset que más se ajusta es "Flat glass, coated $\{R E R\} \mid$ production | Alloc Def, U". El dataset escogido representa un recubrimiento mixto de cromo y níquel; con el fin de reflejar un proceso de fabricación más aproximado a la realidad del producto, estos materiales se han sustituido por plata, manteniéndose el resto de las entradas constante.

Los datos de inventario correspondientes al pedestal y estructura del heliostato (torquetubo, celosías y atirantados) han sido obtenidos del informe "Heliostat Cost Reduction Study" del Sandia National Laboratories (EEUU) (Kolb et al. June 2007), que representa un heliostato de $148 \mathrm{~m}^{2}$.

- Camión de limpieza

El camión para la limpieza de colectores pesa aproximadamente 4 toneladas y se fabrica exclusivamente para este fin. Para representar este dato de inventario, debido a la falta de datos específicos adicionales se ha decidido utilizar como aproximación una dataset de un camión común. El camión representado con la dataset de ecoinvent "Lorry, 16 metric ton $\{R E R\}$ | production | Alloc Def, U" se ha modificado para incluir el consumo de agua, electricidad y algún 
material españoles. Se ha supuesto una relación directa del inventario con la masa, por lo que se ha incluido 0,25 unidades de camión (16/4 t). Además, se ha incluido una bomba de agua de 40 kW que lleva integrada el camión cuya potencia real es desconocida (Pump, 40W \{GLO\}| market for | Alloc Def, U, SD2=1,20).

\subsection{Sistema receptor}

El sistema receptor consiste en la torre central, el receptor al que van dirigida la luz solar concentrada, las tuberías, válvulas y conectores necesarios para el circuito de sales fundidas, y las bombas de torre (para la circulación de sales fundidas).

El traceado de tuberías en este sistema incluye el tramo que une la torre con el tanque caliente de sales y el que une el tanque frío de sales con la torre.

Como aproximación a los materiales presentes en la torre central (no fueron suministrados por la empresa), se ha utilizado de referencia las cantidades proporcionadas por Whitaker et al. (2013), usando la altura de la torre como factor de escala (203 m de torre, respecto a $172 \mathrm{~m}$ de la torre de Whitaker et al.). El inventario relativo a tuberías, válvulas y conectores fue adaptado con el factor de escala 1,6 (de $50 \mathrm{MW}$ a $100 \mathrm{MW}$ ).

- Las bombas de circulación

El circuito de las sales fundidas necesita bombas de circulación específicas para su funcionamiento. Según la información recogida, se necesitan 6 bombas de circulación con 1,324 MW de potencia por bomba, compradas a una empresa alemana.

En las bases de datos disponibles no hay bombas de circulación de las características indicadas. Sin embargo, en la base de datos "EU27 input-output (IO)" existe la rama de actividad “_66 Machinery and equipment n.e.c., EU27" que puede aplicarse en esta situación. Para ello, es necesario el peso de las bombas, y su relación con la potencia (ya que es el único dato de inventario disponible). Para ello, se ha buscado esta relación en catálogos e informes técnicos de los principales fabricantes de bombas de circulación, resultando en un peso medio de 4 toneladas por bomba de $600 \mathrm{~kW}$. Para el transporte de la bomba se ha considerado $430 \mathrm{~km}$ de transporte por carretera y $2872 \mathrm{~km}$ de transporte marítimo (SeaRates 2016).

La Tabla 14 describe los procesos incluidos dentro del nuevo dataset creado para bombas, Ilamado “Circulation pump, 600 kW, Alemania”, para el caso de España. 
Tabla 14 Procesos contenidos en el dataset "Circulation pump, 600 kW Alemania"

\begin{tabular}{lccc} 
Dataset & Cantidad & Ud & SD2 \\
\hline a 66 Machinery and equipment n.e.c., EU27 & 4.000 & $\mathrm{~kg}$ & 1,13 \\
\hline $\begin{array}{l}\text { Transport, freight, lorry >32 metric ton, EURO4 \{RER\}| transport, } \\
\text { freight, lorry }>32 \text { metric ton, EURO4 | Alloc Def, U }\end{array}$ & 1.720 & tkm & 1,35 \\
\hline $\begin{array}{l}\text { Transport, freight, sea, transoceanic ship }\{\text { GLO\}| processing | Alloc } \\
\text { Def, U }\end{array}$ & 11.488 & tkm & 1,35
\end{tabular}

\subsection{Sistema de almacenamiento térmico}

El sistema de almacenamiento térmico está compuesto por las sales térmicas y los tanques de almacenamiento, el sistema de purga de sales, las distintas bombas de circulación, y un conjunto de tuberías, válvulas y conectores.

El trazado de tuberías incluye los tramos que van del tanque de sales caliente al tren de generación de vapor y del tren de generación de vapor al tanque de sales frío.

A continuación se detallan aspectos del inventario que han requerido modificar datasets de las bases de datos disponibles en SimaPro.

- Sales térmicas

Las sales térmicas son una mezcla eutéctica de un $40 \%$ de nitrato potásico $\left(\mathrm{KNO}_{3}\right)$ y un $60 \%$ de nitrato sódico $\left(\mathrm{NaNO}_{3}\right)$. El proveedor es una empresa Chilena que produce dichas sales a partir de yacimientos de caliche (depósitos de carbonato de calcio). En el proceso de producción, el caliche se extrae mediante bulldozers y explosivos, se pulveriza mecánicamente y se somete a un proceso de lixiviación con agua en el que se obtiene yodo y nitrato sódico. El nitrato de potasio se produce añadiéndole cloruro de potasio (obtenido del Salar de Atacama) al nitrato sódico, sometiéndolos a intercambio iónico, cristalización y procesos de secado. El control de la estequiometría y cristalización permite una mezcla controlada de nitrato de sodio y nitrato de potasio (SQM 2015).

En las bases de datos disponibles no hay datasets que representen la producción de nitrato sódico, sin embargo, sí que está representada la extracción, molida y lavado de caliza (Limestone, crushed, washed $\{$ RoW\}| production | Alloc Def, U), que se ha escogido como aproximación al proceso de producción del nitrato sódico. Según la memoria anual de la empresa SQM del año 2012 (SQM 2013), se extrae 82192 toneladas de caliche y se producen 66850 toneladas de nitrato sódico cada día, por lo que se necesitan 1,2812 kg de caliche para obtener $1 \mathrm{~kg}$ de nitrato sódico. Según lo anterior, para la modelización de la producción del nitrato sódico (proceso llamado "Nitrato sódico, procedente de mina de caliche| Alloc Def, U") 
se ha introducido 1,2812 de "Limestone, crushed, washed \{RoW\}| production | Alloc Def, U", con una SD2 igual a 1,20.

El nitrato potásico se produce a partir de cloruro potásico y nitrato sódico. Según el informe de "Monitoreo de los minerales industriales" de la Comisión chilena del cobre (Pérez Vidal 2013), se precisan $840 \mathrm{~kg}$ de nitrato de sodio y $740 \mathrm{~kg}$ de cloruro potásico para producir $1000 \mathrm{~kg}$ de nitrato potásico. Como se muestra en la Tabla 15, se han considerado ambos productos para modelizar el proceso correspondiente a la producción de nitrato potásico. Los consumos energéticos y de sustancias del proceso productivo no se han incluido debido a falta de información al respecto.

Tabla 15 Contenido del proceso correspondiente a la fabricación de $1 \mathrm{~kg}$ de nitrato potásico, procedente de mina de caliche

\begin{tabular}{lccc} 
Dataset & Cantidad & Ud. & DS2 \\
\hline Nitrato sódico, procedente de mina de caliche| Alloc Def, U & 0,84 & $\mathrm{~kg}$ & 1,05 \\
\hline Potassium chloride, as K2O \{RoW\}| potassium chloride production & 0,74 & $\mathrm{~kg}$ & 1,07 \\
| Alloc Def, U & & &
\end{tabular}

\subsection{Sistema de bloque de potencia}

El sistema bloque de potencia está compuesto por el tren de generación de vapor, el sistema de refrigeración en seco, el bloque turbina (turbina, condensador y generador de electricidad), el grupo Bryton junto con el nuevo HRS y otros elementos como tanques auxiliares, tuberías y válvulas.

El bloque turbina proviene de Alemania, mientras que el resto de componentes del ciclo Rankine son de fabricación nacional. El transporte de los elementos desde Alemania se hace por barco, desde Hamburgo al puerto de destino y posteriormente por carretera. Para el transporte de los componentes de fabricación nacional se asume una distancia media de $200 \mathrm{~km}$.

La turbina de vapor, generador, condensador y bombas de circulación han sido modeladas según la base de datos "EU27 input-output (IO)" debido a la falta de inventario sobre su fabricación y materiales.

En cuanto a los elementos correspondientes a la estructura, el inventario disponible corresponde al ciclo Rankine de una central parabólica de 50 MW. Para adaptar dicho inventario a las características de la planta de estudio, se le ha aplicado el factor de escala 1,6 según lo determinado por los ingenieros de la planta.

El grupo Brayton consta de todos los elementos adicionales que precisa la tecnología HYSOL. Estos son: la turbina de gas y su generador, el intercambiador de calor entre las sales 
CAPÍTULO 3: Análisis del área ambiental

fundidas y los gases de escape de la turbina (HRS), las tuberías entre el sistema de almacenamiento térmico y el intercambiador de calor, y el intercambiador de calor de baja temperatura.

\subsection{Sistema de instalaciones}

Contiene edificios de control, naves de montaje, bombas de captación y planta de tratamiento de aguas.

Según las fuentes consultadas, el edificio de control y la nave de montaje pueden clasificarse como edificio de oficinas, ya que no tiene otros requerimientos especiales. Por ello, se ha asumido que hay $1600 \mathrm{~m}^{2}$ de oficinas de control y se ha tomado el inventario de un edificio de oficinas genérico por $\mathrm{m}^{2}$ de superficie, publicado por Xing et al. (2008).

\subsubsection{Fase de construcción de la planta}

Incluye materiales de construcción relativos a estructuras, cimientos y carreteras. En los componentes estructurales se ha aplicado un factor de escala de 1,6, ya que el inventario original corresponde a una central de $50 \mathrm{MW}$ de potencia.

\subsubsection{Fase de operación y mantenimiento}

Incluye los consumos realizados durante la operación y mantenimiento. El inventario detallado está descrito en el Anexo I. En esta fase se ha computado la carga ambiental asociada con la reparación y reemplazo de los colectores (asumiendo una tasa de reemplazo de colectores de $1 \%)$.

- Emisiones de la combustión de gas natural en caldera auxiliar

El inventario de las emisiones correspondientes a la combustión del gas natural en la caldera auxiliar han sido obtenidas del EMEP/EEA Air Pollutant Emission Inventory Guidebook 2013 (EMEP 2013), creándose el siguiente dataset: "Heat, industrial, natural gas, Europe, heat production, at industrial furnace $>1 \mathrm{MWth}$ to $<=50 \mathrm{MWth} \mid$ Alloc Def, U_CSP 2012", asociado a $1 \mathrm{MJ}$ de calor obtenido mediante la combustión de gas natural en una caldera industrial con una potencia entre $1 \mathrm{MWth}$ y $50 \mathrm{MW}$ th (las calderas de la planta son de aproximadamente $10 \mathrm{MW}$ ). Además, se han calculado las emisiones de $\mathrm{CO}_{2}$ mediante balance de carbono, resultando igual a $0,047478 \mathrm{~kg} / \mathrm{MJ}$.

- Emisiones de la combustión de gas en turbina de gas

El inventario de las emisiones correspondientes a la combustión del gas natural en la turbina de gas también se han obtenido del EMEP/EEA Air Pollutant Emission Inventory 
Guidebook 2013 (EMEP 2013), creándose el siguiente dataset: "Emissions of gas burned in gas turbine, Europe | Alloc Def, U". Además, se han calculado las emisiones de $\mathrm{CO}_{2}$ mediante balance de carbono, resultando igual a 0,047478 kg/MJ.

- Emisiones de la combustión de biometano

Por considerarse que el biometano adquiere tras la depuración una composición muy similar a la del gas natural, se han asumido las mismas emisiones que en el caso de gas natural, con la excepción de que el origen del carbono es biogénico.

\subsubsection{Fase de desmantelamiento y gestión de residuos}

El inventario del desmantelamiento de la central incluye el consumo energético de la maquinaria de desmantelamiento y el transporte durante el desmantelamiento. Debido a falta de datos ha sido necesario tomar el consumo energético de los inventarios publicados por Burkhardt et al. (2012). La información del inventario está descrita en el Anexo I

Para la disposición de residuos se ha considerado un escenario de gestión de residuos según lo indicado en la Tabla 16. Los porcentajes de residuos se han escogido de forma que representen la realidad actual de forma conservadora. Se ha escogido los tratamientos de residuos indicados por la base de datos ecoinvent como los tratamientos más comunes para cada residuo. En ellos se incluye las entradas (consumos) y salidas (residuos y emisiones) de cada tratamiento junto con el transporte de los residuos.

Tabla 16 Escenario de tratamiento de residuos generados tras el desmantelamiento de la central termosolar

\begin{tabular}{lll} 
Material & Tratamiento principal, $\%$ & $\begin{array}{l}\text { Otros tratamientos, } \\
\%\end{array}$ \\
\hline Acero y hierro & Reciclaje, $80 \%$ & Vertedero, $20 \%$ \\
\hline Aluminio & Reciclaje, $90 \%$ & Vertedero, $10 \%$ \\
\hline Plástico & Reciclaje, $60 \%$ & Incineración, $40 \%$ \\
\hline Papel & Reciclaje, $60 \%$ & Incineración, $40 \%$ \\
\hline Vidrio & Reciclaje, $60 \%$ & Vertedero, $40 \%$ \\
\hline Ladrillos & Reciclaje, $60 \%$ & Vertedero, $40 \%$ \\
\hline Hormigón & Reciclaje, $60 \%$ & Vertedero, $40 \%$ \\
\hline Madera & Incineración, $100 \%$ & - \\
\hline Cobre & Reciclado, $95 \%$ & Vertedero, $5 \%$ \\
\hline Cables & Reciclado, $95 \%$ & Vertedero, $5 \%$ \\
\hline Aceite (lubricante y térmico) & Incineración de residuos peligrosos, $100 \%$ & - \\
\hline Sales fundidas & Vertedero de residuos peligrosos, $100 \%$ & - \\
\hline Pintura & Incineración de residuos peligrosos, $80 \%$ & Vertedero, $20 \%$ \\
\hline Otros materiales & Vertedero, $100 \%$ & - \\
\hline
\end{tabular}




\subsubsection{Evaluación de impacto}

\subsubsection{Escenario HYSOL BIO}

La Tabla 17 muestra los impactos asociados a la generación de $1 \mathrm{MWh}$ de en la planta HYSOL BIO. En la tabla se muestran resultados de caracterización de las doce categorías de punto medio más relevantes para esta tecnología, así como el resultado de la huella hídrica y del consumo primario de energía (CED). Los impactos del ciclo de vida de la tecnología HYSOL fueron los siguientes: cambio climático 45,9 $\mathrm{kg} \mathrm{CO}_{2}$ eq/MWh, acidificación terrestre $515 \mathrm{~g} \mathrm{SO}_{2} \mathrm{eq} / \mathrm{MWh}$, eutrofización de agua dulce 16,9 g P eq/MWh, toxicidad humana 27,5 kg 1,4-DB eq/MWh, formación de partículas $217 \mathrm{~g} \mathrm{PM}$ P/MWh, eco-toxicidad de agua dulce 1.035 g 1,4-DB eq/MWh, eco-toxicidad marina 1.030 g 1, 4-DB eq/MWh, CED 1338 MJ/MWh, y estrés hídrico 0,164 $\mathrm{m}^{3} / \mathrm{MWh}$.

Tabla 17 Impactos caracterizados en diferentes fases del ciclo de vida de la planta HYSOL BIO

\begin{tabular}{lcccccc} 
Categoría de impacto & Ud/MWh & E\&F & C & O\&M & D\&D & TOTAL \\
\hline Cambio climático & $\mathrm{kg} \mathrm{CO}_{2}$ eq & 9,80 & 1,79 & 37,7 & $-3,35$ & 45,9 \\
\hline Acidificación terrestre & $\mathrm{g} \mathrm{SO}_{2}$ eq & 47,6 & 8,41 & 471 & $-11,7$ & 515 \\
\hline Eutrofización de agua dulce & $\mathrm{g} \mathrm{P} \mathrm{eq}$ & 4,21 & 0,44 & 13,0 & $-0,80$ & 16,9 \\
\hline Toxicidad humana & $\mathrm{kg} \mathrm{1,4-DB}$ eq & 5,21 & 0,59 & 22,4 & $-0,68$ & 27,5 \\
\hline Formación de partículas & $\mathrm{g} \mathrm{PM}_{10}$ eq & 27,6 & 4,9 & 195 & $-10,5$ & 217 \\
\hline Ecotoxicidad de agua dulce & $\mathrm{g} \mathrm{1,4-DB} \mathrm{eq}$ & 216 & 19,5 & 794 & 4,71 & 1.035 \\
\hline Ecotoxicidad de agua marina & $\mathrm{g} \mathrm{1,4-DB} \mathrm{eq}$ & 209 & 19,9 & 799 & 2,76 & 1.030 \\
\hline Demanda acumulada de energía (CED) & $\mathrm{MJ}$ & 120 & 21,0 & 1.222 & $-25,1$ & 1.338 \\
\hline Estrés hídrico & $\mathrm{m}^{3}$ & & & 0,164 & & 0,164
\end{tabular}

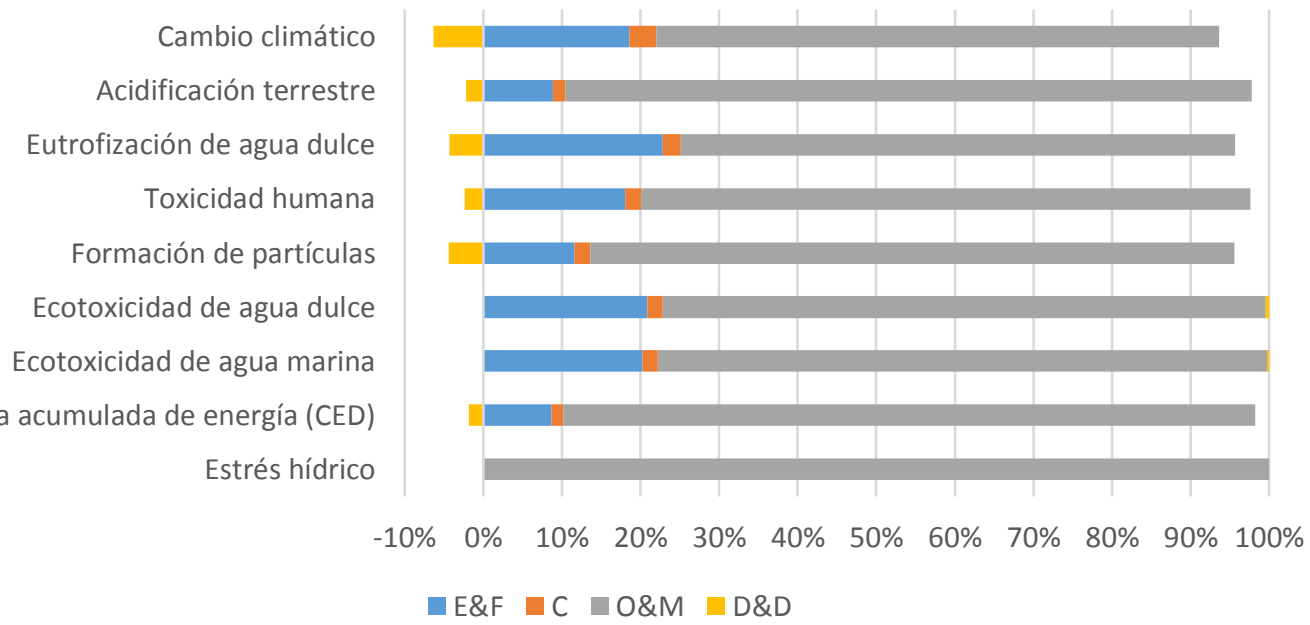

Figura 28 Contribución relativa de cada fase del ciclo de vida a los impactos ambientales caracterizados de la planta HYSOL BIO 
La Figura 28 muestra la contribución de cada fase del ciclo de vida a las categorías de impacto analizadas. La mayoría de los impactos ambientales de la configuración de HYSOL se atribuyen a la fase de O\&M, ya que los impactos derivados de la producción y combustión del combustible auxiliar son superiores a los de la fabricación de componentes de la planta. Los resultados sugieren que el ciclo de vida del biometano presenta entre el $68 \%$ y $91 \%$ del impacto ambiental de la planta HYSOL en cada categoría, excepto en estrés hídrico, cuya contribución es del $8,4 \%$. La contribución del biometano al impacto ambiental total fue más alta en las categorías de CED, cambio climático y toxicidad humana ( $91 \%, 81 \%$ y $80 \%$ respectivamente). Los efectos de la producción de biometano en CED y toxicidad humana son debidos principalmente al mayor consumo de electricidad durante la generación y depuración del biogás. El mix de electricidad español presenta impactos en la categoría de toxicidad humana debido especialmente a los residuos de la explotación minera de combustibles fósiles. Los impactos de la producción de biometano en el cambio climático están asociados por una parte con este consumo eléctrico, y por otra, con las emisiones de metano durante el proceso de depuración. La combustión de biometano en la turbina de gas presenta el $23 \%$ del impacto de ciclo de vida de la categoría de acidificación y menos del 0,2 \% del resto de categorías. Este mayor impacto en la categoría de acidificación está asociado con las emisiones directas de óxidos de azufre producidas durante el proceso de combustión (0,281 g SO $/$ /GJ quemado).

La fase D\&D presenta resultados negativos en algunas categorías debido a los impactos evitados gracias al reciclaje de materiales utilizados en los componentes de la planta.

La CED asociada con el ciclo de vida de la planta HYSOL BIO asciende a $1.338 \mathrm{MJ} / \mathrm{MWh}$. El consumo de energía externa (teniendo en cuenta todo el ciclo de vida de la tecnología) representa el $37 \%$ de toda la electricidad vertida a la red. O\&M es la fase más intensiva en energía (34 \% de la electricidad vertida a la red) debido principalmente al consumo de biometano durante las operaciones de generación, mantenimiento y puesta en marcha de la planta. La siguiente fase es $E \& F$ ( $3,3 \%$ de la electricidad vertida a la red) debido al uso de energía para la extracción de materias primas involucradas en la construcción de la planta. El consumo de energía en las fases de construcción (C), desmantelamiento y disposición de residuos (D\&D) es muy limitada (menos del $1 \%$ ). Considerando que el resultado obtenido de CED para las etapas de fabricación y construcción es $2,82 \times 10^{9} \mathrm{MJ}$, que el obtenido para la operación y mantenimiento es $9,74 \times 10^{8} \mathrm{MJ} / \mathrm{yr}$ y que la electricidad producida es $2,87 \times 10^{9} \mathrm{MJ} / \mathrm{yr}$, el TRE de la tecnología HYSOL es 0,51 años o 6,1 meses (según la ecuación (2)). Debe tenerse en cuenta que la biomasa utilizada para producir el biometano no se ha contabilizado como consumo de energía primaria. 
La fase de E\&F es la segunda fase con mayores impactos. La Figura 29 muestra la contribución de los sistemas de componentes de la planta HYSOL al impacto ambiental de la fase E\&F del ciclo de vida. En la gráfica se observa que el campo solar es el sistema con mayores impactos, presentando el 68-77 \% de impactos de la fase E\&F (dependiendo de la categoría).

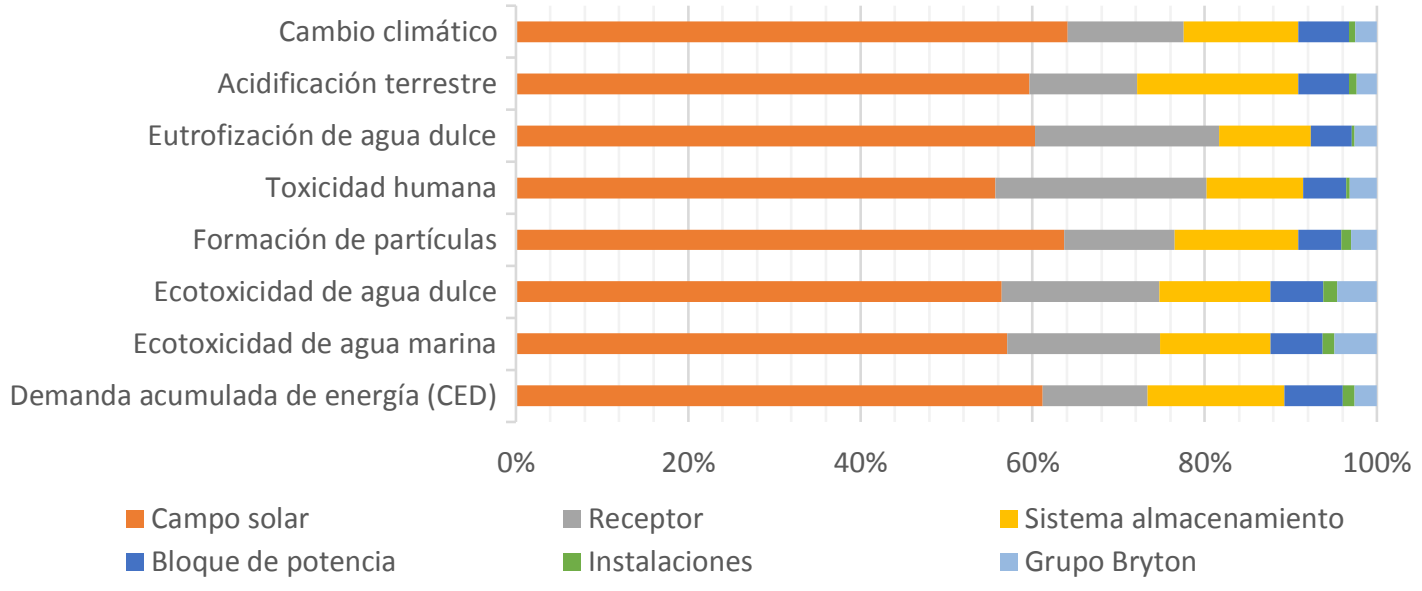

Figura 29 Contribución relativa de los sistemas de la fase de fabricación a los impactos ambientales caracterizados de la planta HYSOL BIO

El impacto del campo solar viene dado por la fabricación de los heliostatos, principalmente por el uso del acero en la estructura (24-59 \% de impacto de construir los heliostatos se atribuyen a la fabricación del acero y $16-48 \%$ al procesado del mismo). Entre el 9 y el $22 \%$ de los impactos de fabricación del heliostato (dependiendo de la categoría) se asocian con la fabricación de los espejos. Además, el campo solar también presenta impactos debido al cobre presente en los cables y el control electrónico del seguidor solar. El siguiente sistema de componentes con mayor impacto es el receptor central, debido al acero necesario para construir el cilindro receptor y la torre. El sistema de almacenamiento es el tercer bloque con mayores impactos, asociados con la fabricación y transporte de sales térmicas y del acero de los tanques.

Sin embargo, la fase de D\&D supone un beneficio (de entre $0 \%$ y $7 \%$ del total de impactos del ciclo de vida, dependiendo de la categoría) que está asociado principalmente con el reciclaje del acero y el hierro. Este proceso supone el 82-100 \% de los beneficios asociados con la fase D\&D (dependiendo de la categoría), lo que reduce considerablemente el impacto relativo del acero en el ciclo de vida de la planta.

Los resultados sugieren que el impacto ambiental asociado con la construcción del ciclo Brayton es relativamente bajo (entre el 3 y el 6 \% de los impactos de la fase de fabricación dependiendo de la categoría) en comparación con el resto de componentes de la planta. 
En el perfil normalizado de la Figura 30 se puede observar que la categoría más afectada en la fase de O\&M (y también en todo el ciclo de vida) es ecotoxicidad marina, seguido de toxicidad humana y ecotoxicidad de agua dulce. El impacto sobre ecotoxicidad marina en la fase de E\&F se asocia principalmente con el uso acero en distintos elementos de la planta, la utilización de cobre en el TES y bloque de potencia, y la producción de las sales de nitrato. El impacto sobre ecotoxicidad marina y de agua dulce en la fase de O\&M se asocia principalmente con la producción de biometano ( $79 \%$ del impacto de ciclo de vida en la categoría). El impacto normalizado en otras categorías ambientales como el cambio climático y acidificación terrestre es considerablemente más bajo.

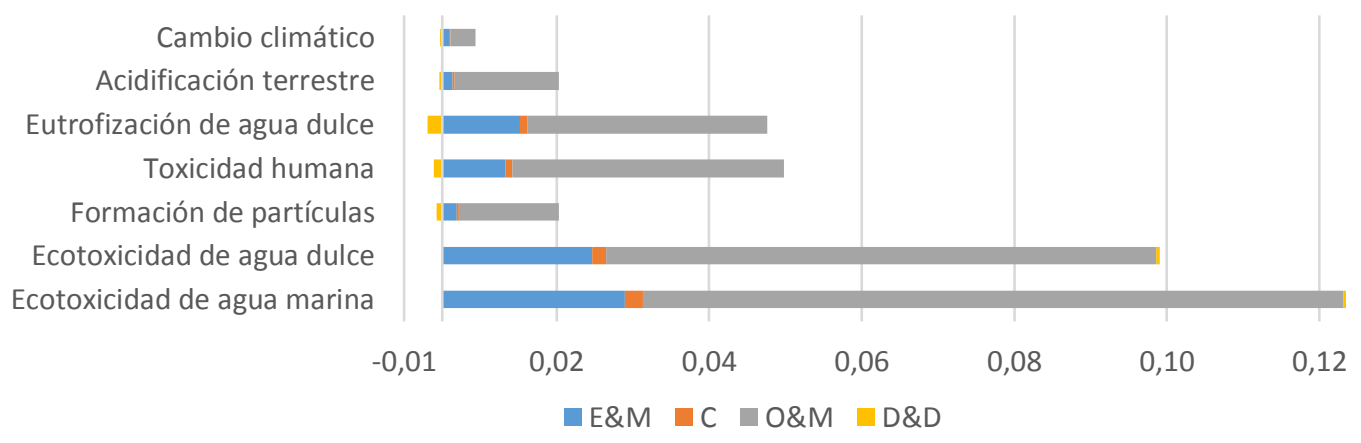

Figura 30 Impactos de normalización asociados al ciclo de vida de la planta HYSOL BIO por categoría y fase

Según el método de evaluación ReCiPe Endpoint Europe H/H v 1.12, el resultado ponderado de punto final indica que la planta HYSOL BIO presenta 8,27 pt/MWh, de los cuales el $55 \%$ corresponde a consumo de recursos, el $25 \%$ a salud humana, y el $20 \%$ a daño en ecosistemas.

\subsubsection{Escenario HYSOL GN}

La Tabla 18 y Figura 31 describen el desempeño ambiental caracterizado y normalizado asociado a la generación de $1 \mathrm{MWh}$ de electricidad considerando la planta HYSOL utilizando gas natural como combustible auxiliar en vez de biometano. Los resultados indican una alta contribución de la fase de O\&M en el impacto ambiental del ciclo de vida, especialmente en las categorías de cambio climático (97 \% del impacto de la fase de O\&M) y CED (98 \%). La segunda fase con mayor impacto es E\&F, especialmente en ecotoxicidad marina ( $30 \%$ del impacto de la fase de E\&F), eutrofización del agua dulce (30\%) y toxicidad humana (24\%). Los impactos ambientales de la fase E\&F están principalmente asociados a la producción y fabricación de componentes hechos de acero y cobre. 
Tabla 18 Impactos caracterizados por fases del ciclo de vida de la planta HYSOL GN

\begin{tabular}{lcccccc} 
Categoría de impacto & Ud/MWh & E\&F & C & O\&M & D\&D & TOTAL \\
\hline Cambio climático & $\mathrm{kg} \mathrm{CO}_{2}$ eq & 9,80 & 1,79 & 285 & $-3,35$ & 294 \\
\hline Acidificación terrestre & $\mathrm{g} \mathrm{SO}_{2}$ eq & 47,6 & 8,41 & 649 & $-11,66$ & 694 \\
\hline Eutrofización de agua dulce & $\mathrm{g} \mathrm{P} \mathrm{eq}$ & 4,21 & 0,44 & 10,52 & $-0,80$ & 14,4 \\
\hline Toxicidad en humanos & $\mathrm{kg} \mathrm{1,4-DB} \mathrm{eq}$ & 5,21 & 0,59 & 16,3 & $-0,68$ & 21,4 \\
\hline Formación de partículas & $\mathrm{g} \mathrm{PM}_{10}$ eq & 27,6 & 4,9 & 198 & $-10,48$ & 220 \\
\hline Eco-toxicidad de agua dulce & $\mathrm{g} \mathrm{1,4-DB} \mathrm{eq}$ & 216 & 19,5 & 811 & 4,71 & 1.052 \\
\hline Eco-toxicidad de agua marina & $\mathrm{g} \mathrm{1,4-DB} \mathrm{eq}$ & 209 & 19,9 & 480 & 2,76 & 711 \\
\hline $\begin{array}{l}\text { Demanda acumulada de energía } \\
\text { (CED) }\end{array}$ & $\mathrm{MJ} / \mathrm{MWh}$ & 120 & 21,0 & 6.227 & $-25,08$ & 6.344 \\
\hline Estrés hídrico & $\mathrm{m} / \mathrm{MWh}$ & & & 0,151 & & 0,151 \\
\hline
\end{tabular}

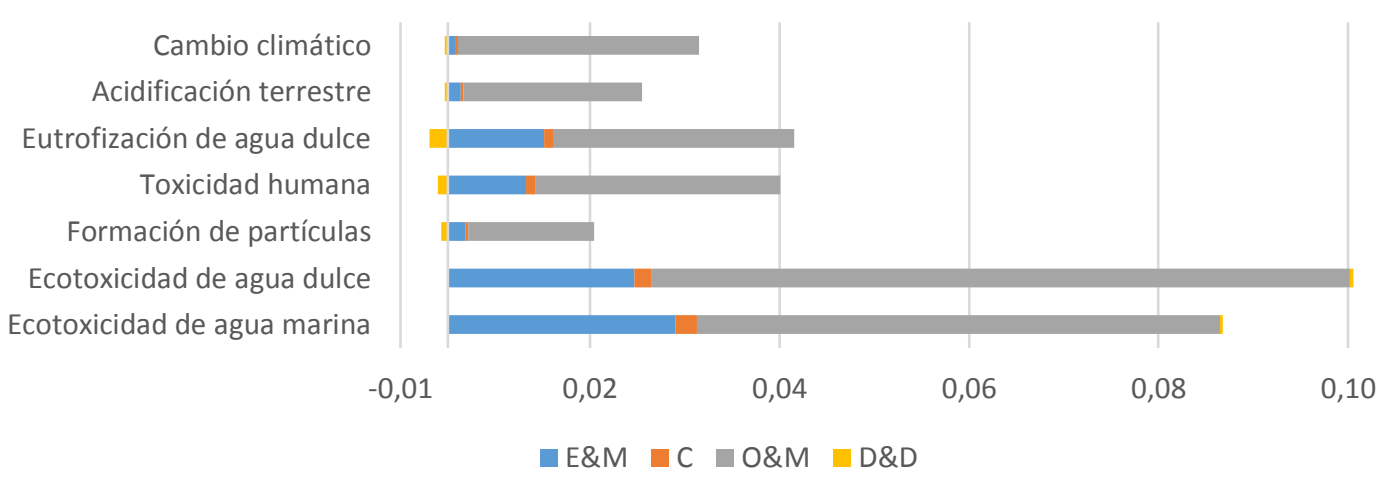

Figura 31 Perfil normalizado asociado al ciclo de vida de la planta HYSOL GN

Al comparar los resultados obtenidos en este caso con los obtenidos para la planta HYSOL $\mathrm{BIO}$, algunos indicadores de categoría muestran un aumento significativo, como los de cambio climático y CED. El alto impacto para la categoría de cambio climático durante la fase de O\&M es atribuible a la combustión de gas natural en la turbina de gas (presentando el $73 \%$ del impacto de ciclo de vida) y a su extracción, producción y transporte (24\%). La combustión de gas natural también contribuye al $20 \%$ de los impactos de acidificación del ciclo de vida, mientras que su contribución a otras categorías es insignificante. El ciclo de vida de gas natural previo a su combustión (extracción, producción y transporte) contribuye a 66-75 \% de las categorías de la acidificación, la eutrofización y la toxicidad, siendo el proceso con mayor impacto en la mayoría de las categorías ambientales.

El resultado obtenido para la categoría de CED indica que la energía primaria consumida durante el ciclo de vida de la planta de energía en este escenario es $6.344 \mathrm{MJ} / \mathrm{MWh}$. La proporción de energía neta es 1,76 , lo que significa que el consumo de energía primaria (teniendo en cuenta el ciclo de vida del sistema) representa el $136 \%$ de toda la electricidad generada vertida en la red. Considerando que el resultado obtenido de CED para las etapas de 
fabricación y construcción es $2,82 \times 10^{9} \mathrm{MJ}$, el obtenido para la operación y mantenimiento es 4,97 $\times 10^{9} \mathrm{MJ} / \mathrm{yr}$ y la electricidad producida es $2,87 \times 10^{9} \mathrm{MJ} / \mathrm{yr}$, el TRE de la tecnología HYSOL es 1,86 años o 22,3 meses (según la ecuación (2)).

El resultado ponderado de punto final (según el método de evaluación ReCiPe Endpoint Europe $\mathrm{H} / \mathrm{H}$ v 1.12) indica que la planta HYSOL GN presenta $35,2 \mathrm{pt} / \mathrm{MWh}$, de los cuales el $62 \%$ corresponde a consumo de recursos, el $20 \%$ a salud humana, y el $17 \%$ a daño en ecosistemas.

\subsubsection{Análisis de incertidumbre}

Esta sección contiene los resultados del análisis de propagación de la incertidumbre de los datos de inventario en los resultados caracterizados. No incluye la incertidumbre asociada con el método de evaluación de impacto (incertidumbre de factores de caracterización o normalización), ni la incertidumbre asociada con errores inesperados al introducir cantidades. El método de simulación utilizado para la propagación de la incertidumbre es Monte Carlo, utilizando 1000 iteraciones, según lo recomendado por Steen (1997). Se calculó con un 95 \% de intervalo de confianza, según lo recomendado por Sonneman et al. (2003).

Los resultados de la incertidumbre asociadas a los impactos ambientales caracterizados de la planta HYSOL BIO se describen en la Tabla 19 y Figura 32.

Tabla 19 Resultados de Monte Carlo para los impactos ambientales caracterizados de la planta HYSOL BIO (95\% de intervalo de confianza)

\begin{tabular}{|c|c|c|c|c|c|c|c|}
\hline Escenarios & $\begin{array}{l}\text { Unidades } \\
\text { (por MWh) }\end{array}$ & Media & SD & CV & $2,5 \%$ & $97,5 \%$ & SEM \\
\hline Cambio climático & $\mathrm{kg} \mathrm{CO} 2 \mathrm{eq}$ & 45,9 & 1,0 & $2 \%$ & 44,2 & 48,0 & 0,031 \\
\hline Acidificación terrestre & $\mathrm{g} \mathrm{SO}_{2} \mathrm{eq}$ & 515 & 19,9 & $4 \%$ & 477 & 553 & 0,630 \\
\hline Eutrofización de agua dulce & g P eq & 16,9 & 2,3 & $14 \%$ & 14,94 & 22,4 & 0,074 \\
\hline Toxicidad en humanos & kg 1,4-DB eq & 27,5 & 38,5 & $140 \%$ & $-54,9$ & 105 & 1,22 \\
\hline Formación de partículas & $\mathrm{g} \mathrm{PM}_{10}$ eq & 217 & 8,4 & $4 \%$ & 201,9 & 234 & 0,27 \\
\hline Eco-toxicidad de agua dulce & g 1,4-DB eq & 1.035 & 159,6 & $15 \%$ & 731 & 1.364 & 5,05 \\
\hline Eco-toxicidad de agua marina & g 1,4-DB eq & 1.030 & 132,6 & $13 \%$ & 783 & 1.305 & 4,19 \\
\hline $\begin{array}{l}\text { Demanda acumulada de } \\
\text { energía (CED) }\end{array}$ & MJ & 1.338 & 12 & $1 \%$ & 1.316 & 1.364 & 0,381 \\
\hline
\end{tabular}

*SD=Desviación típica; CV=Coeficiente de Variación; SEM= Error estándar de la media

Los resultados con un $95 \%$ de intervalo de confianza indican que el cambio climático es la categoría con menor incertidumbre acumulada ( $C V=2 \%)$, seguida de acidificación terrestre ( $C V=$ $4 \%$ ) y eutrofización de agua dulce ( $C V=14 \%)$. La categoría que presenta la mayor incertidumbre es toxicidad humana ( $C V=140 \%$ ), con valores para confianzas de $2,5 \%$ y $97,5 \%$ muy lejos de la media de la categoría. 
CAPÍTULO 3: Análisis del área ambiental

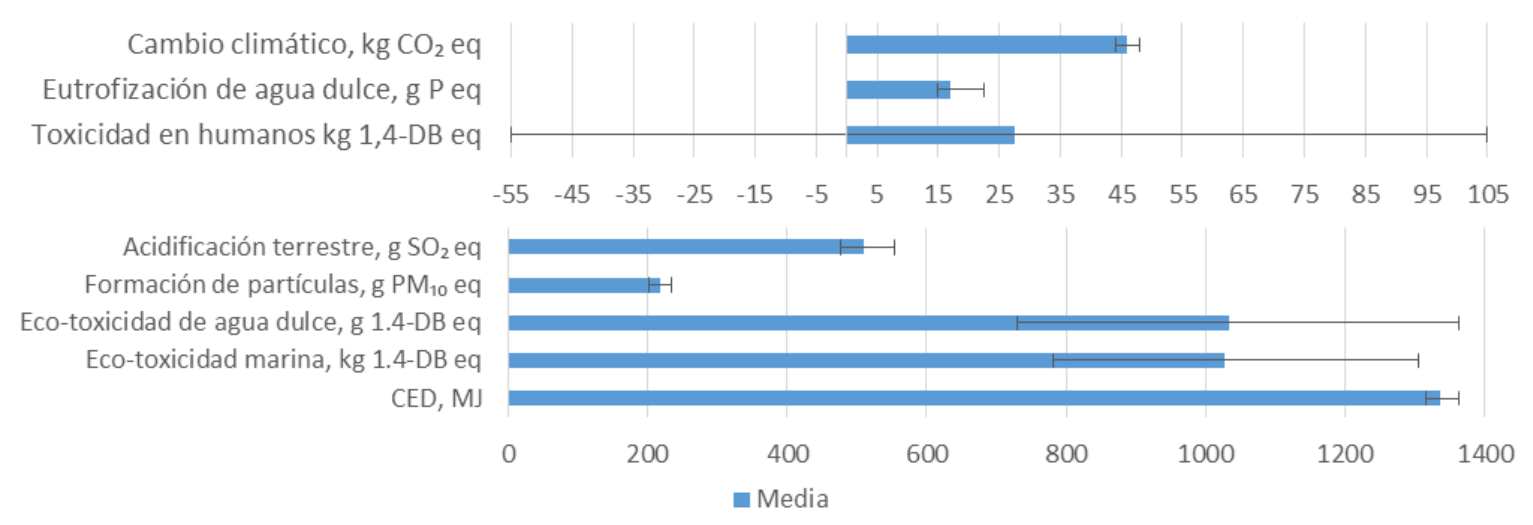

Figura 32 Resultados de caracterización (por MWh) para la planta HYSOL BIO representando la incertidumbre con barras de error (95\% de intervalo de confianza)

Los resultados de incertidumbre sugieren que la categoría de toxicidad humana tiene demasiada incertidumbre como para comparar o tomar decisiones basadas únicamente en ese valor. El resto de las categorías presentan un coeficiente de variación menor al $15 \%$, lo que se considera adecuado en este tipo de estudios.

\subsubsection{Enfoque consecuencial}

El objetivo del estudio con enfoque consecuencial responde a la siguiente sub- pregunta de sostenibilidad: ¿Cuánto se reduce el impacto ambiental del ciclo de vida al proveer de electricidad HYSOL al mercado eléctrico español?

Realizar un análisis consecuencial de ciclo de vida de la tecnología HYSOL implica ampliar el alcance del estudio para incluir los cambios en el mercado eléctrico español al introducir en el mismo la planta bajo estudio. Esta ampliación implica considerar los efectos ambientales que supone el cambio de la demanda de bienes en el mercado español. A pesar de esta diferencia de enfoque, las fases del ciclo de vida coinciden con las del modelado atribucional, al igual que los métodos de evaluación y las categorías de impacto midpoint y CED. El estrés hídrico no se ha analizado bajo un enfoque consecuencial, ya que al considerar únicamente consumo de agua directa por la planta su resultado no cambia respecto al cálculo mediante el enfoque atribucional.

Este análisis contempla los dos escenarios establecidos en la definición de alcance y objetivos del ASCV, en el primero se considera la planta HYSOL BIO (operación con biometano), y en el segundo se considera la planta HYSOL GN. 
A continuación se describen las principales diferencias de modelado y el proceso seguido para escoger la tecnología marginal desplazada debido a la producción de electricidad mediante la planta HYSOL.

\subsubsection{Elección de la tecnología marginal}

La tecnología marginal es aquella tecnología que se ve afectada por un cambio pequeño en la demanda del producto bajo estudio (Weidema et al. 1999). En el caso de estudio (una planta termosolar), la tecnología marginal será aquella que se ve afectada por la producción y provisión de $1 \mathrm{MWh}$ en el mercado eléctrico español. Es decir, aquella tecnología que en ausencia de la planta termosolar oferta el último megavatio hora que cubre la demanda, y que por lo tanto, será desplazada por la oferta de electricidad de la tecnología termosolar.

Las publicaciones existentes sobre las consecuencias de un aumento marginal en la demanda o provisión de electricidad conducen a la elección de centrales térmicas convencionales y ciclos combinados como las tecnologías marginales (García Redondo and Román Collado 2014, Lund et al. 2010, Weinrebe et al. 1998). La principal razón es que su producción se puede ajustar más fácilmente al aumento o descenso de la demanda, ya que no tienen restricciones técnicas, naturales o de mercado. Además, son las tecnologías con mayores costes de operación, por lo que si baja la demanda marginal, serán las menos competitivas en el mercado y las primeras en dejar de producir electricidad. Sin embargo, cada estudio tiene alcances, objetivos y contextos diferentes, por lo tanto es necesario conocer y comprender el mercado de electricidad específico antes de elegir la tecnología marginal.

Considerando que el actual mercado eléctrico español sigue un sistema marginal liberalizado donde el precio se determina cada hora mediante el megavatio hora más caro que cubre la demanda prevista, podría decirse que las tecnologías más baratas siempre venden su electricidad, mientras que las más caras sólo lo harán cuando haya mucha demanda. Sin embargo, el mercado español no siempre está gobernado por costes tecnológicos, sino también por estrategias políticas y financieras que obedecen a intereses empresariales. Por ejemplo, las centrales hidroeléctricas se ven restringidas por las variaciones en las precipitaciones. Debido a sus bajos costes de operación y a su capacidad de almacenar energía, suelen vender su electricidad a diferentes precios dependiendo de sus beneficios esperados. Si los embalses están Ilenos, ofertan a bajo precio, por el contrario, si están más vacíos, guardan su energía para ofertar la electricidad sólo cuando el precio de mercado es más alto (cuando hay más demanda) (Gallego and Victoria 2012). Esto hace que, en ocasiones, no vendan su electricidad aunque sea una tecnología barata. 
A continuación se exploran las características del caso bajo estudio para determinar la tecnología marginal con mayor precisión.

\subsection{La tendencia del mercado eléctrico}

Según la metodología consecuencial, si el mercado de interés está decreciendo en demanda (con mayor rapidez que las inversiones en el reemplazamiento de la potencia instalada), la tecnología marginal es aquella con menores costes en el corto plazo. Sin embargo, si la tendencia del mercado es el crecimiento, la tecnología marginal sería aquella con menores costes a largo plazo (Mathiesen et al. 2009). Por lo tanto, la tendencia del mercado es importante para saber la tecnología marginal a largo plazo, ya que la tecnología marginal puede cambiar si en un futuro cambia la capacidad instalada de cada una de las tecnologías participantes en el mix eléctrico.

La demanda de electricidad en el mercado eléctrico español ha decrecido desde el año 2010, alcanzando un 2,3 \% de disminución durante el año 2012-2013 (REE, 2014a). Esta reducción de la demanda de electricidad se ha atribuido principalmente a la crisis financiera, que se espera superar lentamente en los años siguientes. Además, la actual potencia instalada del sistema eléctrico español se encuentra infrautilizada, ya que la potencia instalada (102262 MW en diciembre de 2014) es más del doble que la demanda máxima horaria (38666 MWh en 2014) (REE 2015). Esta situación hace que no se espere un aumento significativo de la capacidad instalada en un futuro cercano.

La tendencia de Europa es aumentar la potencia instalada de tecnologías de origen renovable. Un posible aumento a largo plazo de capacidad renovable (especialmente eólica, cuyos costes de inversión están disminuyendo) vinculado con condiciones climáticas favorables podría afectar al mix de tecnologías marginales, aumentando su componente renovable. Sin embargo, las tecnologías de origen renovable están pasando por un momento de inestabilidad en España debido a la reciente normativa retroactiva que afecta a la retribución de las mismas (Atanassov 2014, Real Decreto 413/2014 2014). Esta situación desincentiva la inversión en tecnologías renovables, y hace este escenario menos probable y altamente incierto.

Por lo tanto, este estudio considera que la capacidad instalada se mantiene constante (respecto a la demanda) en un futuro cercano.

\subsection{El papel del sistema bajo estudio en el mercado eléctrico.}

Una de las principales ventajas de la tecnología HYSOL es la capacidad de producir electricidad en cualquier momento del día, ya sea procedente de recursos solares, biogás/gas natural o almacenamiento térmico. Por lo tanto, la planta bajo estudio puede proporcionar y 
vender electricidad a cualquier hora. Puesto que es una tecnología renovable, su retribución se supone por el gobierno español, lo que le permite ofertar toda su electricidad producida a un precio menor que el de su coste (va a recibir incentivos).

\subsection{Cálculo de la tecnología marginal}

Según lo expuesto anteriormente, se ha decidido calcular la tecnología marginal como el mix de tecnologías que fijan el precio marginal horario ${ }^{8}$ durante un año promedio. La planta HYSOL bajo estudio está diseñada para adaptarse a la curva de la demanda, de tal manera que produce electricidad durante todas las horas del día. La Tabla 20 muestra el promedio anual para todas las horas del año 2014 calculado por meses estacionales mediante información del OMIE (OMIE 2015). La Tabla 21 muestra la participación de cada tecnología en la cobertura de la demanda eléctrica nacional, según datos de la REE (REE 2014). La información desagregada sobre la contribución a la fijación del precio marginal por parte del grupo de tecnologías fotovoltaica, solar térmica, eólica combustión de biomasa y cogeneración no estaba disponible. Observando la información disponible publicada por el OMIE, se ha detectado una participación mayor de eólica y termosolar, explicada por la ausencia de retribución extra en casos concretos (por ejemplo, si se ha superado el máximo de horas de operación susceptibles de retribución, o producción mediante gas natural que no percibe retribución). El resto de tecnologías de fuentes renovables suelen entrar siempre dentro del mix eléctrico ya que reciben retribución extra. Por lo tanto, con el objeto de realizar este estudio, la participación de otras tecnologías renovables se ha considerado insignificante y la participación de eólica y termosolar en la fijación del precio marginal se ha calculado usando el método desarrollado por García Redondo y Román Collado (García Redondo and Román Collado 2014). En este método, los coeficientes de desplazamiento se calculan considerando el peso relativo de cada tecnología en la cobertura de la demanda eléctrica total, utilizando las Ecuaciones (3) y (4). Esto resulta en un 11,1 \% de participación de eólica y un $1,1 \%$ de termosolar.

\footnotetext{
8 Precio que adquiere el último kilowatio-hora que satisface la demanda horaria.
} 
CAPÍTULO 3: Análisis del área ambiental

Tabla 20 Mix de tecnología marginal por tramos mensuales, calculado para las 24 horas del día

\begin{tabular}{llllll} 
PERIODO & $\begin{array}{l}\text { Dic, ene, } \\
\text { feb }\end{array}$ & $\begin{array}{l}\text { mar, } \\
\text { abr,may }\end{array}$ & $\begin{array}{l}\text { jun, jul, } \\
\text { ago }\end{array}$ & $\begin{array}{l}\text { sept, oct, } \\
\text { nov }\end{array}$ & $\begin{array}{l}\text { MEDIA ANUAL } \\
\text { (2014) }\end{array}$ \\
\hline Bombeo & $15 \%$ & $17 \%$ & $11 \%$ & $13 \%$ & $14,0 \%$ \\
\hline Hidraulica & $35 \%$ & $42 \%$ & $29 \%$ & $40 \%$ & $36,5 \%$ \\
\hline Importaciones & $6,3 \%$ & $2,2 \%$ & $0,0 \%$ & $0,0 \%$ & $1,9 \%$ \\
\hline Térmica convencional & $21 \%$ & $19 \%$ & $42 \%$ & $27 \%$ & $27,1 \%$ \\
\hline $\begin{array}{l}\text { Ciclo combinado } \\
\text { Renovables, cogeneración } \\
\text { y residuos }\end{array}$ & $9,4 \%$ & $2,8 \%$ & $4,1 \%$ & $5,2 \%$ & $5,3 \%$ \\
\hline
\end{tabular}

Tabla 21 Cobertura de la demanda de electricidad por tecnologías, media del año 2014

\begin{tabular}{l} 
Tecnología \\
\hline Hidroeléctrica \\
\hline Nuclear \\
Ciclo combinado \\
Carbón \\
Eólica \\
Solar fotovoltaica \\
Termosolar \\
Combustion de biomasa \\
\hline Cogeneración y otras \\
$\qquad \propto c=\frac{\beta c}{\beta c+\beta g}$ \\
$\qquad \propto g=\frac{\beta g}{\beta c+\beta g}$
\end{tabular}

Cobertura de la demanda año 2014 ( \%)

15,4

22,0

8,4

16,3

20,4

3,2

2,1

1,9

10,3

Donde $\alpha c$ y $\alpha$ g son los coeficientes de desplazamiento para generación de electricidad con carbón y ciclos combinados respectivamente, y $\beta c$, $\beta g$ son los porcentajes medios de cobertura de la demanda de electricidad entre Agosto 2013 y Agosto 2014 (REE 2014b).

Por consiguiente, asumiendo un escenario BAU (Business As Usual), el mix de tecnologías marginales se ha calculado como sigue: hidroeléctrica $36,5 \%$, ciclo combinado 5,3\%, carbón $27,1 \%$, eólica $13,7 \%$, termosolar 1,4 \%, bombeo 14,0 \% e importaciones de Francia 1,9\%.

\subsection{Modelado consecuencial del biometano}

Según el escenario propuesto en el análisis atribucional, el digestato obtenido en el procesamiento de residuos biológicos se devuelve al medio en forma de fertilizante gratuito y libre de cargas ambientales. Para el modelado consecuencial se ha asumido que el digestato 
aplicado por los agricultores sustituye fertilizante, por lo que la carga ambiental asignada a la producción de fertilizantes sintéticos equivalentes se deducen de las del ciclo de vida del biometano. La fracción de residuos de biodigestión de lodos de aguas residuales y del estiércol de cerdo/vaca se excluye de esta expansión del sistema ya que estos residuos también se aplican como fertilizantes en el manejo convencional, es decir, sin producción de biogás.

\subsubsection{Inventario}

El inventario de procesos principales coincide con el del análisis atribucional, con algunas modificaciones que se describen a continuación:

- En los procesos aguas arriba, la diferencia de modelado se introduce al utilizar la base de datos ecoinvent 3 en su versión consecuencial, compuesta por datasets que incluyen el cambio de entradas y salidas que supone la demanda marginal de cada bien y servicio necesario para proveer la unidad funcional del sistema.

- El desplazamiento de tecnologías de generación eléctrica por la venta de electricidad del sistema bajo estudio se ha considerado en una fase adicional denominada "Desplazamiento de tecnologías marginales", que ha sido modelada con la entrada de 19935575 MWh de electricidad proveniente del mix de tecnologías marginales (esta cantidad representa la venta total de electricidad de la planta HYSOL durante la fase O\&M).

- El consumo de electricidad durante la construcción y fabricación de componentes se ha modificado para coincidir con lo dispuesto en la sección anterior (modelando el dataset con un enfoque consecuencial, que sólo tiene en cuenta el mix de tecnologías marginales).

- El uso de acero desempeña un papel importante en el impacto ambiental de una planta termosolar (Corona et al. 2014), por lo tanto, se ha modificado el dataset de acero consecuencial presente en ecoinvent 3 para incluir el mix de tecnologías marginales español como electricidad de entrada (en lugar de la media Europea presente en la base de datos de ecoinvent).

\subsubsection{Evaluación de impacto ambiental consecuencial}

Esta sección presenta, en primer lugar, los resultados de aplicar el enfoque consecuencial al análisis de ciclo de vida de la planta HYSOL BIO, y en segundo lugar los obtenidos para la planta HYSOL GN.

\subsection{Planta HYSOL BIO}

La Tabla 22 muestra los impactos ambientales asociados a la generación de $1 \mathrm{MWh}$ en la planta HYSOL, según un enfoque consecuencial. En la tabla se muestran resultados de 
caracterización para cada fase del ciclo de vida, incluyendo una fase específica que considera el mix de tecnologías marginales de producción de electricidad. Los beneficios asociados al desplazamiento del mix de tecnologías marginales son mucho mayores que el impacto producido por la planta HYSOL, de tal forma que todos los indicadores del ciclo de vida para cada categoría presentan resultados negativos. Estos resultados negativos implican que producir electricidad mediante la planta HYSOL evita impactos ambientales en todas las categorías. Los resultados caracterizados obtenidos para la fase de E\&F, C y D\&D de la planta HYSOL BIO son similares a los obtenidos mediante el modelado atribucional, aumentando ligeramente en la fase de E\&F y disminuyendo ligeramente en la de $\mathrm{C}$. La fase de O\&M presenta menores impactos debido al efecto del modelado consecuencial del biometano (que considera el beneficio asociado a la sustitución de fertilizantes por digestato).

Tabla 22 Impactos consecuenciales caracterizados por diferentes fases del ciclo de vida de la planta HYSOL BIO

\begin{tabular}{llllllll} 
Categoría de impacto & Ud/MWh & E\&F & C & O\&M & D\&D & Desplaz. & TOTAL \\
\hline Cambio climático & $\mathrm{kg} \mathrm{CO}$ eq & 10,5 & 1,65 & 18,4 & $-3,35$ & -441 & -414 \\
\hline Acidificación terrestre & $\mathrm{g} \mathrm{SO}_{2}$ eq & 48,7 & 8,52 & 294,1 & $-11,7$ & -3.352 & -3.013 \\
\hline Eutrofización de agua dulce & $\mathrm{g} \mathrm{P} \mathrm{eq}$ & 4,46 & 0,43 & 10,1 & $-0,80$ & -135 & -120 \\
\hline Toxicidad en humanos & $\mathrm{kg} \mathrm{1,4-DB} \mathrm{eq}$ & 4,03 & 0,47 & 20,2 & $-0,68$ & $-99,4$ & $-75,4$ \\
\hline Formación de partículas & $\mathrm{g} \mathrm{PM} 10$ eq & 34,1 & 4,5 & 45,1 & $-10,49$ & -1.019 & -946 \\
\hline Ecotoxicidad de agua dulce & $\mathrm{g} \mathrm{1,4-DB} \mathrm{eq}$ & 223 & 17,9 & 688 & 4,52 & -4.166 & -3.233 \\
\hline Ecotoxicidad de agua marina & $\mathrm{g} \mathrm{1,4-DB}$ eq & 251 & 18,4 & 689 & 2,60 & -3.800 & -2.839 \\
\hline Demanda acumulada de energía (CED) & $\mathrm{MJ} / \mathrm{MWh}$ & 133 & 20,3 & 1.022 & $-25,08$ & -7.352 & -6.202 \\
\hline
\end{tabular}

La Figura 33 muestra la contribución de cada fase del ciclo de vida a las categorías de impacto analizadas según el enfoque consecuencial. La mayoría de los impactos ambientales de la configuración de HYSOL se atribuyen a la fase de O\&M, y están asociados principalmente con el ciclo de vida del biometano. La categoría que mayores beneficios presenta debido al desplazamiento de otras tecnologías es cambio climático y formación de partículas. Estas categorías ven disminuido su impacto ya que el mix de tecnologías marginales está compuesto en un $27 \%$ por tecnologías de combustibles fósiles. 


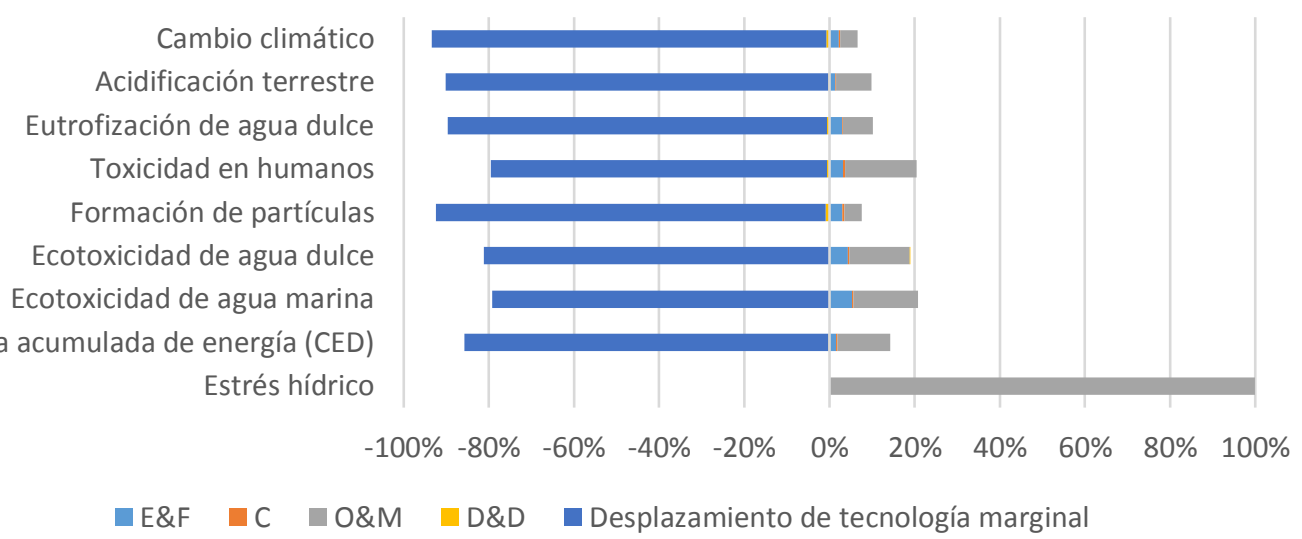

Figura 33 Contribución relativa de cada fase del ciclo de vida a los impactos ambientales caracterizados de la planta HYSOL BIO, según el enfoque consecuencial

La Figura 33 muestra la contribución de cada fase del ciclo de vida a las categorías de impacto analizadas según el enfoque consecuencial. La mayoría de los impactos ambientales de la configuración de HYSOL BIO se atribuyen a la fase de O\&M, y están asociados principalmente con el ciclo de vida del biometano. La categoría que mayores beneficios presenta debido al desplazamiento de otras tecnologías es cambio climático y formación de partículas. Estas categorías ven disminuido su impacto ya que el mix de tecnologías marginales está compuesto en un $27 \%$ por centrales térmicas convencionales (que utilizan carbón como combustible).

El modelado consecuencial del biometano supone una disminución del impacto de la fase O\&M de entre un 5 y un $76 \%$ respecto al modelado atribucional (dependiendo de la categoría). Esta disminución de impacto es mayor en las categorías de formación de partículas, cambio climático y acidificación terrestre (un $76 \%, 49 \%$ y $34 \%$ de disminución de impacto respectivamente).

La fase de E\&F es la segunda fase con mayores impactos. La Figura 34 muestra la contribución de los sistemas de componentes de la planta HYSOL al impacto ambiental de la fase E\&F según el modelado consecuencial. En la gráfica se observa que el campo solar es el sistema con mayores impactos (54-70 \% de impactos de la fase E\&F, dependiendo de la categoría). Al igual que en el modelado atribucional, el impacto del campo solar viene dado por la fabricación de los heliostatos, principalmente por el uso del acero en la estructura. 


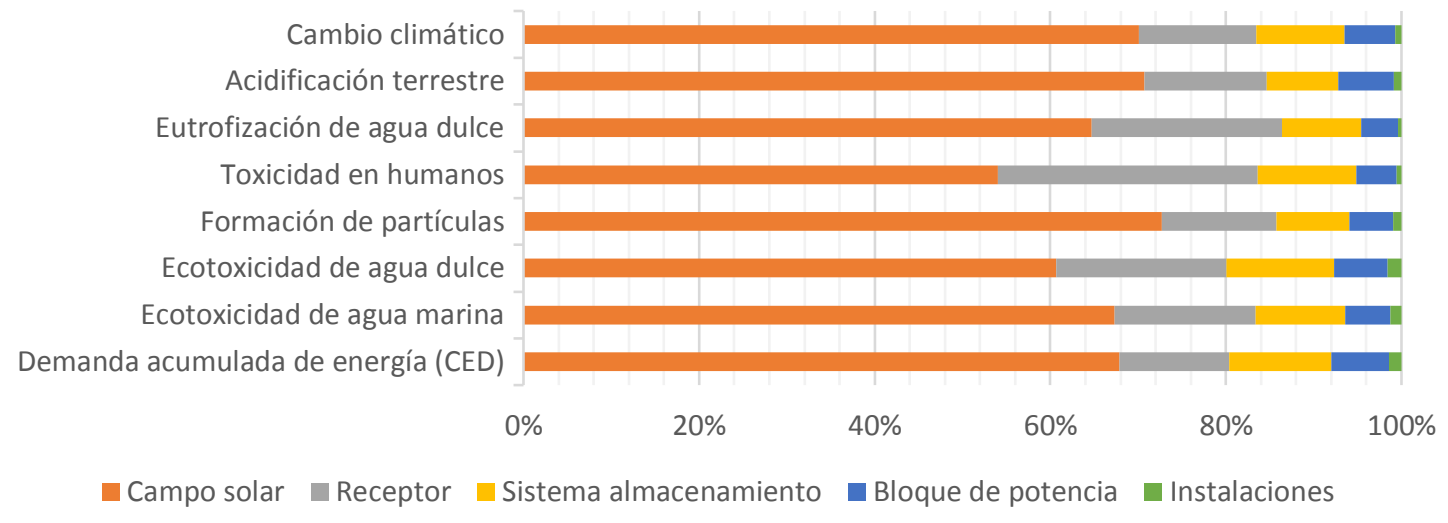

Figura 34 Contribución relativa de los sistemas de la planta HYSOL a los impactos de la fase E\&F según el enfoque consecuencial

En el perfil normalizado de la Figura 35 se puede observar que la fase con mayor contribución al comportamiento ambiental de la planta HYSOL es la de desplazamiento de tecnologías marginales, ya que supone la evitación de impactos en todas las categorías. Esta evitación es comparativamente mayor en las categorías de eco-toxicidad de agua marina y de agua dulce, seguidas por la eutrofización de agua dulce.

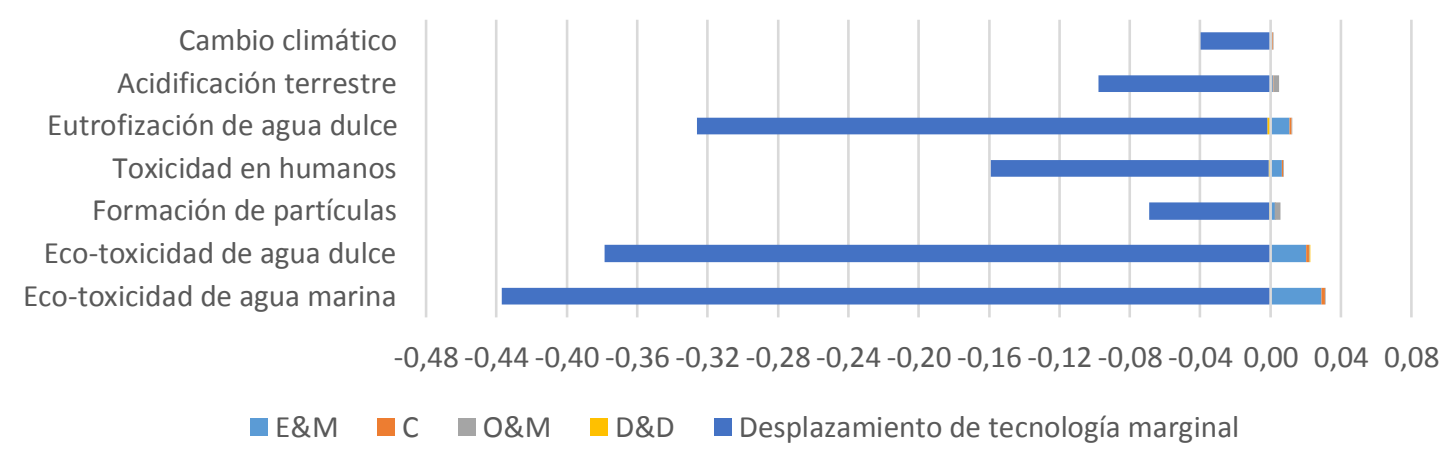

Figura 35 Impactos de normalización asociados al ciclo de vida de la planta HYSOL según el enfoque consecuencial

El impacto sobre eco-toxicidad marina y de agua dulce asociado con el mix de tecnologías marginales desplazadas viene dado principalmente por el tratamiento de los residuos producidos durante el proceso de extracción de carbón (aprox. el $45 \%$ del impacto en estas categorías se asocian con dicho proceso) y con el uso de metales para la infraestructura de las centrales (principalmente acero). El impacto sobre eutrofización de agua dulce y toxicidad en humanos se asocia principalmente con el tratamiento de los residuos producidos durante el proceso de extracción de carbón (un 95 \% del impacto en eutrofización y el 75 \% en toxicidad en humanos producido por el mix de tecnologías marginales viene dado por este proceso). 
El resultado ponderado de punto final indica que la planta HYSOL BIO bajo un enfoque consecuencial presenta $-59,8 \mathrm{pt} / \mathrm{MWh}$, de los cuales el $64 \%$ corresponde a consumo de recursos, el $23 \%$ a salud humana, y el $13 \%$ a daño en ecosistemas. Este resultado indica que la planta genera un beneficio neto cuando se considera el efecto de desplazamiento de tecnologías en el mercado eléctrico español.

\subsection{Planta HYSOL GN}

La Tabla 23 muestra los impactos ambientales asociados a la generación de $1 \mathrm{MWh}$ en la planta HYSOL GN, según un enfoque consecuencial. En la tabla se muestran resultados de caracterización para cada fase del ciclo de vida, incluyendo la fase adicional que considera el mix de tecnologías marginales de producción de electricidad. Los beneficios asociados al desplazamiento del mix de tecnologías marginales son iguales que para la planta HYSOL BIO, ya que el cambio de combustible no afecta al mix de tecnologías marginales. La fase de O\&M presenta mayores impactos que en la planta HYSOL BIO debido a la carga ambiental asociada con el consumo de gas natural. Sin embargo, las fases E\&F, C, y D\&D presentan los mismos impactos que la planta HYSOL BIO ya que el inventario para dichas fases es el mismo.

Tabla 23 Impactos consecuenciales caracterizados por diferentes fases del ciclo de vida de la planta HYSOL GN

\begin{tabular}{llllllll} 
Categoría de impacto & Ud/MWh & E\&F & C & O\&M & D\&D & Desplaz. & TOTAL \\
\hline Cambio climático & $\mathrm{kg} \mathrm{CO}_{2}$ eq & 10,5 & 1,65 & 257 & $-3,35$ & -441 & -175 \\
\hline Acidificación terrestre & $\mathrm{g} \mathrm{SO}_{2}$ eq & 48,7 & 8,52 & 518 & $-11,7$ & -3.352 & -2.789 \\
\hline Eutrofización de agua dulce & $\mathrm{g} \mathrm{P} \mathrm{eq}$ & 4,46 & 0,43 & 8,07 & $-0,80$ & -135 & -122 \\
\hline Toxicidad en humanos & $\mathrm{kg} \mathrm{1,4-DB}$ eq & 4,03 & 0,47 & 12,4 & $-0,68$ & $-99,4$ & -83 \\
\hline Formación de partículas & $\mathrm{g} \mathrm{PM}$ 10 eq & 34,1 & 4,5 & 160 & $-10,5$ & -1.019 & -830 \\
\hline Ecotoxicidad de agua dulce & $\mathrm{g} \mathrm{1,4-DB}$ eq & 223 & 17,9 & 618 & 4,52 & -4.166 & -3.306 \\
\hline Ecotoxicidad de agua marina & $\mathrm{g} \mathrm{1,4-DB} \mathrm{eq}$ & 251 & 18,4 & 382 & 2,60 & -3.800 & -3.148 \\
\hline Demanda acumulada de energía (CED) & $\mathrm{MJ} / \mathrm{MWh}$ & 133 & 20,3 & 4805 & $-25,1$ & -7.352 & -2.420
\end{tabular}

El resultado ponderado de punto final indica que la planta HYSOL GN analizada bajo un enfoque consecuencial presenta $-21,5$ pt/MWh, de los cuales el $51 \%$ corresponde a consumo de recursos, el $36 \%$ a salud humana, y el $13 \%$ a daño en ecosistemas. Este resultado indica que la planta genera un beneficio neto cuando se considera el efecto de desplazamiento de tecnologías en el mercado eléctrico español. 


\subsubsection{Interpretación}

El análisis de ciclo de vida atribucional de la planta HYSOL operando con biometano y gas natural indica que el proceso con mayor carga ambiental es, en ambos casos, el uso de combustible durante la fase de O\&M (junto con el ciclo de vida asociado a dicho combustible). En el caso del biometano, la carga ambiental asociada con producir y transportar el combustible supone de 77 \% a 91 \% del impacto del ciclo de vida en las categorías de cambio climático, CED, eutrofización y ecotoxicidad, mientras que las emisiones de combustión suponen el $23 \%$ del impacto en acidificación y menos del 0,2 \% en el resto de las categorías. Cuando se opera con gas natural, la carga asociada con producir y transportar el combustible supone 66-75 \% del impacto del ciclo de vida de las categorías de eutrofización, acidificación y toxicidad, mientras que las emisiones de combustión suponen el $73 \%$ de impacto en cambio climático, $20 \%$ en acidificación, y menos del 0,2 \% en el resto de categorías. En ambas plantas, la única forma de disminuir esas emisiones es el aumento de la eficiencia de conversión térmica, que reduciría el consumo de combustible, y por tanto el impacto por unidad funcional.

La siguiente fase con mayor impacto en ambos escenarios es E\&F, con mayor contribución de carga ambiental por parte del campo solar. Este mayor impacto está asociado con el uso de una gran cantidad de acero para la estructura de los heliostatos. Este material también es el que presenta mayor carga ambiental en los otros sistemas de la planta. Sin embargo, el reciclaje del acero que tiene lugar durante la fase de D\&D genera unos beneficios ambientales que compensan parte del impacto ambiental de su fabricación, disminuyendo su impacto relativo dentro del ciclo de vida de la planta. Por lo tanto, una de las principales medidas para disminuir el impacto ambiental asociado con los componentes de la planta es reciclar la mayor cantidad de acero y hierro posible. Los siguientes materiales con mayor impacto en la fase E\&F son los espejos de los heliostatos, las sales térmicas (fabricación y trasporte), y el cobre utilizado en los elementos del sistema eléctrico y electrónico. Las medidas de diseño que permitan reducir la cantidad de dichos materiales supondrán una mejora ambiental. También debe considerarse que el impacto de fabricación de las sales térmicas puede estar subestimado, ya que no incluye el consumo de sustancias y energía para la transformación de caliche en nitrato sódico ni de nitrato sódico en nitrato potásico.

La Figura 36 muestra la comparación del perfil normalizado de punto medio de las plantas HYSOL BIO y HYSOL GN bajo los enfoques atribucional y consecuencial. 


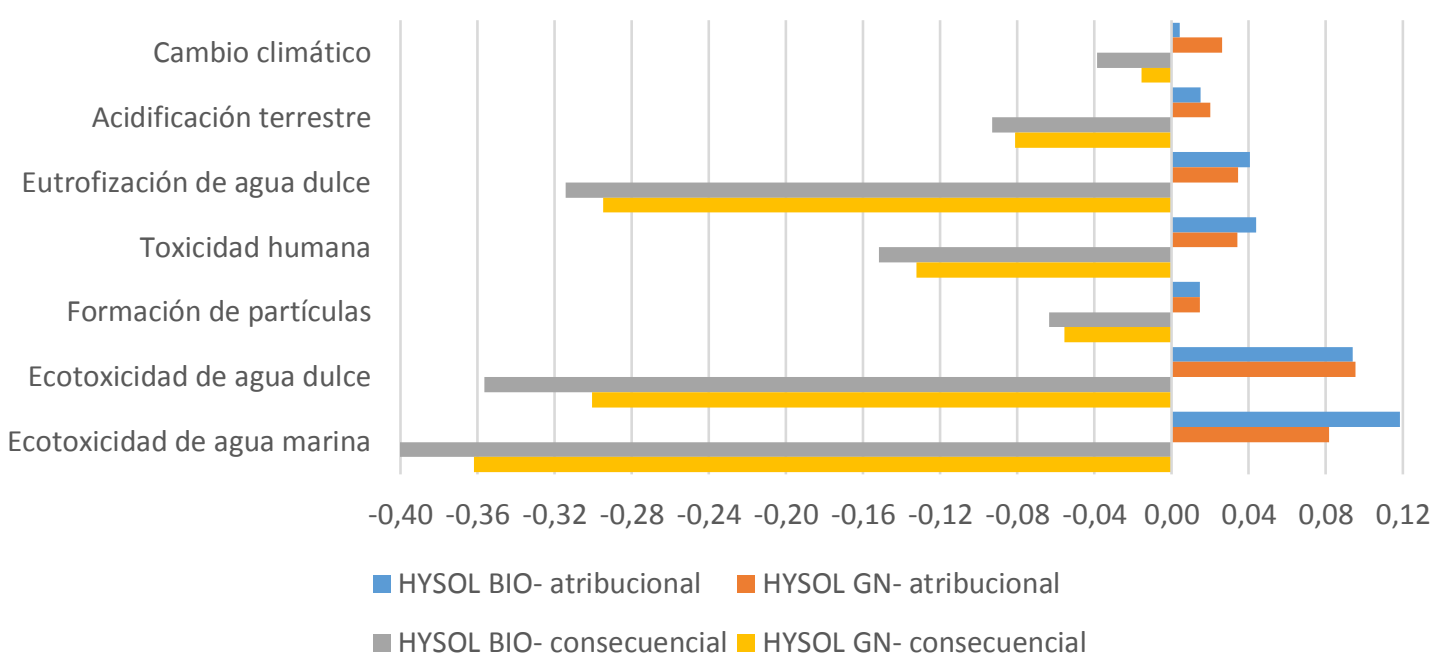

Figura 36 Comparación del perfil normalizado de punto medio de la planta HYSOL BIO y el escenario alternativo (HYSOL con gas natural) bajo los enfoques atribucional y consecuencial

Los resultados evidencian un deterioro significativo en la categoría de cambio climático cuando la planta opera con gas natural, tanto en el enfoque atribucional como el consecuencial. El resultado atribucional de cambio climático para el escenario HYSOL GN es seis veces mayor que en la planta HYSOL BIO. Esta diferencia se debe principalmente a las emisiones producidas durante la combustión de gas natural (que presenta el 73 \% de los impactos del ciclo de vida en la categoría de cambio climático) en comparación con las emisiones de biometano producidas en la planta HYSOL BIO, ya que la naturaleza de las segundas es biogénica y no contribuye a los impactos de cambio climático. La planta HYSOL GN también presenta peor resultado atribucional para las categorías de acidificación (35 \% peor), formación de partículas (1 \% peor) y ecotoxicidad de agua dulce ( $2 \%$ peor) que la planta HYSOL BIO, aunque si consideramos el margen de error obtenido en el análisis de incertidumbre para estas categorías ( $C V=4 \%, 4 \%$ y 15 \% respectivamente) las diferencias sólo son significativas para la categoría de acidificación.

Cabe señalar que los impactos ambientales en la eutrofización de agua dulce, la toxicidad humana $y$, especialmente, la eco-toxicidad de agua marina en el escenario HYSOL GN son menores que en la planta HYSOL BIO (17\%, 29 \% y $45 \%$ menores). Esto es debido a la mayor toxicidad y potencial de eutrofización del ciclo de vida del biometano en comparación con el ciclo de vida de gas natural. Este mayor impacto se asocia con el proceso de depuración del biometano, las actividades de transporte durante la gestión de residuos de lodos y los materiales empleados en la construcción de la planta de biogás. Cabe destacar que la incertidumbre asociada a la categoría de toxicidad humana es muy alta ( $C V=140 \%)$ por lo que los resultados obtenidos en esta categoría no son lo suficientemente precisos como para resultar relevantes en la toma de decisiones. 
Cuando se comparan los resultados de cambio climático de la planta HYSOL BIO obtenidos bajo un enfoque consecuencial con los obtenidos bajo un enfoque atribucional, se observa que los beneficios son nueve veces mayores. Esto es debido a que el mix de tecnologías marginales presenta 9,6 veces más emisiones de cambio climático que la tecnología HYSOL BIO. Los resultados consecuenciales del escenario HYSOL GN también indican beneficios, aunque en menor grado.

Los resultados de CED indican que la energía primaria consumida durante el ciclo de vida de la planta HYSOL GN es casi cuatro veces mayor que el de la planta HYSOL BIO. Además, el CED obtenido para la planta HYSOL GN excede en $1.308 \mathrm{MJ}$ la electricidad producida durante la vida útil. La diferencia observada entre la planta HYSOL BIO (1.278 MJ/MWh) y la HYSOL GN (4.921 $\mathrm{MJ} / \mathrm{MWh}$ ) es atribuible a las diferencias en la demanda de energía primaria asociadas con los ciclo de vida del biometano y gas natural, ya que la materia prima del primero no se considera como energía primaria (proviene de residuos que no computan como energía primaria en el cálculo del CED). Las variaciones en otras categorías de impacto como la acidificación y el estrés hídrico fueron menos significativas. El menor impacto por estrés hídrico en el escenario HYSOL GN en comparación con la planta HYSOL BIO obedece a cuestiones metodológicas. Esta categoría solo considera el consumo de agua directo asociado a la fase O\&M de la planta HYSOL y a la producción de biometano. Puesto que el gas natural se considera como un proceso aguas arriba, no se contabiliza el consumo de agua que pueda suponer su producción.

La Figura 37 muestra la comparación del perfil ponderado de punto final obtenido para los dos escenarios considerados (planta HYSOL BIO y HYSOL GN) bajo los enfoques atribucional y consecuencial. Los resultados endpoint según el método ReCiPe indican que el escenario HYSOL BIO tiene cuatro veces menos impacto ambiental que el escenario HYSOL GN. El mayor impacto obtenido en algunas categorías midpoint en el escenario HYSOL BIO respecto al escenario HYSOL GN se ve compensado por el mayor impacto en cambio climático y acidificación del segundo. Los resultados indican un beneficio mayor para salud humana en el enfoque consecuencial, y un mayor impacto para agotamiento de recursos en el enfoque atribucional. 
CAPÍTULO 3: Análisis del área ambiental

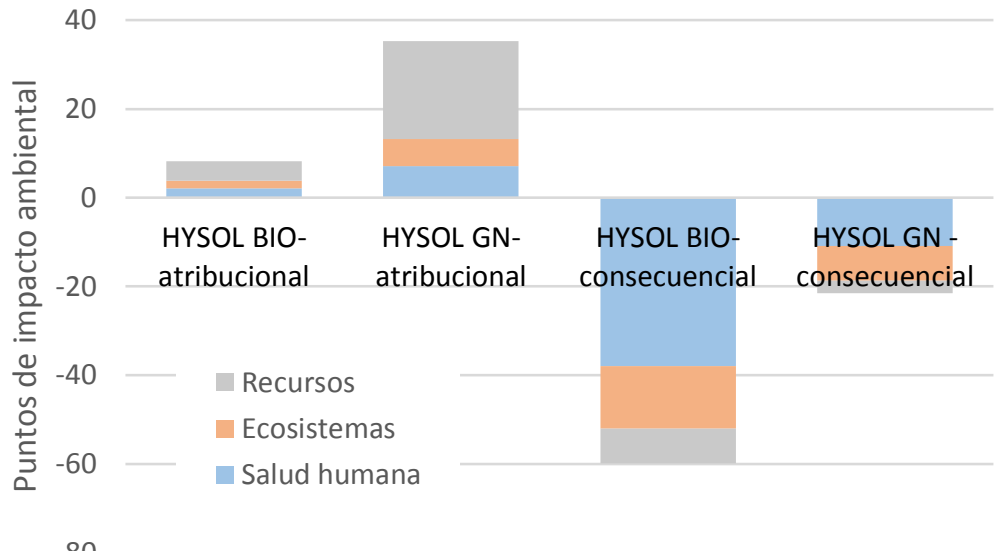

Figura 37 Comparación del perfil ponderado de punto final de la planta HYSOL BIO y el escenario alternativo (HYSOL con gas natural) bajo los enfoques atribucional y consecuencial 


\subsection{ANÁLISIS DE CICLO DE VIDA AMBIENTAL DE DISTINTAS TECNOLOGÍAS TERMOSOLARES}

Con el objetivo de comparar el comportamiento ambiental de la tecnología HYSOL con respecto a la termosolar convencional, en esta sección se analizan las tecnologías termosolares cilindro-parabólica y de torre. Para ambas tecnologías se han planteado varios escenarios adicionales en los que la producción eléctrica se ve incrementada mediante la hibridación con gas natural y biometano. Entre los escenarios analizados de la tecnología cilindro-parabólica se incluye el escenario TERMOSOLAR CCP planteado en el objetivo y alcance del ASCV (Según lo dispuesto en el Capítulo 2de esta tesis) También se ha realizado un análisis de sensibilidad en cuanto al porcentaje de hibridación con gas natural.

\subsubsection{ACV-A de la tecnología termosolar cilindro-parabólica}

\subsubsection{Definición del objetivo y del alcance}

El objetivo principal de este análisis es obtener el impacto ambiental del ciclo de vida la tecnología termosolar en sus posibles variantes. El objetivo final es comparar los resultados de este estudio con la tecnología desarrollada por el proyecto HYSOL, para determinar las mejoras ambientales asociadas con la nueva tecnología. Los datos se van a gestionar y tratar con el software SimaPro 8.

La metodología de evaluación de impacto es la misma que la escogida para la planta HYSOL BIO, ya que los resultados deben ser comparables (según lo dispuesto en la sección 3.2.1.2 de este capítulo). Las fuentes principales de datos y los requisitos de calidad de los mismos son los mismos que en la planta HYSOL BIO (secciones 3.2.1.3, 3.2.1.4, 3.2.1.5)

Este análisis consta de un escenario base y cuatro escenarios alternativos, que servirán para evaluar la tecnología en sus distintas formas de operación. El escenario base consiste en una central termosolar de $50 \mathrm{MW}$ de potencia instalada ubicada en Talarrubias, Badajoz y funcionando en modo sólo solar (sin hibridación con ningún combustible). Las características principales de la central se encuentran descritas en la Tabla 24. 
Tabla 24 Características de la central de la planta termosolar cilindro-parabólica base (50 MW, operación en modo sólo solar).

\begin{tabular}{ll}
\hline Características de la planta & Cantidad \\
\hline Potencia Instalada, MW & 50 \\
Radiación Directa Normal, kWh/m²/año & 2.086 \\
Electricidad bruta generada al año, MWh/año & 186,421 \\
Electricidad neta generada al año, MWh/año & 175,903 \\
Electricidad vertida a red anualmente, MWh/año & 164,876 \\
Eficiencia anual media del campo solar & $43 \%$ \\
Eficiencia térmica del ciclo Rankine & $35 \%$ \\
Eficiencia neta solar-eléctrica & $16,5 \%$ \\
Vida útil de la central, años & 25 \\
No de colectores & 624 \\
Tipo de colectores & SENERTROUGH \\
Apertura, m ${ }^{2}$ & 510.120 \\
Área ocupada por la central, ha & 200 \\
Horas al año en plena carga, h/año & 3.298 \\
Fracción solar (electricidad generada mediante energía & $100 \%$ \\
solar) & \\
Capacidad de almacenamiento, horas & 7,5 \\
Consumo de gas natural durante la fase O\&M, MJ/año & $6,80 \times 10^{6}$ \\
\hline
\end{tabular}

En el siguiente diagrama de flujo (Figura 38), se muestra el árbol de procesos simplificado del ciclo de vida de la central, junto con sus entradas principales. En él están contempladas las fases de Extracción de materias primas y Fabricación de materiales/elementos (E\&F), Construcción de la planta (C), Operación y Mantenimiento (O\&M), Desmantelamiento y Gestión de los residuos (D\&G).

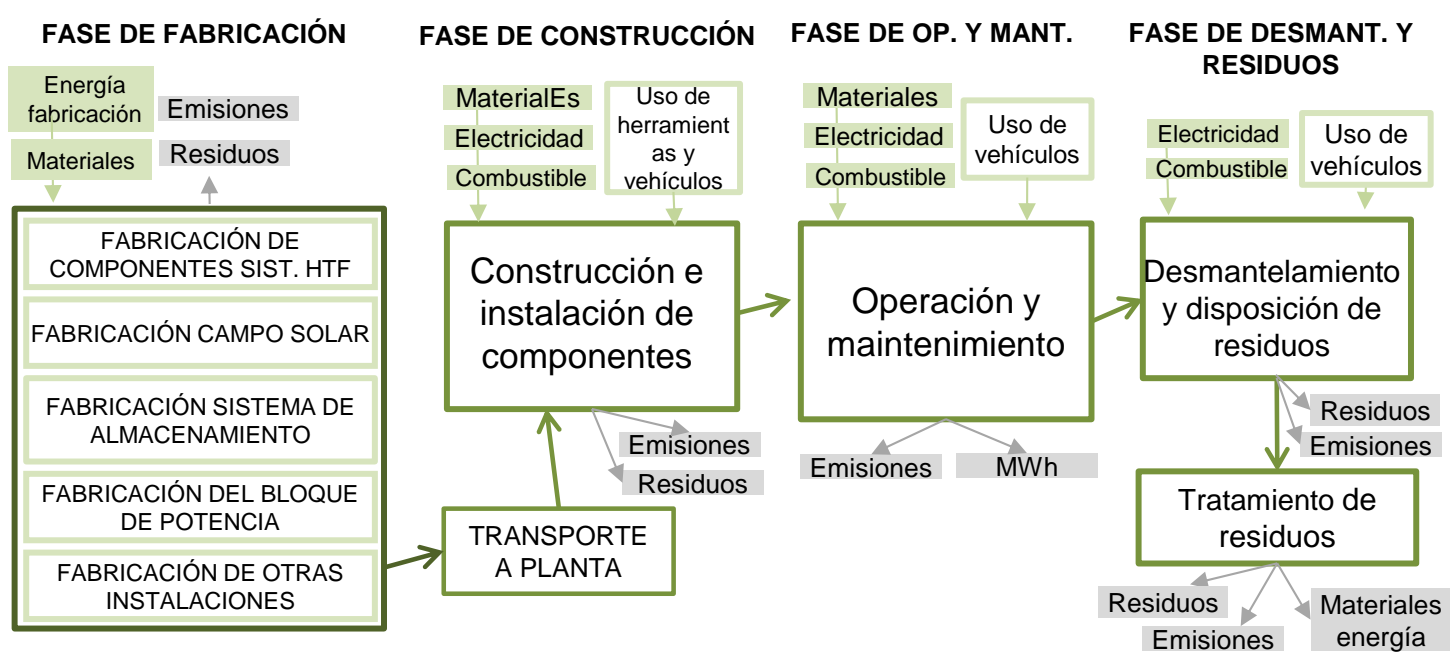

Figura 38 Árbol de procesos principales del ciclo de vida de la planta termosolar cilindro-parabólica 
Al ser una instalación cuya principal fuente de energía es el sol, la mayor parte de materiales y recursos minerales consumidos se concentran en la primera fase (adquisición y fabricación).

Esta primera fase se ha dividido en cinco bloques, cada uno dedicado a la fabricación de los componentes de las principales partes de la instalación. Los elementos principales de cada bloque o sistema se detallan a continuación:

- Circuito HTF (del inglés, Heat Transfer Fluid), con todos los elementos necesarios para que el fluido de transmisión térmica circule por la planta. Esto incluye tuberías, bombas de circulación, el sistema de producción de nitrógeno, los tanques correspondientes y el aceite térmico.

- Campo solar, compuesto por los colectores solares (espejos y estructura), el sistema de seguimiento solar, válvulas y el camión de limpieza de colectores.

- Sistema de almacenamiento térmico, contiene el conjunto de tuberías, bombas, intercambiadores de calor entre aceite y sales, tanques, y las sales de nitrato.

- Bloque de potencia, con los componentes típicos de un ciclo de vapor Rankine (caldera auxiliar, calentadores, precalentadores, turbina de vapor y generador, desgasificador, condensador, torres de refrigeración y bombas de circulación.)

- Instalaciones, que incluye carreteras, edificios, naves auxiliares, y el sistema de tratamiento de aguas.

Cada bloque contemplará los impactos de fabricación de sus componentes. Esto inlcuye la fabricación de sus materiales e impactos derivados de la extracción de la materia prima, el transporte y procesado de la misma. También están incluidos en esta fase los impactos del transporte de los componentes a la planta termosolar.

La fase de construcción contempla los impactos derivados del uso de herramientas y maquinaria de construcción, incluyendo los consumibles utilizados. Además, también considera la obra civil de la construcción de la central, que incluye estructuras metálicas de cada sistema y cimientos.

La fase de operación y mantenimiento incluye la electricidad y combustible consumidos durante dicha fase, contemplando una vida útil de 25 años. También se incluye el consumo de agua, materiales y componentes de repuesto y su transporte a planta. Quedan fuera del estudio los impactos de posibles accidentes o fugas ocasionados durante la fase de operación. 
En el desmantelamiento de la planta se consideran los materiales y combustibles utilizados en la maquinaria de demolición, mientras que en la gestión de residuos se plantea el mismo escenario de reciclaje que la planta HYSOL.

Los límites de corte del sistema se harán en función de la masa y energía, considerando principalmente aquellos procesos del ciclo de vida que supongan más de un 0,5 \% de la masa y energía primaria total.

\section{- Escenarios de análisis alternativos}

En total hay cuatro escenarios alternativos al caso base. El primer escenario alternativo es una central con las mismas características técnicas que el caso base, pero utilizando refrigeración en seco para el ciclo Rankine. La planta principal utiliza torres de refrigeración en húmedo para disminuir la temperatura del vapor tras su paso por la turbina. Sin embargo, esto supone un alto consumo de agua que puede suponer una desventaja para el desarrollo de esta tecnología, ya que los lugares del mundo con mayor radiación directa suelen presentar escasez de agua. Por lo tanto, la refrigeración en seco permite implantar la tecnología donde el agua es un recurso escaso.

Los otros tres escenarios contemplados se basan en la central descrita en el caso base, pero considerando una operación híbrida en el que se utilizan combustibles auxiliares para aumentar la generación de electricidad. Los tres escenarios asumen que el $15 \%$ de la electricidad bruta generada se obtiene mediante la energía primaria de tres combustibles distintos: gas natural, biometano y biomasa sólida. El aporte de energía adicional se lleva a cabo en calderas auxiliares donde se queman los combustibles correspondientes elevando la temperatura del HTF. A continuación, se describen las principales características de cada escenario.

\section{A. Refrigeración en seco}

Este escenario plantea el uso de aerocondensadores como método de refrigeración del ciclo termodinámico en lugar de las torres evaporativas de agua fría. Las segundas son más utilizadas por su eficiencia y menor precio, sin embargo, suponen un consumo alto de agua ya que es el fluido que absorbe el calor de condensación. Los aerocondensadores, también llamados refrigeración en seco, favorecen que el vapor de agua tras su paso por la turbina de vapor transfiera su calor de condensación al aire ambiental, por lo que no precisan de consumo de agua adicional. Este cambio afecta a la producción de electricidad (ya que disminuye la eficiencia de la conversión térmica-eléctrica) y al consumo de agua, así como a algunos componentes necesarios para el bloque de potencia de la central. 


\section{B. Escenario híbrido con gas natural: TERMOSOLAR CCP}

Algunas centrales en España utilizan un combustible auxiliar, generalmente gas natural, para aumentar su producción durante nubes transitorias y por la noche. De esta forma se consigue una mejor gestión de la producción eléctrica en función de la demanda. El porcentaje de hibridación habitual es un $15 \%$ (producción que se adiciona a la que se produciría en un modo de operación sólo solar), debido a regulaciones de retribución anteriores en las que se permitía un máximo de $15 \%$ de aporte de gas natural. Este escenario coincide con lo que se ha definido como TERMOSOLAR CCP en la sección de objetivo y alcance del ASCV de esta tesis.

\section{Escenario híbrido con biometano}

Mediante este escenario se plantea estudiar la hibridación de la central bajo estudio con el mismo combustible que se asume para la planta HYSOL, para así comparar dos centrales $100 \%$ renovables.

Las instalaciones de biogás de tamaño medio suelen producen del orden de 10.000-100.000 $\mathrm{Nm}^{3} /$ año, volumen que resultaría insuficiente para alimentar la planta termosolar en modo híbrido. Las grandes instalaciones centralizadas generalmente tienen una capacidad de generación de biogás de entre 1 y $5 \cdot 10^{6} \mathrm{Nm}^{3} /$ año, aunque algunas plantas del norte de Europa superan este valor (AEBIOM 2009). Esto sugiere que una planta termosolar como la investigada en este trabajo (50 MWe) operando en modo híbrido (15\% de la electricidad de salida de combustibles auxiliares) sólo podría satisfacer su demanda de energía auxiliar mediante la asociación con una planta centralizada a gran escala. Sin embargo, es poco probable que se cumplan los mismos los requisitos para la generación de biogás a gran escala y de irradiación solar en la misma ubicación geográfica. Por lo tanto, este estudio asume que el biogás es depurado hasta el grado de biometano e inyectado en la red de gas natural.

Se supone que el consumo auxiliar de combustible necesario para operaciones de mantenimiento y para la puesta en marcha de las sales térmicas (primera fundición) se satisface también con biometano.

\section{Escenario híbrido con biomasa sólida}

Este escenario plantea un $15 \%$ de producción de electricidad mediante astillas de un cultivo energético (chopo), como combustible renovable alternativo al biometano. El escenario contempla una eficiencia menor de la caldera $(90 \%)$ y un contenido energético de la biomasa igual a $18,2 \mathrm{MJ} / \mathrm{kg}$ en base seca. 
El cultivo de plantas forestales de rotación corta como el chopo se están investigando como un medio para suministrar grandes cantidades de biomasa lignocelulósica de alta calidad de una manera controlada, sostenible y rentable (Halford and Karp 2011). En particular, la producción de chopo está atrayendo interés científico y comercial en muchas áreas del mundo, incluyendo la cuenca del Mediterráneo (Cañellas et al. 2012, Sixto et al. 2010), el norte de Europa (Nielsen et al. 2014) y Norte América (Elferjani et al. 2014). Esta especie es conocida por su fuerte resistencia a las heladas, su capacidad para volver a brotar de su tocón y su tasa de crecimiento rápido cuando se cultiva bajo condiciones climáticas y suelo adecuados. A pesar de sus requerimientos de agua, la producción industrial del chopo está particularmente bien establecida en el sur y norte de España, principalmente para la producción de madera (Tolosana et al. 2011). Las plantaciones de chopo convencionales se administran en períodos de rotación que abarcan generalmente los 10-15 años, con densidades de árboles típicamente entre 350 y 700 árboles por hectárea, y el retiro del tocón al final de cada rotación (Cañellas et al. 2012, Pérez-Cruzado et al. 2014). Se han planteado densidades más altas ( $>15.000$ árboles/ha) y ciclos de rotación más rápidos para aumentar el rendimiento de biomasa a valores superiores a 35 $t_{M S} /$ ha.yr (Testa et al. 2014). Publicaciones recientes indican que el cultivo de chopo tendría el potencial para suministrar hasta un 1,0 \% de la demanda de energía de España en el año 2020 (Pérez-Cruzado et al. 2014).

Este escenario se basa en una parcela de 2,0 ha ubicada en el valle del Genil (Granada, España) ( $\left.37^{\circ} 12^{\prime} 13,72^{\prime \prime}, 3^{\circ} 42^{\prime} 46,30^{\prime \prime}\right)$ plantada con el clon Populus x Canadensis AF2 a una densidad de 13333 árboles/ha. La parcela se estableció en 2009 y se gestiona mediante cuatro rotaciones de 3 años consecutivos, seguidas por el retiro de los tocones a finales del año 12. Los datos experimentales sólo estaban disponibles para la primera rotación, por lo que los datos para rotaciones posteriores se han estimado según información publicada en la literatura. El suelo se clasifica como limo arcillosa, la parcela se encuentra a una altitud de $602 \mathrm{~m}$, la precipitación media (2009-2011) es de 479 mm y la temperatura media (2009-2011) es de $15,7^{\circ} \mathrm{C}$. El rendimiento de producción medio anual es de 17,1 $\mathrm{t}_{\mathrm{MS}} /$ haxyr. Información adicional sobre el cultivo ha sido publicada en la revista Journal of Cleaner Production, y puede encontrarse en (2015). En la sección de inventario de este análisis (Sección 3.3.1.2) se detallan las características y asunciones relacionadas con el ciclo de vida de las astillas de chopo.

Las astillas son transportadas desde la plantación hasta la planta termosolar, a donde llegan con un contenido de humedad igual al $25 \%$ en peso. La distancia entre la parcela de cultivo y la ubicación de la planta HYSOL es $300 \mathrm{~km}$. Esta distancia resulta demasiado elevada ya que el cultivo planteado no se diseñó con el objetivo de proveer de biomasa a la planta HYSOL, por lo 
CAPÍTULO 3: Análisis del área ambiental

que para este escenario se ha planteado un análisis de sensibilidad en relación a la distancia de transporte de biomasa (de 5 a $300 \mathrm{~km}$ ).

La Tabla 25 reúne las características principales de producción de electricidad y consumo de combustible para cada escenario.

Tabla 25 Principales características que difieren en los distintos escenarios analizados

\begin{tabular}{|c|c|c|c|c|c|c|}
\hline & & $\begin{array}{l}\text { Base, } \\
\text { Sólo solar }\end{array}$ & $\begin{array}{c}\text { Refrigeración } \\
\text { en seco, sólo } \\
\text { solar }\end{array}$ & $\begin{array}{c}\text { Gas Natural } \\
15 \%\end{array}$ & $\begin{array}{c}\text { Biometano } \\
15 \%\end{array}$ & $\begin{array}{c}\text { Biomasa } \\
\text { sólida } 15 \%\end{array}$ \\
\hline \multirow{2}{*}{$\begin{array}{l}\text { Energía primaria del } \\
\text { combustible auxiliar } \\
\text { (MJ/yr) }\end{array}$} & Para operación & 0 & 0 & $3,37 \mathrm{E}+08$ & $3,37 \mathrm{E}+08$ & $3,56 E+08$ \\
\hline & $\begin{array}{l}\text { Para } \\
\text { mantenimiento }\end{array}$ & $6,80 E+06$ & $6,80 \mathrm{E}+06$ & $6,80 \mathrm{E}+06$ & $6,80 \mathrm{E}+06$ & $7,18 \mathrm{E}+06$ \\
\hline \multicolumn{2}{|c|}{ Volumen combustible $\left(\mathrm{Nm}^{3} / \mathrm{yr}\right)$} & $1,74 \mathrm{E}+05$ & $1,74 \mathrm{E}+05$ & $8,81 \mathrm{E}+06$ & & \\
\hline \multirow{2}{*}{ Número de calderas } & 10 MWth & 1 & 1 & 0 & 0 & 0 \\
\hline & 20 MWth & 0 & 0 & 2 & 2 & 2 \\
\hline \multicolumn{2}{|c|}{ Horas equivalentes a plena carga (hr) } & 3.298 & 3.067 & 3.298 & 3.973 & 3.973 \\
\hline \multicolumn{2}{|c|}{ Electricidad bruta (MWh/yr) } & 186.421 & 177.127 & 186.421 & 219.319 & 219.319 \\
\hline \multicolumn{2}{|c|}{ Electricidad neta (MWh/yr) } & 175.904 & 163.604 & 175.904 & 206.946 & 206.946 \\
\hline \multicolumn{2}{|c|}{ Electricidad vendida (MWh/yr) } & 164.876 & 153.347 & 164.876 & 198.668 & 198.668 \\
\hline \multicolumn{2}{|c|}{$\begin{array}{l}\text { Consumo directo de agua en planta, } \\
\mathrm{m}^{3} / \mathrm{yr}\end{array}$} & 945.527 & 38.900 & 1.112 .385 & 1.112 .385 & 1.112 .385 \\
\hline
\end{tabular}

E. Análisis de sensibilidad

Debido a la gran influencia de la hibridación con gas natural en los impactos potenciales del ciclo de vida de la plantas termosolares, se ha llevado a cabo un análisis de sensibilidad variando el porcentaje de hibridación (porcentaje de electricidad producida de origen fósil). Para ello, se ha simulado la planta variando el porcentaje de contribución del gas natural a la producción de electricidad desde el 0 \% (sólo solar) hasta el $55 \%$. En la Tabla 26 se muestran los datos de consumo de gas natural y producción eléctrica para los distintos porcentajes de hibridación propuestos. 
Tabla 26 Consumo de gas natural y producción de electricidad para distintos porcentajes de hibridación de la planta TERMOSOLAR CCP

\begin{tabular}{|c|c|c|c|c|c|c|c|}
\hline & $0 \%$ & $5 \%$ & $15 \%$ & $25 \%$ & $35 \%$ & $45 \%$ & $55 \%$ \\
\hline Gas natural (MJ) & 0 & $2,51 E+09$ & $8,42 E+09$ & $1,59 E+10$ & $2,57 E+10$ & $3,91 \mathrm{E}+10$ & $5,83 E+10$ \\
\hline $\begin{array}{l}\text { Ebruta gas natural } \\
\text { (MWh) }\end{array}$ & 0 & $2,45 E+05$ & $8,22 \mathrm{E}+05$ & $1,55 \mathrm{E}+06$ & $2,51 E+06$ & $3,81 E+06$ & $5,70 E+06$ \\
\hline Ebruta (MWh/año) & $1,86 \mathrm{E}+05$ & $1,96 \mathrm{E}+05$ & $2,19 E+05$ & $2,49 E+05$ & $2,87 E+05$ & $3,39 E+05$ & $4,14 \mathrm{E}+05$ \\
\hline Eneta (MWh/año) & $1,76 \mathrm{E}+05$ & $1,85 E+05$ & $2,07 E+05$ & $2,35 E+05$ & $2,71 E+05$ & $3,20 E+05$ & $3,91 \mathrm{E}+05$ \\
\hline $\begin{array}{l}\text { Evendida } \\
\text { (MWh/año) }\end{array}$ & $1,65 \mathrm{E}+05$ & $1,74 \mathrm{E}+05$ & $1,95 \mathrm{E}+05$ & $2,21 E+05$ & $2,56 \mathrm{E}+05$ & $3,03 E+05$ & $3,71 E+05$ \\
\hline $\begin{array}{l}\text { Horas equivalentes a } \\
\text { plenta carga }\end{array}$ & 3.298 & 3.555 & 3.973 & 4.503 & 5.116 & 6.061 & 7.425 \\
\hline
\end{tabular}

\subsubsection{Análisis de inventario}

Los datos han sido recopilados según la información proporcionada por Cobra t\&i e IDie, las empresas desarrolladoras de plantas termosolares del consorcio HYSOL. A continuación se describen las decisiones tomadas y particularidades del inventario para esta tecnología. Todas las tablas de inventario con información de componentes, cantidades, datasets asociadas e incertidumbre se encuentran en el Anexo I.

\subsection{Fase de extracción de materias primas y fabricación de componentes}

La información de inventario relativa a los componentes de la central se ha organizado en los siguientes subsistemas: campo solar, circuito HTF, sistema de almacenamiento, bloque de potencia, y otras instalaciones.

Algunos procesos de la base de datos ecoinvent se han modificado para reflejar de una forma más precisa el consumo energético del país de origen. Como la mayoría de componentes de la planta se fabrican en España, se ha sustituido el mix eléctrico original del dataset (por lo general, el europeo) por el mix español para el año 2013, manteniendo la misma cantidad de consumo eléctrico.

También se ha sustituido el consumo de gas natural (cuando el proceso requería su consumo) para el mix español del año 2012

Por último, se ha modificado el origen del consumo de agua, adaptándolo al origen español. Estos datasets modificados han sido identificados con un asterisco $\left({ }^{*}\right)$ en las tablas de inventario (Anexo I). 
CAPÍTULO 3: Análisis del área ambiental

\section{- Circuito HTF}

Los procesos que han requerido la creación de nuevos datasets (respecto a los utilizados en la planta HYSOL BIO) han sido los siguientes:

\section{El aceite HTF}

Como fluido de transmisión de calor se utiliza el aceite comercial Therminol, fabricado y comercializado actualmente por la compañía EASTMAN para su uso en plantas termosolares. La planta de producción más cercana a España está en Bélgica.

El Therminol utilizado está compuesto por una mezcla de óxido de difenilo $(73,5 \%$ y bifenilo (26,5\%). Actualmente no existen bases de datos específicas para estos compuestos, por lo que se ha decidido utilizar otras bases de datos por aproximación.

Para conocer el método de fabricación del bifenilo, se ha utilizado el informe "Chemical market Input/Output analysis of selected chemical substances to assess sources of environmental contamination: TASK II. Biphenyl and Diphenyl Oxide" de la U.S. Environmental Protection Agency (1977). Según dicho informe, el bifenilo se puede obtener como un subproducto de la producción de benceno, mediante la hidrodesalquilación térmica del tolueno. En la base de datos de ELCD hay una dataset "Benzene, prod. mix, liquid EU-27 S" que puede representar esta producción, y que se ha escogido para la aproximación del bifenilo. Mediante este método, el rendimiento de producción del benceno es de un 95 \% en masa con relación a la del tolueno. La producción del bifenilo es un 1 \% en masa con relación a la del tolueno. Por lo tanto, para producir $1 \mathrm{~kg}$ de bifenilo se necesita producir $95 \mathrm{~kg}$ de benceno.

Para incluir estas relaciones en la dataset, se ha asignado al difenilo el 1,04 \% de los impactos de la producción del benceno. De tal forma que la cantidad del dataset "Benzene, prod. mix, liquid EU-27 S" que se necesita es $95 \mathrm{~kg} \mathrm{x} \mathrm{1,04 \%} \mathrm{(de} \mathrm{asignación} \mathrm{de} \mathrm{impactos),} \mathrm{es} \mathrm{decir,}$ $0,988 \mathrm{~kg}$ de benzeno para $1 \mathrm{~kg}$ de difenilo. La desviación típica geométrica al cuadrado asociada a este proceso, calculada con la matriz pedigree, es de 1,22.

La catálisis del fenol es el método de producción utilizado para el óxido de difenilo en su uso como HTF. En la base de datos de ecoinvent hay una dataset que representa la producción de fenol. Se ha decidido utilizar como aproximación a la producción del difenil éter la cantidad de fenol necesaria para producirlo. Esta decisión significa una subestimación del impacto de producción al no incluir los catalizadores ni el consumo energético, sin embargo, es necesaria ya que no se ha tenido acceso a dicha información. 
Según el informe de la US EPA (Neylan and Howard 1977), se puede asumir un rendimiento de producción de difenil éter de un $90 \%$ en masa respecto a la del fenol. Por lo tanto, la entrada para la producción de $1 \mathrm{~kg}$ de óxido de difenilo es 1,11 kg de "Phenol \{RER\}| production | Alloc Def, U". La desviación típica geométrica al cuadrado asociada al proceso, calculada mediante la matriz pedigree, es 1,22 .

\section{- Campo solar}

El campo solar está compuesto por los colectores cilindro parabólicos y su estructura de soporte, el sistema de tuberías y accesorios, el equipamiento eléctrico y electrónico, y el camión de limpieza de colectores.

A continuación se detallan aspectos del inventario que han requerido modificar datasets de las bases de datos disponibles en SimaPro. El camión de limpieza se asume igual que en la planta HYSOL BIO (Sección 3.2.2.1).

\section{Colectores solares}

El inventario para un colector cilindro parabólico (hay 624 colectores en total) incluye los impactos de fabricación de los materiales de los espejos y del tubo absorbedor, así como el transporte desde Asturias en el caso de los espejos, y Alemania en el caso de los tubos absorbedores.

El dataset asociado a los espejos ha sido modificado para reflejar el método de fabricación utilizado para este producto. Según el informe "MENA Assessment of the Local Manufacturing Potential for Concentrated Solar Power (CSP) Projects" del Banco Mundial (Ernst \&Young and Fraunhofer Institute 2010), los espejos reflectores se fabrican por flotación en estaño. Posteriormente se doblan en un proceso térmico en el que adoptan la forma del molde por gravedad, y tras lavarse con agua desmineralizada, se aplica mediante pistolas pulverizadoras una solución de nitrato de plata y agentes reductores. Por último, se aplica una capa protectora de cobre secada con calentadores radiantes y cubierta con un lacado especial para resistir impactos de regiones desérticas. Según la información disponible en la base de datos de ecoinvent, el dataset que más se ajusta es "Flat glass, coated $\{$ RER $\} \mid$ production | Alloc Def, U". El dataset escogido representa un recubrimiento mixto de cromo y níquel; con el fin de reflejar un proceso de fabricación más aproximado a la realidad del producto, estos materiales se han sustituido por plata, manteniéndose el resto de las entradas constante. 
CAPÍTULO 3: Análisis del área ambiental

- Sistema de almacenamiento térmico

El sistema de almacenamiento térmico está compuesto por las sales térmicas y los tanques de almacenamiento, el sistema de purga de sales, las distintas bombas de circulación, y el intercambiador de calor aceite-sales. Las sales térmicas se han modelado según lo dispuesto en el inventario de la planta HYSOL BIO (Sección 3.2.2.1).

- Sistema del bloque de potencia

El sistema bloque de potencia está compuesto por el tren de generación de vapor, la torre de refrigeración, el bloque turbina (turbina, condensador y generador de electricidad), y otros elementos como tanques auxiliares, tuberías y válvulas.

El bloque turbina proviene de Alemania, mientras que el resto de componentes son de fabricación nacional. El transporte de los elementos desde Alemania se hace por barco, desde Hamburgo a Cádiz y posteriormente por carretera. Para el transporte de los componentes de fabricación nacional se asume una distancia media de $200 \mathrm{~km}$.

La turbina de vapor, generador, condensador y bombas de circulación han sido modeladas de la misma forma que en la planta HYSOL BIO (Sección 3.2.2.1).

- Sistema de instalaciones auxiliares

Contiene edificios de control, naves de montaje, bombas de captación y planta de tratamiento de aguas. El edificio de oficinas se ha modelado de forma similar al de la planta HYSOL BIO (Sección 3.2.2.1).

\subsection{Fase de construcción de la planta}

Incluye materiales de construcción relativos a estructuras, cimientos y carreteras.

\subsection{Fase de operación y mantenimiento}

Incluye los consumos realizados durante la operación y mantenimiento. También incluye una tasa de reemplazo de colectores de $1 \%$. Las emisiones de combustión de gas natural y biometano por MJ de combustible en la caldera auxiliar coinciden con las de la planta HYSOL BIO (Sección 3.2.2.3.).

- Ciclo de vida de las astillas de chopo

Las astillas de chopo fueron modeladas considerando los siguientes procesos: preparación del suelo y acondicionamiento, cultivo, cosechado, transporte a planta y astillado. El sistema de cultivo energético del chopo se describe en detalle en el artículo "Environmental, energy and 
economic analysis of a biomass supply chain based on a poplar short rotation coppice in Spain" de la revista Journal of Cleaner Production (San Miguel et al. 2015).

La preparación del suelo y acondicionamiento incluyen los siguientes procesos: el subsolado, la labranza, la siembra y la fertilización NPK. Se han calculado las emisiones difusas de fosfatos y nitratos en aguas naturales asociadas con el uso de fertilizantes de NPK según Powers (2005) y también las emisiones difusas de $\mathrm{N}_{2} \mathrm{O}, \mathrm{CH}_{4}$ y NH 3 a la atmósfera según las pautas publicadas por el IPCC (IPCC 2006).

La fase de cultivo incluye los siguientes procesos: fertilización con $\mathrm{N}$, el tratamiento con herbicidas, el control mecánico de malezas y el riego. Las emisiones difusas derivadas de la fertilización con $\mathrm{N}$ consideran los mismos supuestos descritos anteriormente. El oxifluorfen (herbicida pre-emergencia) se aplica el primer año de cada rotación. El glifosato (herbicida postemergencia) se aplica en los años 2 y 3 de la primera rotación. Las emisiones difusas (Tabla 27) se han calculado usando la herramienta de PestLCl 2.0 (Dijkman et al. 2012).

Tabla 27 Emisiones difusas de los herbicidas, calculadas mediante la herramienta PestLCI 2.0

\begin{tabular}{lll} 
Compartimento & Glifosato & Oxifluorfen \\
\hline Aire (baja población) & $1,6 \mathrm{E}-05$ & $7,0 \mathrm{E}-07$ \\
\hline Agua (río) & 0 & $4,0 \mathrm{E}-07$ \\
\hline Aguas subterráneas & $1,5 \mathrm{E}-03$ & $1,3 \mathrm{E}-05$
\end{tabular}

* Valores según la fracción de dosis aplicada $(\mathrm{kg} / \mathrm{ha} / \mathrm{kg} / \mathrm{ha})$

El riego se realiza mediante inundación, asumiendo un consumo de agua anual de 2,767 $\mathrm{m}^{3} /$ ha en la primera rotación y un aumento del $10 \%$ en cada uno de los períodos de rotación posterior. El control de malas hierbas se hace dos veces en la primera rotación y una vez en las otras tres rotaciones, usando un rodillo de trabajo.

La fase de cosechado incluye el recogido de biomasa en pacas al final de cada período de rotación y su entrega a la planta de energía en forma de astillas de madera. Las pacas permanecen en los campos de uno a tres meses donde se reduce el contenido de humedad de la biomasa desde el $50 \%$ en peso al $25 \%$ en peso (base materia húmeda). El transporte a la planta de energía se realiza mediante un camión de $38 \mathrm{t}$ (70 $\mathrm{m}^{3}$ capacidad), donde al llegar las pacas se reducen a astillas de madera.

El inventario detallado se encuentra en el Anexo I. 


\subsection{Fase de desmantelamiento y gestión de residuos}

El inventario del desmantelamiento de la central incluye el consumo energético de la maquinaria de desmantelamiento y el transporte durante el desmantelamiento. Debido a falta de datos ha sido necesario tomar el consumo energético de los inventarios publicados por Burkhardt et al. (2012). El escenario de residuos considerado coincide con el de la planta HYSOL (Tabla 16).

\subsubsection{Evaluación de impacto ambiental}

La Tabla 28 indica los impactos ambientales asociados a la generación de $1 \mathrm{MWh}$ de electricidad de la central termosolar cilindro-parabólica según el escenario base definido en este estudio (operación sólo solar). En la tabla se muestran los resultados de caracterización de las siete categorías de punto medio más relevantes para esta tecnología, así como el resultado del consumo primario de energía (CED) y el estrés hídrico asociado al consumo directo de agua. Los impactos del ciclo de vida de la tecnología estudiada fueron los siguientes: cambio climático 24,1 $\mathrm{kg} \mathrm{CO}$ eq/MWh, acidificación terrestre 127 g SO $\mathrm{S}_{2}$ eq/MWh, eutrofización 6,3 g P eq/MWh, toxicidad humana 9,18 kg 1,4-DB eq/MWh, formación de partículas 58,0 g PM10 eq /MWh ecotoxicidad de agua dulce $390 \mathrm{~g}$ 1, 4-DB eq/MWh, eco-toxicidad marina 393 g 1, 4-DB eq/MWh, CED $383 \mathrm{MJ} / \mathrm{MWh}$ y estrés hídrico $3,70 \mathrm{~m}^{3} / \mathrm{MWh}$.

Tabla 28 Impactos caracterizados en diferentes fases del ciclo de vida de la planta termosolar convencional base (con tecnología cilindro-parabólica y operación en modo sólo solar)

\begin{tabular}{lllllll} 
Categoría de impacto & Ud/MWh & E\&F & C & O\&M & D\&D & TOTAL \\
\hline Cambio climático & $\mathrm{kg} \mathrm{CO}_{2}$ eq & 16,1 & 4,33 & 2,88 & 0,77 & 24,1 \\
\hline Acidificación terrestre & $\mathrm{g} \mathrm{SO}_{2}$ eq & 90,6 & 24,0 & 6,31 & 6,22 & 127 \\
\hline Eutrofización de agua dulce & $\mathrm{g} \mathrm{P} \mathrm{eq}$ & 4,43 & 1,39 & 0,12 & 0,33 & 6,3 \\
\hline Toxicidad humana & $\mathrm{kg} \mathrm{1,4-DB} \mathrm{eq}$ & 6,66 & 1,79 & 0,20 & 0,54 & 9,18 \\
\hline Formación de partículas & $\mathrm{g} \mathrm{PM}$ 10 eq & 43,0 & 13,6 & 2,10 & $-0,76$ & 58,0 \\
\hline Eco-toxicidad de agua dulce & $\mathrm{g}$ 1,4-DB eq & 266 & 66,9 & 9,01 & 47,9 & 390 \\
\hline Eco-toxicidad marina & $\mathrm{g} 1,4-\mathrm{DB}$ eq & 273 & 65,4 & 6,61 & 47,3 & 393 \\
\hline CED & $\mathrm{MJ}$ & 265 & 58,4 & 53,8 & 5,21 & 383 \\
\hline Estrés hídrico & $\mathrm{m}^{3}$ & & & 3,70 & & 3,70 \\
\hline
\end{tabular}

La Figura 39 muestra la contribución relativa de cada fase del ciclo de vida a las distintas categorías de impacto analizadas. Los resultados muestran que el impacto ambiental en la mayoría de las categorías es atribuible principalmente a la fase de E\&F, mientras que la contribución de las otras fases del ciclo de vida es limitada. En particular, el 66,8 \% de las emisiones asociadas con el cambio climático derivan de E\&F, mientras que O\&M contribuye a sólo el 11,9\% del total. El impacto estimado para el ciclo de vida de la planta termosolar en esta 
categoría (24,1 $\mathrm{kg} \mathrm{CO} 2$ eq/MWh) es similar a los publicados por otros autores para este tipo de plantas (Burkhardt et al., 2011 y 2012).

A diferencia de las demás categorías, el estrés hídrico $\left(3,70 \mathrm{~m}^{3} / \mathrm{MWh}\right)$ se ve afectado únicamente por la fase O\&M, ya que sólo considera los consumos directos de agua durante la operación: el agua de refrigeración, el agua del ciclo de vapor y una pequeña cantidad asociada con la limpieza de colectores solares (0,7\%). El consumo de agua indirecta asociado a otras fases del ciclo de vida no se ha considerado, debido a inconsistencias entre la base de datos ecoinvent y el cálculo de impacto hídrico con SimaPro.

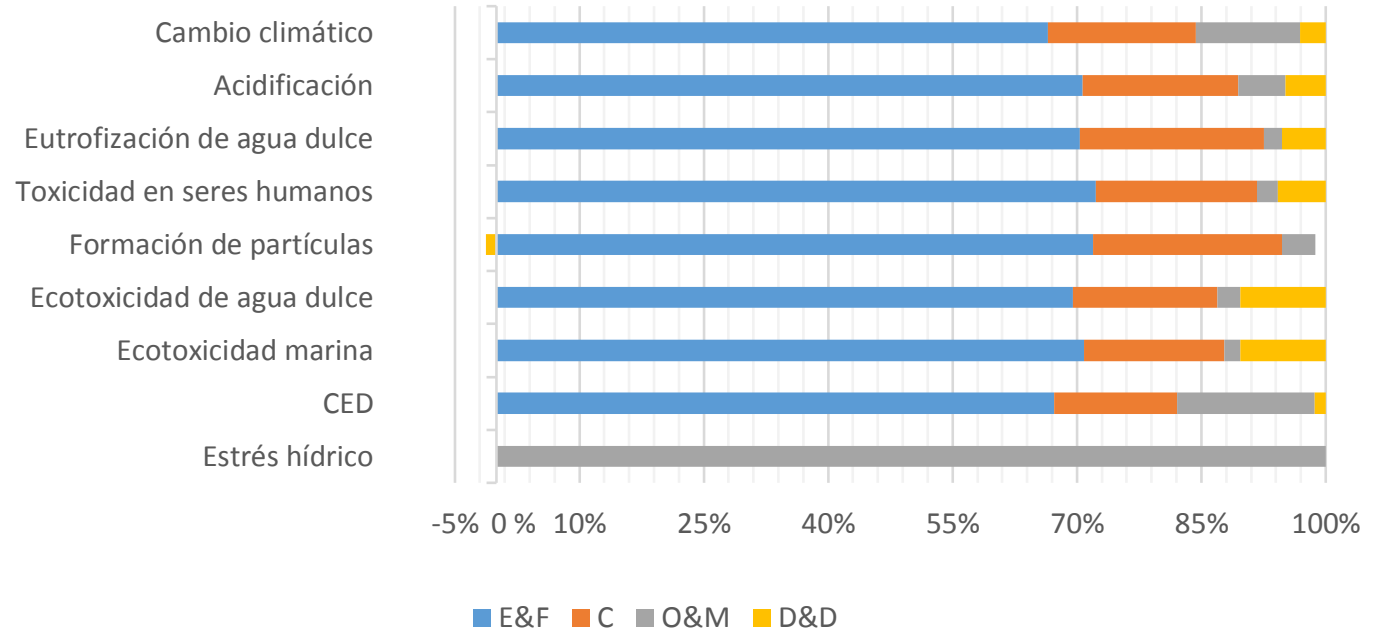

Figura 39 Contribución relativa de cada fase del ciclo de vida a los impactos ambientales caracterizados de la planta termosolar cilindro-parabólica base (con tecnología cilindro-parabólica y operación en modo sólo solar)

La Figura 40 muestra la contribución de cada sistema de componentes al impacto ambiental de la fase E\&F. Según se observa en la figura, los sistemas con mayor impacto son el sistema de almacenamiento y el campo solar, seguidos por el bloque de potencia y el circuito HTF. El impacto del sistema de instalaciones es comparativamente insignificante para todas las categorías. La mayor parte del impacto del sistema de almacenamiento viene determinado por la fabricación de sales fundidas (entre el 42 y el $77 \%$ del impacto del sistema de almacenamiento, dependiendo de la categoría) y los tanques de almacenamiento (entre el 22 y el 58 \%). En el caso del campo solar, el componente que mayores impactos acumula es el colector solar (entre el 29 y $56 \%$ del impacto atribuido al campo solar dependiendo de la categoría), seguido de las tuberías (14 - $24 \%$ ) y la estructura del colector (10 - $23 \%$ ). El equipamiento eléctrico y electrónico del campo solar presenta menor impacto en la mayoría de categorías, pero mayor impacto en la categoría de toxicidad humana y eutrofización de agua dulce. 


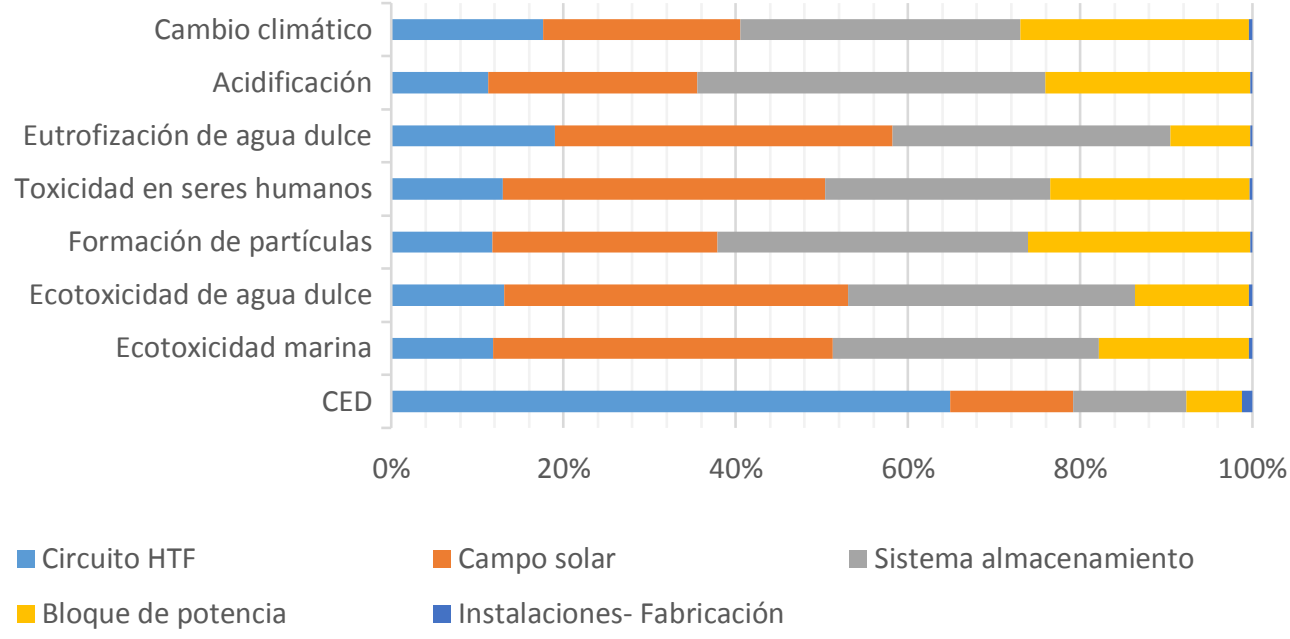

Figura 40 Contribución relativa de cada sistema de la planta termosolar cilindro-parabólica a los impactos ambientales asociados con la fase de E\&F del ciclo de vida

La CED asociada con el ciclo de vida de la planta termosolar convencional a $383 \mathrm{MJ} / \mathrm{MWh}$. El consumo de energía primaria externa (teniendo en cuenta todo el ciclo de vida de la tecnología) representa el $11 \%$ de toda la electricidad vertida a la red. Considerando que el resultado obtenido de CED para las etapas de fabricación y construcción es 2,19 x 1099 MJ, que el obtenido para la operación y mantenimiento es $1,08 \times 10^{7} \mathrm{MJ} / \mathrm{yr}$ y que la electricidad producida es 5,94 × $10^{8} \mathrm{MJ} / \mathrm{yr}$, el TRE de la tecnología HYSOL es 1,65 años o 20 meses (según la ecuación (2)).

Los resultados normalizados mostrados en la Figura 41 indican que la categoría más afectada por el ciclo de vida de la planta bajo estudio (según factores de normalización europeos) es eco-toxicidad marina, seguida de eco-toxicidad de agua dulce, eutrofización y toxicidad humana. El impacto sobre eco-toxicidad marina se asocia principalmente con el uso de acero al carbono en distintos elementos de la planta (que representa el $33 \%$ del impacto en esta categoría), la utilización de cobre en los TES y el bloque de potencia (17\%), el uso de acero de cromo en el campo solar (12 \%) y la producción del HTF (8 \%). El impacto normalizado en otras categorías ambientales como el cambio climático y la acidificación es comparativamente más bajo. 


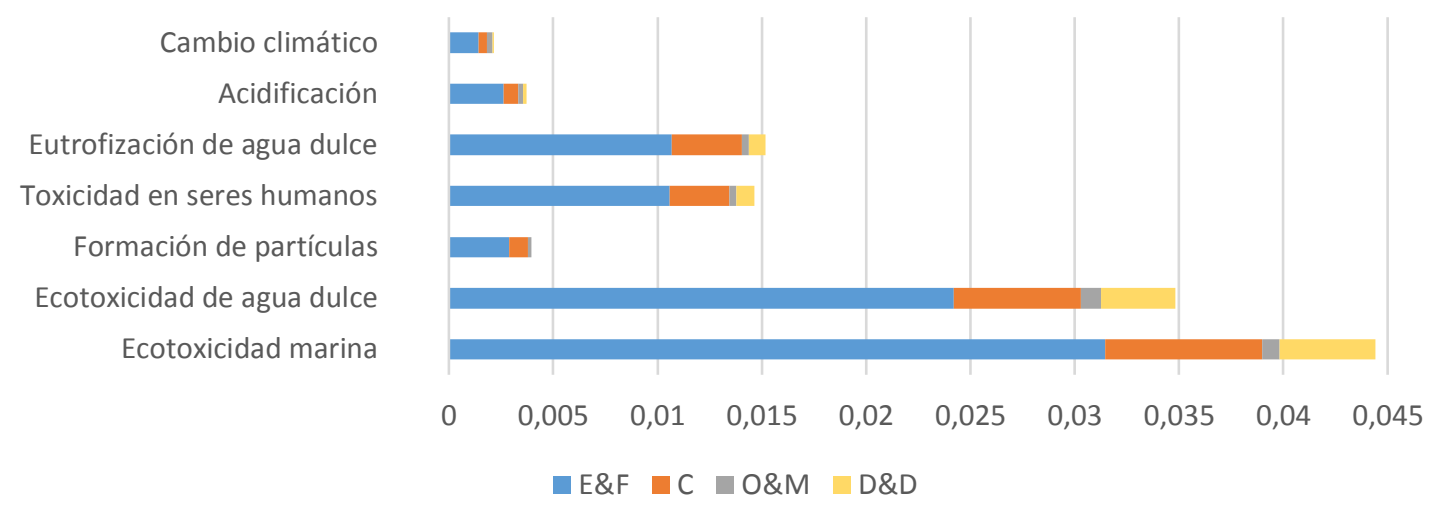

Figura 41 Perfil normalizado del impacto ambiental de la central termosolar cilindro-parabólica operando en modo solo solar (escenario base)

El resultado ponderado de punto final indica que la planta termosolar convencional operando en modo solo solar presenta un impacto ambiental potencial final ponderado de 3,75 $\mathrm{pt} / \mathrm{MWh}$, de los cuales el $47 \%$ corresponde a consumo de recursos, el $22 \%$ a salud humana, y el $31 \%$ a daño en ecosistemas.

\subsubsection{Evaluación de escenarios}

A continuación se muestran los resultados obtenidos para cada escenario alternativo planteado para la planta termosolar convencional con tecnología cilindro-parabólica.

\section{A. Refrigeración en seco}

La Tabla 29 de caracterización y Figura 42 de normalización muestran los impactos potenciales ambientales cuando la planta termosolar cilindro-parabólica utiliza un sistema de refrigeración por aire en vez de un sistema de refrigeración con agua. A pesar de que todas las fases ven aumentados sus impactos respecto a la planta base (refrigeración con agua), los resultados dan un perfil muy similar. La fase E\&F es la que presenta mayores cambios ya que el inventario de ambos sistemas de refrigeración son diferentes. La variación de la fase E\&F de este escenario respecto a la planta base supone un aumento del impacto entre un $8 \%$ (para CED) y un $26 \%$ (para la categoría eco-toxicidad de agua dulce). En cuanto a los impactos totales de ciclo de vida, la variación de este escenario respecto al de la planta base supone un impacto de entre 9 \% (para acidificación) y $18 \%$ (para eco-toxicidad de agua dulce). Esta variación es debida en primer lugar por el cambio de materiales que supone un sistema de refrigeración respecto al otro, y en segundo lugar por la disminución de eficiencia en la producción de electricidad que supone el sistema de refrigeración en seco. La única categoría que presenta mejor resultado es estrés hídrico, que presenta un impacto 13 veces menor, debido al ahorro de agua en el sistema de refrigeración. 
La CED asociada con el ciclo de vida de esta planta es $434 \mathrm{MJ} / \mathrm{MWh}$. El consumo de energía primaria externa (teniendo en cuenta todo el ciclo de vida de la tecnología) representa el $12 \%$ de toda la electricidad vertida a la red. Considerando que el resultado obtenido de CED para las etapas de fabricación y construcción es $1,53 \times 10^{9} \mathrm{MJ}$, que el obtenido para la operación y mantenimiento es $1,12 \times 10^{7} \mathrm{MJ} / \mathrm{yr}$ y que la electricidad producida es $5,52 \times 10^{8} \mathrm{MJ} / \mathrm{yr}$, el TRE de la tecnología cilindro-parabólica con refrigeración con aire es 1,24 años o 15 meses (según la Ecuación (2)).

Tabla 29 Impactos caracterizados en diferentes fases del ciclo de vida de la planta termosolar cilindroparabólica con refrigeración en seco

\begin{tabular}{lllllll} 
Categoría de impacto & Ud/MWh & E\&F & C & O\&M & D\&D & TOTAL \\
\hline Cambio climático & $\mathrm{kg} \mathrm{CO}_{2}$ eq & 18,9 & 4,65 & 3,23 & $-0,37$ & 26,5 \\
\hline Acidificación terrestre & $\mathrm{g} \mathrm{SO}_{2}$ eq & 106,6 & 25,8 & 7,65 & $-1,31$ & 139 \\
\hline Eutrofización de agua dulce & $\mathrm{g} \mathrm{P} \mathrm{eq}$ & 5,56 & 1,50 & 0,19 & 0,01 & 7,25 \\
\hline Toxicidad humana & $\mathrm{kg} \mathrm{1,4-DB} \mathrm{eq}$ & 8,23 & 1,93 & 0,30 & 0,16 & 10,6 \\
\hline Formación de partículas & $\mathrm{g} \mathrm{PM}$ PM eq & 50,9 & 14,7 & 2,56 & $-4,39$ & 63,7 \\
\hline Eco-toxicidad de agua dulce & $\mathrm{g} 1,4-\mathrm{DB}$ eq & 336 & 71,9 & 12,4 & 40,0 & 461 \\
\hline Eco-toxicidad marina & $\mathrm{g} \mathrm{1,4-DB} \mathrm{eq}$ & 342 & 70,3 & 9,80 & 39,4 & 461 \\
\hline CED & $\mathrm{MJ}$ & 285 & 62,8 & 57,9 & 28,1 & 434 \\
\hline Estrés hídrico & $\mathrm{m}^{3}$ & - & - & 0,28 & - & 0,28
\end{tabular}

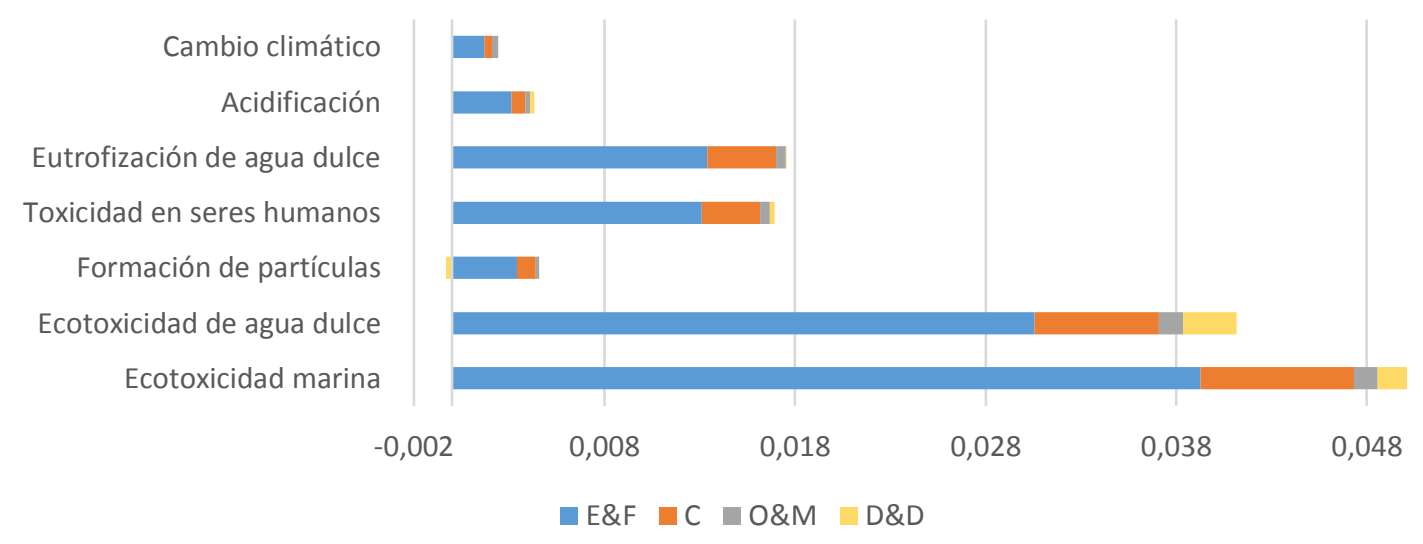

Figura 42 Perfil normalizado del impacto ambiental de la central termosolar cilindro-parabólica con refrigeración en seco

El resultado ponderado de punto final (ReCiPe Endpoint Europe $H / H \vee 1.12$ ) indica que la planta termosolar cilindro-parabólica operando en modo solo solar y refrigeración en seco presenta un impacto ambiental potencial final ponderado de 4,03 pt/MWh, de los cuales el 47 $\%$ corresponde a consumo de recursos, el $22 \%$ a salud humana, y el $31 \%$ a daño en ecosistemas. Cabe destacar que este indicador no considera el consumo de agua ni estrés hídrico. 


\section{B. Escenario híbrido con gas natural (TERMOSOLAR CCP)}

La Tabla 30 y Figura 43 describen el desempeño ambiental caracterizado y normalizado de la generación de $1 \mathrm{MWh}$ de electricidad mediante la tecnología termosolar cilindro-parabólica hibridada con un $15 \%$ de gas natural. Los resultados indican una alta contribución de la fase de O\&M en el impacto ambiental del ciclo de vida, especialmente en las categorías de cambio climático ( $86 \%$ del impacto de la fase de O\&M) y CED ( $88 \%)$. La segunda fase con mayor impacto es E\&F, especialmente en ecotoxicidad marina ( $47 \%$ del impacto de la fase de E\&F), eutrofización del agua dulce (43\%) y toxicidad humana (43\%). Los impactos ambientales de la fase E\&F están principalmente asociados a la producción y fabricación de componentes hechos de acero y cobre.

El resultado obtenido para la categoría de CED indica que la energía primaria consumida durante el ciclo de vida es $2390 \mathrm{MJ} / \mathrm{MWh}$. El consumo de energía primaria (teniendo en cuenta el ciclo de vida del sistema) representa el $66 \%$ de toda la electricidad generada y vertida a la red. Considerando que el resultado obtenido de CED para las etapas de fabricación y construcción es $1,13 \times 10^{9} \mathrm{MJ}$, que el obtenido para la operación y mantenimiento es 5,02 × $10^{8}$ $\mathrm{MJ} / \mathrm{yr}$ y que la electricidad producida es 7,01 × $10^{8} \mathrm{MJ} / \mathrm{yr}$, el TRE de la tecnología cilindroparabólica con un $15 \%$ de hibridación con gas natural es 1,05 años o 13 meses (según la Ecuación (2)).

Tabla 30 Impactos caracterizados en diferentes fases del ciclo de vida de la planta termosolar cilindroparabólica con un $15 \%$ de electricidad producida por gas natural (TERMOSOLAR CCP)

\begin{tabular}{lllllll} 
Categoría de impacto & Ud/MWh & E\&F & C & O\&M & D\&D & TOTAL \\
\hline Cambio climático & $\mathrm{kg} \mathrm{CO}_{2}$ eq & 13,6 & 3,66 & 118 & 0,65 & 136 \\
\hline Acidificación terrestre & $\mathrm{g} \mathrm{SO}_{2}$ eq & 76,7 & 20,3 & 261 & 5,27 & 364 \\
\hline Eutrofización de agua dulce & $\mathrm{g} \mathrm{P} \mathrm{eq}$ & 3,75 & 1,18 & 4,36 & 0,28 & 9,57 \\
\hline Toxicidad humana & $\mathrm{kg} \mathrm{1,4-DB} \mathrm{eq}$ & 5,64 & 1,52 & 6,76 & 0,45 & 14,4 \\
\hline Formación de partículas & $\mathrm{g} \mathrm{PM}_{10}$ eq & 36,4 & 11,6 & 79,8 & $-0,64$ & 127 \\
\hline Eco-toxicidad de agua dulce & $\mathrm{g} 1,4-\mathrm{DB}$ eq & 226 & 56,6 & 337 & 40,6 & 660 \\
\hline Eco-toxicidad marina & $\mathrm{g} 1,4-\mathrm{DB}$ eq & 232 & 55,4 & 200 & 40,0 & 527 \\
\hline CED & $\mathrm{MJ}$ & 225 & 49,4 & 2.579 & 22,1 & 2.875 \\
\hline Estrés hídrico & $\mathrm{m}^{3}$ & - & - & 3,69 & - & 3,69
\end{tabular}




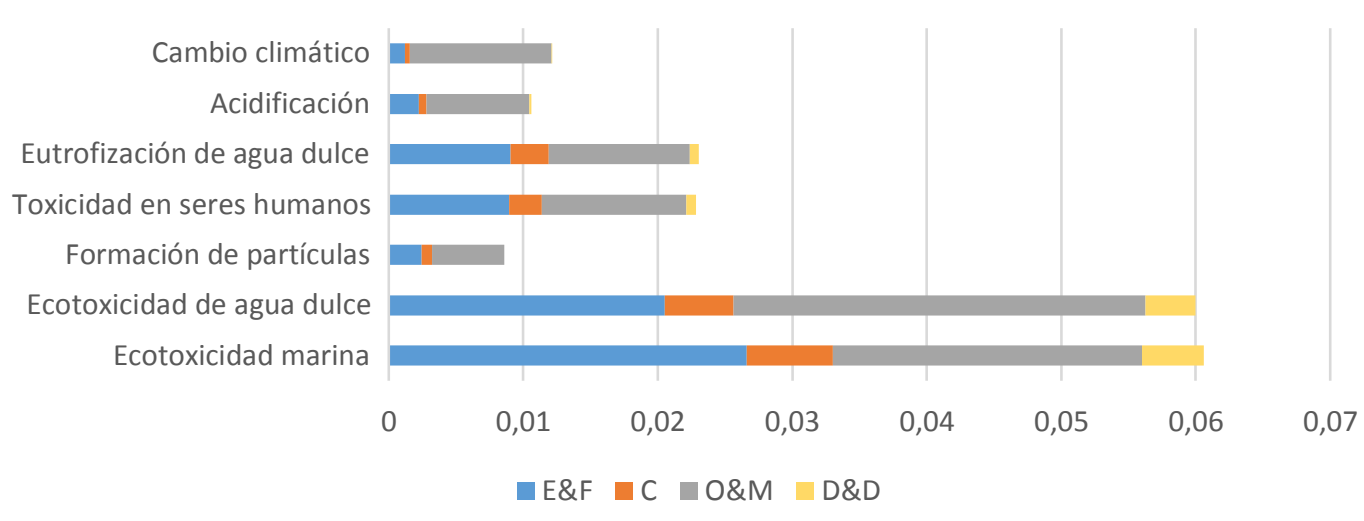

Figura 43 Perfil normalizado del impacto ambiental de la central termosolar cilindro-parabólica con un 15 $\%$ de electricidad producida por gas natural (TERMOSOLAR CCP)

Al comparar los resultados obtenidos en este caso con los obtenidos para la planta termosolar cilindro-parabólica en modo solar, algunos indicadores de categorías muestran un aumento significativo, como los de cambio climático y CED. El alto impacto para la categoría de cambio climático durante la fase de O\&M es atribuible a la combustión de gas natural en la caldera auxiliar (presentando el 64 \% del impacto de ciclo de vida) y a su extracción, producción y transporte (21\%). La combustión de gas natural también contribuye al $12 \%$ de los impactos de acidificación del ciclo de vida, y al 14,8 \% de los de formación de partículas, mientras que la contribución de las emisiones de combustión a otras categorías es insignificante. El ciclo de vida de gas natural (extracción, producción y transporte) contribuye al 34 - 55 \% de las categorías de acidificación, eutrofización y toxicidad, siendo el proceso con mayor impacto en la mayoría de las categorías ambientales.

El resultado ponderado de punto final indica que la planta termosolar cilindro-parabólica operando con un $15 \%$ de gas natural (TERMSOLAR CCP) presenta un impacto final ponderado de 16,7 pt/MWh, de los cuales el $61 \%$ corresponde a consumo de recursos, el $21 \%$ a salud humana, y el $19 \%$ a daño en ecosistemas.

\section{Escenario híbrido con biometano}

La Tabla 31 y Figura 44 describen el desempeño ambiental caracterizado y normalizado de la generación de $1 \mathrm{MWh}$ de electricidad mediante la tecnología termosolar cilindro-parabólica hibridada con biometano (15\%). Los resultados indican una mayor contribución de la fase de O\&M en el impacto ambiental del ciclo de vida, especialmente en las categorías de acidificación (65\%), formación de partículas (62 \%) y toxicidad humana (55\%). La segunda fase con mayor impacto es E\&F, especialmente en CED (66 \%) y cambio climático (41 \%). 
El resultado obtenido para la categoría de CED indica que la energía primaria consumida durante el ciclo de vida de la planta de energía en este escenario es $342 \mathrm{MJ} / \mathrm{MWh}$. El consumo de energía primaria (teniendo en cuenta el ciclo de vida del sistema) representa el 9,5\% de toda la electricidad generada y vertida en la red. Considerando que el resultado obtenido de CED para las etapas de fabricación y construcción es $1,13 \times 10^{9} \mathrm{MJ}$, que el obtenido para la operación y mantenimiento es $8,88 \times 10^{6} \mathrm{MJ} / \mathrm{yr}$ y que la electricidad producida es $7,01 \times 10^{8} \mathrm{MJ} / \mathrm{yr}$, el TRE de la tecnología cilindro-parabólica con un $15 \%$ de hibridación con biometano es 0,72 años o 9 meses (según la Ecuación (2)).

Tabla 31 Impactos caracterizados en diferentes fases del ciclo de vida de la planta termosolar cilindroparabólica con un $15 \%$ de electricidad producida por biometano

\begin{tabular}{lcccccc} 
Categoría de impacto & Ud/MWh & E\&F & C & O\&M & D\&D & TOTAL \\
\hline Cambio climático & $\mathrm{kg} \mathrm{CO}_{2}$ eq & 13,6 & 3,66 & 15,7 & 0,65 & 33,7 \\
\hline Acidificación terrestre & $\mathrm{g} \mathrm{SO}_{2}$ eq & 76,7 & 20,3 & 187 & 5,27 & 290 \\
\hline $\begin{array}{l}\text { Eutrofización de agua } \\
\text { dulce }\end{array}$ & $\mathrm{g} \mathrm{P} \mathrm{eq}$ & 3,75 & 1,18 & 5,40 & 0,28 & 10,6 \\
\hline Toxicidad humana & $\mathrm{kg} \mathrm{1,4-DB} \mathrm{eq}$ & 5,64 & 1,52 & 9,30 & 0,45 & 16,9 \\
\hline Formación de partículas & $\mathrm{g} \mathrm{PM}$ 10 eq & 36,4 & 11,6 & 78,6 & $-0,64$ & 126 \\
\hline $\begin{array}{l}\text { Eco-toxicidad de agua } \\
\text { dulce }\end{array}$ & $\mathrm{g} \mathrm{1,4-DB} \mathrm{eq}$ & 226 & 56,6 & 330 & 40,6 & 653 \\
\hline Eco-toxicidad marina & $\mathrm{g} \mathrm{1,4-DB} \mathrm{eq}$ & 232 & 55,4 & 332 & 40,0 & 659 \\
\hline CED & $\mathrm{MJ}$ & 225 & 49,4 & 45,6 & 22,1 & 342 \\
\hline Estrés hídrico & $\mathrm{m}^{3}$ & - & - & 3,69 & - & 3,69
\end{tabular}

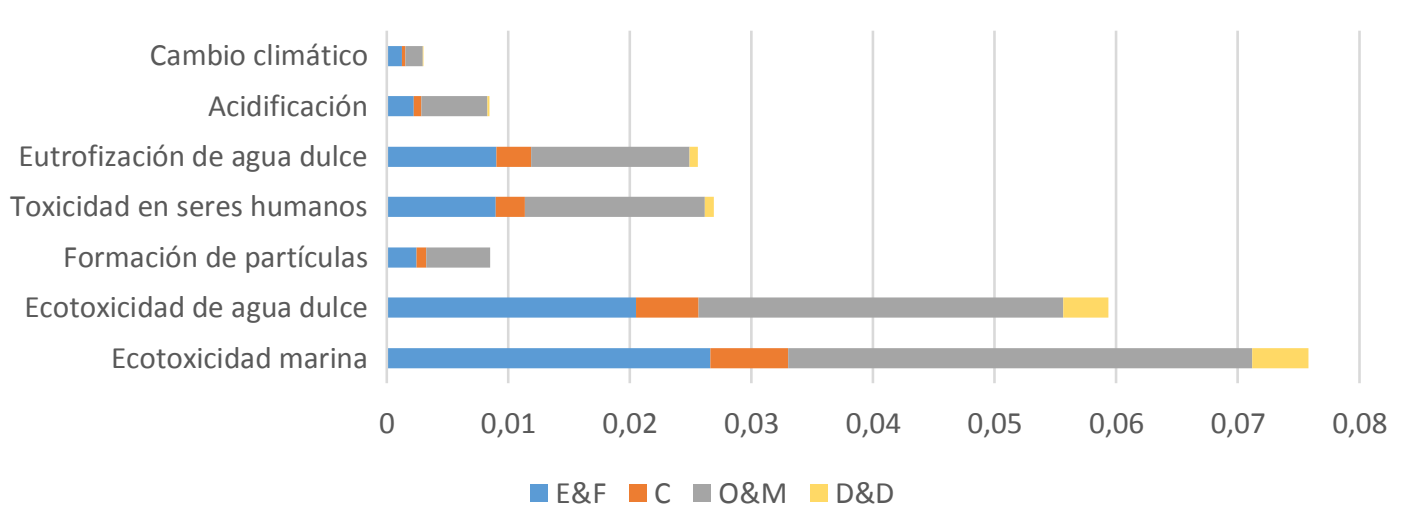

Figura 44 Perfil normalizado del impacto ambiental de la central termosolar cilindro-parabólica con un 15 $\%$ de electricidad producida por biometano

Al comparar los resultados obtenidos en este escenario con los obtenidos para la planta termosolar cilindro-parabólica base, algunos indicadores de categorías muestran un aumento significativo, como los de acidificación y formación de partículas (más del doble de impacto en ambas categorías). El mayor impacto para la categoría de cambio climático durante la fase de O\&M (1,4 veces el impacto de la planta base) es atribuible al ciclo de vida del biometano, al igual 
que el de acidificación y formación de partículas. El ciclo de vida del biometano (extracción, producción y transporte) contribuye al 49-54 \% del impacto del ciclo de vida en las categorías de acidificación, eutrofización y toxicidad, siendo el proceso con mayor impacto en la mayoría de las categorías ambientales. La combustión de biometano contribuye al $14 \%$ de los impactos del ciclo de vida en acidificación y formación de partículas, mientras que la contribución de las emisiones de combustión a otras categorías es insignificante.

El resultado ponderado de punto final (según el método de evaluación ReCiPe Endpoint Europe $H / H$ v 1.12) indica que la planta termosolar cilindro-parabólica operando con un $15 \%$ de biometano presenta un impacto final ponderado de 5,6 pt/MWh, de los cuales el $52 \%$ corresponde a consumo de recursos, el $24 \%$ a salud humana, y el $23 \%$ a daño en ecosistemas.

\section{Escenario híbrido con biomasa}

La Tabla 32 y Figura 45 describen el desempeño ambiental caracterizado y normalizado de la generación de $1 \mathrm{MWh}$ de electricidad mediante la tecnología termosolar cilindro-parabólica hibridada con biomasa sólida proveniente de un cultivo energético (15\% de electricidad generada mediante astillas de chopo). Los resultados indican una mayor contribución de la fase de O\&M al impacto ambiental potencial del ciclo de vida, especialmente en las categorías de formación de partículas (81 \%), acidificación (70\%), y toxicidad humana (64 \%). La segunda fase con mayor impacto es E\&F, especialmente en CED (51 \%) y eco-toxicidad de agua dulce (50 \%).

Tabla 32 Impactos caracterizados en diferentes fases del ciclo de vida de la planta termosolar cilindroparabólica con un $15 \%$ de electricidad producida por biomasa (astillas de chopo)

\begin{tabular}{llccccc} 
Categoría de impacto & Ud/MWh & E\&F & C & O\&M & D\&D & TOTAL \\
\hline Cambio climático & $\mathrm{kg} \mathrm{CO}_{2}$ eq & 13,6 & 3,66 & 11,27 & 0,65 & 29,2 \\
\hline Acidificación terrestre & $\mathrm{g} \mathrm{SO}_{2}$ eq & 76,7 & 20,3 & 239 & 5,27 & 342 \\
\hline Eutrofización de agua dulce & $\mathrm{g} \mathrm{P} \mathrm{eq}$ & 3,75 & 1,18 & 8,35 & 0,28 & 13,6 \\
\hline Toxicidad humana & $\mathrm{kg} \mathrm{1,4-DB} \mathrm{eq}$ & 5,64 & 1,52 & 13,8 & 0,45 & 21,4 \\
\hline Formación de partículas & $\mathrm{g} \mathrm{PM} 10$ eq & 36,4 & 11,6 & 202 & $-0,64$ & 249 \\
\hline Eco-toxicidad de agua dulce & $\mathrm{g} \mathrm{1,4-DB} \mathrm{eq}$ & 226 & 56,6 & 125 & 40,6 & 448 \\
\hline Eco-toxicidad marina & $\mathrm{g} \mathrm{1,4-DB} \mathrm{eq}$ & 232 & 55,4 & 177 & 40,0 & 504 \\
\hline CED & $\mathrm{MJ}$ & 225 & 49,4 & 218 & 22,1 & 514 \\
\hline Estrés hídrico & $\mathrm{m}^{3}$ & - & - & 20,9 & - & 20,9
\end{tabular}

El resultado obtenido para la categoría de CED indica que la energía primaria consumida durante el ciclo de vida de la planta de energía en este escenario es $514 \mathrm{MJ} / \mathrm{MWh}$. El consumo de energía primaria (teniendo en cuenta el ciclo de vida del sistema) representa el $12 \%$ de toda la electricidad generada vertida en la red. Considerando que el resultado obtenido de CED para 
las etapas de fabricación y construcción es $1,13 \times 10^{9} \mathrm{MJ}$, que el obtenido para la operación y mantenimiento es 4,04 × $10^{8} \mathrm{MJ} / \mathrm{yr}$ y que la electricidad producida es $7,01 \times 10^{8} \mathrm{MJ} / \mathrm{yr}$, el TRE de la tecnología cilindro-parabólica con un 15 \% de hibridación con biomasa es 0,96 años o 9 meses (según la Ecuación (2)).

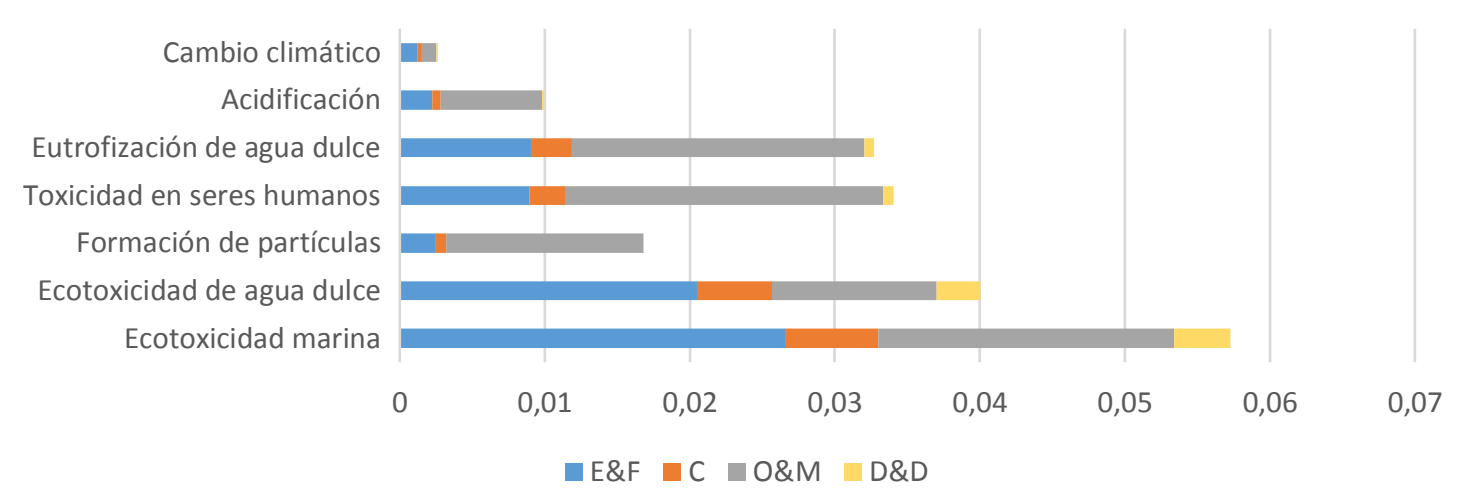

Figura 45 Perfil normalizado del impacto ambiental de la central termosolar cilindro-parabólica con un 15 $\%$ de electricidad producida por biomasa (astillas de chopo)

El ciclo de vida de las astillas de chopo (extracción, producción y transporte) contribuye al 9-32 \% del impacto del ciclo de vida de la planta termosolar cilindro-parabólica en las distintas categorías de impacto, excepto para el estrés hídrico, cuyo impacto supone el $82 \%$. La mayor parte del impacto del ciclo de vida de las astillas de chopo viene dado en primer lugar por el transporte de la biomasa a la planta, seguido por el uso de la cosechadora (Biobaler) y el consumo de electricidad necesario para astillar las pacas.

La combustión de las astillas de chopo contribuye al 71 \% de los impactos del ciclo de vida en formación de partículas, al 50 - 53 \% de las emisiones del ciclo de vida en eutrofización, acidificación y toxicidad humana, al 12 - $17 \%$ de las emisiones de ecotoxicidad y al $6 \%$ de las emisiones de cambio climático.

La categoría de estrés hídrico se ve considerablemente aumentada respecto a los resultados de los otros escenarios considerados. Esto es debido a que el chopo es un cultivo energético que requiere irrigación (9,34 $\mathrm{m}^{3}$ por GJ de biomasa) y cuya parcela se encuentra situada en una zona donde el índice de estrés hídrico es máximo.

El resultado ponderado de punto final (según el método de evaluación ReCiPe Endpoint Europe $\mathrm{H} / \mathrm{H} \vee \mathrm{1.12}$ ) indica que la planta termosolar cilindro-parabólica operando con un $15 \%$ de biomasa de chopo presenta un impacto final ponderado de 7,16 pt/MWh, de los cuales el $26 \%$ corresponde a consumo de recursos, el $25 \%$ a salud humana, y el $49 \%$ a daño en ecosistemas. 
Debido a la gran influencia del transporte en los impactos del ciclo de vida de las astillas de chopo, se ha llevado a cabo un análisis de sensibilidad variando la distancia de transporte. En la Tabla 33 se muestran los resultados de la caracterización considerando distintas distancias de transporte de la biomasa en un rango de 5 a $300 \mathrm{~km}$. La tabla también muestra el porcentaje de variación de impactos de la distancia más corta considerada $(5 \mathrm{~km})$ a la distancia más larga (300 km). Esta variación es mayor para las categorías de CED (25\%), cambio climático (23\%), Ecotoxicidad marina y de agua dulce (14 \% y $10 \%$ ), y toxicidad humana (11\%).

Tabla 33 Impactos caracterizados del ciclo de vida de una planta termosolar CCP hibridada en un $15 \%$ con astillas de chopo considerando distintas distancias de transporte de la biomasa

\begin{tabular}{|c|c|c|c|c|c|c|c|c|c|}
\hline \multirow{2}{*}{ Categoría de impacto } & \multirow{2}{*}{ Ud/MWh } & \multicolumn{7}{|c|}{ Distancia de transporte de la biomasa (km) } & \multirow{2}{*}{$\begin{array}{l}\text { Variación } \\
5-300 \text { km }\end{array}$} \\
\hline & & 5 & 50 & 100 & 150 & 200 & 250 & 300 & \\
\hline Cambio climático & $\mathrm{kg} \mathrm{CO} 2 \mathrm{eq}$ & 23,8 & 24,7 & 25,6 & 26,5 & 27,4 & 28,3 & 29,2 & $23 \%$ \\
\hline Acidificación terrestre & $\mathrm{g} \mathrm{SO}_{2} \mathrm{eq}$ & 320 & 324 & 327 & 331 & 334 & 338 & 342 & $7 \%$ \\
\hline Eutrofización de agua dulce & g P eq & 13,2 & 13,2 & 13,3 & 13,4 & 13,4 & 13,5 & 13,6 & $3 \%$ \\
\hline Toxicidad humana & kg 1,4-DB eq & 19,3 & 19,6 & 20,0 & 20,3 & 20,7 & 21,1 & 21,4 & $11 \%$ \\
\hline Formación de partículas & g PM10 eq & 238 & 239 & 241 & 243 & 245 & 247 & 249 & $5 \%$ \\
\hline Eco-toxicidad de agua dulce & g 1,4-DB eq & 408 & 414 & 421 & 427 & 434 & 441 & 448 & $10 \%$ \\
\hline Eco-toxicidad marina & g 1,4-DB eq & 443 & 452 & 462 & 473 & 483 & 494 & 504 & $14 \%$ \\
\hline CED & MJ & 352 & 365 & 380 & 395 & 410 & 425 & 440 & $25 \%$ \\
\hline Estrés hídrico & $\mathrm{m}^{3}$ & 20,9 & 20,9 & 20,9 & 20,9 & 20,9 & 20,9 & 20,9 & $0 \%$ \\
\hline
\end{tabular}

\subsubsection{Análisis de sensibilidad del gas natural}

En la Tabla 34 se muestran los resultados de la caracterización considerando un rango de hibridación del 0 \% (solo solar) al 55 \% (porcentaje de hibridación en HYSOL). La tabla también muestra el porcentaje de variación de impactos entre la menor y la mayor hibridación considerada. Esta variación ronda entre el $123 \%$ y el $2.151 \%$ de aumento de impactos ambientales, excepto para la categoría de estrés hídrico cuya variación es negativa y mucho menor (- $2 \%)$. La variación de impactos es mayor para las categorías de CED (2.151 \%), cambio climático (1.678 \%), y acidificación terrestre (668 \%).

El estrés hídrico viene dado por el consumo de agua para el ciclo de vapor y la limpieza de los colectores. El consumo del ciclo de vapor es mucho mayor, y crece de forma directa con la hibridación de gas natural, pero al producirse mayor electricidad, el impacto por unidad funcional se mantiene constante. Sin embargo, el consumo de agua para limpieza no varía respecto a la hibridación con gas natural, por lo que el estrés hídrico total por unidad funcional disminuye ligeramente. 
Tabla 34 Impactos caracterizados del ciclo de vida de una planta termosolar cilindro-parabólica considerando distintos porcentajes de hibridación con gas natural (0-55 \%)

\begin{tabular}{|c|c|c|c|c|c|c|c|c|c|}
\hline Categoría de impacto & Ud/MWh & $0 \%$ & $5 \%$ & $15 \%$ & $25 \%$ & $35 \%$ & $45 \%$ & $55 \%$ & $\begin{array}{l}\text { Variación } \\
\text { de } 0 \text { a } 55 \%\end{array}$ \\
\hline Cambio climático & $\mathrm{kg} \mathrm{CO}_{2}$ eq & 24,2 & 61,6 & 136 & 210 & 284 & 358 & 431 & $1678 \%$ \\
\hline Acidificación terrestre & $\mathrm{g} \mathrm{SO}_{2}$ eq & 128 & 207 & 364 & 520 & 675 & 830 & 984 & $668 \%$ \\
\hline Eutrofización de agua dulce & g P eq & 6,29 & 7,39 & 9,57 & 11,75 & 13,9 & 16,1 & 18,2 & $189 \%$ \\
\hline Toxicidad humana & kg 1,4-DB eq & 9,21 & 10,9 & 14,4 & 17,8 & 21,2 & 24,6 & 28,0 & $203 \%$ \\
\hline Formación de partículas & g $P_{10}$ eq & 58,3 & 81,3 & 127 & 173 & 218 & 263 & 308 & $429 \%$ \\
\hline Eco-toxicidad de agua dulce & g 1,4-DB eq & 392 & 481 & 660 & 837 & 1.014 & 1.190 & 1.365 & $248 \%$ \\
\hline Eco-toxicidad marina & g 1,4-DB eq & 394 & 438 & 527 & 615 & 703 & 791 & 878 & $123 \%$ \\
\hline CED & MJ & 394 & 1.237 & 2.875 & 4.505 & 6.127 & 7.742 & 9.348 & $2151 \%$ \\
\hline Estrés hídrico & $\mathrm{m}^{3}$ & 3,70 & 3,70 & 3,69 & 3,68 & 3,66 & 3,65 & 3,64 & $-2 \%$ \\
\hline
\end{tabular}

Dichas categorías han sido parametrizadas en función de la distancia en la Figura 46, donde se puede observar que los impactos caracterizados siguen una relación polinómica y ascendente con la hibridación de gas natural.

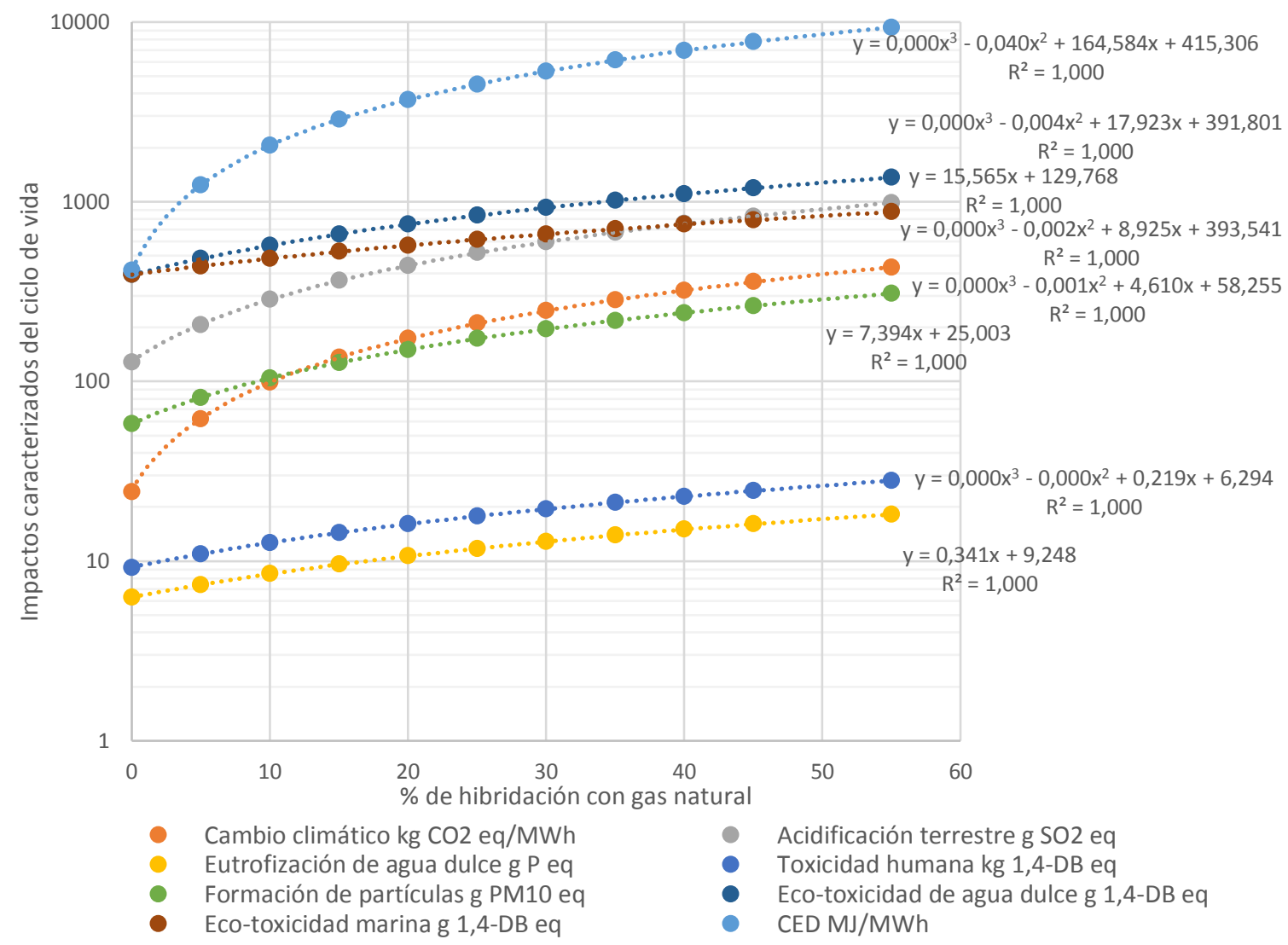

Figura 46 Relación entre el impacto caracterizado y el porcentaje de hibridación con gas natural para las distintas categorías de impacto

La Tabla 35 recoge el resultado ponderado de punto final (según el método de evaluación ReCiPe Endpoint Europe H/H v 1.12) para distintos porcentajes de hibridación con gas natural (0-55 \%). Los resultados indican que el impacto ponderado final aumenta de 3,75 pt/MWh 
(modo solo solar) a 50,9 pt/MWh cuando se hibrida al $55 \%$. Este aumento es mayor en la categoría de recursos debido al consumo del gas natural.

Tabla 35 Impactos ponderados de punto final del ciclo de vida de una planta termosolar cilindroparabólica considerando distintos porcentajes de hibridación con gas natural (0-55\%)

\begin{tabular}{lcccccccc}
$\begin{array}{l}\text { Categoría de punto final, } \\
\text { en Pt/MWh }\end{array}$ & $\mathbf{0} \%$ & $\mathbf{5} \%$ & $\mathbf{1 5} \%$ & $\mathbf{2 5} \%$ & $\mathbf{3 5} \%$ & $\mathbf{4 5} \%$ & $\mathbf{5 5} \%$ & $\begin{array}{c}\text { Variación } \\
\text { de } \mathbf{0} \text { a } \mathbf{5 5} \%\end{array}$ \\
\hline Salud humana & 0,82 & 1,71 & 3,47 & 5,23 & 6,97 & 8,71 & 10,4 & $1.266 \%$ \\
\hline Ecosistemas & 1,16 & 1,81 & 3,11 & 4,40 & 5,68 & 6,96 & 8,23 & $\mathbf{7 1 1} \%$ \\
\hline Recursos & 1,77 & 4,57 & 10,2 & 15,7 & 21,3 & 26,8 & 32,2 & $1.823 \%$ \\
\hline Total agregado & 3,75 & 8,09 & 16,7 & 25,3 & 33,9 & 42,4 & 50,9 & $1.357 \%$ \\
\hline
\end{tabular}

\subsubsection{Análisis de incertidumbre}

Esta sección contiene los resultados del análisis de propagación de la incertidumbre de los datos de inventario en los resultados caracterizados de la planta termosolar cilindro-parabólica base. No incluye la incertidumbre asociada con el método de evaluación de impacto (incertidumbre de factores de caracterización o normalización), ni la incertidumbre asociada con errores inesperados al introducir cantidades. El método de simulación utilizado para la propagación de la incertidumbre es Monte Carlo, utilizando 1000 iteraciones, según lo recomendado por Steen (1997). Se calculó con un 95 \% de intervalo de confianza, según lo indicado por Sonneman et al. (2003).

Los resultados de la incertidumbre asociadas a los impactos ambientales caracterizados de la planta termosolar cilindro-parabólica se describen en la Tabla 36 y Figura 47.

Tabla 36 Resultados de Monte Carlo para los impactos ambientales caracterizados de la planta termosolar cilindroparabólica (95\% de intervalo de confianza)

\begin{tabular}{llllllll}
\hline Categorías & Ud/MWh & Media & SD & CV & $\mathbf{2 , 5} \%$ & $\mathbf{9 7 , 5} \%$ & SEM \\
\hline Cambio climático & kg CO2 eq & 24,2 & 1,81 & $7 \%$ & 21,1 & 28,1 & 0,057 \\
Acidificación terrestre & g SO2 eq & 128 & 11,1 & $9 \%$ & 108 & 150 & 0,351 \\
Eutrofización de agua dulce & g P eq & 6,3 & 2,59 & $41 \%$ & 3,12 & 13,0 & 0,082 \\
Toxicidad en humanos & kg 1,4-DB eq & 9,21 & 97,5 & $1108 \%$ & -179 & 192 & 3,08 \\
Formación de partículas & g PM10 eq & 58,3 & 6,20 & $11 \%$ & 48,6 & 70,7 & 0,20 \\
Eco-toxicidad de agua dulce & g 1,4-DB eq & 383 & 374 & $99 \%$ & -387 & 1108 & 11,83 \\
Eco-toxicidad de agua marina & g 1,4-DB eq & 386 & 307 & $80 \%$ & -241 & 976 & 9,71 \\
$\begin{array}{l}\text { Demanda acumulada de } \\
\text { energía (CED) }\end{array}$ & MJ & 416 & 35 & $8 \%$ & 354 & 486 & 1,1 \\
*SD=Desviación típica; CV & & & & & & &
\end{tabular}

*SD=Desviación típica; CV = Coeficiente de Variación; SEM = Error estándar de la media 
Cambio climático, $\mathrm{kg} \mathrm{CO}_{2}$ eq Eutrofización de agua dulce, g P eq

Acidificación terrestre, $\mathrm{g} \mathrm{SO}_{2}$ eq Toxicidad en humanos kg 1,4-DB eq Formación de partículas, g $\mathrm{PM}_{10}$ eq Eco-toxicidad de agua dulce, g 1.4-DB eq Eco-toxicidad marina, kg 1.4-DB eq CED, MJ

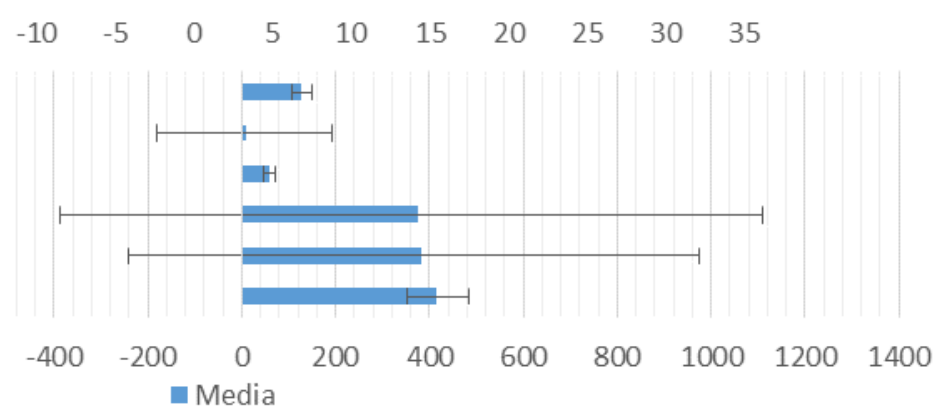

Figura 47 Resultados de caracterización (por MWh) para la planta termosolar cilindroparabólica representando la incertidumbre con barras de error (95\% de intervalo de confianza)

Los resultados indican que el cambio climático es la categoría con menor incertidumbre acumulada ( $C V=7 \%)$, seguida de CED (CV= $8 \%$ ) acidificación terrestre ( $C V=9 \%)$ y formación de material patrticulado ( $\mathrm{CV}=11 \%$ ). La categoría que presenta la mayor incertidumbre es toxicidad humana ( $C V=1108 \%$ ), con valores para confianzas de $2,5 \%$ y $97,5 \%$ muy lejos de la media de la categoría.

Los resultados de incertidumbre sugieren que las categorías de toxicidad humana y ecotoxicidad acuática tienen demasiada incertidumbre como para comparar o tomar decisiones basadas únicamente en esos valores. El resto de las categorías presentan un coeficiente de variación menor al $15 \%$, lo que se considera adecuado en este tipo de estudios (excepto eutrofización, que presenta un 41 \% de CV).

\subsubsection{Interpretación}

El impacto ambiental potencial obtenido para la planta termosolar cilindro-parabólica según el escenario base (50 MW de potencia instalada, refrigeración en húmedo y operación en modo sólo solar) se encuentra dentro del rango de los resultados publicados por la comunidad científica en todas las categorías de las que se dispone datos, excepto para la toxicidad humana. Según la bibliografía, el impacto en cambio climático de las plantas termosolares con tecnología cilindro-parabólica y operación sólo solar presenta un rango de $17-73 \mathrm{~kg} \mathrm{CO}_{2}$ eq/MWh, mientras que el resultado obtenido en este análisis es de $24,2 \mathrm{~kg} \mathrm{CO}_{2}$ eq/MWh. El resultado de eutrofización obtenido es 6,29 g P eq, que se encuentra en el límite inferior del rango encontrado en la bibliografía (6 - $45 \mathrm{~g} \mathrm{PO}_{4}{ }^{3-} / \mathrm{MWh}$ ). La acidificación de la planta analizada asciende a $128 \mathrm{~g} \mathrm{SO}_{2} / \mathrm{MWh}$ mientras que el rango en la bibliografía es de $98-590 \mathrm{~g} \mathrm{SO}_{2}$ eq/MWh. El TRE obtenido (1,65 años) se encuentra en el punto medio del rango de la bibliografía (1 - 2 años). Para la toxicidad humana únicamente se disponía de un dato para plantas 
hibridadas con un $15 \%$ de gas natural (90,2 $\mathrm{Kg} 1,4 \mathrm{DB} / \mathrm{MWh}$ )(Lechon et al. 2008). El resultado obtenido para el escenario de 15 \% de hibridación con gas natural es de 14,4 Kg 1,4 DB/MWh. Esta diferencia de resultados puede ser en parte atribuida a la utilización de diferentes métodos de caracterización, ya que el análisis de Lechon et al. está evaluado con el método CML. El método CML en este tipo de plantas proporciona resultados más altos de toxicidad humana que el ReCiPe perspectiva H (Corona et al. 2014). Además, según el análisis de Montecarlo, la categoría de toxicidad es la que mayor incertidumbre presenta (coeficiente de variación= 1.108 $\%)$.

Al igual que en la bibliografía consultada, los resultados indican que la fase con mayor impacto en una operación en modo sólo solar es E\&F, mientras que cuando se hibrida con algún combustible, la fase con mayor impacto pasa a ser O\&M. Las fases $C$ y $D \& D$ tienen un impacto comparativamente menor (en torno al $18 \%$ y al $6 \%$ respectivamente).

Los sistemas de componentes con mayor impacto en la fase E\&F son el sistema de almacenamiento y el campo solar, seguidos por el bloque de potencia y el circuito HTF. El impacto del sistema de instalaciones es comparativamente insignificante para todas las categorías. La mayor parte del impacto del sistema de almacenamiento viene determinado por la fabricación de sales fundidas (42 - 77 \% del impacto del sistema de almacenamiento, dependiendo de la categoría) y los tanques de almacenamiento (22-58\%). En el caso del campo solar, el componente que mayores impactos acumula es el colector solar ( $29-56 \%$ del impacto atribuido al campo solar dependiendo de la categoría), seguido de las tuberías (14 - 24 \%) y la estructura del colector (10 - $23 \%)$. El equipamiento eléctrico y electrónico del campo solar presenta menor impacto en la mayoría de categorías, pero mayor impacto en la categoría de toxicidad humana y eutrofización de agua dulce.

Cabe mencionar que el impacto del aceite HTF podría estar subestimado, ya que no considera el impacto del consumo de energía y recursos de la transformación catalítica del fenol para la producción del óxido de difenilo.

La Tabla 37 y la Figura 48 muestran los resultados de caracterización y normalización del ciclo de vida de la planta termosolar cilindro-parabólica operando en los distintos escenarios planteados: el escenario base (con operación en modo sólo solar y refrigeración en húmedo), (A) con refrigeración en seco, (B) hibridación del 15 \% con gas natural, (C) hibridación del $15 \%$ con bimetano, (D) hibridación del $15 \%$ con biomasa de astillas de chopo.

Los resultados indican que introducir un combustible adicional en la planta aumenta el impacto ambiental potencial en todas las categorías analizadas. El aumento de electricidad 
producida no se ve compensada por la carga ambiental asociada a producir y quemar el combustible auxiliar. Sin embargo, el TRE es mayor en el escenario base (20 meses) que en el resto de escenarios (9-15 meses). El escenario de refrigeración en seco es el que presenta mejor resultado en la categoría de estrés hídrico (13 veces menos estrés hídrico que en el escenario base), mientras que el resto de las categorías presentan un impacto ambiental potencial ligeramente superior al escenario base.

Tabla 37 Comparación de los resultados caracterizados entre los distintos escenarios planteados para la tecnología termosolar cilindro-parabólica

\begin{tabular}{llccccc} 
Categoría de impacto & Ud/MWh & $\begin{array}{c}\text { Base } \\
\text { (sólo solar) }\end{array}$ & $\begin{array}{c}\text { A: } \\
\text { Refrig. seco }\end{array}$ & $\begin{array}{c}\text { B: } \\
\mathbf{1 5} \text { \% GN }\end{array}$ & $\begin{array}{c}\text { C: } \\
\mathbf{1 5} \text { \% BM }\end{array}$ & $\begin{array}{c}\text { D: } \\
\mathbf{1 5} \text { \% CH }\end{array}$ \\
\hline Cambio climático & $\mathrm{kg} \mathrm{CO}$ eq & 24,1 & 26,5 & 130 & 33,7 & 29,2 \\
\hline Acidificación terrestre & $\mathrm{g} \mathrm{SO}$ eq & 127 & 139 & 321 & 290 & 342 \\
\hline Eutrofización de agua dulce & $\mathrm{g} \mathrm{P} \mathrm{eq}$ & 6,27 & 7,25 & 8,74 & 10,6 & 13,6 \\
\hline Toxicidad humana & $\mathrm{kg} \mathrm{1,4-DB} \mathrm{eq}$ & 9,18 & 10,6 & 13,1 & 16,9 & 21,4 \\
\hline Formación de partículas & $\mathrm{g} \mathrm{PM}$ 10 eq & 58,0 & 63,7 & 115 & 126 & 249 \\
\hline Eco-toxicidad de agua dulce & $\mathrm{g} \mathrm{1,4-DB} \mathrm{eq}$ & 390 & 461 & 593 & 653 & 448 \\
\hline Eco-toxicidad marina & $\mathrm{g} \mathrm{1,4-DB} \mathrm{eq}$ & 393 & 461 & 494 & 659 & 504 \\
\hline CED & $\mathrm{MJ}$ & 383 & 434 & 2390 & 342 & 440 \\
\hline Estrés hídrico & $\mathrm{m}^{3}$ & 3,70 & 13,4 & 3,69 & 3,69 & 20,9 \\
\hline TRE & meses & 20 & 15 & 13 & 9 & 12
\end{tabular}

* GN= Gas Natural; $\mathrm{BM}=$ Biometano; $\mathrm{CH}=$ Astillas de chopo

El escenario de hibridación con gas natural es el que mayores impactos ambientales presenta en las categorías de cambio climático (5,6 veces mayor que el escenario base), acidificación ( 2 veces mayor que el base), ecotoxicidad de agua dulce (1,7 veces mayor) y CED (7,3 veces mayor). El impacto en cambio climático es mucho mayor en este escenario debido a las emisiones de combustión del gas natural (es el único escenario que incluye un combustible de origen fósil). Las categorías de acidificación y ecotoxicidad de agua dulce se ven afectadas principalmente por el ciclo de vida del gas natural, aunque un $13 \%$ del impacto en acidificación de este escenario es debido también a las emisiones de combustión. Los escenarios de hibridación con biometano y biomasa presentan impactos ambientales superiores al de gas natural en las categorías de eutrofización, toxicidad humana y toxicidad acuática. Esto se debe a que el ciclo de vida de dichos combustibles precisa de un mayor consumo de electricidad y diésel para el uso de vehículos. Además, el escenario con biomasa presenta mayor impacto en la formación de partículas debido a las emisiones de combustión.

En la figura de normalización (Figura 48) se observa que las categorías con mayor impacto para todos los escenarios son la ecotoxicidad marina y de agua dulce, seguida de la toxicidad en seres humanos y la eutrofización de agua dulce. Estas categorías además son las que mayor 
diferencia de resultados presentan entre los distintos escenarios, y las que mayor incertidumbre contienen según el análisis de Montecarlo.

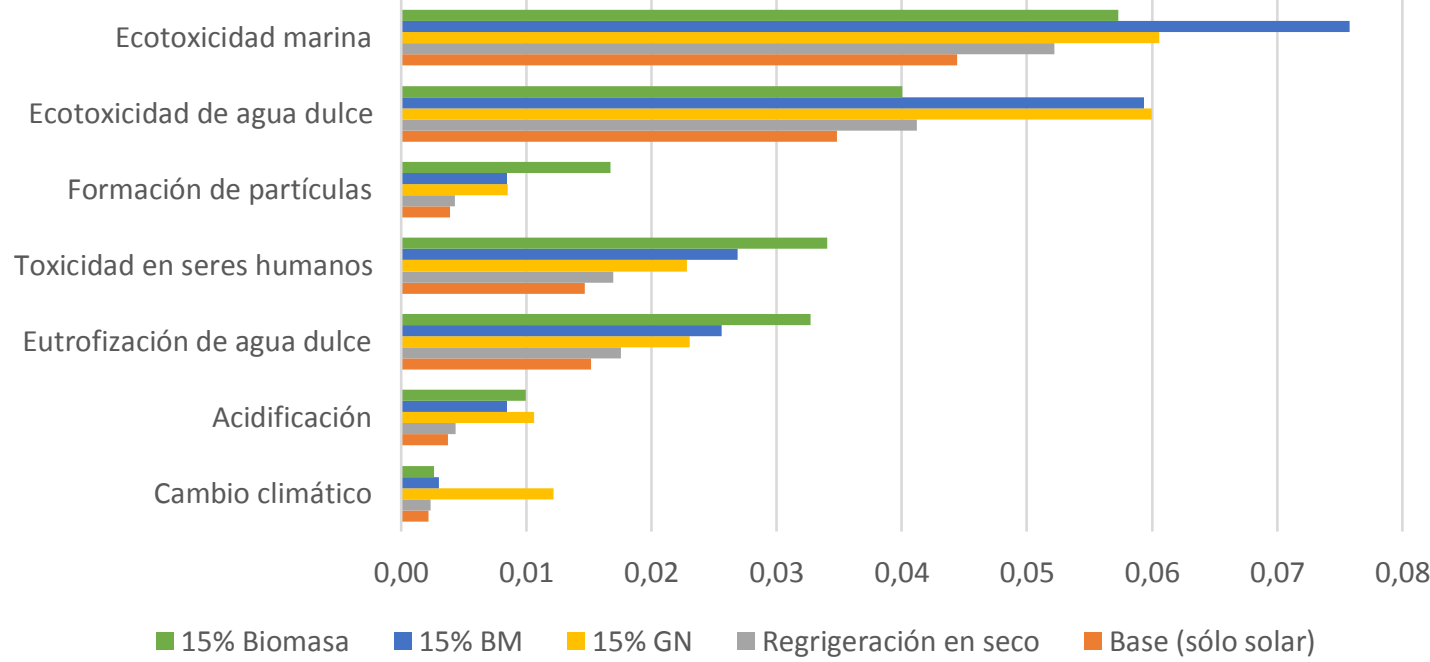

Figura 48 Comparación de impactos normalizados entre los distintos escenarios planteados para la tecnología termosolar cilindro-parabólica

\subsubsection{ACV-A de la tecnología termosolar de torre}

\subsubsection{Definición del objetivo y alcance}

El objetivo principal de este análisis es obtener el impacto ambiental del ciclo de vida la tecnología termosolar de torre o receptor central. El objetivo final es comparar los resultados de este estudio con la tecnología desarrollada por el proyecto HYSOL, para determinar las mejoras ambientales asociadas con la nueva tecnología. Los datos se van a gestionar y tratar con el software SimaPro 8.

Este estudio consta de un escenario base y un alternativo, que servirán para evaluar la tecnología en sus distintas formas de operación. El escenario base contempla la operación de la planta termosolar de torre en modo sólo solar, sin aporte de combustible para la generación de electricidad (aunque sí para operaciones de puesta en marcha y mantenimiento). El escenario alternativo plante al hibridación con gas natural, de tal forma que la planta produzca la misma cantidad de electricidad que la planta HYSOL y sean completamente comparables (lo que implica un mayor consumo de gas natural). La Tabla 38 resume las características principales del escenario principal (termosolar torre, solo solar) y el escenario alternativo (con gas natural). 
Tabla 38 Características principales de la tecnología termosolar torre, en modo solo solar y en el escenario de hibridación con gas natural

\begin{tabular}{lcc} 
Características de la planta & $\begin{array}{c}\text { Termosolar torre (solo } \\
\text { solar) }\end{array}$ & $\begin{array}{c}\text { Termosolar torre, con } \\
\text { gas natural }\end{array}$ \\
\hline Radiación directa normal, $\mathrm{KWh} / \mathrm{m}^{2}$ & 2086 & 2086 \\
\hline Heliostatos, unidades & 9151 & 9151 \\
\hline Apertura, $\mathrm{m}^{2}$ & 1.321 .174 & 1.321 .174 \\
\hline Altura de la torre, $\mathrm{m}$ & 201 & 201 \\
\hline Generación de electricidad anual bruta, MWh/yr & 491331 & 935.683 \\
\hline Electricidad neta vendida, MWh/yr & 418730 & 797.423 \\
\hline Horas de almacenamiento térmico, $\mathrm{h}$ & 14 & 14 \\
\hline Fracción solar, \% & 100 & 46 \\
\hline Eficiencia del ciclo térmico (gas-electricidad) ( \%) & - & 40 \\
\hline Consumo de gas, MJ/yr & $1,70 \mathrm{E}+8$ & $1,14 \mathrm{E}+11$ \\
\hline
\end{tabular}

La central termosolar de torre estudiada en este análisis tiene $100 \mathrm{MW}$ de potencia instalada y se asume que está ubicada en Talarrubias, Badajoz. La configuración de la planta termosolar de torre se muestra en la Figura 49. En esta configuración, la radiación solar reflejada por los heliostatos (1) se dirige a un receptor central externo (2) donde se aumenta la energía térmica contenida en el HTF (consistente en sales fundidas). La planta consta de 14 horas de almacenamiento térmico en un TES indirecto de dos tanques (3) utilizado para aumentar la despachabilidad y la generación de electricidad. La energía térmica recogida por el HTF se utiliza posteriormente para conducir el ciclo termodinámico de Rankine (4) que utiliza refrigeración por aire. El escenario alternativo de hibridación incluye varias calderas auxiliares (5) que se utilizan para aumentar la generación de electricidad cuando el almacenamiento térmico está agotado o en momentos de transición de nubes.

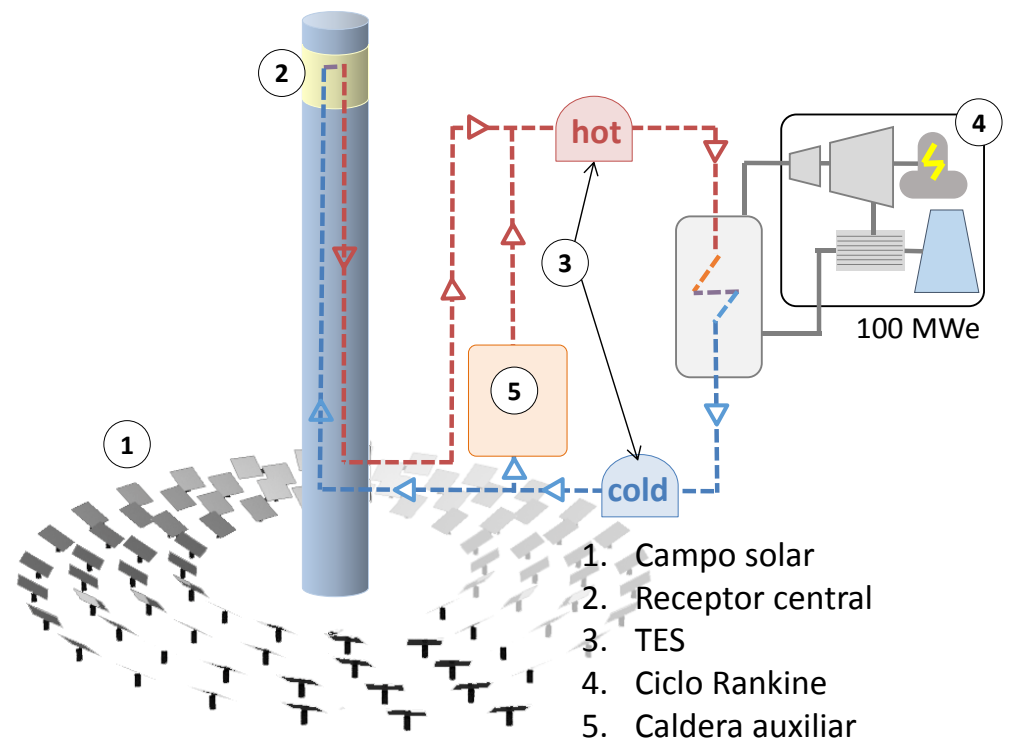

Figura 49 Configuración de la central termosolar de torre analizada 
Para mantener la consistencia en la comparación con la tecnología HYSOL, se supone que la configuración del campo solar y la cantidad de electricidad anual vertida a la red es la misma que en la configuración de HYSOL BIO. Además, la metodología de evaluación de impacto es la misma que la escogida para la planta HYSOL BIO, ya que los resultados deben ser comparables (mirar sección 3.2.1.2). Las fuentes principales de datos y los requisitos de calidad de los mismos son los mismos que en la planta de referencia (secciones 3.2.1.3, 3.2.1.4, 3.2.1.5).

Las fases del ciclo de vida consideradas son las mismas que en la planta HYSOL y la termosolar cilindro-parabólica: E\&F, C, O\&M y D\&D.

\subsubsection{Análisis de inventario}

El inventario de esta planta presenta la misma estructura, origen y fuentes de datos que la planta HYSOL BIO. Según las hipótesis iniciales, los componentes del campo solar, del sistema de receptor central, del almacenamiento térmico y de las instalaciones son las mismas que los de la planta HYSOL. El bloque de potencia tiene también los mismos componentes, salvo el generador y turbina de gas, los intercambiadores de calor de gases de escape y tuberías auxiliares del ciclo Brayton, que no están incluidos en esta tecnología.

\subsubsection{Evaluación de impacto ambiental}

La Tabla 39 indica los impactos ambientales asociados a la generación de $1 \mathrm{MWh}$ de electricidad según el escenario base (operación sólo solar) de la central termosolar de torre. En la tabla se muestran los resultados de caracterización de las siete categorías de punto medio más relevantes para esta tecnología, así como el resultado del consumo primario de energía (CED) y el estrés hídrico asociado al consumo directo de agua. Los impactos del ciclo de vida de la tecnología fueron los siguientes: cambio climático $18,5 \mathrm{~kg} \mathrm{CO} 2 \mathrm{eq} / \mathrm{MWh}$, acidificación terrestre $91 \mathrm{~g} \mathrm{SO}_{2}$ eq/MWh, eutrofización 7,4 g P eq/MWh, toxicidad humana 9,75 kg 1,4-DB eq/MWh, formación de partículas 43,4 g PM10 eq /MWh, eco-toxicidad de agua dulce 452 g 1, 4-DB eq/MWh, eco-toxicidad marina 431 g 1, 4-DB eq/MWh, CED 274 MJ/MWh y estrés hídrico 0,27 $\mathrm{m}^{3} / \mathrm{MWh}$.

La Figura 50 muestra la contribución relativa de cada fase del ciclo de vida a las distintas categorías de impacto analizadas. Los resultados muestran que el impacto ambiental en la mayoría de las categorías es atribuible principalmente a la fase de E\&F, mientras que la contribución de las otras fases del ciclo de vida es limitada (excepto para estrés hídrico). En particular, el $74 \%$ de las emisiones asociadas con el cambio climático derivan de E\&F, mientras que O\&M contribuye a sólo al $12 \%$ del total. La mayor contribución al impacto ambiental por parte de la fase E\&F se da en las categorías de eco-toxicidad (aprox. $87 \%$ ), debido al uso del 
acero en los componentes de la central (cuya fabricación presenta gran impacto en estas categorías).

Tabla 39 Impactos caracterizados en diferentes fases del ciclo de vida de la planta termosolar de torre (modo sólo solar)

\begin{tabular}{|c|c|c|c|c|c|c|}
\hline Categoría de impacto & Ud/MWh & E\&F & C & O\&M & D\&D & TOTAL \\
\hline Cambio climático & $\mathrm{kg} \mathrm{CO} 2 \mathrm{eq}$ & 18,2 & 3,41 & 3,19 & $-6,27$ & 18,5 \\
\hline Acidificación terrestre & $\mathrm{g} \mathrm{SO}_{2}$ eq & 88,6 & 16,0 & 8,07 & $-21,9$ & 91 \\
\hline Eutrofización de agua dulce & g P eq & 7,81 & 0,83 & 0,21 & $-1,50$ & 7,4 \\
\hline Toxicidad humana & kg 1,4-DB eq & 9,60 & 1,12 & 0,30 & $-1,27$ & 9,75 \\
\hline Formación de partículas & $\mathrm{g} \mathrm{PM}_{10}$ eq & 51,0 & 9,3 & 2,71 & $-19,6$ & 43,4 \\
\hline Eco-toxicidad de agua dulce & g 1,4-DB eq & 393 & 37,1 & 13,3 & 8,84 & 452 \\
\hline Eco-toxicidad marina & g 1,4-DB eq & 378 & 37,8 & 9,88 & 5,22 & 431 \\
\hline CED & MJ & 223 & 40,1 & 70,1 & $-59,3$ & 274 \\
\hline Estrés hídrico & $\mathrm{m}^{3}$ & & & 0,27 & & 0,27 \\
\hline
\end{tabular}

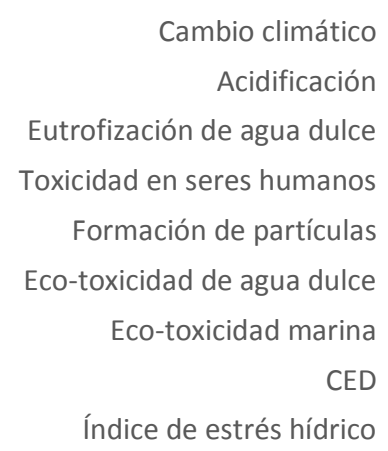

CED

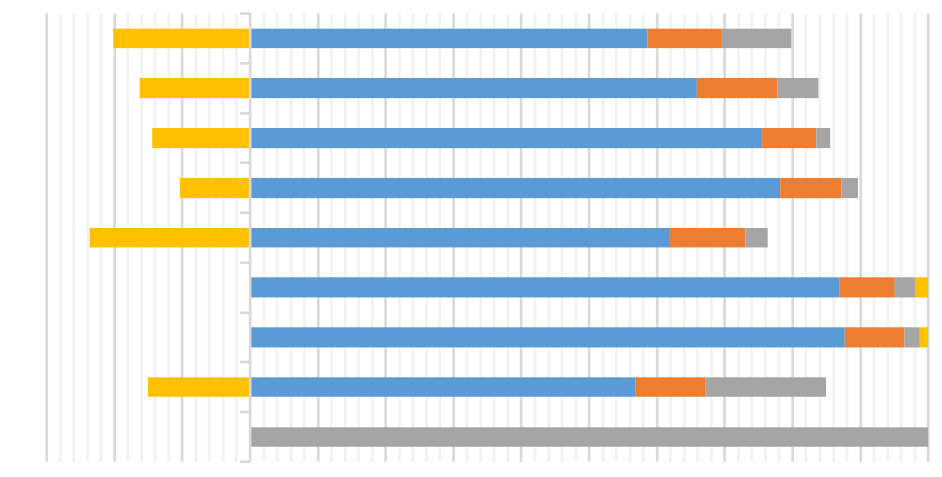

$-30 \%-20 \%-10 \% \quad 0 \% \quad 10 \% \quad 20 \% \quad 30 \% \quad 40 \% \quad 50 \% \quad 60 \% \quad 70 \% \quad 80 \% \quad 90 \% 100 \%$

Figura 50 Contribución relativa de cada fase del ciclo de vida a los impactos ambientales caracterizados de una planta termosolar torre (modo sólo solar)

La fase D\&D presenta un impacto beneficioso en la mayoría de categorías (especialmente formación de partículas y cambio climático). Esto es debido a los beneficios derivados por el reciclaje del acero utilizado en distintas partes de la central (y especialmente en el campo solar).

A diferencia de las demás categorías, el estrés hídrico se ve afectado únicamente por la fase O\&M, ascendiendo a $0,27 \mathrm{~m}^{3} / \mathrm{MWh}$. Esto es debido a que esta categoría sólo considera el consumo de agua de refrigeración, el del ciclo de vapor y una pequeña cantidad asociada con la limpieza de heliostatos (0,7 \%). El consumo de agua indirecta asociado a otras fases del ciclo de vida no se ha considerado, debido a inconsistencias en la base de datos ecoinvent y el cálculo de impacto hídrico de SimaPro. 
La Figura 51 muestra la contribución de cada sistema de componentes al impacto ambiental de la fase E\&F. Según se observa en la figura, el sistemas con mayor impacto es el campo solar, que concentra entre el $58 \%$ y el $66 \%$ de los impactos de la fase E\&F (dependiendo de la categoría). El siguiente sistema de componentes con mayor impacto es el receptor central, seguido por el sistema de almacenamiento y el bloque de potencia. El impacto del sistema de instalaciones es comparativamente insignificante para todas las categorías.

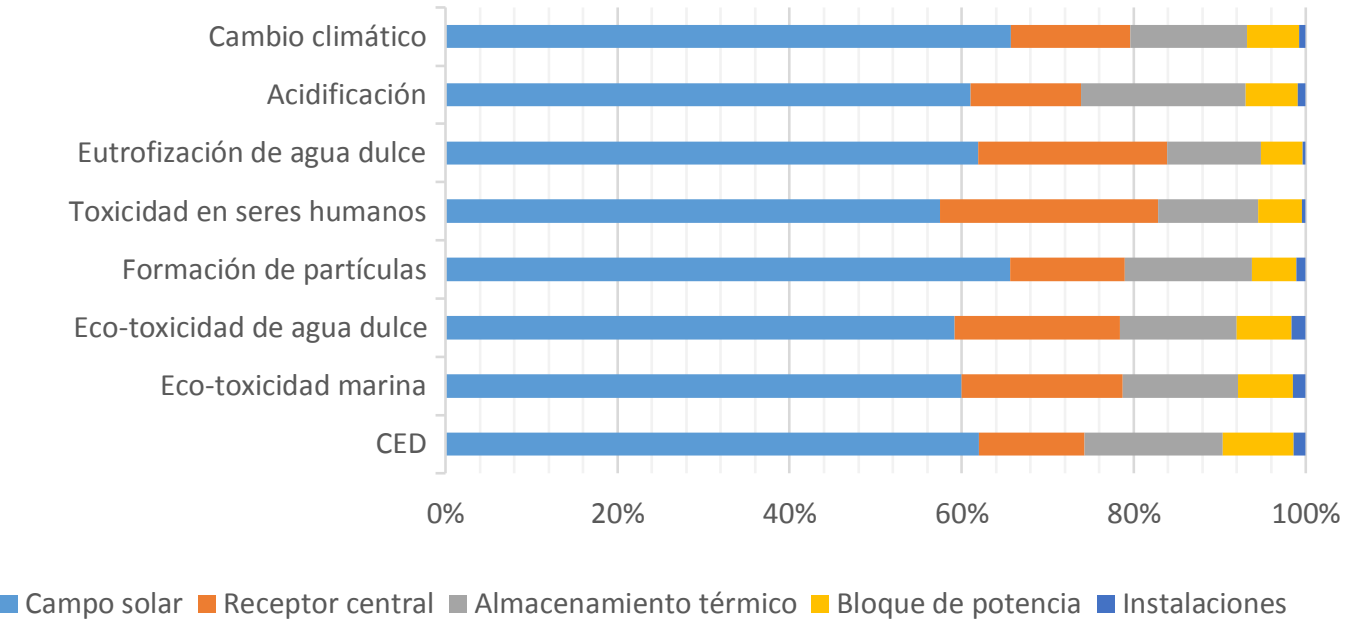

Figura 51 Contribución relativa de cada sistema de la planta termosolar de torre a los impactos ambientales asociados con la fase de E\&F del ciclo de vida

La mayor parte del impacto del campo solar viene dado por los heliostatos (más del $90 \%$ de los impactos producidos por el campo solar en todas las categorías). El equipamiento eléctrico y electrónico del campo solar presenta menor impacto en la mayoría de categorías, pero mayor impacto en la categoría de toxicidad humana y eutrofización de agua dulce.

El impacto ambiental potencial del sistema de almacenamiento viene determinado por la fabricación de sales fundidas (entre el $42 \%$ y el $77 \%$ del impacto del sistema de almacenamiento, dependiendo de la categoría) y el acero de los tanques de almacenamiento (entre el $22 \%$ y el $58 \%$ ).

La CED asociada con el ciclo de vida de la planta termosolar de torre en modo solo solar asciende a $274 \mathrm{MJ} / \mathrm{MWh}$. El consumo de energía primaria externa (teniendo en cuenta todo el ciclo de vida de la tecnología) representa el 7,6 \% de toda la electricidad vertida a la red. E\&F es la fase más intensiva en energía ( $6 \%$ de la electricidad vertida a la red) debido al uso de energía para la extracción de materias primas involucradas en la construcción de la planta. El consumo de energía en las fases de construcción (C), desmantelamiento y disposición de residuos (D\&D) es muy limitada (menos del $1 \%$ ). Considerando que el resultado obtenido de CED para las etapas 
de fabricación y construcción es $2,76 \times 10^{9} \mathrm{MJ}$, que el obtenido para la operación y mantenimiento es $9,94 \times 10^{7} \mathrm{MJ} / \mathrm{yr}$ y que la electricidad producida es $1,51 \times 10^{9} \mathrm{MJ} / \mathrm{yr}$, el TRE de la tecnología HYSOL es 0,82 años o 9,8 meses (según la Ecuación (2)).

Los resultados normalizados mostrados en la Figura 52 indican que la categoría más afectada por el ciclo de vida de la planta bajo estudio (según factores de normalización europeos) es eco-toxicidad marina, seguida de eco-toxicidad de agua dulce, eutrofización y toxicidad humana. El impacto sobre eco-toxicidad marina se asocia principalmente con el uso de acero al carbono en distintos elementos de la planta, la utilización de cobre en los TES y el bloque de potencia, y la producción de sales fundidas. El impacto normalizado en otras categorías ambientales como el cambio climático y la acidificación es comparativamente más bajo.

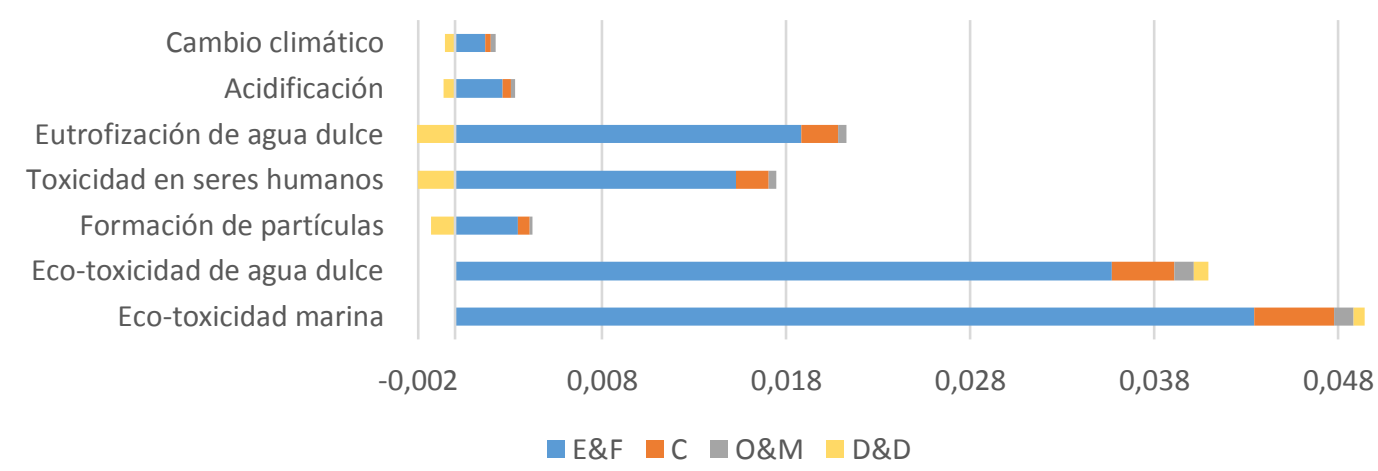

Figura 52 Perfil normalizado del impacto ambiental de la central termosolar de torre (modo solo solar)

El resultado ponderado de punto final (según el método de evaluación ReCiPe Endpoint Europe $\mathrm{H} / \mathrm{H} \vee 1.12$ ) indica que la planta termosolar de torre operando en modo sólo solar presenta un impacto final ponderado de 3,53 pt/MWh, de los cuales el $38 \%$ corresponde a consumo de recursos, el $19 \%$ a salud humana, y el $43 \%$ a daño en ecosistemas.

\section{A. Resultados del escenario alternativo para la planta termosolar de torre hibridada con gas natural}

Este escenario contempla la hibridación con gas natural de tal forma que produzca la misma cantidad de electricidad que la tecnología HYSOL, lo que implica un mayor consumo de gas natural.

La Tabla 40 y Figura 53 describen el impacto ambiental caracterizado y normalizado de la generación de 1 MWh de electricidad mediante la tecnología termosolar de torre, hibridada con gas natural de forma que produzca la misma cantidad de electricidad que la tecnología HYSOL. 
CAPÍTULO 3: Análisis del área ambiental

Los resultados indican una alta contribución de la fase de O\&M en el impacto ambiental del ciclo de vida, especialmente en las categorías de cambio climático (98\% del impacto de la fase de O\&M) y CED (98\%). La segunda fase con mayor impacto es E\&F, especialmente en eutrofización del agua dulce ( $27 \%$ ), ecotoxicidad marina ( $26 \%$ del impacto de la fase de E\&F), y toxicidad humana (22\%).

El resultado obtenido para la categoría de CED indica que la energía primaria consumida durante el ciclo de vida de la planta de energía en este escenario es $8484 \mathrm{MJ} / \mathrm{MWh}$. El consumo de energía primaria (teniendo en cuenta el ciclo de vida del sistema) representa el $236 \%$ de toda la electricidad generada vertida a la red. Considerando que el resultado obtenido de CED para las etapas de fabricación y construcción es $2,76 \times 10^{9} \mathrm{MJ}$, que el obtenido para la operación y mantenimiento es $6,67 \times 10^{9} \mathrm{MJ} / \mathrm{yr}$ y que la electricidad producida es $2,87 \times 10^{9} \mathrm{MJ} / \mathrm{yr}$, el TRE de la tecnología termosolar de torre hibridada con gas natural es negativo. Este resultado implica que este escenario nunca va a recuperar la energía consumida en su ciclo de vida.

Tabla 40 Impactos caracterizados en diferentes fases del ciclo de vida de la planta termosolar de torre hibridada con gas natural

\begin{tabular}{llccccc} 
Categoría de impacto & Ud/MWh & E\&F & C & O\&M & D\&D & TOTAL \\
\hline Cambio climático & $\mathrm{kg} \mathrm{CO}$ eq & 9,6 & 1,79 & 384 & $-3,29$ & 392 \\
\hline Acidificación terrestre & $\mathrm{g} \mathrm{SO}_{2}$ eq & 46,5 & 8,4 & 847 & $-11,5$ & 891 \\
\hline Eutrofización de agua dulce & $\mathrm{g} \mathrm{P} \mathrm{eq}$ & 4,10 & 0,44 & 14,1 & $-0,79$ & 17,9 \\
\hline Toxicidad humana & $\mathrm{kg} \mathrm{1,4-DB} \mathrm{eq}$ & 5,04 & 0,59 & 21,9 & $-0,67$ & 26,8 \\
\hline Formación de partículas & $\mathrm{g} \mathrm{PM}_{10}$ eq & 26,8 & 4,9 & 258 & $-10,3$ & 280 \\
\hline Eco-toxicidad de agua dulce & $\mathrm{g} \mathrm{1,4-DB} \mathrm{eq}$ & 206 & 19,5 & 1.090 & 4,6 & 1.320 \\
\hline Eco-toxicidad marina & $\mathrm{g} 1,4-\mathrm{DB}$ eq & 198 & 19,9 & 645 & 2,7 & 866 \\
\hline CED & $\mathrm{MJ}$ & 117 & 21,0 & 8.370 & $-24,6$ & 8.484 \\
\hline Estrés hídrico & $\mathrm{m}^{3}$ & - & - & 0,161 & - & 0,161 \\
\hline
\end{tabular}

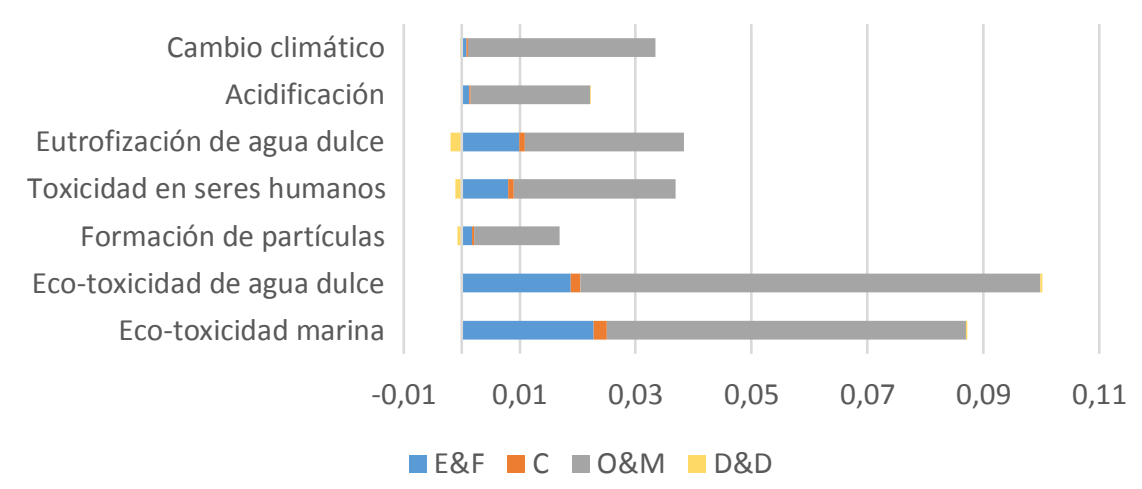

Figura 53 Perfil normalizado del impacto ambiental de la central termosolar torre hibridada con gas natural 
El resultado ponderado de punto final (según el método de evaluación ReCiPe Endpoint Europe $\mathrm{H} / \mathrm{H} \vee 1.12$ ) indica que la planta termosolar de torre hibridada con gas natural, $\mathrm{y}$ produciendo la misma cantidad de electricidad que HYSOL, presenta un impacto final ponderado de $46,7 \mathrm{pt} / \mathrm{MWh}$, de los cuales el $63 \%$ corresponde a consumo de recursos, el $20 \%$ a salud humana, y el $17 \%$ a daño en ecosistemas.

\subsubsection{Interpretación de resultados}

El impacto ambiental potencial obtenido para una planta termosolar de torre en modo solo solar es algo inferior a los dos estudios similares publicados (Weinrebe et al. 1998, Whitaker et al. 2013). Por ejemplo, los resultados publicados para la categoría de cambio climático se encuentran en un rango de $23-42 \mathrm{~kg} \mathrm{CO}_{2} / \mathrm{MWh}$, mientras que el resultado obtenido en este estudio para la termosolar de torre es $18,5 \mathrm{~kg} \mathrm{CO} / \mathrm{MWh}$. Estas diferencias se asocian principalmente con la fase $O \& M$, ya que las referencias consultadas utilizan electricidad para los consumos de operación de la planta, mientras que la planta bajo estudio asume que esta electricidad se autoconsume (por motivos de regulación de compra-venta de electricidad).

La fase que mayores impactos presenta en la operación en modo solo solar es la fase de $E \& F$, debido principalmente a los heliostatos, ya que contienen una cantidad elevada de acero en su estructura. Esta gran cantidad de acero tiene como consecuencia que la fase de D\&D presente beneficios derivados del reciclaje de dicho material. Estos beneficios suponen que el impacto de la fase E\&F se reduzca entre un $15 \%$ y un $40 \%$ para todas las categorías excepto para las de eco-toxicidad acuática. Cabe señalar que las tasas de reciclaje asumidas para este estudio son altas ( $80 \%$ para acero y hierro), por lo que dichos beneficios están supeditados a que realmente se produzca dicho reciclaje.

La Tabla 41 y la Figura 54 muestran los resultados de caracterización y normalización de la planta termosolar de torre operando en modo solar o hibridada con gas natural de tal forma que produzca la misma cantidad de electricidad que la planta HYSOL.

Al comparar los resultados obtenidos en el escenario de hibridación con gas natural (misma producción que HYSOL) con los obtenidos para la planta termosolar torre en modo sólo solar, todos los indicadores de categorías muestran un aumento significativo. El alto impacto para la categoría de cambio climático durante la fase de O\&M es atribuible a la combustión de gas natural en la caldera auxiliar (presentando el $73 \%$ del impacto de ciclo de vida) y a su extracción, producción y transporte ( $24 \%$ ). La combustión de gas natural también contribuye al $17 \%$ de los impactos de acidificación del ciclo de vida, y al 23 \% de los de formación de partículas, mientras que la contribución de las emisiones de combustión a otras categorías es insignificante. El ciclo 
CAPÍTULO 3: Análisis del área ambiental

de vida de gas natural (extracción, producción y transporte) contribuye al 71-78 \% de las categorías de acidificación, eutrofización y toxicidad, siendo el proceso con mayor impacto en la mayoría de las categorías ambientales.

Tabla 41 Comparación de los resultados caracterizados entre los distintos escenarios planteados para la tecnología termosolar torre

\begin{tabular}{llcc} 
Categoría de impacto & Ud/MWh & $\begin{array}{c}\text { Termosolar torre, } \\
\text { sólo solar }\end{array}$ & $\begin{array}{c}\text { Termosolar torre, } \\
\text { hibridación gas natural }\end{array}$ \\
\hline Cambio climático & $\mathrm{kg} \mathrm{CO}_{2}$ eq & 18,5 & 392 \\
\hline Acidificación terrestre & $\mathrm{g} \mathrm{SO}_{2}$ eq & 90,9 & 891 \\
\hline Eutrofización de agua dulce & $\mathrm{g} \mathrm{P} \mathrm{eq}$ & 7,35 & 17,9 \\
\hline Toxicidad humana & $\mathrm{kg} \mathrm{1,4-DB} \mathrm{eq}$ & 9,75 & 26,8 \\
\hline Formación de partículas & $\mathrm{g} \mathrm{PM}$ 10 eq & 43,4 & 280 \\
\hline Eco-toxicidad de agua dulce & $\mathrm{g} \mathrm{1,4-DB} \mathrm{eq}$ & 452 & 1.320 \\
\hline Eco-toxicidad marina & $\mathrm{g} \mathrm{1,4-DB} \mathrm{eq}$ & 431 & 866 \\
\hline CED & $\mathrm{MJ}$ & 274 & 8.484 \\
\hline Estrés hídrico & $\mathrm{m}^{3}$ & 0,27 & 0,03 \\
\hline
\end{tabular}

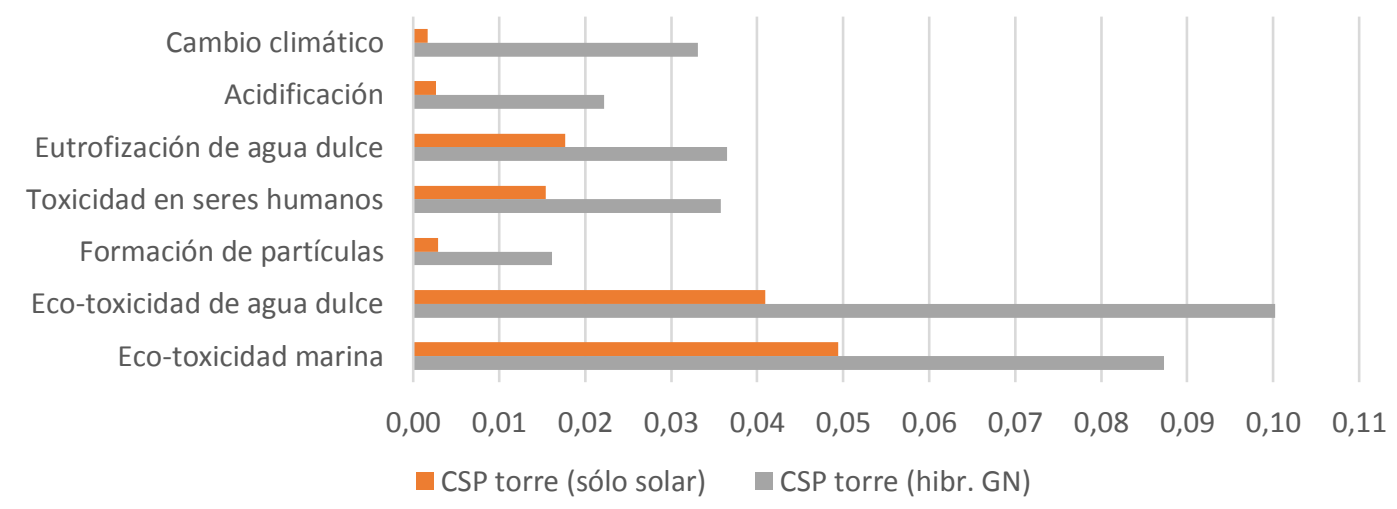

Figura 54 Comparación de los resultados normalizados entre los distintos escenarios planteados para la tecnología termosolar torre 


\subsection{DISCUSIÓN Y CONCLUSIONES}

Este capítulo analiza el impacto ambiental potencial del ciclo de vida de la planta HYSOL en los dos escenarios planteados según la definición de alcance y objetivo del ASCV (Capítulo 2), así como el de las tecnologías termosolar cilindro-parabólica y de torre para distintos escenarios. La Tabla 42 y la Figura 55 muestran los resultados de caracterización y normalización para las tecnologías y escenarios analizados.

La mayoría de los impactos ambientales de la configuración de HYSOL se atribuyen a la fase de O\&M, ya que los impactos derivados de la producción y combustión del combustible auxiliar son superiores a los de la fabricación de componentes de la planta ( $y$ todo el ciclo de vida del combustible se contabiliza como impacto a la fase de O\&M). Este patrón en el que la fase de O\&M produce la mayor parte de los impactos ambientales es similar al obtenido en la evaluación del ciclo de vida de las plantas termosolares híbridas convencionales. Sin embargo, las plantas termosolares convencionales que funcionan en modo sólo solar presentan mayor contribución al impacto de ciclo de vida por parte de la fase E\&F que por parte de la fase O\&M. El subsistema de componentes con mayor impacto de la planta HYSOL (en la fase E\&F) es el campo solar, debido al acero presente en la estructura de los heliostatos; aunque su reciclado durante la fase de D\&D compensa en parte este impacto. Por ello, el reciclaje de los elementos de acero es un proceso necesario para reducir el impacto de la fabricación de componentes. Este patrón es similar en las plantas termosolares de torre "convencionales", mientras que en las de tecnología cilindro-parabólica el sistema con mayor impacto es el de almacenamiento térmico, al precisar de menos acero para los colectores.

Los resultados para la tecnología HYSOL indican que la operación con biometano supone un menor impacto ambiental global que la operación con gas natural. Esto se debe principalmente a que presenta menores emisiones de cambio climático $(6,4$ veces menos) y de acidificación (1,3 veces menos). El ciclo de vida del biometano produce mayor impacto ambiental que el gas natural para las categorías de toxicidad humana, eutrofización de agua dulce y especialmente eco-toxicidad de agua marina. Sin embargo, cuando se consideran los resultados de punto final, el impacto ambiental potencial ponderado es 4,2 veces mayor con gas natural que con biometano.

Cuando se compara el ciclo de vida de la planta HYSOL con el de la tecnología termosolar cilindro-parabólica y de torre operando en modo solar se observa que los impactos ambientales potenciales son mayores en la primera que en las segundas. Esto es debido a que la mayor electricidad producida en HYSOL no compensa el impacto ambiental del combustible. Sin 
embargo, la primera funciona durante más horas al año que las segundas, por lo que no cumplen exactamente la misma función. Con el objetivo de comparar la tecnología HYSOL con una planta produciendo electricidad durante el mismo número de horas -y por lo tanto con la misma funcionalidad de firmeza y gestionabilidad- se han calculado los escenarios de la planta termosolar de torre y cilindro-parabólica asumiendo la misma producción de electricidad en el primer caso y el mismo porcentaje de hibridación en el segundo (al presentar distintas potencias instaladas en la planta de torre y cilindro-parabólica no es razonable asumir la misma producción de electricidad). En ambos casos se confirma que el impacto ambiental potencial de la tecnología HYSOL es menor que el de las termosolares convencionales, ya que se consigue mayor eficiencia de producción con una menor carga ambiental.

El análisis consecuencial realizado en la sección 3.2.4 de esta tesis permite conocer las consecuencias ambientales potenciales de la tecnología HYSOL cuando se integra en el sistema eléctrico español. Los resultados obtenidos indican que introducir una unidad marginal de electricidad de la planta HYSOL en el mercado eléctrico español produce un beneficio ambiental neto en todas las categorías. Esto es debido a que el mix anual promedio de tecnologías marginales que sustituye la tecnología HYSOL (según datos para el año 2014) produce mayor impacto ambiental que la propia HYSOL. Por lo tanto, al integrar la tecnología HYSOL en el sistema eléctrico español, no sólo no se aumentaría el impacto ambiental de la producción eléctrica en España, si no que se evitarían impactos ambientales derivados de las tecnologías a las que sustituye.

EI TRE es menor en la tecnología HYSOL BIO que en el resto de escenarios analizados $(6,1$ meses), mientras que el TRE de la termosolar de torre hibridada con gas natural para producir la misma cantidad de electricidad que HYSOL es negativo, indicando que nunca va a llegar a recuperarse toda la energía primaria invertida en el ciclo de vida de la planta. La planta cilindroparabólica operando con un $55 \%$ de gas natural también tiene un TRE negativo. El TRE del resto de escenarios se encuentra en un rango de 8,6 - 22 meses, similar al encontrado en la bibliografía. Los mayores TRE obtenidos son para la operación con gas natural. Cabe destacar que el cálculo realizado para el TRE no incluye la carga o beneficio ambiental de la fase de D\&D.

Los resultados de punto final permiten clasificar los distintos escenarios analizados según el impacto ambiental potencial ponderado. El método de evaluación y ponderación utilizado (ReCiPe Endpoint Europe $\mathrm{H} / \mathrm{H}$ v 1.12) considera un mayor impacto ponderado en aquellos escenarios que utilizan gas natural como combustible (HYSOL GN, termosolar de torre con gas natural, y termosolar cilindro-parabólica con $15 \%$ y $55 \%$ de gas natural). Para los escenarios de 
CAPÍTULO 3: Análisis del área ambiental

operación en modo sólo solar, la planta termosolar de torre presenta menor impacto que la termosolar cilindro-parabólica, aunque las diferencias son menores al $15 \%$. La hibridación de la planta termosolar con biometano presenta menor impacto que la hibridación con biomasa procedente de un cultivo energético de chopo. 
Tabla 42 Resultados de caracterización para los escenarios planteados en el área ambiental: planta HYSOL BIO, planta HYSOL GN, termosolar cilindro-parabólica en 6 escenarios, termosolar de torre en modo sólo solar, y termosolar de torre hibridada con gas natural. También incluye el modelado consecuencial de los escenarios para la planta HYSOL

\begin{tabular}{|c|c|c|c|c|c|c|c|c|c|c|c|c|c|}
\hline \multirow[b]{2}{*}{ Categoría de impacto } & \multirow[b]{2}{*}{$\begin{array}{l}\text { Unidades } \\
\text { (por MWh) }\end{array}$} & \multirow[b]{2}{*}{$\begin{array}{c}\text { HYSOL } \\
\text { BIO }\end{array}$} & \multirow[b]{2}{*}{$\begin{array}{l}\text { HYSOL } \\
\text { GN }\end{array}$} & \multirow{2}{*}{$\begin{array}{c}\text { HYSOL } \\
\text { BIO } \\
\text { conseq }\end{array}$} & \multirow{2}{*}{$\begin{array}{l}\text { HYSOL } \\
\text { GN } \\
\text { conseq }\end{array}$} & \multicolumn{6}{|c|}{ Termosolar cilindro-parabólica } & \multirow{2}{*}{$\begin{array}{l}\text { Torre } \\
\text { solo } \\
\text { solar }\end{array}$} & \multirow[b]{2}{*}{ Torre GN } \\
\hline & & & & & & $\begin{array}{l}\text { Base- } \\
\text { Sólo solar }\end{array}$ & $\begin{array}{l}\text { Refrig. en } \\
\text { seco }\end{array}$ & $\begin{array}{c}\text { Hibrid. } 15 \\
\% \text { Gas } \\
\text { natural }\end{array}$ & $\begin{array}{c}\text { Hibrid. } 15 \\
\% \\
\text { Biometano }\end{array}$ & $\begin{array}{c}\text { Hibrid. } 15 \\
\% \\
\text { Biomasa }\end{array}$ & $\begin{array}{c}\text { Hibrid. } 55 \\
\% \text { gas } \\
\text { natural }\end{array}$ & & \\
\hline Cambio climático & $\mathrm{kg} \mathrm{CO}_{2}$ eq & 45,9 & 294 & -414 & -175 & 24 & 27 & 136 & 34 & 29 & 431 & 18,4 & 392 \\
\hline Acidificación terrestre & $\mathrm{g} \mathrm{SO}_{2}$ eq & 515 & 694 & -3.013 & -2.789 & 128 & 140 & 364 & 290 & 342 & 984 & 89,9 & 891 \\
\hline Eutrofización de agua dulce & g P eq & 16,9 & 14,4 & -120 & -122 & 6 & 7 & 10 & 11 & 14 & 18,2 & 7,33 & 17,9 \\
\hline Toxicidad humana & kg 1,4-DB eq & 27,5 & 21,4 & -75 & -83 & 9 & 11 & 14 & 17 & 21 & 28,0 & 9,72 & 26,8 \\
\hline Formación de partículas & g PM10 eq & 217 & 220 & -946 & -830 & 58 & 64 & 127 & 126 & 249 & 308 & 43,1 & 280 \\
\hline Ecotoxicidad de agua dulce & g 1,4-DB eq & 1.035 & 1.052 & -3.236 & -3.306 & 383 & 453 & 660 & 653 & 441 & 1.365 & 451 & 1.320 \\
\hline Ecotoxicidad de agua marina & g 1,4-DB eq & 1.030 & 711 & -2.842 & -3.148 & 386 & 454 & 527 & 659 & 498 & 878 & 430 & 866 \\
\hline Demanda acumulada de energía (CED) & $\mathrm{MJ} / \mathrm{MWh}$ & 1.338 & 6.344 & -6.202 & -2.420 & 394 & 460 & 2.875 & 342 & 514 & 9.348 & 263 & 8.484 \\
\hline Estrés hídrico & $\mathrm{m}^{3} / \mathrm{MWh}$ & 0,164 & 0,151 & 0,16 & 0,16 & 3,70 & 0,28 & 3,69 & 3,69 & 20,9 & 3,65 & 0,27 & 0,16 \\
\hline TRE & meses & 6,14 & 22,3 & - & - & 20 & 15 & 13 & 8,6 & 11,5 & $-32,1$ & 9,79 & $-14,4$ \\
\hline
\end{tabular}




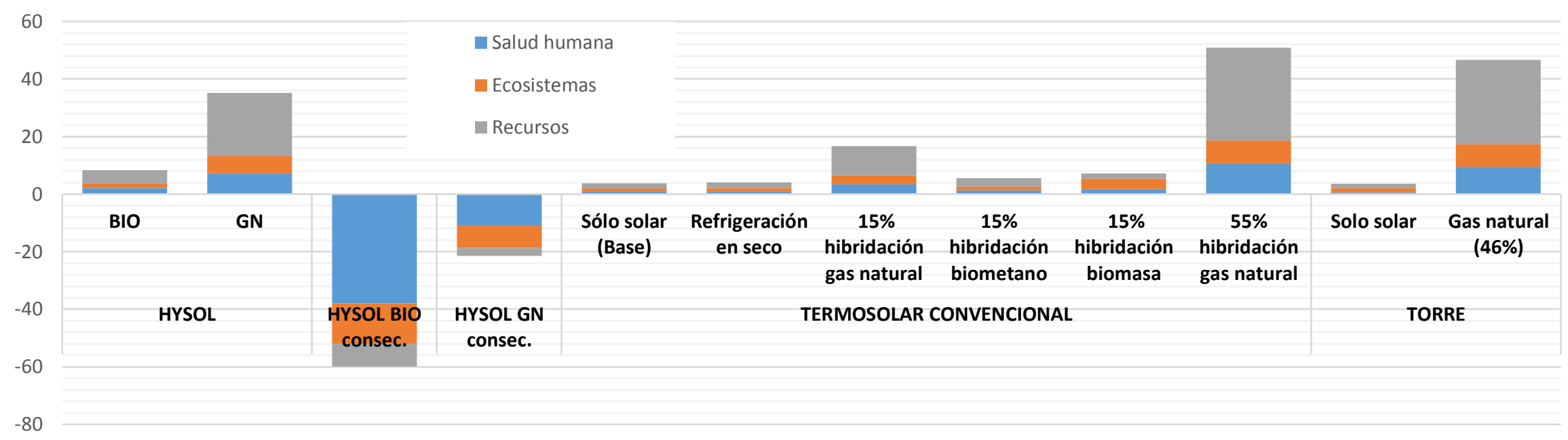

Figura 55 Perfil de ponderación de los escenarios planteados en el área ambiental: planta HYSOL BIO, planta HYSOL GN, termosolar convencional en 6 escenarios, termosolar de torre en modo sólo solar, y termosolar de torre hibridada con gas natural 



\section{CAPÍTULO 4 Análisis del área económica}

Este capítulo contiene el análisis del área económica de tecnología HYSOL según lo definido en el Capítulo 2 de esta tesis, y está compuesto por dos apartados principales. El primer apartado contiene el estado del arte, metodología y resultados del Análisis de Costes de Ciclo de Vida (CCV). En él se describe el análisis CCV-Ambiental Completo de la tecnología HYSOL en sus dos escenarios (HYSOL BIO y HYSOL GN), así como de la tecnología termosolar convencional (TERMOSOLAR CCP). El objetivo es evaluar y comparar el impacto económico de las tecnologías en cuestión, considerando no sólo las externalidades susceptibles de internalizarse en un futuro próximo (como los GEI) si no también otras externalidades derivadas de impactos ambientales. El estudio también proporciona una descripción detallada del procedimiento diseñado para integrar los resultados del ACV-A en un CCV dentro de un contexto energético. El análisis se basa en la perspectiva del promotor del proyecto y no toma en consideración los aspectos económicos y ambientales asociados con el uso de la electricidad por el usuario final.

El segundo apartado de este capítulo describe el estado de arte, metodología y resultados del Análisis Input Output Multiregional (MRIO) de la tecnología HYSOL. En él se describe la metodología de dicho análisis y se propone una adaptación de la misma para integrar el enfoque consecuencial en el análisis MRIO de una tecnología de generación de electricidad. También se aportan, discuten y comparan los resultados del MRIO aplicado a la planta HYSOL (en sus dos escenarios) y a la planta termosolar convencional (TERMOSOLAR CCP).

Viable

Economía

Equitativo

Figura 56 Área económica de la sostenibilidad 


\subsection{ANÁLISIS DE COSTES DE CICLO DE VIDA}

\subsubsection{Introducción}

El análisis de Costes de Ciclo de Vida (CCV) es una herramienta encaminada a cuantificar todos los costes monetarios asociados con el ciclo de vida de un producto según la perspectiva de uno o varios agentes vinculados a dicho ciclo de vida. Su objetivo principal es la gestión (no contabilidad) de los costes económicos para encontrar puntos de doble beneficio (en inglés, winwin) tanto en el aspecto económico como en el ambiental y ayudar en la toma de decisiones. Los orígenes de esta metodología se remontan al año 1930, cuyo desarrollo vino determinado por necesidades militares de gestión de costes económicos en distintas fases del ciclo de vida de los productos. Se aplicó oficialmente por primera vez en 1960, por el Departamento de Defensa de Estados Unidos (Ciroth et al. 2008). No fue hasta más adelante, con la aparición del pensamiento de ciclo de vida y el desarrollo de las metodologías de ACV, que surgieron otros tipos de análisis CCV que incluían costes ambientales y/o sociales.

Más adelante, en el año 2003, Rebitzer y Hunkeler (2003) abordaron la metodología del CCV desde un punto de vista conceptual, explorando la relación del CCV con los aspectos de la Gestión de Ciclo de Vida, y definiendo los distintos costes que se incluyen. En su publicación diferencian entre costes internos (aquellos costes asociados con la producción, uso, o fin de vida del sistema que son pagados por algún actor del ciclo de vida) y externos (aquellos que incluyen la monetización de los efectos ambientales o sociales de producir, usar, o desechar el producto y que no son directamente pagados por la empresa, consumidor o gobierno). También hacen una reflexión sobre los impuestos y subvenciones estatales y el papel que tienen a la hora de internalizar los costes externos de los productos. Por ejemplo, en el caso de los cigarrillos, el gobierno impone un impuesto a su compraventa que pretende internalizar los costes sociales sanitarios derivados del consumo de tabaco. Sin embargo, en muchas ocasiones esta tarificación no se realiza de forma justa, o no incluye todos los costes asociados al daño que provoca el tabaco en los humanos y el entorno.

La revisión bibliográfica sobre CCV revela cierta heterogeneidad en las denominaciones de los distintos tipos de CCV por la comunidad científica, aunque la más extendida podría ser la denominación de los autores Ciroth et al. (2008), en la que hay tres tipos de análisis CCV:

- "CCV tradicional". Corresponde al histórico y convencional, cuyo origen se remonta a 1930. El objetivo principal es tener en cuenta los gastos de operación, mantenimiento y fin de 
vida, no sólo los costes de adquisición. La perspectiva se toma desde un solo actor (el productor, consumidor, etc.). No suelen incluirse los gastos que tienen otros actores. Este CCV se ha desarrollado debido principalmente a aplicaciones específicas (edificios públicos, productos de alto coste como los vehículos militares...). No hay un marco metodológico aplicable general, aunque sí algunas tendencias.

- "CCV Ambiental". Incluye el análisis de todos los costes asociados al ciclo de vida de un producto que están cubiertos por uno o más actores en su vida -proveedor, fabricante, usuario- con la inclusión de externalidades que vayan a internalizarse en un futuro próximo (por ej. Emisiones de $\mathrm{CO}_{2}$ ) y que servirán para la toma de decisiones. El resto de impactos ambientales que no se prevé internalizar en un futuro próximo se reportan de forma separada, no monetizados. Las subvenciones o impuestos suelen incluirse. El CCV ambiental no debería sustituir otros métodos de contabilidad o gestión económica, sino servir como una herramienta estandarizada para estimar diferencias relevantes entre alternativas o encontrar puntos de mejora dentro de un ciclo de vida. Una vez combinado con un ACV, sirve para identificar situaciones win-win en el ciclo de vida de un sistema/producto.

- "CCV Social". Tiene en cuenta todos los costes asociados al ciclo de vida de un producto/sistema que son cubiertos por cualquiera en la sociedad (tanto hoy como en un futuro). Incluye externalidades asociadas a impactos sociales además de ambientales. Este método todavía no está completamente desarrollado por la comunidad científica. Hoogmartens et al. (2014) denominan también este tipo de estudios como “CCV Ambiental Completo" (traducido del inglés, Full environmental Life Cycle Costing, FeLCC) a aquel CCV Ambiental que no monetiza sólo las externalidades que se esperan internalizar en un futuro próximo, sino también otro tipo de externalidades ambientales.

Para el cálculo de costes externos es necesaria la aplicación de metodologías de monetización de externalidades. Éstas se basan en asignar costes monetarios a los impactos producidos en el medioambiente o sociedad, como en el enfoque de costes de daños, o en calcular los costes que supondrían evitar dichos impactos, como en el enfoque de evitación del daño. Para ello se utilizan herramientas desarrolladas por economistas como los Precios Hedónicos, Costes de Viaje, Costes de Control o Métodos de Valoración Contingente.

Algunos autores como Gluch y Baumann (2004) dudan de la idoneidad de utilizar el CCV en su sentido tradicional como herramienta para evaluar consecuencias medio ambientales. En sus argumentos indican que la teoría económica neoclásica actual que plantea un crecimiento infinito no se ajusta satisfactoriamente a la monetización de recursos naturales (que son de 
CAPÍTULO 4: Análisis del área económica

naturaleza finita). Por ello, justifican lo inadecuado de utilizar una unidad monetaria para contabilizar algo tan complejo como es el medioambiente. Además, resaltan la gran incertidumbre que va asociada a estas técnicas de monetización. Para evitar las imprecisiones del CCV Ambiental, proponen asegurar la calidad de la información de partida y combinar con estudios de ACV para medir el impacto mediante valores físicos.

\subsubsection{Aspectos metodológicos}

El marco general para el desarrollo de la metodología de CCV, basado en las normas UNEEN ISO 14040 -14044 se describe en las siguientes subsecciones (Ciroth et al. 2008).

\subsection{Definición de objetivo y alcance.}

El objetivo de análisis debe definirse antes de empezar el estudio, ya que no existe una estructura metodológica única en cuanto a categorías y resultados, si no que la estructura del CCV presenta variaciones dependiendo del objetivo del estudio y de la disponibilidad de información. A continuación se muestran ejemplos de posibles objetivos:

- Identificación de costes totales para cada actor de la cadena de valor con el objetivo de: Analizar la competitividad de un producto (identificando los costes para el consumidor), identificar una ocasión de negocio o considerar el efecto de costes a largo plazo.

- Reportar, monitorear e influenciar proactivamente sobre los costes de una empresa.

- Identificar distintas alternativas para el desarrollo de producto o para oportunidades de márquetin.

- Identificar procesos que producen beneficios o perjuicios tanto en el ámbito ambiental como económico.

- Estimar el coste real para la sociedad de varias alternativas de negocio.

- Fiscalización ambiental de actividades económicas.

El alcance de un CCV ambiental y la unidad funcional deberían coincidir en el ACV y el CCV en el caso de que fueran a analizarse en conjunto. Sin embargo, hay ciertas actividades que no se suelen incluir en un ACV debido a su baja carga ambiental, pero sí deberían incluirse en el $\mathrm{CCV}$, ya que suponen partidas de costes relevantes. Ejemplo de actividades que suelen incluirse en un CCV y no en un ACV serían las fases de investigación y desarrollo o márquetin. Esta diferencia de alcances está permitida y no afecta a la coherencia del análisis de sostenibilidad 
Los impuestos y subvenciones a actividades de producción que están regulados adecuadamente deberían representar en el mercado a las externalidades causadas por impactos ambientales y sociales. Sin embargo, en la mayor parte de las ocasiones esto no ocurre y es necesario incluir el cálculo de externalidades para conocer el coste real de las actividades de producción.

\subsection{Recogida y evaluación de información: Análisis de inventario}

En esta etapa se recogen todos los datos técnicos, económicos y financieros necesarios para la evaluar los costes internos y externos del ciclo de vida. Los flujos de referencia deben definirse en concordancia con la unidad funcional. La unidad funcional en un CCV debe coincidir con la del ACV cuando se analizan de forma conjunta (o en el marco de un análisis de sostenibilidad).

Al igual que en el ACV, la recogida de inventario se basa en recopilar información asociada a procesos unitarios, cuyos niveles de agregación dependen de la información recogida y de la naturaleza del análisis. En muchas ocasiones hay puntos de conexión entre el inventario ambiental y el económico, ya que muchos materiales y flujos ( $p$ ej. la electricidad) están directa o indirectamente relacionados con los costes. Sin embargo, mientras que es común que en un ACV se utilicen datos promedio del mercado, especial atención debe prestarse al escoger costes generales para el inventario de un CCV, ya que estos pueden variar enormemente. Lo mejor es conseguir información específica para el objeto o sistema bajo estudio.

\subsection{Evaluación de impacto}

En esta etapa se procesa la información recogida en la fase de inventario para obtener los resultados del análisis. Primero se realiza una clasificación de costes (internos y externos) en las categorías de costes predefinidas. En un CCV tradicional o Social, estas categorías se cuantifican teniendo en cuenta un modelo semiestático en el que se incluye el valor del dinero en el tiempo, y por lo tanto, se aplican tasas de descuento. Por último, se procede a la agregación de los resultados para obtener el coste de ciclo de vida del sistema analizado.

Junto al coste de ciclo de vida del producto, los resultados pueden representarse mediante indicadores de distinta naturaleza. En aquellos ciclos de vida donde se evalúa un proyecto de inversión, puede ser interesante representar los resultados mediante el Valor Actual Neto (VAN) o la Tasa Interna de Retorno (TIR), ya que proporcionan información sobre la rentabilidad del sistema. En aquellos ciclos de vida en los que se consideran distintos agentes de la cadena de valor, puede ser interesante representar los resultados mediante el valor añadido acumulado en dicha cadena de valor. En el caso de la producción de electricidad, el resultado 
del coste de ciclo de vida de la electricidad es muy similar al cálculo del coste nivelado de la energía (LEC, del inglés, Levelized Cost of Energy), que representa el precio constante de la electricidad producida por una tecnología considerando todos los costes del ciclo de vida.

\subsection{Interpretación de resultados.}

En esta etapa se determinan qué fases generan los principales costes internos y externos para identificar los puntos conflictivos en común, con el objetivo de incidir en ellos y encontrar puntos de mejora. También deben indicarse las decisiones metodológicas más relevantes cuando éstas afectan al resultado final, por ejemplo, debe indicarse si los resultados son específicos de los productos analizados, ya que si no lo fueran deberían contener información de los productos de la media del mercado y definirse como tales.

Aunque los análisis de sensibilidad no son obligatorios, se recomiendan encarecidamente. Dichos análisis deberían ser la base de la discusión final y del desarrollo de recomendaciones, ya que permiten saber cómo varían los resultados cambiando los valores de entradas, o cómo se pueden variar valores de entrada sin que cambien significativamente los de salida.

\subsection{La tasa de descuento en el análisis de Costes de Ciclo de Vida}

La tasa de descuento es un parámetro del CCV que adquiere distintos significados y valores según el tipo de análisis, el objetivo, y el alcance. La tasa de descuento representa el cambio del valor del dinero en el tiempo, y puede variar dependiendo de si hace referencia únicamente a la tasa de inflación general, o refleja también la rentabilidad esperada por el proyecto de inversión (que generalmente incluye una prima representativa del riesgo característico del proyecto). Además de la tasa de descuento económica, un CCV Ambiental o Social debería incluir también una tasa de descuento social aplicada a las externalidades. Esta tasa se basa en las decisiones de la sociedad en cuanto al coste de los daños y perjuicios producidos por la contaminación ambiental y representa la tasa de preferencia temporal (aquella que incluye las preferencias sociales del presente respecto a las del futuro). La tasa de descuento intergeneracional (o tasa de descuento a largo plazo) se aplica a aquellos impactos que ocurren en un futuro medio o lejano (Rabl et al. 2014). La literatura científica reporta tasas de descuento sociales que oscilan entre un 2 y $15 \%$ para proyectos de energía (Harrison 2010).

El uso de una tasa de descuento en un CCV cuyos resultados van a integrarse con un ACV puede presentar incoherencias, ya que la metodología de ACV no considera ninguna tasa de descuento en los resultados al tratarse de modelos estáticos en el tiempo. Por ello, algunos autores recomiendan no utilizar tasas de descuento en los resultados de CCV-Ambientales, 
aunque sí recomiendan considerar el descuento para flujos monetarios que ocurren en distintos momentos de un ciclo temporal corto (entre 5 y 15 años) (Hunkeler et al. 2008).

\subsubsection{Cálculo monetario de externalidades}

Las externalidades se definen como cambios en el medioambiente o el bienestar social cuyo coste no está incluido en el precio de la actividad comercial que los causa (Hunkeler et al. 2008). Cuando las consecuencias de dichos cambios se expresan en términos monetarios se llaman externalidades monetizadas. La monetización de las externalidades se debe realizar e interpretar con cautela, ya que es un proceso complejo con alta incertidumbre en el que se tiende a generar perspectivas antropogénicas, occidentalizadas, y simplistas.

Hay principalmente dos enfoques encaminados a la valorización económica de impactos ambientales: enfoque por Costes del Daño (del inglés, Damage Cost Approach) o enfoque de costes de Evitación del Daño (del inglés, Abatement Costs). El primero consiste en asignar un valor económico a los daños o contaminación producida, mientras que el segundo consiste en considerar los costes de evitar o controlar que el daño se produzca (p. ej. el cálculo de los costes asociados con la implementación técnicas de reducción o mitigación de emisiones generadas). Algunos autores recomiendan enfoques de Costes del Daño en lugar de Evitación del Daño, ya que estos últimos se basan generalmente en los mercados y regulaciones que no siempre representan adecuadamente la realidad (Burtraw et al. 2012).

La principal dificultad del primer enfoque es la asignación de valor económico a los bienes ambientales o sociales no mercantilizados, p. ej. los años de vida perdidos o las muertes ocasionadas. Los métodos desarrollados para la monetización de bienes no mercantilizados pueden agruparse en dos categorías: preferencias reveladas o preferencias establecidas

Los métodos de Valorización Contingente (VC) se incluyen en la categoría de preferencias reveladas. Están basados en preguntar a individuos sobre su disposición a pagar (WTP, del inglés, Willingness To Pay) o disposición a aceptar (WTA, del inglés, Willingness to Accept) para evitar impactos ambientales que ocurrirían en escenarios hipotéticos. Estos estudios suelen aplicarse para determinar el Valor Estadístico de Vida, o el Valor Monetario de un Año de Vida. Mientras que el primero está basado en monetizar muertes accidentales, el segundo mide los cambios en la esperanza de vida (adelanto del momento de la muerte) sin que haya cambios significativos en la naturaleza de la muerte, como es el caso de los impactos de la contaminación aérea en la salud humana (Desaigues et al. 2011). 
En la categoría de preferencias establecidas se incluyen métodos donde la valoración económica se realiza mediante el análisis de la elección de consumidores ante distintas opciones que presentan distintos riesgos. Métodos aquí clasificados serían los Precios Hedónicos o Costes de Viajes (Rabl et al. 2014). Los Salarios Hedónicos es un ejemplo de método de Precios Hedónicos que trata de cuantificar mediante unidades monetarias la disposición marginal a pagar de los trabajadores ante una reducción del riesgo de muerte mediante el análisis de la relación salario-riesgo (Font et al. 2007). Este tipo de métodos puede tener sesgos que induzcan a interpretaciones erróneas, como en el caso de actividades en las que los trabajadores con menores sueldos son las que presentan mayores riesgos y viceversa ( $p$. ej. Mineros versus directivos de empresas mineras).

La monetización de externalidades ha sido abordada por varios proyectos internacionales, siendo los más importantes ExternE, NEEDS y CASES.

El proyecto ExternE, financiado por la Comisión Europea, evalúa las externalidades de la producción eléctrica siguiendo el enfoque de ciclo de vida. En su informe final (Bickel and Friedrich 2004, Krewitt 2002), ofrece una metodología para calcular dichas externalidades. Para la monetización de los impactos de la contaminación en el medioambiente sigue el enfoque de Costes de Daño, mediante el desarrollo del "Enfoque del Camino de Impacto". Para los efectos nocivos del calentamiento global, recomienda el enfoque de Evitación del Daño.

El Enfoque del Camino de Impacto consiste en los siguientes pasos (ver Figura 57): en primer lugar se determinan las emisiones producidas por el producto/sistema, después se calcula la dispersión en el medio de dichas emisiones para obtener el impacto físico en el medio. Finalmente, se procede a calcular el coste o monetización de dichos impactos.

El informe final del proyecto ExternE proporciona varios valores de costes de daño, medidos en euros por tonelada de contaminante emitida, para distintos contaminantes. Krewitt (2002) indica que el proyecto ExternE aporta herramientas para calcular los costes externos, y que a pesar de presentar muchas incertidumbres, se pueden utilizar satisfactoriamente para poyar políticas medioambientales.

El proyecto internacional NEEDS tuvo lugar entre los años 2005 y 2009, y fue financiado por la Comisión Europea (NEEDS 2009). El objetivo final del proyecto era evaluar la totalidad de los costes y beneficios (costes directos y externos) de las políticas y sistemas de energía futuros, tanto a nivel de países individuales como para la UE ampliada en su totalidad. Para ello, se proponen distintos métodos que incluyen el Análisis Multi-criterio, el CCV y el “Enfoque de Coste Total". 

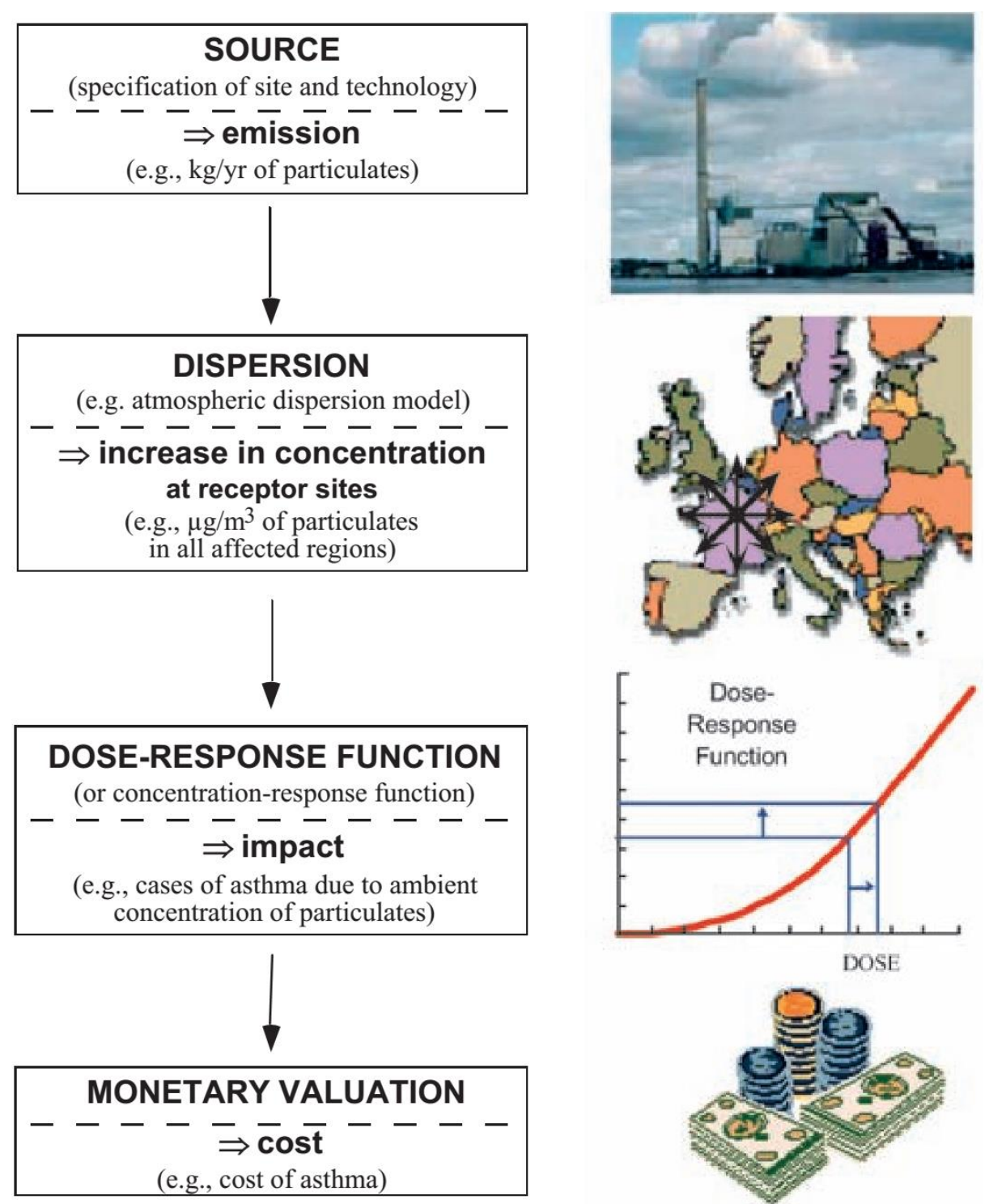

Figura 57 Ejemplo de la metodología "Enfoque de camino de impacto" aplicada en ExternE, siguiendo el ejemplo de la contaminación aérea. (Bickel and Friedrich 2004)

El Enfoque de Coste Total mantiene un enfoque económico en el que se tienen en cuenta los costes privados y externos (externalidades) del sistema/producto. Según se indica en el informe, la monetización debería basarse en preferencias sociales y no mediante el juicio de expertos o políticos, y en el caso de que los daños producidos sean inciertos (como en el caso del cambio climático), son preferibles los métodos de Evitación del Daño que los de Costes del Daño.

El proyecto CASES, cuyo nombre es un acrónimo de "Cost Assessment for Sustainable Energy Systems", profundiza en la metodología y resultados desarrollados previamente en los proyectos ExternE y NEEDS (CASES Project 2009). Sus objetivos principales son la estimación de costes internos y externos de la producción de energía para distintos países, la evaluación de opciones políticas para mejorar la eficiencia del uso energético teniendo en cuenta información 
de costes completa, y diseminar los resultados tanto al sector energético como a los usuarios y los legisladores.

Uno de los informes finales del proyecto, está enfocado a la metodología de monetización de externalidades debidas a cambios de uso del suelo, acidificación, eutrofización, intrusión visual y cambio climático (Kuik et al. 2007). Este informe incluye una pequeña disertación sobre la moralidad relativa a la valorización económica de recursos naturales, ya que resulta controvertido monetizar la naturaleza, de tal forma que pueda "reducirse" a una mercancía intercambiable en un mercado. Además, lo más probable es que en el proceso de monetización, sea inevitable una visión antropocéntrica que subestime el bien de generaciones futuras o de otras especies. Es por ello que se asume que la monetización de las externalidades relativas a la pérdida de biodiversidad y usos del suelo están basadas únicamente en preferencias humanas actuales, que pueden tener en cuenta (o no) los intereses de otras especies, o de generaciones futuras.

En la monetización de los cambios de uso del suelo, se indica que el enfoque utilizado se basa en el desarrollado por el proyecto NEEDS. Calcula la fracción potencial de desaparición (PDF, del inglés, Potentialy Dissapeared Fraction) de biodiversidad debida al cambio de tipo de suelo. Además, también incluye el daño en el ecosistema vía contaminación aérea, calculado como la PDF producida por emisiones aéreas causantes de acidificación (SOx, $\mathrm{NOx}, \mathrm{NH}_{3}$ ). Para la valorización económica, propone utilizar los costes de restauración del ecosistema (enfoque de control del daño) mediante estudios alemanes que lo cuantifican. El proyecto también tiene en cuenta daños a ecosistemas acuáticos debidos a la acidificación y eutrofización (el proyecto NEEDS no los tenía en cuenta).

Mediante el proyecto CASES también se calculan funciones para monetizar según enfoques de valoración contingente WTP para prevenir daños en distintos países; este valor depende de cuestiones como la densidad de población, área del ecosistema, o escala de cambio de uso, entre otros, y resultan ser ligeramente superiores a los aportados por el enfoque de Costes del Daño.

Para el impacto de acidificación, eutrofización e intrusión visual de la las tecnologías de producción eléctrica eólica e hidroeléctrica, el proyecto CASES hace un estudio de las publicaciones existentes para aplicar la función de transferencia de beneficios (traducido del inglés, benefit transfer function). Esta función permite adaptar los resultados de valorización económica de una región a otra. Estas aproximaciones pueden hacerse de varias formas; utilizando los mismos datos de emisión y adaptándolos a las concentraciones, efectos en la salud 
y/o WTP de la población estudiada, o utilizando distintos datos de emisión, pero mismas concentraciones, efectos en la salud y/o WTP de la población bajo estudio.

Debido a la complejidad de predicción en el cambio climático, se suelen utilizar modelos específicos llamados Modelos de Análisis Integrados (del inglés, Integrated Assessment Models, $I A M)$, que combinan conocimientos de distintas áreas y naturaleza junto con modelos numéricos con el objetivo de facilitar la toma de decisiones políticas.

El proyecto CASES introduce varios puntos de controversia y debate sobre los distintos tipos de métodos de monetización de externalidades. Según el estudio de Stern (Stern 2007) los impactos económicos del cambio climático (calculados mediante el modelo IAM Ilamado PAGE) podrían estar entre el $5 \%$ y $20 \%$ o más del Producto Interior Bruto (PIB) global, dependiendo del escenario. Sin embargo, los impactos económicos calculados mediante el coste de reducción de emisiones podrían estar en torno al $1 \%$ del PIB global cada año. Cabe destacar que Stern aplicó una tasa de preferencia temporal pura muy baja $(0,1 \%)$, y un horizonte infinito, por lo que los resultados pueden estar sobredimensionados. Además se argumenta que tal vez no sea el mejor método debido a las grandes incertidumbres de efectos en catástrofes extremas, y que otro tipo de enfoques basados en la prevención del coste deberían aplicarse.

Otro aspecto que añade incertidumbre y controversia es el ponderado ético. El agregar impactos monetizados del cambio climático (que es un impacto global) en personas con muy diferentes niveles de ingreso es problemático; aplicar ponderado ético hace que el coste de daño de $\mathrm{CO}_{2}$ sea superior (Anthoff et al. 2009). Sin embargo, esto crea incongruencias cuando se trata de utilizar los datos para regiones específicas como Europa, ya que puede hacer que los impactos en esta categoría tengan un valor menor que en otros tóxicos aéreos no ponderados éticamente.

\subsubsection{Revisión de estudios de Costes de Ciclo de Vida}

A continuación, se comentan brevemente algunos de los estudios que se han considerado relevantes para el desarrollo internacional del CCV como metodología. Estos estudios han sido encontrados mediante las herramientas de búsqueda bibliográfica de la Web Of Science (WOS) y Google Scholar, escogiéndose sólo aquellas publicaciones de revistas de investigación internacionales, así como informes de proyectos o de instituciones reconocidas a nivel internacional. Los 12 estudios escogidos (Burtraw et al. 2012, L. Simões et al. 2013, Lee et al. 2009, Lee et al. 2010, Mirasgedis and Diakoulaki 1997, Notarnicola et al. 2004, Rebitzer et al. 2003, Roth and Ambs 2004, Schau et al. 2011, Silalertruksa et al. 2012, Söderholm and Sundqvist 2003, Sundqvist 2004) incluyen análisis CCV de los siguientes sectores: tecnologías de generación eléctrica, combustibles para transporte, alternadores eléctricos, sistemas de 
tratamiento de aguas, materiales, productos alimenticios y/o discusiones sobre cuestiones de desarrollo metodológico.

La primera publicación encontrada sobre CCV de tecnologías de producción eléctrica se remonta a finales de los 90, cuando Mirasgedis y Diakoulaki (1997) comparaba en su estudio ambiental y económico distintos métodos (la monetización de externalidades o el análisis multicriterio) para evaluar la idoneidad de algunas fuentes de producción eléctrica: nuclear, carbón, petróleo, lignito, gas natural, eólica, hidroeléctrica. Para la cuantificación y evaluación de externalidades medioambientales aplicaba el enfoque de Costes del Daño en base al análisis del ciclo de vida. En sus resultados y conclusiones, destacaba que aunque el análisis multicriterio evita las incertidumbres de la monetización, la monetización permite obtener resultados más comprensibles por la sociedad (al ser su indicador comprendido por todos) y por lo tanto son más aptos para la toma de decisiones. En cuanto a resultados, ambos métodos concluían en que hay una relación directa entre las fuentes de electricidad más utilizadas y las que presentan mayor impacto ambiental.

Roth y Ambs (2004) determinaron el LEC de 14 tecnologías de generación eléctrica, incorporando las externalidades como costes añadidos. Como técnica de cálculo, utilizaron el CCV. Para la incorporación de externalidades se utilizó el enfoque de Costes del Daño y distintos factores de emisión. Los Costes del Daño en este caso se contabilizan como el coste de los efectos externos de un contaminante, incluyendo costes del daño aproximados derivados de costes de control (el coste de limpiar dichas emisiones, asumiendo que son aproximaciones razonables al impacto económico del daño causado). Utilizan tres valores: el más bajo, el "best estimate" (las medianas de las referencias consultadas) y el más alto. Ni el más bajo ni el más alto representan valores extremos, sino rangos consistentes de la literatura científica. Las referencias de las que se sirven para obtener los datos de monetización de las externalidades son anteriores al año 2000.

Debido al aumento de estudios sobre las externalidades de la producción eléctrica, surgen dudas y cuestionamientos en la comunidad científica sobre las metodologías empleadas. En el informe titulado "The True Cost of Electric Power" (El verdadero precio de la electricidad), de Resources for the Future (RFF) (Burtraw et al. 2012), se hace un repaso crítico de las metodologías para contabilizar externalidades sociales y medioambientales en la electricidad. En primer lugar analiza los métodos asociados a estudios primarios que desarrollan estimaciones para costes sociales, discutiendo el enfoque Costes del Daño contra Costes de Evitación del Daño y revisando las diferencias entre estudios primarios y "Estudios de transferencia de beneficios". 
Como conclusiones, señala las principales cuestiones que deben tenerse en cuenta al asignar externalidades, éstas son:

- Lugar específico: No produce el mismo impacto en el ambiente emitir determinados contaminantes de efecto local (como los precursores de ozono) en una zona con alta densidad demográfica que en una con ninguna.

- Nivel de tecnología: No tienen la misma eficiencia ni el mismo control de emisiones una planta con tecnología antigua que una con tecnología nueva (normalmente a las nuevas se le aplican medidas más restrictivas).

- Se debe tener en cuenta todo el ciclo de vida, o en su defecto el "ciclo del combustible" y la fase de generación (si es que son los elementos con mayor impacto).

- Considerar la idoneidad de los caminos de impacto escogidos y la validez de sus técnicas de estimación.

- El tiempo y el espacio: La extensión del espacio afectado por los contaminantes es un factor importante a considerar. En cuanto al tiempo, resulta difícil de comparar un combustible que genera impactos año a año, con otros cuyo impacto se espera más a futuro (por ejemplo, carbón versus nuclear). El "descuento social" está pensado para lidiar con esas situaciones.

- Reconocer los daños que ya están monetizados y no incluirlos en las externalidades. Por ejemplo, un trabajador de una mina con peligro tiene mayor sueldo debido al riesgo, aunque resulta complicado saber hasta qué punto refleja la realidad.

- La incertidumbre: Es importante contabilizar las incertidumbres que se van acumulando en la cadena. El análisis de Monte Carlo se ofrece como opción para el análisis de incertidumbre.

Söderholm y Sundqvist (2003) han explorado las limitaciones éticas de la monetización ambiental, así como la implicación de los límites para la elección social de las distintas fuentes de electricidad. Afirman que la investigación sobre externalidades medioambientales de la energía debe abarcar instrumentos y contenidos del debate moral y político. Según los autores, uno de los objetivos principales de las políticas energéticas y medioambientales es conseguir precios justos, teniendo en cuenta las externalidades. Los investigadores del campo de las ciencias sociales cuestionan el uso de las técnicas de valorización considerando que producen descripciones pobres de los valores medioambientales que la gente tiene y por lo tanto suponen indicaciones inadecuadas para las decisiones políticas. No obstante, también argumentan que las externalidades confirman la diferencia del precio privado y el social, afirmando que aunque 
éstas no se reflejen en el mercado, tienen un impacto directo en el bienestar de las personas, y por lo tanto en el valor económico. Los autores reconocen que la visión del artículo es, al igual que la de la economía del bienestar, antropocéntrica. Sin embargo, la gente posee distintas predisposiciones dependiendo de las circunstancias ( $y$ no solo una, como se supone en la economía del bienestar). Por lo tanto, no sólo deberían tenerse en cuenta criterios económicos para la toma de decisiones, si no también acuerdos sociales sobre cuáles son los criterios más importantes. Como conclusión, afirman que las externalidades y compensaciones son necesarias, sin embargo, los métodos actuales se basan en asunciones de comportamiento restrictivas y principios éticos de la literatura de economía del bienestar. Contra esto argumentan que no se puede asumir que todos los humanos tienen una función de utilidad bien definida para todas las ocasiones, sino que ésta cambia con el tiempo y las situaciones emergentes, y por lo tanto, es compleja y dinámica. Cualquier proceso político de toma de decisiones debería incorporar estas complejidades.

Un año después, Sundqvist (2004) analizó 38 estudios de externalidades en el sector de la electricidad para encontrar la causa de las diferencias entre resultados. Estimó que las diferencias estaban debidas principalmente a cuestiones metodológicas: las magnitudes entre combustibles, la inclusión de distintos impactos o fases del ciclo de vida, etc. Sin embargo, no fue capaz de explicar toda la variabilidad encontrada. En conclusión, indicaba que los estudios de externalidades deberían desarrollarse con mayor profundidad para ser de mayor utilidad en la formulación política.

Rebitzer et al. (2003) realizan en su estudio un CCV (con la denominación "CCV basado en ACV") de tratamientos de depuración de aguas en Suiza. Aclaran que no es un método para realizar contabilidad detallada de costes, sino que tiene como objetivo realizar estimaciones para mejorar el desarrollo del producto o su desenvoltura en el mercado. Afirman que el inventario de un ACV es un buen punto de partida para identificar y asignar costes a todas aquellas actividades o procesos del ciclo de vida del sistema. En su estudio, no estructura los resultados por categoría de costes (sólo por actividades), y tampoco tiene en cuenta las externalidades en términos monetarios, aunque sí aporta para sus comparaciones el dato de emisión de GEl (Gases de Efecto Invernadero) medido en $\mathrm{kg} \mathrm{CO}_{2}$ eq.

El estudio de Notarnicola et al. (2004) analiza bajo la perspectiva del ACV y el CCV, la producción "orgánica" de aceite de oliva italiano y la compara con la convencional. El objetivo es determinar sus perfiles ambientales y económicos para verificar si las dos dimensiones van en la misma dirección. El ACV sigue los estándares ISO 14040 y 14044, y utiliza el método de 
evaluación CML. En el análisis CCV se tienen en cuenta las externalidades según el informe de ExternE relativo a Italia, incluyendo los costes sociales de los pesticidas calculados en otro estudio de la Universidad de Bocconi (Italia). No especifica ningún tipo de categorías de coste (salvo externos e internos), y tampoco especifica detalles sobre la metodología de CCV aplicada. En los resultados se puede observar que, a pesar de que los costes internos sean menores en la producción convencional, cuando se tienen en cuenta los costes externos, la producción orgánica pasa a obtener mejor resultado.

Lee et al (2009) utiliza la metodología CCV con el fin de estimar la vía más económicamente eficiente para utilizar el hidrógeno como combustible de transporte en Korea. En su estudio, además de tener en cuenta los costes internos de los ciclos "del pozo al tanque" y "del tanque a la rueda", relativos a la producción y uso del combustible, también tienen en cuenta las externalidades asociadas a los efectos de los GEI y de la contaminación aérea. Los autores denominan estas externalidades como "costes sociales", en la línea de la definición de "CCV Social" que consideran Ciroth et al. (2008). Para obtener los costes del daño asociados a cada contaminante utilizan tres valores: el máximo, la media y el mínimo obtenidos de una serie de 6 referencias bibliográficas. Las categorización de los costes del estudio difiere según la fase del ciclo analizada; en el sistema "del pozo al tanque" las categorías de coste son costes capitales, costes de materias primas, costes de operación y mantenimiento, costes de distribución del combustible e impuestos de combustible, mientras que en el sistema "del tanque a la rueda" las categorías de coste son costes de registro, costes de operación y costes del vehículo.

Más adelante, los mismos autores publican otro estudio (Lee et al. 2010), en el que se analiza el impacto ambiental y aspectos económicos de una estación de hidrógeno para combustible de vehículos utilizando energía eólica, comparada con una de gasolina. La metodología utilizada es ACV (incluyendo las categorías de calentamiento global, agotamiento de recursos abióticos y contaminantes aéreos regulados) y CCV. Este último incluye las categorías de costes capitales (preparación, construcción y compra de componentes), costes de operación y mantenimiento (materiales, energía, personal etc.) y otros costes (compra del vehículo, distribución del combustible, impuestos, seguros, pruebas de control, etc.). El CCV está estimado para dos sistemas: el pozo-tanque (WTT) y el tanque-ruedas (TTW). Los cálculos incluyen la reducción de los costes de combustibles para el 2015, aplicando una tasa de descuento diferente para la instalación eólica (7\%) y la planta de hidrógeno (8\%). Como resultados, indican que el ahorro económico y de $\mathrm{kg}^{\mathrm{CO}_{2}}$ obtenido por la alternativa propuesta compensaría con creces sustituir el $5 \%$ de vehículos convencionales en Korea por otros operados con hidrógeno. 
Los combustibles para el transporte también han sido objeto de estudio para Silalertruksa et al. (2012), que analizan los costes internos y externos de ciclo de vida del biodiesel procedente de aceite de palma en comparación con el diésel convencional. Para ello utilizan la metodología CCV. En dicho estudio, calculan las externalidades mediante los WTP (voluntad a pagar) utilizados para la ponderación en el método de evaluación de impacto ambiental llamado EPS 2000 (del inglés, Environmental Priority Strategy). En este caso, la categorización del coste interno también difiere según la fase del ciclo de vida del sistema (cultivo de la palma, fabricación del aceite y fabricación de biodiesel), siendo la suma total de costes el valor comparativo entre escenarios. Al igual que en el estudio del aceite de oliva orgánico italiano, cuando se internalizan los costes externos de la producción de los combustibles comparados, el biodiesel pasa a ser competitivo respecto al diésel convencional.

Schau et al (2011) estudian la aplicación de la metodología CCV como parte de un análisis de sostenibilidad donde también se estudia la parte social y ambiental. El sistema de estudio son tres diseños diferentes de alternadores re-fabricados según 3 ubicaciones diferentes. En su estudio, indica la importancia de aportar distintas perspectivas (la del fabricante o la del usuario), ya que resulta imposible adoptar una perspectiva integral en la que los costes del primero equivalgan al coste de adquisición del segundo. También diserta sobre el crecimiento económico que supone crear valor añadido (beneficios) en la cadena de producto, y cuestiona que sea el fin del pilar económico de la sostenibilidad.

Simões et al. (2013) integran en su estudio las metodologías ACV y CCV para comparar un material polimérico reciclado con su variante sin reciclar. En su revisión bibliográfica detectan que la mayoría de artículos de investigación sobre CCV no tienen en cuenta las externalidades. En su estudio de CCV, analiza las externalidades debido a emisiones de $\mathrm{CO}_{2}$ eq, $\mathrm{SO}_{2}, \mathrm{NOx}$ y partículas menores a 2,5 $\mu \mathrm{m}$. Para los gases de efecto invernadero utiliza el precio del mercado de carbono según el mercado europeo de emisiones. Para el resto de emisiones, al no haber un mercado, se han considerado los costes de daño según Watkiss et al. (2002).

En resumen, las publicaciones revisadas cuestionan la precisión de la monetización de externalidades, y su utilidad dentro de un CCV. La incertidumbre asociada a la monetización es muy amplia y los métodos de monetización muy variados, sin embargo varios estudios (Lee et al. 2009, Notarnicola et al. 2004) han permitido visibilizar que la integración de externalidades en el coste de ciclo de vida de un producto puede inclinar la balanza en la toma de decisiones. Además también hay mucha variación respecto a las categorías de costes analizadas, tanto internas como externas. 


\subsubsection{Análisis CCV de la tecnología HYSOL}

En esta sección se describe el análisis CCV de la tecnología HYSOL. El análisis contempla 4 fases: la definición de objetivos y alcance (sección 4.1.2.1), el análisis de inventario económico (sección 4.1.2.2), la evaluación de impacto económico (sección 4.1.2.3) y la interpretación del CCV de la tecnología HYSOL (que se encuentra en la sección 4.1.4, junto con la interpretación del CCV de la TERMOSOLAR CCP).

\subsubsection{Definición de objetivos y alcance}

El objetivo principal de este estudio es responder a la siguientes sub-pregunta de sostenibilidad definidas en la sección 2.1.2: ¿Cuál es el coste del ciclo de vida de la tecnología HYSOL?. Además, se han fijado los siguientes objetivos secundarios:

- Cuantificar los costes internos y externos asociados con el ciclo de vida de la planta HYSOL.

- Determinar si el proyecto es rentable.

- Describir y desarrollar una metodología que integre los impactos ambientales y económicos bajo un enfoque de ciclo de vida.

Las características tecnológicas principales de la planta HYSOL BIO y HYSOL GN están definidas en la sección 2.1.2 del Capítulo 2 de esta tesis.

\subsection{Límites del sistema}

La Figura 58 muestra un diagrama de ciclo de vida simplificado de la planta HYSOL, incluyendo las entradas y salidas ambientales y económicas del modelo. Con el principal objetivo de mantener la coherencia en el análisis de sostenibilidad, la unidad funcional (1 MWh) y las fases del ciclo de vida consideradas en el modelo son las mismas que las indicadas para el ACV (E\&F, C, O\&M, D\&D).

Algunas actividades no incluidas en el ACV se han incluido en el CCV por su relevancia en cuanto a costes económicos. Estas son: gestión y desarrollo del proyecto (incluida en la fase de Construcción), costes económicos derivados de la administración de la planta, seguros y alquiler de terreno. Estos tres últimos se han incluido en la fase de O\&M, al tener una naturaleza de pago anual.

Este estudio mantiene una perspectiva de promotor del proyecto, por lo que sólo se han considerado los costes asumidos por el promotor. Dichos costes representan la compra de los distintos componentes de la central, y el pago de las actividades necesarias para construir, 
operar y desmantelar la planta. Se considera que la planta HYSOL está construida bajo una licitación de ingeniería y construcción (EPC), donde el contratista diseña la instalación, compra los materiales y construye la planta. En este caso, el contratista es una filial del promotor, por lo que dichos gastos también se han considerado como costes del promotor.

Según lo dispuesto en la definición del objetivo y alcance del ASCV (Capítulo 2), se van a considerar dos escenarios de análisis: (1) la planta HYSOL BIO (operando con biometano) y (2) la planta HYSOL GN. En el primer caso se supone que la planta de biometano también está gestionada por el promotor del proyecto, por lo tanto, se incluyen todos los costes del ciclo de vida del biometano (incluyendo la construcción y la operación de la planta), mientras que en el segundo caso se asume el precio base de la materia prima de gas natural para España como coste del gas natural. Los costes internos considerados se encuentran descritos en detalle en la sección 4.1.2.2.

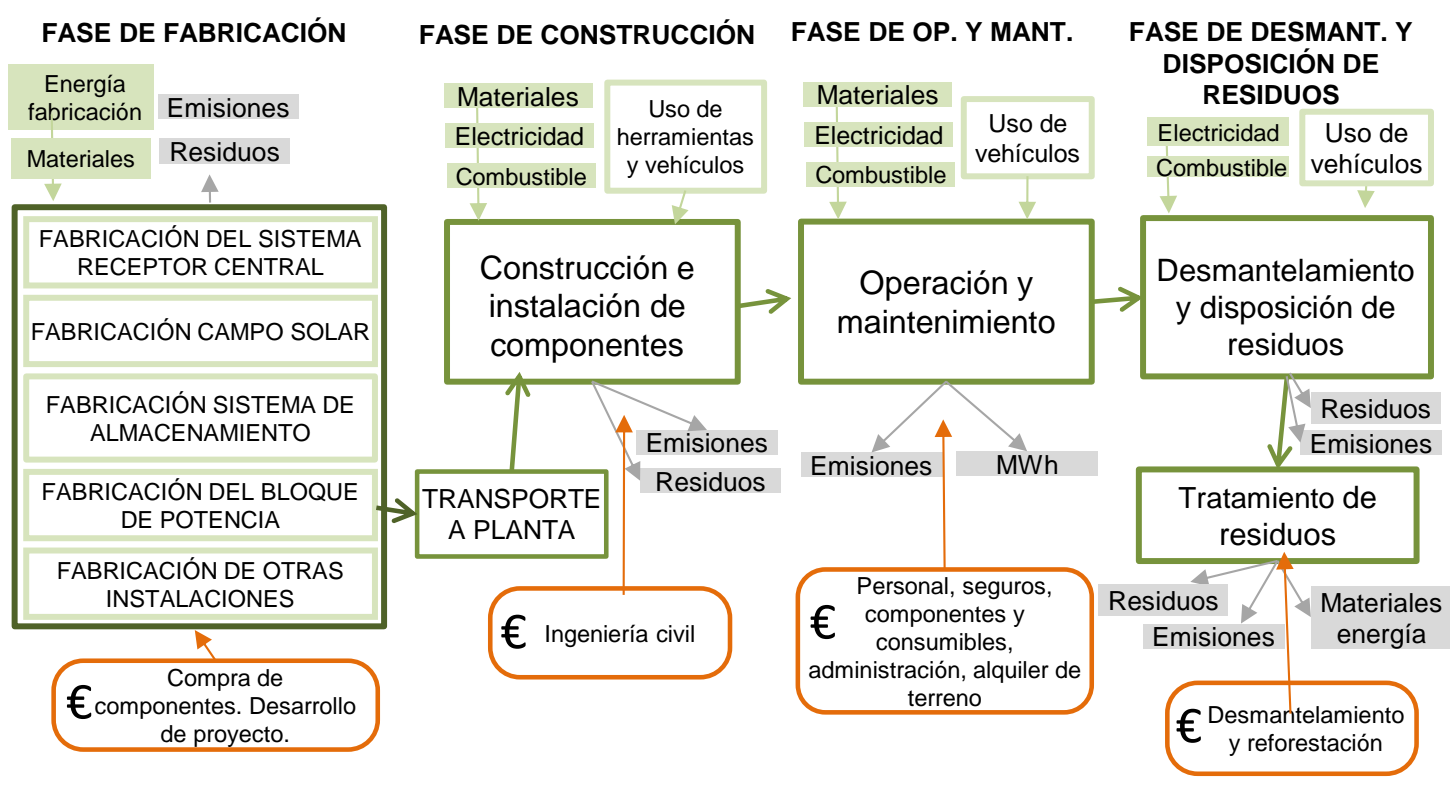

Figura 58 Diagrama de ciclo de vida de la planta HYSOL incluyendo materiales, energía y flujos económicos de entrada y salida

\subsection{Costes financieros y tasas de descuento}

Este estudio considera el valor del dinero en el tiempo así como los costes de oportunidad de la inversión, ya que la perspectiva asumida es la del promotor del proyecto y éste espera recibir una rentabilidad. Por lo tanto, se ha incluido una tasa de descuento para valores monetarios ya que uno de los objetivos de este estudio es conocer la rentabilidad del proyecto.

Debido a la alta inversión inicial necesaria para construir grandes centrales de producción eléctrica y a los beneficios de la diversificación del capital, la construcción de este tipo de plantas no suele estar financiada en su totalidad por el promotor, sino cofinanciada por bancos u otras 
instituciones financieras. Por ello, se asume que el $70 \%$ de la inversión de la planta está financiada mediante un préstamo a plazo fijo de 20 años, mientras que el $30 \%$ restante lo cubre el promotor del proyecto. La rentabilidad requerida por el proyecto se ha asumido como $7,398 \%$, siendo igual al valor calculado por el gobierno como "tasa de rentabilidad razonable" para proyectos de energías renovables (Orden IET/1045/2014 2014). La tasa de interés del préstamo se supone un punto inferior a la tasa de rentabilidad, es decir, 6,398\%. La tasa de descuento para la actualización de flujos futuros a valores presentes es $6,698 \%$, calculada como la media ponderada de la tasa de rentabilidad y la tasa de interés bancario usando el apalancamiento como peso.

El préstamo es devuelto a la institución financiera mediante pagos anuales que cubren tanto los intereses como la amortización del capital. Sin embargo, esta financiación añade complejidad a la aplicación de la metodología CCV en coherencia con el ACV-A, ya que el pago de la inversión inicial (que por las actividades que representa debería ser atribuible a las fases E\&F y C) se distribuye en pagos anuales, desplazando su pago al momento temporal en el que ocurre la fase de O\&M. Para mantener la coherencia de este análisis con el ACV-A, este estudio considera que los intereses se pagan anualmente durante la fase de $0 \& M$ mientras que la amortización del capital se paga en los dos primeros años que dura la construcción de la planta (fase E\&F y C). Esta consideración se basa en la hipótesis de que la demanda de bienes para la fabricación de componentes y construcción de la planta se realiza en el momento de compra, y no en el momento en el que el promotor devuelve el dinero a la institución financiera.

Se asume que el proyecto comienza a principios del 2015 (año 0). El diseño del proyecto se lleva a cabo durante el año 0 (2015) y las actividades dentro de las fases E\&M y C tienen lugar en los años 1 y 2 (2016 y 2017). La fase de O\&M cubre desde el año 3 a 27 (del 2018 al 2042), considerando una vida útil de 25 años. La fase de D\&D se lleva a cabo en el año 28 (2043). Las salidas y entradas de efectivo anuales se han descontado teniendo en cuenta el tiempo de ocurrencia, mediante la Ecuación (5):

$$
\text { Flujos de caja descontados }=\sum_{n=0}^{28} \frac{\text { Costes o ingresos }(\text { en términos reales })}{(1+r)^{n}}
$$

$\mathrm{n}=$ año en el que tiene lugar el movimiento económico

$r=$ tasa de descuento real, considera tanto los costes de oportunidad como el riesgo de la inversión (6,698 \%).

Los cálculos presentados en este análisis se han realizado en términos reales, sin considerar el efecto de la inflación durante la vida útil del proyecto. Sin embargo, sí se han utilizado índices 
de inflación según la OCDE (OECD 2014) para convertir valores monetarios de inventario desde el año de obtención del dato hasta el año $2015\left(€_{2015}\right)$.

Los resultados de un CCV deben estar referidos a la unidad funcional, y no limitarse a un sumatorio de costes a lo largo del ciclo de vida del proyecto. Cuando se incluye la producción eléctrica en el cálculo y se dan los resultados por unidad funcional, dichos resultados representan el coste de ciclo de vida de la electricidad producida de forma similar al LEC. Este parámetro representa el precio constante de la electricidad producida, independientemente del año en el que se venda. Dicho precio nivelado debe estar descontado para representar el precio constante, y por lo tanto, incluye en su cálculo el descuento de la producción de electricidad. La decisión metodológica de descontar la electricidad producida puede resultar cuestionable, ya que representa la eletricidad una unidad física cuyo valor no debería cambiar con el tiempo. Con el objetivo de demostrar esta decisión metodológica, a continuación se incluyen las fórmulas matemáticas correspondientes al cálculo del LEC y el descuento de la electricidad producida, según lo indicado por IEA y NEA en un informe sobre el cálculo de LEC de tecnologías eléctricas (IEA and NEA 2010). En la fórmula (1) se puede apreciar que lo que se descuenta no es la electricidad en sí, si no el precio de dicha electricidad.

$$
\begin{aligned}
& \sum_{i=0}^{n}\left(E_{i} * C_{\text {elec }} *(1+r)^{-i}\right)=\sum_{i=0}^{n}(I i+M i+D i) *(1+r)^{-i} \\
& C_{\text {elec }}=\sum_{i=0}^{n}\left((I i+M i+D i) *(1+r)^{-i}\right) /\left(E_{i} *(1+r)^{-i}\right)
\end{aligned}
$$

donde:

$E_{i}(\mathrm{MWh} / \mathrm{año})$ es la electricidad producida,

$\mathrm{C}_{\text {elec }}(€ / \mathrm{MWh})$ es el coste nivelado de la electricidad,

I (M€/año) es la inversión inicial,

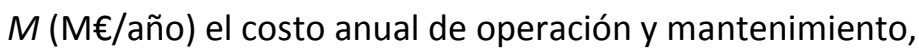

$D$ (M€/año) el costo de desmantelamiento,

$r$ la tasa de descuento $(6,698 \%)$,

$n$ (años) los años que dura el proyecto (28 años).

En este estudio se ha decidido descontar la electricidad para el cálculo de resultados del coste de ciclo de vida y proporcionar así un indicador comparable al obtenido mediante el cálculo del LEC. 


\subsection{El descuento aplicado a las externalidades ambientales}

La Ecuación (6) se ha utilizado para determinar el valor presente (PV) de daños ambientales asociados con el ciclo de vida de la planta termosolar. Esta ecuación es una adaptación de la propuesta por Gluch y Baumann (2004), donde VP representa el valor presente de los costos de daño total para todo el período durante el cual se emite la sustancia; $r_{\text {dis }}$ representa la tasa social de descuento; $n$ es el número de años de emisión de la sustancia; y $A$ representa los costos anuales del daño por la sustancia emitida (en el primer año de emisión).

$$
V P=\frac{A}{\frac{r_{d i s}}{1-\left(1+r_{d i s}\right)^{-n}}}
$$

Un elemento clave en este cálculo es la tasa de descuento social, que se basa en las decisiones de la sociedad en cuanto al coste de los daños y perjuicios producidos por la contaminación ambiental. Este valor considera la tasa de preferencia temporal (aquella que incluye las preferencias sociales del presente respecto a las del futuro). Además, según lo sugerido por Rabl et al. (Rabl et al. 2014) y el proyecto CASES, se ha considerado una tasa de descuento intergeneracional (o tasa de descuento a largo plazo) para aquellos impactos que ocurren en un futuro medio o lejano. Para este estudio se ha considerado adecuado aplicar una tasa social de descuento igual al 3 \% para la generación actual (2013-2029) seguida de un 2 \% para la siguiente generación (después de 2030), tal y como se sugiere en el proyecto CASES (Kuik et al. 2007).

\subsection{Metodología de evaluación de impacto económico y ambiental}

La metodología de evaluación de impacto económico aplicada en esta tesis consta de dos principales categorías de impacto: categoría de costes internos y categoría de costes externos. Estas categorías están a su vez divididas en subcategorías de impacto. La Tabla 43 describe las subcategorías de la categoría costes internos, junto con los elementos considerados para cada subcategoría. Estos elementos se han asociado con elementos específicos del ciclo de vida de la planta HYSOL. De esta manera, las fases de E\&F y $\mathrm{C}$ incluyen los costes de materiales y equipos, transporte de componentes, prestaciones, gastos de ingeniería, alquiler de equipos, personal, administración y alquiler de terreno durante los dos primeros años. La fase de O\&M incluye los siguientes costes anuales: personal, materiales y consumibles (incluyendo combustible y agua), alquiler de terreno, seguros y gastos de administración. 
CAPÍTULO 4: Análisis del área económica

Tabla 43 Subcategorías pertenecientes a la categoría de costes internos

Subcategorías de costes internos (en €) Descripción

\begin{tabular}{ll}
\hline Personal & Costes de mano de obra durante la operación de la central. \\
\hline Equipos y materiales & $\begin{array}{l}\text { Componentes de la planta de energía (maquinaria y } \\
\text { consumibles) }\end{array}$ \\
\hline Transporte & $\begin{array}{l}\text { Transporte gastos de fábrica a planta de energía (calculado } \\
\text { como el } 3 \% \text { de todos los costes de equipo). }\end{array}$ \\
\hline Alquiler de terreno & Alquiler de terreno \\
\hline Construcción & $\begin{array}{l}\text { Costes relativos al alquiler de maquinaria, instalación de } \\
\text { equipos, reparación y montaje. También se incluye en este } \\
\text { grupo el pago de mano de obra asociado a dichas } \\
\text { actividades. }\end{array}$ \\
\hline Ingeniería, gestión y seguros & $\begin{array}{l}\text { Gastos relativos a los permisos y gestión de proyectos, } \\
\text { administración y desarrollo, antes y durante el tiempo de } \\
\text { vida de la planta. }\end{array}$ \\
\hline Combustible y agua & $\begin{array}{l}\text { Coste del gas y el agua utilizados para la operación de la } \\
\text { central. }\end{array}$ \\
\hline Costes financieros & $\begin{array}{l}\text { Pago de intereses asociados a la financiación bancaria de la } \\
\text { central. }\end{array}$ \\
\hline
\end{tabular}

\subsection{Monetización de los impactos ambientales}

La Tabla 44 describe las subcategorías de costes externos consideradas para la monetización de las externalidades. Todas estas categorías se han monetizado según el enfoque de Costes de Daño. El coste de daño asociado con la emisión de cada uno de estos contaminantes se ha basado en datos publicados por el proyecto CASES (CASES project 2008).

Tabla 44 Subcategorías pertenecientes a la categoría de costes externos

Subcategorías de costes externos

Salud humana

\section{Descripción}

Los costes de daño derivados de la mortalidad y morbilidad humana debido a emisiones aéreas de $\mathrm{NH}_{3}, \mathrm{NMVOC}, \mathrm{NO}_{x}, \mathrm{PM}_{\mathrm{co}}, \mathrm{PM}_{25}, \mathrm{SO}_{2}$, metales pesados y varios radionucleidos (estos últimos también se incluye la emisión al agua).

Pérdida de biodiversidad

Costes de daños de impactos sobre fauna y flora debido a la acidificación y la eutrofización (causada por las emisiones de aire de $\mathrm{NH}_{3}, \mathrm{NMVOC}, \mathrm{NO}, \mathrm{PM}, \mathrm{SO}_{2}$ ).

Efecto local en cultivos: Emisión Daño debido pérdidas en los cultivos por contaminación de $\mathrm{O}_{3} \mathrm{y}$ regional de $\mathrm{N}_{\text {y }} \mathrm{O}_{3}$ beneficio esperado de la deposición de nitrógeno en el suelo (evitación de fertilizantes).

Daño global a cultivos: $\mathrm{SO}_{2} \quad$ Coste del daño en cultivos por emisiones de $\mathrm{SO}_{2}$.
Costes de daños de la contaminación atmosférica en los materiales de construcción (corrosión y suciedad). 
A continuación se detallan los procedimientos utilizados para calcular los costes de daño de las categorías propuestas. Las emisiones de gases durante el ciclo de vida se han determinado mediante el análisis ACV-A, según lo dispuesto en el Capítulo 3.

- Coste del daño para los contaminantes del aire: los costes de daño marginales de contaminantes individuales se obtuvieron del proyecto CASES (en $€_{2000 / t}$ ) considerando los siguientes escenarios metodológicos: "altura desconocida de las emisiones" y "Euro2000 por tonelada para España". Los costes por contaminante considerados en este estudio están descritos en el Anexo II. Los valores monetarios se han convertido a $€_{2015}$ usando el Índice de Precios de Consumo (Eurostat 2014). La tasa de descuento social aplicada fue la siguiente: $3 \%$ para costes de daños ocurridos entre el año 2015 y el año 2030, y 2 \% a partir del año 2030.

Aunque la mayoría de los procesos del ciclo de vida de la planta analizada se producen en España, otros (como la extracción de recursos naturales) pueden ocurrir en otros países y continentes. Debido a la falta de datos de lugares específicos, se han aplicado todos los costes de daño según los valores españoles.

- Costes de Daño Marginal para los GEI: Como se muestra en la Tabla 45, se han considerado los costes de daño marginal publicados por el proyecto CASES para los dos escenarios de cambio climático propuestos por el IPCC (Panel Intergubernamental de Cambio Climático): realista y ambicioso. El potencial de calentamiento global de todos los gases que contribuyen a esta categoría de impacto se ha tomado del IPCC (IPCC 2013) suponiendo un plazo de 100 años (Stocker et al. 2013).

Tabla 45 Costes de daño marginales para las emisiones de gases de efecto invernadero en diferentes períodos, según el proyecto CASES (CASES project 2008) y convertidos a $€_{2013}$

\begin{tabular}{llll} 
& $\begin{array}{l}\text { Media para el periodo } \\
\mathbf{2 0 1 0 - 2 0 1 5}(\mathbf{a})\end{array}$ & $\begin{array}{l}\text { Media para el periodo } \\
\mathbf{2 0 1 6 - 2 0 4 0}(\mathbf{b})\end{array}$ & $\begin{array}{l}\text { Año } \mathbf{2 0 4 2} \\
\text { (c) }\end{array}$ \\
\hline Escenario realista, $\boldsymbol{\epsilon}_{2013} / \mathrm{t} \mathrm{CO}_{2 \text { eq }}$ & 29,88 & 37,01 & 47,06 \\
\hline Escenario ambicioso, $\boldsymbol{\epsilon}_{2013} / \mathrm{t} \mathrm{CO}_{2 \text { eq }}$ & 29,88 & 57,36 & 110,66 \\
\hline
\end{tabular}

$\begin{array}{llll}\text { (a) Aplicado a la fase E\&F } & \text { (b) Aplicado a la fase O\&M } & \text { (c) Aplicado a la fase D\&D }\end{array}$

Los impactos debidos a cambios del uso del suelo no están incluidos en este análisis, aunque los costes de restauración de tierra y reforestación se incluyen en la fase de desmantelamiento.

\subsubsection{Análisis de inventario económico}

\subsection{Producción de biometano}

Los datos económicos relativos a la producción de biogas fueron proporcionados por Biogas Fuel Cell, una empresa productora de biogás, y son relativos a la misma planta de producción 
que la considerada para el ACV de esta tesis (capítulo 3). Dicha planta produce $1.300 .000 \mathrm{Nm}^{3}$ de biogás al año, que equivalen a 2,935 x 107 MJ/año de biometano (asumiendo una pérdida de metano del $2 \%$ durante el proceso de depuración y transporte, un contenido del $65 \%$ de metano en el biogás producido, y un poder calorífico inferior del metano igual a 35,9 MJ/m³). La planta utiliza como sustrato para la producción de biogás residuos procedentes de la industria agroalimentaria (residuos de matadero y comida caducada), lodos de aguas residuales de aguas municipales y de la industria lechera y estiércol de ganado vacuno y porcino. Aunque la planta gestionada por Biogas Fuel Cell utiliza el biogás producido para generar electricidad in situ, el escenario planteado en esta tesis supone que el biogás se depura hasta el grado de biometano mediante la tecnología de lavado con agua a presión PSA (adsorción por cambio de presión, del inglés, Pressure Swing Adsorption). Posteriormente, el biometano se transporta y comprime hasta 60 bar para su inyección en la red de gas natural.

Se supone que todo el biometano necesario para la planta HYSOL está producido en numerosas plantas similares a la gestionada por Biogas Fuel Cell, distribuidas por el territorio español. Ya que los datos suministrados por la empresa de biogás colaboradora no presentan costes de depuración e inyección a red, dichos costes se han obtenido utilizando la herramienta Biomethane-Calculator, desarrollada durante el proyecto IEE-Biomethane Regions y cofinanciada por la Comisión Europea (BioMethane Regions 2013). El cálculo del coste de depuración e inyección se ha realizado considerando la tecnología de depuración PSA, e incluyendo una tubería de transporte de biometano a baja presión de $100 \mathrm{~m}$, una estación de transferencia de gas para su inyección en la red, y la compresión del biometano a 60 bar. La inyección de biometano en la red gasista de España es todavía minoritaria, por lo que todos los proyectos que hay en este momento tienen carácter demostrativo o son fruto de un acuerdo bilateral entre la empresa gasista y la empresa productora del biometano. Ya que no se disponen datos relativos a ninguno de estos acuerdos bilaterales, se ha considerado como coste de transporte del biometano los mismos peajes de transporte aplicados a la materia prima del gas natural según la resolución del BOE-A-2013-2876 correspondiente al segundo semestre del año 2013 (MINETUR 2013). Estos peajes incluyen las mermas de transporte, regasificación y distribución, y los términos fijos y variables de regasificación, reserva de capacidad, conducción y almacenamiento de gas. Según la información aportada por dicha resolución, se ha calculado que el peaje corresponde aproximadamente a 5,2622 c€/ $/ \mathrm{Nm}^{3}$ (considerando un peaje de 0,4681 c€/kWh PCS y un PCS del gas natural de $40,47 \mathrm{MJ} / \mathrm{Nm}^{3}$ ). El biometano transportado se considera que tiene un $\mathrm{PCl}$ de $35,9 \mathrm{MJ} / \mathrm{Nm}^{3}$, por lo que el precio de transporte del biometano se asume como 0,1986 c€ por MJ de gas. 
El inventario de costes está descrito en la Tabla 46. Dicho inventario representa los costes del ciclo de vida de una planta de producción de biogás cuyas principales funciones son la gestión de residuos y la producción de electricidad mediante biogás.

Tabla 46 Inventario de costes para la producción de biometano

\begin{tabular}{|c|c|}
\hline Partidas de coste & Costes $(€)$ \\
\hline Construcción de la planta de biogas (ingeniería civil) & 1.147 .545 \\
\hline Instalación eléctrica & 98.900 \\
\hline Tuberías y válvulas & 230.000 \\
\hline Maquinaria y equipos producción biogas & 1.116 .300 \\
\hline Maquinaria y equipos unidad depuración e inyección* & 1.212 .158 \\
\hline Compra de terreno & 311.395 \\
\hline $\begin{array}{l}\text { Costes de operación y mantenimiento producción } \\
\text { biogás ( } € / \text { año) }\end{array}$ & 239.960 \\
\hline $\begin{array}{l}\text { Costes generales (Administración, gestión, limpieza, } \\
\text { seguridad) }\end{array}$ & 30.000 \\
\hline Seguro & 12.000 \\
\hline Electricidad & 39.420 \\
\hline Agua & 540 \\
\hline Personal & 92.000 \\
\hline Mantenimiento & 36.000 \\
\hline Transporte de digestato & 30.000 \\
\hline $\begin{array}{l}\text { Costes operación y mantenimiento de depuración e } \\
\text { inyección biometano (€/año)* }\end{array}$ & 187.551 \\
\hline $\begin{array}{l}\text { Coste aproximado de transporte de biometano en red } \\
\text { (€/año) }\end{array}$ & 2.783 \\
\hline \multicolumn{2}{|l|}{ Ingresos (€/año) } \\
\hline Por gestión de residuos: & 467.253 \\
\hline $\mathrm{ABP}$ & 74.987 \\
\hline Industria lechera & 119.736 \\
\hline Industria del procesado de alimentos (y otras) & 60.379 \\
\hline Lodo de depuradoras & 214.525 \\
\hline Tanques sépticos & 140.415 \\
\hline $\begin{array}{l}\text { Programa CLIMA (solo durante los cuatro primeros } \\
\text { años) }\end{array}$ & 50.000 \\
\hline
\end{tabular}

*Costes obtenidos de la herrarmienta Biomethane-Calculator

El cálculo del coste de producción de biometano incluye los ingresos obtenidos por la gestión de residuos y por la subvención pública del programa CLIMA. El programa CLIMA proporciona un subsidio a la producción de biogás durante los cuatro primeros años de operación de la planta. Este subsidio es proporcional a las emisiones que dejan de emitirse debido a la mejor gestión del estiércol (la digestión del estiércol supone una mejora de tratamiento de residuos respecto a la gestión convencional). No se ha incluido ningún coste de transporte de residuos ya que los productores los transportan gratuitamente a la planta de biogás. 
Se asume que la planta de biometano se financia con fondos propios, con una rentabilidad esperada de 7,398\%. Todos los costes se han actualizado al año cero del proyecto según la Ecuación (5), con una tasa de descuento real igual a la rentabilidad esperada.

\subsection{Gas natural y agua}

El precio del gas natural ha sido determinado usando el modelo de proyección de precio de mercado publicado por el IDAE para el período 2010-2030 (IDAE 2011), ya que generalmente el coste del gas natural no sigue las tendencias de inflación general. Se ha escogido el escenario de "incremento alto" del modelo ya que ha sido más preciso en la predicción de precios del mercado actual. Como precio de partida se ha tomado el coste de la materia prima del gas natural para el año 2010 según el BOE-A-2010-5945, que asciende a 2,2073 c€/kWh (MINETUR 2010). Considerando que el proyecto empieza en el año 2015, y según la proyección de precios del IDEA; el precio medio del gas natural considerado para los 25 años de operación asciende a $1,550 \mathrm{c€} / \mathrm{MJ}$ de gas natural.

El precio del agua consumida fue suministrado por IDIE, ascendiendo a $483.464 €$ al año. EI precio del agua se supone que permanece constante durante todo el proyecto, pues se espera que siga las tendencias de inflación general.

\subsection{Construcción, operación, mantenimiento y desmantelamiento de la planta HYSOL}

Los datos económicos relativos a la planta HYSOL empleados en este análisis se refieren a precios de mercado en el año 2015 y fueron provistos por IDie.

El inventario económico de la planta HYSOL se ha organizado por las fases de ciclo de vida considerada en el análisis ambiental, y se describe en las siguientes tablas: Tabla 47 (componentes de la planta HYSOL), Tabla 48 (construcción e ingeniería civil),

Tabla 49 (operación y mantenimiento) y Tabla 50 (Desmantelamiento y disposición de residuos). Salvo indicación de lo contrario, las cantidades aportadas representan euros del 2015.

La fase de E\&F incluye los costes asociados con la compra de componentes de la planta HYSOL, mientras que la fase $\mathrm{C}$ incluye los gastos de obra civil (hormigón para cimentaciones y edificios, estructuras metálicas, montaje de componentes, vías de acceso, mano de obra de construcción y equipo). La fase de O\&M incluye costos anuales imputables a personal, compra de materiales consumibles (incluyendo combustible y agua) y piezas de repuesto, alquiler de terrenos, seguros y costes de administración. La fase de D\&D incluye los costes asociados con el desmantelamiento de la planta y reforestación. Los costes de la gestión de residuos considerados en este análisis fueron los siguientes: cuota de $12 € / \mathrm{m}^{3}$ para el tratamiento de 
residuos en las plantas correspondientes, $7 € / \mathrm{m}^{3}$ de tasa de vertido para residuos industriales no-peligrosos y $10 € /$ t para residuos peligrosos (sales térmicas) (Comunidad de Madrid 2006). Los costes o ingresos asociados a la gestión de materiales reciclables no han sido incluidos.

Tabla 47 Costes asociados con la compra y transporte de componentes de la planta HYSOL (fase E\&F)

\begin{tabular}{|c|c|c|c|}
\hline & COMPONENTES & $\begin{array}{l}\text { COSTES } \\
\left(\mathrm{M} €_{2015}\right)\end{array}$ & 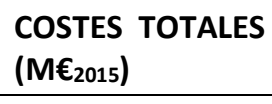 \\
\hline \multirow{5}{*}{$\begin{array}{l}\text { Torre y receptor } \\
\text { central }\end{array}$} & Torre (hormigón) & 11,8 & \multirow{5}{*}{58,3} \\
\hline & Torre (acero) & 5,57 & \\
\hline & Cilindro receptor (cuarzo) & 22,5 & \\
\hline & Cilindro receptor (acero) & 14,3 & \\
\hline & Tuberías & 4,09 & \\
\hline \multirow{3}{*}{ Campo solar } & Heliostatos (espejos) & 39,2 & \multirow{3}{*}{117,7} \\
\hline & Sistema de seguidor solar & 6,04 & \\
\hline & Pedestales & 72,4 & \\
\hline \multirow{5}{*}{$\begin{array}{l}\text { Almacenamiento } \\
\text { térmico }\end{array}$} & Sales térmicas & 27,6 & \multirow{5}{*}{61,9} \\
\hline & Tanques de almacenamiento & 12,4 & \\
\hline & Válvulas y tuberías & 18,2 & \\
\hline & Bombas de circulación & 2,47 & \\
\hline & Materiales de aislamiento & 1,24 & \\
\hline \multirow{2}{*}{$\begin{array}{l}\text { Bloque de } \\
\text { potencia }\end{array}$} & Turbina, generadores y condensadores & 48,7 & \multirow[b]{2}{*}{112,0} \\
\hline & $\begin{array}{l}\text { Otros elementos del bloque de } \\
\text { potencia }\end{array}$ & 63,4 & \\
\hline \multirow{3}{*}{$\begin{array}{l}\text { Otras } \\
\text { instalaciones }\end{array}$} & Sistema eléctrico & 22,6 & \multirow[b]{3}{*}{56,8} \\
\hline & Bombas de captación de agua & 0,90 & \\
\hline & $\begin{array}{l}\text { Edificios auxiliaries (control, } \\
\text { dosificación química y muestreo, aire } \\
\text { comprimido) }\end{array}$ & 33,4 & \\
\hline COSTES TOTALES & & & 406,7 \\
\hline
\end{tabular}

Tabla 48 Costes de construcción e ingeniería civil de la planta HYSOL (fase C)

Partidas económicas

Personal y alquiler/compra de maquinaria

Preparación del terreno, montaje de estructuras y construcción de caminos/carreteras

\begin{tabular}{ll}
\hline Cimientos & 26,9 \\
\hline Transporte de componentes a planta & 11,6 \\
\hline Desarrollo de proyecto (consultoría e ingeniería) & 60,6 \\
\hline Contingencias & 39,7 \\
\hline Intereses & 37,3 \\
\hline COSTES TOTALES & 322,9
\end{tabular}

\section{Costes $\left(\mathrm{M} €_{2015}\right)$}

109,4

37,4 
CAPÍTULO 4: Análisis del área económica

Tabla 49 Costes de operación y mantenimiento de la planta HYSOL (fase O\&M)

\begin{tabular}{ll} 
Partidas económicas & Costes (M $\left.\boldsymbol{\epsilon}_{\mathbf{2 0 1 5}} / \mathbf{a n ̃ o}\right)$ \\
\hline Personal & 2,099 \\
\hline Agua & 0,483 \\
\hline \multirow{2}{*}{ HYmbustible $\quad$ HYSOL GN: gas natural* } & 96,29 \\
\cline { 2 - 3 } & 52,74 \\
\hline Alquiler de terreno & 0,080 \\
\hline Consumibles y reparación & 1,602 \\
\hline Elementos adicionales ciclos Rankine y Brayton & 0,560 \\
\hline Elementos adicionales campo solar & 2,344 \\
\hline Seguros & 0,667 \\
\hline Intereses & 13,398 \\
\hline CosteS TOTALES & 52,35 \\
\hline
\end{tabular}

* Media del coste anual durante los 25 años de consumo, según la proyección de aumento de precio considerada en la sección 4.1.2.2.

Tabla 50 Costes de desmantelamiento de la planta HYSOL (fase D\&D)

\begin{tabular}{ll} 
Partidas económicas & Costes $\left(\mathbf{M} \mathbf{\epsilon}_{\mathbf{2 0 1 5}}\right)$ \\
\hline $\begin{array}{ll}\text { Desmantelamiento del campo solar y bloque de } \\
\text { potencia }\end{array}$ & 12,25 \\
\hline Transplante y reforestación & 0,024 \\
\hline Tasas de vertederos y plantas de tratamiento & 1,217 \\
\hline TOTAL COSTS & 13,49 \\
\hline
\end{tabular}

El inventario ambiental es el mismo que el utilizado para el ACV de la planta HYSOL BIO.

\subsection{Ingresos por venta de electricidad}

Los ingresos por la venta de energía eléctrica se han estimado teniendo en cuenta el marco regulatorio existente en España según el Real Decreto 413/2014. Este real decreto establece distintos regímenes retributivos que se aplican a un catálogo de instalaciones tipo definidas en la Orden Ministerial IET/1045/2014 . Como se describe en la sección 1.5.5 del Capítulo 1, el nuevo régimen retributivo para las renovables contempla un parámetro retributivo a la inversión y otro a la operación. La retribución a la operación se calcula como la diferencia entre los costes de operación y el precio recibido por la venta en el mercado eléctrico, considerando un incremento anual de $1 \%$ de los costes de operación. La Orden Ministerial considera que la retribución a la inversión y a la operación dejará de percibirse cuando se supere la vida útil regulatoria. Por otro lado, en el año en que la instalación alcance el nivel de rentabilidad razonable, se dejará de percibir la retribución a la inversión (no así la retribución a la operación). 
El citado Real Decreto admite a trámite instalaciones híbridas que utilicen algún combustible adicional a la energía solar, aplicando distinto régimen retributivo a la fracción de electricidad producida mediante este combustible adicional. Dicho régimen retributivo correspondería con lo dispuesto en la orden para el combustible considerado, por lo que si la planta utiliza biogás, se beneficiaría de retribución extra, pero si la planta utiliza gas natural, deberá percibir únicamente la retribución estándar del mercado eléctrico. En el caso de la planta HYSOL, el combustible utilizado es biometano, cuyo origen es biogás. Sin embargo, el biometano se distribuye mediante la red de gas natural, algo que no está regulado y que es poco probable de ser susceptible de financiación extra. Por lo tanto, considerando el escenario más desfavorable, la retribución económica del escenario HYSOL BIO se ha calculado considerando que la planta utiliza gas natural.

Según lo dispuesto en la citada Orden Ministerial, se han tomado los siguientes parámetros retributivos para la tecnología HYSOL (ambos escenarios): 1.193.641 €/MW como retribución a la inversión (considerando $100 \mathrm{MW}$ de potencia instalada correspondiente a la producción solar) y 76,443 €/MWh como retribución a la operación atribuible únicamente a la electricidad producida mediante energía solar (45\% del total). Estos parámetros corresponden, según la citada Orden Ministerial, a una planta termosolar de torre con almacenamiento superior a $12 \mathrm{~h}$ cuyo año de autorización de explotación definitiva es el 2011.

La electricidad generada a partir del combustible no se beneficia de ningún apoyo económico adicional a la retribución estándar del mercado. El precio estándar del mercado de la electricidad en España se ha obtenido de las estimaciones publicadas en la mencionada Orden Ministerial, ascendiendo a 53,08€/MWh. También se ha incluido el impuesto estándar a la venta de electricidad $(7,0 \%)$ y un peaje de acceso de red de 0,5 $€ / M W h$. El impuesto de sociedades (30 \% para empresas españolas) ha sido calculado e incluido, según lo dispuesto por la Ecuación (7).

Impuesto $=\sum_{n=1}^{28}\left(\right.$ Ingresos $_{n}-$ coste construir $_{n}-{\text { coste } O \& M_{n}}-\frac{\text { coste de inmovilizados }}{25}-$ intereses $\left._{n}\right) * 0,3$ (7) $\mathrm{n}=$ año en el que tiene lugar cada pago.

Los cálculos se han hecho bajo las hipótesis de que el valor de la rentabilidad razonable se mantiene constante durante toda la vida útil, y los costes de explotación aumentan un 1 \% cada año (según se indica en la citada Orden Ministerial). 


\subsubsection{Evaluación de impacto económico}

\subsection{Coste de la producción de biometano}

El coste de la producción de biometano se ha calculado como la suma de todos los costes e ingresos por unidad de energía según el inventario provisto por Biogas Fuel Cell (en €2015) y la herramienta Biomethane-Calculator (considerando una tasa de descuento de 7,398 \%). La Tabla 51 recopila los costes e ingresos de la construcción, operación y mantenimiento de la planta por MJ de biometano producido. La producción de biometano también se ha descontado con un 7,398\%, según los argumentos aportados en la sección 4.1.2.1 de este capítulo.

Los resultados indican que la producción de biometano tiene un coste final para el promotor del proyecto HYSOL igual a 2,829 c€ por MJ de biometano. Considerando que la planta HYSOL consume $3,404 \times 10^{9} \mathrm{MJ}$ de biometano al año, el coste anual de biometano para la planta HYSOL asciende a 96,29 M€2015.

Tabla 51 Costes del ciclo de vida de la producción de biometano por unidad energética (MJ)

\begin{tabular}{llll}
\cline { 2 - 4 } & Construcción & $\begin{array}{l}\text { Operación y } \\
\text { mantenimiento }\end{array}$ & Total \\
\hline Costes (c€/MJ) & 1,365 & 3,112 & 4,467 \\
\hline Ingresos (c€/MJ) & 0 & 1,647 & 1,592 \\
\hline Coste total biometano (c€/MJ) & $\mathbf{1 , 3 6 5}$ & $\mathbf{1 , 4 6 4}$ & $\mathbf{2 , 8 2 9}$ \\
\hline
\end{tabular}

\subsection{Evaluación de impacto económico de la planta HYSOL BIO}

La Tabla 52 muestra los costes internos por unidad funcional atribuibles a la planta HYSOL BIO (operando con biometano) según lo determinado por la aplicación de la metodología CCV, y considerando un coste anual del biometano igual a 96,29 M€. La producción de electricidad se ha descontado para el cálculo de los costes por unidad funcional, según lo indicado en la sección 4.1.2.1 de este capítulo. Los resultados muestran que los costes internos ascienden a 210,5 $€ / M W h$ con una mayor contribución procedente de la fase de O\&M (150,6 $€ / M W h)$. La fase E\&F es la segunda fase con mayor contribución (37,5€/MWh), debido únicamente a la compra de equipos de los componentes de la central. La fase de D\&D tiene una contribución muy limitada, atribuible tanto a los bajos costes asociados con la demolición de la planta, como al efecto de la tasa de descuento aplicada a pagos que tienen lugar a los 28 años de empezar el proyecto. 
Tabla 52 Costes internos por unidad funcional (€2015/MWh) de la planta HYSOL BIO (todos los valores descontados hasta el presente)

\begin{tabular}{llllll}
\hline $\begin{array}{l}\text { Subcategorías de costes } \\
\text { internos }\end{array}$ & $\begin{array}{l}\text { TOTAL } \\
(€ / M W h)\end{array}$ & $\begin{array}{l}\text { E\&F } \\
(€ / M W h)\end{array}$ & $\begin{array}{l}\text { C } \\
(€ / M W h)\end{array}$ & $\begin{array}{l}\text { O\&M } \\
(€ / M W h)\end{array}$ & $\begin{array}{l}\text { D\&D } \\
\text { (€/MWh) }\end{array}$ \\
\hline Personal & 2,63 & 0 & 0 & 2,63 & 0 \\
\hline Materiales y equipos & 42,8 & 37,5 & 1,62 & 3,64 & 0 \\
\hline Transporte & 0,849 & 0 & 0,849 & 0 & 0 \\
\hline Alquiler de terreno & 0,110 & 0 & 0,010 & 0,100 & 0 \\
\hline Construcción & 11,3 & 0 & 9,11 & 2,01 & 0,229 \\
\hline $\begin{array}{l}\text { Ingeniería, gestión y } \\
\text { seguros }\end{array}$ & $\mathbf{7 , 3 5}$ & 0 & 6,49 & 0,836 & 0,023 \\
\hline Combustible y agua & 121,4 & 0 & 0 & 121,4 & 0 \\
\hline Costes financieros & $\mathbf{2 4 , 1}$ & 0 & 4,03 & $\mathbf{2 0 , 0}$ & 0 \\
\hline Costes totales & $\mathbf{2 1 0 , 5}$ & $\mathbf{3 7 , 5}$ & $\mathbf{2 2 , 1}$ & $\mathbf{1 5 0 , 6}$ & $\mathbf{0 , 2 5 2}$ \\
\hline Ingresos* & $\mathbf{1 9 7 , 9}$ & $\mathbf{0}$ & $\mathbf{0}$ & $\mathbf{1 9 7 , 9}$ & $\mathbf{0}$ \\
\hline Balance & $\mathbf{- 1 2 , 6 2}$ & & & & \\
\hline
\end{tabular}

* Incluye el peaje de acceso a la red, el impuesto a la venta de electricidad, y el impuesto de sociedades. Tasa de descuento: $6,698 \%$

En relación al análisis de las subcategorías consideradas dentro de los costes internos, los costes más altos son atribuibles a la compra de agua y combustible $(121,4 € / \mathrm{MWh})$, suponiendo un $57,6 \%$ de los costes totales internos de ciclo de vida. El coste de combustible supone un 99,5 \% del gasto en esta categoría, siendo la contribución del coste del agua de tan solo un 0,5\%. La siguiente categoría con mayores costes es la de compra de equipos y materiales, contribuyendo al 20,3\% de los costes totales internos del ciclo de vida. Los costes asociados con la compra de componentes de los distintos subsistemas de la planta se distribuyen como sigue: campo solar $30 \%$, bloque de potencia $27 \%$, sistema de almacenamiento térmico $15 \%$, torre y receptor $14 \%$, y otras instalaciones $14 \%$. Los costes financieros es la tercera categoría con mayor contribución $(24,1 € / \mathrm{MWh})$, presentando el $11,4 \%$ de los costes internos totales.

Los ingresos considerados se originan de la venta de electricidad al mercado eléctrico español durante la fase de O\&M. Esta partida se ha calculado como 197,9 €/MWh, valor que también incorpora impuestos aplicables y el peaje de acceso de red. Los ingresos por producción de electricidad se han calculado en base a tres parámetros: la retribución a la inversión, la retribución a la operación y la venta en el mercado eléctrico. El primer parámetro deja de percibirse en el año en que la suma acumulada de ingresos supera a la suma acumulada de costes. Según los cálculos realizados para la planta HYSOL BIO, el proyecto alcanza dicho momento en el año 17, a los 15 años de operación. Por lo tanto, la planta no percibe retribución a la inversión a partir del año 18 (durante los últimos 10 años de operación). Sin embargo, el alto coste del combustible provoca que la planta presente pérdidas en los últimos años de operación, ya que los costes de operación son superiores a la retribución por megavatio-hora producido. 
El $37 \%$ de los ingresos obtenidos por la venta de electricidad corresponden a la venta en el mercado eléctrico, mientras que el 63 \% restante procede de la retribución extra definida según los parámetros de la Orden Ministerial IET 1045/2014.

Cabe mencionar que el cálculo de ingresos para la planta HYSOL aquí realizado es especulativo, ya que no existen datos reales de retribución para una planta de estas características.

Cuando los ingresos por la venta de electricidad en el mercado se incluyen en el cálculo de coste de ciclo de vida, los resultados muestran un balance del ciclo de vida igual a $-12,65 € / \mathrm{MWh}$, lo que sugiere que el proyecto es no es económicamente viable, ya que supone unas pérdidas de $12,62 € / M W h$. Cabe señalar que este valor es muy sensible a la tasa de descuento considerada en los cálculos (6,698\%).

La Tabla 53 muestra los costes externos por MWh producido por la planta HYSOL BIO (operando con biometano). La producción de electricidad se ha descontado utilizando la misma tasa de descuento que los costes externos ( $3 \%$ hasta el 2030 y un $2 \%$ a partir de entonces). Los costes externos totales ascienden a 4,50 €/MWh y 5,07 €/MWh, dependiendo del escenario considerado para la estimación de costes de abatimiento del cambio climático (realista y ambicioso, respectivamente).

Tabla 53 Costes externos ( $€_{2015} / \mathrm{MWh}$ ) de la planta HYSOL BIO (todos los valores descontados hasta el presente)

\begin{tabular}{|c|c|c|c|c|c|c|}
\hline \multicolumn{2}{|c|}{ Subcategorías de costes externos } & Total (€/MWh) & E\&F & C & O\&M & D\&D \\
\hline \multicolumn{2}{|c|}{ Salud humana } & 2,59 & $22 \%$ & $3,4 \%$ & $79 \%$ & $-3,7 \%$ \\
\hline \multicolumn{2}{|c|}{ Pérdida de biodiversidad } & 0,208 & $14 \%$ & $3,0 \%$ & $84 \%$ & $-1,3 \%$ \\
\hline \multicolumn{2}{|c|}{$\begin{array}{l}\text { Efecto local en cultivos: Emisión } \\
\text { regional de } \mathrm{N} \text { y } \mathrm{O3}\end{array}$} & 0,087 & $11 \%$ & $3,2 \%$ & $86 \%$ & $-0,7 \%$ \\
\hline \multicolumn{2}{|c|}{ Daño global a cultivos: SO2 } & $-0,0011$ & $25 \%$ & $2,7 \%$ & $77 \%$ & $-4,3 \%$ \\
\hline \multicolumn{2}{|c|}{ Daño a materiales: SO2 y NO2 } & 0,0135 & $20 \%$ & $2,8 \%$ & $80 \%$ & $-2,9 \%$ \\
\hline \multirow{2}{*}{$\begin{array}{l}\text { Cambio } \\
\text { climático }\end{array}$} & Realista, $\mathrm{R}$ & 1,60 & $32 \%$ & $5,8 \%$ & $83 \%$ & $-20 \%$ \\
\hline & Ambicioso, $\mathrm{A}$ & 2,17 & $27 \%$ & $4,9 \%$ & $101 \%$ & $-33 \%$ \\
\hline \multicolumn{2}{|c|}{ COSTES EXTERNOS TOTALES (R) } & 4,50 & 0,743 & 0,126 & 2,418 & $-0,282$ \\
\hline \multicolumn{2}{|c|}{ COSTES EXTERNOS TOTALES (A) } & 5,07 & 0,793 & 0,136 & 2,996 & $-0,540$ \\
\hline
\end{tabular}

La mayor parte de los costes externos de la planta HYSOL operando con biometano corresponden a la subcategoría salud humana (2,59 €/MWh), que presenta entre el $23 \%$ y el $56 \%$ de los costes atribuibles las distintas fases (según el escenario realista). La siguiente categoría con mayores impactos es cambio climático (1,60€/MWh realista y 2,17 €/MWh 
ambicioso). La mayor contribución de costes externos para todas las categorías se atribuye a la fase O\&M, presentando entre el $77 \%$ y el $101 \%$ de costes para todas las categorías.

\subsection{Evaluación de impacto económico del escenario alternativo: HYSOL GN}

La Tabla 54 muestra los costes internos por unidad funcional atribuibles al escenario alternativo de la planta HYSOL, es decir, la planta HYSOL GN. Los resultados obtenidos en la mayoría de categorías son muy similares a los de la planta HYSOL BIO, ya que la única partida de costes que cambia es el combustible y los ingresos recibidos. Ya que los costes de operación son menores en este escenario que en el de HYSOL BIO, la rentabilidad del proyecto se alcanza antes (el balance de costes es menor que el balance de ingresos) y deja de percibirse la retribución a la inversión en el año 11 del proyecto.

Tabla 54 Costes internos por unidad funcional (€2015/MWh) de la planta HYSOL GN (todos los valores descontados hasta el presente)

\begin{tabular}{|c|c|c|c|c|c|}
\hline $\begin{array}{l}\text { Subcategorías de costes } \\
\text { internos }\end{array}$ & $\begin{array}{c}\text { TOTAL } \\
\text { (€/MWh) }\end{array}$ & $\begin{array}{c}E \& F \\
(€ / M W h)\end{array}$ & $\begin{array}{c}\mathrm{C} \\
(€ / \mathrm{MWh})\end{array}$ & $\begin{array}{c}\text { O\&M } \\
\text { (€/MWh) }\end{array}$ & $\begin{array}{c}\text { D\&D } \\
(€ / \mathrm{MWh})\end{array}$ \\
\hline Personal & 2,63 & 0 & 0 & 2,63 & 0 \\
\hline Materiales y equipos & 42,8 & 37,5 & 1,62 & 3,64 & 0 \\
\hline Transporte & 0,849 & 0 & 0,849 & 0 & 0 \\
\hline Alquiler de terreno & 0,110 & 0 & 0,010 & 0,100 & 0 \\
\hline Construcción & 11,3 & 0 & 9,11 & 2,01 & 0,229 \\
\hline Ingeniería, gestión y seguros & 7,35 & 0 & 6,49 & 0,836 & 0,023 \\
\hline Combustible y agua & 64,7 & 0 & 0 & 64,7 & 0 \\
\hline Costes financieros & 24,1 & 0 & 4,03 & 20,0 & 0 \\
\hline Costes totales & 153,9 & 37,5 & 22,1 & 94,0 & 0,252 \\
\hline Ingresos* & 161,7 & 0 & 0 & 160,2 & 0 \\
\hline Valor Actual Neto & 6,33 & & & & \\
\hline
\end{tabular}

Los costes e ingresos por unidad funcional en este escenario son $153,9 € / \mathrm{MWh}$ y 161,7 $€ / \mathrm{MWh}$ respectivamente, lo que produce un balance positivo de 6,33 $€ / \mathrm{MWh}$. Este resultado indica que el proyecto es rentable ya que proporciona 6,33€ por MWh adicionales a la rentabilidad esperada.

La Tabla 55 muestra los costes externos por unidad funcional de la HYSOL GN. Los costes externos totales ascienden a $17,1 € / M W h$ y $27,8 € / M W h$, dependiendo del escenario considerado para la estimación de costos de abatimiento del cambio climático (realista y ambicioso, respectivamente). La mayor parte de los costes externos corresponden a la subcategoría de cambio climático, que presenta entre el $46 \%$ y el $80 \%$ de los costes atribuibles 
CAPÍTULO 4: Análisis del área económica

las distintas fases (según el escenario realista). La mayor contribución de costes de la categoría cambio climático se atribuye a la fase O\&M ( $80 \%$ de todos los costes de dicha fase). Dicha fase es además la que mayores costes presenta (entre el $95 \%$ y el $98 \%$ de los costes externos totales del ciclo de vida para el escenario realista y el ambicioso respectivamente). La siguiente subcategoría con mayores costes es salud humana (4,47 €/MWh), debido principalmente a la emisión de dióxido de azufre, óxidos de nitrógeno y partículas $\left(\mathrm{PM}_{2.5}\right)$ durante el transporte y producción del gas natural (76 \%) y durante la combustión del mismo (13 \%).

La fase D\&D presenta costes negativos debido a la evitación de impactos ambientales durante el reciclado de materiales.

Tabla 55 Costes externos ( $€_{2015} / \mathrm{MWh}$ ) de la planta HYSOL GN (todos los valores descontados hasta el presente)

\begin{tabular}{|c|c|c|c|c|c|c|}
\hline \multicolumn{2}{|c|}{ Subcategorías de costes externos } & Total (€/MWh) & E\&F & C & O\&M & D\&D \\
\hline \multicolumn{2}{|l|}{ Salud humana } & 4,47 & $13 \%$ & $2,0 \%$ & $88 \%$ & $-2,2 \%$ \\
\hline \multicolumn{2}{|c|}{ Pérdida de biodiversidad } & 0,283 & $10 \%$ & $2,2 \%$ & $88 \%$ & $-0,9 \%$ \\
\hline \multicolumn{2}{|c|}{$\begin{array}{l}\text { Efecto local en cultivos: Emisión regional } \\
\text { de } \mathrm{N}_{\text {y }} \mathrm{O}_{3}\end{array}$} & 0,109 & $9 \%$ & $2,5 \%$ & $89 \%$ & $-0,6 \%$ \\
\hline \multicolumn{2}{|c|}{ Daño global a cultivos: $\mathrm{SO}_{2}$} & $-0,0028$ & $10 \%$ & $1,0 \%$ & $91 \%$ & $-1,7 \%$ \\
\hline \multicolumn{2}{|c|}{ Daño a materiales: $\mathrm{SO}_{2}$ y $\mathrm{NO}_{2}$} & 0,0276 & $10 \%$ & $1,4 \%$ & $90 \%$ & $-1,4 \%$ \\
\hline \multirow{2}{*}{ Cambio climático } & Realista, $\mathrm{R}$ & 17,1 & $3,0 \%$ & $0,5 \%$ & $98 \%$ & $-1.9 \%$ \\
\hline & Ambicioso, $\mathrm{A}$ & 27,8 & $2,1 \%$ & $0,4 \%$ & $100 \%$ & $-2.6 \%$ \\
\hline \multicolumn{2}{|c|}{ COSTES EXTERNOS TOTALES (R) } & 22,0 & 1,113 & 0,189 & 21,1 & $-0,423$ \\
\hline \multicolumn{2}{|c|}{ COSTES EXTERNOS TOTALES (A) } & 32,7 & 1,188 & 0,203 & 32,1 & $-0,810$ \\
\hline
\end{tabular}




\subsubsection{Análisis CCV de la planta TERMOSOLAR CCP}

En esta sección se describe el caso de estudio de CCV para la tecnología TERMOSOLAR CCP. Este estudio se organiza en las cuatro fases de un ACV según las normas ISO 14040: la definición de objetivos y alcance, el análisis de inventario económico, la evaluación de impacto económico y la interpretación, que se encuentra en la sección 4.1.4, junto con la interpretación del CCV de la tecnología HYSOL.

\subsubsection{Definición de objetivos y alcance}

El objetivo principal de este estudio es responder a la siguiente sub-pregunta de sostenibilidad definida en la sección 2.1.2: ¿Disminuyen los costes de ciclo de vida por unidad funcional de la tecnología HYSOL respecto a los de la TERMOSOLAR CCP?

Además, se han fijado los siguientes objetivos secundarios:

- Cuantificar los costes internos y externos asociados con el ciclo de vida de la planta TERMOSOLAR CCP operando con distintos porcentajes de gas natural.

- Comparar los escenarios de financiación propia y financiación bancaria en la viabilidad económica de un proyecto termosolar.

Las características principales de la planta termosolar analizada están definidas en la sección 2.1.2.3 del Capítulo 2.

\subsection{Límites del sistema}

Este análisis considera los mismos límites del sistema que los definidos para la planta HYSOL en la sección 4.1.2.1.

\subsection{Costes financieros y tasas de descuento}

Se ha asumido que el proyecto comienza a principios del 2013 (año 0). El diseño del proyecto se lleva a cabo durante el año 0 (2013) y las actividades dentro de las fases E\&M y C tienen lugar en los años 1 y 2 (2014 y 2015). La fase de O\&M cubre desde el año 3 al 27 (del 2016 al 2040), considerando una vida útil de 25 años. La fase de D\&D se lleva a cabo en el año 28 (2041). El año de comienzo del proyecto de la planta TERMOSOLAR CCP difiere de la tecnología HYSOL, ya que el invetario corresponde a momentos diferentes. Los resultados obtenidos mediante este análisis han sido publicados en la revista Solar Energy (Corona et al. 2016).

En cuanto a la financiación de la inversión, se consideran las mismas condiciones que lo dispuesto en la financiación para la planta HYSOL, descrita en la sección 4.1.2.1 (el 70 \% de la inversión está cubierta mediante una entidad bancaria). 
CAPÍTULO 4: Análisis del área económica

\subsection{Análisis de sensibilidad}

Ya que la hibridación con gas natural de este tipo de plantas termosolares presentan gran relevancia en el impacto ambiental (según los resultados obtenidos en el capítulo anterior de esta tesis), se ha planteado un escenario de sensibilidad respecto a la hibridación con gas natural de la planta TERMOSOLAR CCP (desde un $0 \%$ de hibridación hasta un $30 \%$ ). Esto requiere la instalación de calderas auxiliares adicionales (hasta cinco unidades de 20 MWT). Estos escenarios suponen un aumento de producción eléctrica, y también del consumo de agua y gas natural. La Tabla 26 de la sección 3.3.1.1 del Capítulo 3 (análisis ACV) describe la producción eléctrica y consumo de gas natural considerado para este análisis de sensibilidad.

\subsection{Metodología de evaluación de impacto ambiental}

La metodología de evaluación de impacto ambiental es la misma que la aplicada para la planta HYSOL, según lo descrito en la sección 4.1.2.1.

\subsubsection{Análisis de inventario económico}

Los datos económicos empleados en este análisis se refieren a precios de mercado en el año 2013 y fueron provistos por IDIE.

El inventario económico se ha organizado por las fases de ciclo de vida consideradas en el análisis, y se describe en las siguientes tablas: Tabla 56 (componentes de la planta HYSOL), Tabla 57 (construcción e ingeniería civil), Tabla 58 (operación y mantenimiento) y Tabla 59 (Desmantelamiento y disposición de residuos). Salvo indicación de lo contrario, las cantidades aportadas representan euros del 2013.

La fase de E\&F incluye los costes asociados con la compra de componentes de la planta HYSOL, mientras que la fase $\mathrm{C}$ incluye los gastos de obra civil (hormigón para cimentaciones y edificios, estructuras metálicas, montaje de componentes, vías de acceso, mano de obra de construcción y equipo). La fase de O\&M incluye costos anuales imputables al personal, compra de materiales consumibles (incluyendo combustible y agua) y piezas de repuesto, alquiler de terrenos, seguros y costes de administración.

La fase de D\&D incluye los costes asociados con el desmantelamiento de la planta y reforestación. Los costes de la gestión de residuos considerados en este análisis fueron los siguientes: cuota de $12 € / \mathrm{m}^{3}$ para el tratamiento de residuos en las plantas correspondientes, $7 € / \mathrm{m}^{3}$ de tasa de vertido para residuos industriales no-peligrosos y $10 € / \mathrm{t}$ para residuos peligrosos (principalmente las sales térmicas) (Comunidad de Madrid 2006). Los costes o ingresos asociados a la gestión de materiales reciclables no han sido incluidos. 
Tabla 56 Costes asociados con la compra y transporte de componentes de la planta TERMOSOLAR CCP (fase E\&F)

\begin{tabular}{|c|c|c|c|}
\hline & COMPONENTES & $\begin{array}{l}\text { COSTES } \\
\left(\mathrm{M} €_{2013}\right)\end{array}$ & $\begin{array}{l}\text { COSTES } \\
\text { TOTALES } \\
\left(\mathrm{M} €_{2013}\right) \\
\end{array}$ \\
\hline \multirow{4}{*}{ Circuito HTF } & Aceite HTF & 10,3 & \multirow{4}{*}{23,1} \\
\hline & Tuberías & 6,4 & \\
\hline & Bombas de circulación & 1,9 & \\
\hline & $\begin{array}{l}\text { Tanques de expansión, rebose y gas } \\
\text { natural. Caldera auxiliar }\end{array}$ & 4,5 & \\
\hline \multirow{6}{*}{ Campo solar } & Espejos & 14,3 & \multirow{6}{*}{64,8} \\
\hline & Tubos absorbedores & 15,9 & \\
\hline & Estructura y pilones de los colectores & 26,4 & \\
\hline & Sistema de seguimiento solar & 1,0 & \\
\hline & Sistema electric y electrónico & 5,6 & \\
\hline & Juntas rotatorias & 1,6 & \\
\hline \multirow{6}{*}{$\begin{array}{l}\text { Almacenamiento } \\
\text { térmico }\end{array}$} & Sales térmicas & 21,1 & \multirow{6}{*}{29,0} \\
\hline & Tanques de almacenamiento & 1,5 & \\
\hline & Bombas de circulación & 0,47 & \\
\hline & Materiales de aislamiento & 0,84 & \\
\hline & Intercambiadores de calor & 0,82 & \\
\hline & Otros (BoS) & 4,1 & \\
\hline \multirow{7}{*}{$\begin{array}{l}\text { Bloque de } \\
\text { potencia }\end{array}$} & Turbina, generadores y condensadores & 17,5 & \multirow{7}{*}{41,5} \\
\hline & Sistema eléctrico & 10,0 & \\
\hline & Tren de generación de vapor & 5,0 & \\
\hline & Bombas & 5,0 & \\
\hline & Válvulas & 1,0 & \\
\hline & Desgasificador & 1,0 & \\
\hline & Torres de refrigeración & 2,0 & \\
\hline \multirow{3}{*}{$\begin{array}{l}\text { Otras } \\
\text { instalaciones }\end{array}$} & Planta de tratamiento de agua & 2,5 & \multirow{3}{*}{4,5} \\
\hline & Bombas de captación de agua & 1,0 & \\
\hline & $\begin{array}{l}\text { Edificios auxiliaries (control, } \\
\text { dosificación química y muestreo, aire } \\
\text { comprimido) }\end{array}$ & 1,0 & \\
\hline COSTES TOTALES & & & 162,9 \\
\hline
\end{tabular}


CAPÍTULO 4: Análisis del área económica

Tabla 57 Costes de construcción e ingeniería civil de la planta TERMOSOLAR CCP (fase C)

\begin{tabular}{|c|c|}
\hline Partidas económicas & Costes $\left(\mathrm{M} €_{2013}\right)$ \\
\hline Personal & 25,0 \\
\hline Equipo y maquinaria & 23,0 \\
\hline Cimientos y estructuras & 10,4 \\
\hline \multicolumn{2}{|c|}{ Otros costes de desarrollo de proyecto: } \\
\hline Desarrollo de proyecto & 8,7 \\
\hline Gestión del EPC & 20,0 \\
\hline Contingencias & 10,0 \\
\hline COSTES TOTALES & 97,1 \\
\hline
\end{tabular}

Tabla 58 Costes de operación y mantenimiento de la planta TERMOSOLAR CCP (fase O\&M)

\begin{tabular}{ll} 
Partidas económicas & $\begin{array}{l}\text { Costes } \\
\text { (M€2013/año) }\end{array}$ \\
\hline Personal & 1,92 \\
\hline Agua & 0,909 \\
\hline Gas natural & 5,209 \\
\hline Alquiler de terreno & 0,312 \\
\hline Consumibles y reparación & 1,70 \\
\hline Administración y gestión & 0,90 \\
\hline Seguros & 1,5 \\
\hline Intereses & 5,077 \\
\hline CosteS TOTALES & 17,53 \\
\hline
\end{tabular}

Tabla 59 Costes de desmantelamiento de la planta TERMOSOLAR CCP (fase D\&D)

\begin{tabular}{ll} 
Partidas económicas & $\begin{array}{l}\text { Costes } \\
\left(\mathbf{M \epsilon _ { 2 0 1 3 }}\right)\end{array}$ \\
\hline $\begin{array}{l}\text { Desmantelamiento del campo solar y bloque de } \\
\text { potencia }\end{array}$ & 4,425 \\
\hline Transplante y reforestación & 0,008 \\
\hline Tasas de vertederos y plantas de tratamiento & 0,433 \\
\hline TOTAL COSTS & 4,867 \\
\hline
\end{tabular}

El inventario ambiental es el mismo que el utilizado para realizar el ACV-A de la planta TERMOSOLAR CCP.

\subsection{Ingresos por venta de electricidad}

Los ingresos por ventas de energía eléctrica se han calculado teniendo en cuenta el marco regulatorio existente en España según el Real Decreto 413/2014 y la Orden Ministerial IET/1045/2014. Según los citados documentos, los parámetros retributivos para la generación 
de electricidad en una central termosolar como la descrita en este análisis en el año 2014 son: $549.818 € / \mathrm{MW}$ de retribución a la inversión, y 37,785 €/MWh de retribución a la operación para las primeras $2720 \mathrm{~h}$ (equivalentes a plena carga). La electricidad producida por la hibridación con gas natural no se beneficia de ningún parámetro retributivo adicional a lo percibido por la venta estándar en el mercado eléctrico. El precio de mercado de la electricidad en España se obtuvo de las estimaciones publicadas en la mencionada Orden Ministerial como sigue: 50,78 $€ / M W h$ en 2016, y 53,08 €/MWh a partir del año 2017. También se ha incluido el impuesto estándar a la venta de electricidad $(7,0 \%)$ y un peaje de acceso de red de 0,5 €/ MWh. EI impuesto de sociedades (30 \% para empresas españolas) ha sido calculado e incluido, según lo dispuesto por la Ecuación (7).

\subsection{Coste del gas natural y agua}

Los costes de gas natural y agua han sido determinados en función de su precio unitario para permitir variar su valor de acuerdo a la cantidad de gas natural utilizado para hibridación. El precio del gas natural ha sido determinado de la misma forma que en la planta HYSOL GN (asciende a 2,2073 c€/kWh). Los costes asociados al consumo de agua se han basado en información publicada por la Asociación Española de Abastecimiento de agua y Saneamiento (AEAS). El precio de mercado del agua cruda para usos industriales en el lugar donde se encuentra la planta termosolar fue de $0,76 € / \mathrm{m}^{3}$ en $2010\left(0,814 € / \mathrm{m}^{3}\right.$ en 2013 teniendo en cuenta la inflación)(AEAS 2011). El precio del agua se supone que permanece constante durante todo el proyecto, pues se espera que siga las tendencias de inflación general.

\subsubsection{Evaluación de impacto económico}

La Tabla 60 muestra los costes internos por unidad funcional atribuibles a la planta TERMOSOLAR CCP. La producción de electricidad también se ha descontado según los argumentos aportados en la sección 4.1.1.1 de este capítulo. Además, se han convertido los resultados a $€_{2015}$ para permitir una mejor comparación con los obtenidos para la planta HYSOL. Los resultados indican que los costes internos ascienden a $192 € / \mathrm{MWh}$ con una mayor contribución procedente de la fase O\&M (102 €/MWh), debido principalmente a los costes financieros (40,1€/MWh) y a los gastos asociados con el combustible y agua (30,3€/MWh). La fase E\&F es la segunda fase con mayor contribución $(60,2 € / \mathrm{MWh})$, seguida por la fase de construcción $(28,8 € / M W h)$. La fase de $D \& D$ tiene una contribución muy limitada, atribuible tanto a los bajos costes asociados con la demolición de la planta, como al efecto de la tasa de descuento aplicada a pagos que tienen lugar a los 28 años de empezar el proyecto. 
CAPÍTULO 4: Análisis del área económica

Tabla 60 Costes internos por unidad funcional (€2015/MWh) de la planta TERMOSOLAR CCP (todos los valores descontados hasta el presente)

\begin{tabular}{lccccc}
\hline $\begin{array}{l}\text { Subcategorías de costes } \\
\text { internos }\end{array}$ & $\begin{array}{c}\text { TOTAL } \\
(€ / M W h)\end{array}$ & $\begin{array}{c}\text { E\&F } \\
(€ / M W h)\end{array}$ & $\begin{array}{c}\text { C } \\
(€ / M W h)\end{array}$ & $\begin{array}{c}\text { O\&M } \\
(€ / M W h)\end{array}$ & $\begin{array}{c}\text { D\&D } \\
(€ / M W h)\end{array}$ \\
\hline Personal & 9,73 & 0 & 0 & 9,73 & 0 \\
\hline Materiales y equipos & 69,6 & 58,4 & 2,65 & 8,62 & 0 \\
\hline Transporte & 1,89 & 1,80 & 0,082 & 0 & 0 \\
\hline Alquiler de terreno & 1,75 & 0 & 0,164 & 1,58 & 0 \\
\hline Construcción & 13,0 & 0 & 12,63 & 0 & 0,337 \\
\hline Ingeniería, gestión y seguros & 22,4 & 0 & 10,18 & 12,2 & 0,063 \\
\hline Combustible y agua & 30,3 & 0 & 0 & 30,3 & 0 \\
\hline Costes financieros & 43,2 & 0 & 3,09 & 40,1 & 0 \\
\hline Costes totales & 192 & 60,2 & 28,8 & 102 & 0,400 \\
\hline Ingresos* & 197 & 0 & 0 & 204 & 0 \\
\hline Balance (€/MWh) & 4,91 & & & & \\
\hline
\end{tabular}

En relación al análisis de las subcategorías consideradas dentro de los costes internos, los costes más altos son atribuibles a la compra de materiales y equipos (69,6 $€ / M W h)$, que contribuyen al $36,3 \%$ de los costes totales internos de ciclo de vida. Los costes asociados con la compra de componentes de los distintos subsistemas de la planta se distribuyen como sigue: campo solar $40 \%$, bloque de potencia $25 \%$, sistema de almacenamiento térmico $18 \%$, sistema HTF $14 \%$, y otras instalaciones $2,7 \%$.

La siguiente subcategoría con mayores costes es la de costes financieros, que contribuyen al $22,5 \%$ de los costes totales internos del ciclo de vida. Los costes de combustible y agua es la tercera subcategoría con mayor contribución (30,3€/MWh), presentando el 15,7 \% de los costes internos totales. Los costes de combustible incluidos en esta subcategoría suponen un $85 \%$ del gasto en la categoría (el resto del coste corresponde al consumo de agua).

La venta de electricidad al mercado eléctrico español proporciona al promotor del proyecto unos ingresos de $197 € / M W h$. Este valor también incorpora impuestos aplicables y el peaje de acceso de red. Los parámetros retributivos a la inversión y a la operación se perciben durante toda la vida regulatoria, ya que los ingresos no llegan a superar a los costes en ningún momento. Cuando estos ingresos se incluyen en los cálculos, los resultados muestran un balance del ciclo de vida igual a 4,91 €/MWh, lo que sugiere que el proyecto es económicamente viable al presentarse unas ganancias sobre la rentabilidad esperada de 4,91 €/MWh. Cabe señalar que este valor es muy sensible a la tasa de descuento considerada en los cálculos (6,698 \%). 
La Tabla 61 muestra los costes externos por unidad funcional de la planta TERMOSOLAR CCP. Los costes externos totales ascienden a $12,5 € / \mathrm{MWh}$ y $17,6 € / \mathrm{MWh}$, dependiendo del escenario considerado para la estimación de costes del cambio climático (realista y ambicioso, respectivamente). La mayor parte de los costes externos corresponden a la subcategoría de cambio climático, que presenta entre el $44 \%$ y el $86 \%$ de los costes atribuibles a las distintas fases. La mayor contribución de costes de la categoría cambio climático se atribuye a la fase O\&M ( $88 \%$ de todos los costes de dicha fase para el escenario realista, y $91 \%$ para el ambicioso). La siguiente subcategoría con mayores costes es salud humana (3,84 €/MWh), debido principalmente a la emisión de dióxido de azufre, óxidos de nitrógeno y partículas $\left(\mathrm{PM}_{2.5}\right)$ durante el transporte y producción del gas natural y durante la combustión del mismo.

Tabla 61 Costes externos ( $€_{2015} / \mathrm{MWh}$ ) de la planta convencional (15 \% gas natural, todos los valores descontados hasta el presente)

\begin{tabular}{|c|c|c|c|c|c|}
\hline Subcategorías de costes externos & $\begin{array}{c}\text { Total } \\
\text { (€/MWh) }\end{array}$ & $E \& F$ & C & O\&M & D\&D \\
\hline Salud humana & 3,84 & $22 \%$ & $5.3 \%$ & $73 \%$ & $0.5 \%$ \\
\hline Pérdida de biodiversidad & 0,264 & $20 \%$ & $5.1 \%$ & $73 \%$ & $1.4 \%$ \\
\hline $\begin{array}{l}\text { Efecto local en cultivos: Emisión } \\
\text { regional de } \mathrm{N}_{\text {y }} \mathrm{O}_{3}\end{array}$ & 0,1059 & $20 \%$ & $5.5 \%$ & $73 \%$ & $1.7 \%$ \\
\hline Daño global a cultivos: $\mathrm{SO}_{2}$ & $-0,0020$ & $19 \%$ & $3.4 \%$ & $77 \%$ & $0.3 \%$ \\
\hline Daño a materiales: $\mathrm{SO}_{2}$ y $\mathrm{NO}_{2}$ & 0,0215 & $19 \%$ & $4.0 \%$ & $76 \%$ & $0.7 \%$ \\
\hline \multirow{2}{*}{$\begin{array}{l}\text { Cambio } \\
\text { climático }\end{array}$} & 8,32 & $9 \%$ & $2.3 \%$ & $88 \%$ & $0.7 \%$ \\
\hline & 13,3 & $6 \%$ & $1.6 \%$ & $91 \%$ & $1.0 \%$ \\
\hline COSTES EXTERNOS TOTALES (R) & 12,5 & 1,62 & 0,413 & 10,4 & 0,085 \\
\hline COSTES EXTERNOS TOTALES (A) & 17,6 & 1,72 & 0,441 & 15,3 & 0,160 \\
\hline
\end{tabular}

La fase O\&M es la que presenta mayores costes externos, debido principalmente a la extracción y combustión del gas natural. La fase E\&F es la siguiente fase con mayores costes, causados por la fabricación de los componentes de la central. La participación de cada sistema de componentes a los costes externos de la fase E\&F se distribuye como sigue: almacenamiento térmico $37 \%$, campo solar $26 \%$, bloque de potencia $24 \%$, circuito HTF $13 \%$ y otras instalaciones $0,3 \%$.

\subsection{Efecto de la hibridación con distintos porcentajes de gas natural}

La operación de la planta termosolar en modo híbrido implica mayores costes (absolutos) debido a los gastos asociados con el consumo de agua y gas natural. La Tabla 62 muestra la producción de electricidad, la retribución obtenida, los costes internos y los costes externos para la operación de la planta termosolar con diferentes aportaciones de gas natural (entre 0 y $30 \%$ ). 
Tabla 62 Producción de electricidad, retribución obtenida, costes internos y costes externos de la central TERMOSOLAR CCP con distintos porcentajes de gas natural (en $€_{2015}$ )

\begin{tabular}{|c|c|c|c|c|c|c|}
\hline & \multirow{2}{*}{$\begin{array}{l}\text { Electricidad } \\
\text { producida } \\
\text { (GWh) }\end{array}$} & \multirow[t]{2}{*}{$\begin{array}{l}\text { Retribución }^{1} \\
\text { (€/MWh) }\end{array}$} & \multirow{2}{*}{$\begin{array}{c}\text { Costes } \\
\text { internos } \\
\text { (€/MWh) }\end{array}$} & \multirow[t]{2}{*}{$\begin{array}{l}\text { Balance } \\
\text { (€/MWh) }\end{array}$} & \multicolumn{2}{|c|}{$\begin{array}{c}\text { Costes externos } \\
(€ / M W h)\end{array}$} \\
\hline & & & & & Realista & Ambicioso \\
\hline Sólo solar (0 \% GN) & 4.122 & 217 & 197 & 19,3 & 5,85 & 4,74 \\
\hline $10 \%$ GN & 4.591 & 204 & 194 & 9,75 & $-2,17$ & 9,94 \\
\hline $15 \%$ GN & 4.867 & 198 & 193 & 4,91 & $-6,19$ & 12,54 \\
\hline $20 \%$ GN & 5.177 & 191 & 192 & $-0,2$ & $-10,5$ & 15,12 \\
\hline $30 \%$ GN & 5.931 & 173 & 189 & $-15,8$ & $-22,8$ & 20,27 \\
\hline
\end{tabular}

${ }^{1}$ Incluyendo impuestos y peajes. ${ }^{*} \mathrm{GN}=$ Gas natural

Los resultados muestran reducidos costes internos por unidad funcional como resultado de la creciente utilización de gas natural. Esto se debe a que el incremento de electricidad producida compensa los mayores costes derivados de la compra de combustible. Sin embargo, la retribución percibida se reduce ya que la electricidad producida mediante gas natural no se beneficia de subvenciones públicas. El balance de costes e ingresos muestra un valor positivo para el modo de operación solo solar, indicando que el proyecto es rentable. Sin embargo, los resultados obtenidos para una hibridación del $20 \%$ o superior indican pérdidas progresivas de la rentabilidad del proyecto. El balance de costes e ingresos del proyecto se iguala a cero cuando el porcentaje de hibridación asciende aproximadamente a 7,4 \%.

Los costes externos por unidad funcional incrementan considerablemente al aumentar el porcentaje de hibridación. Este incremento se debe principalmente al aumento de costes externos asociados en la subcategoría de cambio climático, que se ve afectada principalmente por el consumo de gas natural. La planta TERMOSOLAR CCP operando con un $30 \%$ de gas natural presenta entre 4 y 6 veces más costes externos que la misma planta operando en modo solo solar.

Tanto los costes ambientales como económicos presentan un perfil similar, donde la fase O\&M presenta mayor contribución, seguida por las fases E\&F, C y en menor medida D\&D. Los resultados obtenidos implican que la operación en modo solo solar para la planta TERMOSOLAR CCP es la mejor opción según criterios ambientales y económicos, ya que tanto la rentabilidad como el impacto ambiental empeora conforme se aumenta el porcentaje de gas natural. Sin embargo, cabe señalar que este estudio no ha considerado los beneficios asociados a la mayor gestionabilidad y capacidad de producción conseguida mediante la hibridación con gas natural, que puede influir positivamente en el comportamiento de la planta termosolar en el mercado eléctrico. 


\subsubsection{Interpretación y discusión de resultados}

Esta sección incluye la interpretación y comparación de resultados obtenidos mediante el análisis de CCV Ambiental Completo de la tecnología HYSOL (en sus dos escenarios HYSOL BIO y HYSOL GN) y de la tecnología termosolar cilindro-parabólica (TERMOSOLAR CCP). Los resultados del análisis incluyen la monetización de externalidades para integrar en el coste de ciclo de vida los impactos medioambientales no internalizados. Dicha monetización se ha basado en el inventario de emisiones de ciclo de vida obtenido por el ACV-A del capítulo 3.

Los resultados obtenidos mediante el análisis llevado a cabo en este capítulo son comparables con los cálculos de LEC, ya que también representan el coste nivelado del ciclo de vida de la electricidad producida. Por lo tanto, se podría decir que la metodología CCV aquí aplicada es una extensión del cálculo del LEC que incluye costes externos y permite conocer la distribución de costes de ciclo de vida en función de las fases y categorías de interés. Además, se han calculado los ingresos obtenidos por la venta de electricidad (incluyendo subvenciones) con el objetivo de conocer la rentabilidad del proyecto en cada escenario.

\subsubsection{Escenario HYSOL BIO}

El análisis de costes internos de la planta HYSOL BIO revela que el proyecto no es rentable económicamente, ya que los costes superan los ingresos (el balance de costes e ingresos asciende a $-12,6 € / M W h)$. El gasto en la fase O\&M supone el $71,2 \%$ de todos los costes, siendo el coste del biometano el principal contribuyente $(56,9 \%$ de todos los costes internos del ciclo de vida). La fase de E\&F presenta el 18,3\% de los costes internos, la fase $C$ supone el 10,6 \% y la fase D\&D el 0,12\%. Por lo tanto, el mayor potencial de reducción de costes se encuentra en la fase de O\&M, especialmente en el 56,9\% de los costes de combustible. La siguiente partida con mayor potencial de reducción es la de compra de componentes $(20,7 \%$ de los costes internos totales), especialmente en el campo solar y el bloque de potencia.

Las principales acciones potenciales de reducción de costes en la planta HYSOL es aumentar la eficiencia de conversión de energía térmica a eléctrica (y así ahorrar en combustible), y disminuir los costes de componentes gracias a una posible economía de escala.

El análisis de costes externos indica que la monetización de impactos debidos a emisiones atmosféricas a lo largo del ciclo de vida de la planta HYSOL BIO asciende a 4,50 y 5,07 €/MWh para un escenario realista y ambicioso respectivamente. Esta cantidad (debida principalmente a los costes ambientales de la producción y combustión del biometano) supone el 2,1 \% y 2,4 \% respectivamente de los costes totales internos. 


\subsubsection{Escenario HYSOL GN}

El escenario HYSOL GN presenta diferencias económicas significativas respecto al escenario HYSOL BIO. Mientras la planta HYSOL BIO presenta pérdidas económicas $(-12,6 € / \mathrm{MWh})$, el escenario HYSOL GN presenta ganancias adicionales a la rentabilidad esperada (6,33 €/MWh). Esta diferencia es debida únicamente al menor coste del gas natural respecto al de biometano. Cabe mencionar que no se ha considerado retribución extra para la fracción de electricidad producida con biometano, a pesar de ser de origen renovable. Esta decisión se basa en la inexistencia de directrices específicas que consideren una retribución específica asociada al biometano distribuido por red de gas natural.

Sin embargo, los costes externos de la planta HYSOL GN son considerablemente mayores (22,0 €/MWh y $32,7 € /$ MWh respectivamente), representando el $14,1 \%$ y el $21,0 \%$ de los costes totales internos. El escenario HYSOL GN presenta entre 4 y 6 veces más costes externos que la planta HYSOL BIO. Además, las ganancias económicas adicionales obtenidas por la planta HYSOL GN no serían suficientes como para internalizar los costes externos sin perder la rentabilidad esperada por el proyecto.

\subsubsection{Comparación de escenarios HYSOL con TERMOSOLAR CCP}

En la Figura 59 se comparan los costes internos de las fases del ciclo de vida de las plantas HYSOL BIO y HYSOL GN con los de la planta TERMOSOLAR CCP. El hecho de que la tecnología HYSOL tenga mayor eficiencia de producción eléctrica hace que los costes de inversión por unidad funcional sean menores que en la tecnología TERMOSOLAR CCP. Sin embargo, el alto coste del biometano ocasiona que los costes de operación de la planta HYSOL BIO sean mayores que en los otros escenarios planteados.

Si consideramos los ingresos por unidad funcional, la planta HYSOL en sus dos escenarios obtiene $198 € / M W h$ y $160 € / M W h$ (para el escenario HYSOL BIO y HYSOL GN respectivamente), mientras que la TERMOSOLAR CCP obtiene $197 € / \mathrm{MWh}$. Esta diferencia se debe a que HYSOL presenta una menor fracción solar y sólo se ha considerado retribución extra para la producción de electricidad de origen solar, por lo que el MWh que tiene mayor fracción solar está mejor retribuido (la TERMOSOLAR CCP tiene una fracción solar de $85 \%$ mientras que la de HYSOL es de $45 \%$ ). Los ingresos de la planta HYSOL BIO son mayores que en HYSOL GN debido a que percibe la retribución a la inversión durante toda su vida útil (en ningún año llega a alcanzar la rentabilidad razonable, al contrario que en HYSOL GN). Sin embargo, el balance de costes e ingresos para las tecnologías HYSOL GN y TERMOSOLAR CCP es positivo $(6,33 € / M W h$ y 4,91 $€ / \mathrm{MWh}$ respectivamente), mientras que en la planta HYSOL BIO es negativo (-12,6 $€ / \mathrm{MWh})$, 
implicando pérdidas. Estos resultados indican que la rentabilidad de la tecnología HYSOL utilizando gas natural es mucho mayor que la TERMOSOLAR CCP, a pesar de requerir una mayor inversión en términos absolutos.

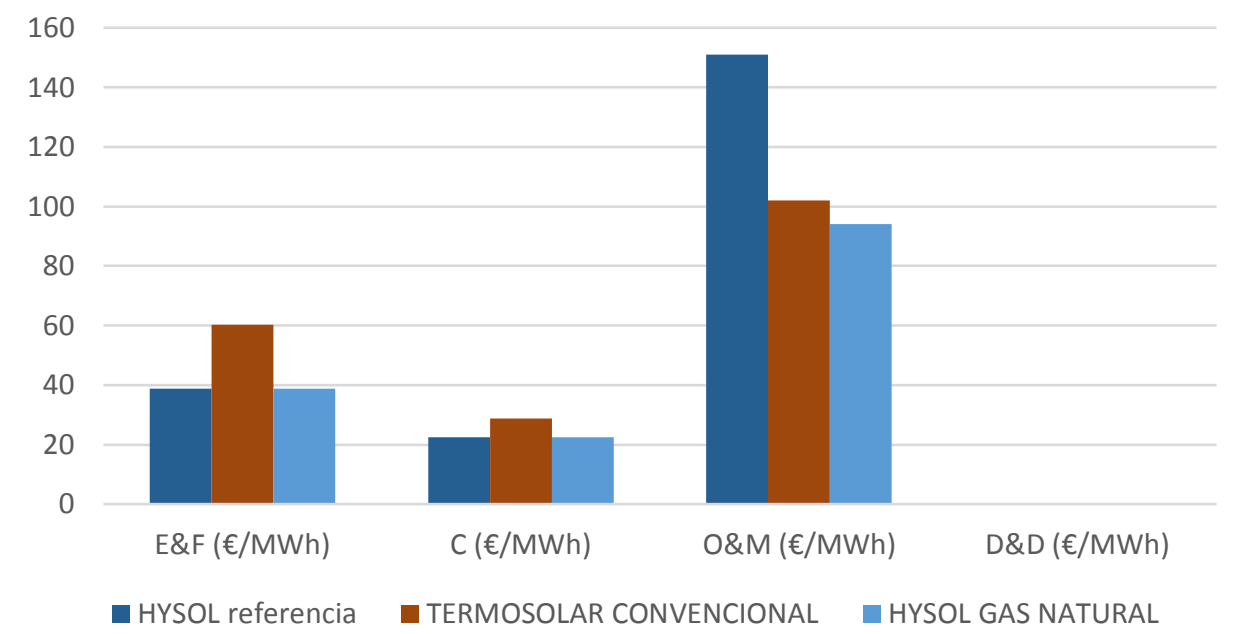

Figura 59 Comparación de costes internos de ciclo de vida de la planta HYSOL y la planta TERMOSOLAR CCP, por fases

La Tabla 63 muestra los costes internos, externos y totales de la planta HYSOL BIO comparados con la planta HYSOL GN y con la planta TERMOSOLAR CCP. En la tabla se observa que la planta con menores costes externos es HYSOL operando con biometano, mientras que la planta con mayores costes externos es HYSOL GN. Estos resultados coinciden con lo obtenido en el ACV-A de dichas tecnologías.

Cuando se internalizan los costes externos y se integran en los costes internos, el menor coste total de ciclo de vida se obtiene para la planta HYSOL GN, seguida por la planta HYSOL BIO y la TERMOSOLAR CCP. Esto indica que, en términos monetarios, la planta HYSOL GN es una mejor opción aun cuando se internalizan los impactos ambientales.

Tabla 63 Comparación de costes externos ( $€_{2015} / \mathrm{MWh}$ ) entre la planta HYSOL BIO, la planta HYSOL GN, y la planta TERMOSOLAR CCP

\begin{tabular}{lccc}
\cline { 2 - 4 } & $\begin{array}{c}\text { HYSOL BIO } \\
(\boldsymbol{E} / \mathrm{MWh})\end{array}$ & $\begin{array}{c}\text { HYSOL GN } \\
(\boldsymbol{E} / \mathrm{MWh})\end{array}$ & $\begin{array}{c}\text { TERMOSOLAR CCP } \\
(\boldsymbol{€} / \mathbf{M W h})\end{array}$ \\
\hline Coste interno & 211 & 154 & 192 \\
\hline Coste externo realista & 4,50 & 22,0 & 12,5 \\
\hline Coste externo ambicioso & 5,07 & 32,7 & 17,6 \\
\hline COSTE TOTAL REALISTA & $\mathbf{2 1 5}$ & $\mathbf{1 7 6}$ & $\mathbf{2 0 5}$ \\
\hline COSTE TOTAL AMBICIOSO & $\mathbf{2 1 6}$ & $\mathbf{1 8 7}$ & $\mathbf{2 1 0}$ \\
\hline
\end{tabular}


CAPÍTULO 4: Análisis del área económica 


\subsection{EL ANÁLISIS INPUT OUTPUT}

\subsubsection{Introducción}

La herramienta de análisis Input-Output (IO) surgió con el objetivo principal de analizar la interdependencia de las distintas industrias de una economía, a nivel nacional o regional (Miller and Blair 2009). Durante los últimos siglos algunos economistas como François Quesnay Leon Walras habían intentado aproximarse a este objetivo mediante la construcción de tablas y fórmulas económicas. Sin embargo, no fue hasta el año 1936 cuando el Profesor Wassily Leontief creó esta herramienta, obteniendo por ello el Premio Nobel en Ciencias Económicas (Leontief 1970, Leontief 1936, Leontief 1941). Desde sus inicios en el año 1936, la técnica IO ha sido desarrollada y extendida por varios autores, hasta el punto de incluir no sólo información económica de la interdependencia entre industrias, sino también datos sobre empleo, métricas sociales, intercambios internacionales, consumo de energía y contaminación ambiental. Su capacidad de análisis y planificación económica ha hecho de esta técnica una herramienta utilizada a nivel mundial.

El análisis 10 es una técnica para medir la actividad económica generada, directa e indirecta, por la demanda de determinados bienes y servicios (B\&S). Para ello, se utilizan tablas que recopilan las relaciones de compra y venta entre los distintos sectores de producción (o ramas de actividad económica) dentro de un país o región determinada. La tabla origen representa la oferta y producción de B\&S por producto y tipo de proveedor, mientras que la tabla destino representa el uso que hace la economía con dichos productos o servicios, indicando los consumos intermedios, finales, exportaciones, el valor añadido, etc. La tabla simétrica 10 representa la relación entre producción y consumo de los distintos sectores/ramas económicas. Esta tabla es necesaria para obtener los coeficientes técnicos que expresan los consumos intermedios (en unidades monetarias) de cada rama necesarios para producir una unidad de producto de otra rama.

La matriz inversa de Leontief está compuesta por dichos coeficientes técnicos, y describe los requerimientos directos e indirectos por unidad de producción de cada rama de actividad. Si se multiplica dicha matriz por el vector que representa la demanda final de un sistema o producto, obtenemos la producción bruta necesaria para satisfacer la demanda intermedia y final. Dicha matriz, se calcula y representa como $(I-A)^{-1}$, donde $\mathrm{A}$ es la matriz de coeficientes técnicos (que expresa los consumos intermedios necesarios por cada rama para producir una unidad de producto de otra rama) e I es la matriz identidad. 
Mediante esta metodología se obtiene la producción de B\&S totales (directos, indirectos e inducidos) de la economía de una región generada por un proyecto, así como el valor añadido obtenido, el efecto multiplicador, el impacto sobre la importación de B\&S, y otros indicadores socioeconómicos como la generación de empleo indirecta e inducida.

Las tablas IO son confeccionadas por cada país utilizando datos nacionales. Sin embargo, no todos los países las confeccionan ni las actualizan con frecuencia. El proyecto World Input Output Database (WIOD) (Timmer et al. 2012) del séptimo programa marco de la Unión Europea, nace con el objetivo de crear una base de datos que contenga tablas 10 a nivel nacional e internacional. Estas tablas están estandarizadas según el Sistema de Contabilidad Europea 2010 (European Commission 2013) y se basan todas en los mismos criterios aportando datos económicos, ambientales y socioeconómicos para 40 países y 35 sectores. Esta base de datos contiene valores más actuales que otras tablas nacionales oficiales, como en el caso de España cuya última tabla IO data del año 2005. Además, la WIOD consta de una tabla IO Multi-regional en la que se recogen las relaciones comerciales entre todos los sectores económicos de los 40 países contenidos en la base de datos.

La globalización de la economía mundial ha llevado a cadenas de suministro cada vez más extensas donde la extracción de materias primas y fabricación de componentes tienen lugar en unos países o regiones del mundo, mientras que la distribución y consumo de servicios o productos tienen lugar en otros. En este contexto, el análisis MRIO proporciona la oportunidad de analizar las consecuencias globales de un sistema mediante la inclusión de diferentes regiones o países y sus relaciones comerciales dentro de una sola tabla de IO (Wiedmann et al. 2011).

\subsubsection{Objetivos del análisis 10}

Los objetivos del presente estudio son los siguientes:

- Calcular la producción de B\&S (directa, indirecta e inducida), el valor añadido, el efecto multiplicador y la generación de empleo, producidos por el ciclo de vida de las plantas HYSOL BIO, HYSOL GN y TERMOSOLAR CCP, tanto en la economía española como en la internacional.

- Calcular el efecto neto del ciclo de vida de las plantas HYSOL BIO, HYSOL GN y TERMOSOLAR CSP en dichos indicadores socioeconómicos, incluyendo el efecto evitado por desplazar otras tecnologías en el mercado eléctrico español. 


\subsubsection{Características del sistema estudiado}

Las plantas HYSOL BIO, HYSOL GN y TERMOSOLAR CCP analizadas mediante las tablas IO Multi-regionales mantienen las mismas características técnicas que las descritas en la sección 2.1.2 del Capítulo 2 de esta tesis.

En todos los escenarios se asume que el $70 \%$ de la inversión de la planta está financiada mediante un préstamo a plazo fijo de 20 años, mientras que el $30 \%$ restante lo cubre el promotor del proyecto. La rentabilidad requerida por el proyecto se ha asumido como 7,398 \%, siendo igual al valor calculado por el gobierno como "tasa de rentabilidad razonable" para proyectos de energías renovables (Orden IET/1045/2014 2014). La tasa de interés del préstamo se ha fijado como un punto inferior a la tasa de rentabilidad, es decir, 6,398 \%. La tasa de descuento para la actualización de flujos futuros a valores presentes es 6,698 \%, calculada como la media ponderada de la tasa de rentabilidad y la tasa de interés bancario usando el apalancamiento como peso. El préstamo se devuelve a la institución financiera mediante pagos anuales que cubren tanto los intereses como la amortización del capital. Sin embargo, para este estudio se considera que los intereses se pagan anualmente mientras que la amortización del capital se paga en los dos primeros años que dura la construcción de la planta. Esta consideración se basa en la hipótesis de que la demanda de B\&S para la fabricación de componentes y construcción de la planta se realiza en el momento de compra, y no en el momento en el que el promotor devuelve el dinero a la institución financiera. Además, permite mantener la coherencia con los análisis CCV y ACV-A llevados a cabo en esta tesis.

Los costes anuales se han descontado desde el momento en el que ocurren hasta el año inicial del proyecto (año 0, 2013), asumiendo una tasa de descuento real de 6,698 \%, según la Ecuación (8). Esta tasa incluye primas de riesgos y costes de oportunidad.

$$
\text { Costes actualizados }=\sum_{n=0}^{28} \frac{\text { Costes }}{(1+r)^{n}}
$$

$$
\begin{aligned}
& n=\text { año en el que el coste tiene lugar } \\
& r=\text { tasa de descuento }(6,698 \%)
\end{aligned}
$$

El inventario económico ha sido recopilado y agrupado en costes de inversión (compra de componentes, construcción y diseño de planta), costes de operación y mantenimiento (costes anuales) y disposición final. El inventario detallado y su asignación a cada sector se encuentran descritos en el Anexo II de esta tesis. El pago de intereses se realiza en 20 años, por lo tanto, como la construcción dura 2 años, un décimo de los intereses se pagan en la fase de inversión, 
y el resto en los siguientes 18 años. A efectos de cálculo se ha prorrateado el pago de los intereses durante los 25 años de la fase $O \& M$, ya que los resultados de dicha fase están agregados anualmente (en M€ por año).

\subsubsection{Planta HYSOL}

El proyecto comienza en el año 2015 (año 0), momento en el que tiene lugar el diseño de la planta. La fabricación y compra de componentes (Inversión inicial) y la Construcción de la central tienen lugar a lo largo de los años 2016 y 2017 (años 1 y 2). La Operación y Mantenimiento (O\&M) de la central ocurre desde el año 2018 hasta el 2042 (años 3-27). Finalmente, el Desmantelamiento y Disposición de residuos (D\&D) tiene lugar en el año 2043 (año 28).

El inventario de costes ha sido recopilado para el año 2015 (en €2015), sin embargo, los datos más actuales de la WIOD son del año 2011. Por lo tanto, se ha convertido cada coste a la moneda de 2011 (€2011) aplicando el IPC para España según datos de la OCDE (OECD 2014). A continuación, se ha asociado un sector económico (o industria) a cada partida del inventario económico. Las actividades industriales/sectores económicos de las tablas WIOD están agregadas en 35 grupos. La clasificación de actividades en dichos grupos está basada en la clasificación universal del Sistema de Contabilidad Europea 2010.

\subsection{Producción de biometano}

Las tablas IO permiten considerar el consumo del gas natural como demanda del sector "Suministro de electricidad, gas y agua", sin embargo no hay ningún sector que represente adecuadamente la producción de biometano. Para incluir el consumo de biometano en el análisis IO se ha considerado como demanda la construcción, operación y mantenimiento de las plantas de biometano de forma paralela a la de la planta HYSOL. Esta demanda incluye los B\&S demandados por todas las plantas de biometano que son necesarias para satisfacer la demanda de gas de la planta HYSOL. Por tanto, considerando que el consumo total de biometano de la planta HYSOL asciende a $8,51 \times 10^{10} \mathrm{MJ}$ y que cada planta de biometano analizada produce 5,87 x $10^{8} \mathrm{MJ}$ de biometano en toda su vida útil, el número de plantas necesarias para este estudio son 145. A efectos de cálculo, este valor se ha multiplicado por todas las partidas de inventario necesarias para construir y operar una planta de biometano (descritas en la sección 4.1.2.2 de este capítulo). El inventario detallado de las plantas de biometano y su asignación a cada sector se encuentran descritos en el Anexo I de esta tesis. 


\subsubsection{Planta TERMOSOLAR CCP}

Se asume que este proyecto comienza en el año 2013 (año 0), momento en el que tiene lugar el diseño del proyecto. El año de comienzo difiere de la planta HYSOL debido a que los datos de partida para esta planta fueron suministrados en el año 2013. La fabricación y compra de componentes (Inversión inicial) y la Construcción de la central (C) tienen lugar a lo largo de los años 2014 y 2015 (años 1 y 2). La Operación y Mantenimiento (O\&M) de la central ocurre desde el año 2016 hasta el 2040 (años 3-27). Finalmente, el Desmantelamiento y Disposición de residuos (D\&D) tiene lugar en el año 2041 (año 28).

El inventario de costes ha sido recopilado para el año 2013 (en $€_{2013}$ ), sin embargo, los datos más actuales de la WIOD son del año 2011. Por lo tanto, se ha convertido cada coste a la moneda de $2011\left(€_{2011}\right)$ aplicando el IPC para España según datos de la OCDE (OECD 2014). A continuación, se ha asociado un sector económico (o industria) a cada partida del inventario económico.

\subsubsection{Metodología de análisis MRIO}

\subsubsection{Tablas 10 Multi-regionales}

Para el cálculo de los efectos socioeconómicos de la central se han utilizado las tablas 10 multi-regionales elaborada por el proyecto europeo WIOD. La base de datos desarrollada incluye tablas simétricas 10 nacionales para 40 países, agrupadas en 35 sectores, con valores desde el año 1995 hasta el año 2011. También incluye información por sectores de numerosas variables socioeconómicas (relacionadas con el empleo) y ambientales (relacionadas con el consumo energético, gases de efecto invernadero, y emisión de contaminantes al aire).

Los datos de inventario relativos a la compra de componentes de la planta representan el coste de adquisición de dichos componentes. Sin embargo, los sectores de las WIOT asociados se refieren a costes de producción, generalmente inferiores a los de adquisición. Para evitar la sobreestimación de costes de fabricación se ha utilizado la transformación de precios básicos a precios de adquisición según la tabla de origen de España para el año 2009, publicada por el INE (INE 2015). Para ello se han calculado los porcentajes que representan el margen de transporte, el margen comercial e impuestos para cada producto (y sector) y se han aplicado a los costes y sectores correspondientes. Los márgenes asociados con cada ítem del inventario se encuentran detallados en el Anexo II de esta tesis. 


\subsubsection{Producción de B\&S}

La Ecuación (9) representa el cálculo necesario para obtener la producción de B\&S generada por la actividad del proyecto (Leontief 1970).

$$
X=(I-A)^{-1} Y
$$

Donde $Y$ es el vector de demanda final de bienes y productos necesarios para el ciclo de vida de la planta termosolar, $X$ es la producción bruta de B\&S domésticos necesarios para satisfacer dicha demanda, A es la matriz de coeficientes técnicos, e $(I-A)^{-1}$ es la matriz inversa de Leontief.

La tabla IO Multi-regional permite incluir la demanda de B\&S de distintos países en un mismo cálculo, por lo que el vector demanda tendrá un componente para cada sector de los 40 países contenidos en la tabla.

\subsection{Producción de B\&S directos}

El vector $Y$ está compuesto por toda la demanda de B\&S, en M€ y ordenada por sectores, que tiene lugar en cada fase del ciclo de vida del proyecto. Dicha demanda supone el efecto directo en la generación de B\&S.

\subsection{Producción de B\&S indirectos}

Se definen como la producción de B\&S intermedia necesaria para satisfacer la demanda $Y$ de B\&S. El efecto indirecto se calcula como la resta entre la producción doméstica total de B\&S y la producción directa. Es decir, $\mathrm{X}_{\text {indirecto }}=X-Y$.

\subsection{Efectos domésticos y no domésticos}

La tabla IO multi-regional está desagregada por sectores y países de tal forma que podemos obtener la producción de B\&S clasificada por países de origen. Por lo tanto, se pueden distinguir los efectos domésticos, entendidos como aquellos originados en España, y los no domésticos, entendidos como aquellos originados en otros países distintos a España.

\subsubsection{Empleo generado}

La tabla WIOD SEA contiene información sobre el número de horas trabajadas por cada sector, desde el año 1995 hasta el 2011. Para calcular el empleo generado por el proyecto se han utilizado dichos datos para el 2011, que divididos por la producción total en cada sector forman el vector empleo en horas trabajadas por millón de euros. Dicho vector multiplicado por la generación de $B \& S$ por el ciclo de vida de la planta analizada $(X$, en $M €)$ da como resultado la cantidad de horas trabajadas para dicha generación de B\&S en cada sector. Para saber el empleo equivalente generado, se ha dividido el resultado por la media de horas trabajadas por 
empleado para España en 2011: 1.700 horas por empleado y año según la OCDE (OECD 2014). El resultado, medido en personas-año, representa la generación total de empleos para cada fase del proyecto.

\subsubsection{Valor añadido}

El valor añadido representa el valor económico adicional que adquiere cada bien y servicio al ser creado o fabricado mediante la actividad productiva de cada sector.

Para su cálculo, se ha tomado los datos de la fila "Valor añadido en precios básicos" de la tabla WIOT y se ha calculado su porcentaje respecto al total generado (columna "Total output") para aplicárselo a la producción de $B \& S, X$, tanto en su fracción directa como indirecta, para cada una de las fases consideradas.

El resultado representa el valor añadido directo e indirecto generado por el proyecto.

\subsubsection{Efectos inducidos}

Los efectos inducidos directos representan la generación de B\&S y de valor añadido derivada del gasto salarial de los empleados de la central durante la fase de operación y mantenimiento. Se asume que el salario de los trabajadores se va a gastar en un patrón de consumo, y este consumo va a generar actividad económica (producción de B\&S).

En el caso de estudio, el dato de partida proporcionado por IDie es el coste laboral de la empresa promotora. Para considerar el salario percibido por los trabajadores hay que descontar el porcentaje correspondiente de cotizaciones salariales al coste laboral de partida. Según los datos del INE para el segundo semestre del año 2011 en el sector industrial, el coste salarial medio es un $74,4 \%$ del coste laboral (INE 2012). Además, según la encuesta de estructura salarial del INE para el año 2010 (INE 2012), el salario neto medio de un trabajador (el salario que realmente percibe cada mes) es un $79 \%$ del salario bruto. La tasa de ahorro de los hogares, que según los datos del INE para el año 2011 (INE 2012) se sitúa en torno al 9,6\%, por lo tanto se asume que el porcentaje de renta salarial que los trabajadores van a gastar en B\&S de consumo es $90,4 \%$.

Teniendo en cuenta el coste salarial, la retención de impuestos del salario bruto, y la tasa de ahorro de los hogares, se ha asumido como vector de demanda (Yinducido) para el cálculo de los efectos inducidos el 53,2 \% del coste laboral total de la fase de operación y mantenimiento (0,983 M€ $\left.€_{2011} / \mathrm{yr}\right)$, distribuido en los distintos sectores según el patrón de consumo de la WIOD (definido por la distribución de la columna "Gasto de consumo final de los hogares" de la tabla WIOT española). El resultado de multiplicar este vector por la matriz inversa de Leontief 
CAPÍTULO 4: Análisis del área económica

representa la generación de B\&S debida al gasto salarial de los trabajadores de la planta. También se ha calculado el valor añadido directo e indirecto y la generación de empleo inducidos por dicho consumo

El porcentaje de coste laboral correspondiente a impuestos y cotizaciones, es decir, el $46,8 \%$ del coste laboral menos el ahorro del hogar (en total, $39,7 \%$ del coste laboral) se ha añadido como demanda al sector de impuestos y cotizaciones de la seguridad social (c31, Public Admin and Defence; Compulsory Social Security) en el vector demanda $Y$.

Además de los efectos inducidos producidos por los empleados de la planta, también se ha calculado los efectos inducidos producidos por el consumo salarial de todo el empleo generado en el ciclo de vida del sistema. Para ello se ha considerado la tasa de ahorro mencionada anteriormente, el salario neto medio español para el año 2010 (INE 2012), el número de empleos generados calculado según la metodología del apartado 2.1 y el patrón de consumo según la tabla de WIOT española. El efecto inducido debido a la actividad económica indirecta que se genera por el consumo de los nuevos empleados generados por el gasto salarial no ha sido calculado.

Para los bienes no domésticos o importados no se ha calculado ningún efecto inducido.

\subsubsection{El efecto multiplicador}

Este indicador nos da una medida del incremento de la renta nacional a consecuencia del incremento indirecto producido al demandar un bien (esto es, la demanda indirecta de B\&S de otros sectores para abastecer un bien o servicio del sector demandado).

Por lo tanto, el efecto multiplicador doméstico, calculado según la Ecuación (10), proporciona la relación entre el efecto total (directo, indirecto e inducido) y el efecto directo en la producción doméstica de B\&S.

$$
E m d=\left(X_{\text {doméstico }}+X_{\text {inducido }}\right) / Y
$$

El efecto multiplicador total se calcula incluyendo en el numerador la producción de B\&S no doméstica, según la Ecuación (11).

$$
E m=\left(X_{\text {total }}+X_{\text {inducido }}\right) / Y
$$




\subsubsection{Metodología consecuencial para el cálculo de los efectos netos}

Para calcular los efectos socioeconómicos netos del proyecto es necesario determinar aquellos efectos que dejan de producirse al introducir la electricidad producida mediante termosolar en el sistema. Para ello es necesario considerar la tecnología desplazada por la termosolar, es decir, la tecnología marginal. El mix de tecnologías marginales se ha tomado según lo calculado en la sección 3.2.4.1 del Capítulo 3.

\subsection{El vector demanda del mix de tecnologías marginales}

Para saber el efecto socioeconómico que deja de producirse debido el desplazamiento de las tecnologías marginales, es necesario conocer el coste de producción de dichas tecnologías. El coste de producción equivale a la demanda económica necesaria para suministrar electricidad mediante las tecnologías marginales. Para ello se ha escogido como indicador el LEC, ya que representa el coste de todo el ciclo de vida (ciclo de vida) por unidad funcional, de una forma análoga al cálculo del coste interno de ciclo de vida de la tecnología HYSOL. Una vez conocidos los costes de ciclo de vida del mix de tecnologías marginales por unidad funcional, se calculan los costes equivalentes de producir la misma cantidad de electricidad que la producida por la planta termosolar bajo estudio y se introducen en la tabla IO española como demanda del sector "Electricity, Gas and Water Supply". Dicha demanda se calcula mediante la Ecuación (12),

$$
Y_{\text {mix }}=\sum_{i=3}^{27} \frac{L E C_{m i x} \times E_{i}}{(1+r)^{i}}
$$

donde:

$Y_{\text {mix }}(\mathrm{M} €)$, la demanda de la tecnología marginal desplazada (para el sector "Electricity, Gas and Water Supply"),

$L E C_{\text {mix }}(€ / \mathrm{MWh})$, es el coste nivelado de producir $1 \mathrm{MWh}$ mediante el mix de tecnologías marginales,

$E_{i}$ (MWh/año) es la producción eléctrica anual de la planta termosolar bajo estudio, $r$ es la tasa de descuento $(6,698 \%)$,

$i$ son los años del proyecto durante los cuales hay producción eléctrica.

El cálculo incluye una actualización de la demanda anual, ya que al considerar el LEC como coste de producción, volvemos a introducir el factor tiempo. EI LEC está condicionado a una producción eléctrica, es decir, a un ingreso por MWh que se va a producir anualmente a lo largo de 25 años. Por lo tanto, para mantener el mismo sistema de cálculo que en el análisis IO bruto, debemos descontar dichos costes de producción (o dicha demanda). 
CAPÍTULO 4: Análisis del área económica

Ya que parte del mix de tecnologías marginales es de procedencia francesa, la demanda correspondiente se asignará al sector correspondiente francés de la WIOT.

El resultado de calcular la generación de B\&S, valor añadido y empleo relacionados con dicha demanda representará la diferencia entre el efecto socioeconómico bruto y el efecto socioeconómico neto del proyecto termosolar. De tal forma que el efecto socioeconómico neto del ciclo de vida de la planta termosolar queda definido por la Ecuación (13).

$$
\text { Efecto neto }=\text { Efectos }_{\text {termosolar }}-\text { Efectos }_{\text {mix }}
$$

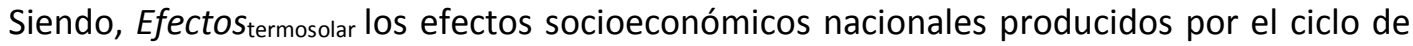
vida de la planta termosolar, y Efectos $_{\text {mix }}$ los efectos socioeconómicos nacionales de demandar la misma cantidad de electricidad producida por la termosolar mediante el mix de tecnologías marginales.

\subsection{Cálculo de costes nivelados de las distintas tecnologías marginales}

EI LEC de cada tecnología que interviene en el mix de tecnologías marginales se ha calculado siguiendo características generales comunes para conseguir la mayor armonización posible de resultados respecto a los cálculos de la planta termosolar.

Los cálculos de LEC han sido realizados según la Ecuación (14),

$$
L E C=\frac{\sum_{i=0}^{n} \frac{I i+M i+F i+C i+D i}{(1+r)^{i}}}{\sum_{i=0}^{n} \frac{E_{i}}{(1+r)^{i}}}
$$

donde:

I (M€/año) es la inversión inicial,

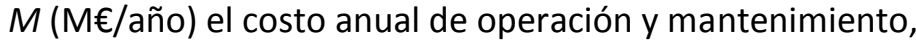

$F(\mathrm{M} € /$ año) el costo anual de combustible,

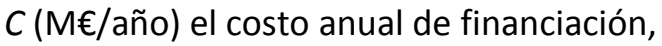

$D$ (M€/año) el costo de desmantelamiento,

$E_{i}(\mathrm{MWh} / \mathrm{año})$ la electricidad producida,

$r$ la tasa de descuento $(6,698 \%)$,

$n$ (años) los años que dura el proyecto (28 años). 
Se asume en todos los casos que la financiación del proyecto se realiza mediante préstamos de 20 años a plazo fijo, cubriendo un 70 \% de la inversión. La tasa de interés bancaria es 6,398 \%, calculada como un punto inferior a la "tasa de rentabilidad razonable" para proyectos de energías renovables según el gobierno español.

La tasa de descuento a aplicar ha sido 6,698 \% (media ponderada de la tasa de interés y la rentabilidad razonable usando el apalancamiento como peso). Se ha considerado como moneda el euro de $2011\left(€_{2011}\right)$, por lo tanto, se ha convertido cada partida económica a dicha moneda mediante los tipos de cambio e índices de precios de consumo publicados por la OECD.

Todos los datos de costes de partida se han tomado del informe "Costes previstos de la energía 2010" (traducido del inglés, Projected costs of energy 2010) de la IEA (IEA and NEA 2010), excepto los costes de combustible y los financieros. Los costes considerados para el cálculo de la LEC de cada tecnología están indicados en la Tabla 64, junto con algunas características técnicas de cada central.

En el caso de la central hidroeléctrica, se ha escogido la información (disponible en el IEA) de una central de embalse sueca de $70 \mathrm{MW}$ al ser la que más se podía ajustar a las características deseadas de la tecnología hidroeléctrica marginal. Para la central de bombeo, la única información disponible era para una estación de 1000 MW, según el grupo industrial EUROELECTRIC.

Se asume que la tecnología marginal termosolar se corresponde con el escenario de TERMOSOLAR CCP contemplado en esta tesis (está hibridada con gas natural: el $15 \%$ de la electricidad se produce mediante la combustión de gas natural).

Tabla 64 Características y costes (valor presente) del ciclo de vida de las tecnologías marginales, en $€_{2011}$

\begin{tabular}{|c|c|c|c|c|c|c|c|c|}
\hline $\begin{array}{l}\text { Tecnología de } \\
\text { producción } \\
\text { eléctrica }\end{array}$ & $\begin{array}{l}\text { Potencia } \\
\text { instalada } \\
\text { (MW) }\end{array}$ & $\begin{array}{l}\text { Factor } \\
\text { de } \\
\text { carga } \\
(\%)\end{array}$ & $\begin{array}{l}\text { Vida } \\
\text { útil } \\
\text { (a) }\end{array}$ & $\begin{array}{l}\text { Coste de } \\
\text { inversión } \\
(€ / \text { kW) }\end{array}$ & $\begin{array}{l}\text { Coste } \\
\text { financiero } \\
\text { (M€) }\end{array}$ & $\begin{array}{l}\text { Coste de } \\
\text { O\&M } \\
\text { (€/MWh) }\end{array}$ & $\begin{array}{l}\text { Coste de } \\
\text { combust }^{1} \\
\text { (€/MWh) }\end{array}$ & $\begin{array}{l}\text { Coste de } \\
\text { desmant. } \\
\text { (€/MWh) }\end{array}$ \\
\hline $\begin{array}{l}\text { Térmica de } \\
\text { carbón }\end{array}$ & 400 & 34,9 & 40 & 1546,4 & 176,40 & 4,048 & 19,586 & 0,063 \\
\hline Ciclo combinado & 400 & 22,3 & 30 & 951,43 & 108,53 & 3,113 & 105,02 & 0,071 \\
\hline Hidroeléctrica & 70 & 40 & 80 & 3433,4 & 68,54 & 12,01 & - & 0,103 \\
\hline Bombeo & 1000 & 29 & 80 & 2871,7 & 818,97 & 8,358 & - & 0,002 \\
\hline Eólica & 100 & 21 & 25 & 1584,4 & 45,18 & 27,66 & - & 0,261 \\
\hline Termosolar & 50 & 38,4 & 25 & 5004,8 & 86,91 & 32,53 & $30,31^{*}$ & 0,362 \\
\hline
\end{tabular}

*Debido a la hibridación con gas natural (en un $15 \%$ )

${ }^{1}$ Nótese que el valor está referido por MWh final producido en la planta 
Las horas de funcionamiento equivalente de las centrales de carbón y ciclo combinado (3057 h y 1953 h respectivamente) se han tomado del informe anual de supervisión del mercado eléctrico de la Comisión Nacional de la Energía (CNE 2011), ya que actualmente en España estas centrales funcionan con factores de carga inferiores que en otros países.

Se ha supuesto que la tecnología marginal térmica de carbón utiliza como combustible el carbón importado, ya que el carbón nacional está subvencionado y suele entrar en el mercado eléctrico. El precio del carbón importado $\left(27,02077 \$ 2013 / \mathrm{MWh}_{\text {producido }}\right)$ se ha obtenido del boletín oficial del estado "BOE A 2013 -13807, Resolución por la que se fijan las cantidades de carbón, el volumen máximo de producción y los precios de retribución para el 2013." Según esta resolución, el poder calorífico inferior del carbón considerado es $5971 \mathrm{kCal} / \mathrm{kg}$, con una eficiencia de conversión eléctrica de $45 \%$. Se asume que el precio del carbón se mantiene constante en toda la vida útil de la central.

El precio base del gas natural se ha considerado igual a 24,41 $€_{2011} / \mathrm{MWh}$ para el año 2010 (23,65 $€_{2010}$ por MWh bruto de gas natural, según lo publicado en el BOE-A-2010-5945), y se ha asumido creciente en el tiempo según las predicciones del PER (IDAE 2011). En el caso de los ciclos combinados, se ha considerado una eficiencia de conversión eléctrica del $58 \%$, mientras que en la tecnología termosolar la eficiencia es de $35 \%$.

Se desconoce la LEC de la electricidad importada de Francia, por lo que se ha asumido como LEC francesa una media ponderada de las LEC del resto de tecnologías marginales, usando como peso la participación en la fijación del precio marginal.

\subsubsection{Resultados del análisis MRIO aplicado a la planta HYSOL}

Los resultados del análisis MRIO aplicado a la planta HYSOL se estructuran en dos apartados:

- Resultados socioeconómicos brutos, en los que se incluye la producción domésticae imp ortada de B\&S, el efecto multiplicador, el valor añadido y el empleo generado por el ciclo de vida (ciclo de vida) de la planta HYSOL BIO y del escenario alternativo (HYSOL GN).

- Resultados socioeconómicos netos, que incluye :

- El cálculo del vector demanda del mix de tecnologías marginales.

- El resultado de los indicadores socioeconómicos del mix de tecnologías marginales. 
- El cálculo neto socioeconómico del ciclo de vida de las plantas HYSOL BIO y HYSOL GN.

\subsubsection{Efectos socioeconómicos brutos}

\subsection{Efectos socioeconómicos de la producción de biometano}

En la Tabla 65 se describe la actividad económica generada por las fases del ciclo de vida de las 145 plantas de biometano necesarias para abastecer de gas a la planta HYSOL BIO. Teniendo en cuenta los efectos directos, indirectos, inducidos y no domésticos, el total de la actividad económica generada asciende a $2441 \mathrm{M} €$. La mayor parte de la producción de B\&S se da en la fase de inversión inicial (1336 M€), seguida de la fase O\&M (1105 M€). El efecto producido por la importación nacional de B\&S (efecto no doméstico) asciende a $425 \mathrm{M} €$, que representa el 17,4 \% del total de B\&S generados totales por la construcción y operación de las plantas de biometano.

El efecto multiplicador doméstico, que tiene en cuenta la relación entre los efectos totales domésticos y el directo, asciende a 1,94 para todo el ciclo de vida, resultando ser mayor en la fase de Inversión inicial $(2,04)$ y menor en la fase de O\&M $(1,85)$. El efecto multiplicador total, que incluye los efectos no domésticos, asciende a 2,35.

El efecto inducido por el consumo de los empleados de la central y de los empleos generados por la actividad económica asciende a $187 \mathrm{M€}$, un 7,7 \% del total de B\&S generados.

Tabla 65 Impacto del ciclo de vida de las 145 plantas de biometano sobre la producción de B\&S (en $€ 2011)$

\begin{tabular}{llccc}
\hline Efectos sobre la producción de B\&S & $\begin{array}{c}\text { Inversión inicial } \\
(\mathbf{M} \boldsymbol{)}\end{array}$ & $\begin{array}{c}\text { O\&M } \\
\text { (M€) }\end{array}$ & $\begin{array}{c}\text { TOTAL ciclo } \\
\text { (M€) }\end{array}$ \\
\hline \multirow{2}{*}{$\begin{array}{l}\text { Efecto } \\
\text { doméstico }\end{array}$} & Directo & 535 & 502 & 1.037 \\
\cline { 2 - 5 } & Indirecto & 466 & 327 & 793 \\
\cline { 2 - 5 } & Inducido & 88 & 99 & 187 \\
\hline Efecto no doméstico & 248 & 177 & 425 \\
\hline TOTAL & 1.336 & 1.105 & 2.441 \\
\hline Efecto multiplicador doméstico & 2,04 & 1,85 & 1,94 \\
\hline Efecto multiplicador total & 2,50 & 2,20 & 2,35 \\
\hline
\end{tabular}

*O\&M = Operación y Mantenimiento

La Tabla 66 muestra el valor añadido (directo, indirecto e inducido) producido por las 145 plantas de biometano que abastecen a la planta HYSOL. Se observa que el valor añadido en cada fase representa casi la mitad del resultado en generación de B\&S, siendo el valor añadido en España un 44,9\% de los B\&S generados en el país. Este valor es superior al 33,6 \% de valor añadido medio correspondiente al sector español de la producción de gas ("Suministro de 
CAPÍTULO 4: Análisis del área económica

electricidad, gas y agua, ES"). Por lo tanto, la producción de biometano estaría aumentando el porcentaje de valor añadido del sector de la electricidad.

Tabla 66 Valor añadido producido por el ciclo de vida delas 145 plantas de biometano (en €2011)

\begin{tabular}{lccc}
\hline Valor añadido & Inversión inicial (M€) & O\&M (M€/yr) & TOTAL ciclo(M€) \\
\hline Efecto Directo & 218 & 250 & 468 \\
\hline Efecto Indirecto & 191 & 146 & 337 \\
\hline Efecto Inducido & 47,2 & 52,3 & 100 \\
\hline No doméstico & 97,1 & 83,0 & 180 \\
\hline TOTAL & 553 & 532 & 1085 \\
\hline
\end{tabular}

La Tabla 67 describe el empleo generado (directo, indirecto e inducido) en la construcción y operación de las 145 plantas de biometano que abastecen a la planta HYSOL. El total de personas-año contratadas (durante un año, con una media de 1.700 horas de trabajo al año) durante el ciclo de vida asciende a 13.260, siendo su mayor contribución el empleo generado en la fase de Inversión inicial (7.609 personas-año). El empleo directo supone casi la mitad del empleo generado (6.236 personas·año). El porcentaje de empleo creado fuera de la economía española respecto al total creado por la planta HYSOL asciende a 12,8 \%. Considerando que el proyecto supone una generación doméstica de B\&S de $2.017 \mathrm{M} €$, la intensidad laboral del proyecto en España es 5,73 personas-año/M€. Este valor es casi cinco veces mayor que la intensidad laboral media de 1,23 personas-año/M€ correspondiente al sector español de electricidad ("Suministro de electricidad, gas y agua, ES"). Por lo tanto, el proyecto HYSOL estaría aumentando la intensidad laboral del sector de la electricidad español.

Tabla 67 Empleo generado durante el ciclo de vida de las 145 plantas de biometano

\begin{tabular}{lccc}
\hline Empleo generado & $\begin{array}{c}\text { Inversión inicial } \\
\text { (personas·año*) }\end{array}$ & $\begin{array}{c}\text { O\&M } \\
\text { (personas·año*) }\end{array}$ & $\begin{array}{c}\text { TOTAL ciclo } \\
\text { (personas·año*) }\end{array}$ \\
\hline Directo & 3.490 & 2.746 & 6.236 \\
\hline Indirecto & 2.510 & 1.642 & 4.151 \\
\hline Inducido & 554 & 615 & 1.169 \\
\hline No doméstico & 1.056 & 647 & 1.703 \\
\hline TOTAL & 7.609 & 5.651 & 13.260 \\
\hline
\end{tabular}

*Se consideran empleos de un año de duración, y una media de 1.700 horas trabajadas al año

\subsection{Efectos socioeconómicos de la planta HYSOL BIO}

En la Tabla 68 se describe la actividad económica generada por las fases del ciclo de vida de la planta HYSOL BIO, incluyendo la correspondiente al ciclo de vida del biometano dentro de la fase O\&M. Teniendo en cuenta los efectos directos, indirectos, inducidos y no domésticos, el total de la actividad económica generada asciende a $4.439 \mathrm{M} €$. La mayor producción de B\&S se 
da en la fase O\&M (2.866 M€), debido principalmente al ciclo de vida del biometano. La actividad económica generada por el biometano supone el 55,3 \% de los B\&S generados durante todo el ciclo de vida de la planta HYSOL BIO, mientras que la inversión inicial (compra de componentes y construcción) supone el 35,4 \% del total de B\&S generados.

El efecto económico producido por la importación nacional de B\&S (efecto no doméstico) asciende a $850 \mathrm{M} €$, concentrándose en su mayoría durante la fase de O\&M. Esta cantidad, que supone el $19,2 \%$ del total de B\&S generados, también incluye el efecto indirecto producido en los países de origen de las mercancías importadas.

El efecto multiplicador doméstico, que tiene en cuenta la relación entre los efectos totales domésticos y el directo, asciende a 1,96 para todo el ciclo de vida, resultando ser mayor en la fase $D \& D(2,24)$ y de Inversión inicial $(2,03)$, y menor en la fase de O\&M $(1,93)$. Esto es muestra del mayor efecto indirecto que presenta la fase $D \& D$ respecto a las demás, superando incluso al efecto directo. El efecto multiplicador total, que incluye los efectos no domésticos, asciende a 2,42 .

Tabla 68 Impacto del ciclo de vida de la planta HYSOL BIO sobre la producción de B\&S (en €2011)

\begin{tabular}{|c|c|c|c|c|c|}
\hline \multicolumn{2}{|c|}{ Efectos sobre la producción de B\&S } & $\begin{array}{c}\text { Inversión } \\
\text { inicial (M€) }\end{array}$ & $\begin{array}{l}\text { O\&M } \\
(\mathrm{M} €)\end{array}$ & $D \& D(M €)$ & $\begin{array}{c}\text { TOTAL } \\
\text { ciclo (M€) }\end{array}$ \\
\hline \multirow{3}{*}{$\begin{array}{l}\text { Efecto } \\
\text { doméstico }\end{array}$} & Directo & 586 & 1242 & 2,02 & 1.832 \\
\hline & Indirecto & 512 & 920 & 2,14 & 1.434 \\
\hline & Inducido & 92 & 230 & 0,36 & 323 \\
\hline \multicolumn{2}{|c|}{ Efecto no doméstico } & 376 & 473 & 0,61 & 850 \\
\hline \multicolumn{2}{|l|}{ TOTAL } & 1.568 & 2.866 & 5,14 & 4.439 \\
\hline \multicolumn{2}{|c|}{ Efecto multiplicador doméstico } & 2,03 & 1,93 & 2,24 & 1,96 \\
\hline \multicolumn{2}{|c|}{ Efecto multiplicador total } & 2,67 & 2,31 & 2,54 & 2,42 \\
\hline
\end{tabular}

*O\&M = Operación y Mantenimiento, D\&D = Desmantelamiento y Disposición de residuos

La Tabla 66 muestra el valor añadido (directo, indirecto e inducido) producido por la planta HYSOL BIO en todas sus fases del ciclo de vida. Se observa que el valor añadido doméstico en cada fase del ciclo de vida representa casi la mitad del resultado en generación de B\&S, siendo el valor añadido total un $45,0 \%$ de los B\&S generados. Siendo que la demanda directa total de B\&S del ciclo de vida de la planta HYSOL BIO (actualizada al presente e incluyendo la demanda del ciclo de vida del biometano) asciende a $2.014 \mathrm{M} €$, el porcentaje de valor añadido creado en España respecto al dinero invertido en el proyecto asciende a 97,7 \% (economía global) y $80,2 \%$ (economía española). 
CAPÍTULO 4: Análisis del área económica

Tabla 69 Valor añadido producido por el ciclo de vida de la planta HYSOL BIO (en €2011)

\begin{tabular}{lcccc}
\hline Valor añadido & Inversión inicial (M€) & O\&M (M€/yr) & D\&D (M€) & TOTAL ciclo(M€) \\
\hline Efecto Directo & 243 & 581 & 0,79 & 825 \\
\hline Efecto Indirecto & 218 & 401 & 0,88 & 620 \\
\hline Efecto Inducido & 49,7 & 122 & 0,19 & 172 \\
\hline No doméstico & 149 & 202 & 0,25 & 352 \\
\hline TOTAL & 659 & 1.307 & 2,11 & 1.968 \\
\hline \% de B\&S & 42,8 & 46,1 & 41,2 & 45,0 \\
\hline
\end{tabular}

La Tabla 70 describe el empleo generado (directo, indirecto e inducido) en cada fase del ciclo de vida de la planta HYSOL BIO. El total de personas-año contratadas (durante un año, con una media de 1.700 horas de trabajo al año) durante el ciclo de vida asciende a 25.161 personas·año, siendo su mayor contribución el empleo generado en la fase O\&M (16.639 personas-año). El ciclo de vida del biometano es responsable de la creación del 53,0 \% de empleo de todo el ciclo de vida de la planta HYSOL, mientras que la fase de inversión inicial es la responsable de la creación del 33,8 \% del empleo. El empleo directo supone casi la mitad del empleo total generado (12.007 personas-año). El porcentaje de empleo creado fuera de la economía española respecto al total creado por la planta HYSOL asciende a 14,0\%. Considerando que la producción de B\&S de todo el ciclo de vida de la planta HYSOL BIO asciende a 4.439 M€, la intensidad laboral equivale a 5,67 personas·año/M€.

Tabla 70 Empleo generado durante el ciclo de vida de la planta HYSOL BIO

\begin{tabular}{lcccc}
\hline $\begin{array}{l}\text { Empleo } \\
\text { generado }\end{array}$ & $\begin{array}{c}\text { Inversión inicial } \\
\text { (personas·año*) }\end{array}$ & $\begin{array}{c}\text { O\&M } \\
\text { (personas·año*) }\end{array}$ & $\begin{array}{c}\text { D\&D } \\
\text { (personas·año*) }\end{array}$ & $\begin{array}{c}\text { TOTAL ciclo } \\
\text { (personas·año*) }\end{array}$ \\
\hline Directo & 3.525 & 8470 & 12,7 & 12.007 \\
\hline Indirecto & 2.788 & 4814 & 11,9 & 7.615 \\
\hline Inducido & 583 & 1435 & 2,28 & 2.020 \\
\hline No doméstico & 1597 & 1919 & 2,74 & 3.519 \\
\hline TOTAL & 8.492 & 16.639 & 29,7 & 25.161 \\
\hline
\end{tabular}

*Se consideran empleos de un año de duración, y una media de 1.700 horas trabajadas al año

La Tabla 71 describe los beneficios económicos globales por unidad funcional (1 MWh) del ciclo de vida de la planta HYSOL BIO. Los efectos por unidad funcional se han calculado dividiendo el efecto bruto por la suma de la producción eléctrica anual descontada durante la vida útil de la planta. La producción de B\&S generada por el ciclo de vida de la central asciende a $529 € / M W h$. De esta cantidad, el $44,4 \%$ es valor añadido. 
Tabla 71 Beneficios socioeconómicos globales generados durante el ciclo de vida de la planta HYSOL BIO, por unidad funcional

\begin{tabular}{lccc}
\hline & $\begin{array}{c}\text { Valor añadido } \\
(€ / \text { MWh) }\end{array}$ & $\begin{array}{c}\text { Producción de B\&S } \\
\text { (€/MWh) }\end{array}$ & $\begin{array}{c}\text { Empleo } \\
\text { (horas/MWh) }\end{array}$ \\
\hline Beneficio total & 235 & 529 & 5,10 \\
\hline
\end{tabular}

La Tabla 72 describe la generación de B\&S, porcentaje de valor añadido y generación de empleo en cada región económica que participa en el ciclo de vida de la planta HYSOL BIO. La tabla también presenta los países que contribuyen en más de un $1 \%$ a la demanda de B\&S del ciclo de vida de la planta. La región económica con mayor contribución es la Unión Europea, ya que contiene los cuatro países con mayor contribución a la generación de B\&S: España (3.589 M€), Alemania (131 M€), Italia (113 M€) y Francia (76,1 M€). Los siguientes países con mayor contribución son China, Estados Unidos, Rusia e India. En cuanto al porcentaje de valor añadido, el ranking de países es similar, aunque Estados Unidos presenta mayor valor añadido que Francia y China. Respecto al empleo generado, Europa concentra el $95 \%$ del empleo generado durante todo el ciclo de vida de la planta. Cabe mencionar que Rusia presenta mayor generación de empleo que Francia (el cuarto país con mayor generación de B\&S). El valor de empleo generado de China no se ha calculado ya que WIOD no proporciona información respecto a estadísticas laborales en China.

Tabla 72 Contribución de las regiones económicas y los países más relevantes en la cadena de valor a la generación de B\&S (más de un 1\%), valor añadido y empleo de la planta HYSOL BIO

\begin{tabular}{lccc} 
& $\begin{array}{c}\text { Generación B\&S } \\
(\$ M)\end{array}$ & $\begin{array}{c}\text { Contribución al } \\
\text { valor añadido } \\
\text { total }\end{array}$ & $\begin{array}{c}\text { Empleo } \\
\text { (personas·año*) }\end{array}$ \\
\hline Unión Europea & $\mathbf{4 . 0 6 3}$ & $\mathbf{9 1 \%}$ & $\mathbf{2 3 . 8 3 4}$ \\
\hline España & 3.589 & $82 \%$ & 21.642 \\
Alemania & 128 & $2,7 \%$ & 559 \\
Italia & 111 & $2,0 \%$ & 427 \\
Francia & 72,9 & $1,3 \%$ & 290 \\
\hline Este asiático y Pacífico & $\mathbf{9 3 , 8}$ & $\mathbf{1 , 5} \%$ & $\mathbf{2 0 5}$ \\
\hline China & 59,9 & $0,8 \%$ & $\mathbf{3 5 5}$ \\
\hline TLCAN & $\mathbf{7 7 , 1}$ & $\mathbf{2 , 2} \%$ & 249 \\
\hline Estados Unidos & 37,5 & $1,7 \%$ & $\mathbf{7 6 7}$ \\
\hline Otros & $\mathbf{2 0 5}$ & $\mathbf{5 , 1} \%$ & 311 \\
\hline Rusia & 29,5 & $0,76 \%$ & \\
\hline
\end{tabular}

†Unión Europea: Alemania, Francia, Gran Bretaña, España, Italia, Suecia, Bélgica, Polonia, República Checa, Dinamarca, Austria, Hungría, Eslovaquia y Rumanía. Este asiático y Pacífico: China, Japón, Corea del Sur, Taiwán, Indonesia. TLCAN: Estados Unidos, Canada, México. Otros: Brasil, Rusia, Turquía, India, Australia and Resto del Mundo 
Como se describe en la Tabla 72, la contribución española a los tres efectos considerados se encuentra entre el 81 y el 86 \%, lo que indica que España es con diferencia la economía más beneficiada en el ciclo de vida de la planta HYSOL (seguida por Alemania).

\subsection{Efectos socioeconómicos del escenario HYSOL GN}

En la Tabla 73 se describe la actividad económica generada por las fases del ciclo de vida de la planta HYSOL GN. Teniendo en cuenta los efectos directos, indirectos, inducidos y no domésticos, el total de la actividad económica generada asciende a 2.764 M€. La mayor producción de B\&S se da en la fase de Inversión inicial, que asciende a $1.568 \mathrm{M€}$. El efecto producido por la importación nacional de B\&S (efecto no doméstico) asciende a $602 \mathrm{M€}$, concentrándose en su mayoría durante la fase de O\&M.

El efecto multiplicador doméstico asciende a 1,94 para todo el ciclo de vida, resultando ser mayor en la fase $D \& D(2,24)$ y de Inversión inicial $(2,03)$ menor en la fase O\&M $(1,85)$. Esto demuestra del mayor efecto indirecto que presenta la fase D\&D respecto a las demás, superando incluso al efecto directo. El efecto multiplicador total, que incluye los efectos no domésticos, asciende a 2,48.

El efecto inducido es mayor en la fase de Inversión inicial, sin embargo, en términos relativos resulta tener una importancia mayor en la fase de O\&M, debido a la mayor contribución de costes laborales (que repercuten en efectos inducidos) en dicha fase.

Tabla 73 Impacto del ciclo de vida de la planta HYSOL GN sobre la producción de B\&S (en €2011)

\begin{tabular}{llcccc}
\hline \multirow{2}{*}{ Efectos sobre la producción de B\&S } & $\begin{array}{c}\text { Inversión } \\
\text { inicial (M€) }\end{array}$ & $\begin{array}{c}\text { O\&M } \\
\text { (M€) }\end{array}$ & D\&D (M€) & $\begin{array}{c}\text { TOTAL } \\
\text { ciclo (M€) }\end{array}$ \\
\hline \multirow{2}{*}{$\begin{array}{l}\text { Efecto } \\
\text { doméstico }\end{array}$} & Directo & 588 & 522 & 2,02 & 1.113 \\
\cline { 2 - 6 } & Indirecto & 512 & 382 & 2,14 & 896 \\
\cline { 2 - 6 } & Inducido & 92 & 61,4 & 0,36 & 154 \\
\hline Efecto no doméstico & 376 & 226 & 0,61 & 602 \\
\hline TOTAL & 1.568 & 1.191 & 5,14 & 2.764 \\
\hline Efecto multiplicador doméstico & 2,03 & 1,85 & 2,24 & 1,94 \\
\hline Efecto multiplicador total & 2,67 & 2,28 & 2,54 & 2,48 \\
\hline
\end{tabular}

*Donde O\&M es Operación y Mantenimiento, y D\&D es Desmantelamiento y Disposición de residuos

La Tabla 74 muestra el valor añadido (directo, indirecto e inducido) producido por la planta HYSOL GN en todas sus fases del ciclo de vida. Se observa que el valor añadido en cada fase del ciclo de vida representa casi la mitad del resultado en generación de B\&S, siendo el valor añadido total un $43,0 \%$ de los B\&S generados. Siendo que la demanda directa (doméstica y no doméstica) de B\&S del ciclo de vida de la planta HYSOL GN (actualizada al presente) asciende a 
1.169 M€, el porcentaje de valor añadido creado respecto al dinero invertido asciende a 101,6\% (economía global) y 79,5 \% (economía española).

Tabla 74 Valor añadido producido por el ciclo de vida de una planta HYSOL GN (en €2011)

\begin{tabular}{lcccc}
\hline Valor añadido & $\begin{array}{c}\text { Inversión } \\
\text { inicial (M€) }\end{array}$ & O\&M (M€/yr) & D\&D (M€) & $\begin{array}{c}\text { TOTAL } \\
\text { ciclo(M€) }\end{array}$ \\
\hline Efecto Directo & 243 & 219 & 0,79 & 463 \\
\hline Efecto Indirecto & 218 & 166 & 0,88 & 385 \\
\hline Efecto Inducido & 49,7 & 32,5 & 0,19 & 82 \\
\hline No doméstico & 149 & 109 & 0,25 & 258 \\
\hline TOTAL & 659 & 527 & 2,11 & 1.188 \\
\hline \% de B\&S & 42,8 & 43,3 & 41,2 & 43,0 \\
\hline
\end{tabular}

La Tabla 75 describe el empleo generado (directo, indirecto e inducido) en cada fase del ciclo de vida de la planta HYSOL en España. El total de personas año contratadas (durante un año, con una media de 1.700 horas de trabajo al año) durante el ciclo de vida asciende a 13.776, siendo su mayor contribución el empleo generado en la fase de Inversión inicial (8.492 personas-año). El empleo directo supone casi la mitad del empleo generado (6.083 personas-año). Considerando que la producción de B\&S de todo el ciclo de vida de la planta HYSOL GN asciende a $2.764 \mathrm{M} €$, la intensidad laboral equivale a 4,98 personas·año/M€.

Tabla 75 Empleo generado durante el ciclo de vida de la planta HYSOL GN

\begin{tabular}{lcccc}
\hline Empleo generado & $\begin{array}{c}\text { Inversión inicial } \\
\text { (personas·año*) }\end{array}$ & $\begin{array}{c}\text { O\&M } \\
\text { (personas·año*) }\end{array}$ & $\begin{array}{c}\text { D\&D } \\
\text { (personas·año*) }\end{array}$ & $\begin{array}{c}\text { TOTAL ciclo } \\
\text { (personas·año*) }\end{array}$ \\
\hline Directo & 3.525 & 2.546 & 12,7 & 6.083 \\
\hline Indirecto & 2.788 & 1.595 & 11,9 & 4.395 \\
\hline Inducido & 583 & 381 & 2,28 & 966 \\
\hline No doméstico & 1.597 & 733 & 2,74 & 2.332 \\
\hline TOTAL & 8.492 & 5.254 & 29,7 & 13.776 \\
\hline
\end{tabular}

*Se consideran empleos de un año de duración, y una media de 1.700 horas trabajadas al año

La Tabla 76 describe los beneficios económicos globales del ciclo de vida de la planta HYSOL, representados por unidad funcional (1 MWh). Los efectos por unidad funcional se han calculado dividiendo el efecto bruto por la suma de la producción eléctrica anual descontada durante la vida útil de la planta. La producción de B\&S generada en España por el ciclo de vida de la central asciende a $330 € / \mathrm{MWh}$. De esta cantidad, el $43,0 \%$ es valor añadido. 
Tabla 76 Beneficios socioeconómicos globales generados durante el ciclo de vida de la planta HYSOL GN, por unidad funcional

\begin{tabular}{lccc}
\hline & $\begin{array}{c}\text { Valor añadido } \\
(€ / \mathbf{M W h})\end{array}$ & $\begin{array}{c}\text { Producción de B\&S } \\
(€ / \mathbf{M W h})\end{array}$ & $\begin{array}{c}\text { Empleo } \\
\text { (horas/MWh) }\end{array}$ \\
\hline Beneficio total & 142 & 330 & 2,79 \\
\hline *Se consideran empleos de un año de duración, y una media de 1.700 horas trabajadas al año
\end{tabular}

\subsubsection{Efectos socioeconómicos netos}

Tabla 77 describe los resultados del cálculo del LEC para cada tecnología marginal. Teniendo en cuenta estos valores y una producción anual de $797.423 \mathrm{MWh} / \mathrm{año}$, el vector de demanda español (Ymix) asciende a 1.275,2 M€. Este valor se ha asignado al sector "Electricidad, Gas y suministro de agua", mientras que la demanda francesa de electricidad $(26,700 \mathrm{M} €)$ se ha asignado al correspondiente sector francés.

Tabla 77 Resultados LEC para cada tecnología marginal y su porcentaje de participación en el mix de tecnologías marginales

\begin{tabular}{lccc}
\hline Tecnología & LEC $\left(\boldsymbol{(}_{2011} / \mathrm{MWh}\right)$ & $\begin{array}{c}\text { Fijación precio } \\
\text { marginal }(\%)\end{array}$ & $\begin{array}{c}\text { Electricidad desplazada } \\
\text { por la planta termosolar } \\
\text { (MWh/yr) }\end{array}$ \\
\hline Central térmica Carbón & 129,75 & $27,1 \%$ & 216.102 \\
\hline Ciclo combinado & 177,93 & $5,35 \%$ & 42.662 \\
\hline Hidroeléctrica & 164,96 & $36,5 \%$ & 291.059 \\
\hline Bombeo & 155,50 & $14,0 \%$ & 111.639 \\
\hline Eólica & 165,21 & $13,7 \%$ & 109.247 \\
\hline Termosolar & 231,38 & $1,40 \%$ & 11.164 \\
\hline Importaciones (FRANCIA) & 156,8 & $1,90 \%$ & 15.151 \\
\hline $\begin{array}{l}\text { Mix de tecnologías } \\
\text { marginales }\end{array}$ & 156,80 & $100 \%$ & 797.423 \\
\hline
\end{tabular}

La Tabla 78 muestra los efectos socioeconómicos de la demanda del mix de tecnologías marginales, es decir, aquellos que se ven desplazados por la venta de electricidad producida mediante la planta HYSOL.

La producción total de B\&S doméstica desplazada en España son 2.371 M€ y el empleo desplazado equivale a 5.465 personas-año, mientras que en otros países (no doméstico) estos valores son $769 \mathrm{M} €$ y 2.231 personas-año respectivamente. El valor añadido evitado en España representa un 37,0 \% de la generación doméstica de B\&S evitada, mientras que en otros países este porcentaje asciende a $48,1 \%$ (si se consideran ambos, el porcentaje de valor añadido asciende a 39,7\%). Estos resultados sugieren que el valor añadido evitado en otros países es 
mayor que en España, por lo que las tecnologías marginales resultan más beneficiosas para otros países.

Tabla 78 Efectos socioeconómicos de la demanda de electricidad por parte del mix de tecnologías marginales

\begin{tabular}{llllllll} 
& \multicolumn{3}{l}{ Efectos en España } & & No- & TOTAL \\
& Directo & Indirecto & Inducido & Total & domésticos & TOT \\
\hline Producción B\&S (€M) & 1.275 & 1.023 & 73 & $\mathbf{2 . 3 7 1}$ & 769 & $\mathbf{3 . 1 4 0}$ \\
\hline Valor añadido (€M) & 429 & 409 & 39 & $\mathbf{8 7 7}$ & 370 & $\mathbf{1 . 2 4 7}$ \\
\hline Empleo (personas*año) & 1.255 & 3.748 & 462 & $\mathbf{5 . 4 6 5}$ & 2.231 & $\mathbf{7 . 6 9 6}$ \\
\hline
\end{tabular}

\subsection{Efectos socioeconómicos netos de la planta HYSOL BIO}

En la Tabla 79 se describen los efectos netos del ciclo de vida de la planta HYSOL BIO a nivel nacional e internacional. El resultado neto nacional representa la diferencia entre los efectos producidos por la planta HYSOL BIO y aquellos que han dejado de producirse al desplazar del mercado otras tecnologías marginales españolas, mientras que el resultado neto global incluye también el efecto de desplazar la electricidad importada de Francia. Ya que los efectos económicos evitados al desplazar las tecnologías marginales son menores que los producidos por el ciclo de vida de la planta HYSOL BIO, los efectos netos siguen siendo positivos. La producción neta total de B\&S asciende a 1.218 M€ en España y 1.299 M€ incluyendo el resto del mundo, el empleo generado es 16.178 y 17.465 personas.año respectivamente y el valor añadido es 740 y $721 \mathrm{M} €$ respectivamente.

El porcentaje de valor añadido en la planta HYSOL es mayor que el de las tecnologías evitadas (45,2 \% respecto a 39,7 \%), lo que indica que la planta HYSOL crea mayor valor añadido que las tecnologías evitadas aun considerando la misma inversión de dinero. El valor añadido neto español es mayor que el global debido a que el aumento neto del valor añadido sucede en España y no en otros países (en otros países se pierde valor añadido).

Tabla 79 Efectos socioeconómicos netos del ciclo de vida de la planta HYSOL BIO a nivel nacional e internacional

\begin{tabular}{lccccc}
\cline { 2 - 5 } & \multicolumn{3}{c}{ EFECTOS NETOS NACIONALES } & EFECTOS NETOS \\
& Directo & Indirecto & Inducido & TOTAL & TOTAL \\
\cline { 2 - 6 } & 557 & 412 & 250 & 1.218 & 1.299 \\
\hline Generación de B\&S & 396 & 211 & 133 & 740 & 721 \\
\hline Valor añadido (M€) & 10.753 & 3.867 & 1.558 & 16.178 & 17.465 \\
\hline Empleo (personas-año) & 10.758 & \\
\hline
\end{tabular}


En la Figura 60 y Figura 61 se comparan los beneficios socio-económicos brutos, desplazados y netos por unidad funcional producidos por el ciclo de vida de la planta HYSOL BIO. Los resultados sugieren que el valor añadido neto global representa un valor de $86,0 € / \mathrm{MWh}$, mientras que la generación de B\&S neta es $155 € / M W h$. El empleo neto generado es 3,5 h/MWh. Si consideramos los efectos netos en España, el valor añadido presenta un beneficio de 88,2 $€ / M W h$, y un empleo de 3,3 h/MWh.

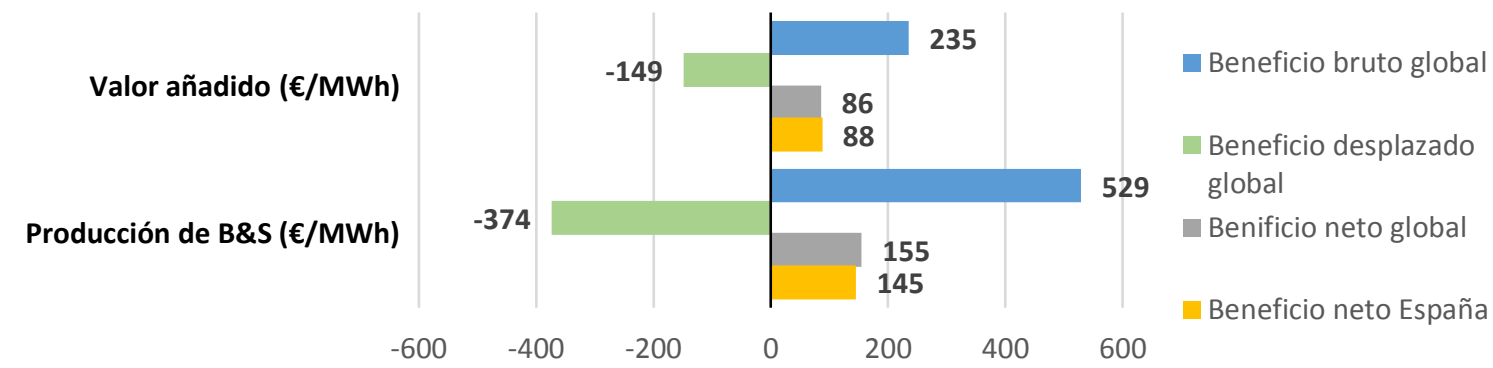

Figura 60 Efectos económicos brutos, netos y desplazados producidos por la planta HYSOL BIO por unidad funcional

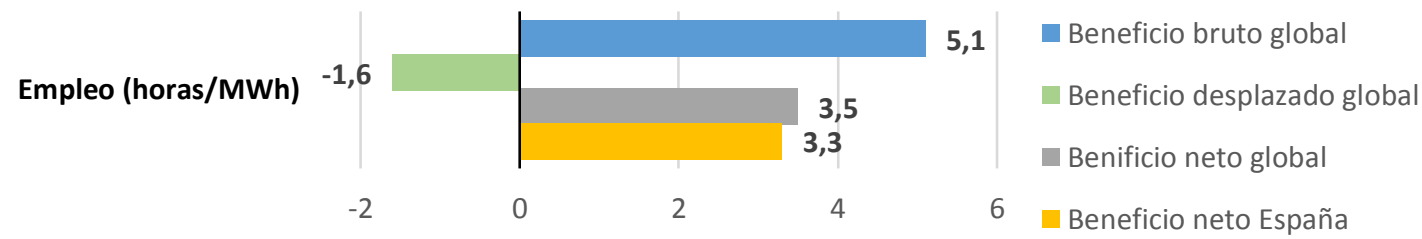

Figura 61 Empleo generado bruto, neto y desplazado por la planta HYSOL BIO por unidad funcional

\subsection{Efectos socioeconómicos netos de la planta HYSOL GN}

En la Tabla 80 se describen los efectos netos del ciclo de vida de la planta HYSOL GN a nivel nacional e internacional. Ya que los efectos económicos evitados al desplazar las tecnologías marginales son mayores que los producidos por el ciclo de vida de la planta HYSOL GN, los efectos netos presentan valores negativos, indicando una pérdida de B\&S. La producción neta total de B\&S asciende a -208 M€ en España y -376 M€ incluyendo el resto del mundo. El único valor puramente económico de generación de B\&S que presenta un saldo positivo es el efecto inducido, ya que está estrechamente ligado al empleo generado. El empleo generado neto es positivo (5.980 personas-año en España), ya que la planta HYSOL presenta más empleo por MWh producido que las tecnologías desplazadas.

El resultado de valor añadido neto global es también negativo, es decir, cuando la tecnología HYSOL GN se introduce en el mercado español, se destruye valor añadido a nivel global. Sin embargo, el valor añadido neto en España presenta un valor positivo, lo que indica que la disminución de valor añadido tiene lugar en otros países, mientras que España se ve beneficiada al obtener un aumento de 52,6 M€. 
También cabe destacar que el porcentaje de valor añadido en la planta HYSOL GN es mayor que el de las tecnologías evitadas (43,0 \% respecto a $39,7 \%$ ), lo que indica que la planta HYSOL GN crea mayor valor añadido que las tecnologías evitadas si se considera la misma inversión monetaria.

Tabla 80 Efectos socioeconómicos netos del ciclo de vida de la planta HYSOL GN a nivel nacional e internacional

\begin{tabular}{lccccc}
\cline { 2 - 6 } & \multicolumn{3}{c}{ EFECTOS NETOS NACIONALES } & $\begin{array}{c}\text { EFECTOS NETOS } \\
\text { GLOBALES }\end{array}$ \\
\cline { 2 - 6 } & Directo & Indirecto & Inducido & TOTAL & TOTAL \\
\hline Generación de B\&S & -163 & -127 & 80,9 & -208 & -376 \\
\hline Valor añadido (M€) & 34 & -25 & 43,0 & 52,6 & -59 \\
\hline Empleo (personas·año) & 4.828 & 647 & 504 & 5.980 & 6.081 \\
\hline
\end{tabular}

En la Figura 62 y Figura 63 se comparan los beneficios económicos brutos, desplazados y netos por unidad funcional producidos por el ciclo de vida de la planta HYSOL GN. Los resultados sugieren que el valor añadido neto global representa un valor negativo de $-11,2 € / M W h$, mientras que la generación de B\&S neta es igual a $-55,7 € / \mathrm{MWh}$. El empleo neto generado es 1,24 h/MWh. Si consideramos los efectos netos en España, el valor añadido presenta un beneficio de 3,5€/MWh, y el efecto de generación de B\&S es mayor (-33,1€/MWh). El valor de empleo es similar en ambos casos ya que la mayor creación de empleo tiene lugar en el territorio español.

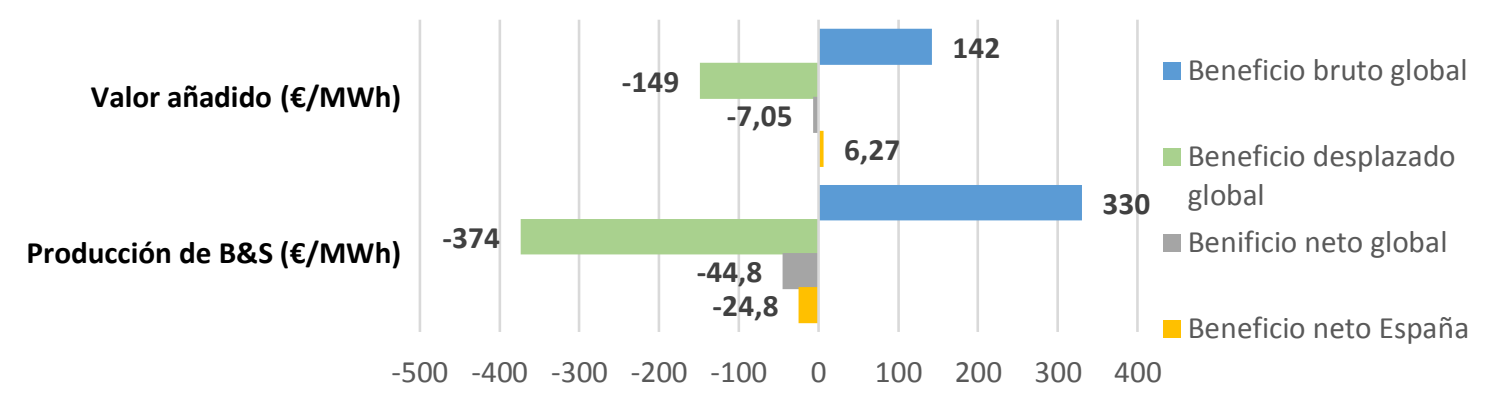

Figura 62 Efectos económicos brutos, netos y desplazados producidos por la planta HYSOL GN por unidad funcional

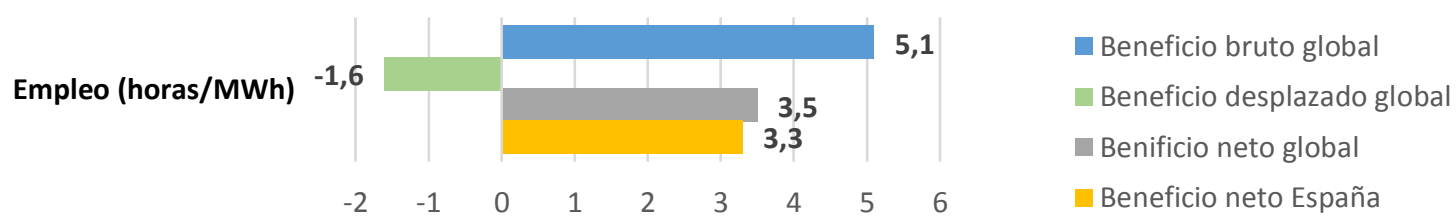

Figura 63 Empleo generado bruto, neto y desplazado por la planta HYSOL GN por unidad funcional 


\subsubsection{Resultados del análisis MRIO aplicado a la planta TERMOSOLAR CCP}

Los resultados del análisis MRIO aplicado a la planta TERMOSOLAR CCP se estructuran en dos apartados:

- Resultados socioeconómicos brutos, en los que se incluye la producción doméstica, no doméstica, e importada de B\&S, el efecto multiplicador, el valor añadido y el empleo generado por el ciclo de vida de la planta TERMOSOLAR CCP.

- Resultados socioeconómicos netos, que incluye :

- El cálculo del vector demanda del mix de tecnologías marginales.

- El resultado de los indicadores socioeconómicos del mix de tecnologías marginales.

- Teniendo en cuenta todo lo anterior, el cálculo neto socioeconómico del ciclo de vida de la planta TERMOSOLAR CCP.

La metodología, discusión y resultados del análisis MRIO aplicado a la tecnología termosolar convencional derivados de esta tesis han sido publicados en la revista Solar Energy Materials and Solar Cells (Corona et al. 2016).

\subsubsection{Efectos socioeconómicos brutos de la planta TERMOSOLAR CCP}

En la Tabla 81 se describe la actividad económica generada por las fases del ciclo de vida del proyecto, medida mediante la producción de B\&S (M€). Teniendo en cuenta los efectos directos, indirectos, inducidos y no domésticos, el total de la actividad económica generada asciende a 966 M€. La mayor producción de B\&S se da en la fase de Inversión inicial, que asciende a $597 \mathrm{M} €$, con un efecto indirecto sobre la producción que representa el $85 \%$ del efecto directo. El efecto producido por la importación nacional de B\&S (efecto no doméstico) asciende a $231 \mathrm{M€}$, concentrándose en su mayoría durante la fase de Inversión inicial.

Tabla 81 Producción de B\&S durante el ciclo de vida de una planta TERMOSOLAR CCP

\begin{tabular}{llcccc}
\hline \multicolumn{2}{l}{ Efectos sobre la producción de B\&S } & $\begin{array}{c}\text { Inversión } \\
\text { inicial (M€) }\end{array}$ & O\&M (M€) & D\&D (M€) & $\begin{array}{c}\text { TOTAL } \\
\text { ciclo (M€) }\end{array}$ \\
\hline \multirow{2}{*}{$\begin{array}{l}\text { Efecto } \\
\text { doméstico }\end{array}$} & Directo & 206 & 166 & 0,76 & 373 \\
\cline { 2 - 6 } & Indirecto & 175 & 108 & 0,78 & 284 \\
\cline { 2 - 6 } Inducido & 40 & 38,2 & 0,17 & 79 \\
\hline Efecto no doméstico & 175 & 56 & 0,23 & 231 \\
\hline TOTAL & $\mathbf{5 9 7}$ & $\mathbf{3 6 8}$ & $\mathbf{1 , 9 4}$ & $\mathbf{9 6 6}$ \\
\hline Efecto multiplicador doméstico & 2,05 & 1,88 & 2,24 & 1,97 \\
\hline Efecto multiplicador total & 2,89 & 2,22 & 2,54 & 2,59 \\
\hline
\end{tabular}


El efecto multiplicador doméstico, que tiene en cuenta la relación entre los efectos totales domésticos y el directo, asciende a 2,59 para todo el ciclo de vida, resultando ser mayor en la fase de Inversión inicial $(2,89)$ y de $D \& D(2,54)$, y menor en la fase O\&M $(2,22)$. Esto es muestra del mayor efecto indirecto y no doméstico que presenta la fase E\&M respecto a las demás. EI efecto multiplicador total en la economía española asciende a 1,97.

La Tabla 82 especifica los países con una contribución mayor al 1 \% de la generación total de $B \& S$ y sus contribuciones a los sectores económicos con mayor relevancia dentro del ciclo de vida de la planta termosolar (aquellos con más de un $3 \%$ participación respecto a la total B\&S generados en cada sector). Los países con mayor aporte son Alemania (contribución de 62,6 $\mathrm{M} €)$, Bélgica (17,7 M€), Francia (14,7 M€), China (13,0 M€), Italia (11,7 M€) y Estados Unidos $(8,44 \mathrm{M} €)$. La mayoría de la contribución alemana y belga está directamente relacionada con la compra de la turbina de vapor, generador y condensador utilizados para el ciclo termodinámico de la planta y el HTF, mientras que la contribución de otros países está relacionada con la demanda indirecta de B\&S. Los sectores económicos más relevantes son "Alquiler de maquinaria y equipos, y otras actividades empresariales", "Intermediación financiera", "Construcción" y "Metales básicos y fabricados". Como se describe en la tabla, la contribución española a los cuatro sectores económicos más relevantes se encuentra entre el $67 \%$ y el $98 \%$, lo que indica que España es con diferencia la economía más beneficiada en el ciclo de vida de la planta TERMOSOLAR CCP.

Tabla 82 Contribución de los países más relevantes en la cadena de valor de la planta TERMOSOLAR CCP (más del 1 \% de la generación de B\&S) a los sectores económicos más relevantes (más de 3 \% de contribución a B\&S)

\begin{tabular}{lcccccccccc}
\hline $\begin{array}{l}\text { Sectores que contribuyen a más del } \\
\text { 3 \% de la generación de B\&S. }\end{array}$ & $\begin{array}{c}\text { ESP } \\
\mathbf{( \% )}\end{array}$ & $\begin{array}{c}\text { USA } \\
\mathbf{( \% )}\end{array}$ & $\begin{array}{c}\text { ITA } \\
\mathbf{( \% )}\end{array}$ & $\begin{array}{c}\text { CHN } \\
\mathbf{( \% )}\end{array}$ & $\begin{array}{c}\text { FRA } \\
\mathbf{( \% )}\end{array}$ & $\begin{array}{c}\text { DEU } \\
(\%)\end{array}$ & $\begin{array}{c}\text { BEL } \\
\text { (\%) }\end{array}$ & $\begin{array}{c}\text { RoW } \\
\text { (\%) }\end{array}$ & $\begin{array}{c}\text { TOTAL } \\
\text { B\&S } \\
\text { (M€) }\end{array}$ \\
\hline Extracción de recursos y minería & 55 & 1,3 & 0,2 & 1,3 & 0,2 & 0,1 & 0,0 & 42 & 36,2 \\
\hline Otros minerals no metálicos & 94 & 0,2 & 0,7 & 0,9 & 0,6 & 1,1 & 0,3 & 3 & 24,9 \\
\hline Metales básicos y fabricados & 67 & 0,7 & 3,3 & 2,8 & 3,7 & 8,7 & 1,2 & 13 & 71,8 \\
\hline Maquinaria, nec. & 36 & 0,6 & 1,3 & 1,1 & 1,0 & 55 & 0,2 & 4,6 & 59,2 \\
\hline Equipo eléctrico y óptico & 56 & 1,7 & 1,8 & 11 & 3,4 & 8,1 & 0,4 & 18 & 26,0 \\
\hline Suministro de electricidad, gas y agua & 86 & 0,2 & 0,7 & 1,4 & 0,8 & 3,0 & 0,7 & 7,0 & 31,2 \\
\hline Construcción & 98 & 0,1 & 0,2 & 0,0 & 0,1 & 0,4 & 0,4 & 0,9 & 76,5 \\
\hline Intermediación financiera & 92 & 2,5 & 0,7 & 0,2 & 0,3 & 1,0 & 0,6 & 2,2 & 110 \\
\hline $\begin{array}{l}\text { Alquiler de M\&Eq y otras actividades } \\
\text { empresariales }\end{array}$ & 81 & 2,7 & 1,0 & 0,3 & 2,6 & 4,8 & 1,6 & 5,7 & 113 \\
\hline Otros sectores & 66 & 2,3 & 2,0 & 2,2 & 2,4 & 5,6 & 6,2 & 13 & 210
\end{tabular}

*ESP= España, USA=Estados Unidos, ITA=Italia, CHN= China, FRA= Francia, DEU= Alemania, BEL=Bélgica, RoW $=$ Resto del mundo 
La Tabla 83 muestra el valor añadido (directo, indirecto e inducido) producido por la planta TERMOSOLAR CCP en todas sus fases del ciclo de vida. Se observa que el valor añadido en cada fase del ciclo de vida representa casi la mitad del resultado en generación de B\&S, siendo un 45,6 \% el porcentaje de valor añadido respecto a B\&S correspondiente a la economía española, y un $44,7 \%$ el correspondiente a la economía global. Siendo que la demanda directa de B\&S del ciclo de vida de la planta TERMOSOLAR CCP (actualizada al presente) asciende a 410,0 M€, el porcentaje de valor añadido creado respecto al dinero invertido es 106 \% (economía global) y 81,8 \% (economía española).

Tabla 83 Valor añadido producido por el ciclo de vida de una planta TERMOSOLAR CCP

\begin{tabular}{lcccc}
\hline Valor añadido & $\begin{array}{c}\text { Inversión } \\
\text { inicial }\end{array}$ & O\&M & D\&D & TOTAL ciclo \\
\hline Efecto Directo (M€) & 86 & 82,5 & 0,299 & 169 \\
\hline Efecto Indirecto (M€) & 75 & 49,9 & 0,317 & 125 \\
\hline Efecto Inducido (M€) & 22 & 20,1 & 0,090 & 41,9 \\
\hline No doméstico (M€) & 69 & 26,8 & 0,091 & 95,7 \\
\hline TOTAL (M€) & 251 & 179 & 0,797 & 431 \\
\hline \% de B\&S & 42,1 & 48,7 & 41,1 & 44,7 \\
\hline
\end{tabular}

La Tabla 84 describe el empleo generado (directo, indirecto e inducido) en cada fase del ciclo de vida de la planta TERMOSOLAR CCP. El total de personas contratadas por un año durante el ciclo de vida asciende a 7.197, siendo su mayor contribución el empleo generado en la fase de Inversión inicial (3.988 personas·año). El empleo directo supone más de la mitad del empleo generado (3.590 personas·año). Considerando que la producción de B\&S de todo el ciclo de vida de la planta TERMOSOLAR CCP asciende a $966 \mathrm{M€}$, la intensidad laboral equivale a 7,45 personas·año/M€.

Tabla 84 Empleo generado durante el ciclo de vida de una planta TERMOSOLAR CCP

\begin{tabular}{lcccc}
\hline $\begin{array}{l}\text { Empleo generado } \\
\text { (personas-año)* }\end{array}$ & $\begin{array}{c}\text { Inversión } \\
\text { inicial }\end{array}$ & $\begin{array}{c}\text { O\&M } \\
\text { (personas·año*) }\end{array}$ & $\begin{array}{c}\text { D\&D } \\
\text { (personas·año*) }\end{array}$ & $\begin{array}{c}\text { TOTAL ciclo } \\
\text { (personas·año*) }\end{array}$ \\
\hline Directo & 1.570 & 2.014 & 6,02 & 3.590 \\
\hline Indirecto & 1.197 & 628 & 5,35 & 1.830 \\
\hline Inducido & 321 & 298 & 1,32 & 620 \\
\hline No doméstico & 900 & 254 & 1,28 & 1.156 \\
\hline TOTAL & 3.988 & 3.194 & 14,0 & 7.197 \\
\hline
\end{tabular}

La Tabla 85 describe los beneficios económicos totales del ciclo de vida de la planta TERMOSOLAR CCP, representados por unidad funcional (1 MWh). Los efectos por unidad funcional se han calculado dividiendo el efecto bruto por la suma de la producción eléctrica 
durante toda la vida útil de la planta. La producción de B\&S en España generada por el ciclo de vida de la central asciende a $472 € / M W h$. De esta cantidad, el 44,6\% (217 €/MWh) es valor añadido.

Tabla 85 Beneficios socioeconómicos brutos generados por España durante el ciclo de vida de la planta TERMOSOLAR CCP, por unidad funcional

\begin{tabular}{lccc} 
& $\begin{array}{c}\text { Valor añadido } \\
\text { ( } € \text { /MWh) }\end{array}$ & $\begin{array}{c}\text { Producción de B\&S } \\
\text { (€/MWh) }\end{array}$ & $\begin{array}{c}\text { Empleo } \\
\text { (horas/MWh) }\end{array}$ \\
\hline Beneficio total & 211 & 472 & 5,97 \\
\hline
\end{tabular}

\subsubsection{Efectos socioeconómicos netos de la planta TERMOSOLAR CCP}

\subsection{Demanda del mix de tecnologías marginales}

La Tabla 86 muestra la contribución de cada tecnología al mix de tecnologías marginales correspondiente a la tecnología TERMOSOLAR CCP (que difiere al de HYSOL debido a que funcionan durante distinto número de horas del día). La tecnología más cara es la termosolar, seguida del ciclo combinado y la eólica. Como se puede observar, no hay correlación entre costes de producción (ni de LEC), con la participación en la fijación del precio marginal, ya que éste obedece a estrategias políticas y financieras, así como a la disponibilidad de recursos.

Tabla 86 Resultados LEC para cada tecnología marginal y su porcentaje de participación en el mix de tecnologías marginales

\begin{tabular}{lccc}
\hline Tecnología & LEC $\left(\boldsymbol{\epsilon}_{\mathbf{2 0 1 1}} / \mathrm{MWh}\right)$ & $\begin{array}{c}\text { Fijación precio } \\
\text { marginal (\%) }\end{array}$ & $\begin{array}{c}\text { Electricidad desplazada } \\
\text { por la planta termosolar } \\
\text { (MWh/yr) }\end{array}$ \\
\hline Central térmica Carbón & 129,75 & $22,0 \%$ & 42.829 \\
\hline Ciclo combinado & 177,93 & $5,0 \%$ & 9.734 \\
\hline Hidroeléctrica & 164,96 & $41,3 \%$ & 80.401 \\
\hline Bombeo & 155,50 & $17,6 \%$ & 34.263 \\
\hline Eólica & 165,21 & $11,1 \%$ & 21.609 \\
\hline Termosolar & 186,88 & $1,1 \%$ & 2.141 \\
\hline Importaciones (FRANCIA) & 156,8 & $1,9 \%$ & 3.699 \\
\hline $\begin{array}{l}\text { Mix de tecnologías } \\
\text { marginales (ESPAÑA) }\end{array}$ & 153,82 & $98,1 \%$ & 190.987 \\
\hline
\end{tabular}

Teniendo en cuenta estos resultados, la tasa de descuento anual de 6,698\%, y la producción anual de la planta TERMOSOLAR CCP (190.978 MWh/año), el vector demanda español para el cálculo de Efectomix equivale a 315,06 M€ de la rama "Electricity, Gas and Water Supply", mientras que el vector demanda francés equivale a 6,10 M€. 
La Tabla 87 muestra los efectos socioeconómicos en España y Francia que se ven desplazados por la venta de electricidad producida mediante la planta termosolar bajo estudio.

La producción total de B\&S doméstica desplazada en España son 584 M€ y el empleo desplazado equivale a 1.208 personas-año, mientras que si se considera la economía global, estos valores son $774 \mathrm{M} €$ y 1.705 personas.año respectivamente. El valor añadido evitado en España representa un $36,9 \%$ de la generación doméstica de B\&S evitada, mientras que considerando toda la economía este porcentaje asciende a 39,7 \%.

Tabla 87 Efectos socioeconómicos de la demanda de electricidad por parte del mix de tecnologías marginales

\begin{tabular}{lccccccc}
\cline { 2 - 6 } & \multicolumn{4}{c}{ EFECTOS ESPAÑA } & EFECTOS NO & TOTAL \\
\cline { 2 - 6 } & Directo & Indirecto & Inducido & TOTAL & DOMÉSTICOS & TOT4 \\
\hline Producción de B\&S (M€) & 315 & 253 & 16,27 & $\mathbf{5 8 4}$ & 190 & $\mathbf{7 7 4}$ \\
\hline Valor añadido (M€) & 106 & 101 & 8,78 & $\mathbf{2 1 6}$ & 91,4 & $\mathbf{3 0 7}$ \\
\hline Empleo (personas*año) & 280 & 835 & 92,9 & $\mathbf{1 . 2 0 8}$ & 497 & $\mathbf{1 . 7 0 5}$ \\
\hline
\end{tabular}

En la Tabla 88 se describen los efectos netos del ciclo de vida de la planta termosolar a nivel nacional e internacional. El resultado neto de España representa la diferencia entre los efectos producidos por la planta TERMOSOLAR CCP y aquellos que han dejado de producirse al desplazar del mercado otras tecnologías marginales españolas, mientras que el resultado neto global incluye también el efecto en el resto de la economía global. Ya que los efectos evitados al desplazar las tecnologías marginales son menores que los producidos por el ciclo de vida de la planta TERMOSOLAR CCP, los efectos netos siguen siendo positivos. La producción neta total de B\&S asciende a 151 M€ en España y 192 M€ incluyendo otros países, el empleo generado neto es 4.833 y 5.492 personas-año respectivamente, y el valor añadido representa un $79 \%$ y un $65 \%$ de la producción de $B \& S$ respectivamente.

Tabla 88 Efectos socioeconómicos netos del ciclo de vida de una planta TERMOSOLAR CCP a nivel nacional e internacional

\begin{tabular}{lccccc}
\cline { 2 - 6 } & \multicolumn{3}{c}{ EFECTOS NETOS ESPAÑA } & & $\begin{array}{c}\text { EFECTOS NETOS } \\
\text { GLOBALES }\end{array}$ \\
\cline { 2 - 6 } & Directo & Indirecto & Inducido & TOTAL & TOTAL \\
\hline Producción de B\&S (M€) & 57,9 & 31,0 & 62,4 & $\mathbf{1 5 1}$ & 192 \\
\hline Valor añadido (M€) & 62,8 & 24,0 & 33,2 & $\mathbf{1 2 0}$ & 124 \\
\hline Empleo (personas*año) & 3.311 & 995 & 528 & $\mathbf{4 . 8 3 3}$ & $\mathbf{5 . 4 9 2}$
\end{tabular}


En la Tabla 89 se comparan los beneficios económicos brutos, desplazados y netos por unidad funcional producidos por el ciclo de vida de la planta TERMOSOLAR CCP. Los resultados sugieren que el valor añadido neto representa un $29 \%$ del valor añadido bruto, mientras que la generación de B\&S neta es un $20 \%$ de la bruta y el empleo neto un $76 \%$ del bruto. Por lo tanto, aunque los beneficios económicos netos descienden, la venta de electricidad de una planta TERMOSOLAR CCP en España sigue suponiendo un efecto beneficioso en la economía internacional, especialmente en cuanto al empleo generado.

Tabla 89 Beneficios económicos brutos, netos y desplazados de la planta TERMOSOLAR CCP por unidad funcional

\begin{tabular}{lccc}
\cline { 2 - 4 } & $\begin{array}{c}\text { Valor añadido } \\
(\boldsymbol{€} / \mathbf{M W h})\end{array}$ & $\begin{array}{c}\text { Producción de B\&S } \\
(€ / \text { MWh })\end{array}$ & $\begin{array}{c}\text { Empleo } \\
\text { (horas/MWh) }\end{array}$ \\
\hline Beneficio bruto global & 211 & 472 & 5,97 \\
\hline Beneficio desplazado global & 150 & 378 & 1,42 \\
\hline Benificio neto global & 60,7 & 93,9 & 4,56 \\
\hline Benificio neto España & 58,6 & 73,9 & 4,01 \\
\hline
\end{tabular}

\subsubsection{Discusión y conclusiones}

El análisis 10 realizado en esta sección ha permitido obtener los efectos socioeconómicos de la tecnología TERMOSOLAR CCP y de la tecnología HYSOL en sus dos escenarios. Los resultados integran el enfoque consecuencial del ACV en el análisis IO, proporcionando el efecto macroeconómico neto en España y en el resto del mundo producido al introducir la tecnología bajo estudio en el mercado eléctrico español. El cálculo de los efectos netos incluye el estudio del mercado eléctrico para conocer el mix de tecnologías marginales y la estimación del LEC para cada tecnología marginal.

Cabe destacar que los resultados obtenidos para el mix de tecnologías marginales están basados en el supuesto de que el sector agregado "Suministro de agua, electricidad y gas" representa adecuadamente el sector de la producción de electricidad. Sin embargo, dicho sector incluye otras actividades de distinta naturaleza a la producción de electricidad, que presentan distintos indicadores de valor añadido e intensidad laboral. Para ganar precisión en este estudio sería conveniente calcular la demanda del mix de tecnologías marginales utilizando un sector más desagregado, donde se pueda discriminar entre las actividades de suministro de agua, gas y electricidad.

A continuación, se discuten y comparan los resultados obtenidos brutos y netos. 


\subsubsection{Generación de B\&S y valor añadido}

Los resultados brutos permiten conocer los efectos socioeconómicos de producir electricidad con las tecnologías bajo estudio, sin tener en cuenta su integración en el mercado eléctrico español. La discusión de esta sección se basa principalmente en los resultados por unidad funcional (y no en los resultados absolutos) para mantener una misma línea de comparación que en la metodología de ACV.

La Figura 64 presenta los B\&S y valor añadido por unidad funcional creados durante el ciclo de vida de la planta HYSOL en sus dos escenarios (HYSOL BIO y HYSOL GN) comparados con los de la planta TERMOSOLAR CCP. La generación de B\&S nos da una medida del movimiento de la economía nacional y global debido a la demanda del ciclo de vida de la planta, pero es la generación de valor añadido la que nos indica el beneficio y creación de riqueza que genera dicho ciclo de vida. En la Figura 64 se describe el total de B\&S brutos por unidad funcional generados por cada escenario, junto con su componente de valor añadido y el porcentaje que éste representa. Los resultados indican que la planta HYSOL BIO es la que produce mayor cantidad de B\&S y de valor añadido, seguida de la TERMOSOLAR CCP y de la planta HYSOL GN. Esto es debido principalmente a los efectos socioeconómicos derivados de las 145 plantas de biometano necesarias para suministrar combustible a la planta. Cuando no se incluye el efecto socioeconómico del biometano, si no el del gas natural, la generación de electricidad en HYSOL produce menos B\&S que la de la planta TERMOSOLAR CCP. Esto se explica debido a la mayor eficiencia y generación de electricidad que tiene la planta HYSOL, ya que se demandan menos B\&S para producir cada MWh.

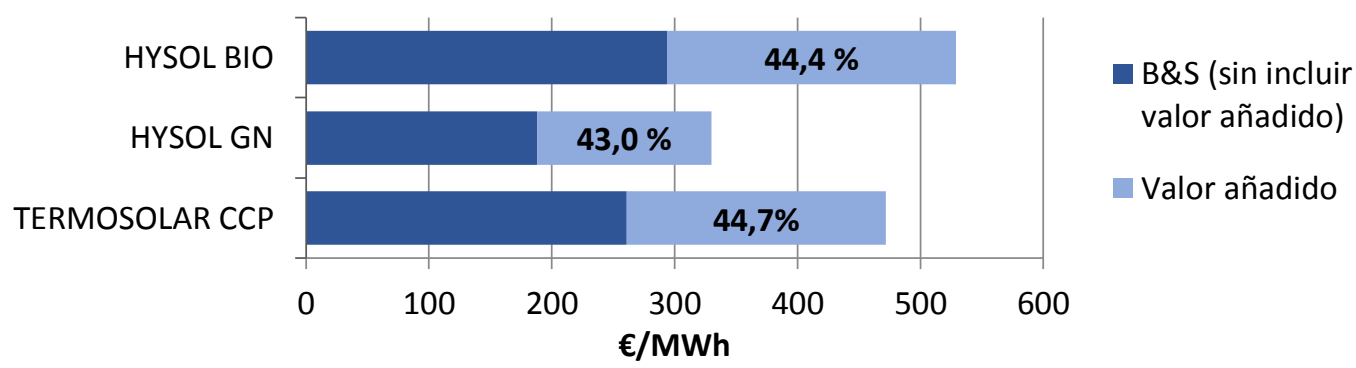

Figura 64 Generación de B\&S y de valor añadido brutos en todos los escenarios considerados (resultados globales que incluyen los efectos en España y en el resto del mundo)

Si consideramos el porcentaje de valor añadido creado en España respecto a la inversión monetario realizada por el promotor durante el ciclo de vida, la tecnología TERMOSOLAR CCP (81,9 \% de valor añadido respecto demanda directa de B\&S) presenta valores ligeramente mayores que la HYSOL BIO y HYSOL GN (80,2 \% y 79,5 \% respectivamente). Esto se debe principalmente al efecto del combustible en la creación del valor añadido, ya que tanto la 
producción de biometano como la del gas natural presentan menor ratio de valor añadido en España que la construcción y operación de una planta termosolar.

El efecto multiplicador de la planta TERMOSOLAR CCP es ligeramente mayor que el de las plantas HYSOL, sugiriendo que la inversión en el primer caso genera más B\&S indirectos que en el segundo.

La Figura 65 muestra los efectos socioeconómicos netos por unidad funcional del ciclo de vida de la planta HYSOL en sus dos escenarios (HYSOL BIO y HYSOL GN) comparados con los de la planta TERMOSOLAR CCP. Los resultados netos de la planta HYSOL BIO y de la planta TERMOSOLAR CCP tanto en España como a nivel global suponen beneficios en todos los indicadores considerados. Estos beneficios son especialmente mayores en la economía española, ya que el porcentaje de valor añadido sobre los B\&S generados es mucho mayor cuando sólo consideramos la economía española.

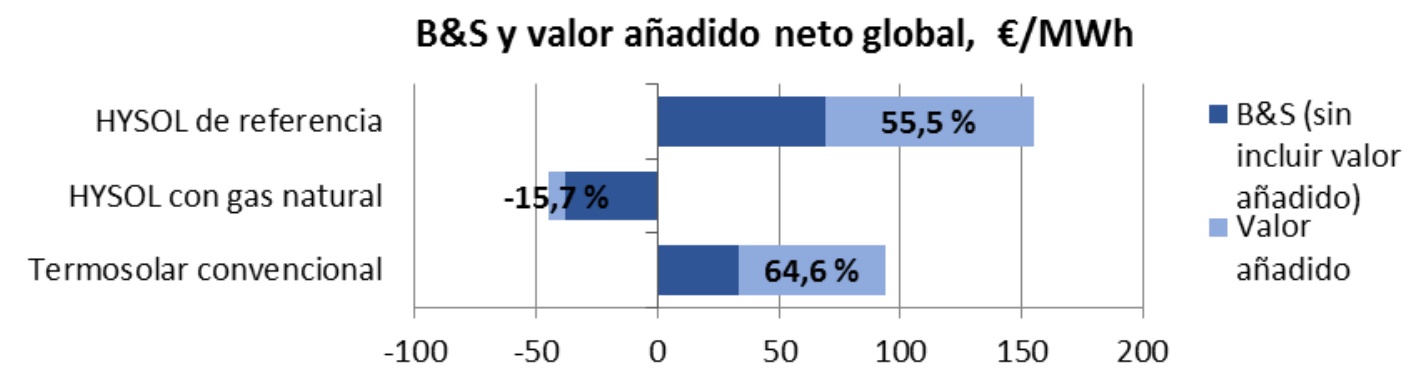

B\&S y valor añadido neto, solo en España, $€ / M W h$

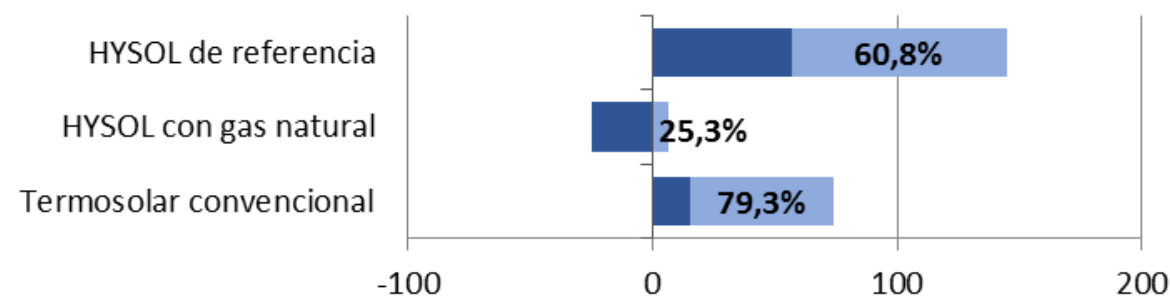

Figura 65 Generación de B\&S y de valor añadido netos en todos los escenarios considerados a nivel global y a nivel nacional (sólo España)

En el caso de la planta HYSOL GN, el resultado neto en España indica beneficios para el empleo generado y el valor añadido, aunque supone una destrucción neta de la generación de B\&S. Si consideramos los efectos a nivel global, el valor añadido neto de la tecnología HYSOL GN es negativo, ya que al desplazar el mix de tecnologías marginales se deja de generar una gran cantidad de valor añadido en los sectores de la minería y la extracción de recursos de otros países. 


\subsubsection{Generación de empleo}

La Figura 66 muestra la creación de empleo bruta y neta por unidad funcional del ciclo de vida de la planta HYSOL en sus dos escenarios (HYSOL BIO y HYSOL GN) comparados con los de la planta TERMOSOLAR CCP. Los resultados indican una creación neta de empleo en todos los escenarios, ya que la generación bruta de empleo de las tecnologías estudiadas es mucho mayor que el mix de tecnologías marginales.

Los resultados indican que la planta TERMOSOLAR CCP genera más empleo por unidad funcional que la tecnología HYSOL BIO. El principal motivo subyace en la fase de O\&M, ya que ambas plantas emplean el mismo número de personas (48 empleados por año), pero la tecnología HYSOL precisa de mayor inversión y genera más electricidad. Además, la mayor producción de electricidad de la planta HYSOL reduce el ratio de empleo por unidad funcional. La planta TERMOSOLAR CCP también genera mayor proporción de empleo nacional que la tecnología HYSOL, ya que la planta HYSOL presenta un 84-87 \% de empleo generado en España respecto al total generado (dependiendo del escenario), y la planta TERMOSOLAR CCP un $88 \%$.

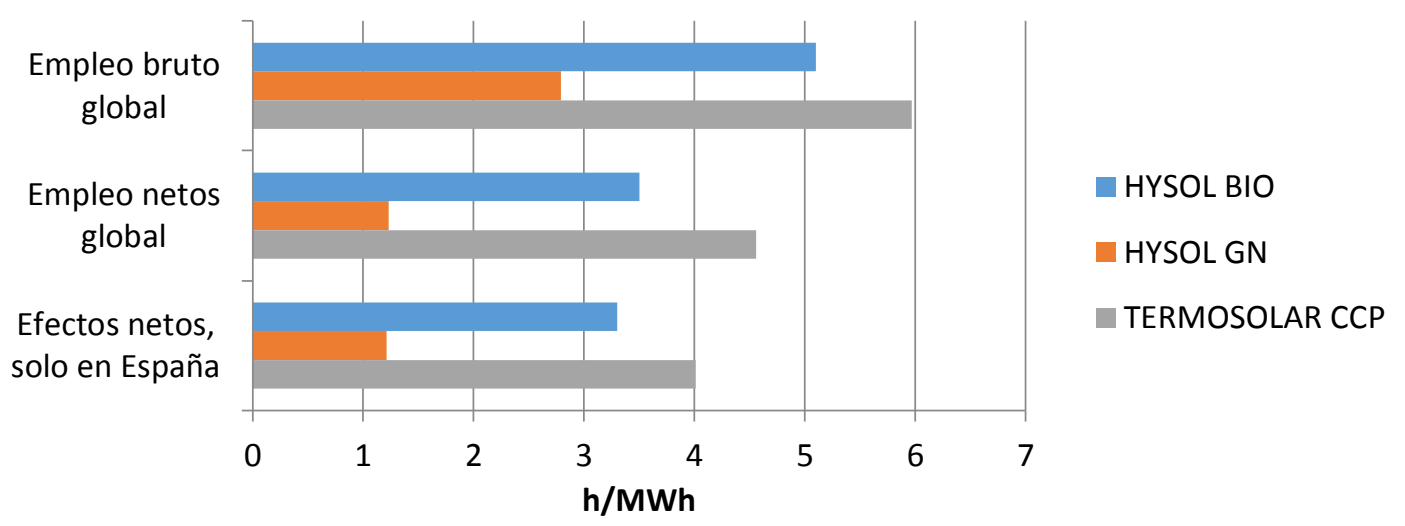

Figura 66 Generación de empleo bruto y neto en todos los escenarios considerados a nivel global y a nivel nacional 


\section{CAPÍTULO 5 Análisis del área social}

Este capítulo contiene el estado del arte, metodología y resultados del Análisis de Ciclo de Vida Social (ACV-S) de la tecnología HYSOL. En la sección de introducción se describe el estado actual de la metodología ACV-S (5.1.1 Definición y orígenes, y 5.1.2 Estado del arte de la metodología), mientras que en la siguiente sección se detalla la metodología desarrollada y propuesta para evaluar el comportamiento social de una planta de producción de electricidad utilizando como ejemplo el ciclo de vida de la planta HYSOL. En los últimos apartados (5.3 y 5.4) se aportan, discuten y comparan los resultados del ACV-S de una planta HYSOL con los de una planta TERMOSOLAR CCP.

Saludable Equitativo

Sociedad

Figura 67 Área social de la sostenibilidad 


\subsection{INTRODUCCIÓN}

\subsubsection{Definición y orígenes}

El ACV-S es una metodología que evalúa los impactos potenciales sociales y socioeconómicos que afectan a los actores vinculados al ciclo de vida de un producto o servicio. Su principal aplicación es encontrar puntos de mejora en los impactos sociales de los productos, así como disponer de criterios sociales para la comparación de productos/sistemas o para la toma de decisiones políticas. Para ello combina datos cualitativos con datos cuantitativos, implicando la participación activa de todos los actores del ciclo de vida del producto. Un actor (traducido del inglés, stakeholder) se considera a aquel grupo o individuo que puede afectar o ser afectado por el cumplimiento del objetivo de una organización (Freeman 2010), como los consumidores, la población local, el gobierno, los productores y los trabajadores.

Según Brent y Labuschagne (2005), en la mayoría de las definiciones de desarrollo sostenible se asigna la misma importancia a cada uno de los tres pilares de sostenibilidad; sin embargo, el pilar social ha recibido menos atención desde los inicios del análisis de ciclo de vida, provocando un desarrollo menor de metodologías sociales que de metodologías económicas o ambientales. Esta carencia de desarrollo en los análisis de ciclo de vida social está siendo enmendada principalmente por la iniciativa de ciclo de vida de la UNEP-SETAC (UNEP-SETAC Life Cycle Initiative 2009), que durante los últimos diez años ha impulsado, desarrollado y creado guías para su aplicación. El mayor desarrollo metodológico en el ACV-S ha venido de la mano de esta iniciativa en la forma de una guía, titulada "Guía para el análisis de ciclo de vida social de productos"(UNEP-SETAC Life Cycle Initiative 2009), denominada en esta tesis como la guía. Este documento surge por la necesidad de establecer una metodología consistente y armonizada, emulando la guía que desarrolló la SETAC en 1993 sobre el ACV en su vertiente ambiental (Consoli 1993). Según la guía, el ACV-S no pretende aportar información sobre si un producto debería producirse o no, pero sí pretende aportar datos y criterios sociales que ayuden a la decisión y valoración de productos, aunque siempre en compañía de otros criterios. Por otro lado, esta metodología no pretende dar una solución para un consumo sostenible, sino más bien informar sobre mejoras progresivas a aplicar en dicho consumo.

Mattioda et al (2015) ha publicado recientemente una revisión exhaustiva sobre el estado actual de la metodología de ACV-S y su aplicabilidad para el análisis social de productos y servicios en una amplia gama de sectores. Esta revisión ha encontrado 99 publicaciones en el campo del ACV-S desde sus inicios hasta el año 2013. La mayoría de estas publicaciones se 
centran en el desarrollo teórico y en el análisis de cuestiones metodológicas, mientras que sólo trece publicaciones analizan productos o servicios específicos. Dentro de las publicaciones de casos de estudio, Mattioda et al. reportan cuatro estudios relacionados con el análisis de fuentes de energía (tres sobre biocombustibles más uno en diésel y gasolina), mientras que el resto de estudios analizan productos del sector manufacturero (4 estudios), del sector agrícola (2 estudios), envases ( 2 estudios) y gestión de residuos ( 2 estudios). Teniendo en cuenta dicha revisión y la realizada para esta tesis, se han encontrado hasta la fecha cinco publicaciones sobre análisis ACV-S de sistemas de energía en revistas indexadas, en particular, tres sobre biocombustibles, uno sobre diésel y gasolina, y uno sobre sistemas fotovoltaicos (EkenerPetersen et al. 2014, Macombe et al. 2013, Manik et al. 2013, Traverso et al. 2012). Esta alta proporción de ACV-S sobre producción de energía indica que es un sector con gran interés para la comunidad ACV-S.

Actualmente el ACV-S tiene un alcance muy limitado, ya que los impactos sociales se derivan y evolucionan a partir de la combinación de varias circunstancias culturales y políticas, mientras que la metodología del ACV-S sólo considera la situación actual ceteris paribus. Además, no es capaz de determinar cómo de buenos son los productos o servicios, sino catalogarlos de mejor a peor (Macombe et al. 2013). Sin embargo, algunos analistas de ciclo de vida concluyen que actualmente es posible realizar un ACV-S simple y preliminar, aunque la metodología aún está evolucionando y precisa de debate metodológico y más casos de estudio para poder llevar a cabo un ACV-S completo y preciso (Ekener-Petersen and Finnveden 2013, Macombe et al. 2013).

El estudio social descrito en este capítulo tiene como objetivo presentar un caso de estudio de la metodología ACV-S aplicado a la generación de electricidad en una planta termosolar, contribuyendo al desarrollo de la metodología con una nueva clasificación y método de caracterización. Aunque los impactos ambientales y económicos de la tecnología termosolar han sido estimados previamente por diversos autores (Burkhardt et al. 2010, Caldés et al. 2009, Corona and San Miguel 2015, Klein and Rubin 2013, San Miguel and Corona 2014), los impactos sociales todavía no han sido abordados. Por lo tanto, los resultados de este estudio ayudarán a comprender por primera vez las implicaciones sociales de la implementación de esta tecnología en España. 


\subsubsection{Estado del arte de la metodología}

El desarrollo de un ACV-S se apoya principalmente en la metodología del ACV Ambiental. Las cuatro fases de análisis se corresponden con las establecidas en las normas ISO 14040 y 14044, aunque presentan ciertas diferencias en cuanto a su contenido y modus operandi.

A continuación se describen las principales cuestiones a tener en cuenta en cada una de las cuatro fases principales del análisis ACV-S.

\subsubsection{Definición del objetivo y alcance}

El objetivo y alcance de estudio deben definirse especificando la unidad funcional (o utilidad del producto), las variables de actividad a utilizar, el método de recolección de datos y los actores afectados por el sistema.

La relación entre los impactos sociales y la unidad funcional es compleja, ya que las cuestiones físicas no miden correctamente la implicación social. En este sentido, se introduce el concepto de variable de actividad, que sirve para ponderar las diferentes empresas o procesos que participan o tienen lugar en el ciclo de vida del producto o servicio (UNEP-SETAC Life Cycle Initiative 2009). Al procedimiento de asignar importancia a los distintos procesos de la cadena de valor mediante una variable de actividad se le llama ACV Atributivo (del inglés, Life Cycle Attribute Assessment)(Andrews et al. 2009). Mediante este proceso el enlace cuantitativo de la unidad funcional se pierde, pero los resultados del estudio contienen la importancia relativa de cada proceso dentro del ciclo de vida (Parent et al. 2010). Las unidad más frecuentemente utilizada para cuantificar esta variable de actividad son las horas trabajadas (Andrews et al. 2009, Martínez-Blanco et al. 2014, Parent et al. 2010). Algunos autores sugieren también como variable el valor añadido creado por el ciclo de vida. En cualquier caso, se debe utilizar un valor que sea conocido para todos los procesos o actividades (Dreyer et al. 2006).

Uno de los factores clave a la hora de realizar un ACV-S (y que no se contempla en el ACVA) es la identificación de los actores del ciclo de vida. La guía distingue 5 categorías principales de actores, entendidas como un conjunto de actores que tienen intereses compartidos debido a su relación similar con el producto o sistema estudiado. Estas son: los trabajadores, la comunidad local, la sociedad (nacional y global), los consumidores y los actores de la cadena de valor. Estas categorías pueden verse complementadas con otras categorías y/o subgrupos, por ejemplo, Organizaciones No Gubernamentales y/o accionistas, proveedores, etc. El Estado o gobierno es un actor que debe considerarse de forma transversal a lo largo del análisis, 
especialmente en el caso de que un determinado ciclo de vida pueda verse afectado por la intervención del Estado (mediante políticas, regulaciones, acciones...).

En cuanto a la recolección de información, debe distinguirse entre información específica o genérica. La primera incluye información obtenida directamente de los actores implicados, mientras que la segunda incluye información general del país y de otras empresas del sector.

\subsubsection{Análisis de Inventario del Ciclo de Vida}

El análisis de inventario y la elección correcta de los datos de partida en el análisis de ciclo de vida determinan la utilidad y exactitud de los resultados finales. Este paso presenta especial complejidad en el caso del ACV-S, ya que a diferencia del ACV-A y del CCV, los datos de inventario definen relaciones sociales e incluyen datos cualitativos que aumentan la complejidad del análisis de inventario.

Para facilitar la recopilación de información de inventario, algunos estudios reúnen datos sociales en distintos niveles considerando una escala geográfica. Esta escala se distingue entre dos niveles principales: (1) sectores y países, representados por datos genéricos sobre los problemas sociales inherentes a dichos sectores o países y (2) la región y empresas involucradas en el ciclo de vida, representadas por datos específicos (Dreyer et al. 2006, Macombe et al. 2013, Martínez-Blanco et al. 2014). Esta escala geográfica se utiliza para examinar y comparar las cuestiones sociales en todos los niveles de toma de decisiones. Algunos estudios consideran el análisis del nivel 1 (sectores y países) como un "screening ACV-S" (es decir, un ACV-S simplificado y preliminar) ya que los datos de inventario se obtienen únicamente de fuentes genéricas con el objetivo de identificar los procesos de la cadena de valor que presentan mayor importancia relativa (Ekener-Petersen and Finnveden 2013, Ekener-Petersen et al. 2014). La recolección de datos genéricos puede realizarse mediante la consulta de informes oficiales elaborados por organizaciones reconocidas en cuestiones sociales (por ejemplo, la ONU y la OCDE) y también de bases de datos internacionales desarrolladas por la comunidad de ACV, como la base de datos Social Hotspots Database (SHDB) (Benoit-Norris et al. 2013). Por el contrario, los datos específicos de inventario son particulares para cada análisis (como la libertad de asociación sindical dentro de la empresa, o la explotación laboral llevada a cabo por algún proveedor) y deben ser recopilados directamente por el analista. El uso de datos específicos aumenta la complejidad metodológica del análisis social, ya que requiere la asignación de grandes recursos económicos y temporales (Jørgensen et al. 2008). 


\subsubsection{Evaluación de Impacto de Ciclo de Vida}

Los datos de inventario se transforman en indicadores de categorías de impacto durante la fase de evaluación de impacto. Esta fase ha sido la más discutida entre los practicantes de ACV$S$, y es la que presenta mayor variabilidad entre los casos de estudios publicados hasta la fecha (Petti et al. 2014), principalmente debido a que las directrices de la guía dejan esta fase como un campo abierto. Parent et al. (2010) clasifica la evaluación de impacto social en dos enfoques metodológicos, descritos en la Figura 68: tipo 1 o método de grupo de trabajo (que evalúa el comportamiento social) y tipo 2 o vía enfoque de impacto (que evalúa el impacto social). El primer enfoque se sirve de Puntos de Referencia de Comportamiento (PRP, del inglés, Performance Reference Points) para la caracterización y cuantificación de los datos recogidos, así como de la variable de actividad que pondera los resultados según la importancia relativa de cada proceso del ciclo de vida del producto (UNEP-SETAC Life Cycle Initiative 2009). En el segundo enfoque, el impacto se evalúa según las vías de impacto, donde el indicador de inventario se traduce en un indicador de punto medio $y$, opcionalmente, en un indicador de punto final (Parent et al. 2010, Weidema 2006).

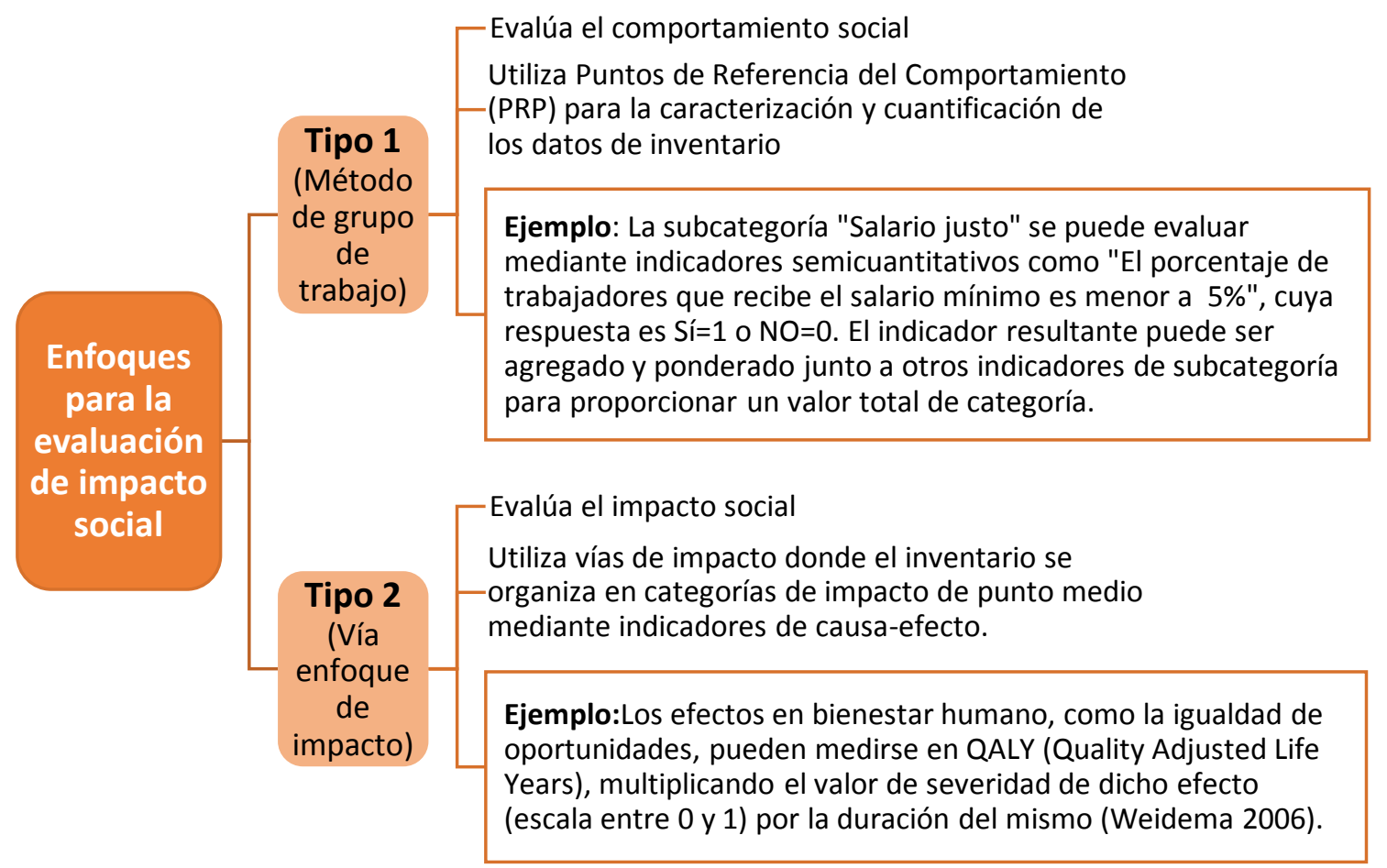

Figura 68 Los dos tipos de enfoque para la evaluación de impacto social de ciclo de vida

Según la revisión de métodos de evaluación de impacto publicada por Chhipi-Shrestha et al. (2014), 11 de los 20 estudios analizados utilizan el método tipo 1 mientras que los 9 estudios restantes utilizan el tipo 2. Estos autores subrayan la ausencia de estandarización en los métodos de evaluación de impacto, el problema de la ambigüedad y de la ponderación cuando se analizan 
impactos sociales fuera de su cultura específica y su entorno, la necesidad de identificar impactos negativos pero también positivos, la importancia de utilizar datos de inventario específicos y la utilidad de usar la base de datos Social Hotspots Database (SHDB) como herramienta para los priorización de búsqueda de datos específicos de inventario.

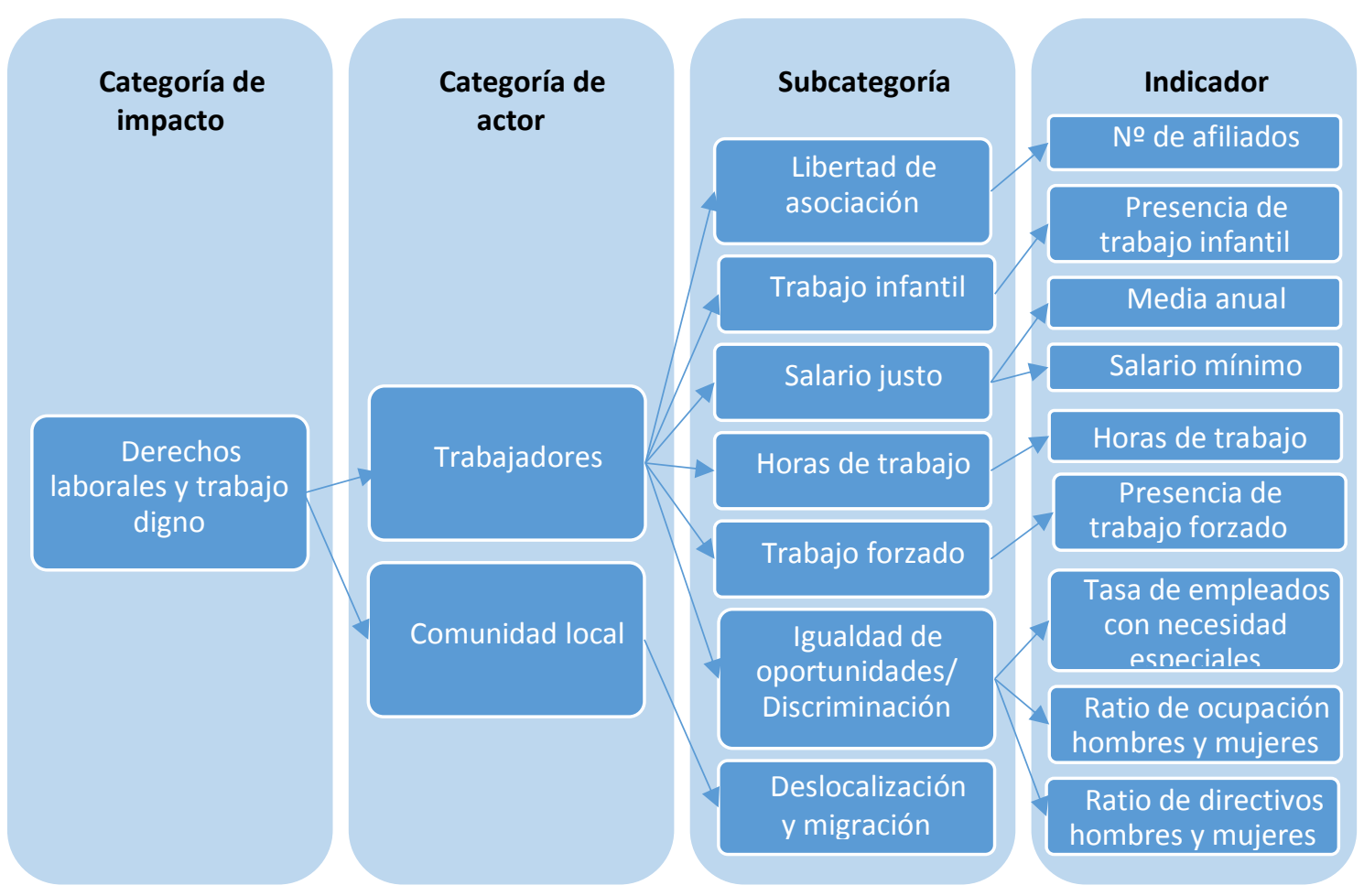

Figura 69 Diagrama de la categoría de impacto Derechos laborales y trabajo digno

Los resultados de la fase EICV se organizan en categorías de impacto generales, compuestas por subcategorías de impacto específicas. La Figura 69 muestra el diagrama de una categoría de impacto (Derechos laborales y trabajo digno) junto con sus subcategorías e indicadores. Aunque la guía no indica claramente las distintas categorías de impacto, sí que define 31 subcategorías para clasificar el comportamiento social en los distintos actores envueltos en el ciclo de vida. Por ejemplo, tal y como se muestra en la Figura 69, el actor "trabajador" tiene las siguientes ocho subcategorías: libertad de asociación y negociación colectiva, salario laboral, trabajo infantil, horas de trabajo, trabajo forzoso, igualdad de oportunidades, salud y seguridad y seguridad social (Benoît Norris et al. 2013). Estas categorías sirven un paso intermedio entre la información recogida y la categoría de impacto ( $p$ ej. la categoría "Derechos laborales y trabajo digno" se analiza primero mediante las subcategorías "salario justo", "discriminación", etc.).

La guía especifica que las categorías de impacto deben representar temas sociales de interés y deben cubrir los derechos humanos, las condiciones de trabajo, salud y seguridad, patrimonio cultural, gobierno y repercusiones socio-económicas. Aparte de estas áreas sociales 
de interés, la guía no ofrece instrucciones adicionales con respecto a la clasificación y caracterización de subcategorías en categorías de impacto. Los profesionales del ACV-S tampoco han aceptado mayoritariamente ningún modelo de caracterización concreto. La revisión de estudios de ACV-S llevada a cabo evidencia la falta de uniformidad y práctica en la caracterización de subcategorías en categorías de impacto. Según la revisión de Chhipi Shrestha (2014), sólo 2 de los 11 estudios encontrados que utilizan el método de evaluación de impacto tipo 1 clasifican subcategorías en categorías de impacto social (Franze and Ciroth 2011, Manik et al. 2013). Estos dos estudios utilizan las mismas categorías de impacto que las áreas sociales de interés nombradas en las normas, aunque no proporcionan ninguna definición de las categorías elegidas ni explican la lógica de la clasificación aplicada. Los restantes estudios citados en la revisión de Chhipi-Shresta caracterizan los resultados en categorías de actores, mientras que dos de ellos se centran sólo en la categoría de actores «Trabajadores». Benoît Norris (2012), Norris y Norris (Benoit-Norris et al., 2012) y Lehmann et al. (2013) aplican la clasificación y caracterización de categorías propuesta por las categorías sociales de la SHDB: derechos y trabajo decente, salud y seguridad, derechos humanos, gobernabilidad e infraestructura comunitaria. Estas categorías constan de subcategorías que pueden ser directamente relacionadas con lo estipulado en las normas (para más información sobre la SHDB, ver sección 5.2.2.1). Sin embargo, algunas de las subcategorías son específicas de la base de datos y no corresponden a las subcategorías en la guía y viceversa.

Como en el proceso de normalización del ACV-A, las subcategorías y categorías de impacto sociales también se ponderan en función de su importancia relativa. La ponderación en el ACVS es una cuestión controvertida, ya que implica juicios subjetivos y preferencias que cambian según la persona, la cultura y ubicación geográfica. Por lo tanto, los analistas generalmente agregan todas las subcategorías con el mismo peso (Ciroth and Franze 2011, Ekener-Petersen et al. 2014), aunque algunos desarrollan un procedimiento de ponderación adaptado a su caso de estudio (Manik et al. 2013).

\subsubsection{Interpretación}

El objetivo de la fase de interpretación es identificar las cuestiones más importantes, evaluar el estudio en cuanto a consistencia e integridad, identificar las conclusiones y ofrecer recomendaciones.

Se recomienda que los principales hallazgos y conclusiones se acompañen de la discusión sobre el alcance del estudio las decisiones tomadas en la elaboración del inventario. Hay que 
analizar si se ha considerado las cuestiones más importantes y si los indicadores han sido los más adecuados.

Como en el resto de metodologías de análisis de ciclo de vida, esta fase debe realizarse con la mayor transparencia, y debe informar sobre los actores involucrados en el análisis.

\subsection{Metodología del ACV-S}

Aunque el desarrollo actual de la metodología de ACV-S no permite abarcar toda la complejidad de los impactos sociales ${ }^{9}$, sí puede aplicarse para evaluar el comportamiento social simplificado de un producto o servicio. Debido al desarrollo incipiente de la metodología, uno de los objetivos de este estudio es proponer un nuevo método de evaluación de impacto (Tipo 1) para medir el comportamiento social de un sistema energético dentro de una región determinada. Este nuevo método está diseñado conforme a las preferencias metodológicas de las guías de la UNEP/SETAC y las sugerencias de la comunidad científica publicadas hasta la fecha. Se pretende ofrecer un método de evaluación de impacto sencillo, fácil de entender por los actores envueltos y que permita presentar los resultados de forma simple y transparente. Además, también se propone una nueva clasificación de subcategorías en categorías sociales.

A continuación se muestra la metodología desarrollada utilizando como ejemplo de aplicación la tecnología HYSOL y la tecnología TERMOSOLAR CCP.

\subsubsection{Definición del objetivo y alcance}

Los objetivos principales de este estudio son:

- Aplicar la metodología de ACV-S mediante las guías de la UNEP/SETAC y la base de datos SHDB, y contribuir con un caso de estudio al acervo de conocimientos sobre esta metodología.

- Proponer y probar un nuevo método de evaluación de impacto (tipo 1) para medir el comportamiento social de un sistema de producción de energía dentro de una región.

\footnotetext{
${ }^{9}$ Esta tesis considera como impactos sociales las "consecuencias negativas o positivas en cuestiones sociales que conciernen el bienestar humano".
} 
- Investigar el comportamiento social de la planta HYSOL y la planta TERMOSOLAR CCP para identificar hotspots sociales ${ }^{10}$, encontrar aquellos puntos donde los impactos sociales negativos pueden reducirse y comparar los resultados.

Ya que el fin último de este estudio es analizar la sostenibilidad del sistema, este análisis se ha hecho en concordancia con el objetivo y alcance de los análisis ACV, CCV y análisis MRIO realizados previamente. En ese sentido, se ha establecido que la unidad funcional sea $1 \mathrm{MWh}$ y el alcance vaya desde la extracción de materias primas hasta la gestión de los residuos. Las cuatro fases de ciclo de vida del estudio son: Extracción de materias primas y Fabricación de componentes (E\&F), Construcción de las instalaciones (C), Operación y Mantenimiento de la central (O\&M) y Desmantelamiento y Disposición de residuos (D\&D). La misma empresa es responsable del desarrollo de proyecto, construcción, operación, mantenimiento y desmantelamiento de la central, mientras que los componentes de la central son proporcionados por distintos proveedores, y los residuos son tratados por distintos organismos.

Todas las centrales productoras de electricidad españolas venden su electricidad mediante el operador del mercado eléctrico (OMIE), que determina el precio de la electricidad. Posteriormente, la empresa de distribución eléctrica en España (REE) gestiona el transporte de dicha electricidad por el territorio español. Según este sistema, el consumidor no tiene el poder real de escoger qué tecnología produce la electricidad que consume, y todas las tecnologías comparten la misma fase de distribución y consumo. Por lo tanto, este estudio sigue el enfoque "de la cuna a la puerta" donde la distribución y consumo del producto final (electricidad) no se incluye en el alcance.

La variable de actividad escogida en este estudio son las horas de trabajo, obtenidas mediante el análisis Input Output llevado a cabo previamente. Este dato se ha tomado del empleo directo generado en España durante las fases de O\&M y C (sección 4.2.3.1 del Capítulo 4).

Las características de las plantas de estudio están descritas en la sección 2.1.2 del Capítulo 2. Ambas plantas (HYSOL y TERMOSOLAR CCP) se van a analizar de forma conjunta, ya que se supone que es la misma empresa la que se encarga de la construcción, operación y

${ }^{10}$ Un hotspot social se refiere a una situación que puede ser considerada un problema, riesgo u oportunidad en términos de preocupación social (UNEP-SETAC Life Cycle Initiative 2009). 
desmantelamiento de las mismas. Sin embargo, en algunos casos habrá diferencia de resultados, debido a que el inventario físico, la producción eléctrica y el número de horas invertidas en el ciclo de vida de la planta son distintos en cada caso. Dicha diferencia de resultados será reportada cuando proceda.

La guía recomienda clasificar las categorías sociales según grupos de actores. Este estudio considera los siguientes cuatro actores:

- Los trabajadores: todos los empleados en cada fase del ciclo de vida.

- La comunidad local: aquella que se ubica en los alrededores de la planta termosolar.

- La sociedad (nacional y global): La comunidad social en su conjunto, incluyendo ONG y medios de comunicación.

- Los actores de la cadena de valor: Proveedores, empresas del sector.

El actor consumidor no se ha considerado ya que el consumo de electricidad queda fuera del alcance de este estudio.

Hoy en día es muy común que productos y sistemas contengan materiales o piezas procedentes de diversos países, especialmente aquellos productos cuya fabricación ha sido globalizada. En el caso de estudio, se sabe que la mayoría de los componentes de la planta termosolar se fabrican en España (a excepción de algunos componentes en el bloque de potencia), sin embargo, es probable que algunos de los materiales de fabricación tengan su origen en otros países. Para obtener esta información específica de cada sitio sería necesario rastrear el origen de los materiales para cada empresa encargada del suministro de componentes y materiales a la planta eléctrica. Sin embargo, la búsqueda de esa información para los múltiples proveedores del ciclo de vida es un proceso altamente complejo y largo. Debido a estas limitaciones en los datos de inventario, la guía sugiere la priorización y valoración de la importancia relativa de cada actividad con el fin de detectar hotspots sociales.

El primer paso para la consecución de este análisis ha sido realizar un análisis de hotspots sociales con el fin de detectar posibles riesgos sociales en el ciclo de vida del sistema. Tras el análisis de hotspots, se ha llevado a cabo un análisis específico en el nivel de la empresa para determinar cuestiones y riesgos potenciales detectados. Para ello, la información de inventario social se ha recogido en dos niveles: nivel sector económico/país y nivel empresa.

Para el primer nivel se ha considerado información de carácter genérico representativa de todos los sectores y/o países que participan en el ciclo de vida de la central. Estos datos han sido obtenidos de la base de datos SHDB (Benoit-Norris et al. 2013) y administrados mediante el 
software SimaPro. En este nivel se ha analizado la planta TERMOSOLAR CCP y los dos escenarios de la tecnología HYSOL: HYSOL BIO (operando con biometano) y HYSOL GN (operando con gas natural).

Para el segundo nivel (nivel empresa) se ha considerado información representativa de los procesos llevados a cabo por la empresa principal, que se ha denominado "información específica". Este segundo nivel no considera los procesos aguas arriba de las actividades llevadas a cabo por la empresa, es decir: la fase de extracción de materias primas y fabricación de componentes, la producción del combustible y la gestión de residuos. Esta exclusión de procesos se debe a la dificultad y falta de recursos para investigar en profundidad una cadena de valor tan larga y desagregada.

Como se indicó en la introducción de este capítulo, existen dos enfoques principales para la evaluación de impacto social. Este estudio sigue el enfoque de tipo 1, ya que "las relaciones causa-efecto no son lo bastante simples o no se conocen con precisión suficiente como para permitir el modelado cuantitativo de causa y efecto' '(Chhipi-Shrestha et al. 2014, UNEP-SETAC Life Cycle Initiative 2009). Parent et al. (2010) animan a utilizar el término "comportamiento social" en vez de "impacto social" para evaluar el sistema con el enfoque de tipo 1, ya que el uso de puntos de referencia social "dan una indicación sobre el estado de la dimensión de los contextos sociales a lo largo del ciclo de vida" en lugar de "las consecuencias sociales" del ciclo de vida. Por lo tanto, aunque se utilizará el término "Categorías de impacto", el resultado se referirá al comportamiento social positivo o negativo sobre los problemas sociales en cuanto al bienestar humano.

La principal vía de recolección va a ser la consulta de informes públicos de la empresa promotora de proyecto, como el informe de Responsabilidad Social Corporativa (RSC). Además, se consultarán noticias o informes de los medios de comunicación y ONG que se refieran a alguna fase del ciclo de vida de la planta termosolar.

Una revisión crítica de la evaluación social ha sido realizada por algunos miembros de una ONG nacional cuyo campo de acción está relacionado con el sector de la energía (Ingeniería Sin Fronteras).

\subsubsection{Análisis de inventario}

Esta sección describe la información recopilada para cada nivel de estudio: el análisis de hotspots sociales, y el análisis específico. 


\subsubsection{Análisis genérico de riesgos sociales}

El análisis genérico de riesgos sociales se ha llevado a cabo con el objetivo de explorar cuestiones sociales que se desarrollan en cada país y sector proveedor de bienes o servicios al sistema bajo estudio. De esta forma se pueden detectar aquellos países y/o sectores con mayor importancia en el ciclo de vida social, para poder priorizar la búsqueda de información específica. La base de datos SHDB desarrollada por New Earth (Benoit-Norris et al. 2013) se ha utilizado para representar la cadena de suministro global de cada producto. La SHDB se basa en un modelo estático IO global con datos GTAP (análisis de comercio global, del inglés, Global Trade Analysis Project) que considera 113 regiones/países con 57 sectores, cada uno. Utilizando como dato de partida el coste de cada componente y proceso del ciclo de vida de las plantas HYSOL y TERMOSOLAR CCP, la SHDB proporciona los riesgos sociales en cada uno de lo más de 100 indicadores sociales de la base de datos que tienen lugar en cada sector y país involucrado en la cadena de valor.

El inventario económico necesario para el análisis de hotspots coincide con el utilizado para el análisis del área económica (Capítulo 4). Las distintas partidas económicas han sido asignadas a los correspondientes sectores económicos del país productor y convertidas a la moneda de \$2002 (unidad en la que se mide los datasets de la SHDB) usando el índice IPC y los tipos de cambio de mercado de la OCDE (OECD 2014).

El inventario detallado está descrito en el Anexo III de esta tesis.

\subsubsection{Análisis específico}

El análisis de información específica a nivel empresa se ha realizado tras el análisis genérico con el objetivo de analizar los mayores riesgos potenciales detectados. También se han analizado otros indicadores de bajo riesgo social cuando la información recopilada lo ha permitido.

El enfoque principal para la realización de un ACV-S en el nivel específico es explorar el comportamiento social de las organizaciones relacionadas con el ciclo de vida del sistema bajo estudio. Para ello se necesita la siguiente información de inventario: flujos elementales, lugar de origen de cada componente (país o región), las empresas/organizaciones involucradas y la variable de actividad (horas de trabajo precisas para cada actividad del ciclo de vida). La información sobre flujos elementales económicos y físicos se recolectó para los análisis ACV y $\mathrm{CCV}$ realizados previamente, mientras que las horas de trabajo por proceso y fase del ciclo de vida se obtuvieron mediante el análisis 10 (utilizando como dato el empleo directo creado en España para cada fase). 
La recogida de información específica se ha centrado en la empresa principal a cargo del proyecto (desarrollo, construcción, operación y desmantelamiento), en adelante denominada como "la empresa promotora". Se ha evitado utilizar el nombre real de la empresa para evitar posibles conflictos con las empresas involucradas. Esta empresa es un grupo de empresas que trabajan en los sectores de la Construcción y de los Servicios Industriales. Al mismo tiempo, la empresa promotora es parte de un grupo multinacional de empresas, que según lo indicado en sus informes oficiales, comparten los mismos accionistas, Asamblea General, Consejo de Administración y código de valores.

La recolección de esta información específica se ha llevado a cabo mediante la investigación en internet, la comunicación con la empresa y la revisión de los siguientes informes corporativos:

- El informe anual de Responsabilidad Social Corporativa (RSC) del grupo de empresas (año 2014).

- El Informe Anual Corporativo de la empresa promotora (año 2013).

- El acuerdo colectivo de una filial de la empresa promotora (año 2010).

Para poder entender la magnitud y significado de la información recogida - p. ej. considerar los efectos positivos o negativos causados por la empresa promotora en un contexto social determinado - es necesario recopilar información que nos sirva de referencia (PRP, del inglés, Performance Reference Points). Según se indica en la guía, los PRP podrían ser umbrales u objetivos sociales según convenciones internacionales o buenas prácticas. En el caso de estudio se ha decidido mantener como referencia el comportamiento social de la media española siempre que cumpla la legalidad y respete los derechos humanos. De esta forma podemos determinar si el comportamiento de la empresa está suponiendo un impacto positivo o negativo en la sociedad española, según mejore o empeore cuestiones sociales que tienen lugar en el país.

Los PRP se han recolectado de fuentes genéricas como estadísticas nacionales, informes oficiales y periódicos. Para el análisis específico sólo se han tenido en cuenta las fases de C, O\&M y Desmantelamiento, ya que son las fases sobre las que tiene control la empresa promotora. Los indicadores de inventario para cada subcategoría y fase del ciclo de vida se describen en la Tabla 90. Se han considerado 24 indicadores según lo dispuesto en las hojas metodológicas de la guía (Benoit-Norris et al. 2011), de los cuales 11 son cuantitativos, 10 semi-cuantitativos y 3 cualitativos.

Tabla 90 Indicadores de inventario para cada subcategoría considerados en el ACV-S de la planta bajo estudio 


\begin{tabular}{|c|c|c|}
\hline & Subcategorías & Indicadores \\
\hline \multirow{15}{*}{ 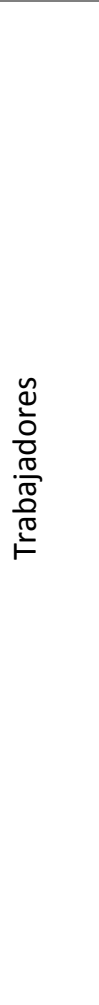 } & \multirow{2}{*}{$\begin{array}{l}\text { Libertad de asociación y } \\
\text { negociación colectiva }\end{array}$} & $\begin{array}{l}\text { Se apoya adecuadamente la presencia de sindicatos dentro de la } \\
\text { organización se y los trabajadores son libres de afiliarse a } \\
\text { sindicatos de su elección. }\end{array}$ \\
\hline & & $\begin{array}{l}\text { \% de afiliados sobre el total de personas empleadas ( } 2009 \text { vs } \\
\text { 2014) }\end{array}$ \\
\hline & Trabajo infantil & Presencia de trabajo infantil \\
\hline & \multirow{3}{*}{ Salario justo } & $\begin{array}{l}\text { Desigualdad salarial (salario medio en comparación con el } \\
\text { salario de ejecutivos) ( } 2012 \text { vs 2013) }\end{array}$ \\
\hline & & Salario medio anual, (2012 vs 2012) \\
\hline & & Salario mínimo en la empresa (2010 vs 2010) \\
\hline & Horas de trabajo & Horas de trabajo (2008 vs 2010) \\
\hline & Trabajo forzado & Presencia de trabajos forzados \\
\hline & \multirow{3}{*}{$\begin{array}{l}\text { Igualdad de oportunidades/ } \\
\text { Discriminación }\end{array}$} & $\begin{array}{l}\text { Tasas de empleo de personas con necesidades especiales en } \\
\text { relación con el total de personas empleadas ( } 2013 \text { vs } 2014 \text { ) }\end{array}$ \\
\hline & & $\begin{array}{l}\text { Relación de hombres y mujeres en los trabajadores de la } \\
\text { empresa ( } 2013 \text { vs 2013) }\end{array}$ \\
\hline & & $\begin{array}{l}\text { Relación de hombres y mujeres en los puestos directivos de la } \\
\text { empresa ( } 2013 \text { vs 2014) }\end{array}$ \\
\hline & & $\begin{array}{l}\text { Programas de educación, formación, asesoramiento, prevención } \\
\text { de riesgos para ayudar a los trabajadores }\end{array}$ \\
\hline & salud y seguridad & Presencia de una política formal sobre salud y seguridad \\
\hline & & Ratio de accidentes por empleado 2008 vs 2013 \\
\hline & Seguridad social & Seguridad social de los empleados \\
\hline \multirow{9}{*}{ 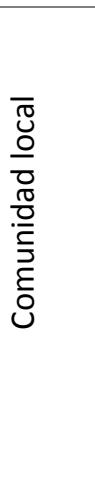 } & Empleo local & Promoción de empleo local en el proyecto \\
\hline & Acceso a recursos materiales & \multirow{8}{*}{$\begin{array}{l}\text { La planta no afecta a estas cuestiones, ya que se encuentra lejos } \\
\text { de la población (a } 6 \mathrm{~km} \text { del pueblo más cercano) y no interactúa } \\
\text { con personas locales (a excepción de los trabajadores, que son } \\
\text { evaluados en la categoría de partes interesadas de los } \\
\text { trabajadores) }\end{array}$} \\
\hline & Acceso a recursos inmateriales & \\
\hline & Delocalización y migración & \\
\hline & Patrimonio cultural & \\
\hline & $\begin{array}{l}\text { Condiciones de vivienda y } \\
\text { salud }\end{array}$ & \\
\hline & $\begin{array}{l}\text { Respecto de derechos } \\
\text { indígenas }\end{array}$ & \\
\hline & Compromiso de la comunidad & \\
\hline & Condiciones de vida seguras & \\
\hline \multirow{6}{*}{$\begin{array}{l}\frac{0}{\pi} \\
\frac{\pi}{0} \\
\frac{d}{0} \\
\text { ¿ }\end{array}$} & $\begin{array}{l}\text { Compromisos públicos en } \\
\text { temas de sostenibilidad }\end{array}$ & Existencia de informes públicos de sostenibilidad \\
\hline & Corrupción & Acciones legales durante el período \\
\hline & Desarrollo tecnológico & $\begin{array}{l}\text { Desarrollo de la tecnología, participación en proyectos } \\
\text { nacionales e internacionales. Inversión en I+D }\end{array}$ \\
\hline & $\begin{array}{l}\text { Prevención y mitigación de los } \\
\text { conflictos armados }\end{array}$ & No hay conflictos armados para prevenir o mitigar \\
\hline & $\begin{array}{l}\text { Contribución al desarrollo } \\
\text { económico }\end{array}$ & Efecto multiplicador \\
\hline & Utilididad social del producto & El producto contribuye a satisfacer necesidades básicas \\
\hline \multirow{4}{*}{ 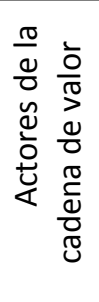 } & Competencia justa & Acciones legales durante el período \\
\hline & Relación con proveedores & $\begin{array}{l}\text { Aplicación de criterios sociales en la homologación de } \\
\text { proveedores }\end{array}$ \\
\hline & $\begin{array}{l}\text { Promoción de la } \\
\text { responsabilidad social }\end{array}$ & $\begin{array}{l}\text { Documentos indicando la promoción de este tema dentro de la } \\
\text { empresa }\end{array}$ \\
\hline & $\begin{array}{l}\text { Respecto de derechos } \\
\text { intelectuales y de propiedad }\end{array}$ & Acciones legales durante el período \\
\hline
\end{tabular}




\subsubsection{Calidad de los datos}

La incertidumbre y validez de la información dependen, entre otras cosas, de la naturaleza geográfica, temporal y tecnológica de los datos recopilados. Para mantener validez temporal, la información se ha recopilado con un máximo de 5 años de diferencia con el momento de inicio del proyecto (2013). Debido a que una de las principales fuentes de información es el informe de RSC del grupo de empresas donde se encuentra la empresa promotora, existe el riesgo de que algunos datos específicos no representen con exactitud a la empresa promotora. Además, también existe el riesgo de sesgo por intereses empresariales en el informe RSC, ya que las empresas suelen ser reacias a exponer sus deficiencias sociales. A este respecto, el informe de la empresa fue revisado positivamente por una empresa de consultoría independiente en concordancia con la Código Internacional de Ética para los Profesionales de la Contabilidad.

\subsubsection{Evaluación de impacto}

\subsubsection{Análisis de genérico de riesgos sociales}

En el análisis genérico de riesgos sociales se ha aplicado el método de evaluación de impacto "Social LCIA método 1" desarrollado por New Earth y adaptado al software SimaPRO (Benoit-Norris et al. 2013). Como se observa en la Figura 70, este método reúne datos sobre 22 temas sociales, que se clasifican en las siguientes 5 categorías sociales: Derechos laborales y trabajo digno, Salud y seguridad, Derechos humanos, Gobernanza y Estructura comunitaria. 


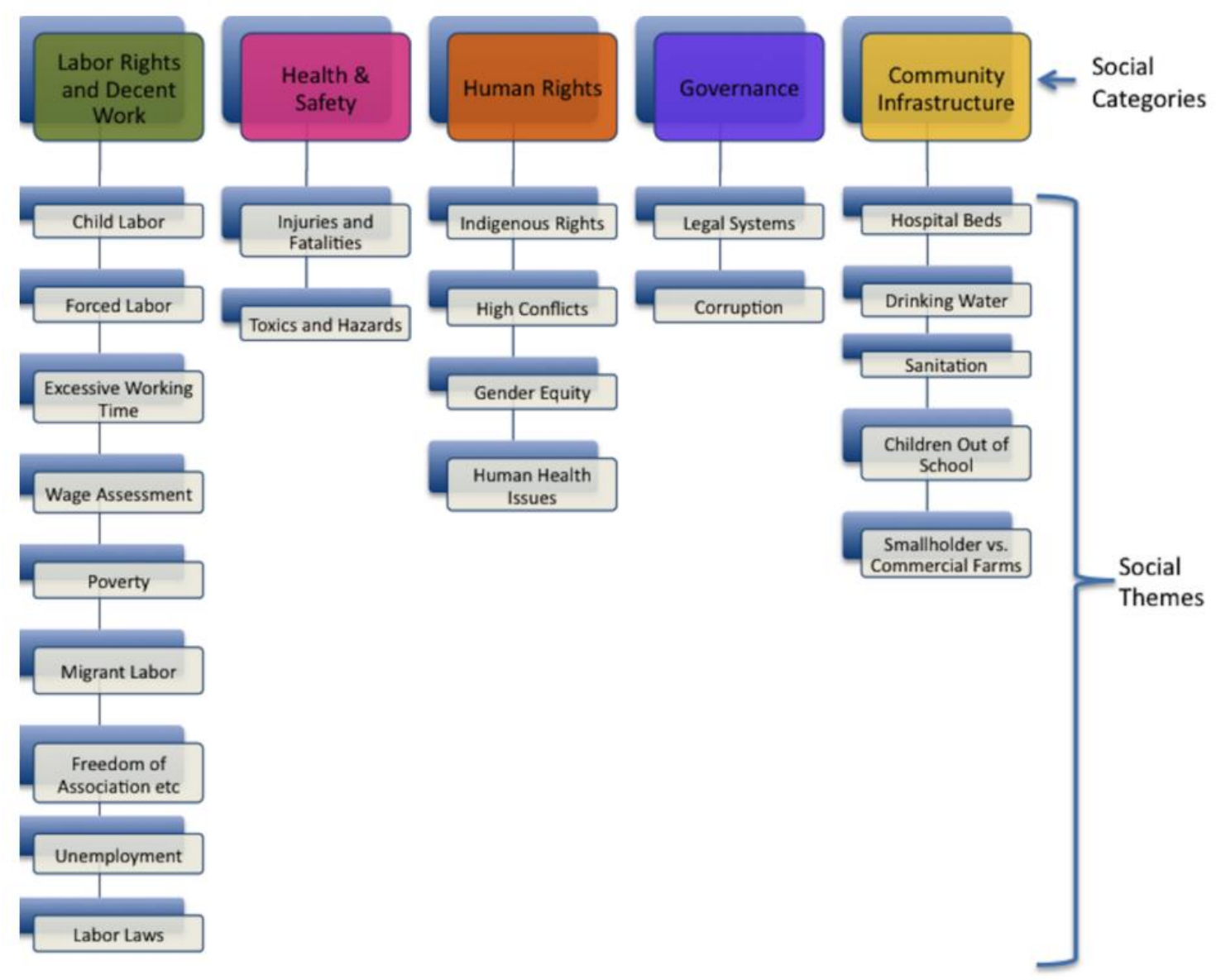

Figura 70 Los 22 temas sociales y cinco categorías de la Social Hotspots Database (Benoit-Norris et al. 2013)

Cada problema o cuestión social se caracteriza en uno de los 22 temas sociales, considerando el nivel de riesgo identificado para cada problema social. Luego, se agregan los temas sociales en categorías sociales aplicando factores de ponderación. Los resultados obtenidos por este método representan el riesgo de distintos problemas sociales en diferentes países y sectores económicos. Estos riesgos sirven como base para priorizar la investigación específica.

Por ejemplo, la provisión de un heliostato a la fase de E\&F de la planta HYSOL genera una demanda de metales en el sector de metales español. Este sector presenta riesgos determinados (entre ninguno y muy alto) en los indicadores que definen los 22 temas sociales considerados por la SHDB. A su vez, este sector demanda materiales y servicios de otros sectores (a nivel internacional) que presentan también determinados riesgos sociales. Para determinar la relevancia de cada sector involucrado en los riesgos sociales asociados a la provisión de un heliostato a nuestra planta, la SHDB utiliza las horas trabajadas en cada sector por unidad monetaria demandada. Por último agrega todos los riegos sociales obtenidos para cada tema social y proporciona un resultado final. 
Este análisis se ha aplicado a la planta HYSOL en sus dos escenarios (HYSOL BIO y HYSOL GN) y a la TERMOSOLAR CCP.

\subsubsection{Análisis específico}

La fase de evaluación de impacto en el ACV-S no puede abordarse de la misma manera que en análisis ambiental ya que la información de inventario no es cuantitativa y la caracterización del inventario en una categoría de impacto no es directa, objetiva ni está sujeta a leyes físicas. Por esta razón, se ha seguido la sugerencia de las guías de la UNEP/SETAC, y se ha modificado la fase de evaluación de impacto para recoger la caracterización, normalización y ponderado de subcategorías en un mismo paso llamado "paso de aporte de significado".

Como se indica en la revisión del estado del arte de la metodología (sección 5.1.2), el paso de clasificación y caracterización entre subcategorías y categorías de impacto no está desarrollado aún en la guía. Por ello, se ha creado un nuevo modelo de aporte de significado en el que las subcategorías se clasifican en categorías de impacto para posteriormente aplicarles un factor de caracterización en función de su relación con los PRP asignados. Esta caracterización se describe en detalle en la sección 5.2.3.3. El nuevo método comparte similitudes con el desarrollado por Ciroth y Franze (2011), sin embargo, se diferencia en que permite representar adecuadamente los impactos positivos y negativos, incluye los resultados de todas las subcategorías aunque no se vean significativamente afectadas, y se basa en una agregación de impactos utilizando las horas de trabajo como variable de actividad.

Según la guía, las categorías de impacto deben representar temas sociales de interés y pueden cubrir los siguientes temas con respecto a los actores afectados: salud y seguridad, derechos humanos, condiciones de trabajo, repercusiones socio-económicas, patrimonio y gobernanza. Considerando dichos temas de interés social, así como las categorías sociales incluidas en el método de evaluación del análisis de hotspots (de la SHDB), y lo aprendido en la revisión bibliográfica, se han establecido para este estudio las siguientes categorías de impacto (ver Figura 71): Derechos laborales y trabajo decente, Salud y seguridad, Patrimonio Cultural y natural, Relaciones justas y Sostenibilidad socio-económica. Se ha decidido no incluir la gobernanza como una categoría de impacto debido a que la gobernanza en una empresa corresponde más a una "causa de impacto" que a un impacto en sí mismo. Los derechos humanos tampoco se han incluido como una categoría, ya que se considera un tema social muy amplio que se corresponde con una categoría de punto final (los derechos laborales, la salud y la seguridad o el patrimonio cultural representan también derechos humanos). Además, se ha añadido una nueva subcategoría que represente la utilidad social del producto (subcategoría 
utilidad social en la categoría sostenibilidad socio-económica). A continuación se describe la definición de cada una de estas categorías de impacto junto con la clasificación y justificación de las subcategorías.

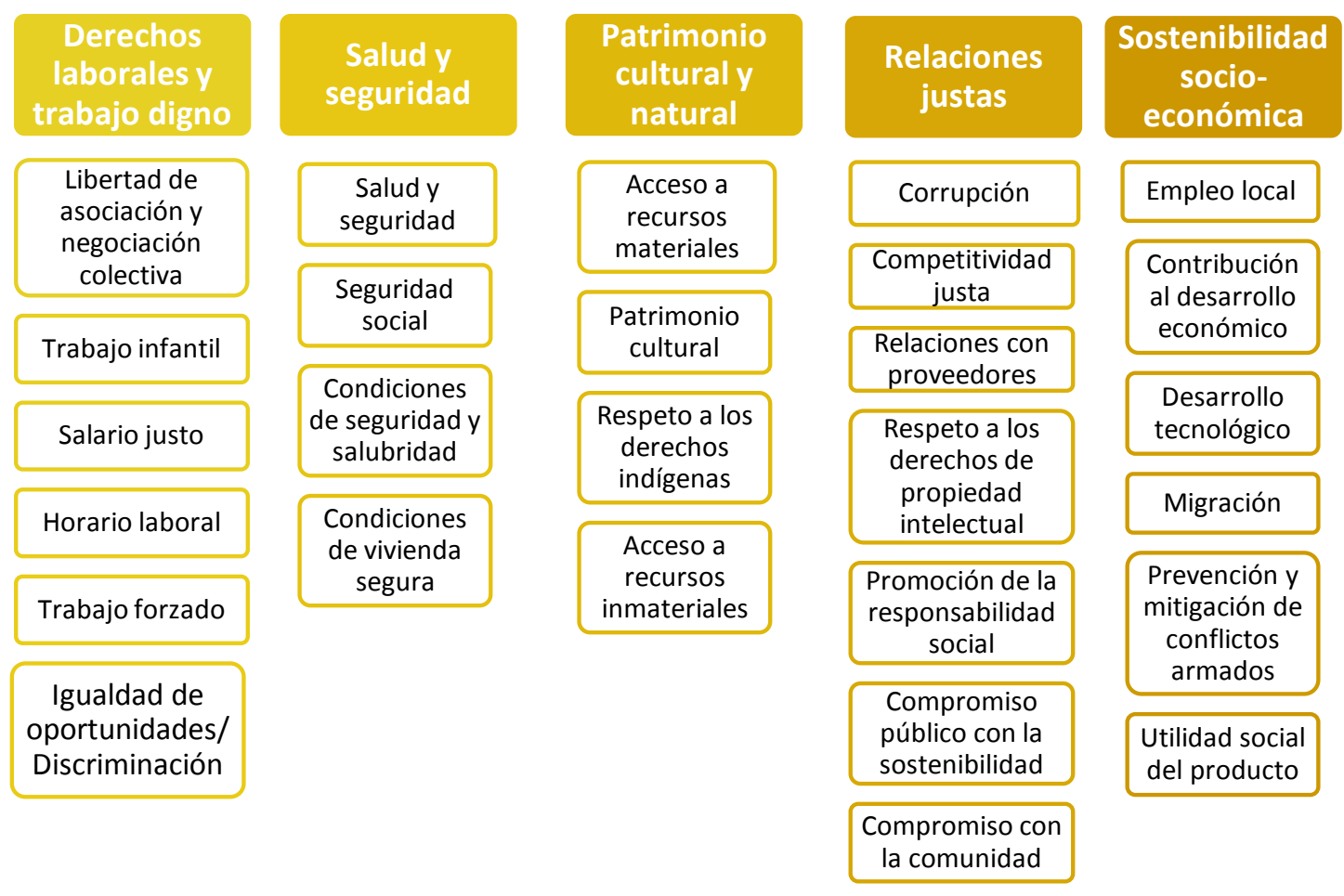

Figura 71 Categorías de impacto y subcategorías consideradas en el análisis específico

\subsection{Derechos laborales y trabajo digno}

Esta categoría representa el comportamiento social de la empresa con respecto a los derechos humanos y jurídicos de los empleados. Incluye el comportamiento social en la libertad de asociación y negociación colectiva, el trabajo infantil, el salario justo, el horario laboral, los trabajos forzados, y la reubicación y migración. La clasificación de las subcategorías y su justificación se encuentran en la Tabla 91.

Tabla 91 Clasificación de las subcategorías descritas por la guía en la categoría de impacto de Derechos laborales y trabajo digno

\begin{tabular}{lll}
\hline $\begin{array}{l}\text { Subcategoría } \\
\begin{array}{l}\text { Libertad de asociación } \\
\text { y negociación } \\
\text { colectiva }\end{array}\end{array}$ & $\begin{array}{l}\text { Actor } \\
\text { involucrado }\end{array}$ & Justificación de la clasificación \\
\hline Trabajo infantil & Trabajadores & $\begin{array}{l}\text { Contempladas como tal en la categoría social } \\
\text { correspondiente de la SHDB }\end{array}$ \\
\hline Salario justo & & \\
\hline Horario laboral & & \\
\hline Trabajo forzado &
\end{tabular}


Igualdad de oportunidades/ Discriminación
La categoría social contemplada en la SHDB con mayor similitud a esta subcategoría es "trabajadores migrantes". La subcategoría definida en la guía como Igualdad de oportunidades/ Discriminación presenta un significado más amplio, que incluye no solo trabajadores migrantes pero también la igualdad de género y otros tipos de Trabajadores discriminación. Se ha decidido incluir esta subcategoría en esta categoría de impacto debido a que la discriminación y la igualdad de oportunidades relativa a los trabajadores está directamente relacionada con los derechos humanos y laborales (Artículo 1 de la Declaración de Derechos Humanos: Todos los humanos nacen libres e iguales en dignidad y derechos (Assembly 1948)).

\subsection{Salud y seguridad}

Esta categoría describe el comportamiento social de la empresa en cuanto a la salud y seguridad de todos los actores involucrados en el ciclo de vida del producto/sistema, incluyendo seguridad social, condiciones de salubridad y condiciones de vivienda segura. La clasificación de las subcategorías y su justificación se encuentran en la Tabla 92.

Tabla 92 Clasificación de las subcategorías descritas por la guía en la categoría de impacto de Salud y seguridad

\begin{tabular}{|c|c|c|}
\hline Subcategoría & $\begin{array}{l}\text { Actor } \\
\text { involucrado }\end{array}$ & Justificación de la clasificación \\
\hline Salud y seguridad & Trabajadores & \multirow{4}{*}{$\begin{array}{l}\text { Las únicas cuestiones sociales de seguridad y salud } \\
\text { que incluye la SHDB en la categoría con el mismo } \\
\text { nombre son aquellas relacionadas a entornos de } \\
\text { trabajo. Sin embargo, se ha decidido incluir en esta } \\
\text { categoría todas aquellas subcategorías relativas a la } \\
\text { salud y seguridad independientemente de si éstas } \\
\text { afectan a los trabajadores o a la comunidad local. }\end{array}$} \\
\hline Seguridad social & Trabajadores & \\
\hline $\begin{array}{l}\text { Condiciones de } \\
\text { seguridad y salubridad }\end{array}$ & $\begin{array}{l}\text { Comunidad } \\
\text { local }\end{array}$ & \\
\hline $\begin{array}{l}\text { Condiciones de vivienda } \\
\text { segura }\end{array}$ & $\begin{array}{l}\text { Comunidad } \\
\text { local }\end{array}$ & \\
\hline
\end{tabular}

\subsection{Patrimonio cultural y natural}

Según la definición de la UNESCO (United Nations Educational, Scientific and Cultural Organization)(UNESCO 2015), el término de patrimonio cultural abarca varios tipos de patrimonio:

Patrimonio cultural material:

- Patrimonio cultural móvil (pinturas, esculturas, monedas, manuscritos)

- Patrimonio cultural inamovible (monumentos, sitios arqueológicos y otros edificios)

- patrimonio cultural subacuático (naufragios, ruinas y ciudades bajo el agua)

Patrimonio cultural inmaterial: tradiciones orales, artes escénicas, rituales.

Patrimonio cultural: lugares naturales con aspectos culturales tales como paisajes culturales y formaciones físicas, biológicas o geológicas.

Patrimonio en lugares de conflicto armado.

La clasificación de las subcategorías y su justificación se encuentran en la Tabla 93. 
Tabla 93 Clasificación de las subcategorías descritas por la guía en la categoría de impacto de Patrimonio cultural

\begin{tabular}{|c|c|c|}
\hline Subcategoría & $\begin{array}{l}\text { Actor } \\
\text { involucrado }\end{array}$ & Justificación de la clasificación \\
\hline $\begin{array}{l}\text { Acceso a recursos } \\
\text { materiales }\end{array}$ & Comunidad local & $\begin{array}{l}\text { Según la guía, esta subcategoría se corresponde con } \\
\text { recursos materiales locales (agua, tierra, minerales y } \\
\text { recursos biológicos), e infrastructura (carreteras, } \\
\text { instalaciones sanitarias, escuelas). Por lo tanto, esta } \\
\text { subcategoría se engloba como patrimonio cultural material } \\
\text { y natural. }\end{array}$ \\
\hline Patrimonio cultural & Comunidad local & Coincide en nombre y significado con la categoría analizada. \\
\hline $\begin{array}{l}\text { Respeto a los } \\
\text { derechos indígenas }\end{array}$ & Comunidad local & $\begin{array}{l}\text { Esta subcategoría está directamente relacionada con el } \\
\text { patrimonio cultural inmaterial de la comunidad local. }\end{array}$ \\
\hline $\begin{array}{l}\text { Acceso a recursos } \\
\text { inmateriales }\end{array}$ & Comunidad local & $\begin{array}{l}\text { Según la guía, el objetivo de esta subcategoría es evaluar el } \\
\text { grado en que las organizaciones respetan, protegen, } \\
\text { proporcionan o mejoran el acceso de la comunidad a los } \\
\text { recursos inmateriales. Los recursos inmateriales incluyen } \\
\text { servicios a la comunidad, derechos de propiedad } \\
\text { intelectual, libertad de expresión y acceso a la información. }\end{array}$ \\
\hline
\end{tabular}

\subsection{Relaciones justas}

Esta categoría representa el comportamiento social de la empresa con respecto a sus relaciones con la sociedad, la comunidad local y los actores de la cadena de valor. Se relaciona directamente con la gestión de la empresa, ya que el logro de estas relaciones justas depende de las decisiones de la empresa analizada (a través de las normas, los mandatos o el lenguaje). La relación de la empresa con los trabajadores no está incluida en esta categoría ya que dichas relaciones están representadas en la categoría de impacto de Derechos laborales y trabajo digno. La categoría de Relaciones justas incluye el comportamiento social en corrupción, competencia leal, relaciones con los proveedores, respeto a los derechos de propiedad intelectual, promoción de la responsabilidad social y el compromiso con la comunidad. La clasificación de las subcategorías y su justificación se encuentran en la Tabla 94.

Tabla 94 Clasificación de las subcategorías descritas por la guía en la categoría de impacto de Relaciones justas

\begin{tabular}{|c|c|c|}
\hline Subcategoría & Actor involucrado & Justificación de la clasificación \\
\hline Corrupción & Sociedad & \multirow{7}{*}{$\begin{array}{l}\text { Estas subcategorías están } \\
\text { afectadas directamente por las } \\
\text { relaciones entre las empresas, } \\
\text { organismos y grupos sociales } \\
\text { involucradas en el ciclo de vida del } \\
\text { producto/sistema. }\end{array}$} \\
\hline Competitividad justa & Actores de la cadena de valor & \\
\hline Relaciones con proveedores & Actores de la cadena de valor & \\
\hline $\begin{array}{l}\text { Respeto a los derechos de } \\
\text { propiedad intelectual }\end{array}$ & Actores de la cadena de valor & \\
\hline $\begin{array}{l}\text { Promoción de la } \\
\text { responsabilidad social }\end{array}$ & Actores de la cadena de valor & \\
\hline $\begin{array}{l}\text { Compromiso público con la } \\
\text { sostenibilidad }\end{array}$ & Sociedad & \\
\hline $\begin{array}{l}\text { Compromiso con la } \\
\text { comunidad }\end{array}$ & Comunidad local & \\
\hline
\end{tabular}




\subsection{Sostenibilidad socio-económica}

Esta categoría de impacto comprende los impactos causados en la sociedad y la comunidad local que están indirectamente relacionados con la gobernanza de las empresas involucradas, y que no están relacionados con los derechos humanos, patrimonio o salud y seguridad. La categoría incluye la contribución al desarrollo local económico y de empleo, el desarrollo tecnológico, la prevención y mitigación de conflictos armados y la utilidad social del producto estudiado.

Tabla 95 Clasificación de las subcategorías descritas por la guía en la categoría de impacto Sostenibilidad socio-económica

\begin{tabular}{lll}
\hline Subcategoría & $\begin{array}{l}\text { Actor } \\
\text { involucrado }\end{array}$ & $\begin{array}{l}\text { Justificación de la clasificación } \\
\text { Empleo local }\end{array}$ \\
\hline Comunidad & $\begin{array}{l}\text { La guía indica que las organizaciones tienen un gran potencial para } \\
\text { fomentar el desarrollo sostenible a través de contratación de } \\
\text { población local. Los empleados locales poseen conocimiento de las } \\
\text { cuestiones importantes de la comunidad y pueden ayudar a } \\
\text { construir relaciones fuertes entre la organización y la comunidad } \\
\text { local. Las organizaciones que trabajan para desarrollar la } \\
\text { transferencia de conocimientos entre los empleados y la } \\
\text { comunidad local están fomentando el desarrollo sostenible. }\end{array}$ \\
\hline
\end{tabular}

\begin{tabular}{lll}
\hline $\begin{array}{l}\text { Contribución al } \\
\text { desarrollo económico }\end{array}$ & Sociedad & \\
\cline { 1 - 2 } Desarrollo tecnológico & Sociedad & \\
\cline { 1 - 2 } Migración & $\begin{array}{l}\text { Comunidad } \\
\text { local }\end{array}$ & $\begin{array}{l}\text { Estas subcategorías se ajustan a la definición dada para la categoría } \\
\text { de impacto de Sostenibilidad socio-económica. }\end{array}$ \\
\cline { 1 - 2 } $\begin{array}{l}\text { Prevención y } \\
\text { mitigación de } \\
\text { conflictos armados }\end{array}$ & Sociedad & \\
\hline
\end{tabular}

\section{Esta subcategoría no se incluye en la guía ni en la SHDB. Se ha} decidido incluirla al considerarse que la utilidad del producto debe ser uno de los temas importantes a evaluar dentro de un S-ACV. Representa el valor inherente al producto o servicio ofrecido para mejorar el bienestar de la sociedad. La caracterización de esta

Utilidad social del producto
Sociedad subcategoría no está exenta de juicio subjetivo, ya que es difícil saber hasta qué punto un producto es bueno para la sociedad. Los productos con mayores utilidades sociales serían los que cumplen con necesidades básicas tales como: nutrición, educación, salud, saneamiento, abastecimiento de agua y vivienda e infraestructura (Streeten and Burki 1978). Productos con utilidades sociales bajas son aquellos cuyo uso causa impactos sociales negativos (como las minas antipersona).

\subsubsection{Paso de aporte de significado}

El paso de aporte de significado se ha llevado a cabo siguiendo las siguientes siete reglas, representadas en el diagrama de flujo de la Figura 72: 
1. Cuando el indicador de la empresa es mejor que la media española, el comportamiento social se considera como "mejor" y se cuantifica con +1 punto de comportamiento social $(p-c s)$.

2. Si el valor cuantitativo del indicador se comporta dos veces mejor (o más) que la medida nacional, entonces se considera como "mucho mejor" y se cuantifica con +2 p-cs.

3. Cuando el indicador muestra resultados similares a la media nacional, entonces se considera como "similar" y se cuantifica con 0 p-cs.

4. Cuando el indicador muestra un comportamiento social peor a la media española, entonces se considera como "peor" y se cuantifica con -1 p-cs.

5. Cuando el valor cuantitativo de indicador se comporta dos veces peor (o más) entonces se califica como "mucho peor" y se cuantifica con -2 p-cs.

6. Cuando no hay información sobre el indicador de subcategoría, pero hay un riesgo social bajo en dicha subcategoría (determinado mediante el análisis de hotspots), se considera como "similar" y se cuantifica como 0 p-cs (según las guías, todas las subcategorías deben de incluirse en un estudio).

7. Cuando una subcategoría tiene diferentes indicadores, se toma como puntuación de subcategoría la media de la puntuación asignada a cada indicador. Cuando una categoría se compone de distintas subcategorías, la media de las subcategorías se asume como la puntuación de la categoría.

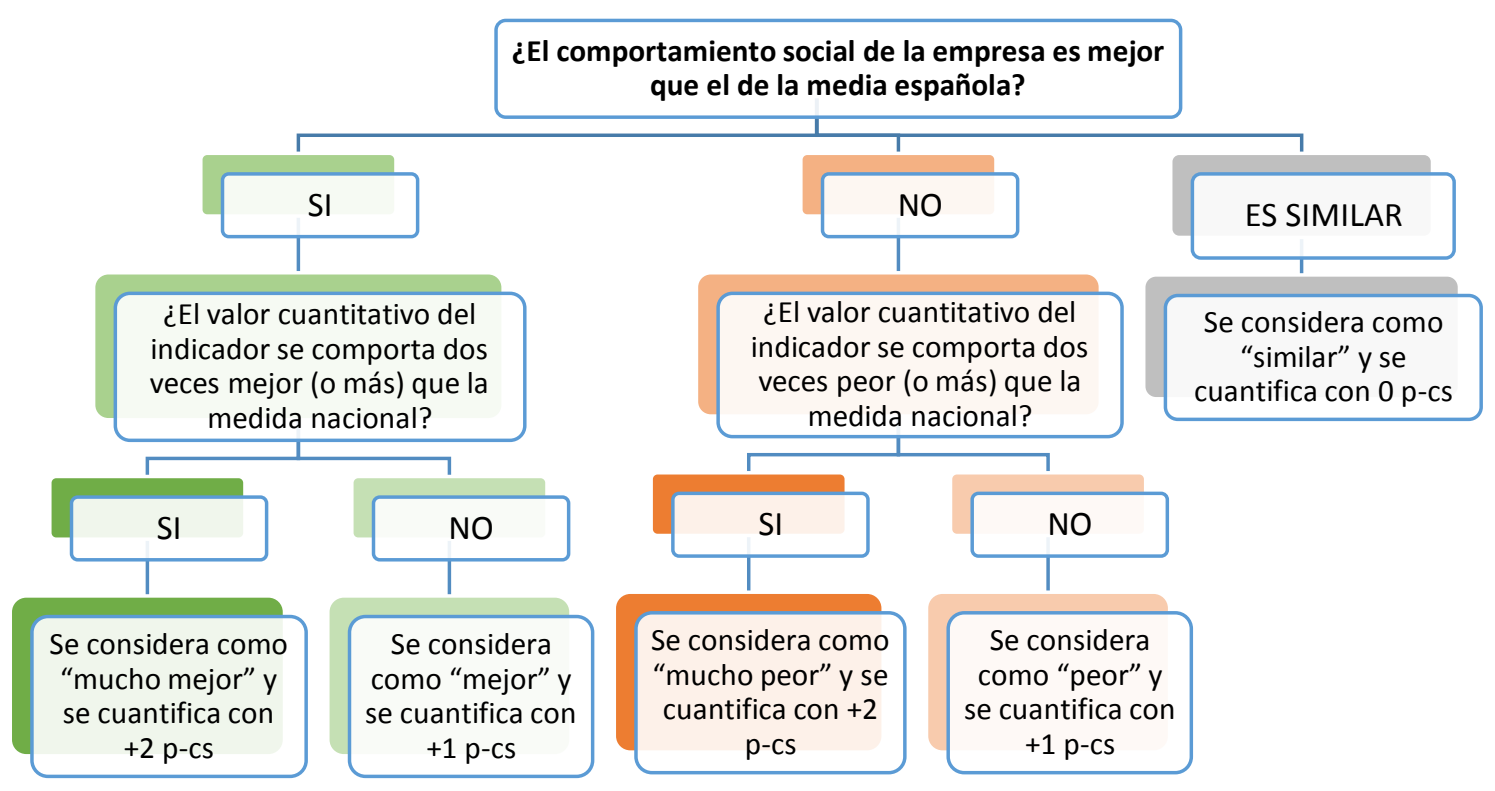

Figura 72 Diagrama de flujo para el paso de aporte de significado

Aunque la misma empresa opera en las distintas fases del ciclo de vida (C, O\&M, y D), los indicadores pueden presentar distintos resultados en cada fase. Estas diferencias se derivan de 
la media genérica y específica según el correspondiente sector económico ( $C$ y D: sector de la construcción, O\&M: sector de la provisión de electricidad).

Puesto que la clasificación de subcategorías puede afectar a los resultados, el mismo método se aplicará a la clasificación por categorías de actores con el objetivo de comparar resultados.

\subsection{Paso final de asignación de cargas y agregación de categorías}

Para considerar la importancia relativa de los resultados en cada fase se asignan cargas a los resultados utilizando como peso el porcentaje de horas de trabajo de cada fase respecto al total del ciclo de vida (considerando sólo las fases de C, O\&M y D). La puntuación final se obtiene realizando la media de las puntuaciones obtenidas para cada categoría de impacto. Ya que actualmente no hay ninguna orientación para el ponderado de categorías en ACV-S, el mismo peso se ha asignado a todas las categorías y subcategorías de impacto.

Este método sencillo de cuantificación permite estimar si el comportamiento social de la empresa tiene un impacto social positivo, negativo o neutro en el país. Un resultado final positivo representa un beneficio en la sociedad del país, mientras que un resultado ponderado negativo representa un daño en la sociedad del país, y un resultado cercano a cero representa que el contexto social no está afectado ni positiva ni negativamente. Esta simplificación debe tomarse con cuidado, y siempre presentarse con los indicadores de subcategorías, ya que un resultado cercano a cero no implica que el comportamiento de la empresa carezca de efectos positivos o negativos en cuestiones sociales de interés, si no que la media ponderada del comportamiento social dentro del país de referencia permanece neutra.

Al interpretar estos resultados es importante conocer el peligro asociado a utilizar números para representar cuestiones sociales, ya que simplifica en exceso cuestiones que sólo pueden definirse mediante la consideración de numerosos matices imposibles de representar mediante números. Por ello, es importante conocer los resultados por indicadores y subcategorías, y tomar los resultados finales únicamente como una guía cuantitativa para la toma de decisiones. Además, debido al estado de desarrollo actual de la metodología ACV-S, estos resultados no deberían tomarse como único indicador para la comparación entre productos o para la toma de decisiones (UNEP-SETAC Life Cycle Initiative 2009). 


\subsection{RESULTADOS DEL ACV-S}

\subsubsection{Análisis genérico de riesgos sociales}

\subsubsection{Planta HYSOL BIO}

La Figura 73 muestra los resultados caracterizados del análisis de hotspots social aplicado a la planta HYSOL BIO por subcategoría y fase de ciclo de vida. La fase de O\&M reúne los mayores riesgos, especialmente en el trabajo migrante (74\% del riesgo social en esta categoría), heridas y accidentes (73 \%), productos tóxicos y peligrosos (71 \%) y horas de trabajo excesivas (70 \%). E\&F fase es la siguiente fase con mayores riesgos, especialmente en saneamiento (26 \%), trabajo infantil (25\%), agua potable (23\%), y salario de pobreza (22\%). El mayor riesgo social relativo obtenido en la fase de O\&M se deriva de la producción del biometano, ya que esta actividad presenta entre el $63 \%$ y el $74 \%$ de riesgo social para cada categoría dentro de esta fase.

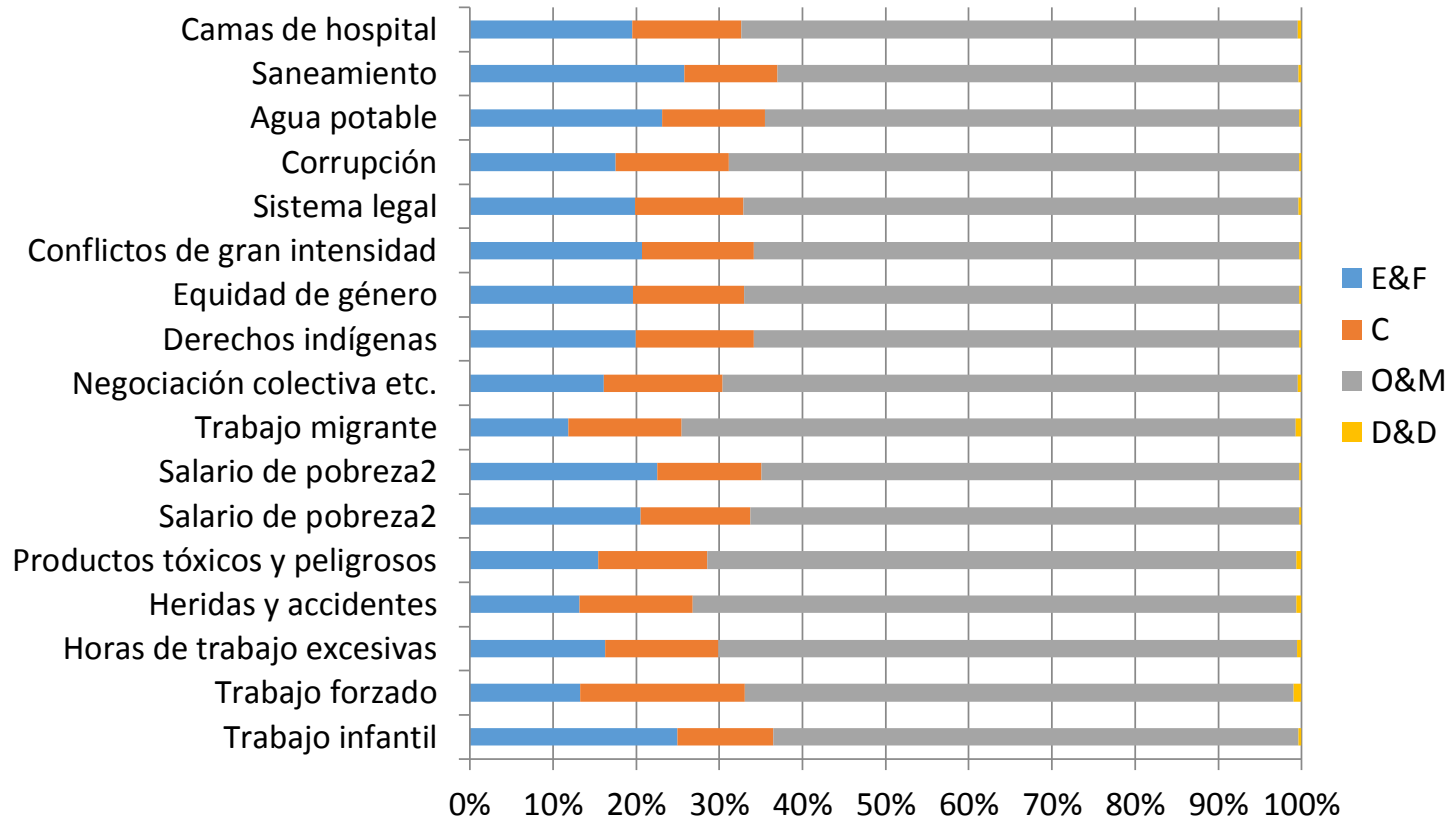

Figura 73 Resultados de caracterización por fases del análisis de hotspots de la planta HYSOL BIO

La Figura 74 muestra los riesgos sociales por fases de ciclo de vida tras de la asignación de pesos a cada subcategoría y categoría social. Estos resultados sugieren que Salud y seguridad es la categoría social con mayor riesgo ponderado para todas las fases del ciclo de vida de la planta HYSOL, seguida por la categoría de Trabajo digno y derechos laborales. El proceso que presenta mayor riesgo en dichas categorías es principalmente el biometano (una contribución del 50 \% y $53 \%$ a cada categoría respectivamente), seguido por los intereses pagados por el préstamo financiero ( $23 \%$ y $14 \%$ respectivamente). 
Infraestructura de la comunidad Governanza

Derechos humanos

Salud y seguridad

Derechos laborales y trabajo decente

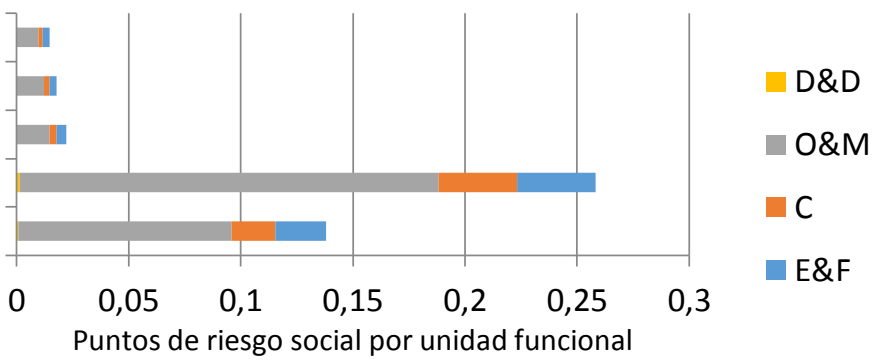

Figura 74 Resultados ponderados del análisis de hotspots sociales de la planta HYSOL BIO por categoría y fase de ciclo de vida

La Tabla 96 muestra los sectores económicos que contribuyen a más de un $1 \%$ del riesgo social ponderado del ciclo de vida de la planta HYSOL BIO. La tabla incluye también la contribución al riesgo total ponderado por cada sector económico influyente en el ciclo de vida social. Que un sector determinado tenga elevada contribución al riesgo social del ciclo de vida puede explicarse por dos razones principales: (1) que haya una elevada cantidad de dinero gastado en dicho sector (una alta demanda de B\&S aumenta proporcionalmente el riesgo en cada cuestión social) y (2) el alto nivel de riesgo de problemas sociales correspondiente a dicho sector (es decir, cuando muchos asuntos sociales presentan un riesgo muy alto en el sector determinado).

Tabla 96 Sectores económicos que contribuyen con más de 1 \% al riesgo social ponderado del ciclo de vida de la planta HYSOL BIO

\begin{tabular}{lcccc|c}
\hline Sectores económicos de la SHDB & E\&M & C & O\&M & D\&D & Total (\%) \\
\hline Servicios financieros nec/ES (\%) & 0,13 & 1,3 & 12 & 0,01 & 13 \\
\hline Servicios empresariales nec/ES (\%) & 0,32 & 0,44 & 10 & 0,01 & 11 \\
\hline Construcción/ES (\%) & 1,0 & 3,8 & 5,7 & 0,32 & 11 \\
\hline Comercio/DZ (\%) & 0,25 & 0,98 & 4,2 & 0,00 & 5,5 \\
\hline Comercio/ES (\%) & 0,83 & 0,37 & 2,9 & 0,02 & 4,1 \\
\hline Electricidad/ES (\%) & 0,03 & 0,67 & 2,9 & 0,00 & 4,0 \\
\hline Productos metálicos/ES (\%) & 2,0 & 0,26 & 1,2 & 0,01 & 3,4 \\
\hline Maquinaria y equipos nec/ES (\%) & 0,57 & 0,07 & 2,5 & 0,00 & 3,2 \\
\hline Productos minerales/ES (\%) & 0,64 & 0,36 & 0,98 & 0,01 & 2 \\
\hline Comercio/AO (\%) & 0,37 & 0,29 & 1,2 & 0,00 & 1,9 \\
\hline Metales nec/MZ (\%) & 0,57 & 0,08 & 0,72 & 0,00 & 1,4 \\
\hline Comercio/MZ (\%) & 0,47 & 0,06 & 0,60 & 0,00 & 1,1 \\
\hline Maquinaria y equipos nec/CN (\%) & 0,27 & 0,13 & 0,72 & 0,01 & 1,1 \\
\hline Electricidad/MZ (\%) & 0,45 & 0,06 & 0,57 & 0,00 & 1,1 \\
\hline Otros sectores (\%) & 7,3 & 4,9 & 25 & 0,1 & 37 \\
\hline
\end{tabular}

*ES=España, $\mathrm{DZ}=$ Argelia, $\mathrm{AO}=$ Angola, $\mathrm{MZ}=$ Mozambique, $\mathrm{CN}=$ China

Como se observa en esta tabla, España y Argelia presentan sectores económicos con alto riesgo social relativo, mientras que Angola, Mozambique y China presentan sectores con un 1-2 
$\%$ de riesgo social relativo. En el caso de Argelia, el riesgo está asociado con el consumo de gas natural en el mix eléctrico español (que en su mayoría procede de este país), puesto que la producción de todo el biometano necesario para abastecer la planta HYSOL durante la fase O\&M supone una demanda de 494 M\$ 2002 del sector de la electricidad español. Debido a la importación de gas natural argelino para la producción de electricidad española, el sector argelino del comercio presenta un porcentaje relativamente alto de los riesgos sociales en el ciclo de vida de la planta (5,5\% de riesgo).

Angola y Mozambique no pertenecen a la cadena de suministro directa de la planta y por lo tanto no habría razón aparente para presentar un alto porcentaje de riesgos. Aunque la demanda de B\&S de Angola es relativamente baja (47.500 \$2002 en el sector Comercio/AO durante todo el ciclo de vida), los riesgos sociales son muy altos en varias cuestiones relacionadas con la infraestructura de la comunidad, corrupción, lesiones, trabajo infantil, derechos laborales, conflictos de alta intensidad y múltiples enfermedades. Según la SHDB, la conexión del comercio de Angola con la fase de O\&M de la planta HYSOL se deriva del consumo de electricidad en el proceso de fabricación del biometano (principalmente durante la depuración del biogás), ya que España importa productos del sector "Petróleo y productos del carbón" de Angola.

Mozambique presenta altos riesgos en los sectores de los Metales, Comercio, y Electricidad. Estos riesgos se derivan de la demanda de $296.000 \$ 2002$ del sector de metales mozambiqueño. La conexión de dicho sector con la planta HYSOL se asocia con la importación de metales mozambiqueños por parte de los sectores españoles del metal, de los productos electrónicos y de la maquinaria y equipos (tanto por los componentes de la planta HYSOL como por los de las plantas de biometano). Sin embargo, el principal metal exportado de Mozambique a España es el aluminio (Ministry of foreign affairs 2015), que en la planta TERMOSOLAR CCP no se utiliza en cantidades significativas. Por lo tanto, los riesgos presentados por la SHDB en este país pueden estar sobrestimados debido a la agregación de todos los metales en un solo sector.

En el caso de China, el ciclo de vida de la planta HYSOL presenta una demanda final de 3,77 $M €$ de su sector de los equipos y maquinaria. Este sector chino se ve demandado de forma indirecta por múltiples sectores españoles, por lo que es difícil determinar una sola actividad que esté generando este impacto.

Los sectores económicos españoles con mayor contribución a los riesgos sociales son: Servicios financieros nec/ES, Servicios empresariales nec/ES y Construcción/ES. El riesgo social derivado del sector Servicios financieros nec/ES (13\%) se debe principalmente a la elevada 
demanda de B\&S en este sector, cuya demanda directa asciende a 283 M\$ 2002. Además, este sector presenta "riesgos muy elevados" en los siguientes problemas sociales: corrupción en los últimos 3 años, lesiones fatales y no fatales, riesgo de que los trabajadores migrantes sean tratados injustamente y riesgo de VIH (Virus de Inmunodeficiencia Humana). Dicho sector también tiene "alto riesgo" en las cuestiones sociales siguientes: muerte o pérdida relacionada con enfermedad debido a la ocupación (cáncer de pulmón, leucemia, asma), riesgo de neoplasias malignas y alta población inmigrante.

La demanda directa de B\&S para el sector Construcción/ES asciende a 152 M\$ y está relacionada principalmente con la construcción y la demolición de la planta (fases C y D\&D). Este sector presenta riesgos sociales altos y muy altos en los mismos temas que el sector financiero, pero incluyendo el desempleo como "muy alto riesgo", y la desigualdad de género en la fuerza laboral y el trabajo forzoso como "alto riesgo".

Aunque la fase de O\&M acapara mayores riesgos sociales debido a la elevada demanda de B\&S por parte del biometano, se ha decidido investigar con mayor detalle los riesgos sociales de la fase E\&F para determinar posibles hotspots en la fabricación de los componentes de la planta. La Figura 75 muestra la caracterización del análisis de hotspots sociales aplicada a la fase E\&F de la planta HYSOL (tanto BIO como GN) por subcategoría y sistema de componentes. En la figura se observa que el campo solar es el sistema con mayores riesgos sociales, seguido por el sistema de almacenamiento.

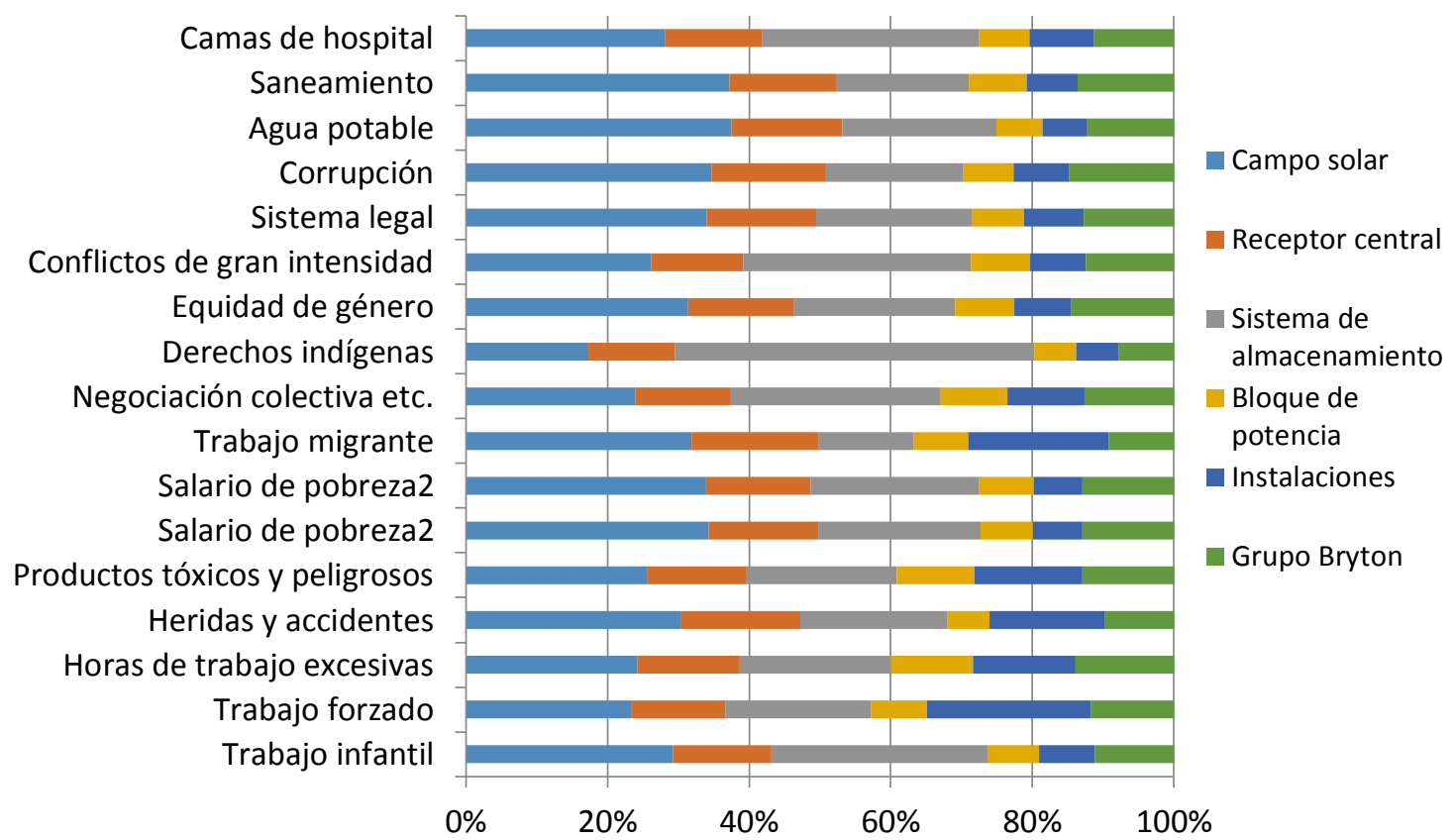

Figura 75 Resultados de caracterización del análisis de hotspots de la fase E\&F de la planta HYSOL, por sistemas de componentes 
El sistema que presenta menores riesgos es el bloque de potencia. El mayor riesgo del campo solar viene dado principalmente por una mayor demanda de bienes que en otros sistemas (82 M\$2002). Dicho sistema presenta mayor riesgo social en el sector de los metales en España, por la misma razón. El sistema de almacenamiento presenta menor demanda que el subsistema con menor riesgo (52 M\$2002 respecto a $95 \mathrm{M} \$ 2002$ del bloque de potencia), sin embargo, presenta mayor riesgo social debido principalmente a la demanda de sales de Chile, y al sector de los metales español.

Los sectores económicos causantes de más del $2 \%$ del riesgo social ponderado de la fase E\&F se presentan en la Tabla 97. Esta tabla muestra las contribuciones de cada subsistema de la planta HYSOL al riesgo social ponderado en los sectores económicos más afectados. El subsistema que presenta mayor riesgo ponderado es el campo solar ( $30 \%$ de los riesgos sociales de la fase de E\&F), seguido por el almacenamiento térmico (23\%), el receptor central (16\%), las instalaciones (14\%), el grupo Brayton (11\%) y el bloque de potencia $(7,3 \%)$.

Tabla 97 Sectores económicos que contribuyen a más de un 2\% del riesgo social ponderado en los sistemas de la fase E\&F de la planta HYSOL.

\begin{tabular}{lcccccc|c}
\hline $\begin{array}{l}\text { Sectores económicos de la } \\
\text { SHDB }\end{array}$ & $\begin{array}{c}\text { Campo } \\
\text { solar }\end{array}$ & $\begin{array}{c}\text { Receptor } \\
\text { central }\end{array}$ & $\begin{array}{c}\text { Almace- } \\
\text { namiento } \\
\text { térmico }\end{array}$ & $\begin{array}{c}\text { Bloque } \\
\text { de } \\
\text { potencia }\end{array}$ & $\begin{array}{c}\text { Instalacio- } \\
\text { nes }\end{array}$ & $\begin{array}{c}\text { Grupo } \\
\text { Brayto } \\
\text { n }\end{array}$ & $\begin{array}{c}\text { TOTAL } \\
\text { (\%) }\end{array}$ \\
\hline Productos metálicos/ES (\%) & 7,8 & 2,6 & 2,0 & 0,12 & 0,23 & 0,15 & 13 \\
\hline Construcción/ES (\%) & 0,20 & 0,14 & 0,07 & 0,05 & 6,08 & 0,06 & 6,6 \\
\hline Comercio/ES (\%) & 1,6 & 1,1 & 0,64 & 0,54 & 0,89 & 0,65 & 5,5 \\
\hline Productos minerales/ES (\%) & 1,4 & 2,4 & 0,11 & 0,01 & 0,28 & 0,02 & 4,2 \\
\hline $\begin{array}{l}\text { Maquinaria y equipos } \\
\text { nec/ES (\%) }\end{array}$ & 0,13 & 0,07 & 0,82 & 1,2 & 0,15 & 1,4 & 3,8 \\
\hline Metales nec/MZ (\%) & 1,7 & 0,57 & 0,56 & 0,25 & 0,19 & 0,52 & 3,8 \\
\hline $\begin{array}{l}\text { Servicios empresariales } \\
\text { nec/CL (\%) }\end{array}$ & 0,01 & 0,01 & 3,3 & 0,00 & 0,00 & 0,01 & 3,3 \\
\hline Comercio/MZ (\%) & 1,4 & 0,47 & 0,47 & 0,21 & 0,16 & 0,43 & 3,1 \\
\hline Electricidad/MZ (\%) & 1,3 & 0,45 & 0,45 & 0,20 & 0,15 & 0,41 & 3,0 \\
\hline Comercio/AO (\%) & 0,25 & 0,21 & 1,8 & 0,05 & 0,08 & 0,08 & 2,4 \\
\hline Servicios financieros/MZ (\%) & 1,0 & 0,35 & 0,35 & 0,16 & 0,12 & 0,32 & 2,3 \\
\hline $\begin{array}{l}\text { Servicios empresariales } \\
\text { nec/ES (\%) }\end{array}$ & 0,66 & 0,43 & 0,23 & 0,16 & 0,43 & 0,20 & 2,1 \\
\hline Otros sectores (\%) & 12 & 6,8 & 12 & 4,4 & 5,0 & 6,9 & 47 \\
\hline
\end{tabular}

*ES=España, $\mathrm{CL}=$ Chile, $\mathrm{AO}=$ Angola, $\mathrm{MZ}=$ Mozambique

Como se observa en la Tabla 97, hay cuatro países que presentan sectores económicos con un alto porcentaje de riesgo social ponderado: España, Chile, Angola y Mozambique. España y Chile están directamente relacionados con la fabricación de componentes; sin embargo, Angola y Mozambique no pertenecen a la cadena de suministro directa de la planta. 
Según la SHDB, la conexión del comercio de Angola con la fase de E\&F de la planta HYSOL reside principalmente en la demanda baja de Chile de sales térmicas en el sector de los minerales chilenos (utilizadas en el sistema de almacenamiento de energía térmica), ya que Chile importa petróleo y productos del carbón de Angola.

En el caso de Mozambique, como se ha argumentado anteriormente, los riesgos presentados por la SHDB en este país pueden estar sobrestimados debido a la agregación de metales en el sector de los metales.

El sector económico de Metal productos/ES también presenta un alto porcentaje de riesgos sociales debido a que la mayoría de los componentes de la planta contienen metales (la demanda de este sector asciende a 31,4 M\$ 2002). Según la SHDB, este sector tiene los mismos riesgos sociales altos y muy altos que el sector financiero español, pero incluyendo el desempleo como "muy alto riesgo", y la desigualdad de género en la fuerza de trabajo como "alto riesgo".

El sector chileno de servicios empresariales está demandado principalmente por la importación de sales térmicas chilenas. Según la SHDB, este sector tiene muy alto riesgo de trabajo infantil y de $\mathrm{VIH}$, y alto riesgo de las siguientes cuestiones sociales: carencia de acceso rural a una fuente mejorada de agua potable, muy pocas camas de hospital, lesiones fatales, enfermedades debido a la ocupación laboral (mesotelioma, asma, silicosis), falta de negociación colectiva y derechos de huelga, no ratificar convenios de la OIT (Organización Internacional del Trabajo), el desempleo, eventos de conflicto, riesgo de neoplasias malignas y obesidad.

El siguiente sector con mayor riesgo social es el comercio en España, cuyos B\&S son demandados indirectamente por 32,1 M\$ 2002 dentro del ciclo de vida de la planta. Tiene el mismo alto y muy alto riesgo del sector de productos de Metal, pero incluyendo desempleo y trabajo laboral como riesgos muy altos.

Según estos resultados, los proveedores que deberían ser investigados de forma más específica en España son los que proporcionan equipos, maquinaria y productos metálicos. Los temas sociales con mayor riesgo común para dichos sectores están relacionados con los inmigrantes, el desempleo, la corrupción, las lesiones y la desigualdad de género. Estos problemas sociales se deben investigar también en los servicios relacionados con los sectores del comercio y la construcción. Con respecto a los hotspots sociales que tienen lugar en otros países, debería investigarse con mayor profundidad a los proveedores de sales fundidas (en Chile) y comprobar de dónde y en qué condiciones se están importando los metales de los componentes de la planta. 


\subsubsection{Planta HYSOL GN}

La Figura 76 muestra los resultados caracterizados del análisis de hotspots social aplicado a la planta HYSOL GN por subcategoría y fase de ciclo de vida. La fase de O\&M reúne los mayores riesgos, especialmente en los derechos indígenas (96\%), trabajo forzado ( $94 \%$ del impacto de ciclo de vida de esta subcategoría), la pobreza salarial (94 y 92\%), la equidad de género (94\%) y acceso a agua potable (94\%). E\&F fase es la siguiente fase con mayores riesgos, especialmente en productos tóxicos y peligrosos (20\%), trabajo migrante (13\%), excesivo tiempo de trabajo $(9,2 \%)$, saneamiento (8\%) y trabajo infantil (8\%). El alto riesgo social relativo obtenido en la fase de $O \& M$ se deriva de la importación de gas natural, ya que esta actividad presenta entre el 87 y el 98\% de riesgo social para cada categoría dentro de esta fase, excepto para sustancias tóxicas y mano de obra migrante ( 57 y $63 \%$ respectivamente).

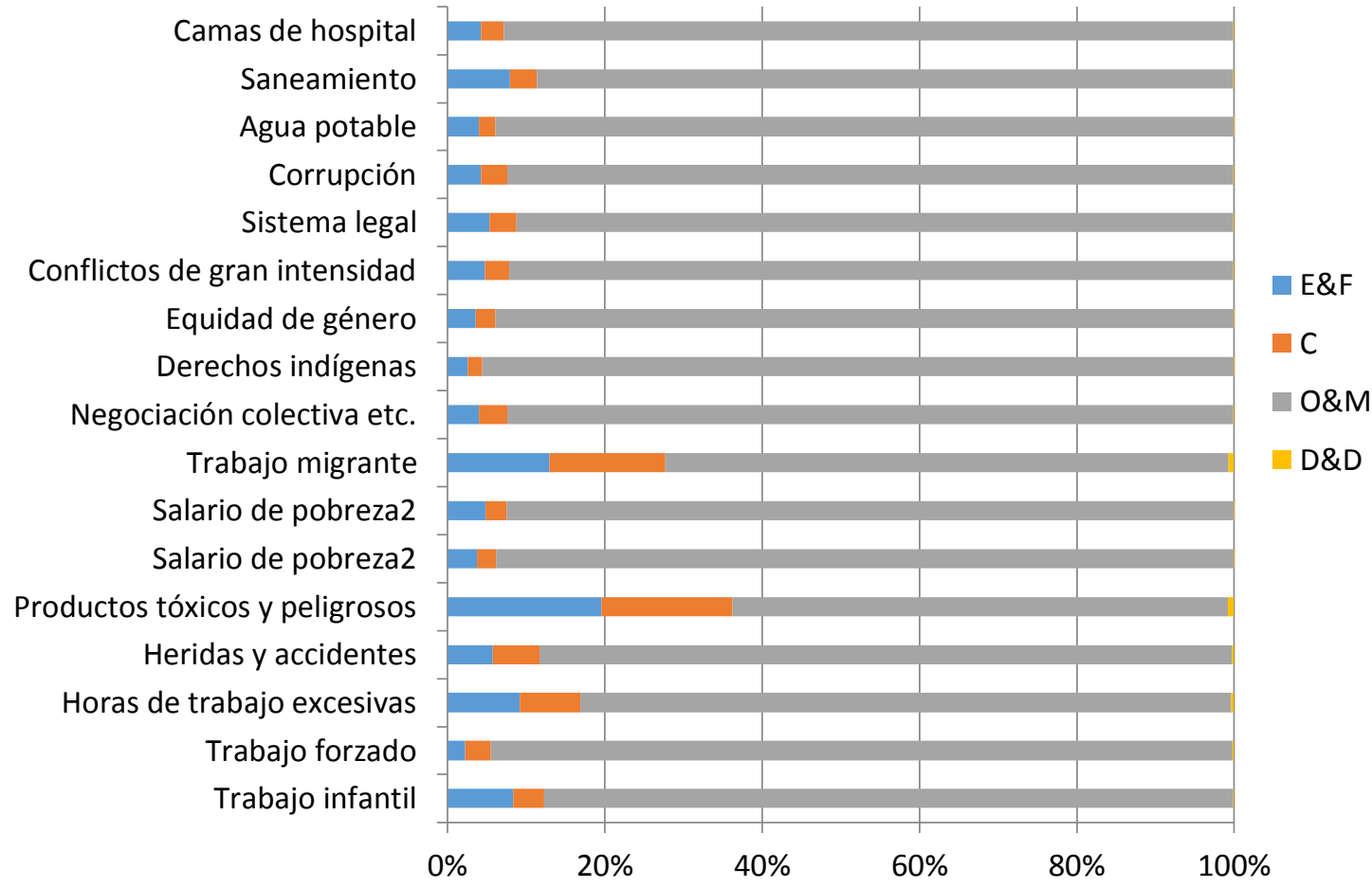

Figura 76 Resultados de caracterización por fases del análisis de hotspots de la planta HYSOL GN

La Figura 77 muestra los riesgos sociales por fases de ciclo de vida tras de la asignación de pesos a cada subcategoría y categoría social. Estos resultados sugieren que Salud y seguridad es la categoría social con mayor riesgo ponderado para todas las fases del ciclo de vida de la planta HYSOL, seguida por la categoría de Trabajo digno y derechos laborales. El proceso que presenta mayor riesgo en dichas categorías es principalmente el gas natural (una contribución del 75 \% y $86 \%$ a cada categoría respectivamente), seguido por los intereses pagados por el préstamo financiero ( $8,3 \%$ y $3,1 \%$ respectivamente). El riesgo social por unidad funcional asociado con el 
gas natural en este escenario es aproximadamente el doble o más que el asociado con el biometano del escenario HYSOL BIO.

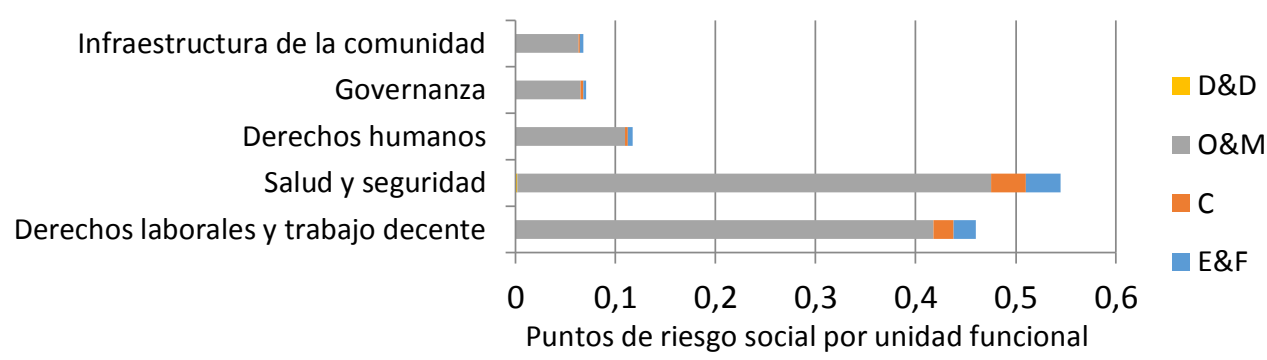

Figura 77 Resultados ponderados del análisis de hotspots sociales de la planta HYSOL GN por categoría y fase de ciclo de vida

La Tabla 98 muestra los sectores económicos que contribuyen a más de un $1 \%$ del riesgo social ponderado del ciclo de vida de la planta HYSOL GN. La tabla incluye también la contribución al riesgo total ponderado por cada sector económico influyente en el ciclo de vida social.

Tabla 98 Sectores económicos que contribuyen con más de 1\% al riesgo social ponderado del ciclo de vida de la planta HYSOL GN

\begin{tabular}{lcccc|c}
\hline Sectores económicos de la SHDB & E\&M & C & O\&M & D\&D & Total (\%) \\
\hline Comercio/DZ (\%) & 0 & 0 & 36 & 0 & 36 \\
\hline Gas/PE (\%) & 0 & 0 & 9,4 & 0 & 9,4 \\
\hline Comunicación/DZ (\%) & 0 & 0 & 4,3 & 0 & 4,3 \\
\hline Vegetales, frutas, frutos secos/DZ (\%) & 0 & 0 & 4,2 & 0 & 4,2 \\
\hline Servicios financieros nec/ES (\%) & 0,05 & 0,45 & 3,6 & 0,001 & 4,1 \\
\hline Transporte nec/DZ (\%) & 0 & 0 & 3,8 & 0 & 3,8 \\
\hline Gas/DZ (\%) & 0 & 0 & 3,0 & 0 & 3,0 \\
\hline Gas/EG (\%) & 0 & 0 & 2,3 & 0 & 2,3 \\
\hline Productos animales nec/DZ (\%) & 0 & 0 & 2,0 & 0 & 2,0 \\
\hline Construcción/ES (\%) & 0,36 & 1,4 & 0,17 & 0,11 & 2,0 \\
\hline Ganado bovino, ovino, caprino y & 0 & 0 & 1,0 & 0 & 1,0 \\
\hline equino/DZ (\%) & 1,5 & 1,4 & 25 & 0,1 & 27 \\
\hline Otros sectores (\%) & & & & &
\end{tabular}

*DZ= Argelia, ES=España, PE= Perú , EG= Egipto

Como se observa en esta tabla, hay cuatro países que presentan sectores económicos con alto riesgo social relativo: Argelia, España, Perú y Egipto. Excepto para España, el riesgo de estos países está asociado con el consumo de gas natural, puesto que $37 \%$ del gas natural se importa de Argelia, 5,6 \% de Perú y 1,5\% de Egipto. Debido a este alto porcentaje de suministro de gas natural de Argelia, el sector argelino del comercio presenta el porcentaje más alto de los riesgos sociales en el ciclo de vida de la planta ( $36 \%$ de riesgo). Otros cuatro sectores argelinos presentan también elevada proporción de riesgo social, debido a la importación del gas natural 
y al elevado riesgo social que tiene este país en distintas cuestiones (especialmente las relacionadas con la salud y seguridad, y los derechos laborales).

Los sectores económicos españoles con mayor contribución a los riesgos sociales son: Servicios financieros nec/ES (en la fase de O\&M) y Construcción/ES (en las fases C y D\&D). El riesgo social derivado del sector Servicios financieros nec/ES $(4,1 \%)$ se debe principalmente a la elevada cantidad de dinero gastado en este sector, cuya demanda directa asciende a $283 \mathrm{M \$}$ 2002. Además, según la SHDB, este sector presenta "riesgos muy elevados" en los siguientes problemas sociales: corrupción en los últimos 3 años, lesiones fatales y no fatales, riesgo de que los trabajadores migrantes sean tratados injustamente y riesgo de $\mathrm{VIH}$ (Virus de Inmunodeficiencia Humana). Dicho sector también tiene "alto riesgo" en las cuestiones sociales siguientes: muerte o pérdida relacionada con enfermedad debido a la ocupación (cáncer de pulmón, leucemia, asma), riesgo de neoplasias malignas y alta población inmigrante.

La demanda directa de B\&S para el sector Construcción/ES asciende a 152 M\$ y está relacionada principalmente con la construcción y la demolición de la planta (fases C y D\&D). Este sector presenta riesgos sociales altos y muy altos en los mismos temas que el sector financiero, pero incluyendo el desempleo como "muy alto riesgo", y la desigualdad de género en la fuerza laboral y el trabajo forzoso como "alto riesgo".

Según estos resultados, cuando la planta HYSOL opera con gas natural, los proveedores que deberían ser investigados de forma más específica en España, mientras que en otros países debería investigarse con mayor profundidad a los proveedores gas natural (principalmente en Argelia) y de sales fundidas (en Chile).

\subsubsection{Planta TERMOSOLAR CCP}

La Figura 78 muestra los resultados caracterizados del análisis de hotspots social aplicado a la planta TERMOSOLAR CCP por subcategoría y fase de ciclo de vida. Al igual que la planta HYSOL, la fase de O\&M reúne los mayores riesgos, especialmente en trabajo forzado ( $90 \%$ del impacto de ciclo de vida de esta subcategoría), derechos indígenas (90\%), pobreza salarial (89 y $86 \%$ ), equidad de género ( $89 \%$ ), agua (87\%) y corrupción ( $87 \%)$. E\&F fase es la siguiente fase con mayores riesgos, especialmente en productos tóxicos y peligrosos (25\%), saneamiento (20 $\%)$, trabajo infantil (19\%) y excesivo tiempo de trabajo (18\%). El alto riesgo social relativo obtenido en la fase de O\&M se deriva de la importación de gas natural, ya que esta actividad presenta entre el 70 y el $97 \%$ de riesgo social para cada categoría dentro de esta fase, excepto para sustancias tóxicas y mano de obra migrante ( 28 y $33 \%$ respectivamente). 


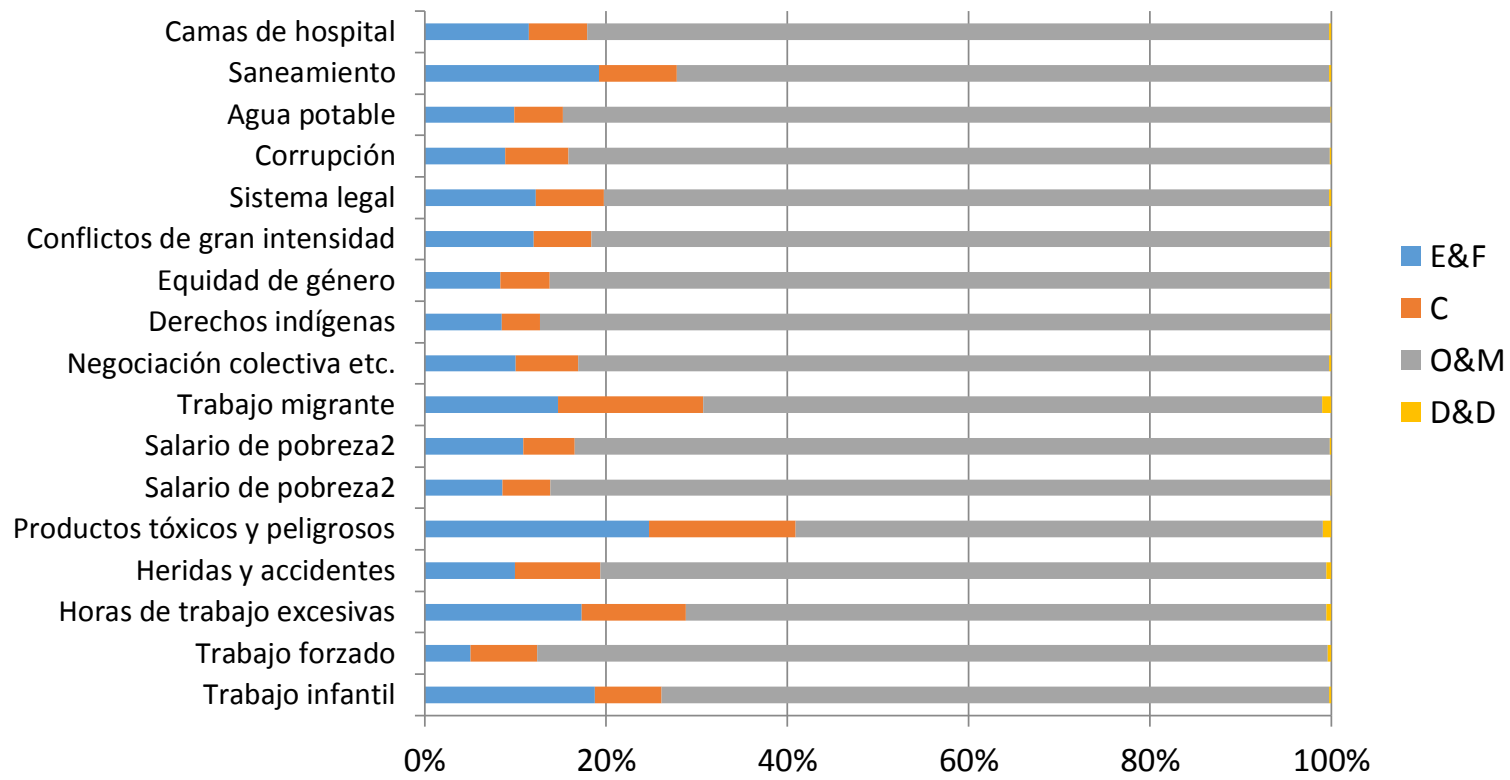

Figura 78 Resultados de caracterización por fases del análisis de hotspots de la planta TERMOSOLAR CCP

La Figura 79 muestra los resultados ponderados por categoría y fase de ciclo de vida. Al igual que en la planta HYSOL, Salud y seguridad es la categoría social con mayor riesgo ponderado para todas las fases del ciclo de vida de la planta termosolar, seguido por la categoría de Trabajo digno y derechos laborales. El proceso que presenta mayor riesgo en dichas categorías es principalmente el gas natural (una contribución del $52 \%$ y $71 \%$ a cada categoría respectivamente), y en menor medida a los intereses pagados por el préstamo financiero ( $8 \% \mathrm{y}$ $18 \%$ respectivamente).

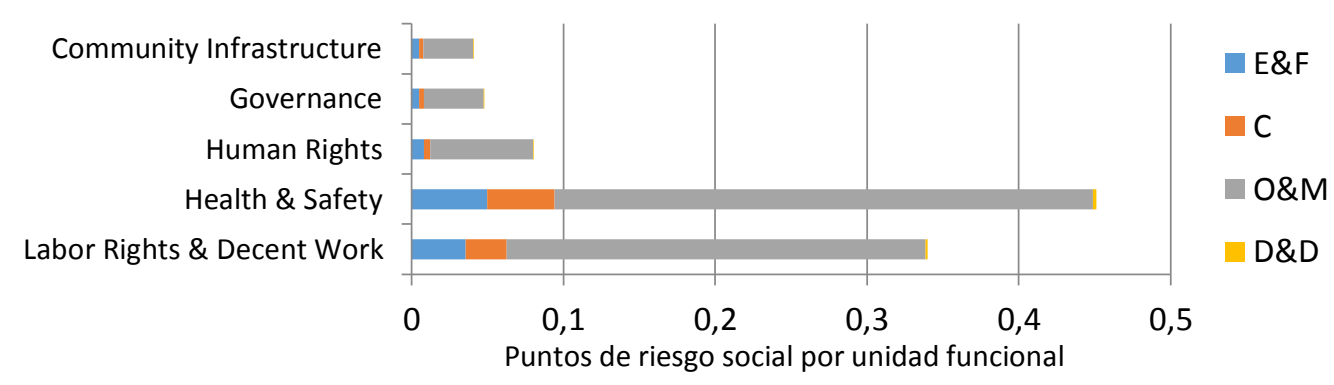

Figura 79 Resultados ponderados del análisis de hotspots sociales de la planta TERMOSOLAR CCP por categoría y fase de ciclo de vida

La Tabla 99 muestra los sectores económicos que contribuyen a más de un $1 \%$ del riesgo social ponderado del ciclo de vida de la planta TERMOSOLAR CCP. La tabla también incluye la contribución al riesgo total ponderado por cada sector económico influyente en el ciclo de vida social de la planta. 
Tabla 99 Sectores económicos que contribuyen con más de 1 \% al riesgo social ponderado del ciclo de vida de la planta TERMOSOLAR CCP

\begin{tabular}{|c|c|c|c|c|c|}
\hline Sectores económicos de la SHDB & $\begin{array}{l}\text { E\&M } \\
\text { (\%) }\end{array}$ & C (\%) & $\begin{array}{c}\text { O\&M } \\
\text { (\%) }\end{array}$ & $\begin{array}{l}\text { D\&D } \\
\text { (\%) }\end{array}$ & $\begin{array}{l}\text { Total } \\
\text { (\%) }\end{array}$ \\
\hline Comercio/DZ & 0,13 & 0,71 & 28 & 0,00 & 29 \\
\hline Servicios financieros nec/ES & 0,08 & 0,12 & 8,0 & 0,00 & 8,2 \\
\hline Gas/PE & 0,00 & 0,00 & 6,4 & 0,00 & 6,4 \\
\hline Construcción/ES & 0,24 & 2,6 & 0,51 & 0,24 & 3,6 \\
\hline Comunicación/DZ & 0,01 & 0,08 & 3,3 & 0,00 & 3,4 \\
\hline Verduras, frutas y frutos/DZ & 0,01 & 0,08 & 3,2 & 0,00 & 3,3 \\
\hline Transporte nec/DZ & 0,01 & 0,07 & 2,9 & 0,00 & 3,0 \\
\hline Gas/DZ & 0,01 & 0,05 & 2,3 & 0,00 & 2,3 \\
\hline Servicios empresariales nec/ES & 0,21 & 0,24 & 1,4 & 0,01 & 1,9 \\
\hline Gas/EG & 0,00 & 0,00 & 1,7 & 0,00 & 1,7 \\
\hline Productos animales nec/DZ & 0,01 & 0,040 & 1,6 & 0,00 & 1,6 \\
\hline Electricidad/ES & 0,02 & 0,50 & 0,91 & 0,00 & 1,4 \\
\hline Productos metálicos/ES & 1,1 & 0,20 & 0,11 & 0,01 & 1,4 \\
\hline Comercio/ES & 0,57 & 0,23 & 0,47 & 0,01 & 1,3 \\
\hline Otros sectores & 7,9 & 3,5 & 19 & 0,13 & 30 \\
\hline
\end{tabular}

*DZ= Argelia, ES=España, PE= Perú , EG= Egipto

Como se observa en esta tabla, hay cuatro países que presentan sectores económicos con alto riesgo social relativo: Argelia, España, Perú y Egipto. Excepto para España, el riesgo de estos países está asociado con el consumo de gas natural, por las mismas razones que en la planta HYSOL. Los sectores económicos españoles con mayor contribución a los riesgos sociales son: Servicios financieros nec/ES (en la fase de O\&M), Construcción/ES (en las fases C y D\&D) y Servicios empresariales nec/ES.

La elevada proporción de riesgo social en Servicios financieros nec/ES (11\%) se debe principalmente a la elevada cantidad de B\&S demandados en este sector, que asciende a 128 M\$ 2002. La demanda de B\&S para el sector Construcción/ES asciende a 58 M\$̦ y está relacionado principalmente con la construcción y la demolición de la planta (fases C y D\&D).

El sector de Servicios empresariales nec/ES (noveno sector con mayor riesgo en el ciclo de vida de la planta) está asociado con la demanda de 50 M\$ 2002. Dicho sector presenta los mismos riesgos altos y muy altos que el sector financiero, pero incluyendo el desempleo como un riesgo muy alto.

La Figura 80 muestra la caracterización del análisis de hotspots sociales aplicado a la fase E\&F de la planta TERMOSOLAR CCP por subcategoría y sistema de componentes. En la figura se observa que el campo solar es el sistema con mayores riesgos sociales, seguido del sistema de 
almacenamiento. El sistema que presenta menores riesgos es el bloque de potencia. El mayor riesgo del campo solar viene dado por una mayor demanda de bienes que en otros sistemas (46 M\$2002) y por el sector de los metales en España. El sistema de almacenamiento presenta menor demanda que el bloque de potencia (20 M\$2002 respecto a 29 M\$2002), sin embargo, presenta mayor riesgo social debido principalmente a la demanda de sales de Chile, y al sector de los metales español.

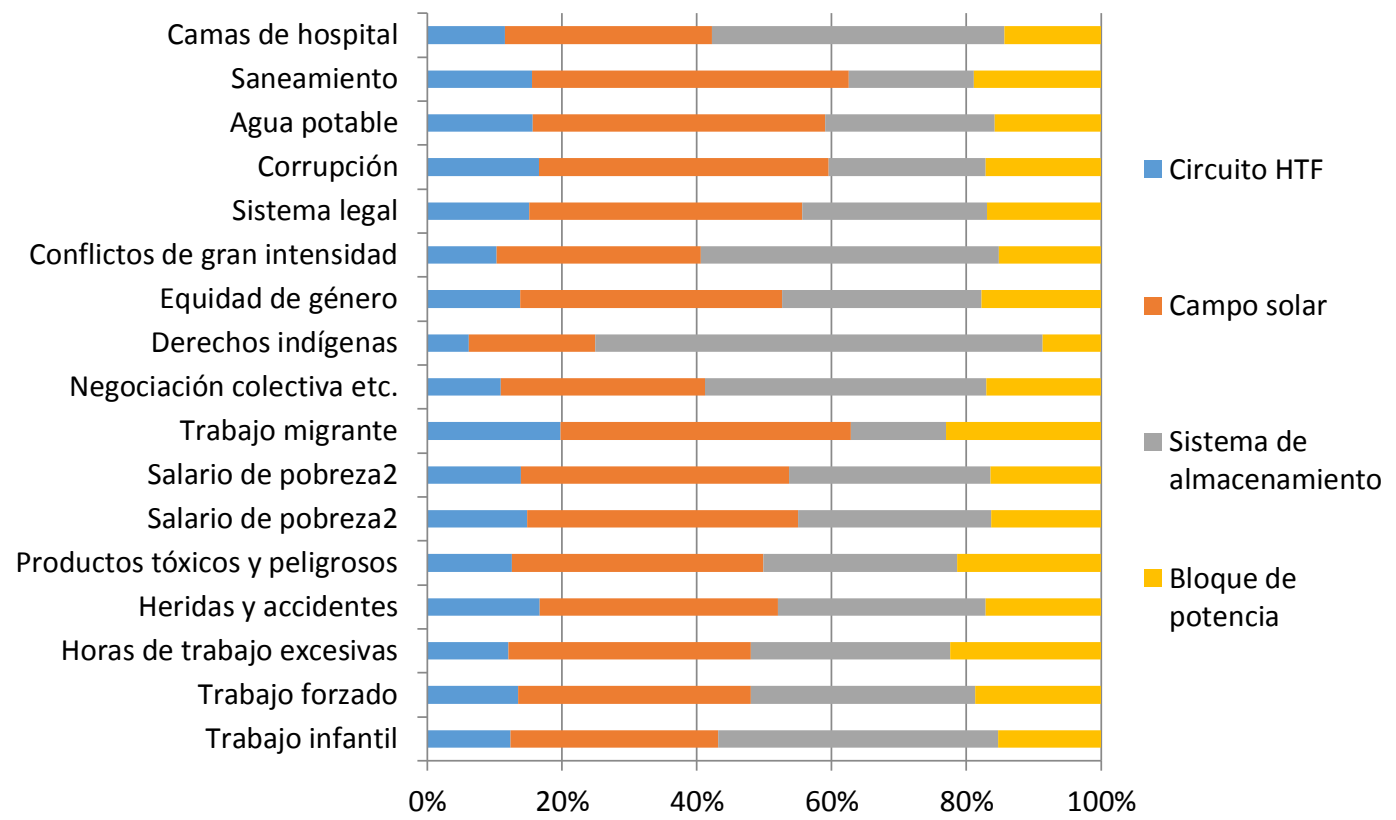

Figura 80 Resultados de caracterización del análisis de hotspots de la fase E\&F de la planta TERMOSOLAR CCP, por sistemas de componentes

Los sectores económicos causantes de más del $2 \%$ del riesgo social ponderado de la fase E\&F se presentan en la Tabla 100. Esta tabla muestra las contribuciones de cada subsistema de la planta TERMOSOLAR CCP al riesgo social ponderado en los sectores económicos más afectados. El subsistema que presenta mayor riesgo ponderado es el campo solar (34 \% de los riesgos sociales de la fase de E\&F), seguido del almacenamiento térmico (31\%), el bloque de potencia (17\%), el sistema HTF (14\%) y los servicios empresariales $(3,4 \%)$. 
Tabla 100 Sectores económicos que contribuyen a más de un $2 \%$ del riesgo social ponderado en los sistemas de la fase E\&F de la planta TERMOSOLAR CCP

\begin{tabular}{lccccc|c}
\hline Sectores económicos de la SHDB & $\begin{array}{c}\text { Sistema } \\
\text { HTF }\end{array}$ & $\begin{array}{c}\text { Campo } \\
\text { solar }\end{array}$ & $\begin{array}{c}\text { Almace- } \\
\text { namiento } \\
\text { térmico }\end{array}$ & $\begin{array}{c}\text { Bloque } \\
\text { de } \\
\text { potencia }\end{array}$ & $\begin{array}{c}\text { Instalacio- } \\
\text { nes }\end{array}$ & $\begin{array}{c}\text { TOTAL } \\
\text { (\%) }\end{array}$ \\
\hline Productos metálicos/ES (\%) & 8,1 & 20 & 16 & 11 & 1,2 & 56 \\
\hline Servicios empresariales nec/CL (\%) & 1,9 & 7,5 & 0,07 & 0,25 & 0,07 & 9,8 \\
\hline Comercio/ES (\%) & 0,00 & 0,02 & 6,6 & 0,00 & 0,00 & 6,6 \\
\hline Comercio/AO (\%) & 1,4 & 1,6 & 0,6 & 1,6 & 0,1 & 5,3 \\
\hline Maquinaria y equipos nec/ES (\%) & 0,20 & 0,31 & 3,5 & 0,17 & 0,02 & 4,2 \\
\hline Minerales nec/CL (\%) & 0,94 & 0,35 & 0,50 & 2,0 & 0,16 & 4,0 \\
\hline Metales nec/MZ (\%) & 0,00 & 0,01 & 3,5 & 0,00 & 0,00 & 3,5 \\
\hline Comercio/MZ (\%) & 0,57 & 1,7 & 0,15 & 0,56 & 0,04 & 3,1 \\
\hline Electricidad/MZ (\%) & 0,47 & 1,5 & 0,13 & 0,46 & 0,04 & 2,6 \\
\hline Construcción/ES (\%) & 0,45 & 1,4 & 0,13 & 0,44 & 0,03 & 2,5 \\
\hline Otros sectores (\%) & 0,13 & 0,19 & 0,06 & 0,15 & 1,7 & 2,2 \\
\hline
\end{tabular}

*ES=España, $\mathrm{CL}=$ Chile, $\mathrm{AO}=$ Angola, $\mathrm{MZ}=$ Mozambique

Como se observa en la Tabla 100, hay cuatro países que presentan sectores económicos con un alto porcentaje de riesgo social ponderado: España, Chile, Angola y Mozambique. Es probable que los riesgos obtenidos en los sectores de Mozambique estén sobreestimados por las mismas razones que las aportadas para la planta HYSOL (no existe una demanda real de dichos sectores por la planta).

El sector económico de Metal productos/ES también presenta un alto porcentaje de los riesgos sociales debido a que la mayoría de los componentes de la planta contienen metales (la demanda de este sector asciende a 31,4 M\$ 2002). El sector chileno de servicios empresariales es demandado principalmente por la importación de sales fundidas chilenas (utilizado en el sistema de almacenamiento de energía térmica). El siguiente sector con más alto riesgo social es el comercio en España, cuyos B\&S son demandados indirectamente por 21,2 M\$ 2002.

\subsubsection{Análisis específico}

Los resultados del análisis específico representan el comportamiento social de la empresa promotora en las fases de Construcción, O\&M y Desmantelamiento de la central. El Anexo III contiene el proceso de caracterización seguido para cada uno de los 28 indicadores y de las 26 subcategorías del ciclo de vida analizadas para las plantas HYSOL y TERMOSOLAR CCP (se asume que todas están construidas, operadas y desmanteladas por la misma empresa). Se han analizado de forma conjunta las fases de construcción y desmantelamiento, ya que ambas las realiza la misma empresa y corresponden al mismo sector económico (construcción). Los 
escenarios HYSOL GN y HYSOL BIO no se han analizado por separado ya que la naturaleza del combustible no ha influido en la información recopilada por el análisis específico (no se han investigado los proveedores ni la producción de biometano).

La Figura 81 describe los resultados de la caracterización para cada subcategoría y categoría de impacto de la planta HYSOL y la planta TERMOSOLAR CCP. Las figuras muestran el comportamiento en las fases O\&M, C y D (similares en todas las categorías salvo en "Derechos laborales y trabajo justo"). Las gráficas representadas en dicha figura contienen información sobre la puntuación de cada subcategoría (en la escala del -2 al 2) en cada categoría de impacto social. Además, se han acompañado con un código de colores de tipo semáforo en el que el rojo representa los resultados más desfavorables y el verde los más favorables.

La categoría de impacto "Patrimonio cultural y natural" no se ha representado debido a que todos sus indicadores presentan un valor similar $(=0)$.

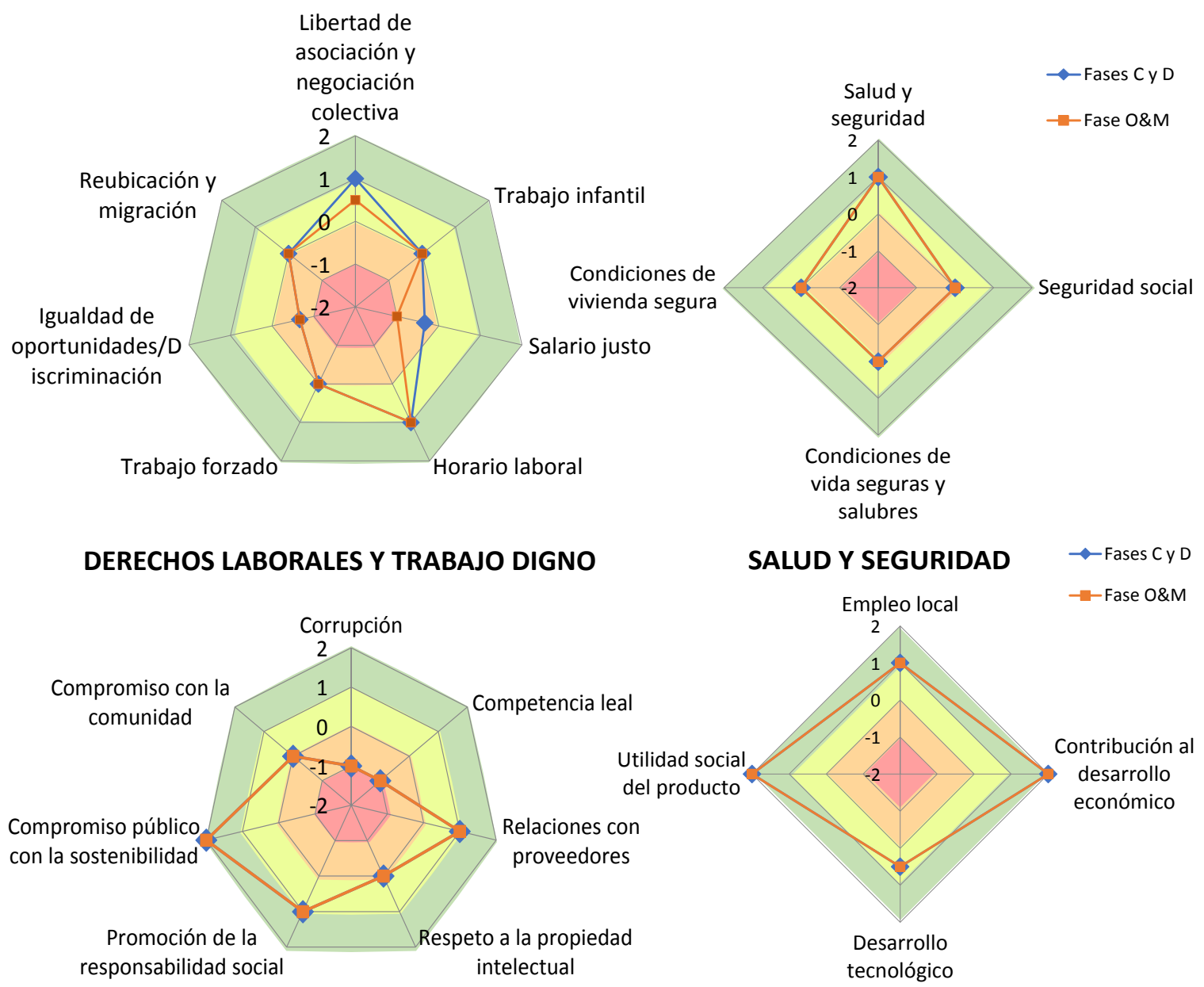

SOSTENIBILIDAD SOCIO-ECONÓMICA

RELACIONES JUSTAS

Figura 81 Caracterización de subcategorías para las categorías de impacto social analizadas 
La mayoría de los indicadores y subcategorías han sido caracterizados con un comportamiento social positivo comparado con la media española. En la fase de construcción, 3 subcategorías fueron calificadas como mucho mejor, 6 como mejor, 1 entre mejor y mucho mejor, 13 como similar, 2 como peor y otras dos entre peor y similar (debido a que la media de indicadores presentaba un peor comportamiento).

Las subcategorías que han presentado un comportamiento peor que similar son "Salario justo", "Discriminación", “Competencia leal” y "Corrupción”, cuyos indicadores se describen a continuación.

- La subcategoría "Salario justo" tiene 3 indicadores en su estudio: "Desigualdad salarial", "Salario medio en el sector" y "Trabajador peor pagado". El único indicador que se comporta peor dentro de esta subcategoría es la "Desigualdad salarial", ya que el salario de los directivos ejecutivos es 771 \% mayor que el salario medio de la empresa (según lo dispuesto en el Informe Anual Corporativo en 2013 de la empresa promotora), mientras que la media en el sector español de la construcción para los salarios de directivos ejecutivos es $134 \%$ mayor que el salario medio (INE 2014).

- La subcategoría "Discriminación" contiene tres indicadores: "Tasa de empleados con necesidades especiales", "Tasa de empleo de mujeres en la empresa" y "Ratio de directivos ejecutivos hombres respecto de mujeres". El primer indicador se comporta mejor que la media española, con un 2,3\% de empleados con necesidades especiales (Informe RSC) comparado con la media española de 1,69 \% en los sectores de la industria y la construcción (INE 2015). Sin embargo, el segundo indicador tiene un comportamiento peor, con una tasa de mujeres de 7,92 \% (Informe corporativo anual) comparado con la media española de 6,34 \% para 2013 en los sectores de la construcción y la provisión de energía (INE 2015). El tercer indicador se comporta mucho peor, con un ratio de 22 veces más hombres que mujeres (Informe Corporativo Anual) comparado con el ratio medio español de 2,75 (considerando cualquier sector)(INE 2015).

- La subcategoría "Competencia leal" tiene únicamente un indicador semi-cuantitativo: "Acciones legales durante el periodo del informe (como compañía miembro de alianzas que se comportan de forma desleal)". La investigación en internet ha revelado dos acciones legales completadas y rechazadas por el Comité Nacional de los Mercados y de la Competencia en torno a actividades de la empresa promotora, y una acción legal ejecutada contra el grupo de empresas donde la empresa promotora es miembro. Ya que sólo una de las tres demandas por competencia desleal fue aprobada y ejecutada por el Comité Nacional, el indicador ha sido calificado como peor (y no como mucho peor). 
- La subcategoría "Corrupción" es semi-cuantitativa y consiste en un solo indicador: "Ha habido acciones legales relacionadas con la corrupción durante el periodo del informe". La investigación en internet ha revelado demandas oficiales contra la empresa principal y sus filiales, entre el año 2010 y el 2014. La empresa ha sido acusada de fraude contable y malversación de fondos públicos (el Triangle 2014, Montaño 2014). En el momento del estudio, ninguna de las demandas han sido resueltas. Aunque desafortunadamente esta situación de demandas por corrupción es usual en España (los casos de corrupción están presentes en los medios de comunicación continuamente), este indicador se ha calificado como peor ya que la corrupción es un delito según la ley.

También cabe destacar que el informe RSC de la empresa no aporta información sobre los indicadores GRI (Global Reporting Initiative) relacionados con "Ratio de salario básico y remuneración de mujeres a hombres por empleado y categoría", "Vuelta al trabajo y tasas de retención tras bajas por paternidad por género", o "Rango de salario inicial estándar por género comparado con salario mínimo local en lugares de operación significativos", mientras que sí están reportados la mayoría de indicadores no relacionados con cuestiones de género. Esta ausencia de indicadores de género, junto con los resultados obtenidos en la subcategoría de discriminación, podría interpretarse como un intento empresarial por ocultar indicadores negativos.

Las subcategorías mejor calificadas (como mucho mejor) han sido las siguientes:

- "Compromisos públicos con cuestiones de sostenibilidad": El indicador correspondiente es "Existencia de informes públicos de sostenibilidad", que ha sido calificado positivamente debido al informe de RSC y al certificado GRI conseguido anualmente por el grupo de empresas desde el año 2004.

- “Contribución al desarrollo económico": Esta subcategoría se ha cuantificado mediante el efecto multiplicador. Este efecto fue calculado mediante el análisis Input Output llevado a cabo previamente. El efecto multiplicador representa el incremento de la renta nacional a consecuencia de demandar los B\&S necesarios para llevar a cabo el proyecto de la central. Ya que el efecto multiplicador del proyecto ha resultado ser mayor a 2 en todos los casos, el indicador se ha calificado como mucho mejor.

- "Utilidad social del producto": Esta subcategoría no está libre de juicios subjetivos, ya que es difícil determinar hasta qué punto un bien es bueno para la sociedad. Sin embargo, parece lógico afirmar que aquellos productos con utilidades sociales más altas son aquellos que satisfacen las necesidades básicas, como nutrición, educación básica, salud, 
saneamiento, suministro de agua y vivienda, e infraestructuras relacionadas (Streeten and Burki 1978). Es por ello que el indicador semi-cuantitativo escogido para esta subcategoría ha sido "El producto es necesario para satisfacer necesidades básicas". Goldemberg et al (1985) afirmó lo siguiente: "Las mejoras importantes en bienestar humano requieren incrementos considerables del nivel de uso de la energía", "El aumento del uso de la energía es valioso en tanto que mejora la calidad de vida mediante la provisión de servicios energéticos como cocinar, iluminar, calentar el agua, calentar o enfriar el ambiente, transporte personal o de mercancías, calor para procesos industriales, energía motriz, etc.", "una manera más efectiva de lidiar con la pobreza es asignar recursos directamente a la satisfacción de las necesidades básicas de los más pobres, asegurando de esta manera los estándares de alimentación, refugio, vestimenta, salud y educación". También hay otras referencias en la sociedad internacional que enlazan la energía con la satisfacción de necesidades básicas, como en "El programa de reconstrucción y desarrollo de Sudáfrica" (African National Context 1994). Por lo tanto, aunque la electricidad en sí no es una necesidad básica, actualmente es una herramienta necesaria para proveer de recursos y estándares básicos destinados a satisfacer necesidades básicas. Por estos argumentos, este indicador se ha calificado como mucho mejor, ya que se ha considerado que la provisión de electricidad juega un papel esencial en el desarrollo humano actual.

La mayoría de las subcategorías relacionadas con el actor comunidad local han sido calificadas como similares, ya que la central está ubicada lejos de la población y se ha constatado -mediante la visita a la central y la búsqueda en periódicos locales- que las cuestiones sociales correspondientes no han sido afectadas significativamente.

La fase de O\&M ha sido calificada de forma similar a la fase de construcción, aunque hay algunas diferencias respecto a las subcategorías "Libertad de asociación y negociación colectiva", y "Salario justo". Esto se debe a que los sectores económicos correspondientes (construcción o provisión de electricidad) presentan distintos valores medios españoles en algunos indicadores. En la primera subcategoría, el porcentaje de afiliados respecto al sector de la provisión de energía es mejor en vez de mucho mejor. En la subcategoría "Salario justo", el salario medio español en el sector de la energía $(52,325 €$, (INE 2014) es mucho más alto que la media salarial en la empresa $(23,283 €$, Informe Anual Corporativo), por lo tanto el indicador correspondiente se ha calificado como mucho peor.

Según estos resultados, el comportamiento social de la empresa debería trabajar en la igualdad de género de sus trabajadores y en la desigualdad salarial (especialmente en la fase de 
O\&M), así como en la competencia leal y en aumentar la transparencia de sus cuentas bancarias e influencias.

\subsection{Paso final de asignación de cargas y agregación de categorías}

La Tabla 101 describe las horas de trabajo, factores de asignación de cargas y resultados agregados para cada categoría de impacto y fase del ciclo de vida de la planta HYSOL, mientras que la Tabla 102 presenta los resultados de la planta TERMOSOLAR CCP. En este caso, las dos plantas analizadas han presentado resultados ligeramente diferentes, ya que no se invierte la misma cantidad de horas de trabajo en ambos casos.

La asignación de cargas mediante la variable de actividad se ha realizado en concordancia con la correspondiente intensidad laboral en cada planta (medida en horas de trabajo) que dan un peso mayor a la fase de O\&M. Ambas plantas presentan resultados muy similares. El resultado agregado total es $0,42 p$-cs, que representa un impacto social ligeramente positivo en España ( 2 p-cs representaría la puntuación más positiva, mientras que -2 p-cs representaría la más negativa). La categoría con mejor comportamiento social es Sostenibilidad socioeconómica, con una puntuación de 1,38 p-cs, seguida de Relaciones justas (0,29 p-cs), mientras que la categoría con peor comportamiento es Patrimonio cultural y natural, que con su puntuación de 0 p-cs representa un comportamiento neutro. Esto último se debe a que todas las subcategorías clasificadas en esta categoría se han calificado como similar, ya que no han sido significantemente afectadas por la central bajo estudio.

Tabla 101 Resultados de asignación de cargas y comportamiento social del ciclo de vida de la planta HYSOL

\begin{tabular}{|l|c|c|c|c|}
\cline { 2 - 5 } \multicolumn{1}{c|}{} & C & O\&M & D & TOTAL \\
\hline Horas trabajadas por fase & 1257886 & 4327184 & 21651 & 5606721 \\
\hline Factores para asignación de cargas & 0,22 & 0,77 & 0,004 & 1 \\
\hline Derechos laborales y trabajo digno & 0,05 & 0,12 & 0,0002 & $\mathbf{0 , 1 7 0}$ \\
Salud y seguridad & 0,06 & 0,19 & 0,001 & $\mathbf{0 , 2 5 0}$ \\
Patrimonio cultural y natural & 0 & 0 & 0 & $\mathbf{0}$ \\
Relaciones justas & 0,06 & 0,22 & 0,001 & $\mathbf{0 , 2 8 6}$ \\
Sostenibilidad socio-económica & 0,31 & 1,06 & 0,005 & $\mathbf{1 , 3 7 5}$ \\
\hline TOTAL (p-cs) & 0,10 & 0,32 & 0,0015 & $\mathbf{0 , 4 1 6}$ \\
\hline
\end{tabular}


Tabla 102 Resultados de asignación de cargas y comportamiento social del ciclo de vida de la planta TERMOSOLAR CCP

\begin{tabular}{|l|c|c|c|c|}
\cline { 2 - 5 } \multicolumn{1}{c|}{} & C & O\&M & D & TOTAL \\
\hline Horas trabajadas por fase & 394357 & 1440256 & 82261 & 1916874 \\
\hline Factores para variable de actividad & 0,21 & 0,75 & 0,04 & 1 \\
\hline Derechos laborales y trabajo digno & 0,043 & 0,120 & 0,002 & $\mathbf{0 , 1 6 5}$ \\
Salud y seguridad & 0,051 & 0,188 & 0,011 & $\mathbf{0 , 2 5 0}$ \\
Patrimonio cultural y natural & 0 & 0 & 0 & $\mathbf{0}$ \\
Relaciones justas & 0,059 & 0,215 & 0,012 & $\mathbf{0 , 2 8 6}$ \\
Sostenibilidad socio-económica & 0,283 & 1,033 & 0,059 & $\mathbf{1 , 3 7 5}$ \\
\hline TOTAL & 0,087 & 0,311 & 0,017 & $\mathbf{0 , 4 1 5}$ \\
\hline
\end{tabular}

La Tabla 103 y la Tabla 104 muestran los resultados ponderados para la clasificación y caracterización de ambas tecnologías según las categorías de actores. Ambos resultados de comportamiento social son ligeramente peores que los obtenidos mediante la caracterización por categorías de impacto $(0,39$ y 0,36 p-cs). La diferencia de resultados se debe a la distinta agrupación de subcategorías, ya que no todas las categorías constan del mismo número de subcategorías, y por lo tanto, aquellas que comparten categoría con un número menor de subcategorías adquieren mayor importancia relativa en el resultado final. Los resultados presentan una mejora del comportamiento social para todos los grupos de actores. En el caso del grupo de Comunidad local, el resultado es menos positivo debido a que sólo una de las 9 subcategorías presenta mejor comportamiento mientras que el resto no están significativamente afectadas por el sistema.

Tabla 103 Asignación de cargas y comportamiento social de la planta HYSOL según las categorías de actores

\begin{tabular}{|l|l|l|l|l|}
\cline { 2 - 5 } \multicolumn{1}{c|}{} & C & O\&M & D & TOTAL \\
\hline Horas de trabajo por fase $(h)$ & 1257886 & 4327184 & 21651 & 5606721 \\
\hline Factores de ponderación & 0,22 & 0,77 & 0,004 & 1 \\
\hline Trabajadores $(p-c s)$ & 0,06 & 0,09 & 0,0011 & 0,29 \\
Comunidad local (p-cs) & 0,02 & 0,09 & 0,0004 & 0,11 \\
Sociedad (p-cs) & 0,21 & 0,71 & 0,0035 & 0,92 \\
Actores de la cadena de valor $(p-c s)$ & 0,06 & 0,19 & 0,0010 & 0,25 \\
\hline TOTAL $(p-c s)$ & $\mathbf{0 , 0 9}$ & $\mathbf{0 , 2 7}$ & $\mathbf{0 , 0 0 2}$ & $\mathbf{0 , 3 9}$ \\
\hline
\end{tabular}


CAPÍTULO 5: Análisis del área social

Tabla 104 Asignación de cargas y comportamiento social de la planta TERMOSOLAR CCP según las categorías de actores

\begin{tabular}{|l|l|l|l|l|}
\cline { 2 - 5 } \multicolumn{1}{c|}{} & C & O\&M & D & TOTAL \\
\hline Horas de trabajo por fases $(\mathrm{h})$ & 394357 & 1440256 & 82261 & 1916874 \\
\hline Factores de ponderación & 0,21 & 0,75 & 0,04 & 1 \\
\hline Trabajadores ( $p$-cs) & 0,06 & 0,09 & 0,01 & $\mathbf{0 , 1 6}$ \\
Comunidad local (p-cs) & 0,02 & 0,08 & 0,00 & $\mathbf{0 , 1 1}$ \\
Sociedad ( $p$-cs) & 0,19 & 0,69 & 0,04 & $\mathbf{0 , 9 2}$ \\
Actores de la cadena de valor $(p$-cs) & 0,05 & 0,19 & 0,01 & $\mathbf{0 , 2 5}$ \\
\hline TOTAL ( $p$-cs) & 0,08 & 0,26 & 0,02 & $\mathbf{0 , 3 6}$ \\
\hline
\end{tabular}




\subsection{DISCUSIÓN Y CONCLUSIONES}

\subsubsection{Análisis genérico de riesgos sociales}

Según los resultados del análisis genérico de riesgos sociales, los principales hotspots del ciclo de vida de la tecnología HYSOL y termosolar están asociados con la provisión de combustible, y en menor medida, con el préstamo financiero y las actividades de construcción. Por lo tanto, la fase con mayor riesgo social es O\&M.

En el caso de la planta HYSOL GN, más del $85 \%$ del riesgo social ponderado en la fase O\&M se atribuye al consumo de gas natural, mientras que en la planta HYSOL BIO el porcentaje asociado con el biometano es inferior al 55 \%. La producción de biometano para abastecer a la planta HYSOL BIO supone una mayor demanda de B\&S que la demanda de gas natural para las otras plantas, lo que podría aumentar el riesgo social absoluto. Sin embargo, dicha demanda está relacionada con sectores españoles con menor riesgo social que los demandados por el gas natural (que se importa principalmente de Argelia y Perú). Por esta razón, el resultado final de riesgo social ponderado por unidad funcional es casi tres veces mayor en la planta HYSOL GN (1,26 pt/MWh) que en la planta HYSOL BIO (0,45 pt/MWh).

La planta TERMOSOLAR CCP también presenta un gran riesgo social debido al consumo de gas natural (que produce un $15 \%$ de la electricidad), obteniendo un resultado final de riesgo social ponderado por unidad funcional igual a 0,95 pt/MWh (el doble que para HYSOL BIO). La planta TERMOSOLAR CCP y HYSOL GN tienen un perfil de riesgos sociales muy similar (mismos sectores, países y elementos de riesgo), con la principal diferencia de que en la primera hay menor riesgo relativo del gas natural al consumir una cantidad menor. En ambas plantas, el país con mayor porcentaje de riesgo social es Argelia debido a que presenta alto riesgo social en múltiples indicadores y es el principal exportador de gas natural en España. La siguiente actividad con el porcentaje más alto de riesgo social es el pago de intereses, debido principalmente a la gran cantidad de dinero involucrada en la demanda del sector Servicios financieros/ES. En la planta HYSOL BIO, el mayor riesgo social tiene lugar en España. En todas las plantas analizadas la categoría con mayores riesgos sociales es Salud y seguridad, seguida de Derechos laborales y trabajo decente.

La Figura 82 muestra la comparación del riesgo social ponderado por fases entre las plantas analizadas. Como se observa en la figura, la fase de O\&M en HYSOL tiene un riesgo social por unidad funcional mayor que en la TERMOSOLAR CCP, sin embargo, la fase de C y E\&F presentan 
un riesgo menor. Esto es debido a que el mayor consumo de gas natural en HYSOL GN induce a mayores riesgos sociales, pero la mayor producción de electricidad conlleva que el impacto por unidad funcional en el resto de las fases sea menor.

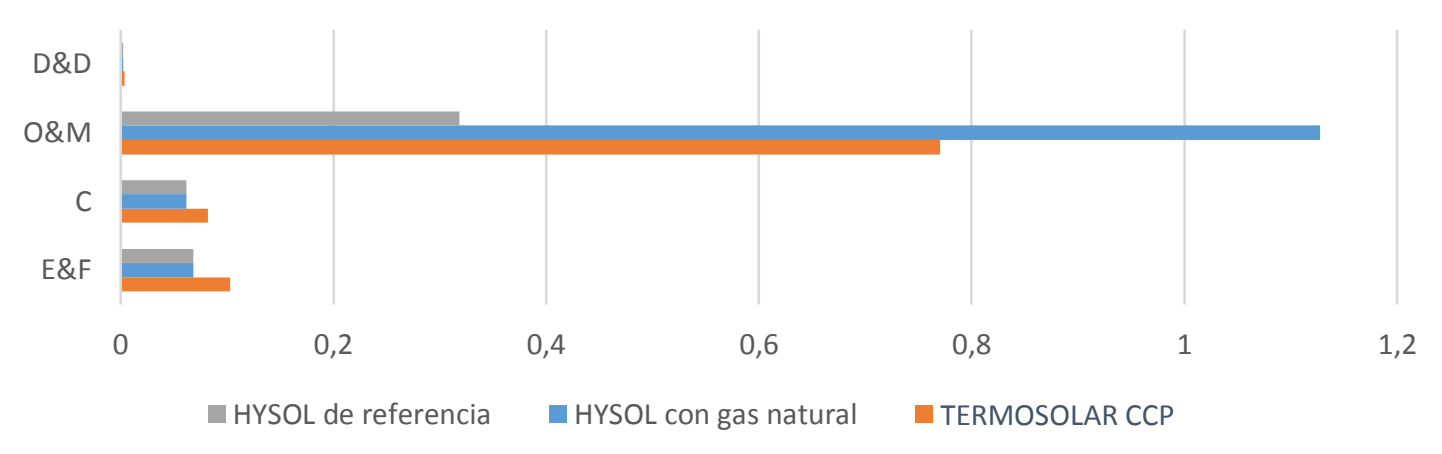

Figura 82 Comparación del riesgo social ponderado de la planta HYSOL y la TERMOSOLAR CCP por fases del ciclo de vida

Cuando se analiza la fase de fabricación de componentes en las tres plantas estudiadas, España es el país que presenta mayor porcentaje de riesgo social ponderado, seguido por Chile (derivado de la importación de sales térmicas). La agregación de productos en sectores económicos durante la fase de inventario ha resultado en un alto porcentaje de riesgo ponderado de Mozambique y Angola. Sin embargo, cuando se tiene en cuenta los productos y materiales específicos involucrados en el sistema existe una probabilidad baja de que estos países contribuyan a la cadena de valor de la planta. Este hecho es indicativo de que los resultados del análisis de hotspots deben analizarse detenidamente para detectar si el producto en cuestión está siendo realmente demandado por los países exportadores, ya que la agregación de productos en sectores económicos añade incertidumbres que pueden dar lugar a errores de interpretación.

Según el análisis genérico, los principales riesgos sociales en España asociados a las fases de $C, O \& M$ y $D \& D$ de las tres plantas se relacionan con la desigualdad de género, la corrupción, las lesiones y los inmigrantes. El riesgo de la desigualdad de género y la corrupción ha sido posteriormente confirmado por la evaluación específica, mientras que no se han detectado problemas sociales relacionados con lesiones e inmigrantes.

\subsubsection{Análisis específico}

Los resultados específicos indican que la provisión de electricidad en España de cualquiera de las tres plantas analizadas implica un ligero aumento del bienestar social en dicho país. Este aumento es especialmente indicativo en el actor Sociedad y en la categoría de impacto 
"Repercusiones socio-económicas". La categoría de impacto "Patrimonio natural y cultural" permanece inalterada por el sistema bajo estudio, mientras que la categoría de "Derechos laborales y trabajo digno" es la que presenta menores beneficios sociales. Los resultados por subcategorías indican un comportamiento social negativo en "Salario justo", "Discriminación", “Competencia leal" y "Corrupción". Esta situación podría mejorarse aumentando la igualdad de género (o la transparencia en cuanto a indicadores de género) y disminuyendo la diferencia salarial de los trabajadores. Además, la empresa promotora debería esforzarse en cumplir las leyes de competencia leal, y aumentar la transparencia en la contabilidad y gestión de fondos públicos. Los resultados indican que estas cuestiones sociales negativas se ven compensadas por el mejor comportamiento social detectado en otras subcategorías.

Este análisis utiliza de referencia la media española, por lo tanto, los resultados obtenidos sólo son representativos para el contexto y leyes españolas, por lo que si se compara con estándares internacionales los resultados podrían arrojar conclusiones diferentes. Por ejemplo, en el estudio de Ciroth y Franze (2011), se identifica como un efecto positivo el hecho de que no haya trabajo infantil o trabajos forzosos, mientras que en este estudio se ha considerado como un impacto neutro ya que la media española en el sector (y la tendencia en España en general) es que no haya trabajo infantil o forzado.

En cuanto a la metodología aplicada, se ha detectado que la manera en la que se clasifican las subcategorías en categorías (bien categorías de impacto o categorías de actores) afecta al resultado final, aunque en el caso de estudio esta diferencia no es significativa. Mientras que la clasificación por categorías de actores es útil para conocer el comportamiento social del sistema hacia los distintos actores relevantes del ciclo de vida, la clasificación por categorías de impacto nos permite conocer el comportamiento social en áreas de protección social. Cabe destacar también que esta metodología dificulta la diferenciación entre los impactos sociales producidos por la empresa promotora y los inherentes a las particularidades de la tecnología estudiada. Por lo tanto, los resultados están estrechamente ligados a la empresa que lo produce, y a diferencia del análisis ambiental, la mayor parte de los impactos vienen dados más por el comportamiento empresarial y menos por la naturaleza del producto o sistema en cuestión.

Los resultados obtenidos han sido fruto del estudio de documentos a disposición del público, por lo que no se ha interrogado a los actores del sistema ni ha habido comunicación directa con la empresa sobre las cuestiones sociales de interés. El haber realizado entrevistas con los trabajadores o los proveedores habría proporcionado mayor profundidad, veracidad y precisión al estudio. Por ejemplo, ya que uno de los riesgos potenciales detectados era la 
excesiva jornada laboral, debería haberse investigado entre los trabajadores si estaban realizando demasiadas horas extra (algo que no está reflejado en los informes). Sin embargo, se decidió no involucrar a la empresa principal en el estudio ya que se mostró muy celosa de su información durante la recopilación de inventario para el análisis ambiental/económico y se temía que obstaculizara el uso de los resultados en el caso de que estos fueran negativos. Por lo general, pocas empresas están dispuestas a airear sus deficiencias en comportamiento social, por lo que en muchas ocasiones los datos no se suministran o se suministran como información confidencial. Esto dificulta la participación de la empresa en el proceso de análisis, cuestión que por el contrario se considera como necesaria según la guía. Debido a la importancia de involucrar a la empresa en el proceso del ACV-S, este análisis queda más como un caso de estudio para la aplicación y desarrollo de una metodología incipiente, que como unos resultados concluyentes a disposición pública.

Por último, incidir en que los resultados obtenidos simplifican en exceso cuestiones sociales que contienen numerosos matices imposibles de representar mediante números, pero que ayudan a conocer el comportamiento social del sistema analizado y su comparación con otros sistemas. Por lo tanto, estos resultados pueden ayudar a la comparación entre productos o la toma de decisiones, pero no deberían tomarse como único indicador. 


\section{CAPÍTULO 6 \\ Integración e interpretación de resultados del Análisis de Sostenibilidad del Ciclo de Vida}

Este capítulo reúne los resultados del ASCV que responden a la pregunta principal: ¿En qué medida puede la nueva tecnología HYSOL mejorar la sostenibilidad (ambiental, social y económica) de la producción eléctrica en el mercado eléctrico español?

El capítulo se divide en dos secciones. La primera sección incluye las respuestas a las preguntas de sostenibilidad planteadas en el capítulo 2 (definición y alcance del ASCV), según los resultados obtenidos tras la aplicación de las herramientas escogidas para cada área (medioambiente, economía y sociedad). En la segunda sección se ofrece una guía para la toma de decisiones respecto a la opción más sostenible de las alternativas planteadas.

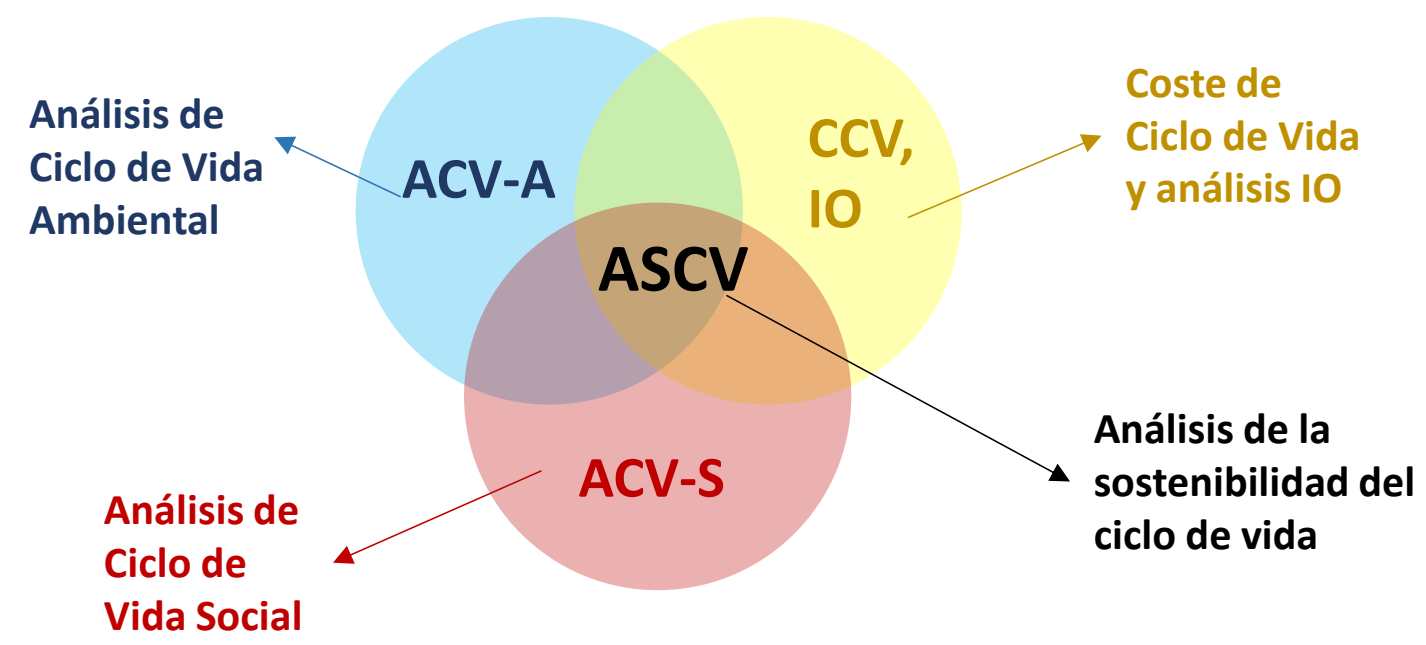

Figura 83 Herramientas de análisis utilizadas para las tres áreas de la sostenibilidad 


\subsection{RESPUESTAS DE SOSTENIBILIDAD}

La pregunta principal planteada en el ASCV de la tecnología HYSOL se responde mediante el conjunto de sub-respuestas obtenidas para cada área de la sostenibilidad, descritas en la sección 0 del Capítulo 2. Dichas respuestas se describen a continuación en dos formatos: respuesta corta y respuesta desarrollada. La primera está encaminada a facilitar los resultados de forma concisa y directa. La segunda pretende aportar información adicional para comprender e interpretar los principales detalles y matices de los resultados. En cualquier caso, la total comprensión de los resultados de sostenibilidad precisa de la lectura de los análisis completos descritos en los capítulos correspondientes a cada área.

\subsection{1 Área ambiental}

\section{PREGUNTA: ¿Cuál es el impacto ambiental potencial de la tecnología HYSOL?}

RESPUESTA CORTA: El impacto ambiental potencial de la tecnología HYSOL en sus dos escenarios HYSOL BIO y HYSOL GN, según los cuatro indicadores ambientales escogidos se describe en la Tabla 105.

Tabla 105 Impacto ambiental potencial de la tecnología HYSOL en los cuatro indicadores principales

\begin{tabular}{lcccc} 
& $\begin{array}{c}\text { Cambio Climático } \\
(\mathbf{k g ~ C O} \text { eq/MWh) }\end{array}$ & $\begin{array}{c}\text { Estrés hídrico } \\
\left(\mathbf{m}^{3} / \mathbf{M W h}\right)\end{array}$ & $\begin{array}{c}\text { TRE } \\
\text { (meses) }\end{array}$ & $\begin{array}{c}\text { Impacto ambiental de } \\
\text { punto final (pt/MWh) }\end{array}$ \\
\hline HYSOL BIO & 45,9 & 0,164 & 6,1 & 8,27 \\
\hline HYSOL GN & 294 & 0,151 & 22 & 35,2 \\
\hline
\end{tabular}

RESPUESTA DESARROLLADA: Los impactos caracterizados (de punto medio) de los escenarios HYSOL BIO y HYSOL GN se encuentran descritos en la Tabla 106. Los resultados para la tecnología HYSOL indican que la operación con biometano supone un menor impacto ambiental que la operación con gas natural en la mayoría de los indicadores. Esto es debido principalmente a que presenta menores emisiones de cambio climático $(6,4$ veces menos) y de acidificación (1,3 veces menos).

El ciclo de vida del biometano produce mayor impacto ambiental que el gas natural para las categorías de toxicidad humana, eutrofización de agua dulce y especialmente eco-toxicidad de agua marina. Sin embargo, cuando se consideran los resultados de punto final, el impacto ambiental potencial ponderado es 4,2 veces mayor con gas natural que con biometano. 
CAPÍTULO 6: Integración e interpretación de resultados del ASCV

Tabla 106 Impacto ambiental potencial de la tecnología HYSOL en las categorías de punto medio

\begin{tabular}{llll} 
Categoría de impacto & $\begin{array}{l}\text { Unidad (por } \\
\text { MWh) }\end{array}$ & HYSOL BIO & HYSOL GN \\
\hline Cambio climático & $\mathrm{kg} \mathrm{CO}$ eq & 45,92 & 293,6 \\
\hline Acidificación terrestre & $\mathrm{g} \mathrm{SO}_{2}$ eq & 515 & 693,9 \\
\hline Eutrofización de agua dulce & $\mathrm{g} \mathrm{P} \mathrm{eq}$ & 16,9 & 14,4 \\
\hline Toxicidad humana & $\mathrm{kg} \mathrm{1,4-DB} \mathrm{eq}$ & 27,5 & 21,4 \\
\hline Formación de partículas & $\mathrm{g} \mathrm{PM10} \mathrm{eq}$ & 217 & 219,7 \\
\hline Ecotoxicidad de agua dulce & $\mathrm{g} 1,4-\mathrm{DB}$ eq & 1035 & 1051,8 \\
\hline Ecotoxicidad de agua marina & $\mathrm{g} 1,4-\mathrm{DB}$ eq & 1030 & 711,3 \\
\hline
\end{tabular}

Según los resultados obtenidos, el proceso o actividad que causa mayores impactos de ciclo de vida de la tecnología HYSOL es el consumo de combustible durante la fase de O\&M. En el caso de la planta HYSOL BIO, la combustión y producción del biometano supone entre el $68 \%$ y el $91 \%$ de los impactos ambientales potenciales de ciclo de vida (dependiendo de la categoría), mientras que en el caso de la planta HYSOL GN (operación con gas natural) este porcentaje es aún mayor.

Si se quiere mejorar el perfil ambiental de la tecnología HYSOL es necesario aumentar la fracción solar, disminuyendo el consumo de combustible auxiliar. Además, el reciclaje de los materiales utilizados en el campo solar y el sistema de almacenamiento (especialmente del acero) compensa considerablemente el impacto ambiental generado durante la fase E\&F.

MÁS INFORMACIÓN: Las suposiciones, datos de partida, discusión de resultados, y otros indicadores se encuentran detallados en el análisis ACV-A atribucional de la tecnología HYSOL descrito en la sección 3.2 del Capítulo 3.

\section{PREGUNTA: ¿Es el impacto ambiental del ciclo de vida de la tecnología HYSOL inferior} al de la tecnología termosolar convencional?

RESPUESTA CORTA: El impacto ambiental potencial del ciclo de vida de la tecnología HYSOL en los cuatro indicadores escogidos es menor que el de una planta termosolar cilindro-parabólica que presente similar capacidad de generación eléctrica, firmeza y gestionabilidad.

RESPUESTA DESARROLLADA: Los cuatro indicadores ambientales escogidos presentan mejor resultado en el escenario HYSOL BIO (tecnología HYSOL con biometano) que en el escenario TERMOSOLAR CCP (tecnología cilindro-parabólica con $15 \%$ de gas natural). Por el contrario, el 
escenario HYSOL GN (tecnología HYSOL con gas natural) presenta peores resultados ambientales que el escenario TERMOSOLAR CCP en todos los indicadores excepto en estrés hídrico, debido al tipo de refrigeración (refrigeración húmeda vs refrigeración en seco). Esto se debe a que la plant HYSOL GN depende en mayor medida del consumo de combustible auxiliar para la generación eléctrica que la TERMOSOLAR CCP. Sin embargo, hay que incidir que la planta TERMOSOLAR CCP analizada no presta la misma función de firmeza y gestionabilidad que la planta HYSOL, ya que su capacidad de generación depende en mayor medida de la disponibilidad aleatoria, cíclica y estacional de la radiación solar. Con el objetivo de comparar dos plantas con la misma función, se ha analizado también una planta termosolar cilindro-parabólica de $50 \mathrm{MW}$ con la misma fracción solar que HYSOL y una planta termosolar de torre de $100 \mathrm{MW}$ con la misma producción eléctrica que HYSOL. En ambos casos los escenarios HYSOL BIO y HYSOL GN presentan mejores resultados en todos los indicadores, debido al menor impacto ambiental del combustible en el caso del escenario HYSOL BIO y a la mayor eficiencia de producción de electricidad en el caso de HYSOL GN.

Cabe mencionar que la tecnología HYSOL BIO presenta mejores resultados que la termosolar convencional en todas las categorías de impacto ambiental de punto medio excepto en eutrofización y toxicidad humana, debido al mayor potencial tóxico del ciclo de vida del biometano respecto al gas natural.

MÁS INFORMACIÓN: Las suposiciones, datos de partida, discusión de resultados, y otros indicadores se encuentran detallados en los análisis ACV-A atribucionales de las tecnologías HYSOL y termosolar convencional descritos en las secciones 3.2 y 3.3 del Capítulo 3.

\section{PREGUNTA: ¿Cuánto se reduce el impacto ambiental del sector eléctrico al proveer de electricidad HYSOL al mercado eléctrico español?}

RESPUESTA CORTA: Proveer de electricidad HYSOL al mercado eléctrico español produce una reducción de 414 kg CO y 175 kg CO 2 por megavatio-hora producido por la planta HYSOL en los escenarios HYSOL BIO y HYSOL GN respectivamente, mientras que el impacto ambiental potencial de punto final se reduce $59,8 \mathrm{pt} / \mathrm{MWh}$ y $21,5 \mathrm{pt} / \mathrm{MWh}$ respectivamente.

RESPUESTA DESARROLLADA: Según los resultados obtenidos, todas las categorías analizadas presentan valores negativos, lo que se traduce en un beneficio ambiental neto. Esto es debido a que el mix anual promedio de tecnologías marginales que sustituye la tecnología HYSOL (según datos para el año 2014) produce mayor impacto ambiental que la propia HYSOL. Por lo tanto, al integrar la tecnología HYSOL en el sistema eléctrico español se evitarían impactos ambientales 
derivados de las tecnologías a las que sustituye. La reducción del estrés hídrico no se ha calculado debido a falta de datos de estrés hídrico para las tecnologías marginales.

MÁS INFORMACIÓN: Las suposiciones, datos de partida, discusión de resultados, y otros indicadores se encuentran detallados en el ACV consecuencial de la tecnología HYSOL descrito en la sección 3.2.4 del Capítulo 3.

\subsection{2 Área económica}

\section{PREGUNTA: ¿Cuál es el coste del ciclo de vida de la tecnología HYSOL?}

RESPUESTA CORTA: El coste interno del ciclo de vida de la tecnología HYSOL es $211 € / M W h$ y $154 € /$ MWh para los escenarios HYSOL BIO y HYSOL GN, respectivamente.

RESPUESTA DESARROLLADA: El coste por unidad funcional de ciclo de vida de la tecnología HYSOL BIO asciende a $211 € / M W h$ cuando se consideran costes internos, y a 215-216 $€ / M W h$ cuando se integran las externalidades (dependiendo de si se aplica un escenario realista o ambicioso de cambio climático). Considerando el escenario HYSOL GN, el coste de ciclo de vida asciende a $154 € / M W h$ si se consideran sólo costes internos y a 176-187 €/MWh si se integran las externalidades. El balance de costes y beneficios (internos) para la planta HYSOL BIO es negativo $(-12,6 € / \mathrm{MWh})$, indicando que la producción de electricidad no resulta rentable para el promotor del proyecto. Sin embargo, el mismo valor en el escenario HYSOL GN es positivo $(6,33 € / M W h)$, indicando ganancias adicionales a la rentabilidad esperada por el promotor del proyecto. Estas ganancias consideran como ingresos una estimación de las ayudas a la generación eléctrica que se percibirían según la normativa actual.

MÁS INFORMACIÓN: Las suposiciones, datos de partida, discusión de resultados, y otros indicadores se encuentran detallados en el análisis CCV de la tecnología HYSOL descrito en la sección 4.1.2 del Capítulo 4.

PREGUNTA: ¿Disminuyen los costes de ciclo de vida por unidad funcional de la tecnología HYSOL respecto a los de la termosolar convencional?

RESPUESTA CORTA: El coste interno de ciclo de vida del escenario HYSOL GN es menor que el del escenario TERMOSOLAR CCP (15\% gas natural). Sin embargo, el coste del escenario HYSOL BIO es mayor que el de TERMOSOLAR CCP, debido al alto coste del biometano. 
RESPUESTA DESARROLLADA: El coste por unidad funcional de la tecnología TERMOSOLAR CCP asciende a $192 € / M W h$ cuando sólo se consideran costes internos, y a 205-210 €/MWh cuando se consideran también externalidades. Según estos resultados, el coste interno de ciclo de vida de la tecnología HYSOL BIO no disminuye respecto a la TERMOSOLAR CCP, pero sí se reduce en $38 € / M W h$ cuando se considera el escenario HSYOL GN. Esto es debido a que la tecnología HYSOL es más eficiente en la conversión térmica de energía, pero el coste del biometano en el escenario de referencia es superior al del gas natural, de tal forma que la tecnología HYSOL BIO cuesta 19 $€ / M W h$ más que la TERMOSOLAR CCP.

Cuando se integran las externalidades, los costes totales de ciclo de vida del escenario HYSOL GN disminuyen 23-29 €/MWh respecto a la TERMOSOLAR CCP (los de HYSOL BIO aumentan entre 10 y $6 € / \mathrm{MWh})$.

El balance de costes e ingresos es positivo para los escenarios HYSOL GN y TERMOSOLAR CCP (6,33 €/MWh y 4,91 €/MWh respectivamente) y negativo para el escenario HYSOL BIO $(12,6$ $€ / M W h$ ). Por lo que si se considera una rentabilidad de 7,398 \% (rentabilidad razonable según el ministerio de industria español), sólo las plantas HYSOL GN y TERMOSOLAR CCP serían rentables.

MÁS INFORMACIÓN: Las suposiciones, datos de partida, discusión de resultados, y otros indicadores se encuentran detallados en la aplicación del CCV a las tecnologías HYSOL y TERMOSOLAR CCP en el Capítulo 4, secciones 4.1 .2 y 0 respectivamente.

PREGUNTA: ¿Qué efecto tiene el ciclo de vida de la tecnología HYSOL en la generación de B\&S y valor añadido?

RESPUESTA CORTA: La generación de B\&S total de la tecnología HYSOL en sus escenarios BIO y GN asciende a 529 y $330 € / M W h$, respectivamente, mientras que el valor añadido asciende a $235 € / M W h$ y $142 € / M W h$.

RESPUESTA DESARROLLADA: El valor añadido creado durante el ciclo de vida de los escenarios HYSOL BIO y HYSOL GN supone el 44,4 \% y 43,0 \% de la generación de B\&S respectivamente. El efecto multiplicador total, que mide la capacidad del proyecto de generar B\&S indirectos asciende a 2,42 y 2,48 para los escenarios HYSOL BIO y HYSOL GN respectivamente. La creación de empleo por el ciclo de vida de la tecnología HYSOL es 5,1 h/MWh y 2,8 h/MWh para los escenarios HYSOL BIO y HYSOL GN respectivamente, y la intensidad laboral es 5,67 y 4,98 personas·año/M€ respectivamente. La diferencia entre ambos escenarios viene determinada 
por el efecto del combustible, ya que el biometano presenta mayor valor añadido y empleo generado que el gas natural, especialmente para la economía española.

MÁS INFORMACIÓN: Las suposiciones, datos de partida, discusión de resultados, y otros indicadores se encuentran detallados en la aplicación del análisis IO a la tecnología HYSOL en el Capítulo 4, sección 4.2.

\section{PREGUNTA: ¿Aumenta la generación de B\&S y el valor añadido cuando se introduce la} tecnología HYSOL en el mercado eléctrico español?

RESPUESTA CORTA: Los resultados indican que la generación de B\&S y valor añadido aumentan tanto en la economía española como mundial cuando se considera el escenario HYSOL BIO. Sin embargo, el escenario HYSOL GN presenta disminución de B\&S en la economía mundial y española, pero aumento del valor añadido en la economía española.

RESPUESTA DESARROLLADA: Los efectos netos de introducir la tecnología HYSOL BIO en el mercado eléctrico español presentan beneficios en todos los indicadores (generación de B\&S, valor añadido y creación de empleo). Estos beneficios ascienden a $155 € / M W h$ de B\&S, 86 $\mathrm{M€/MWh}$ de valor añadido y $3,5 \mathrm{~h} / \mathrm{MWh}$ de empleo cuando se considera la economía mundial, y $145 € / M W h$ de $B \& S, 88,2 \mathrm{M} €$ de valor añadido y 3,3 h/MWh de empleo cuando se considera sólo la economía española. Sin embargo, la tecnología HYSOL en el escenario HYSOL GN presenta efectos económicos negativos cuando se considera la economía mundial (-44,8 €/MWh de B\&S, $-7,05 \mathrm{M} €$ de valor añadido y 1,2 h/MWh), pero supone una creación neta de valor añadido cuando sólo se considera la economía española (-24,8 €/MWh de B\&S, 6,27 M€ de valor añadido y $1,2 \mathrm{~h} / \mathrm{MWh}$ de empleo).

MÁS INFORMACIÓN: Las suposiciones, datos de partida, discusión de resultados, y otros indicadores se encuentran detallados en el análisis IO de la tecnología HYSOL, en la sección 4.2 del Capítulo 4. 


\subsection{3 Área social}

PREGUNTA: ¿Aumenta el empleo generado en España por la introducción de la tecnología HYSOL en el mercado eléctrico español?

RESPUESTA CORTA: El empleo neto generado en España por la introducción de la tecnología HYSOL aumenta en 17.465 personas-año durante todo el ciclo de vida para el escenario HYSOL BIO, y 6.081 personas·año para el escenario HYSOL GN.

RESPUESTA DESARROLLADA: El empleo bruto generado por la planta HYSOL BIO es 5,1 horas/MWh o 25.161 personas-año, mientras que el empleo bruto generado por la planta HYSOL GN es 2,8 horas/MWh o 13.776 personas·año.

Los resultados netos de empleo generado indican una creación neta de empleo en los dos escenarios de la planta HYSOL, ya que la generación bruta de empleo de la tecnología HYSOL es mucho mayor que el mix de tecnologías marginales. El empleo neto generado por la planta HYSOL BIO es 3,3 horas/MWh o 17.465 personas·año, mientras que el empleo neto generado por la planta HYSOL GN es 1,2 horas/MWh o 6.081 personas-año. La diferencia entre los dos escenarios es debida a la generación de empleo superior que presenta la producción de biometano respecto al gas natural.

MÁS INFORMACIÓN: Las suposiciones, datos de partida, discusión de resultados, y otros indicadores se encuentran detallados en el análisis IO de la tecnología HYSOL, en la sección 4.2 del Capítulo 4.

PREGUNTA: ¿Cuál es el riesgo de que ocurran problemas sociales en la cadena de valor de la tecnología HYSOL?

RESPUESTA CORTA: El riesgo social ponderado de la planta HYSOL BIO es inferior (0,45 pt/MWh) al observado para el escenario HYSOL GN (1,26 pt/MWh).

RESPUESTA DESARROLLADA: Según los resultados obtenidos mediante el análisis de riesgos sociales de la SHDB, el riesgo social ponderado de la planta HYSOL BIO asciende a 0,45 pt/MWh, mientras que el de la planta HYSOL GN asciende a 1,26 pt/MWh y el de la TERMOSOLAR CCP a 0,96 pt/MWh. La mayor parte del riesgo social estimado para la planta HYSOL BIO se encuentra en la producción del biometano debido a la mayor demanda de B\&S asociada, mientras que el mayor riesgo social para las plantas HYSOL GN y TERMOSOLAR CCP se encuentra en la provisión 
de gas natural, debido a la demanda de B\&S de países con alto riesgo social (principalmente Argelia, pero también Perú y Egipto).

Las tres plantas presentan un perfil de riesgos similar para las fases de E\&F, C y $D \& D$, aunque los riesgos por unidad funcional son mayores en la planta TERMOSOLAR CCP que en las plantas HYSOL (debido a la menor producción de electricidad).

El principal riesgo social en España por el ciclo de vida de las tres plantas está asociado con la desigualdad de género, la corrupción, las lesiones y los inmigrantes.

MÁS INFORMACIÓN: Las suposiciones, datos de partida, discusión de resultados, y otros indicadores se encuentran detallados en el ACV-S de la tecnología HYSOL, en la sección 5.3.1 del Capítulo 5.

PREGUNTA: ¿Cómo afecta el ciclo de vida de la tecnología HYSOL a los derechos laborales, salud y seguridad, herencia cultural y natural, justicia y sostenibilidad socioeconómica de los trabajadores, la comunidad local, la sociedad y los actores de la cadena de valor?

RESPUESTA CORTA: El ciclo de vida de la tecnología HYSOL afecta positivamente a los derechos laborales, salud y seguridad, herencia cultural y natural, justicia y sostenibilidad socioeconómica de todos los actores implicados en España.

RESPUESTA DESARROLLADA: La mayoría de los indicadores y subcategorías han sido caracterizados con un comportamiento social positivo comparado con la media española. Este comportamiento es especialmente positivo en el actor Sociedad y en la categoría de impacto "Repercusiones socio-económicas". La categoría de impacto "Patrimonio natural y cultural" permanece inalterada por el sistema bajo estudio, mientras que la categoría de "Derechos laborales y trabajo digno" es la que presenta menores beneficios sociales. Los resultados por subcategorías indican un comportamiento social negativo en "Salario justo", "Discriminación", "Competencia leal" y "Corrupción". Esta situación podría mejorarse aumentando la igualdad de género y disminuyendo la diferencia salarial de los trabajadores. Además, la empresa promotora debería esforzarse en aumentar la transparencia respecto a cuestiones relacionadas con competencia leal, contabilidad y gestión de fondos públicos. Por el contrario, los resultados indican un comportamiento social muy positivo en las subcategorías de "Compromisos públicos con cuestiones de sostenibilidad" (de la categoría relaciones justas), "Contribución al desarrollo económico" y "Utilidad social del producto" (de la categoría sostenibilidad socio-económica). 
MÁS INFORMACIÓN: Las suposiciones, datos de partida, discusión de resultados, y otros indicadores se encuentran detallados en el ACV-S de la tecnología HYSOL, en la sección 5.3.2 del Capítulo 5.

PREGUNTA: ¿Mejoran las condiciones sociales en España debido al ciclo de vida de la tecnología HYSOL?

RESPUESTA CORTA: Los resultados indican que la provisión de electricidad en España mediante tecnología HYSOL implica un ligero aumento del bienestar social en todas las categorías.

RESPUESTA DESARROLLADA: Este aumento es especialmente indicativo en el actor Sociedad y en la categoría de impacto "Repercusiones socio-económicas". El resultado agregado de comportamiento social de la planta estudiada asciende a 0,416 p-cs, puntuación que se encuentra entre los valores de comportamiento similar $(=0)$ y mejor $(=1)$.

MÁS INFORMACIÓN: Las suposiciones, datos de partida, discusión de resultados, y otros indicadores se encuentran detallados en el ACV-S de la tecnología HYSOL, en la sección 5.3.2 del Capítulo 5. 


\subsection{ALCANCE DEL ESTUDIO Y DECISIONES METODOLÓGICAS}

Los resultados obtenidos deben interpretarse considerando las siguientes cuestiones:

- Los resultados de la tecnología HYSOL en sus dos escenarios (HYSOL BIO y HYSOL GN) se han comparado con la tecnología TERMOSOLAR CCP, que representa una planta cilindroparabólica de $50 \mathrm{MW}$, almacenamiento térmico de $7,5 \mathrm{~h}$ y $15 \%$ de hibridación con gas natural. Se ha escogido este escenario por representar el desarrollo más maduro y típico de la tecnología termosolar en España. Sin embargo, debe considerarse que el escenario TERMOSOLAR CCP produce menos electricidad en términos absolutos y aporta menos firmeza y gestionabilidad a la red eléctrica española que la tecnología HYSOL. Estas funciones adicionales que representa la tecnología HYSOL han sido consideradas en el ACV-A mediante la comparación con tecnologías termosolares que presentan la misma producción eléctrica o fracción solar (dependiendo de si coinciden en la potencia instalada).

- El análisis económico ha considerado un escenario de precios de gas natural ascendente en el tiempo. Es de suponer que la escasez de combustibles fósiles haga aumentar el precio del gas natural a un ritmo mayor que la inflación. Sin embargo, la aparición de gases no convencionales (como gas de esquisto) o de nuevas reservas pueden revertir este aumento de precios. En ese caso, la rentabilidad económica de las plantas HYSOL GN y termosolar cilindro-parabólica híbrida aumentaría en los escenarios con una mayor hibridación de gas natural.

- Las externalidades consideradas en el análisis CCV sólo incluyen los impactos por la contaminación aérea, por lo que el coste real de externalidades producidas por la tecnología podría ser mayor de lo estimado en este análisis.

- Los resultados de la monetización de externalidades no se han tenido en cuenta para valorar la sostenibilidad final, con el objetivo de evitar la contabilidad doble de impactos ambientales. Se ha considerado que los impactos ambientales calculados mediante el ACV-A son más precisos y completos que los costes externos calculados mediante monetización de externalidades (por lo tanto más apropiados para la toma de decisiones).

- El cálculo de los ingresos económicos por la venta de electricidad de la planta HYSOL BIO no ha considerado subvenciones por la producción de biogás. Sin embargo, podría ser que el biometano fuera susceptible de retribución extra en un futuro próximo. En este caso, el escenario HYSOL BIO presentaría mayores ingresos por unidad funcional. Además, cabe mencionar que el cálculo de ingresos para la planta HYSOL aquí realizado es especulativo, ya 
que actualmente no existen datos reales de retribución para una planta de estas características.

- El cálculo de efectos netos mediante el análisis Input Output considera el sector "Suministro de electricidad, agua y gas natural" como representativo del mix de tecnologías marginales, sin embargo, este sector es representativo de un mayor número de actividades. Esta agregación de sectores económicos produce que los resultados netos del análisis llevado a cabo sean menos precisos.

- La guía de ACV-S indica la necesidad de incluir a la empresa evaluada en la realización del análisis social. Sin embargo, este estudio no ha contado con dicha colaboración, que se ha visto suplida por la disponibilidad de informes oficiales sobre indicadores sociales de la empresa.

- El análisis específico del ACV-S no ha considerado el comportamiento social de los proveedores de componentes y materiales o combustibles al ciclo de vida de la planta, por lo que sólo es representativo de la empresa promotora del proyecto.

- Se ha supuesto que las distintas subcategorías y categorías sociales analizadas mediante el ACV-S (análisis específico) presentan la misma relevancia, ya que no se ha aplicado ningún ponderado. En el caso de que los tomadores de decisiones consideren que alguna categoría tiene mayor relevancia (por ejemplo Derechos laborales respecto a Sostenibilidad socioeconómica) deberían aplicar factores de ponderación y reconsiderar el resultado final de comportamiento social. 


\subsection{INTERPRETACIÓN Y TOMA DE DECISIONES}

Según lo indicado en la sección 2.1 del Capítulo 2 de esta tesis, el objetivo secundario de este análisis es escoger la alternativa que debería promoverse en primer lugar para mejorar la sostenibilidad de la producción eléctrica. La toma de decisiones de sostenibilidad considerando criterios de distinta naturaleza es un gran reto, por lo que es tarea del analista representar los resultados del ASCV de forma clara y sencilla de interpretar.

\subsubsection{Confección del diagrama}

Con el objetivo de facilitar la interpretación de resultados y la toma de decisiones multicriterio sobre la alternativa más sostenible, se han confeccionado unos diagramas teniendo en cuenta las siguientes consideraciones:

- Facilitar la visualización de qué alternativa presenta mejores resultados en cada área sin necesidad de instrucciones complejas.

- Mostrar los resultados para cada criterio según el área de la sostenibilidad a la que pertenecen.

- Contener información cuantitativa de los criterios considerados en cada área.

- Representar con la misma importancia cada criterio, ya que dicha importancia debe ser asignada por los tomadores de la decisión.

- Ofrecer información visual sobre qué alternativa es mejor para cada criterio utilizando códigos internacionales y de fácil comprensión, como la escala de colores de un semáforo (rojo, amarillo, verde).

- Representar claramente si las opciones presentan resultados muy similares en un criterio, ya que entonces dicho criterio disminuye su relevancia para la elección de la opción más sostenible.

El esquema del diagrama se presenta en la Figura 84. La información se dispone en un círculo dividido en tres sectores iguales, cada sector se corresponde con cada área de la sostenibilidad. Cada área contiene los criterios de sostenibilidad junto con su valor numérico absoluto y el color que representa su valor relativo. La escala de colores sigue el código de colores de un semáforo (cuanto más rojo menos sostenible y cuanto más verde más sostenible). El color de cada criterio se ha asignado considerando el valor relativo de dicho criterio respecto al valor medio. El valor medio del criterio se calcula como el promedio del resultado obtenido para todas las alternativas estudiadas. 

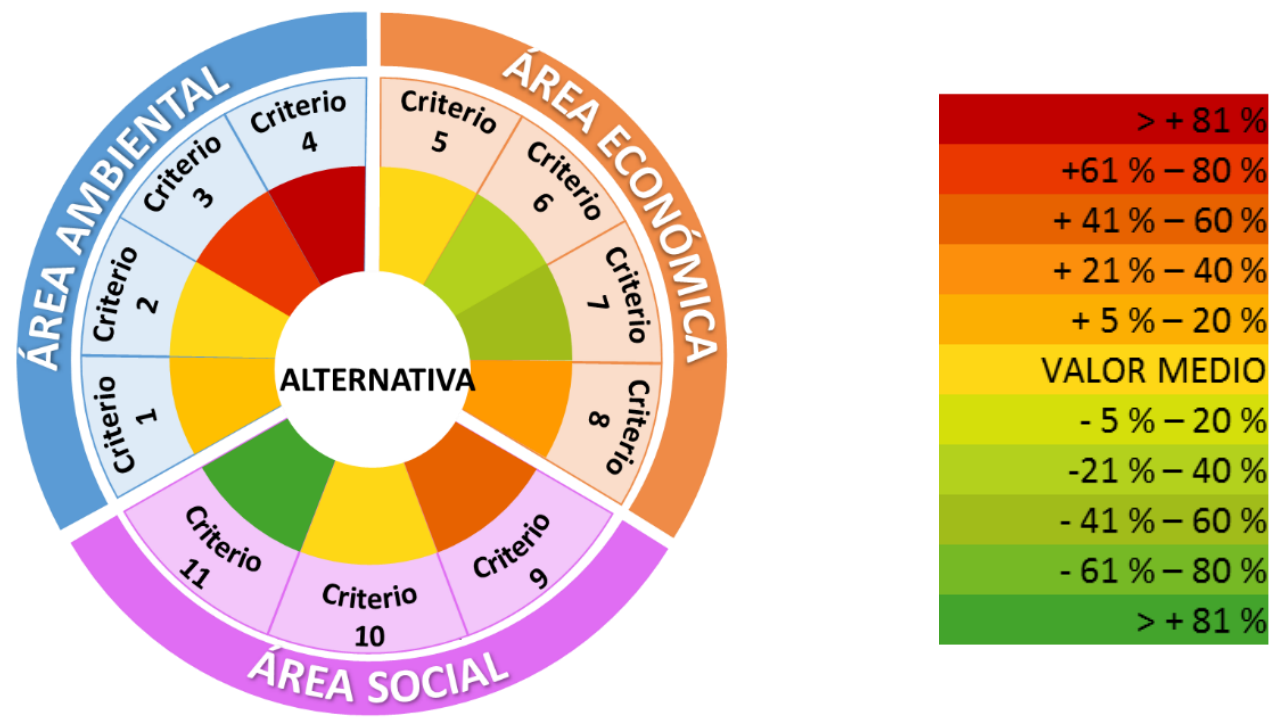

Figura 84 Esquema de diagrama de resultados y código de colores para una alternativa

El proceso para asignar colores a cada criterio para cada alternativa se describe a continuación. Considerando un criterio determinado (por ej. Estrés hídrico), primero se calcula el promedio entre los resultados obtenidos para cada alternativa en dicho criterio. A continuación se calcula el incremento o disminución porcentual de cada tecnología respecto al valor medio, según la Ecuación (15).

Variación porcentual $=\frac{\text { Valor alternativa }- \text { Valor } \text { medio }}{\text { Valor medio }}$

Si la variación porcentual es positiva, se le asignará un color que torna del amarillo al rojo conforme aumenta el valor del incremento (si el Estrés hídrico es 100 \% mayor que el valor medio, adquiere un color rojo intenso). Si la variación porcentual es negativa, se le asignará un color que torna del amarillo al verde conforme disminuye el valor del incremento (si la huella de carbono es $-100 \%$ menor que el valor medio, adquiere un color verde intenso). La Figura 84 contiene la leyenda de colores en función del rango de variación porcentual que presenta el criterio.

La asignación de colores aquí descrita es apropiada para aquellos indicadores que presentan peor sostenibilidad cuando mayor sea su valor (por ej. Estrés hídrico). En aquellos indicadores que presentan peor sostenibilidad cuando menor es su valor (por ej. Valor añadido), el color rojo se asignará a los cambios porcentuales negativos y el verde a los positivos.

La escala se ha diseñado en función de la variación porcentual (y no sólo de que el valor presente mejor o peor resultado) para representar que algunas alternativas muestran 
resultados muy parecidos y evitar basar la decisión solamente en criterios que presentan valores similares, especialmente en aquellos que tienen mayor incertidumbre en su resultado.

\subsubsection{Representación de resultados}

Esta sección presenta un diagrama de resultados para cada alternativa considerada en el ASCV de la tecnología HYSOL, siguiendo las directrices de la sección anterior. La Tabla 107 presenta los incrementos y disminuciones porcentuales respecto al valor medio de cada alternativa y criterio.

Tabla 107 Valores absolutos y variaciones porcentuales de cada criterio de sostenibilidad para cada alternativa

\begin{tabular}{|c|c|c|c|c|}
\hline & HYSOL BIO & $\begin{array}{c}\text { TERMOSOLAR } \\
\text { CCP }\end{array}$ & HYSOL GN & VALOR MEDIO \\
\hline \multirow{2}{*}{$\begin{array}{l}\text { Cambio climático, } \\
\mathrm{kg} \mathrm{CO}_{2} / \mathrm{MWh}\end{array}$} & 45,9 & 136 & 293,6 & 158,5 \\
\hline & $-71 \%$ & $-14 \%$ & $85 \%$ & $0 \%$ \\
\hline \multirow{2}{*}{$\begin{array}{l}\text { Estrés hídrico, } \\
\mathrm{m}^{3} / \mathrm{MWh}\end{array}$} & 0,164 & 3,69 & 0,151 & 1,3 \\
\hline & $-88 \%$ & $176 \%$ & $-89 \%$ & $0 \%$ \\
\hline \multirow{2}{*}{ TRE, meses/MWh } & 6,14 & 13 & 22,31 & 13,8 \\
\hline & $-56 \%$ & $-6 \%$ & $61 \%$ & $0 \%$ \\
\hline \multirow{2}{*}{$\begin{array}{l}\text { Punto final, } \\
\text { pt/MWh }\end{array}$} & 8,27 & 16,7 & 35,2 & 20,1 \\
\hline & $-59 \%$ & $-17 \%$ & $76 \%$ & $0 \%$ \\
\hline \multirow{2}{*}{$\begin{array}{l}\text { Coste ciclo vida, } \\
€ / \mathrm{MWh}\end{array}$} & 210,5 & 208 & 153,9 & 190,8 \\
\hline & $10 \%$ & $9 \%$ & $-19 \%$ & $0 \%$ \\
\hline \multirow{2}{*}{$\begin{array}{l}\text { Balance costes e ingresos, } \\
€ / M W h\end{array}$} & $-12,6$ & 4,91 & 6,33 & $-0,5$ \\
\hline & $2679 \%$ & $-1183 \%$ & $-1496 \%$ & $0 \%$ \\
\hline \multirow{2}{*}{$\begin{array}{l}\text { Valor añadido, } \\
\text { \% de B\&S }\end{array}$} & 44,4 & 44,7 & 43 & 44,0 \\
\hline & $1 \%$ & $2 \%$ & $-2 \%$ & $0 \%$ \\
\hline \multirow{2}{*}{ Efecto multiplicador } & 2,42 & 2,59 & 2,48 & 2,5 \\
\hline & $-3 \%$ & $4 \%$ & $-1 \%$ & $0 \%$ \\
\hline \multirow{2}{*}{$\begin{array}{l}\text { Riesgo social, } \\
\text { p/MWh }\end{array}$} & 0,45 & 0,96 & 1,3 & 0,9 \\
\hline & $-50 \%$ & $6 \%$ & $44 \%$ & $0 \%$ \\
\hline \multirow{2}{*}{$\begin{array}{l}\text { Puntos comportamiento social, } \\
\text { p-cs/MWh }\end{array}$} & 0,416 & 0,415 & 0,416 & 0,4 \\
\hline & $0 \%$ & $0 \%$ & $0 \%$ & $0 \%$ \\
\hline \multirow{2}{*}{$\begin{array}{l}\text { Empleo, } \\
\text { horas/MWh }\end{array}$} & 5,49 & 6,15 & 2,9 & 4,8 \\
\hline & $-13 \%$ & $-27 \%$ & $40 \%$ & $0 \%$ \\
\hline
\end{tabular}

Los diagramas para la toma de decisiones sobre la alternativa de tecnología termosolar más sostenible se presentan en la Figura 86. Existe un diagrama para cada escenario analizado en esta tesis, cuyo nombre está indicado en el centro del mismo (HYSOL BIO, HYSOL GN y TERMOSOLAR CCP). 
Como se observa en los diagramas, la alternativa que presenta mejor sostenibilidad ambiental y social es HYSOL BIO, ya que todos los criterios de dicha área presentan valores similares o mejores que en las otras alternativas. Sin embargo, la hibridación con biometano tiene peor sostenibilidad económica que los otros escenarios, especialmente en el criterio "Balance de costes e ingresos". En cambio, la planta HYSOL GN presenta mejor sostenibilidad económica (todos los criterios económicos presentan valores similares o mejores que en las otras alternativas), pero peor sostenibilidad ambiental y social que las otras alternativas. Las diferencias son más acusadas en el área ambiental.

Esta diferencia de resultados en las distintas áreas de sostenibilidad implica que para tomar una decisión final hay que utilizar juicios de valor sobre qué criterios son más importantes. Si asignáramos la misma importancia a todos los criterios, el escenario HYSOL BIO sería el más adecuado. Sin embargo, asignar la misma importancia a todos los criterios no representa la realidad de las preferencias humanas. Por lo tanto, para aplicar importancias relativas a los distintos cirterios se recomienda realizar un proceso PAJ (Saaty 1990, Wang et al. 2009) para la toma de decisiones final, en el que se evalúen las tres alternativas en base a los 11 criterios y las tres áreas de sostenbilidad, siguiendo la jerarquía mostrada en la Figura 85. Este método asigna importancias a los criterios de cada nivel jerárquico mediante un sistema de comparación por pares. Tras asignar la importancia relativa a todos los criterios, se obtiene un valor númerico para cada alternativa que representa su nivel de prioridad. 


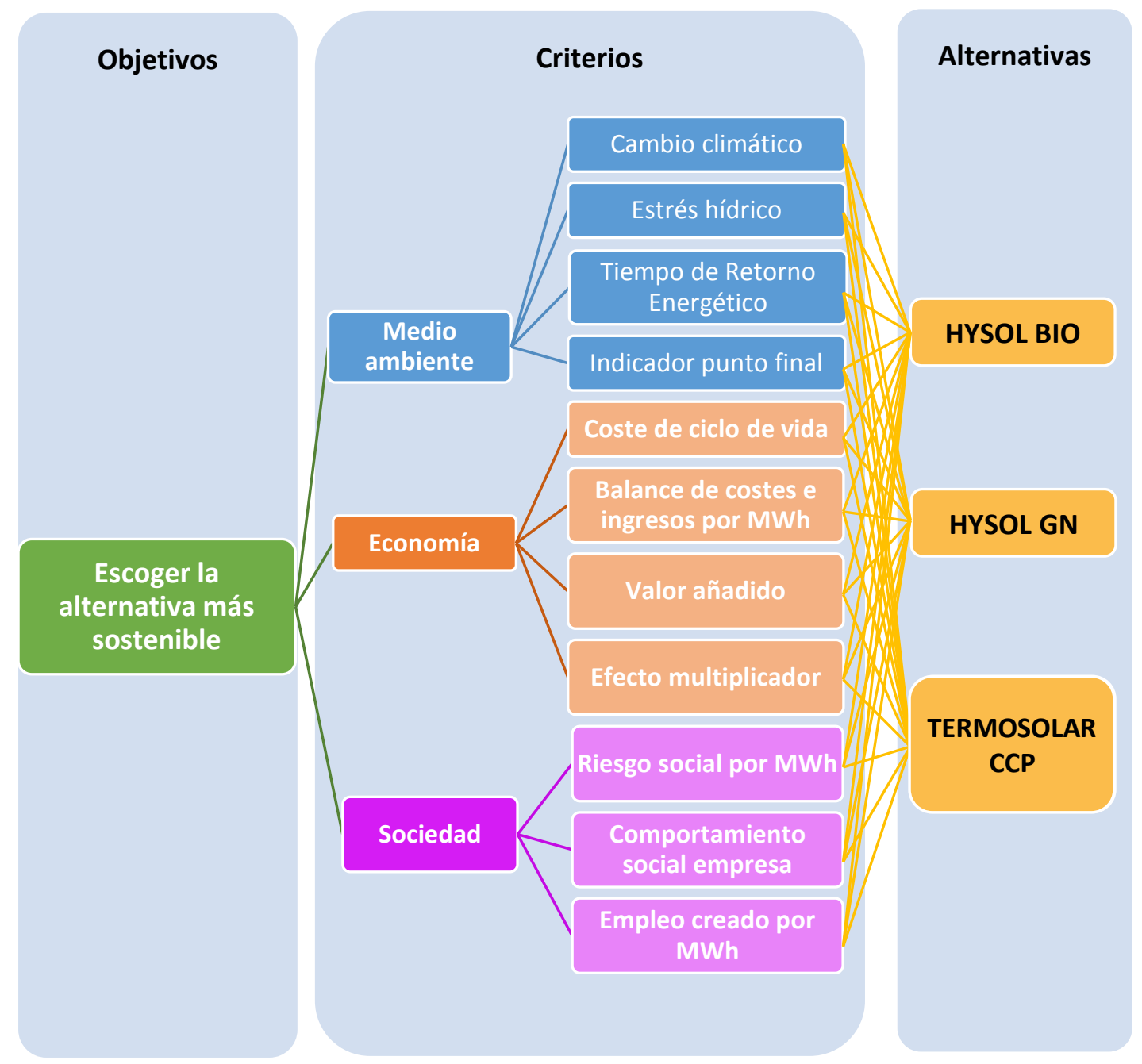

Figura 85 Jerarquía para un Proceso Analítico Jerárquico de toma de decisiones respecto a la alternativa más sostenible 

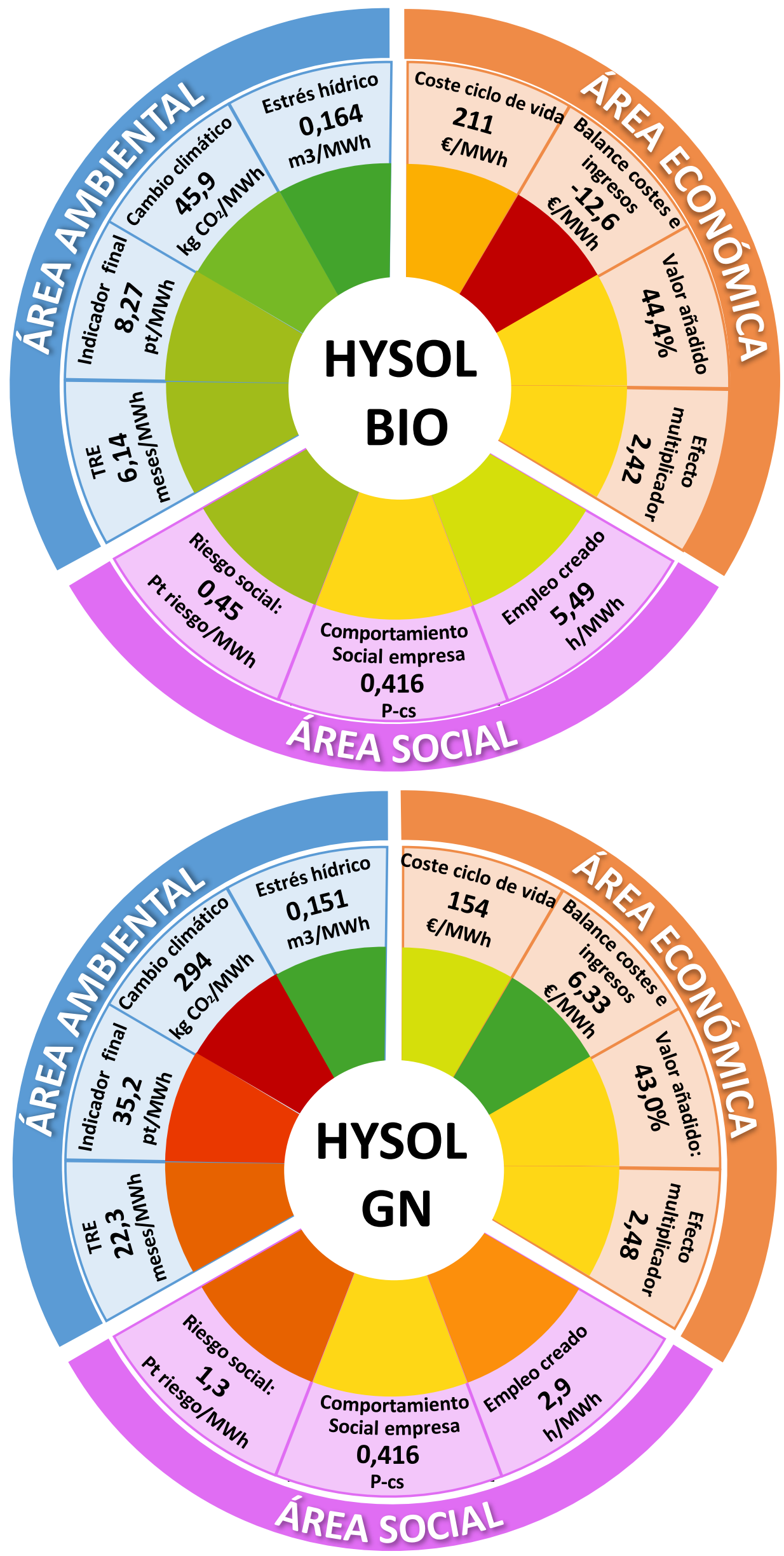


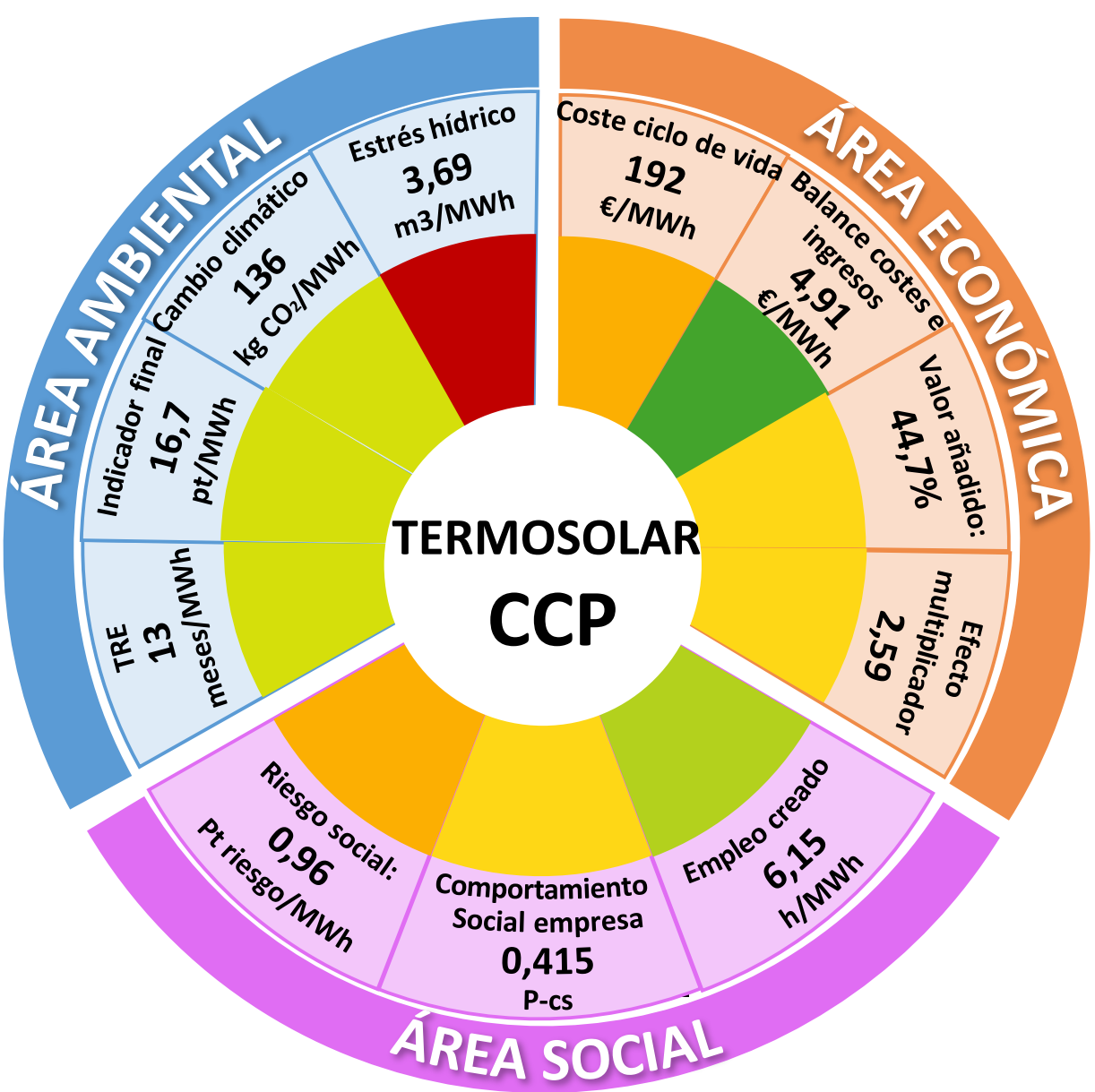

Figura 86 Diagramas de sostenibilidad para la

$>+81 \%$
$+61 \%-80 \%$
$+41 \%-60 \%$
$+21 \%-40 \%$
$+5 \%-20 \%$
VALOR MEDIO
$-5 \%-20 \%$
$-21 \%-40 \%$
$-41 \%-60 \%$
$-61 \%-80 \%$
$>-81 \%$
toma de decisiones sobre la tecnología más adecuada según los criterios evaluados (HYSOL con biometano, HYSOL GN, o TERMOSOLAR CCP). 


\section{CONCLUSIONES Y LÍNEAS FUTURAS DE INVESTIGACIÓN}

\section{Conclusiones sobre metodología ASCV}

- La metodología aplicada en esta tesis ha permitido evaluar la sostenibilidad del ciclo de vida de una tecnología innovadora como HYSOL. Los resultados se sustentan en una base cuantitativa y científica que resulta fundamental para la toma de decisiones sostenible respecto al desarrollo de la tecnología y del sector de la electricidad (tanto a nivel empresarial como a nivel político).

- El uso de sub-preguntas de sostenibilidad para definir las herramientas de análisis ha demostrado ser un enfoque metodológico adecuado para aproximarse al reto multidisciplinar que supone definir la sostenibilidad de un sistema energético.

- La combinación del enfoque atribucional y consecuencial en el Análisis de Ciclo de Vida Ambiental ha permitido conocer los puntos de mejora del impacto ambiental potencial de la tecnología, y también las consecuencias ambientales potenciales de introducir electricidad de la planta HYSOL (en sus dos escenarios principales) en el sector eléctrico español.

- El análisis de Costes de Ciclo de Vida ha permitido conocer el coste interno y externo de ciclo de vida de producir electricidad con la tecnología HYSOL (en sus dos escenarios), así como la rentabilidad económica del proyecto. Además, los conocimientos adquiridos mediante el estudio del arte han hecho patente que el área económica de un ASCV debe incluir también indicadores que muestren la sostenibilidad económica para la sociedad en su conjunto, y no sólo para los intereses particulares de la empresa. Para ello, la integración de la herramienta de análisis Input Output en el ASCV de la tecnología HYSOL ha sido fundamental para conocer el valor añadido (y por lo tanto contribución al PIB) del proyecto, el efecto multiplicador, el empleo generado y la generación de B\&S tanto nacionales como internacionales proporcionados por la planta HYSOL en sus dos escenarios.

- Se ha adaptado la metodología Input Output para incluir un enfoque consecuencial en el análisis económico de la tecnología HYSOL. Gracias a este desarrollo se ha podido conocer el efecto económico que tiene la tecnología cuando se consideran los efectos evitados por las tecnologías a las que desplaza. 
- El desarrollo metodológico llevado a cabo en el área del Análisis de Ciclo de Vida Social (ACVS) ha permitido abordar el reto de cuantificar el comportamiento social y responder a la pregunta de si se mejora el bienestar social en España gracias a la tecnología HYSOL. Esto ha sido posible mediante la comparación del comportamiento social del ciclo de vida de la planta HYSOL con el de la media española. Además, la integración de una escala con valores positivos y negativos ha permitido evaluar tanto los efectos negativos como positivos del proyecto en el bienestar social español.

- Los resultados del ACV-S de la tecnología HYSOL han visto comprometidos su precisión debido a la no colaboración con la empresa evaluada. En el caso de estudio se decidió no involucrar a la empresa por miedo a la negativa de publicar sus deficiencias sociales. Esta cuestión ha sido detectada como un punto crítico para la aplicación y desarrollo del ACV-S.

- La elección de tres a cuatro indicadores cuantitativos principales para cada área de la sostenibilidad ha permitido representar la sostenibilidad del sistema de forma objetiva y sencilla. Su representación gráfica en un diagrama circular utilizando una escala de colores es óptima para facilitar la elección de la alternativa más sostenible, ya que de forma intuitiva se puede apreciar qué área (y qué indicadores) presenta mejor, peor o similar resultado respecto a las alternativas propuestas.

\section{Conclusiones sobre la sostenibilidad de la tecnología HYSOL}

- Los resultados del ASCV indican que la tecnología HYSOL presenta diferencias significativas de sostenibilidad cuando se utiliza biometano o gas natural como combustible de hibridación. La operación con biometano presenta mejor sostenibilidad ambiental y social que la operación con gas natural, pero peor sostenibilidad económica a nivel empresa y mejor sostenibilidad económica a nivel nacional que el gas natural.

- El escenario HYSOL BIO presenta una sostenibilidad similar o superior que el escenario TERMOSOLAR CCP en todas las áreas excepto para el indicador "Balance de costes e ingresos" que presenta mejor resultado en la planta TERMOSOLAR CCP.

- El escenario HYSOL GN presenta una sostenibilidad peor o similar que la planta TERMOSOLAR CCP en todas las áreas excepto en el indicador "Balance de costes e ingresos" y en el "Estrés hídrico", cuyos resultados son mejores.

- Las mejores eficiencias de conversión de energía térmica que presenta la tecnología HYSOL respecto a la tecnología cilindro-parabólica o torre convencionales producen una mejora ambiental, económica y social. Este resultado indica que la innovación tecnológica 
conseguida mediante el proyecto HYSOL está bien encaminada a mejorar la sostenibilidad de la tecnología termosolar.

\section{Líneas futuras de investigación}

En cuanto a metodología:

- Aplicación de la metodología desarrollada a otros productos y/o servicios con el objetivo de comparar resultados y valorar la robustez del método. En especial, el ASCV propuesto en esta tesis debería aplicarse a energías renovables y fósiles para poder completar un análisis de sostenibilidad coherente y comparable de las tecnologías de producción de electricidad. Un análisis de estas características sería muy útil para encaminar y sustentar las políticas nacionales de promoción de tecnologías de producción eléctrica.

- Profundizar en la aplicación del ACV-S para sistemas energético, explorando las opciones de participación con empresas y rastreando el impacto social de proveedores.

- Aplicar la herramienta Input Output con el cálculo de efectos brutos y netos (enfoque consecuencial) utilizando una base de datos con mayor desagregación de sectores, para obtener resultados más precisos.

- Profundizar en el cálculo de externalidades del CCV para orientar las políticas nacionales hacia una óptima fiscalización ambiental en el sector de la electricidad.

En cuanto al análisis de sostenibilidad de la tecnología termosolar:

- Profundizar en la interpretación de resultados para facilitar la toma de decisiones sobre la alternativa más sostenible, llevando a cabo un proceso multicriterio de toma de decisiones (como el PAJ) que cuente con la participación de los sectores más representativos de la población (ingenieros, investigadores, políticos, ciudadanos, oenegés). Dicho proceso permitiría determinar la habilidad de los distintos actores para interpretar los indicadores propuestos y tomar una decisión sostenible basada en las preferencias de la sociedad en su conjunto.

- Incluir un análisis de riesgos ambientales asociados a posibles accidentes en la construcción y operación de las plantas termosolares.

- Expandir el ASCV de la planta HYSOL para considerar escenarios en distintos países, ya que se ha comprobado que el impacto ambiental y socio-económico puede variar considerablemente dependiendo de la ubicación (Corona et al. 2016, Corona et al. 2016). 
- Análisis de otras variantes tecnológicas con potencial comercial de la tecnología termosolar (generación directa de vapor, distintos tipos de almacenamiento térmico, HSYOL con tecnología cilindro-parabólica y sales fundidas como fluido térmico). 



\section{GLOSARIO DE ABREVIATURAS}

ACV Análisis de Ciclo de Vida

ACV-A Análisis de Ciclo de Vida Ambiental

ACV-S Análisis de Ciclo de Vida Social

AICV Análisis de Inventario de Ciclo de Vida

ASCV Análisis de Sostenibilidad de Ciclo de Vida

B\&S Bienes y Servicios

C Construcción

CCV Costes de ciclo de vida

CED Demanda acumulada de energía, del inglés, Cumulative Energy Demand

CV Coeficiente de variación

D\&D Desmantelamiento y Disposición de residuos

DAP Declaraciones Ambientales de Producto

E\&F Extracción de materias primas y Fabricación de componentes

EICV Evaluación de Impacto de Ciclo de Vida

GEI Gases de Efecto Invernadero

GN Gas natural

GWP Potencial de calentamiento global, del inglés, Global Warming Potential

HRS Sistema de recuperación del calor, del inglés, Heat Recovery System

HTF Fluido de transferencia de calor, del inglés Heat Transfer Fluid

ISO Organización Internacional de Estandarización, del inglés, International Organisation for Standardisation

LEC Coste nivelado de la energía, del inglés, Levelized Energy Cost

MCDM Métodos de toma de decisiones multi-criterio, del inglés, Multi Criteria Decision Making

MRIO Input Output Multi-regional, del inglés, Multiregional Input Output

O\&M Operación y Mantenimiento

OCDE Organización para la Cooperación y el Desarrollo Económicos

ODP Potencial de Destrucción de Ozono, del inglés, Ozone Depletion Potential

OIT Organización Internacional del Trabajo

OMIE Operador del Mercado Ibérico Español

PA Potencial de Acidificación

PAJ Proceso Analítico Jerárquico

p-cs Puntos de comportamiento social

PE Potencial de Eutrofización

PIB Producto Interior Bruto

$\mathrm{PM}_{10} \quad$ Partículas con un diámetro inferior a $10 \mu \mathrm{m}$

PRP Puntos de Referencia de Comportamiento, del inglés, Performance Reference Points

PSA Adsorción por cambio de presión, del inglés, Pressure Swing Adsorption

RE Régimen Especial 
REE Red Eléctrica de España

RoW Resto del mundo, del inglés, Rest of the World

RSC Responsabilidad Social Corporativa

SEA Contabilidad socioeconómica, del inglés, Socio Economic Accounts

SETAC Sociedad de Química y Toxicidad Ambiental, del inglés, Society of Environmental Toxicology and Chemistry

TES Sistema de almacenamiento térmico, del inglés, Thermal Energy Storage

TRE Tiempo de Retorno Energético

UNEP Programa de las Naciones Unidas para el Medio Ambiente, del inglés, United Nations Environmental Program

VAN Valor Actual Neto

VIH Virus de Inmunodeficiencia Humana

WIOD Base de datos Input Output mundial, del inglés, World Input Output Database

WIOT Tabla Input Output mundial, del inglés, World Input Output Table

WSI Índice de Estrés Hídrico, del inglés, Water Stress Index

WTP Disposición a pagar, del inglés, Willingness To Pay 


\section{GLOSARIO DE TÉRMINOS}

CED, Demanda

La suma de toda la energía primaria utilizada a lo largo del ciclo de vida acumulada de energía del sistema.

Ciclo de vida
Coste nivelado de la
electricidad
Externalidad
Factor de capacidad

El conjunto de etapas consecutivas e interrelacionadas de un sistema producto desde la adquisición de materias primas o la generación de recursos naturales hasta su disposición final. ISO 14040:1997.

Precio constante de la electricidad producida por una tecnología considerando todos los costes del ciclo de vida.

Cambios en el medioambiente o el bienestar social cuyo coste no está incluido en el precio de la actividad comercial que los causa (Hunkeler et al. 2008).

Factor de capacidad

El cociente entre la energía final que genera la planta y la que hubiera producido si estuviera funcionando durante las 8760 horas del año.

La capacidad de proveer determinada capacidad de producción cuando

Firmeza se requiera por parte del operador de red eléctrica, independientemente de las circunstancias previas de la planta (Servert et al. 2015).

Gestionabilidad Habilidad de la planta de proveer electricidad a cualquier hora del día sin desperdiciar energía primaria (Servert et al. 2015).

Situación que puede ser considerada un problema, riesgo u

Hotspot social oportunidad en términos de preocupación social (UNEP-SETAC Life Cycle Initiative 2009).

Impacto social

Consecuencia negativa o positiva en cuestiones sociales que conciernen el bienestar humano.

Cociente de la potencia térmica generada por el campo solar y la

Múltiplo solar potencia térmica demandada por el bloque de potencia en condiciones nominales.

Precio marginal horario de la electricidad Precio que adquiere el último kilovatio hora que satisface la demanda horaria.

Tasa anual para la cual el efecto de los sucesos futuros se reduce hasta

Tasa de descuento el punto de ser equiparable al efecto de los sucesos actuales (IPCC 1995).

Tecnología marginal

Aquella tecnología que se ve afectada por un cambio pequeño en la demanda del producto bajo estudio (Weidema et al., 1999).

Tiempo de Retorno Energético energía haya generado tanta energía como la empleada en su ciclo de vida.
El periodo de tiempo requerido para que un sistema de producción de 
Unidad funcional Aquella que define la cuantificación de las funciones o características de desempeño del producto o servicio analizado.

Variable de actividad

Medida que refleja la proporción relativa de cada proceso en un conjunto de procesos.

Valor añadido

El valor económico adicional que adquiere cada bien y servicio al ser creado o fabricado mediante la actividad productiva de cada sector. 


\section{BIBLIOGRAFÍA}

ABC (2011) Las centrales termosolares han creado 160 empleos directos. In: . ABC Castilla La Mancha. $\quad$ http://www.abc.es/20110522/comunidad-castillalamancha/abcp-centralestermosolares-creado-empleos-20110522.html. Accessed 04/06 2015

AEAS (2011) Tarifas 2010. Precio de los servicios de abastecimiento y saneamiento en España

AEBIOM A (2009) biogas road map for Europe. European Biomass Association

AENOR (2006) UNE-EN ISO 14040:2006. Environmental management - Life cycle assessment Principles and framework

African National Context (1994) The Reconstruction and Development Programme. A Policy Framework. In: . http://www.polity.org.za/polity/govdocs/rdp/rdp.html. Accessed 06/17 2015

Akhtar S, Reza B, Hewage K, Shahriar A, Zargar A, Sadiq R (2015) Life cycle sustainability assessment (LCSA) for selection of sewer pipe materials. Clean Technologies and Environmental Policy 17:973-992

Andrews E, Lesage P, Benoît C, Parent J, Norris G, Revéret J (2009) Life cycle attribute assessment. J Ind Ecol 13:565-578

Anthoff D, Hepburn C, Tol RS (2009) Equity weighting and the marginal damage costs of climate change. Ecol Econ 68:836-849

APPA (2014) APPA recurre ante el Tribunal Supremo el Real Decreto sobre renovables y la Orden de parámetros retributivos

Assembly UG (1948) Universal declaration of human rights. UN General Assembly

Atanassov V (2014) Spain Supreme Court unveils 1st appeals against renewables reform. In: . SeeNews Renewables. https://renewables.seenews.com/news/spain-supreme-court-unveils1st-appeals-against-renewables-reform-438086. Accessed September 102014

Beneyto PJ (2010) Afiliación y representación sindical en Europa. Ultimos datos y estudios comparados. In: Estudios de la fundación. http://www.1mayo.ccoo.es/nova/files/1018/Estudio37.pdf. Accessed 02/06 2015

Benoît Norris C, Traverso M, Valdivia S, Vickery-Niederman G, Franze J, Azuero L, Ciroth A, Mazijn B, Aulision D (2013) The Methodological Sheets for Sub-Categories in Social Life Cycle Assessment (S-LCA). United Nations Environment Programme (UNEP) and Society for Environmental Toxicology and Chemiastry (SETAC)

Benoit-Norris C, Norris GA, Aulisio D (2013) The Social Hotspots Database V2 
Benoit-Norris C, Vickery-Niederman G, Valdivia S, Franze J, Traverso M, Ciroth A, Mazijn B (2011) Introducing the UNEP/SETAC methodological sheets for subcategories of social LCA. Int J Life Cycle Assess 16:682-690

Bickel P, Friedrich R (2004) ExternE: Externalities of Energy: Methodology 2005 Update. EUR$\mathrm{OP}$

BioMethane Regions (2013) Biomethane-Calculator. V2.1.1, published 16.10.2013. In: . http://bio.methan.at/en/download biomethane-calculator. Accessed 27/05 2016

Blok K, Huijbregts M, Roes L, van Haaster B, Patel M, Hertwich E, Wood R, Hauschild MZ, Sellke P, Antunes P, Hellweg S, Ciroth A, Harmeling M (2013) A novel methodology for the sustainability impact assessment of new technologies.

BOE-A-2010-5945 Resolución de 7 de abril de 2010, de la Secretaría de Estado de Energía, por la que se publican los valores del coste de la materia prima y del coste base de la materia prima del gas natural para el primer trimestre 2010, a los efectos del cálculo del complemento de eficiencia y los valores retributivos de las instalaciones de cogeneración y otras en el Real Decreto 661/2007, de 25 de mayo, por el que se regula la actividad de producción de energía eléctrica en régimen especial. BOE-A-2010-5945 num.90 pag 21477-33283

BOE-A-2013-2876 Resolución de 7 de marzo de 2013, de la Secretaría de Estado de Energía, por la que se publican los valores del coste de la materia prima y del coste base de la materia prima del gas natural para el segundo trimestre de 2013, a los efectos del cálculo del complemento de eficiencia y los valores retributivos de las instalaciones de cogeneración y otras en el Real Decreto 661/2007, de 25 de mayo, por el que se regula la actividad de producción de energía eléctrica en régimen especial. BOE-A-2013-2876. num.65 pag 21477-21479

BOE A 2013 -13807 Resolución por la que se fijan las cantidades de carbón, el volumen máximo de producción y los precios de retribución para el 2013

Brent AC, Labuschagne C (2005) Sustainable life cycle management: a case study in the process industry to develop a calculation procedure for social indicators following conventional LCA methods

Brundtland GH (1987) Report of the World Commission on environment and development:" our common future.". United Nations

Bueno C, Hauschild MZ, Rossignolo JA, Ometto AR, Mendes NC (2015) Sensitivity Analysis of the use of Life Cycle Impact Assessment Methods: A case study on building materials. J Clean Prod

Burchart-Korol D (2013) Sustainability and Eco-Efficiency Assessment of Biomass use in Steelmaking. Metal 2013: 22nd International Conference on Metallurgy and Materials:17401746

Burkhardt III JJ, Heath GA, Turchi CS (2011) Life cycle assessment of a parabolic trough concentrating solar power plant and the impacts of key design alternatives. Environmental Science and Technology 45:2457-2464 
Burkhardt JJ, Heath G, Cohen E (2012) Life Cycle Greenhouse Gas Emissions of Trough and Tower Concentrating Solar Power Electricity Generation. J Ind Ecol 16:S93-S109

Burkhardt JJ,III, Heath G, Turchi C (2010) Life Cycle Assessment of a Model Parabolic Trough Concentrating Solar Power Plant with Thermal Energy Storage

Burtraw D, Krupnick A, Sampson G, Beasley B (2012) The True Cost of Electric Power. RFF Report, Resources for the Future, Washington, DC (June)

Caldés N, Varela M, Santamaría M, Sáez R (2009) Economic impact of solar thermal electricity deployment in Spain. Energy Policy 37:1628-1636

Cañellas I, Huelin P, Hernández M, Ciria P, Calvo R, Gea-Izquierdo G, Sixto H (2012) The effect of density on short rotation Populus sp. plantations in the Mediterranean area. Biomass Bioenergy 46:645-652

CASES Project (2009) Cost Assessment for Sustainable Energy Systems. In: . http://www.feemproject.net/cases/project.php. Accessed 05/05 2014

CASES project (2008) D.02.2 - External costs, Euro/ton values. Last update August 2008. In: . http://www.feem-project.net/cases/downloads deliverables.php. Accessed May 2014

Chhipi-Shrestha GK, Hewage K, Sadiq R (2014) 'Socializing'sustainability: a critical review on current development status of social life cycle impact assessment method. Clean Technologies and Environmental Policy 17:579-596

CIEMAT (2009) Curso sobre Sistemas Solares Térmicos de Concentración

Cinelli M, Coles SR, Jørgensen A, Zamagni A, Fernando C, Kirwan K (2013) Workshop on life cycle sustainability assessment: the state of the art and research needs-November 26, 2012, Copenhagen, Denmark. Int J Life Cycle Assess:1-4

Ciroth A, Finkbeier M, Hildenbrand J, Klöpffer W, Mazijn B, Prakash S, Sonnemann G, Traverso M, Ugaya CML, Valdivia S (2011) Towards a life cycle sustainability assessment: making informed choices on products

Ciroth A, Franze J (2011) LCA of an ecolabeled notebook: consideration of social and environmental impacts along the entire life cycle. ISBN 978-1-4466-0087-0

Ciroth A, Huppes G, Klöpffer W, Rüdenauer I, Steen B, Swarr T (2008) Environmental life cycle costing. SETAC

CNE (2011) Informe anual de supervisión del mercado eléctrico. Año 2011. Comisión Nacional de Energía

CNMC (2009) Expedientes. In: . Comisión Nacional de los Mercados y de la Competencia. http://www.cnmc.es/eses/competencia/buscadorde/expedientes.aspx?num=S/0173/09\&ambito=Conductas \&b=cobra $\& p=0 \&$ empresa=cobra\&ambitos=Concentraciones, Recursos, Sancionadores\%20CCAA,Sanciona dores\%20Ley\%2030,Vigilancia,Medidas\%20cautelares,Conductas\&estado=0\&sector=0\&av=0. Accessed 06/04 2015 
Commision of the European Communities (2003) Communication from the commission to the Council and the European Parliament. Integrated Product Policy, Building on Environmental LifeCycle Thinking. Brussels, 18.6.2003 COM(2003) 302 final

Comunidad de Madrid (2006) Estrategia de residuos de la Comunidad de Madrid (2006-2016). CAM, Consejería de Medio Ambiente y Ordenación del Territorio de la Comunidad de Madrid. In: 
Desaigues B, Ami D, Bartczak A, Braun-Kohlová M, Chilton S, Czajkowski M, Farreras V, Hunt A, Hutchison M, Jeanrenaud C, Kaderjak P, Máca V, Markiewicz O, Markowska A, Metcalf $H$, Navrud S, Nielsen JS, Ortiz R, Pellegrini S, Rabl A, Riera R, Scasny M, Stoeckel M-, Szántó R, Urban J (2011) Economic valuation of air pollution mortality: A 9-country contingent valuation survey of value of a life year (VOLY). Ecol Ind 11:902-910

Desideri U, Zepparelli F, Morettini V, Garroni E (2013) Comparative analysis of concentrating solar power and photovoltaic technologies: Technical and environmental evaluations. Appl Energy 102:765-784

Dijkman TJ, Birkved M, Hauschild MZ (2012) PestLCl 2.0: a second generation model for estimating emissions of pesticides from arable land in LCA. Ecol Model 17:973-986

Dobon A, Cordero P, Kreft F, Ostergaard SR, Antvorskov H, Robertsson M, Smolander M, Hortal $M$ (2011) The sustainability of communicative packaging concepts in the food supply chain. A case study: part 2. Life cycle costing and sustainability assessment. International Journal of Life Cycle Assessment 16:537-547

Dreyer L, Hauschild M, Schierbeck J (2006) A framework for social life cycle impact assessment (10 pp). The International Journal of Life Cycle Assessment 11:88-97

EC (1997) Energy for the Future: Renewable Sources of Energy. White Paper for a Community Strategy and Action Plan. European Comission. Communication. COM (97) 599 final (26/11/1997)

Ehtiwesh IAS, Coelho MC, Sousa ACM (2016) Exergetic and environmental life cycle assessment analysis of concentrated solar power plants. Renewable and Sustainable Energy Reviews 56:145155

EIA (2014) International Energy Outlook 2014. U.S. Energy Information Administration (EIA). U.S. Energy Information Administration

Ekener-Petersen E, Höglund J, Finnveden G (2014) Screening potential social impacts of fossil fuels and biofuels for vehicles. Energy Policy 73:416-426

Ekener-Petersen E, Finnveden G (2013) Potential hotspots identified by social LCA-part 1: a case study of a laptop computer. Int J Life Cycle Assess 18:127-143

el Triangle (2014) Admitida a trámite la demanda contra Florentino por fraude y falseamiento. In: . http://www.eltriangle.eu/es/notices/2014/10/admitida-a-tramite-la-demanda-contraflorentino-por-fraude-y-falseamiento-2736.php. Accessed 04/06 2015

Elferjani R, DesRochers A, Tremblay F (2014) Effects of mixing clones on hybrid poplar productivity, photosynthesis and root development in northeastern Canadian plantations. For Ecol Manage 327:157-166

EMEP E (2013) EEA air pollutant emission inventory guidebook 2013. European Environment Agency, Copenhagen

EPD (2016) The international EPD system. In: . http://www.environdec.com. Accessed 21/06 2016 
Ernst \&Young, Fraunhofer Institute (2010) MENA Assessment of the Local Manufacturing Potential for Concentrated Solar Power (CSP) Projects

European Commission (2013) European System of Accounts, ESA 2010. Publications Offi ce of the European Union 2013 - i-xxx, 1-652 pp - $21 \times 297 \mathrm{~cm} \mathrm{KS-02-13-269-EN-C}$

Eurostat (2014) Harmonised Indices of Consumer Prices Database. In: . http://epp.eurostat.ec.europa.eu/portal/page/portal/hicp/data/database. Accessed 06/30 2014

Fenercom (2012) Guía técnica de la Energía Solar Termoeléctrica:1-317

Finkbeiner M, Schau EM, Lehmann A, Traverso M (2010) Towards Life Cycle Sustainability Assessment. Sustain (Switzerland) 2:3309; 3309-3322; 3322

Finkbeiner M, Schau EM, Lehmann A, Traverso M (2010) Towards Life Cycle Sustainability Assessment. Sustainability 2:3309-22

Finkbeiner M, Schau EM, Lehmann A, Traverso M (2010) Towards Life Cycle Sustainability Assessment. Sustainability 2:3309-22

Font AR, Penalva AMR, Sbert JM (2007) Estimating the value of statistical life in Spain: a hedonic wage model application. Hacienda Publica Esp:29-48

Foolmaun RK, Ramjeawon T (2013) Life cycle sustainability assessments (LCSA) of four disposal scenarios for used polyethylene terephthalate (PET) bottles in Mauritius. Environment Development and Sustainability 15:783-806

Franze J, Ciroth A (2011) A comparison of cut roses from Ecuador and the Netherlands. Int J Life Cycle Assess 16:366-379

Freeman RE (2010) Strategic management: A stakeholder approach. Cambridge University Press

Gallego C, Victoria M (2012) Entiende el mercado eléctrico. Observatorio Crítico de la Energía:1-51

García Garrido S (2009) Curso de Centrales Termosolares. RENOVETEC

García Redondo AJ, Román Collado R (2014) An economic valuation of renewable electricity promoted by feed-in system in Spain. Renew Energ 68:51-57

Giuntoli J, Agostini A, Edwards R, Marelli L (2014) Solid and gaseous bioenergy pathways: input values and GHG emissions. Report EUR 26696

Gluch P, Baumann H (2004) The life cycle costing (LCC) approach: a conceptual discussion of its usefulness for environmental decision-making. Build Environ 39:571-580

Goedkoop M, Heijungs R, Huijbregts M, De Schryver A, Struijs J, van Zelm R (2009) ReCiPe 2008. A life cycle impact assessment method which comprises harmonised category indicators at the midpoint and the endpoint level 1 
Goldemberg J, Johansson TB, Reddy AKN, Williams RH (1985) Basic Needs and Much More with One Kilowatt per Capita. Ambio 14:190-200

Grießhammer R, Buchert M, Gensch C, Hochfeld C, Manhart A, Rüdenauer I, Ebinger F (2007) PROSA-Product Sustainability Assessment. Beschreibung der Methode

Guinée JB, Gorée M, Heijungs R, Huppes G, Kleijn R, Koning A, van de Oers L, Wegener SA, Suh $\mathrm{S}$, Udo HA, Bruijn H, van de Duin R, Huijbregts MAJ (2006) Handbook on Life Cycle Assessment. Operational Guide to the ISO Standards. Kluwer Academic Publishers, (Book Series: EcoEfficiency in Industry and Science: Vol. 7), Dordrecht

Guinee JB, Heijungs R, Huppes G, Zamagni A, Masoni P, Buonamici R, Ekvall T, Rydberg T (2010) Life cycle assessment: past, present, and futuret. Environ Sci Technol 45:90-96

Halford NG, Karp A (2011) Energy crops. Royal Society of Chemistry

Halog A, Manik Y (2011) Advancing Integrated Systems Modelling Framework for Life Cycle Sustainability Assessment. Sustainability 3:469-499

Hardi P, Semple P (2000) The Dashboard of Sustainability: from a metaphor to an operationale set of indices

Harrison M (2010) Valuing the Future: the social discount rate in cost-benefit analysis. Visiting researcher paper, Australien Productivity Commission, Canberra

Hauschild MZ, Potting J (2004) Spatial differentiation in life cycle impact assessment-the EDIP2003 methodology. Guidelines from the Danish EPA

Heijungs R, Settanni E, Guinée J (2012) Toward a computational structure for life cycle sustainability analysis: unifying LCA and LCC. The International Journal of Life Cycle Assessment:1-12

Heijungs R, Huppes G, Guinée J (2009) A scientific framework for LCA. Deliverable (D15) of work package 2

Heijungs R, Huppes G, Guinee JB (2010) Life cycle assessment and sustainability analysis of products, materials and technologies. Toward a scientific framework for sustainability life cycle analysis. Polym Degrad Stab 95:422-428

Hischier R, Weidema B, Althaus H, Bauer C, Doka G, Dones R, Frischknecht R, Hellweg S, Humbert S, Jungbluth N (2010) Implementation of life cycle impact assessment methods. Ecoinvent report

Ho CK, Iverson BD (2014) Review of high-temperature central receiver designs for concentrating solar power. Renewable and Sustainable Energy Reviews 29:835-846

Hofstetter P, Braunschweig A, Mettier T, Müller-Wenk R, Tietje O (1999) The Mixing Triangle: Correlation and Graphical Decision Support for LCA-based Comparisons. J Ind Ecol 3:97-115

Holland M, Watkiss P (2002) Benefits Table database: Estimates of the marginal external costs of air pollution in Europe BeTa Version E1. 02a. Contract report for EC DG Environment 
Hoogmartens R, Van Passel S, Van Acker K, Dubois M (2014) Bridging the gap between LCA, LCC and CBA as sustainability assessment tools. Environ Impact Assess Rev 48:27-33

Hoogmartens R, Van Passel S, Van Acker K, Dubois M (2014) Bridging the gap between LCA, LCC and CBA as sustainability assessment tools. Environ Impact Assess Rev 48:27-33

Hossaini N, Reza B, Akhtar S, Sadiq R, Hewage K (2015) AHP based life cycle sustainability assessment (LCSA) framework: a case study of six storey wood frame and concrete frame buildings in Vancouver. J Environ Plann Manage 58:1217-1241

Hou Q, Mao G, Zhao L, Du H, Zuo J (2015) Mapping the scientific research on life cycle assessment: a bibliometric analysis. The International Journal of Life Cycle Assessment 20:541555

Hu M, Kleijn R, Bozhilova-Kisheva KP, Di Maio F (2013) An approach to LCSA: the case of concrete recycling. International Journal of Life Cycle Assessment 18:1793-1803

Hu M, Kleijn R, Bozhilova-Kisheva KP, Di Maio F (2013) An approach to LCSA: the case of concrete recycling. International Journal of Life Cycle Assessment 18:1793-1803

Hunkeler D, Lichtenvort K, Rebitzer G (2008) Environmental life cycle costing. CRC Press

IDAE (2011) Evaluación del potencial de energía solar termoeléctrica. Estudio técnico PER 2010-2020

IDAE (2011) Plan de Energías Renovables (PER) 2010-2020

IDAE (2005) Plan de Energías Renovables (PER) 2005-2010.Ministerio de Industria, Turismo y Comercio. Instituto para la Diversificación y el Ahorro de Enegía IDAE

IEA (2015) Key world energy statistics. International Energy Agency

IEA (2015) World Energy Outlook Special Report 2015: Energy and Climate Change. International Energy Agency

IEA, NEA (2010) Projected Costs of Generating Electricity: Edition 2010. International Energy Agency (IEA) and Nuclear Energy Agency (NEA);

ILO (2013) Frequency rate of non-fatal occupational injury by sex and economic activity (\%) Spain. In: . http://www.ilo.org/ilostat/faces/help home/data by country/countrydetails/indicator-

details?country=ESP\&subject=INJ\&indicator=INJ NFTL SEX ECO RT\&datasetCode=YI\&collecti onCode $=Y$ I\& afrLoop=529093981354796\#\%40\%3Findicator\%3DINJ NFTL SEX ECO RT\%26su bject\%3DINJ\%26 afrLoop\%3D529093981354796\%26datasetCode\%3DYI\%26collectionCode\%3 DYI\%26country\%3DESP\%26 adf.ctrl-state\%3Df9sc1486d 295. Accessed 06/02 2015

ILO (2010) Mean weekly hours actually worked per employee by sex and economic activity Spain. In: . http://www.ilo.org/ilostat/faces/help home/data by country/countrydetails/indicator-

details?indicator=HOW XEES SEX ECO NB\&subject=HOW\& afrLoop $=535090556531104 \&$ dat asetCode $=$ YI\&collectionCode $=Y \mid \&$ country=ESP\& adf.ctrl- 
state $=180 \mathrm{y} 62 \mathrm{~h} 4 \mathrm{ao}$ 79\#40\%3Findicator\%3DHOW XEES SEX ECO NB\%26subject\%3DHOW\% 26 afrLoop\%3D535090556531104\%26datasetCode\%3DYI\%26collectionCode\%3DYI\%26countr y\%3DESP\%26 adf.ctrl-state\%3Df9sc1486d 316. Accessed 06/02 2015

ILO (2009) The cost of coercion. ILO

INE (2015) Tablas de origen y de destino 2000 . In: . http://www.ine.es/daco/daco42/cne/dacocneio.htm. Accessed 1/2 2015

INE (2015) El empleo de las personas con discapacidad. In: . http://www.ine.es/dynt3/inebase/es/index.htm?padre=1793\&capsel=1797. Accessed 06/02 2015

INE (2015) Mujeres y hombres en España/ Empleo. In: . http://www.ine.es/ss/Satellite?L=es ES\&c=INESeccion C\&cid=1259931459725\&p=125473511 0672\&pagename=ProductosYServicios\%2FPYSLayout\&param3=1259924822888. Accessed 06/02 2015

INE (2014) Encuesta Anual de Estructura Salarial Año 2012:1-10

INE (2012) Encuesta Trimestral de Coste Laboral (ETCL). Segundo trimestre de 2011. In: . Instituto Nacional de Estadística. http://www.ine.es/daco/daco42/etcl/etcl0211.pdf. Accessed $01 / 252014$

INE (2012) Encuesta de Estructura Salarial 2010. Resultados definitivos. In: . Instituto Nacional de Estadística. http://www.ine.es/prensa/np741.pdf. Accessed 01/25 2014

INE (2012) Contabilidad Nacional Trimestral de España. Base 2008 Cuentas no Financieras Trimestrales de los Sectores Institucionales. In: . Instituto Nacional de Estadística. http://www.ine.es/daco/daco42/ctnfsi/ctnfsi0212.pdf. Accessed 01/25 2014

IPCC (2015) Cambio climático 2014: Informe de síntesis. Contribución de los Grupos de trabajo I, II y III al Quinto Informe de Evaluación del Grupo Intergubernamental de Expertos sobre el Cambio Climático [Equipo principal de redacción, R.K. Pachauri y L.A. Meyer (eds.)].:1-197

IPCC (2006) 4: Agriculture, Forestry and Other Land Uses (AFOLU): 2006 IPCC/Guidelines for National Greenhouse Gas Inventories. IPCC/IGES, Hayama, Japan

IPCC (1995) Cambio Climático: Glosario preparado por el Grupo Intergubernamental de Expertos sobre el Cambio Climático (1995). In: . http://ipcc.ch/pdf/glossary/ipcc-glossary.pdf. Accessed 21/06 2016

IRENA (2014) Renewable Power Generation Costs in 2014

IRENA (2012) Renewable energy technologies: cost analysis series. Concentrating Solar Power. Volume 1: Power Sector. Issue 2/5:1-41

Jesinghaus J (2000) On the art of aggregating apples \& oranges. Fondazione Eni Enrico Mattei Milan 
Jolliet O, Margni M, Charles R, Humbert S, Payet J, Rebitzer G, Rosenbaum R (2003) IMPACT 2002 : a new life cycle impact assessment methodology. The International Journal of Life Cycle Assessment 8:324-330

Jørgensen A, Le Bocq A, Nazarkina L, Hauschild M (2008) Methodologies for social life cycle assessment. The international journal of life cycle assessment 13:96-103

Jorgensen A, Herrmann IT, Bjorn A (2013) Analysis of the link between a definition of sustainability and the life cycle methodologies. International Journal of Life Cycle Assessment 18:1440-1449

Jorgensen A, Hermann IT, Mortensen JB (2010) Is LCC relevant in a sustainability assessment?. Int J Life Cycle Assess 15:531-532

JRC (2016) European Platform on Life Cycle Assessment. In: . http://eplca.jrc.ec.europa.eu/. Accessed 21/06 2016

Klein SJ, Rubin ES (2013) Life cycle assessment of greenhouse gas emissions, water and land use for concentrated solar power plants with different energy backup systems. Energy Policy 63:935-950

Kloepffer W (2008) Life cycle Sustainability assessment of products. International Journal of Life Cycle Assessment 13:89-94

Kolb GJ, Jones S, Donnelly M, Gorman D, Thomas R, Davenport R, Lumia R (June 2007) Heliostat Cost Reduction Study,

Krewitt W (2002) External costs of energy-do the answers match the questions?: Looking back at 10 years of ExternE. Energy Policy 30:839-848

Kucukvar M, Gumus S, Egilmez G, Tatari O (2014) Ranking the sustainability performance of pavements: An intuitionistic fuzzy decision making method. Autom Constr 40:33-43

Kucukvar M, Noori M, Egilmez G, Tatari O (2014) Stochastic decision modeling for sustainable pavement designs. International Journal of Life Cycle Assessment 19:1185-1199

Kuhndt M, Liedtke C (1999) COMPASS - Companies' and Sectors' Path to Sustainability-The Methodology. Wuppertal Paper

Kuik O, Brander L, Nikitina N, Navrud S, Magnussen K, El Hadji F (2007) Report on the monetary valuation of energy related impacts on land use changes, acidification, eutrophication, visual intrusion and climate change. Cost Assessment of Sustainable Energy Systems (CASES) Project, Amsterdam

L. Simões C, Costa Pinto LM, Bernardo CA (2013) Environmental and economic assessment of a road safety product made with virgin and recycled HDPE: A comparative study. J Environ Manage 114:209-215

Lechon Y, de la Rua C, Saez R (2008) Life cycle environmental impacts of electricity production by solarthermal power plants in Spain. Journal of Solar Energy Engineering-Transactions of the Asme 130:021012 
Lee J, An S, Cha K, Hur T (2010) Life cycle environmental and economic analyses of a hydrogen station with wind energy. Int J Hydrogen Energy 35:2213-2225

Lee J, Yoo M, Cha K, Lim TW, Hur T (2009) Life cycle cost analysis to examine the economical feasibility of hydrogen as an alternative fuel. Int J Hydrogen Energy 34:4243-4255

Leiden University (2015) CML-IA Characterisation Factors. In: . http://cml.leiden.edu/software/data-cmlia.html\#downloads. Accessed 11/05 2015

Leontief W (1970) Environmental repercussions and the economic structure: an input-output approach. Rev Econ Stat:262-271

Leontief WW (1941) The Structure of American Economy, 1919-1929

Leontief WW (1936) Quantitative input and output relations in the economic systems of the United States. The review of economic statistics:105-125

Lovegrove K, Pye J (2012) Fundamental principles of CSP systems. In: Lovegrove K. (ed) Concentrating solar power technology: Principles, developments and applications. Woodhead Publishing Ltd, pp 266

Lovegrove K, Stein W (2012) Concentrating Solar Power Technology: Principles, Developments and Applications. Elsevier Science

Ley 54/1997, de 27 de noviembre, del Sector Eléctrico. BOE-A-1997-25340 páginas 35097 a 35126

Lu B, Li B, Wang L, Yang J, Liu J, Wang XV (2014) Reusability based on Life Cycle Sustainability Assessment: case study on WEEE. 21st Cirp Conference on Life Cycle Engineering 15:473-478

Lund H, Mathiesen BV, Christensen P, Schmidt JH (2010) Energy system analysis of marginal electricity supply in consequential LCA. The International Journal of Life Cycle Assessment $15: 260-271$

Macombe C, Leskinen P, Feschet P, Antikainen R (2013) Social life cycle assessment of biodiesel production at three levels: a literature review and development needs. J Clean Prod 52:205-216

Manik Y, Leahy J, Halog A (2013) Social life cycle assessment of palm oil biodiesel: a case study in Jambi Province of Indonesia. The International Journal of Life Cycle Assessment 18:1386-1392

Manzardo A, Ren J, Mazzi A, Scipioni A (2012) A grey-based group decision-making methodology for the selection of hydrogen technologies in life cycle sustainability perspective. Int J Hydrogen Energy 37:17663-17670

Martínez-Blanco J, Lehmann A, Muñoz P, Antón A, Traverso M, Rieradevall J, Finkbeiner M (2014) Application challenges for the social Life Cycle Assessment of fertilizers within life cycle sustainability assessment. J Clean Prod 69:34-48

Martínez-Blanco J, Lehmann A, Muñoz P, Antón A, Traverso M, Rieradevall J, Finkbeiner M (2014) Application challenges for the social Life Cycle Assessment of fertilizers within life cycle sustainability assessment. J Clean Prod 69:34-48 
Mathiesen BV, Münster M, Fruergaard T (2009) Uncertainties related to the identification of the marginal energy technology in consequential life cycle assessments. J Clean Prod 17:13311338

Mattioda RA, Mazzi A, Canciglieri Jr O, Scipioni A (2015) Determining the principal references of the social life cycle assessment of products. The International Journal of Life Cycle Assessment:1-11

Menikpura SNM, Gheewala SH, Bonnet S (2012) Framework for life cycle sustainability assessment of municipal solid waste management systems with an application to a case study in Thailand. Waste Manage Res 30:708-719

Miller RE, Blair PD (2009) Input-output analysis: foundations and extensions. Cambridge University Press

MINETUR (2013) Resolución de 7 de marzo de 2013, de la Secretaría de Estado de Energía, por la que se publican los valores del coste de la materia prima y del coste base de la materia prima del gas natural para el segundo trimestre de 2013, a los efectos del cálculo del complemento de eficiencia y los valores retributivos de las instalaciones de cogeneración y otras en el Real Decreto 661/2007, de 25 de mayo, por el que se regula la actividad de producción de energía eléctrica en régimen especial. BOE-A-2013-2876. BOE-A-2013-2876; num.65 pag 21477-21479

MINETUR (2012) La energía en España 2011. Ministerio de Industria, Energía y Turismo de España

MINETUR (2010) Resolución de 7 de abril de 2010, de la Secretaría de Estado de Energía, por la que se publican los valores del coste de la materia prima y del coste base de la materia prima del gas natural para el primer trimestre 2010, a los efectos del cálculo del complemento de eficiencia y los valores retributivos de las instalaciones de cogeneración y otras en el Real Decreto 661/2007, de 25 de mayo, por el que se regula la actividad de producción de energía eléctrica en régimen especial. BOE-A-2010-5945 num.90 pag 21477-33283

Ministry of foreign affairs (2015) Fichas País. In: . http://www.exteriores.gob.es/portal/es/saladeprensa/paginas/fichaspais.aspx. Accessed $06 / 152015$

Mirasgedis S, Diakoulaki D (1997) Multicriteria analysis vs. externalities assessment for the comparative evaluation of electricity generation systems. Eur J Oper Res 102:364-379

Montaño B (2014) Un juez admite a trámite una demanda contra Florentino por fraude y falseamiento de las cuentas de ACS. In: . Vozpópuli. http://vozpopuli.com/economia-yfinanzas/50934-un-juez-admite-a-tramite-una-demanda-contra-florentino-por-fraude-y-

falseamiento-de-las-cuentas-de-acs. Accessed 06/04 2015

Moriizumi Y, Matsui N, Hondo H (2010) Simplified life cycle sustainability assessment of mangrove management: a case of plantation on wastelands in Thailand. J Clean Prod 18:16291638

National Renewable Energy Laboratory. Golden, CO. (2015) System Advisor Model. Accessed March 12, 2015 https://sam nrel gov/content/downloads Version 2015.1.30 (SAM 2015.1.30) 
NEEDS (2009) New Energy Externalities Development for Sustainability. In: . http://www.needs-project.org/index.php. Accessed 03/15 2015

Neugebauer S, Martinez-Blanco J, Scheumann R, Finkbeiner M (2015) Enhancing the practical implementation of life cycle sustainability assessment - proposal of a Tiered approach. J Clean Prod 102:165-176

Neylan WN, Howard PH (1977) Chemical market Input/Output analysis of selected chemical substances to assess sources of environmental contamination: TASK II. Biphenyl and Diphenyl Oxide. U.S. Environmental Protection Agency.:1-109

Nielsen UB, Madsen P, Hansen JK, Nord-Larsen T, Nielsen AT (2014) Production potential of 36 poplar clones grown at medium length rotation in Denmark. Biomass Bioenergy 64:99-109

Notarnicola B, Tassielli G, Nicoletti GM (2004) Environmental and economic analysis of the organic and conventional extra-virgin olive oil. New medit 3:28-34

NREL (2014) Concentrating Solar Power Projects. National Renewable Energy Laboratory. In: . NREL. www.nrel.gov/csp/solarpaces/. Accessed 26/09 2014

Nzila C, Dewulf J, Spanjers H, Tuigong D, Kiriamiti H, van Langenhove H (2012) Multi criteria sustainability assessment of biogas production in Kenya. Appl Energy 93:496-506

O'Brien M, Doig A, Clift R (1996) Social and environmental life cycle assessment (SELCA). The International Journal of Life Cycle Assessment 1:231-237

OECD (2015) Regulatory reform and competition policy. In: . http://www.oecd.org/eco/reform/. Accessed 03/06 2015

OECD (2014) Prices and Purchasing Power Parities. In: . http://stats.oecd.org/Index.aspx?DataSetCode=PPPGDP. Accessed 06/30 2014

OECD (2014) Average annual hours actually worked per worker. In: . http://stats.oecd.org/index.aspx?DataSetCode=ANHRS. Accessed 01/02 2015

OMIE (2016) Operador del Mercado Ibérico Español. In: . http://www.omie.es/inicio. Accessed $17 / 062016$

OMIE (2015) Market results. In: . http://www.omie.es/en/inicio. Accessed 09/29 2015

Onat NC, Kucukvar M, Tatari O (2014) Integrating triple bottom line input-output analysis into life cycle sustainability assessment framework: the case for US buildings. International Journal of Life Cycle Assessment 19:1488-1505

Onat NC, Kucukvar M, Tatari O (2014) Towards Life Cycle Sustainability Assessment of Alternative Passenger Vehicles. Sustainability 6:9305-9342

Orden IET/1045/2014 (2014) Orden IET/1045/2014, de 16 de junio, por la que se aprueban los parámetros retributivos de las instalaciones tipo aplicables a determinadas instalaciones de producción de energía eléctrica a partir de fuentes de energía renovables, cogeneración y residuos. BOE-A-2014-6495. BOE-A-2014-6495; 140 pag 46430-48190 
Oró E, Gil A, de Gracia A, Boer D, Cabeza LF (2012) Comparative life cycle assessment of thermal energy storage systems for solar power plants. Renew Energ 44:166-173

Ostermeyer Y, Wallbaum H, Reuter F (2013) Multidimensional Pareto optimization as an approach for site-specific building refurbishment solutions applicable for life cycle sustainability assessment. International Journal of Life Cycle Assessment 18:1762-1779

Parent J, Cucuzzella C, Revéret J (2010) Impact assessment in SLCA: sorting the SLCIA methods according to their outcomes. The international journal of life cycle assessment 15:164-171

Pérez Vidal V (2013) Monitoreo de los minerales industriales de Chile ANÁLISIS DE LOS RECURSOS SALINOS 2013 DE /18/ 2013. Comisión Chilena del Cobre:1-57

Pérez-Cruzado C, Sanchez-Ron D, Rodríguez-Soalleiro R, Hernández MJ, Mario Sánchez-Martín M, Cañellas I, Sixto H (2014) Biomass production assessment from Populus spp. short-rotation irrigated crops in Spain. GCB Bioenergy 6:312-326

Pesonen H, Horn S (2013) Evaluating the Sustainability SWOT as a streamlined tool for life cycle sustainability assessment. International Journal of Life Cycle Assessment 18:1780-1792

Petti L, Ugaya CML, Di Cesare S (2014) Systematic review of Social-Life Cycle Assessment (SLCA) case studies. In: . http://acvsociale.cirad.fr/content/download/4260/31992/version/1/file/Thema+2+-+Sess1-

4+Petti+et+al.+2014 4thSocSem SLCA Montpellier.pdf 2014

Peukert B, Benecke S, Clavell J, Neugebauer S, Nissen NF, Uhlmann E, Lang K, Finkbeiner M (2015) Addressing sustainability and flexibility in manufacturing via smart modular machine tool frames to support sustainable value creation. 22nd Cirp Conference on Life Cycle Engineering 29:514-519

Pfister et al. (2012) Water Stress Index (Pfister et al. 2009). In: . https://www.google.es/url?sa=t\&rct=j\&q=\&esrc=s\&source=web\&cd=1\&cad=rja\&uact=8\&ved= OahUKEwj3593pruXJAhVJ2BoKHXfKDDkQFggfMAA\&url=http\%3A\%2F\%2Fwww.ifu.ethz.ch\%2Fs taff\%2Fstpfiste\%2Flmpact factors LCA pfister et al.kmz\&usg=AFQjCNEN69B6DyD7sb3KW Cixeo4PPWA\&sig2=5 iVAOZBPtZnpiUAOxQOkA\&bvm=bv.110151844,d.ZWU. Accessed 04/12 2015

Pfister S, Koehler A, Hellweg S (2009) Assessing the environmental impacts of freshwater consumption in LCA. Environ Sci Technol 43:4098-4104

Piemonte V, Falco MD, Tarquini P, Giaconia A (2011) Life Cycle Assessment of a high temperature molten salt concentrated solar power plant. Sol Energy 85:1101-1108

Pizzirani S, McLaren SJ, Seadon JK (2014) Is there a place for culture in life cycle sustainability assessment?. International Journal of Life Cycle Assessment 19:1316-1330

Powers SE (2005) Quantifying cradle-to-farm gate life-cycle impacts associated with fertilizer used for corn, soybean, and stover production

PRé Consultants (2010) SimaPro 7. Introduction into LCA 
Protermosolar (2016) Boletín de febrero 2016. In: . http://us10.campaignarchive2.com/?u=1298d3bcd23d75d1ccc206bdb\&id=aa5d9498f9\&e=92f7681504. Accessed $16 / 062016$

Proyecto FORWAST (2011) EU\& DK Input Output database. In: . http://forwast.brgm.fr/. Accessed 11/05 2014

Rabl A, Spadaro JV, Holland M (2014) 9. Monetary Valuation. In: How Much Is Clean Air Worth? Calculating the Benefits of Pollution Control. Cambridge University Press

Real Decreto 2818/1998, de 23 de diciembre, sobre producción de energía eléctrica por instalaciones abastecidas por recursos o fuentes de energía renovables, residuos y cogeneración. BOE-A-1998-30041 páginas 44077 a 44089

Real Decreto 1955/2000, de 1 de diciembre, por el que se regulan las actividades de transporte, distribución, comercialización, suministro y procedimientos de autorización de instalaciones de energía eléctrica. BOE-A-2000-24019 páginas 45988 a 46040

Real Decreto 841/2002, de 2 de agosto, por el que se regula para las instalaciones de producción de energía eléctrica en régimen especial su incentivación en la participación en el mercado de producción, determinadas obligaciones de información de sus previsiones de producción, y la adquisición por los comercializadores de su energía eléctrica producida. BOE-A2002-17369 páginas 31968 a 31974

Real Decreto 436/2004, de 12 de marzo, por el que se establece la metodología para la actualización y sistematización del régimen jurídico y económico de la actividad de producción de energía eléctrica en régimen especial. BOE-A-2004-5562 páginas 13217 a 13238

Real Decreto 2351/2004, de 23 de diciembre, por el que se modifica el procedimiento de resolución de restricciones técnicas y otras normas reglamentarias del mercado eléctrico. BOEA-2004-21561 páginas 41686 a 41690

Real Decreto 661/2007, de 25 de mayo, por el que se regula la actividad de producción de energía eléctrica en régimen especial. BOE-A-2007-10556 páginas 22846 a 22886

Real Decreto 1565/2010, de 19 de noviembre, por el que se regulan y modifican determinados aspectos relativos a la actividad de producción de energía eléctrica en régimen especial. BOE-A2010-17976 páginas 97428 a 97446

Real Decreto 1614/2010, de 7 de diciembre, por el que se regulan y modifican determinados aspectos relativos a la actividad de producción de energía eléctrica a partir de tecnologías solar termoeléctrica y eólica. BOE-A-2010-18915 páginas 101853 a 101859

Real Decreto 1106/2014 (2014) Real Decreto 1106/2014, de 26 de diciembre, por el que se fija el salario mínimo interprofesional para 2015. BOE-A-2014-13518; 313 pag 105840- 105842

Real Decreto 413/2014 (2014) Real Decreto 413/2014, de 6 de junio, por el que se regula la actividad de producción de energía eléctrica a partir de fuentes de energía renovables, cogeneración y residuos. BOE-A-2014-6123. BOE-A-2014-6123; 140 pag 43876-43978 
Rebitzer G, Hunkeler D (2003) Life cycle costing in LCM: Ambitions, opportunities, and limitations - Discussing a framework. Int J Life Cycle Assess 8:253-256

Rebitzer G, Hunkeler D, Jolliet O (2003) LCC - The economic pillar of sustainability: Methodology and application to wastewater treatment. Environ Prog 22:241-249

REE (2015) Informe del sistema eléctrico español 2014. In: . Red Eléctrica de España. http://www.ree.es/es/publicaciones/sistema-electrico-espanol/informe-anual/informe-delsistema-electrico-espanol-2014. Accessed 10/07 2015

REE (2014) Informe del sistema eléctrico español 2013. In: . Red Eléctrica de España. http://www.ree.es/es/publicaciones/sistema-electrico-espanol/informe-anual. Accessed 10/07 2014

REE (2014) Monthly bulletins of the Spanish electricity system. Red Eléctrica Española. In: . http://www.ree.es/es/publicaciones/sistema-electrico-espanol/boletines-mensuales. Accessed $10 / 232014$

REE (2014) Boletín mensual. Agosto 2014. Número 92. In: . Red Eléctrica de España. http://www.ree.es/es/publicaciones/sistema-electrico-espanol/boletines-mensuales/boletinmensual-agosto-2014-numero-92. Accessed 10/07 2014

Ren J, Manzardo A, Mazzi A, Zuliani F, Scipioni A (2015) Prioritization of bioethanol production pathways in China based on life cycle sustainability assessment and multicriteria decisionmaking. International Journal of Life Cycle Assessment 20:842-853

Rodríguez Trouwborst F (2010) Manual de centrales termosolares. SIALSOL

Roth IF, Ambs LL (2004) Incorporating externalities into a full cost approach to electric power generation life-cycle costing. Energy 29:2125-2144

Saaty TL (1990) How to make a decision: the analytic hierarchy process. Eur J Oper Res 48:926

Sala S, Farioli F, Zamagni A (2013) Life cycle sustainability assessment in the context of sustainability science progress (part 2). Int J Life Cycle Assess 18:1686-1697

Sala S, Farioli F, Zamagni A (2013) Progress in sustainability science: lessons learnt from current methodologies for sustainability assessment: Part 1. International Journal of Life Cycle Assessment 18:1653-1672

San Miguel G, Corona B, Ruiz D, Landholm D, Laina R, Tolosana E, Sixto H, Cañellas I (2015) Environmental, energy and economic analysis of a biomass supply chain based on a poplar short rotation coppice in Spain. J Clean Prod 94:93-101

San Miguel G, Corona B (2014) Hybridizing concentrated solar power (CSP) with biogas and biomethane as an alternative to natural gas: Analysis of environmental performance using LCA. Renew Energ 66:580-587

Schau EM, Traverso M, Lehmann A, Finkbeiner M (2011) Life Cycle Costing in Sustainability Assessment-A Case Study of Remanufactured Alternators. Sustainability 3:2268-2288 
Schepelmann P, Ritthoff M, Santman P, Jeswani H, Azapagic A (2008) Report on the SWOT analysis of concepts, methods and models potentially supporting LCA-deliverable (d10) of work package 3 (WP3) CALCAS project. Wuppertal Institute for Climate and Energy and School of Chemical Engineering and Analytical Science, University of Manchester

Schneider L, Berger M, Schueler-Hainsch E, Knoefel S, Ruhland K, Mosig J, Bach V, Finkbeiner $M$ (2014) The economic resource scarcity potential (ESP) for evaluating resource use based on life cycle assessment. International Journal of Life Cycle Assessment 19:601-610

SeaRates (2016) International container shipping. Freight broker and forwarder. In: . https://www.searates.com/. Accessed 05/01/2015

Servert J, San Miguel G, Lopez D (2011) Hybrid Solar - Biomass Plants for Power Generation; Technical and Economic Assessment. Glob Nest J 13:266-276

SETAC (1993) Guidelines for life-cycle assessment: a"code of practice; from the SETAC Workshop held at Sesimbra, Portugal, 31 March-3 April 1993. SETAC, Pensacola, Florida

Silalertruksa T, Bonnet S, Gheewala SH (2012) Life cycle costing and externalities of palm oil biodiesel in Thailand. J Clean Prod 28:225-232

Sixto H, Hernández MJ, Ciria MP, Carrasco JE, Cañellas I (2010) Manual de cultivo de Populus spp. para la producción de biomasa con fines energéticos. INIA

Söderholm P, Sundqvist T (2003) Pricing environmental externalities in the power sector: ethical limits and implications for social choice. Ecol Econ 46:333-350

Sonnemann G, Vigon B (2011) Global Guidance Principles for Life Cycle Assessment Databases

Sonnemann G, Gemechu ED, Adibi N, De Bruille V, Bulle C (2015) From a critical review to a conceptual framework for integrating the criticality of resources into Life Cycle Sustainability Assessment. J Clean Prod 94:20-34

Sonnemann GW, Schuhmacher M, Castells F (2003) Uncertainty assessment by a Monte Carlo simulation in a life cycle inventory of electricity produced by a waste incinerator. J Clean Prod 11:279-292

SQM (2015) Nitrato de Sodio y Nitrato de Potasio. In: . SQM. http://www.sqm.com/eses/productos/quimicosindustriales/salestermo-solares/nitratosdesodioypotasio.aspx.

Accessed 01/23 2015

SQM (2013) Memoria Anual. In: http://ir.sqm.com/Spanish/inversionistas/filings/memoria-anual/default.aspx. Accessed 03/5 2014

Stamford LJ (2012) Life cycle sustainability assessment of electricity generation: a methodology and an application in the UK context. Dissertation or Thesis, University of Manchester

Stamford L, Azapagic A (2014) Life cycle sustainability assessment of UK electricity scenarios to 2070. Energy for Sustainable Development 23:194-211 
Stamford L, Azapagic A (2011) Sustainability indicators for the assessment of nuclear power. Energy 36:6037-6057

Steen B (1997) On uncertainty and sensitivity of LCA-based priority setting. J Clean Prod 5:255262

Stefanova M, Tripepi C, Zamagni A, Masoni P (2014) Goal and Scope in Life Cycle Sustainability Analysis: The Case of Hydrogen Production from Biomass. Sustainability 6:5463-5475

Stern N (2007) The economics of climate change: the Stern review. cambridge University press

Stocker TF, Qin D, Plattner G, Tignor M, Allen SK, Boschung J, Nauels A, Xia Y, Bex V, Midgley PM (2013) Climate change 2013: The physical science basis. Intergovernmental Panel on Climate Change, Working Group I Contribution to the IPCC Fifth Assessment Report (AR5)(Cambridge Univ Press, New York)

Streeten P, Burki SJ (1978) Basic needs: Some issues. World Dev 6:411-421

Su Xing, Zhang Xu, Gao Jun (2008) Inventory analysis of LCA on steel- and concreteconstruction office buildings. Energy \& Buildings 40:1188-93

Sundqvist T (2004) What causes the disparity of electricity externality estimates?. Energy Policy 32:1753-1766

Swarr TE, Hunkeler D, Klöpffer W, Pesonen H, Ciroth A, Brent AC, Pagan R (2011) Environmental life-cycle costing: a code of practice. The International Journal of Life Cycle Assessment 16:389391

teinteresa (2015) CNMC sanciona con 98,2 millones a 39 empresas y tres asociaciones de gestión de residuos y saneamiento urbano. In: . http://www.teinteresa.es/dinero/SANCIONAMILLONES-ASOCIACIONES-RESIDUOS-SANEAMIENTO 0 1292272515.html. Accessed 06/04 2015

Testa R, Di Trapani AM, Foderà M, Sgroi F, Tudisca S (2014) Economic evaluation of introduction of poplar as biomass crop in Italy. Renewable and Sustainable Energy Reviews 38:775-780

Timmer M, Erumban A, Gouma R, Los B, Temurshoev U, de Vries G, Arto I (2012) The world input-output database (WIOD): contents, sources and methods. WIOD Background document available at www.wiod.org 40

Tolosana E, Laina R, Martínez-Ferrari R, Ambrosio Y (2011) Recovering of forest biomass from Spanish hybrid poplar plantations. Biomass Bioenergy 35:2570-2580

Torresol Energy (2015) Gemasolar. In: . http://www.torresolenergy.com/TORRESOL/plantagemasolar/es 2015

Traverso M, Asdrubali F, Francia A, Finkbeiner M (2012) Towards life cycle sustainability assessment: an implementation to photovoltaic modules. Int J Life Cycle Assess 17:1068-1079 
Traverso M, Finkbeiner M, Jorgensen A, Schneider L (2012) Life Cycle Sustainability Dashboard. $J$ Ind Ecol 16:680-688

Triantaphyllou E (2013) Multi-criteria decision making methods: a comparative study. Springer Science \& Business Media

UNE-EN ISO 14020:2002 Etiquetas ecológicas y declaraciones ambientales. Principios generales. (ISO 14020:2000)

UNE-EN ISO 14021:2002 Etiquetas ecológicas y declaraciones medioambientales. Autodeclaraciones medioambientales (Etiquetado ecológico Tipo II). (ISO 14021:1999)

UNE-EN ISO 14024:2001 Etiquetas ecológicas y declaraciones medioambientales. Etiquetado ecológico Tipo I. Principios generales y procedimientos. (ISO 14024:1999)

UNE-EN ISO 14025:2010 Etiquetas y declaraciones ambientales. Declaraciones ambientales tipo III. Principios y procedimientos. (ISO 14025:2006)

UNE-EN ISO 14040:2006 Gestión ambiental. Análisis del ciclo de vida. Principios y marco de referencia

UNE-EN ISO 14044:2006 Gestión ambiental. Análisis del ciclo de vida. Requisitos y directrices.

UNEP/SETAC (2015) Life Cycle Initiative. In: . http://www.lifecycleinitiative.org/. Accessed $08 / 272015$

UNEP-SETAC Life Cycle Initiative (2009) Guidelines for social life cycle assessment of products. United Nations Environment Programme.ISBN:978-992

UNESCO (2015) What is meant by "cultural heritage"?. In: . http://www.unesco.org/new/en/culture/themes/illicit-trafficking-of-cultural-property/unescodatabase-of-national-cultural-heritage-laws/frequently-asked-questions/definition-of-thecultural-heritage/. Accessed 06/19 2015

United Nations (2015) Transforming our World: the 2030 agenda for sustainable development: $\mathrm{A} / \mathrm{RES} / 70 / 1$

United Nations (1992) Agenda 21. The United Nations Programme for Action from Rio

Valdivia S, Ugaya CML, Hildenbrand J, Traverso M, Mazijn B, Sonnemann G (2013) A UNEP/SETAC approach towards a life cycle sustainability assessment-our contribution to Rio+20. International Journal of Life Cycle Assessment 18:1673-1685

van der Giesen C, Kleijnl R, Kramer GJ, Guinee J (2013) Towards application of life cycle sustainability analysis. Revue De Metallurgie-Cahiers D Informations Techniques 110:29-36

Viebahn P, Kronshage S, Trieb F, Lechon Y (2008) Final report on technical data, costs, and life cycle inventories of solar thermal power plants. Project $n$ ㅇ502687, New Energy Externalities Developments for Sustainability. 
Vinyes E, Oliver-Solà J, Ugaya C, Rieradevall J, Gasol CM (2013) Application of LCSA to used cooking oil waste management. The International Journal of Life Cycle Assessment 18:445-455

Vinyes E, Oliver-Sola J, Ugaya C, Rieradevall J, Gasol CM (2013) Application of LCSA to used cooking oil waste management. International Journal of Life Cycle Assessment 18:445-455

Wang J, Jing Y, Zhang C, Zhao J (2009) Review on multi-criteria decision analysis aid in sustainable energy decision-making. Renew Sust Energ Rev 13:2263-2278

Weidema BP (2006) The integration of economic and social aspects in life cycle impact assessment. The International Journal of Life Cycle Assessment 11:89-96

Weidema BP, Frees N, Nielsen A (1999) Marginal production technologies for life cycle inventories. The International Journal of Life Cycle Assessment 4:48-56

Weidema BP, Ekvall T, Heijungs R (2009) Guidelines for application of deepened and broadened LCA. Deliverable D18 of work package 5:17

Weinrebe G, Bohnke M, Trieb F (1998) Life cycle assessment of an 80 MW SEGS plant and a 30 MW PHOEBUS power tower. Proceedings of the International Solar Energy Conference.Solar Engineering 1998:417; 417-424; 424

Whitaker MB, Heath GA, Burkhardt III JJ, Turchi CS (2013) Life Cycle Assessment of a Power Tower Concentrating Solar Plant and the Impacts of Key Design Alternatives. Environ Sci Technol 47:5896-5903

WHO (2006) Health risks of particulate matter from long-range transboundary air pollution. World Health Organization

Wiedmann T, Wilting HC, Lenzen M, Lutter S, Palm V (2011) Quo Vadis MRIO? Methodological, data and institutional requirements for multi-region input-output analysis. Ecol Econ 70:19371945

Wolf M, Pant R, Chomkhamsri K, Sala S, Pennington D (2012) The International Reference Life Cycle Data System (ILCD) Handbook: Towards More Sustainable Production and Consumption for a Resource-efficient Europe. Publications Office

Wood R, Hertwich EG (2013) Economic modelling and indicators in life cycle sustainability assessment. International Journal of Life Cycle Assessment 18:1710-1721

Wood R, Hertwich EG (2013) Economic modelling and indicators in life cycle sustainability assessment. Int J Life Cycle Assess 18:1710-1721

Yu M, Halog A (2015) Solar Photovoltaic Development in Australia-A Life Cycle Sustainability Assessment Study. Sustainability 7:1213-1247

Zamagni A, Buttol P, Buonamici R, Masoni P, Guinée J, Huppes G, Heijungs R, van der Voet E, Ekvall T, Rydberg T (2009) Blue paper on life cycle sustainability analysis; Deliverable 20 of the CALCAS project, 2009. Available at www. calcasproject. net 
Zamagni A, Pesonen H, Swarr T (2013) From LCA to Life Cycle Sustainability Assessment: concept, practice and future directions. International Journal of Life Cycle Assessment 18:16371641

Zamagni A, Pesonen H, Swarr T (2013) From LCA to Life Cycle Sustainability Assessment: concept, practice and future directions. Int J Life Cycle Assess 18:1637-1641

Zamagni A (2012) Life cycle sustainability assessment. Int J Life Cycle Assess 17:373-376

Zhou Z, Jiang H, Qin L (2007) Life cycle sustainability assessment of fuels. Fuel 86:256-263 



\section{ANEXO I: TABLAS DE INVENTARIO PARA EL ACV-A}

Este anexo incluye las tablas del inventario del ciclo de vida de la planta HYSOL (sección 1), de la planta TERMOSOLAR CCP (sección 2) y de las astillas de chopo (sección 3).

\section{Tablas de inventario de la planta HYSOL}

Tabla 108 Tabla de inventario de la fabricación y transporte del sistema campo solar de una planta HYSOL de torre de 100 MW

\begin{tabular}{|c|c|c|c|c|c|}
\hline Componentes & $\begin{array}{l}\text { Subcompo } \\
\text {-nentes }\end{array}$ & Dataset (ecoinvent) & $\begin{array}{l}\text { TOTAL } \\
\text { (Cantidad) }\end{array}$ & Ud & SD2 \\
\hline \multirow{10}{*}{$\begin{array}{l}\text { Heliostatos } \\
\text { (materiales para } \\
\text { una unidad) }\end{array}$} & \multirow{5}{*}{ Espejos } & Flat glass, coated - with silver - $\{$ RER $\} \mid$ production | Alloc Def, $U$ & $5.523,7658$ & $\mathrm{~kg}$ & 1,09 \\
\hline & & Epoxy resin, liquid $\{R E R\} \mid$ production | Alloc Def, $U$ & 1,0734 & $\mathrm{~kg}$ & 1,09 \\
\hline & & Copper $\{$ GLO $\} \mid$ market for | Alloc Def, U & 2,2194 & $\mathrm{~kg}$ & 1,09 \\
\hline & & Metal working, average for copper product manufacturing $\{R E R\} \mid$ processing | Alloc Def, $U$ & 2,2194 & $\mathrm{~kg}$ & 1,62 \\
\hline & & $\begin{array}{l}\text { Transport, freight, lorry }>32 \text { metric ton, EURO3 }\{\text { RER }\} \mid \text { transport, freight, lorry }>32 \text { metric ton, } \\
\text { EURO3 | Alloc Def, } U\end{array}$ & $3.316,2352$ & $\mathrm{tkm}$ & 1,37 \\
\hline & \multirow{2}{*}{ Estructura } & Steel, unalloyed $\{E S\} \mid$ steel production, converter, unalloyed | Alloc Def, U* & 1675 & $\mathrm{~kg}$ & 1,06 \\
\hline & & Metal working, average for steel product manufacturing $\{E S\} \mid$ processing $\mid$ Alloc Def, $U^{*}$ & 1675 & $\mathrm{~kg}$ & 1,06 \\
\hline & \multirow{3}{*}{$\begin{array}{l}\text { Pedestal y } \\
\text { accionami } \\
\text { ento }\end{array}$} & Steel, unalloyed $\{E S\} \mid$ steel production, converter, unalloyed | Alloc Def, $U^{*}$ & 1.212 .475 & $\mathrm{~kg}$ & 1,06 \\
\hline & & Drawing of pipe, steel $\{R E R\} \mid$ processing | Alloc Def, $U$ & 1.550 & $\mathrm{~kg}$ & 1,06 \\
\hline & & _68 Electrical machinery n.e.c., EU27 & 1,7 & $\mathrm{Kg}$ & 1,09 \\
\hline \multirow{2}{*}{\multicolumn{2}{|c|}{ Control e instrumentación }} & Cable, three-conductor cable $\{G L O\} \mid$ production | Alloc Def, $U$ & 4,87 & $\mathrm{~kg}$ & 1,36 \\
\hline & & Cable, unspecified $\{\mathrm{GLO}\} \mid$ production | Alloc Def, U & 0,50 & kg & 1,36 \\
\hline
\end{tabular}




$\begin{array}{lll}1,51 & \mathrm{~kg} & 1,36 \\ 1,51 & \mathrm{Kg} & 2,36 \\ 1,64 & \mathrm{~kg} & 1,36 \\ 3,3 & \mathrm{~kg} & 1,36 \\ 1,64 & \mathrm{~kg} & 2,36 \\ 647,36 & \mathrm{~kg} & 1,37 \\ 0,25 & \mathrm{p} & 1,1\end{array}$

Vehículo para limpieza de Metal working, average for steel product manufacturing $\{E S\} \mid$ processing | Alloc Def, $U$ Steel, chromium steel 18/8, hot rolled \{GLO\}| market for | Alloc Def, U

Electronics, for control units $\{G L O\} \mid$ market for | Alloc Def, $U$

Metal working, average for chromium steel product manufacturing $\{R E R\} \mid$ processing $\mid$ Alloc Def, U

Transport, freight, lorry $>32$ metric ton, EURO3 $\{$ RoW $\} \mid$ transport, freight, lorry $>32$ metric ton, EURO3 | Alloc Def, U

\begin{tabular}{|c|c|c|c|c|c|}
\hline $\begin{array}{l}\text { Component } \\
\text { es }\end{array}$ & $\begin{array}{l}\text { Subcomponent } \\
\text { es }\end{array}$ & Dataset & $\begin{array}{l}\text { TOTAL } \\
\text { (Cantidad) }\end{array}$ & Ud. & SD2 \\
\hline \multirow{4}{*}{ Torre } & Hormigón & $\begin{array}{l}\text { Concrete, sole plate and foundation \{Europe without switzerland, ES\}| production | Alloc Def, } \\
\mathrm{U}^{*}\end{array}$ & 62.654 .012 & $\mathrm{~kg}$ & 1,06 \\
\hline & $\begin{array}{l}\text { Acero al } \\
\text { carbono }\end{array}$ & Reinforcing steel $\{\mathrm{ES}, \mathrm{MX}, \mathrm{SA}, \mathrm{IN}, \mathrm{CL}, \mathrm{ZA}\} \mid$ market | Alloc Def, U* & 3.877 .456 & $\mathrm{~kg}$ & 1,06 \\
\hline & \multicolumn{2}{|c|}{ Metal working, average for steel product manufacturing $\{\mathrm{ES}, \mathrm{MX}, \mathrm{SA}, \mathrm{IN}, \mathrm{CL}, \mathrm{ZA}\} \mid$ processing $\mid$ Alloc Def, $\mathrm{U}^{*}$} & 3.877 .456 & $\mathrm{~kg}$ & 1,61 \\
\hline & $\begin{array}{l}\text { Transporte } \\
\text { materiales torre }\end{array}$ & Transport, freight, lorry 16-32 metric ton, EURO4 \{GLO\}| market for | Alloc Def, U & 13.306 .293 & $\mathrm{tkm}$ & 1,35 \\
\hline \multirow{5}{*}{ Receptor } & Cuarzo & Glass tube, borosilicate $\{G L O\} \mid$ market for | Alloc Def, $U$ & 52,600 & $\mathrm{t}$ & 1,21 \\
\hline & $\begin{array}{l}\text { Acero Alloy UNS } \\
\text { N06626 steel }\end{array}$ & Steel, chromium steel $18 / 8$, hot rolled $\{$ RoW $\} \mid$ production | Alloc Def, $U$ & 26,300 & $\mathrm{t}$ & 1,21 \\
\hline & \multicolumn{2}{|c|}{ Metal working, average for chromium steel product manufacturing $\{G L O\} \mid$ market for $\mid$ Alloc Def, $U$} & 26,300 & $\mathrm{t}$ & 1,61 \\
\hline & \multicolumn{2}{|c|}{ Transport, freight, lorry >32 metric ton, EURO3 $\{G L O\} \mid$ market for | Alloc Def, $U$} & 15.780 & $\mathrm{tkm}$ & 1,37 \\
\hline & Lana de roca & Rock wool $\{G L O\} \mid$ market for | Alloc Def, $U$ & $12.333,60$ & $\mathrm{~kg}$ & 1,1 \\
\hline
\end{tabular}




\begin{tabular}{|c|c|c|c|c|c|}
\hline \multirow{6}{*}{$\begin{array}{l}\text { Tuberías, } \\
\text { válvulas y } \\
\text { conectores }\end{array}$} & \multirow{2}{*}{$\begin{array}{l}\text { plancha } \\
\text { aluminio } \\
\text { aislamiento }\end{array}$} & Aluminium, wrought alloy $\{G L O\} \mid$ aluminium ingot, primary, to market | Alloc Def, $U$ & $3.938,4$ & $\mathrm{~kg}$ & 1,1 \\
\hline & & Sheet rolling, aluminium $\{R E R\} \mid$ processing | Alloc Def, $U$ & $3.938,4$ & $\mathrm{~kg}$ & 1,1 \\
\hline & $\begin{array}{l}\text { Tubería torre- } \\
\text { tanque caliente } \\
\text { (inox) }\end{array}$ & Steel, chromium steel $18 / 8$, hot rolled $\{\mathrm{ES}, \mathrm{SA}, \mathrm{MX}, \mathrm{IN}, \mathrm{ZA}, \mathrm{CL}\} \mid$ production | Alloc Def, $\mathrm{U}$ & $36.478,7$ & $\mathrm{~kg}$ & 1,1 \\
\hline & \multirow{2}{*}{$\begin{array}{l}\text { Tubería tanque } \\
\text { frío-torre (CS) }\end{array}$} & Steel, unalloyed $\{\mathrm{ES}, \mathrm{SA}, \mathrm{MX}, \mathrm{IN}, \mathrm{ZA}, \mathrm{CL}\} \mid$ market for | Alloc Def, $\mathrm{U}^{*}$ & $54.598,1$ & $\mathrm{~kg}$ & 1,1 \\
\hline & & Drawing of pipe, steel $\{\mathrm{ES}, \mathrm{SA}, \mathrm{MX}, \mathrm{IN}, \mathrm{ZA}, \mathrm{CL}\} \mid$ processing | Alloc Def, $\mathrm{U}^{*}$ & $91.076,8$ & $\mathrm{~kg}$ & 1,61 \\
\hline & Transporte & $\begin{array}{l}\text { Transport, freight, lorry } 16-32 \text { metric ton, EURO3 }\{\text { RER }\} \mid \text { transport, freight, lorry } 16-32 \text { metric } \\
\text { ton, EURO3 | Alloc Def, } U\end{array}$ & $21.469,8$ & $\mathrm{tkm}$ & 1,35 \\
\hline $\begin{array}{l}\text { Bombas de } \\
\text { torre }\end{array}$ & $\begin{array}{l}\text { Bombas de } \\
\text { circulación, }\end{array}$ & Circulation pump, 600 kW Alemania [ES, MX, SA, IN, CL, ZA] & 5 & ud & 1,04 \\
\hline
\end{tabular}

*Estos datasets han sido modificados para representar el consumo eléctrico del país de origen.

Tabla 110 Tabla de inventario de la fabricación y transporte del sistema de almacenamiento térmico de una planta HYSOL de torre de 100 MW

\begin{tabular}{|c|c|c|c|c|}
\hline Componentes & Dataset & $\begin{array}{l}\text { TOTAL } \\
\text { (Cantidad) }\end{array}$ & Ud & SD2 \\
\hline \multirow{10}{*}{$\begin{array}{l}\text { Tanque de } \\
\text { almacenamient } \\
\text { o ( } 2 \text { unidades) }\end{array}$} & Steel, unalloyed $\{\mathrm{ES}\} \mid$ steel production, converter, unalloyed | Alloc Def, U & 1.205 .012 & $\mathrm{~kg}$ & 1,26 \\
\hline & Steel, low-alloyed $\{E S\} \mid$ steel production, converter, low-alloyed | Alloc Def, U & 1.205 .012 & $\mathrm{~kg}$ & 1,26 \\
\hline & Refractory, fireclay, packed $\{D E\} \mid$ production | Alloc Def, $U$ & 1.613 .140 & $\mathrm{~kg}$ & 1,26 \\
\hline & Rock wool $\{\mathrm{CH}\} \mid$ production | Alloc Def, $U$ & 13.217 & $\mathrm{~kg}$ & 1,26 \\
\hline & Reinforcing steel $\{\mathrm{ES}, \mathrm{MX}, \mathrm{SA}, \mathrm{IN}, \mathrm{CL}, \mathrm{ZA}\} \mid$ market | Alloc Def, $\mathrm{U}$ & 2.660 & $\mathrm{~kg}$ & 1,26 \\
\hline & Industrial paint (anticorrosive and fireproof) $\{\mathrm{ES}, \mathrm{SA}, \mathrm{MX}, \mathrm{CL}, \mathrm{IN}, \mathrm{ZA}\}$ & 12,43 & $\mathrm{~kg}$ & 1,19 \\
\hline & Galvanized steel [ES, IN, MX, SA, CL, ZA] & 47 & $\mathrm{~kg}$ & 1,19 \\
\hline & Metal working, average for steel product manufacturing $\{E S, M X, S A, I N, C L, Z A\} \mid$ processing $\mid$ Alloc Def, $U$ & 2.412 .732 & $\mathrm{~kg}$ & 1,37 \\
\hline & $\begin{array}{l}\text { Transport, freight, lorry }>32 \text { metric ton, EURO3 }\{\text { RER }\} \mid \text { transport, freight, lorry }>32 \text { metric ton, EURO3 | Alloc } \\
\text { Def, } U\end{array}$ & 807.276 & $\mathrm{tkm}$ & 1,62 \\
\hline & Industrial paint (anticorrosive and fireproof) $\{\mathrm{ES}, \mathrm{SA}, \mathrm{MX}, \mathrm{CL}, \mathrm{IN}, \mathrm{ZA}\}$ & 12,42 & $\mathrm{~kg}$ & 1,19 \\
\hline
\end{tabular}




\begin{tabular}{lll}
2.660 & $\mathrm{~kg}$ & 1,26 \\
544 & $\mathrm{tkm}$ & 1,37 \\
2.707 & $\mathrm{~kg}$ & 1,62 \\
$27.098,88$ & $\mathrm{~kg}$ & 1,10 \\
\hline 4.424 & $\mathrm{~kg}$ & 1,10 \\
\hline $1.900,16$ & $\mathrm{~kg}$ & 1,10 \\
\hline $12.193,44$ & $\mathrm{~kg}$ & 1,10 \\
\hline $2.010,88$ & $\mathrm{~kg}$ & 1,10 \\
\hline $1.900,16$ & $\mathrm{Kg}$ & 1,10 \\
\hline $39.292,32$ & $\mathrm{Kg}$ & 1,10 \\
\hline $9.525,5$ & $\mathrm{tkm}$ & 1,37 \\
\hline 0,1208 & $\mathrm{ud}$ & 1,04 \\
\hline 31.464 .000 & $\mathrm{~kg}$ & 1,02 \\
\hline 15.732 .000 & $\mathrm{tkm}$ & 1,37 \\
\hline 415.218 .45 & $\mathrm{tkm}$ & 1,37 \\
\hline 2 & &
\end{tabular}

\section{Tuberías}

válvulas y

conectores

Transport, freight, lorry 16-32 metric ton, EURO3 \{GLO\}| market for | Alloc Def, $U$

Metal working, average for steel product manufacturing $\{\mathrm{ES}, \mathrm{SA}, \mathrm{MX}, \mathrm{CL}, \mathrm{IN}, \mathrm{ZA}\} \mid$ processing $\mid$ Alloc Def, $\mathrm{U}^{*}$

Steel, chromium steel $18 / 8$, hot rolled $\{E S, S A, I N, M X, C L, Z A\} \mid$ production | Alloc Def, $U$

Rock wool $\{$ GLO\}| market for | Alloc Def, $U$

Sheet rolling, aluminium $\{R E R\} \mid$ processing | Alloc Def, $U$

Steel, unalloyed $\{\mathrm{SA}, \mathrm{MX}, \mathrm{ES}, \mathrm{IN}$ or $\mathrm{CL}, \mathrm{ZA}\} \mid$ market for | Alloc Def, $\mathrm{U}$

Rock wool $\{G L O\} \mid$ market for | Alloc Def, $U$

Metal working, average for aluminium product manufacturing $\{G L O\} \mid$ market for | Alloc Def, $U$

Drawing of pipe, steel $\{E S, S A, M X, I N, C L, Z A\} \mid$ processing | Alloc Def, $U$

Transport, freight, lorry 16-32 metric ton, EURO3 \{GLO\}| market for | Alloc Def, $U$

Bombas de

Sales minadas ( $60 \%$ sodium nitrate, $40 \%$ Potassium nitrate)

Transport, freight, lorry 16-32 metric ton, EURO3 \{RER\}| transport, freight, lorry 16-32 metric ton, EURO3 | Alloc

Sales térmicas

Def, $U$ 
Tabla 111 Tabla de inventario de la fabricación y transporte del sistema del bloque de potencia de una planta HYSOL de torre de 100 MW

Componentes Dataset

Cantidad Ud

\begin{tabular}{|c|c|c|c|c|}
\hline Aislante & Rock wool, packed $\{G L O\} \mid$ market for | Alloc Def, U & 100.000 & $\mathrm{~kg}$ & \\
\hline \multirow{2}{*}{ Tuberías } & Polyethylene, high density, granulate $\{$ RER $\} \mid$ production | Alloc Def, $U$ & 150.000 & kg & \\
\hline & Extrusion, plastic pipes $\{R E R\} \mid$ production | Conseq, $U$ & 150.000 & $\mathrm{~kg}$ & 1,61 \\
\hline Transporte & Transport, freight, lorry 16-32 metric ton, EURO4 \{RER\}| transport, freight, lorry 16-32 metric ton, EURO4 | Alloc Def, U & 37.816 & tkm & 1.37 \\
\hline $\begin{array}{l}\text { Bomba de } \\
\text { refrigeración }\end{array}$ & Circulation pump, $600 \mathrm{~kW}$ & 4.66 & ud & \\
\hline \multirow{9}{*}{$\begin{array}{l}\text { Refrigeration, } \\
\text { air condenser }\end{array}$} & Concrete, sole plate and foundation \{Europe without switzerland, $\{\mathrm{SA}, \mathrm{MX}, \mathrm{ES}, \mathrm{IN}$ or $\mathrm{CL}, \mathrm{ZA}\} \mid$ production | Alloc Def, U & 423.360 & $\mathrm{~kg}$ & 1,19 \\
\hline & Glass fibre reinforced plastic, polyester resin, hand lay-up $\{R E R\} \mid$ production | Conseq, $S$ & 8.064 & $\mathrm{Kg}$ & 1,19 \\
\hline & Aluminium, wrought alloy $\{R E R\} \mid$ aluminium production, primary | Alloc Def, $U$ & 178.864 & $\mathrm{Kg}$ & 1,19 \\
\hline & Galvanized steel [ES, IN, MX, SA, CL, ZA] & 443.792 & $\mathrm{~kg}$ & 1,19 \\
\hline & Steel, low-alloyed $\{\mathrm{ES}, \mathrm{MX}, \mathrm{SA}$, IN or $\mathrm{CL}, \mathrm{ZA}\} \mid$ market for | Alloc Def, U & 367.680 & $\mathrm{Kg}$ & 1,19 \\
\hline & _68 Electrical machinery n.e.c., EU27 & 80.000 & $\mathrm{Kg}$ & 1,19 \\
\hline & Metal working, average for aluminium product manufacturing $\{G L O\} \mid$ market for | Alloc Def, $U$ & 178.864 & $\mathrm{Kg}$ & 1,19 \\
\hline & Metal working, average for steel product manufacturing $\{\mathrm{ES}, \mathrm{MX}, \mathrm{SA}, \mathrm{IN}, \mathrm{CL}, \mathrm{ZA}\} \mid$ processing $\mid$ Alloc Def, $\mathrm{U}$ & 811.472 & $\mathrm{Kg}$ & 1,19 \\
\hline & Transport, freight, lorry 16-32 metric ton, EURO4 \{RoW\}| transport, freight, lorry 16-32 metric ton, EURO4 | Alloc Def, U & 300.352 & tkm & 1,37 \\
\hline \multirow{7}{*}{$\begin{array}{l}\text { Tren de } \\
\text { generación de } \\
\text { vapor }\end{array}$} & Steel, unalloyed $\{\mathrm{SA}, \mathrm{MX}, \mathrm{ES}, \mathrm{IN}$ or $\mathrm{CL}, \mathrm{ZA}\} \mid$ market for | Alloc Def, $\mathrm{U}$ & 396.310 & $\mathrm{~kg}$ & 1,05 \\
\hline & Chromium steel pipe $\{G L O\} \mid$ market for | Alloc Def, $U$ & 61.850 & $\mathrm{~kg}$ & 1,05 \\
\hline & Metal working, average for steel product manufacturing $\{E S, M X, S A, I N, C L, Z A\} \mid$ processing $\mid$ Alloc Def, $U$ & 350.930 & $\mathrm{~kg}$ & 1,05 \\
\hline & Drawing of pipe, steel $\{G L O\} \mid$ market for | Alloc Def, $U$ & 45.380 & $\mathrm{~kg}$ & 1,05 \\
\hline & Transport, freight, lorry $16-32$ metric ton, EURO3 $\{$ GLO $\} \mid$ market for | Alloc Def, $U$ & 79.262 & tkm & 1,37 \\
\hline & Steel, unalloyed $\{\mathrm{SA}, \mathrm{MX}, \mathrm{ES}, \mathrm{IN}$ or $\mathrm{CL}, \mathrm{ZA}\} \mid$ steel production, converter, unalloyed | Alloc Def, U & 31.400 & $\mathrm{~kg}$ & 1,19 \\
\hline & Epoxy resin, liquid $\{R E R\} \mid$ production | Alloc Def, $U$ & 50 & $\mathrm{~kg}$ & 1,22 \\
\hline
\end{tabular}


condensados

Bombas

condensados

y

Circulation pump, $600 \mathrm{~kW}$

2,65

ud

1

desgasificador

Condensador

_66 Machinery and equipment n.e.c., EU27

106.000

Transport, freight, sea, transoceanic ship $\{G L O\} \mid$ processing | Alloc Def, $U$

$304.432 \mathrm{tkm} \quad 1,61$

Transport, freight, lorry >32 metric ton, EURO4 \{RER\}| transport, freight, lorry >32 metric ton, EURO4 | Alloc Def, U

$68.800 \quad \mathrm{tkm} \quad 1,61$

Tanque de Steel, unalloyed $\{E S\} \mid$ steel production, converter, unalloyed | Alloc Def, $U$

$1.380 \quad \mathrm{~kg} \quad 1,19$

drenado de

Metal working, average for steel product manufacturing $\{\mathrm{ES}\} \mid$ processing | Alloc Def, $U$

$1.380 \quad \mathrm{~kg} \quad 1,61$

Desgasificador

Metal working, average for chromium steel product manufacturing $\{G L O\} \mid$ market for | Alloc Def, $U$

$8.000 \quad \mathrm{~kg} \quad 1,62$

Steel, chromium steel $18 / 8$, hot rolled $\{\mathrm{ES}, \mathrm{SA}, \mathrm{IN}, \mathrm{MX}, \mathrm{CL}, \mathrm{ZA}\} \mid$ production | Alloc Def, $\mathrm{U}$

$8.000 \quad \mathrm{~kg} \quad 1,1$

Bloque

Turbina de

vapor

Steam turbine $[\mathrm{ES}, \mathrm{CL}, \mathrm{IN}, \mathrm{SA}, \mathrm{MX}]$

Generator steam [ES, CL, IN, SA, MX]

1

Gas turbine [ES, CL, IN, SA, MX]

Generator gas [ES, CL, IN, SA, MX]

Steel, chromium steel $18 / 8$, hot rolled $\{E S, S A, I N, M X, C L\} \mid$ production | Alloc Def, $U$

Drawing of pipe, steel $\{E S, S A, M X, I N, C L\} \mid$ processing $\mid$ Alloc Def, $U$

Drawing of pipe, steel $\{E S, S A, M X, I N, C L\} \mid$ processing | Alloc Def, $U$

1

1

$$
\text { Steel, unalloyed }\{\mathrm{SA}, \mathrm{MX}, \mathrm{ES}, \mathrm{IN} \text { or } \mathrm{CL}\} \mid \text { market for | Alloc Def, } \mathrm{U}
$$

Pipes HRS-

Aluminium, wrought alloy $\{G L O\} \mid$ aluminium ingot, primary, to market | Alloc Def, $U$

Sheet rolling, aluminium $\{R E R\} \mid$ processing | Alloc Def, $U$

Rock wool $\{G L O\} \mid$ market for | Alloc Def, $U$

Transport, freight, lorry 16-32 metric ton, EURO3 \{GLO\}| market for | Alloc Def, U

1

1

$7.755,04$

$7.755,04 \quad \mathrm{~kg} \quad 1,10$

TES

\begin{tabular}{lll}
$4.094,4$ & $\mathrm{~kg}$ & 1,10 \\
\hline $4.094,4$ & $\mathrm{~kg}$ & 1,10 \\
686,88 & $\mathrm{~kg}$ & 1,10 \\
686,88 & $\mathrm{~kg}$ & 1,10 \\
$1.899,84$ & $\mathrm{~kg}$ & 1,10 \\
$2.887,2$ & $\mathrm{tkm}$ & 1,37
\end{tabular}


Steel, chromium steel 18/8, hot rolled $\{E S, S A, I N, M X, C L, Z A\} \mid$ production | Alloc Def, $U$

\begin{tabular}{|c|c|c|}
\hline $75.968,8$ & kg & 1,1 \\
\hline $24.032,4$ & kg & 1,1 \\
\hline $57.923,7$ & kg & 1,1 \\
\hline $\begin{array}{l}\text { 114.438, } \\
3\end{array}$ & kg & 1,1 \\
\hline $24.032,4$ & kg & 1,19 \\
\hline $57.923,7$ & kg & 1,19 \\
\hline $\begin{array}{l}\text { 190.407, } \\
0\end{array}$ & kg & 1,62 \\
\hline $54.466,9$ & $\mathrm{tkm}$ & 1,37 \\
\hline $\begin{array}{l}1.902 .80 \\
0\end{array}$ & $\mathrm{~m}$ & 1,62 \\
\hline $\begin{array}{l}\text { 113.953, } \\
2\end{array}$ & kg & 1,1 \\
\hline $36.048,6$ & kg & 1,1 \\
\hline $86.885,6$ & kg & 1,1 \\
\hline $\begin{array}{l}\text { 171.657, } \\
5\end{array}$ & kg & 1,1 \\
\hline $36.048,6$ & kg & 1,19 \\
\hline $86.885,6$ & kg & 1,19 \\
\hline $\begin{array}{l}285.610 \\
7\end{array}$ & kg & 1,62 \\
\hline $81.700,3$ & $\mathrm{tkm}$ & 1,37 \\
\hline $\begin{array}{l}2.854 .20 \\
1\end{array}$ & $\mathrm{~m}$ & 1,62 \\
\hline 14.925 & kg & 1,12 \\
\hline
\end{tabular}


Tabla 112 Sistema de instalaciones de una planta HYSOL de torre de $100 \mathrm{MW}$

\begin{tabular}{|c|c|c|c|c|}
\hline Componentes & Dataset & Cantidad & Ud & SD2 \\
\hline \multirow{2}{*}{$\begin{array}{l}\text { Edificio de oficinas genérico } \\
\left(1600 \mathrm{~m}^{2}\right)\end{array}$} & Reinforcing steel $\{\mathrm{ES}\} \mid$ production | Alloc Def, U Sistema* & 18.480 & $\mathrm{~kg}$ & 1,61 \\
\hline & Autoclaved aerated concrete block $\{$ RoW $\} \mid$ production | Alloc Def, $U$ & 52.640 & $\mathrm{~kg}$ & 1,61 \\
\hline $\begin{array}{l}\text { Bombas de captación de } \\
\text { aguas }\end{array}$ & Circulation pump, $600 \mathrm{~kW}$ & 2 & ud & 1,04 \\
\hline $\begin{array}{l}\text { Planta de tratamiento de } \\
\text { aguas (desionización) }\end{array}$ & Ion-exchanger for water treatment $\{$ RoW $\} \mid$ production | Alloc Def, $U$ & 1 & ud & 1,21 \\
\hline
\end{tabular}

Tabla 113 Tabla de inventario de la construcción de una planta HYSOL de torre de $100 \mathrm{MW}$

\begin{tabular}{|c|c|c|c|c|}
\hline Componente o Actividad & Dataset & Cantidad & Ud & SD2 \\
\hline \multirow{3}{*}{$\begin{array}{l}\text { Excavación y preparación del } \\
\text { terreno }\end{array}$} & Gravel, round $\{G L O\} \mid$ market for | Alloc Def, $U$ & 47.270 .523 & $\mathrm{~kg}$ & 1,03 \\
\hline & Excavation, hydraulic digger $\{$ RER $\} \mid$ processing $\mid$ Alloc Def, $U$ & 274.508 & m3 & 1,03 \\
\hline & Excavation, skid-steer loader $\{R E R\} \mid$ processing | Alloc Def, $U$ & 275.317 & m3 & 1,03 \\
\hline \multirow{2}{*}{$\begin{array}{l}\text { Construcción del bloque de } \\
\text { potencia }\end{array}$} & Diesel, burned in building machine $\{G L O\} \mid$ processing | Alloc Def, $U$ & 21.600 .000 & MJ & 1,1 \\
\hline & Electricity, medium voltage $\{$ ES_2013\}| market for | Alloc Def, U --with CSP & 1.350 .000 & $\mathrm{kWh}$ & 1,1 \\
\hline \multirow{2}{*}{ Estructura edificio sales y HTF } & Industrial paint (anticorrosive and fireproof) & 116 & $\mathrm{~kg}$ & 1,19 \\
\hline & Reinforcing steel $\{\mathrm{ES}\} \mid$ market | Alloc Def, $\mathrm{U}^{*}$ & 55.235 & $\mathrm{~kg}$ & 1,19 \\
\hline
\end{tabular}


Metal working, average for steel product manufacturing $\{E S\} \mid$ processing | Alloc Def, U* 55.235

Transport, freight, lorry $>32$ metric ton, EURO4 \{RER\}| transport, freight, lorry $>32$ metric ton, EURO4 | Alloc Def, U

$55.351 \quad \mathrm{tkm}$

Industrial paint (anticorrosive and fireproof)

Steel, unalloyed $\{$ ES $\} \mid$ market for | Alloc Def, $U^{*}$

$220 \quad \mathrm{~kg} \quad 1,19$

Estructura bombas de sales

Galvanized steel $[\mathrm{ES}]^{*}$

$110.000 \quad \mathrm{~kg} \quad 1,19$

Metal working, average for steel product manufacturing $\{E S\} \mid$ processing $\mid$ Alloc Def, $U^{*}$

$110.410 \quad \mathrm{~kg} \quad 1,19$

Transport, freight, lorry $>32$ metric ton, EURO4 \{RER\}| transport, freight, lorry $>32$ metric ton,

110.000

kg $\quad 1,61$

EURO4 | Alloc Def, U

$220.630 \quad \mathrm{tkm}$

Reinforcing steel $\{E S\} \mid$ market | Alloc Def, $U^{*}$

$\begin{array}{lll}81.215 & \mathrm{~kg} & 1,19 \\ 208,4 & \mathrm{~kg} & 1,19\end{array}$

Estructura para depósitos de expansión, rebose y ullage

Pintura anticorrosiva e ingífuga para estructuras metálicas

Galvanized steel [ES]*

Metal working, average for steel product manufacturing $\{E S\} \mid$ processing $\mid$ Alloc Def, U*

$175 \quad \mathrm{~kg} \quad 1,19$

Transport, freight, lorry $>32$ metric ton, EURO3 $\{R E R\} \mid$ transport, freight, lorry $>32$ metric ton, EURO3 | Alloc Def, U

$81.390 \quad \mathrm{~kg} \quad 1,61$

Industrial paint (anticorrosive and fireproof)

$81.598,4 \quad t k m \quad 1,37$

Reinforcing steel $\{\mathrm{ES}\} \mid$ market | Alloc Def, $\mathrm{U}^{*}$

$22 \quad \mathrm{~kg} \quad 1,19$

Estructura para el bloque de turbina

Galvanized steel [ES]*

$1.750 \quad \mathrm{~kg} \quad 1,19$

Metal working, average for steel product manufacturing $\{E S\} \mid$ processing | Alloc Def, $U$

$52 \quad \mathrm{~kg} \quad 1,19$

Transport, freight, lorry $>32$ metric ton, EURO4 $\{$ RER $\} \mid$ transport, freight, lorry $>32$ metric ton, EURO4 | Alloc Def, U

$1.802 \quad \mathrm{~kg} \quad 1,61$

Industrial paint (anticorrosive and fireproof)

$1.824 \quad \mathrm{tkm} \quad 1,37$

Reinforcing steel $\{E S\} \mid$ market | Alloc Def, U*

$23 \quad \mathrm{~kg} \quad 1,19$

Estructura para el condensador y purgas

Galvanized steel [ES]*

$11.508 \quad \mathrm{~kg} \quad 1,19$

Metal working, average for steel product manufacturing $\{E S\} \mid$ processing $\mid$ Alloc Def, $U^{*}$

$57 \quad \mathrm{~kg} \quad 1,19$

Transport, freight, lorry $>32$ metric ton, EURO4 $\{$ RER $\} \mid$ transport, freight, lorry $>32$ metric ton,

43.400

kg 1,61

EURO4 | Alloc Def, U

$\begin{array}{lll}11.588 & \mathrm{tkm} & 1,37\end{array}$


Estructura para los precalentadores

Estructura-rack generador de vapor

Estructura-Rack turbina y desgasificador

Estructuras planta de tratamiento y edificios auxiliares

Rack eléctrico sistema de vapor y torres de refrigeración

\section{Reinforcing steel $\{E S\} \mid$ market | Alloc Def, $U^{*}$}

Galvanized steel [ES]*

Metal working, average for steel product manufacturing $\{E S\} \mid$ processing | Alloc Def, $U^{*}$

Transport, freight, lorry $>32$ metric ton, EURO4 \{RER\}| transport, freight, lorry $>32$ metric ton, EURO4 | Alloc Def, U

Reinforcing steel $\{\mathrm{ES}\} \mid$ market | Alloc Def, U*

Industrial paint (anticorrosive and fireproof)

Metal working, average for steel product manufacturing $\{E S\} \mid$ processing | Alloc Def, U*

Transport, freight, lorry $>32$ metric ton, EURO4 \{RER\}| transport, freight, lorry $>32$ metric ton, EURO4 | Alloc Def, U

Industrial paint (anticorrosive and fireproof)

Reinforcing steel $\{\mathrm{ES}\} \mid$ market | Alloc Def, $\mathrm{U}^{*}$

Galvanized steel $[\mathrm{ES}]^{*}$

Metal working, average for steel product manufacturing $\{E S\} \mid$ processing | Alloc Def, U*

Transport, freight, lorry $>32$ metric ton, EURO4 \{RER\}| transport, freight, lorry $>32$ metric ton, EURO4 | Alloc Def, U

Industrial paint (anticorrosive and fireproof)

Reinforcing steel $\{\mathrm{ES}\} \mid$ market | Alloc Def, $\mathrm{U}^{*}$

Road, company, internal $\{\mathrm{CH}\} \mid$ construction | Alloc Def, $\mathrm{U}$

Metal working, average for steel product manufacturing $\{\mathrm{ES}\} \mid$ processing | Alloc Def, U*

Transport, freight, lorry $>32$ metric ton, EURO4 $\{$ RER $\} \mid$ transport, freight, lorry $>32$ metric ton, EURO4 | Alloc Def, U

Industrial paint (anticorrosive and fireproof)

Reinforcing steel $\{\mathrm{ES}\} \mid$ market | Alloc Def, U*

Galvanized steel $[\mathrm{ES}]^{*}$

\begin{tabular}{|c|c|c|}
\hline $6.573 * 1,6$ & $\mathrm{~kg}$ & 1,19 \\
\hline $41 * 1,6$ & kg & 1,19 \\
\hline $6.614 * 1,6$ & $\mathrm{~kg}$ & 1,61 \\
\hline $\begin{array}{l}6.627,146^{*} \\
1,6\end{array}$ & $\mathrm{tkm}$ & 1,37 \\
\hline $82.000 * 1,6$ & kg & 1,19 \\
\hline $211,2 * 1,6$ & kg & 1,19 \\
\hline $82.000 * 1,6$ & kg & 1,61 \\
\hline $82.211 * 1,6$ & $\mathrm{tkm}$ & 1,37 \\
\hline 157,28 & $\mathrm{~kg}$ & 1,19 \\
\hline 78.641 & kg & 1,19 \\
\hline 330 & kg & 1,19 \\
\hline 78.971 & kg & 1,61 \\
\hline $79.128,28$ & $\mathrm{tkm}$ & 1,37 \\
\hline 175,6 & kg & 1,19 \\
\hline 69.001 & kg & 1,19 \\
\hline 87.500 & $\mathrm{~m} 2 \mathrm{a}$ & 1,61 \\
\hline 69.001 & kg & 1,61 \\
\hline $156.676,6$ & $\mathrm{tkm}$ & 1,37 \\
\hline 167,89 & kg & 1,19 \\
\hline 83.945 & kg & 1,19 \\
\hline 55 & $\mathrm{~kg}$ & 1,19 \\
\hline
\end{tabular}




\begin{tabular}{|c|c|c|c|c|}
\hline & Metal working, average for steel product manufacturing $\{E S\} \mid$ processing $\mid$ Alloc Def, $U^{*}$ & 84.000 & $\mathrm{~kg}$ & 1,61 \\
\hline & $\begin{array}{l}\text { Transport, freight, lorry >32 metric ton, EURO4 }\{R E R\} \mid \text { transport, freight, lorry }>32 \text { metric ton, } \\
\text { EURO4 | Alloc Def, } U\end{array}$ & $84.167,89$ & $\mathrm{tkm}$ & 1,37 \\
\hline \multirow{2}{*}{ Cimentación bloque potencia } & Concrete, sole plate and foundation \{Europe without switzerland, ES\}| production | Alloc Def, U* & 40.068 .000 & $\mathrm{~kg}$ & 1,1 \\
\hline & Hormigonera $27,5 \mathrm{kw}$ (2150 kg de carga) & 18.636 & $\mathrm{~h}$ & 1,19 \\
\hline \multirow{3}{*}{ Cimentación campo solar } & Concrete, sole plate and foundation \{Europe without switzerland, ES\}| production | Alloc Def, U* & $\begin{array}{l}101.585 .80 \\
0\end{array}$ & $\mathrm{~kg}$ & 1,06 \\
\hline & Reinforcing steel $\{E S\} \mid$ market | Alloc Def, U* & 3.047 .574 & $\mathrm{~kg}$ & 1,06 \\
\hline & Hormigonera $27,5 \mathrm{kw}$ (2150 kg de carga) & 47.249 & $\mathrm{~h}$ & 1,19 \\
\hline $\begin{array}{l}\text { Transporte materiales de } \\
\text { construcción (dentro de la } \\
\text { instalación) }\end{array}$ & Transport, freight, lorry 16-32 metric ton, EURO3 $\{G L O\} \mid$ market for | Alloc Def, U & 22.788 & tkm & 1,37 \\
\hline $\begin{array}{l}\text { Transporte estructuras de } \\
\text { construcción (dentro de la } \\
\text { instalación) }\end{array}$ & Transport, freight, lorry 16-32 metric ton, EURO3 $\{$ GLO $\} \mid$ market for | Alloc Def, U & $42.634,6$ & $\mathrm{tkm}$ & 1,37 \\
\hline Grúa colocación heliostatos & Grúa telescópica autopropulsada 127 HP & 3.165 & $\mathrm{~h}$ & 1,19 \\
\hline $\begin{array}{l}\text { Grúa para bloque de } \\
\text { almacenamiento }\end{array}$ & Grúa telescópica autopropulsada 127 HP & 4.44 & $\mathrm{~h}$ & 1,19 \\
\hline Carreteras & Road, company, internal $\{$ RoW $\} \mid$ construction | Alloc Def, U & 87.500 & $\begin{array}{l}\text { m2a } \\
\text { ño }\end{array}$ & 1,61 \\
\hline \multirow{3}{*}{ Construcción edificio genérico } & Reinforcing steel $\{E S, M X, S A, I N, C L, Z A\} \mid$ market | Alloc Def, U* & 69.001 & $\mathrm{~kg}$ & 1,19 \\
\hline & Industrial paint (anticorrosive and fireproof) $\{\mathrm{ES}, \mathrm{SA}, \mathrm{MX}, \mathrm{CL}, \mathrm{IN}, \mathrm{ZA}\}^{*}$ & 175,6 & $\mathrm{~kg}$ & 1,19 \\
\hline & $\begin{array}{l}\text { Metal working, average for steel product manufacturing }\{E S, M X, S A, I N, C L, Z A\} \mid \text { processing | } \\
\text { Alloc Def, } U^{*}\end{array}$ & 69.001 & $\mathrm{~kg}$ & 1,61 \\
\hline
\end{tabular}




\begin{tabular}{|c|c|c|c|c|}
\hline Componente o Actividad & Dataset & Cantidad & Ud & SD2 \\
\hline Aceite lubricante & Aceite lubricante-Lubricating oil $\{G L O\} \mid$ market for | Alloc Def, $U$ & 3,83E5 & $\mathrm{kg}$ & - \\
\hline $\begin{array}{l}\text { Agua desionizada (ciclo } \\
\text { vapor) }\end{array}$ & Water, deionised, from well water, at user ES (adaptado_2013)| production | Alloc Def, U & 1,67E8 & $\mathrm{kg}$ & - \\
\hline Agua limpieza heliostatos & Water, consumed for cleaning mirrors (CSP $50 \mathrm{MW}, 25$ years) & 1,46E9 & L & - \\
\hline Heliostatos (recambio) & Colector solar cilindro parabólico & 91,5 & $\mathrm{p}$ & - \\
\hline Biometano & Ciclo de vida biogas depurado(1MJ térmico) Sistema & $8,11 \mathrm{E} 10$ & MJ & - \\
\hline $\begin{array}{l}\text { Emisiones de quemar } \\
\text { biometano en turbina de gas }\end{array}$ & $\begin{array}{l}\text { Heat, industrial, biomethane, Europe, heat production, at industrial furnace }>1 \text { MWth to }<=50 \\
\text { MWth | Alloc Def, U_CSP } 2012\end{array}$ & $8,11 \mathrm{E} 6$ & MJ & - \\
\hline $\begin{array}{l}\text { Biometano para puesta en } \\
\text { marcha de sales }\end{array}$ & $\begin{array}{l}\text { Heat, industrial, biomethane, Europe, heat production, at industrial furnace }>1 \text { MWth to }<=50 \\
\text { MWth | Alloc Def, U_CSP } 2012\end{array}$ & 4.916.250.000 & MJ & - \\
\hline Transporte vehículo limpieza & Transport, lorry 3.5-7.5t, EURO5/RER U- vehículo de limpieza & 1.016.255 & $\mathrm{tkm}$ & 1,37 \\
\hline
\end{tabular}

Tabla 115 Tabla de inventario del desmantelamiento de una planta HYSOL de torre de $100 \mathrm{MW}$

Componente o Actividad

Actividades de

desmantelamiento
Dataset

Diesel, burned in building machine $\{$ GLO $\}$ processing | Alloc Def, UTransport, freight, lorry $>32$

metric ton, EURO3 $\{R E R\} \mid$ transport, freight, lorry $>32$ metric ton, EURO3 | Alloc Def, $U$

Transport, freight, lorry $>32$ metric ton, EURO3 $\{R E R\} \mid$ transport, freight, lorry $>32$ metric ton,

EURO3 | Alloc Def, U
Cantidad Ud SD2

3,91E7 MJ 1,11

$50.900 .000 \quad \mathrm{tkm} \quad 1,37$ 


\section{Tablas de inventario de la tecnología termosolar CCP (con tecnología cilindro-parabólica, planta base).}

Tabla 116 Tabla de inventario de la fabricación y transporte del sistema circuito HTF de una planta cilindro-parabólica de 50 MW (escenario TERMOSOLAR CCP)

\begin{tabular}{|c|c|c|c|c|c|}
\hline Componentes & Subcomponentes & Dataset & $\begin{array}{l}\text { TOTAL } \\
\text { (Cantidad) }\end{array}$ & Ud. & $S^{2}$ \\
\hline \multirow{3}{*}{$\begin{array}{l}\text { Fluido de } \\
\text { transmisión térmica } \\
\text { (HTF) }\end{array}$} & - & Bifenilo, aproximación para HTF & 601,55 & \multirow{2}{*}{$\mathrm{t}$} & 1,02 \\
\hline & - & Óxido de difenilo, aproximación para HTF & $1.668,45$ & & 1,02 \\
\hline & Transporte (desde Bélgica) & $\begin{array}{l}\text { Transport, freight, lorry } 16-32 \text { metric ton, EURO4 \{RER }\} \mid \text { transport, freight, } \\
\text { lorry 16-32 metric ton, EURO4 | Alloc Def, U }\end{array}$ & 3.859 & $\mathrm{tkm}$ & 1,35 \\
\hline \multirow{11}{*}{ Tuberías } & \multirow{3}{*}{ Rack tuberías } & Steel, low-alloyed $\{E S\} \mid$ market for | Alloc Def, U* & 44.260 & $\mathrm{~kg}$ & 1,05 \\
\hline & & Industrial paint (anticorrosive and fireproof) & 44,26 & $\mathrm{~kg}$ & 1,05 \\
\hline & & Galvanized steel [ES] & 40 & $\mathrm{~kg}$ & 1,05 \\
\hline & \multirow{2}{*}{ Tuberías 2" } & Steel, unalloyed $\{E S\} \mid$ market for | Alloc Def, $U^{*}$ & $7.605,12$ & $\mathrm{~kg}$ & 1,05 \\
\hline & & Drawing of pipe, steel $\{R E R\} \mid$ processing | Alloc Def, $U$ & $7.606,12$ & $\mathrm{~kg}$ & 1,62 \\
\hline & \multirow{2}{*}{ Tuberías 10" } & Steel, unalloyed $\{E S\} \mid$ market for | Alloc Def, $U^{*}$ & $95.258,2$ & $\mathrm{~kg}$ & 1,05 \\
\hline & & Drawing of pipe, steel $\{R E R\} \mid$ processing | Alloc Def, $U$ & $95.259,2$ & $\mathrm{~kg}$ & 1,62 \\
\hline & \multirow[b]{2}{*}{ Fittings (966 unidades) } & Steel, unalloyed $\{E S\} \mid$ market for | Alloc Def, $U^{*}$ & 2.384 & $\mathrm{~kg}$ & 1,2 \\
\hline & & $\begin{array}{l}\text { Metal working, average for steel product manufacturing }\{E S\} \mid \text { processing | } \\
\text { Alloc Def, } U^{*}\end{array}$ & 2.384 & $\mathrm{~kg}$ & 1,62 \\
\hline & Aislante & Rock wool, packed $\{G L O\} \mid$ market for | Alloc Def, U & 3.802 & $\mathrm{~kg}$ & 1,05 \\
\hline & Transporte & $\begin{array}{l}\text { Transport, freight, lorry } 16-32 \text { metric ton, EURO3 }\{\text { RER }\} \mid \text { transport, freight, } \\
\text { lorry } 16-32 \text { metric ton, EURO3 | Alloc Def, } U\end{array}$ & $30.678,7$ & $\mathrm{tkm}$ & 1,35 \\
\hline Bombas principales & Bombas de circulación, & Circulation pump, $600 \mathrm{~kW}$ & 5 & ud & 1,04 \\
\hline \multirow{2}{*}{$\begin{array}{l}\text { Sistemas de rebose, } \\
\text { expansión y ullage. }\end{array}$} & $\begin{array}{l}\text { Depósito de expansión, }(120 \\
\text { m3) }\end{array}$ & Reinforcing steel $\{E S\} \mid$ market | Alloc Def, $U^{*}$ & 32.000 & $\mathrm{~kg}$ & 1,26 \\
\hline & Depósito de gas natural licuado & Reinforcing steel $\{\mathrm{ES}\} \mid$ market | Alloc Def, $\mathrm{U}^{*}$ & 60.000 & $\mathrm{~kg}$ & 1,26 \\
\hline
\end{tabular}




\begin{tabular}{|c|c|c|c|c|}
\hline 2 Depósitos de rebose $\left(400 \mathrm{~m}^{3}\right)$ & Reinforcing steel $\{E S\} \mid$ market | Alloc Def, $U^{*}$ & 170.000 & kg & 1,26 \\
\hline Bombas de rebose & Circulation pump, $600 \mathrm{~kW}$ & 2 & ud & 1,04 \\
\hline Depósito "ullage flash", & Reinforcing steel $\{E S\} \mid$ market | Alloc Def, $\mathrm{U}^{*}$ & 4.380 & $\mathrm{~kg}$ & 1,26 \\
\hline $\begin{array}{l}\text { Depósito drenaje sistema de } \\
\text { recuperación }\end{array}$ & Reinforcing steel $\{E S\} \mid$ market | Alloc Def, U* & 1.380 & $\mathrm{~kg}$ & 1,26 \\
\hline $\begin{array}{l}\text { Depósito "flash" sistema de } \\
\text { recuperación }(5 \mathrm{~m} 3)\end{array}$ & Reinforcing steel $\{E S\} \mid$ market | Alloc Def, $\mathrm{U}^{*}$ & 1.500 & $\mathrm{~kg}$ & 1,26 \\
\hline Nitrógeno & $\begin{array}{l}\text { Nitrogen, via cryogenic air separation, production mix, at plant, gaseous EU-27 } \\
\mathrm{S}\end{array}$ & 1.051 .785 & $\mathrm{~kg}$ & - \\
\hline
\end{tabular}

*Estos datasets han sido modificados para representar el consumo eléctrico del mix español.

Tabla 117 Tabla de inventario de la fabricación y transporte del sistema campo solar de una planta cilindro-parabólica de 50 MW (escenario TERMOSOLAR CCP)

\begin{tabular}{|c|c|c|c|c|c|}
\hline Componentes & Subcomponentes & Dataset & $\begin{array}{l}\text { TOTAL } \\
\text { (Cantidad) }\end{array}$ & Ud & $S^{2}$ \\
\hline \multirow{8}{*}{$\begin{array}{l}\text { Colectores (624 } \\
\text { unidades) }\end{array}$} & \multirow{5}{*}{ Espejos } & Flat glass, coated - with silver - $\{$ RER $\} \mid$ production | Alloc Def, $U$ & $5.523,7658$ & $\mathrm{~kg}$ & $\begin{array}{l}1,0 \\
9\end{array}$ \\
\hline & & Epoxy resin, liquid $\{R E R\} \mid$ production | Alloc Def, $U$ & 1,0734 & $\mathrm{~kg}$ & $\begin{array}{l}1,0 \\
9\end{array}$ \\
\hline & & Copper $\{$ GLO $\} \mid$ market for | Alloc Def, $U$ & 2,2194 & $\mathrm{~kg}$ & $\begin{array}{l}1,0 \\
9\end{array}$ \\
\hline & & $\begin{array}{l}\text { Metal working, average for copper product manufacturing }\{R E R\} \mid \text { processing | } \\
\text { Alloc Def, } U\end{array}$ & 2,2194 & $\mathrm{~kg}$ & $\begin{array}{l}1,6 \\
2\end{array}$ \\
\hline & & $\begin{array}{l}\text { Transport, freight, lorry >32 metric ton, EURO3 }\{\text { RER }\} \mid \text { transport, freight, lorry } \\
>32 \text { metric ton, EURO3 | Alloc Def, } U\end{array}$ & $3.316,235$ & $\mathrm{tkm}$ & $\begin{array}{l}1,3 \\
7\end{array}$ \\
\hline & \multirow{3}{*}{ Tubos absorbedores } & Steel, chromium steel $18 / 8$, hot rolled $\{$ RER $\} \mid$ production | Alloc Def, $U$ & 206,04 & $\mathrm{~kg}$ & $\begin{array}{l}1,0 \\
9\end{array}$ \\
\hline & & $\begin{array}{l}\text { Metal working, average for chromium steel product manufacturing }\{R E R\} \mid \\
\text { processing | Alloc Def, } U\end{array}$ & 206,04 & $\mathrm{~kg}$ & $\begin{array}{l}1,6 \\
2\end{array}$ \\
\hline & & Glass tube, borosilicate $\{D E\} \mid$ production | Alloc Def, $U$ & 248,17 & $\mathrm{~kg}$ & $\begin{array}{l}1,0 \\
9\end{array}$ \\
\hline
\end{tabular}




\begin{tabular}{|c|c|c|c|c|c|}
\hline & & Anti-reflex-coating, etching, solar glass $\{$ RoW $\} \mid$ processing | Alloc Def, $U$ & 818 & $\mathrm{~m} 2$ & $\begin{array}{l}1,6 \\
2\end{array}$ \\
\hline & & $\begin{array}{l}\text { Transport, freight, lorry } 16-32 \text { metric ton, EURO3 }\{\text { RER }\} \mid \text { transport, freight, lorry } \\
\text { 16-32 metric ton, EURO3 | Alloc Def, } U\end{array}$ & 454,2117 & $\mathrm{tkm}$ & $\begin{array}{l}1,3 \\
7\end{array}$ \\
\hline \multirow{4}{*}{ Estructura colector } & \multirow{4}{*}{$\begin{array}{l}\text { Estructura marco del colector } \\
\text { (cantidad de materiales según } \\
\text { Lechon et al. (2008) }\end{array}$} & Steel, unalloyed $\{E S\} \mid$ steel production, converter, unalloyed | Alloc Def, U* & 1.212 .475 & $\mathrm{~kg}$ & $\begin{array}{l}1,0 \\
9\end{array}$ \\
\hline & & Steel, chromium steel $18 / 8$, hot rolled $\{G L O\} \mid$ market for | Alloc Def, $U$ & 45.957 & $\mathrm{~kg}$ & $\begin{array}{l}1,0 \\
9\end{array}$ \\
\hline & & Graphite $\{R E R\} \mid$ production | Alloc Def, $U$ & 187 & $\mathrm{Kg}$ & $\begin{array}{l}1,0 \\
9\end{array}$ \\
\hline & & $\begin{array}{l}\text { Metal working, average for steel product manufacturing }\{E S\} \mid \text { processing | Alloc } \\
\text { Def, } U^{*}\end{array}$ & 1.258 .432 & $\mathrm{Kg}$ & $\begin{array}{l}1,6 \\
2\end{array}$ \\
\hline \multirow{3}{*}{\multicolumn{2}{|c|}{$\begin{array}{l}\text { válvulas neumáticas, presión de vacío, manuales y } \\
\text { motorizadas para CSP }\end{array}$}} & Reinforcing steel $\{\mathrm{ES}\} \mid$ market | Alloc Def, $U$ & 16.740 & $\mathrm{Kg}$ & $\begin{array}{l}1,1 \\
2\end{array}$ \\
\hline & & $\begin{array}{l}\text { Metal working, average for steel product manufacturing }\{R E R\} \mid \text { processing | } \\
\text { Alloc Def, } U\end{array}$ & 16.740 & $\mathrm{Kg}$ & $\begin{array}{l}1,1 \\
2\end{array}$ \\
\hline & & $\begin{array}{l}\text { Transport, freight, lorry 7.5-16 metric ton, EURO4 \{RER\}| transport, freight, lorry } \\
\text { 7.5-16 metric ton, EURO4 | Alloc Def, U }\end{array}$ & 3.348 & tkm & $\begin{array}{l}1,3 \\
7\end{array}$ \\
\hline \multirow{5}{*}{$\begin{array}{l}\text { Electric and } \\
\text { electronic } \\
\text { equipment }\end{array}$} & $\begin{array}{l}\text { UTP/SP (Unshielded Twisted } \\
\text { Pair/ Braided Shielded cable for } \\
\text { Fast Ethernet 100MBit/s) }\end{array}$ & Cable, network cable, category 5, without plugs $\{G L O\} \mid$ production | Alloc Def, $U$ & $1.343,736$ & $\mathrm{~kg}$ & 1,1 \\
\hline & $\begin{array}{l}\text { Fiber optic (Fiber optic cable } \\
\text { multimode GI 50/125 for } \\
\text { application 100Base-FX, } 4 \\
\text { fibres) }\end{array}$ & Cable, data cable in infrastructure $\{G L O\} \mid$ production | Alloc Def, $U$ & $1.280,037$ & $\mathrm{~kg}$ & 1,1 \\
\hline & Cable BT suministro & Cable, three-conductor cable $\{G L O\} \mid$ production | Alloc Def, $U$ & $40.580,8$ & $\mathrm{~kg}$ & 1,1 \\
\hline & $\begin{array}{l}\text { Cable de cobre desnudo } 50 \\
\mathrm{~mm} 2 \text {, sistema de tierras } \\
\text { (neutral transformer) }\end{array}$ & $\begin{array}{l}\text { Copper wire, technology mix, consumption mix, at plant, cross section } 1 \mathrm{~mm}^{2} \\
\text { EU-15 S }\end{array}$ & 14.157 & $\mathrm{~kg}$ & 1,1 \\
\hline & Transporte & $\begin{array}{l}\text { Transport, freight, lorry } 16-32 \text { metric ton, EURO3 }\{G L O\} \mid \text { market for | Alloc Def, } \\
U\end{array}$ & $11.472,31$ & $\mathrm{tkm}$ & $\begin{array}{l}1,3 \\
7\end{array}$ \\
\hline $\begin{array}{l}\text { Tuberías, codos y } \\
\text { fittings }\end{array}$ & Tubería <2" (small bore) & Steel, unalloyed $\{E S\} \mid$ steel production, converter, unalloyed | Alloc Def, U* & $14.018,88$ & $\mathrm{~kg}$ & $\begin{array}{l}1,0 \\
5\end{array}$ \\
\hline
\end{tabular}




\begin{tabular}{|c|c|c|c|c|}
\hline Tubería >2" (big bore) & Steel, unalloyed $\{\mathrm{ES}\} \mid$ steel production, converter, unalloyed | Alloc Def, U* & $930.545,28$ & $\mathrm{~kg}$ & $\begin{array}{l}1,0 \\
5\end{array}$ \\
\hline Tubería >2" (big bore) & Steel, chromium steel $18 / 8$, hot rolled $\{$ RER $\} \mid$ production | Alloc Def, $U$ & 137.823 & $\mathrm{~kg}$ & $\begin{array}{l}1,0 \\
5\end{array}$ \\
\hline Fabricación & Drawing of pipe, steel $\{R E R\} \mid$ processing | Alloc Def, $U$ & $986.497,1$ & $\mathrm{~kg}$ & $\begin{array}{l}1,6 \\
2\end{array}$ \\
\hline Fabricación & Welding, gas, steel $\{R E R\} \mid$ processing $\mid$ Alloc Def, $U$ & 2.286 & $\mathrm{~m}$ & $\begin{array}{l}1,6 \\
2\end{array}$ \\
\hline Aislante & Rock wool, packed $\{G L O\} \mid$ market for | Alloc Def, U & 259,00 & $\mathrm{~kg}$ & 1,3 \\
\hline Codos & Steel, chromium steel $18 / 8$, hot rolled $\{$ RER $\} \mid$ production | Alloc Def, $U$ & 343 & $\mathrm{~kg}$ & $\begin{array}{l}1,0 \\
5\end{array}$ \\
\hline $\begin{array}{l}\text { Codos, Reducers, tees and } \\
\text { flanges }\end{array}$ & Steel, unalloyed $\{E S\} \mid$ steel production, converter, unalloyed | Alloc Def, U* & 41.933 & $\mathrm{~kg}$ & $\begin{array}{l}1,0 \\
5\end{array}$ \\
\hline Codos y accesorios & $\begin{array}{l}\text { Metal working, average for steel product manufacturing }\{E S\} \mid \text { processing | Alloc } \\
\text { Def, } U^{*}\end{array}$ & 42.276 & $\mathrm{~kg}$ & $\begin{array}{l}1,6 \\
2\end{array}$ \\
\hline Transporte & $\begin{array}{l}\text { Transport, freight, lorry } 16-32 \text { metric ton, EURO3 }\{G L O\} \mid \text { market for | Alloc Def, } \\
U\end{array}$ & $224.984,43$ & $\mathrm{tkm}$ & $\begin{array}{l}1,3 \\
7\end{array}$ \\
\hline & Lorry, 16 metric ton $\{\mathrm{ES}\}$ - limpieza colectores | production | Alloc Def, $\mathrm{U}$ & 0,25 & $\mathrm{p}$ & 1,1 \\
\hline
\end{tabular}


Tabla 118 Tabla de inventario de la fabricación y transporte del sistema de almacenamiento térmico de una planta cilindro-parabólica de 50 MW (escenario TERMOSOLAR CCP)

\begin{tabular}{|c|c|c|c|c|}
\hline Componentes & Dataset & $\begin{array}{l}\text { TOTAL } \\
\text { (Cantidad) }\end{array}$ & Ud & $S^{2}$ \\
\hline \multirow{6}{*}{$\begin{array}{l}\text { Tanque de } \\
\text { almacenamiento ( } 2 \\
\text { unidades) }\end{array}$} & Steel, unalloyed $\{\mathrm{ES}\} \mid$ steel production, converter, unalloyed | Alloc Def, U* & 1.900 .000 & $\mathrm{Kg}$ & 1,26 \\
\hline & Refractory, fireclay, packed $\{$ RoW\}| production | Alloc Def, U & 1.271 .757 & $\mathrm{~kg}$ & 1,26 \\
\hline & Rock wool, packed $\{G L O\} \mid$ market for | Alloc Def, U & $10.419,79$ & $\mathrm{~kg}$ & 1,26 \\
\hline & $\begin{array}{l}\text { Transport, freight, lorry }>32 \text { metric ton, EURO3 }\{\text { RER }\} \mid \text { transport, freight, lorry }>32 \text { metric ton, EURO3 | Alloc } \\
\text { Def, } U\end{array}$ & $636.435,34$ & $\mathrm{tkm}$ & 1,37 \\
\hline & Auxiliary heating unit, electric, 5kW \{RoW\}| production | Alloc Def, U & 16 & u & 1,11 \\
\hline & Metal working, average for steel product manufacturing $\{E S\} \mid$ processing $\mid$ Alloc Def, $U^{*}$ & 1.900 .000 & $\mathrm{~kg}$ & 1,62 \\
\hline \multirow{5}{*}{$\begin{array}{l}\text { Tanque receptor de } \\
\text { drenaje de sales y } \\
\text { estructura }\end{array}$} & Industrial paint (anticorrosive and fireproof) & 62,13 & $\mathrm{~kg}$ & 1,19 \\
\hline & Galvanized steel & 47 & $\mathrm{~kg}$ & 1,19 \\
\hline & Reinforcing steel $\{\mathrm{ES}\} \mid$ market | Alloc Def, U* & 2.660 & $\mathrm{~kg}$ & 1,26 \\
\hline & Transport, freight, lorry $16-32$ metric ton, EURO3 $\{$ GLO\}| market for | Alloc Def, U & 553,826 & $\mathrm{tkm}$ & 1,37 \\
\hline & Metal working, average for steel product manufacturing $\{\mathrm{ES}\} \mid$ processing $\mid$ Alloc Def, $\mathrm{U}^{*}$ & 2.707 & $\mathrm{~kg}$ & 1,62 \\
\hline \multirow[b]{2}{*}{ Aluminio } & Aluminium sheet, primary prod., prod. mix, aluminium semi-finished sheet product RER S & $3.560,81$ & $\mathrm{~kg}$ & 1,26 \\
\hline & $\begin{array}{l}\text { Transport, freight, lorry } 16-32 \text { metric ton, EURO3 }\{\text { RER }\} \mid \text { transport, freight, lorry } 16-32 \text { metric ton, EURO3 | } \\
\text { Alloc Def, } U\end{array}$ & 712.162 & tkm & 1,37 \\
\hline \multirow{2}{*}{$\begin{array}{l}\text { Intercambiador de } \\
\text { calor }\end{array}$} & Reinforcing steel $\{E S\} \mid$ market | Alloc Def, U* & 20.000 & $\mathrm{~kg}$ & 1,26 \\
\hline & $\begin{array}{l}\text { Transport, freight, lorry } 16-32 \text { metric ton, EURO3 }\{\text { RER }\} \mid \text { transport, freight, lorry } 16-32 \text { metric ton, EURO3 | } \\
\text { Alloc Def, } U\end{array}$ & 4.000 .000 & tkm & 1,37 \\
\hline $\begin{array}{l}\text { Bombas de } \\
\text { circulación }\end{array}$ & Circulation pump, $600 \mathrm{~kW}$ & 1.96 & ud & 1,04 \\
\hline \multirow{3}{*}{ Sales térmicas } & Sales minadas ( $60 \%$ sodium nitrate, $40 \%$ Potassium nitrate) & 28.500 .000 & $\mathrm{~kg}$ & 1,02 \\
\hline & $\begin{array}{l}\text { Transport, freight, lorry } 16-32 \text { metric ton, EURO3 }\{R E R\} \mid \text { transport, freight, lorry 16-32 metric ton, EURO3 | } \\
\text { Alloc Def, } U\end{array}$ & 14.250 .000 & $\mathrm{tkm}$ & 1,37 \\
\hline & Transport, transoceanic freight ship/OCE U & 376103670 & $\mathrm{tkm}$ & $1,, 37$ \\
\hline
\end{tabular}




\begin{tabular}{|c|c|c|c|c|}
\hline Componentes & Dataset & Cantidad & Ud & $S D^{2}$ \\
\hline Aislante & Rock wool, packed $\{G L O\} \mid$ market for | Alloc Def, U & 62.500 & $\mathrm{~kg}$ & \\
\hline \multirow{2}{*}{ Tuberías } & Polyethylene, high density, granulate $\{R E R\} \mid$ production | Alloc Def, $U$ & 93.750 & $\mathrm{~kg}$ & \\
\hline & Extrusion, plastic pipes $\{R E R\} \mid$ production | Conseq, $U$ & 93.750 & $\mathrm{~kg}$ & 1,61 \\
\hline Transporte & $\begin{array}{l}\text { Transport, freight, lorry } 16-32 \text { metric ton, EURO4 \{RER\}| transport, freight, lorry } 16-32 \text { metric ton, EURO4 } \\
\text { | Alloc Def, U }\end{array}$ & 58.622 & $\mathrm{tkm}$ & 1.37 \\
\hline $\begin{array}{l}\text { Bomba de } \\
\text { refrigeración }\end{array}$ & Circulation pump, $600 \mathrm{~kW}$ & 2,22 & ud & \\
\hline \multirow{3}{*}{$\begin{array}{l}\text { Torre de } \\
\text { refrigeración }\end{array}$} & Concrete, sole plate and foundation $\{$ Europe without switzerland, ES\}| production | Alloc Def, $U$ & 97.189 & $\mathrm{~kg}$ & 1,19 \\
\hline & Glass fibre reinforced plastic, polyester resin, hand lay-up $\{R E R\} \mid$ production | Conseq, $S$ & 5.472 & $\mathrm{Kg}$ & 1,19 \\
\hline & Polyvinylchloride, emulsion polymerised $\{$ GLO\}| market for | Alloc Def, $U$ & 1.368 & $\mathrm{Kg}$ & 1,19 \\
\hline \multirow{4}{*}{$\begin{array}{l}\text { Tren de generación } \\
\text { de vapor }\end{array}$} & Steel, unalloyed $\{E S\} \mid$ market for | Alloc Def, $U$ & 397.110 & $\mathrm{~kg}$ & 1,05 \\
\hline & Metal working, average for steel product manufacturing $\{G L O\} \mid$ market for | Alloc Def, $U$ & 331.020 & $\mathrm{~kg}$ & 1,05 \\
\hline & Drawing of pipe, steel $\{G L O\} \mid$ market for | Alloc Def, $U$ & 66.090 & $\mathrm{~kg}$ & 1,05 \\
\hline & Transport, freight, lorry $16-32$ metric ton, EURO3 $\{$ GLO\}| market for | Alloc Def, U & 79.422 .000 & $\mathrm{~kg}$ & 1,37 \\
\hline \multirow{3}{*}{$\begin{array}{l}\text { Tanque de agua de } \\
\text { condensados }\end{array}$} & Steel, unalloyed $\{\mathrm{ES}\} \mid$ steel production, converter, unalloyed | Alloc Def, U & 31.400 & $\mathrm{~kg}$ & 1,19 \\
\hline & Epoxy resin, liquid $\{R E R\} \mid$ production | Alloc Def, $U$ & 50 & $\mathrm{~kg}$ & 1,22 \\
\hline & Metal working, average for steel product manufacturing $\{E S\} \mid$ processing $\mid$ Alloc Def, $U$ & 31.400 & $\mathrm{~kg}$ & 1,61 \\
\hline Bombas & Circulation pump, $600 \mathrm{~kW}$ & 0,65 & ud & 1 \\
\hline \multirow{4}{*}{ Condensador } & _66 Machinery and equipment n.e.c., EU27 & 106.000 & $\mathrm{~kg}$ & 1,66 \\
\hline & Transport, freight, sea, transoceanic ship $\{G L O\} \mid$ processing | Alloc Def, $U$ & 304.432 & $\mathrm{tkm}$ & 1,61 \\
\hline & $\begin{array}{l}\text { Transport, freight, lorry }>32 \text { metric ton, EURO4 }\{\text { RER }\} \mid \text { transport, freight, lorry }>32 \text { metric ton, EURO4 | } \\
\text { Alloc Def, } U\end{array}$ & 68.800 & $\mathrm{tkm}$ & 1,61 \\
\hline & Steel, unalloyed $\{\mathrm{ES}\} \mid$ steel production, converter, unalloyed | Alloc Def, U & 1.380 & $\mathrm{~kg}$ & 1,19 \\
\hline
\end{tabular}




\begin{tabular}{|c|c|c|c|c|}
\hline $\begin{array}{l}\text { Tanque de drenado } \\
\text { de condensados }\end{array}$ & Metal working, average for steel product manufacturing $\{E S\} \mid$ processing $\mid$ Alloc Def, $U$ & 1.380 & $\mathrm{~kg}$ & 1,61 \\
\hline \multirow{2}{*}{ Desgasificador } & Metal working, average for chromium steel product manufacturing $\{G L O\} \mid$ market for $\mid$ Alloc Def, $U$ & 8.000 & $\mathrm{~kg}$ & 1,62 \\
\hline & Steel, chromium steel $18 / 8\{G L O\} \mid$ market for | Alloc Def, U & 8.000 & $\mathrm{~kg}$ & 1,1 \\
\hline \multirow{3}{*}{ Generador } & _66 Machinery and equipment n.e.c., EU27 & 97.250 & $\mathrm{~kg}$ & 1,36 \\
\hline & $\begin{array}{l}\text { Transport, freight, lorry }>32 \text { metric ton, EURO } 4\{R E R\} \mid \text { transport, freight, lorry }>32 \text { metric ton, EURO4 | } \\
\text { Alloc Def, } U\end{array}$ & 43.860 & $\mathrm{tkm}$ & 1,61 \\
\hline & Transport, freight, sea, transoceanic ship $\{G L O\} \mid$ processing | Alloc Def, $U$ & 292.944 & $\mathrm{tkm}$ & 1,61 \\
\hline \multirow{3}{*}{ Turbina } & _66 Machinery and equipment n.e.c., EU27 & 107.400 & $\mathrm{~kg}$ & 1,36 \\
\hline & $\begin{array}{l}\text { Transport, freight, lorry >32 metric ton, EURO4 }\{\text { RER }\} \mid \text { transport, freight, lorry }>32 \text { metric ton, EURO4 | } \\
\text { Alloc Def, } U\end{array}$ & $46.183,3$ & $\mathrm{tkm}$ & 1,61 \\
\hline & Transport, freight, sea, transoceanic ship $\{G L O\} \mid$ processing | Alloc Def, $U$ & $308.461,4$ & $\mathrm{tkm}$ & 1,61 \\
\hline \multirow{3}{*}{$\begin{array}{l}\text { Válvulas de bola y } \\
\text { compuerta }\end{array}$} & Reinforcing steel $\{\mathrm{ES}\} \mid$ market | Alloc Def, $U$ & 14.925 & $\mathrm{~kg}$ & 1,12 \\
\hline & Metal working, average for steel product manufacturing $\{R E R\} \mid$ processing $\mid$ Alloc Def, $U$ & 14.925 & $\mathrm{~kg}$ & 1,12 \\
\hline & $\begin{array}{l}\text { Transport, freight, lorry 7.5-16 metric ton, EURO4 }\{\text { RER }\} \mid \text { transport, freight, lorry } 7.5-16 \text { metric ton, } \\
\text { EURO4 | Alloc Def, U }\end{array}$ & 2.985 & $\mathrm{tkm}$ & 1,35 \\
\hline
\end{tabular}

Tabla 120 Inventario de la fabricación y transporte de las instalaciones auxiliares de una planta cilindro-parabólica de 50 MW (escenario TERMOSOLAR CCP)

\begin{tabular}{|c|c|c|c|c|}
\hline Componentes & Dataset & Cantidad & Ud & $S^{2}$ \\
\hline \multirow{2}{*}{$\begin{array}{l}\text { Edificio de oficinas genérico } \\
(1600 \mathrm{~m} 2)\end{array}$} & Reinforcing steel $\{\mathrm{ES}\} \mid$ production | Alloc Def, U Sistema* & 18.480 & $\mathrm{~kg}$ & 1,61 \\
\hline & Autoclaved aerated concrete block $\{$ RoW $\} \mid$ production | Alloc Def, $U$ & 52.640 & $\mathrm{~kg}$ & 1,61 \\
\hline $\begin{array}{l}\text { Bombas de captación de } \\
\text { aguas }\end{array}$ & Circulation pump, $600 \mathrm{~kW}$ & 2 & ud & 1,04 \\
\hline $\begin{array}{l}\text { Planta de tratamiento de } \\
\text { aguas (desionización) }\end{array}$ & Ion-exchanger for water treatment $\{$ RoW $\} \mid$ production | Alloc Def, $U$ & 1 & ud & 1,21 \\
\hline
\end{tabular}


Componente o Actividad

Excavación y preparación del terreno

Construcción del bloque de potencia

Estructura edificio sales y HTF

Metal working, average for steel product manu

Plataforma para intercambiador

aceite-sales

Estructura para depósitos de

expansión, rebose y ullage
Dataset

Gravel, round $\{G L O\} \mid$ market for | Alloc Def, $U$

, hydraulic digger $\{R E R\} \mid$ processing | Alloc Def, $U$

Excavation, skid-steer loader $\{$ RER $\} \mid$ processing | Alloc Def, $U$

Diesel, burned in building machine $\{G L O\} \mid$ processing | Alloc Def, $U$

Electricity, medium voltage \{ES_2013\}| market for | Alloc Def, U --with CSP

Industrial paint (anticorrosive and fireproof)

Reinforcing steel $\{\mathrm{ES}\} \mid$ market | Alloc Def, $\mathrm{U}^{*}$

Transport, freight, lorry $>32$ metric ton, EURO4 \{RER\}| transport, freight, lorry $>32$ metric ton,

EURO4 | Alloc Def, U

Industrial paint (anticorrosive and fireproof)

Steel, unalloyed $\{$ ES $\} \mid$ market for | Alloc Def, $U^{*}$

Galvanized steel [ES]

Metal working, average for steel product manufacturing $\{E S\} \mid$ processing $\mid$ Alloc Def, $U^{*}$

Transport, freight, lorry $>32$ metric ton, EURO4 \{RER\}| transport, freight, lorry $>32$ metric ton, EURO4 | Alloc Def, U

Industrial paint (anticorrosive and fireproof)

Steel, unalloyed $\{\mathrm{SA}, \mathrm{MX}, \mathrm{ES}, \mathrm{IN}$ or $\mathrm{CL}\} \mid$ market for | Alloc Def, $\mathrm{U}$

Galvanized steel $[\mathrm{ES}]^{*}$

Metal working, average for steel product manufacturing $\{E S\} \mid$ processing | Alloc Def, $U^{*}$

Transport, freight, lorry $>32$ metric ton, EURO4 $\{$ RER $\} \mid$ transport, freight, lorry $>32$ metric ton,

EURO4 | Alloc Def, U

Cantidad

$10.636 .333 \mathrm{~kg} \quad 1,03$

$61.767 \quad \mathrm{~m} 3 \quad 1,03$

$61.949 \quad \mathrm{~m} 3 \quad 1,03$

13.500.000 MJ 1,1

$843.750 \quad \mathrm{~kW} \quad 1,1$

$116 \quad \mathrm{~kg} \quad 1,19$

$55.235 \quad \mathrm{~kg} \quad 1,19$

$55.235 \quad \mathrm{~kg} \quad 1,61$

$55.351 \quad \mathrm{tkm}$

220

$110.000 \quad \mathrm{~kg} \quad 1,61$

$220.630 \quad \mathrm{tkm}$

$184,2 \quad \mathrm{~kg} \quad 1,19$

$92.060 \quad \mathrm{~kg} \quad 1,19$

$214 \quad \mathrm{~kg} \quad 1,19$

$92.274 \quad \mathrm{~kg} \quad 1,61$

Reinforcing steel $\{E S\} \mid$ market | Alloc Def, $U^{*}$

92.458,2 tkm

Pintura anticorrosiva e ingífuga para estructuras metálicas

$\begin{array}{lll}81.215 & \mathrm{~kg} & 1,19 \\ 208,4 & \mathrm{~kg} & 1,19\end{array}$


Metal working, average for steel product manufacturing $\{E S\} \mid$ processing | Alloc Def, $U^{*}$

Transport, freight, lorry $>32$ metric ton, EURO3 $\{$ RER $\} \mid$ transport, freight, lorry $>32$ metric ton, EURO3 | Alloc Def, U

Industrial paint (anticorrosive and fireproof)

Reinforcing steel $\{E S\} \mid$ market | Alloc Def, U*

Estructura para el bloque de turbina

Galvanized steel [ES]*

Metal working, average for steel product manufacturing $\{E S\} \mid$ processing | Alloc Def, $U$

$81.390 \quad \mathrm{~kg} \quad 1,61$

Transport, freight, lorry $>32$ metric ton, EURO4 \{RER\}| transport, freight, lorry $>32$ metric ton, EURO4 | Alloc Def, U

Industrial paint (anticorrosive and fireproof)

Reinforcing steel $\{\mathrm{ES}\} \mid$ market | Alloc Def, U*

Estructura para el condensador y purgas

\section{Galvanized steel [ES]*}

Metal working, average for steel product manufacturing $\{E S\} \mid$ processing | Alloc Def, U*

81.598,4 tkm 1,37

Transport, freight, lorry $>32$ metric ton, EURO4 $\{$ RER $\} \mid$ transport, freight, lorry $>32$ metric ton

EURO4 | Alloc Def, U

Industrial paint (anticorrosive and fireproof)

$22 \quad \mathrm{~kg} \quad 1,19$

Reinforcing steel $\{\mathrm{ES}\} \mid$ market | Alloc Def, U*

$1.750 \quad \mathrm{~kg} \quad 1,19$

$52 \quad \mathrm{~kg} \quad 1,19$

$1.802 \quad \mathrm{~kg} \quad 1,61$

Galvanized steel [ES]*

Metal working, average for steel product manufacturing $\{E S\} \mid$ processing $\mid$ Alloc Def, $U^{*}$

$1.824 \quad \mathrm{tkm} \quad 1,37$

$1.824 \quad \mathrm{tkm} \quad 1,37$

$23 \quad \mathrm{~kg} \quad 1,19$

$11.508 \quad \mathrm{~kg} \quad 1,19$

$57 \quad \mathrm{~kg} \quad 1,19$

$43.400 \quad \mathrm{~kg} \quad 1,61$

Estructura para los precalentadores

Transport, freight, lorry $>32$ metric ton, EURO4 $\{$ RER $\} \mid$ transport, freight, lorry $>32$ metric ton, EURO4 | Alloc Def, $U$

Reinforcing steel $\{E S\} \mid$ market | Alloc Def, $U^{*}$

Industrial paint (anticorrosive and fireproof)

Estructura-rack generador de vapor

Metal working, average for steel product manufacturing $\{E S\} \mid$ processing | Alloc Def, $U^{*}$

$11.588 \quad \mathrm{tkm} \quad 1,37$

$13,146 \quad \mathrm{~kg} \quad 1,19$

$6.573 \quad \mathrm{~kg} \quad 1,19$

$41 \quad \mathrm{~kg} \quad 1,19$

$6.614 \quad \mathrm{~kg} \quad 1,61$

$6.627,146 \quad \mathrm{tkm} \quad 1,37$

$82.000 \quad \mathrm{~kg} \quad 1,19$

$211,2 \quad \mathrm{~kg} \quad 1,19$

Transport, freight, lorry $>32$ metric ton, EURO4 $\{$ RER $\} \mid$ transport, freight, lorry $>32$ metric ton, EURO4 | Alloc Def, U

82.000

82.211,2 tkm 1,37

Industrial paint (anticorrosive and fireproof)

157,28 
Estructura-Rack turbina y desgasificador

Galvanized steel [ES]*

Metal working, average for steel product manufacturing $\{E S\} \mid$ processing | Alloc Def, $U^{*}$

Transport, freight, lorry $>32$ metric ton, EURO4 \{RER\}| transport, freight, lorry $>32$ metric ton, EURO4 | Alloc Def, U

Industrial paint (anticorrosive and fireproof)

Reinforcing steel $\{$ ES\}| market | Alloc Def, U*

Estructuras planta de tratamiento y edificios auxiliares

Road, company, internal $\{\mathrm{CH}\} \mid$ construction | Alloc Def, $U$

Metal working, average for steel product manufacturing $\{E S\} \mid$ processing | Alloc Def, $U^{*}$

Transport, freight, lorry $>32$ metric ton, EURO4 $\{$ RER $\} \mid$ transport, freight, lorry $>32$ metric ton, EURO4 | Alloc Def, U

Industrial paint (anticorrosive and fireproof)

Reinforcing steel $\{E S\} \mid$ market | Alloc Def, U*

Rack eléctrico sistema de vapor y torres de refrigeración

Cimentación bloque potencia

Galvanized steel [ES]*

Metal working, average for steel product manufacturing $\{E S\} \mid$ processing $\mid$ Alloc Def, $U^{*}$

78.971

$\mathrm{kg} \quad 1,19$

Transport, freight, lorry $>32$ metric ton, EURO4 $\{$ RER $\} \mid$ transport, freight, lorry $>32$ metric ton

EURO4 | Alloc Def, U

Concrete, sole plate and foundation $\{$ Europe without switzerland, ES\}| production | Alloc Def,

$\mathrm{U}^{*}$

Hormigonera 27,5 kw (2150 kg de carga)

Concrete, sole plate and foundation \{Europe without switzerland, ES\}| production | Alloc Def, U*

Cimentación campo solar

Reinforcing steel $\{$ ES\}| market | Alloc Def, U*

Hormigonera $27,5 \mathrm{kw}$ (2150 kg de carga)

Transport, freight, lorry 16-32 metric ton, EURO3 \{GLO\}| market for | Alloc Def, U

79.128,28 tkm 1,37

$175,6 \quad \mathrm{~kg} \quad 1,19$

$69.001 \quad \mathrm{~kg} \quad 1,19$

$87.500 \quad \mathrm{~m} 2 \quad 1,61$

$69.001 \quad \mathrm{~kg} \quad 1,61$

$156.676,6 \quad$ tkm $\quad 1,37$

$167,89 \quad \mathrm{~kg} \quad 1,19$

$83.945 \quad \mathrm{~kg} \quad 1,19$

$55 \quad \mathrm{~kg} \quad 1,19$

$84.000 \quad \mathrm{~kg} \quad 1,61$

$84.167,89 \quad \mathrm{tkm} \quad 1,37$

$25.042 .500 \mathrm{~kg} \quad 1,1$

$10.500 \quad h \quad 1,19$

$12.277 .980 \quad \mathrm{~kg} \quad 1,07$

$2.957 .073 \quad \mathrm{~kg} \quad 1,07$

5.148

h 1,19

Transporte materiales de construcción (dentro de la instalación)
7.637.083 tkm 1,37 


\begin{tabular}{|c|c|c|c|c|}
\hline $\begin{array}{l}\text { Transporte estructuras de } \\
\text { construcción (dentro de la } \\
\text { instalación) }\end{array}$ & Transport, freight, lorry $16-32$ metric ton, EURO3 $\{$ GLO\}| market for | Alloc Def, U & $42.634,6$ & $\mathrm{tkm}$ & 1,37 \\
\hline Soldadura de tuberías HTF & Welding, gas, steel $\{R E R\} \mid$ processing $\mid$ Alloc Def, $U$ & 957 & $\mathrm{~m}$ & 1,19 \\
\hline Soldadura de tubos absorbedores & Welding, gas, steel $\{R E R\} \mid$ processing $\mid$ Alloc Def, $U$ & $4.942,1$ & $\mathrm{~m}$ & 1,19 \\
\hline Grúa colocación colectores & Grúa telescópica autopropulsada 127 HP & 187 & $\mathrm{~h}$ & 1,19 \\
\hline $\begin{array}{l}\text { Grúa para bloque de } \\
\text { almacenamiento }\end{array}$ & Grúa telescópica autopropulsada 127 HP & 2,8 & $\mathrm{~h}$ & 1,19 \\
\hline Grúa para elementos circuito HTF & Grúa telescópica autopropulsada 127 HP & 3,5 & $\mathrm{~h}$ & 1,19 \\
\hline Carreteras & Road, company, internal $\{$ RoW $\} \mid$ construction | Alloc Def, $U$ & 87.500 & $m^{2} a$ & 1,61 \\
\hline \multirow{3}{*}{ Construcción edificio genérico } & Reinforcing steel $\{\mathrm{ES}\} \mid$ market | Alloc Def, $\mathrm{U}^{*}$ & 69.001 & $\mathrm{~kg}$ & 1,19 \\
\hline & Industrial paint (anticorrosive and fireproof) & 175,6 & $\mathrm{~kg}$ & 1,19 \\
\hline & Metal working, average for steel product manufacturing $\{E S\} \mid$ processing $\mid$ Alloc Def, $U^{*}$ & 69.001 & $\mathrm{~kg}$ & 1,61 \\
\hline
\end{tabular}

*Estos datasets han sido modificados para representar el consumo eléctrico del mix español

Tabla 122 Tabla de inventario de la operación y mantenimiento de una planta cilindro-parabólica de 50 MW en modo sólo solar

\begin{tabular}{|c|c|c|c|c|}
\hline Componente o Actividad & Dataset & Cantidad & Ud & SD2 \\
\hline Aceite lubricante & Aceite lubricante-Lubricating oil $\{\mathrm{GLO}\} \mid$ market for | Alloc Def, $U$ & 8.300 & $\mathrm{~kg}$ & - \\
\hline Aceite HTF (recambio) & Aceite HTF & 10 & ton & - \\
\hline Agua para refrigeración & Water, consumed for cooling (CSP $50 \mathrm{MW}, 25$ years) & $2,24 \mathrm{E}+07$ & m3 & - \\
\hline Agua desionizada (ciclo vapor) & Water, deionised, from well water, at user ES (adaptado_2013)| production | Alloc Def, U & $2,92 \mathrm{E}+08$ & $\mathrm{~kg}$ & - \\
\hline Agua limpieza colectores & Water, consumed for cleaning mirrors (CSP $50 \mathrm{MW}, 25$ years) & 120.515 .850 & L & 1,09 \\
\hline Colectores solares (recambio) & Colector solar cilindro parabólico & 6,24 & $\mathrm{p}$ & - \\
\hline Gas natural mantenimiento & $\begin{array}{l}\text { Heat, district or industrial, natural gas }\{\text { RoW }\} \mid \text { heat production, natural gas, at industrial } \\
\text { furnace }>100 \mathrm{~kW} \mid \text { Alloc Def, } U \text { - Modificado }\end{array}$ & 170.111 .596 & MJ & - \\
\hline
\end{tabular}


Tabla 123 Tabla de inventario del desmantelamiento de una planta cilindro-parabólica de 50 MW (escenario TERMOSOLAR CCP)

\section{Componente o Actividad}

Dataset

Diesel, burned in building machine $\{$ GLO $\} \mid$ processing | Alloc Def, UTransport, freight, lorry $>32$ metric ton, EURO3 $\{$ RER\}| transport, freight, lorry $>32$ metric ton, EURO3 | Alloc Def, $U$

Actividades de desmantelamiento
Transport, freight, lorry $>32$ metric ton, EURO3 $\{R E R\} \mid$ transport, freight, lorry $>32$ metric ton,

EURO3 | Alloc Def, U
Cantidad

Ud

8.800.000 MJ $\quad 1,11$

$50.900 .000 \mathrm{tkm}$ 


\section{Inventario del ciclo de vida de las astillas de chopo}

Tabla 124 Inventario de pretratamiento del suelo para la plantación de chopo

\begin{tabular}{lllll} 
Operación & Herramientas & $\begin{array}{l}\text { Consumo de } \\
\text { combustible } \\
(\mathbf{k g} / \mathrm{ha})\end{array}$ & Cantidad & Proceso de ecoinvent (adaptado) \\
\hline Subsolado & Arado & 14,45 & - & Tillage, cultivating, chiselling \{RER\}| processing | Alloc Def, U- Adapted \\
\hline Siembra & Sembradora & 16,8 & $\begin{array}{l}3,2345 \\
\text { trees/GJ }\end{array}$ & Planting $\{$ RER\}| processing | Alloc Def, U \\
\hline $\begin{array}{llll}\text { Laboreo } \\
\text { Transporte de } \\
\text { fertilizante }\end{array}$ & Arado & 16,8 & - & Tillage, ploughing $\{$ RER\}| processing | Alloc Def, U- adapted \\
\cline { 2 - 5 } & Furgoneta & & $250 \mathrm{~km}$ & $\begin{array}{l}\text { Transport, freight, light commercial vehicle }\{\text { Europe without Switzerland }\} \mid \text { processing | Alloc } \\
\text { Def, U }\end{array}$ \\
\hline $\begin{array}{l}\text { Fertilización } \\
\text { NPK }\end{array}$ & Pulverizadores & 8,4 & $30 \mathrm{~km}$ & $\begin{array}{l}\text { Transport, freight, lorry 3,5-7,5 metric ton, EURO4 }\{\text { RER\}| transport, freight, lorry 3,5-7,5 } \\
\text { metric ton, EURO4 | Alloc Def, U }\end{array}$ \\
\hline
\end{tabular}

Tabla 125 Inventario de fertilizantes aplicados durante la fase de pretratemiento del suelo en la plantación de chopo

\begin{tabular}{|c|c|c|c|c|c|c|c|}
\hline \multirow{2}{*}{\multicolumn{2}{|c|}{ Fertilizante }} & \multirow{3}{*}{$\begin{array}{l}\text { Proceso de ecoinvent } \\
\begin{array}{l}\text { Phosphate fertiliser, as P2O5 }\{\mathrm{RER}\} \mid \text { diammonium phosphate } \\
\text { production | Alloc Def, } U\end{array}\end{array}$} & \multirow{3}{*}{$\begin{array}{l}\begin{array}{l}\text { Cantidad } \\
\text { (g/GJ) }\end{array} \\
16\end{array}$} & \multicolumn{2}{|c|}{ Emisiones al agua } & \multicolumn{2}{|c|}{ Emisiones al aire } \\
\hline & & & & Sustancia & $\begin{array}{l}\% \text { de } \mathrm{P} / \mathrm{N} \\
\text { aplicado }\end{array}$ & Sustancia & $\begin{array}{l}\% \text { de } \mathrm{N} \\
\text { aplicado }\end{array}$ \\
\hline \multirow{5}{*}{ NPK } & Fosfato (22\%) & & & Fosfato & 1,50 & - & - \\
\hline & \multirow{3}{*}{ Nitrógeno (8\%) } & \multirow{3}{*}{$\begin{array}{l}\text { Ammonium nitrate, as } \mathrm{N}\{\mathrm{RER}\} \mid \text { ammonium nitrate production | Alloc } \\
\text { Def, } \mathrm{U}\end{array}$} & \multirow{3}{*}{5,8} & \multirow{3}{*}{ Nitrato } & \multirow{3}{*}{29,78} & $\mathrm{~N}_{2} \mathrm{O}$ & 1,33 \\
\hline & & & & & & $\mathrm{CH}_{4}$ & 1,0 \\
\hline & & & & & & $\mathrm{NH}_{3}$ & 0,99 \\
\hline & Potasio (10\%) & $\begin{array}{l}\text { Potassium chloride, as K2O }\{\text { RER }\} \mid \text { potassium chloride production | } \\
\text { Alloc Def, } U\end{array}$ & 7,3 & - & - & - & - \\
\hline
\end{tabular}




\section{Entradas para cada rotación}

\begin{tabular}{|c|c|c|c|c|c|c|c|c|}
\hline & & $1^{\mathrm{a}}$ & $2^{\mathrm{a}}$ & $3^{\mathrm{a}}$ & $4^{\mathrm{a}}$ & Herramienta & $\begin{array}{l}\text { Consumo de } \\
\text { combustible } \\
\text { (kg/ha) }\end{array}$ & Ecoinvent process \\
\hline \multicolumn{2}{|c|}{ Consumo de agua $\left(\mathrm{m}^{3} / \mathrm{GJ}\right)$} & 2,01 & 2,22 & 2,44 & 2,68 & Indundación & - & - \\
\hline \multirow{2}{*}{$\begin{array}{l}\text { Aplicación } \\
\text { de } \\
\text { herbicida } \\
\text { (L/GJ) }\end{array}$} & Glifosato & $\begin{array}{l}2,18 \mathrm{E}- \\
03\end{array}$ & 0 & 0 & 0 & Pulverizador & $6,67$ ( $\times 3$ times $)$ & $\begin{array}{l}\text { Application of plant protection product, by field } \\
\text { sprayer }\{\text { RER }\} \mid \text { processing | Alloc Def, } U \text { - } \\
\text { Adapted }\end{array}$ \\
\hline & Oxifluorfén & $\begin{array}{l}9,70 \mathrm{E}- \\
04\end{array}$ & $\begin{array}{l}9,70 E- \\
04\end{array}$ & $\begin{array}{l}9,70 \mathrm{E}- \\
04\end{array}$ & $\begin{array}{l}9,70 \mathrm{E}- \\
04\end{array}$ & Pulverizador & 6,67 ( $x 4$ times) & $\begin{array}{l}\text { Application of plant protection product, by field } \\
\text { sprayer }\{\text { RER }\} \mid \text { processing | Alloc Def, } U \text { - } \\
\text { Adapted }\end{array}$ \\
\hline \multicolumn{2}{|c|}{ Desmalezado (times) } & 2 & 1 & 1 & 1 & Desmalezador & 14,3 ( $x 5$ times) & Hoeing $\{$ RER $\} \mid$ processing | Alloc Def, U- Adapted \\
\hline \multicolumn{2}{|c|}{$\begin{array}{l}\text { Aplicación de nitrato de amonio } \\
(27 \%)(\mathrm{kg} / \mathrm{GJ})\end{array}$} & 0 & $\begin{array}{l}5,60 \mathrm{E}- \\
02\end{array}$ & $\begin{array}{l}5,60 \mathrm{E}- \\
02\end{array}$ & $\begin{array}{l}5,60 \mathrm{E}- \\
02\end{array}$ & Pulverizador & 8,4 (x3 times) & $\begin{array}{l}\text { Fertilising, by broadcaster }\{\text { RER }\} \mid \text { processing | } \\
\text { Alloc Def, U-Adapted }\end{array}$ \\
\hline
\end{tabular}

Tabla 127 Inventario para la fase de cosechado del chopo, por GJ de biomasa cosechada

\begin{tabular}{|c|c|c|c|c|}
\hline & Herramienta & $\begin{array}{l}\text { Consumo de } \\
\text { energía }\end{array}$ & Input values & Ecoinvent process \\
\hline Empacado & Biobaler & $152,1 \mathrm{~kg} / \mathrm{ha}$ & 0,20 bales/GJ & Baling $\{$ RER $\} \mid$ processing | Alloc Def, U- Adapted for Biobaler \\
\hline Carga de pacas & Cargador de pacas & & 0,20 bales $/ \mathrm{GJ}$ & Bale loading $\{$ RoW $\} \mid$ processing | Alloc Def, $U$ \\
\hline $\begin{array}{l}\text { Transporte de } \\
\text { pacas }\end{array}$ & Camión, 38 t, $70 \mathrm{~m} 3$ & & $1,46 \mathrm{tkm} / \mathrm{GJ}$ & $\begin{array}{l}\text { Transport, freight, lorry }>32 \text { metric ton, EURO4 }\{\text { RoW }\} \mid \text { transport, freight, lorry }>32 \text { metric } \\
\text { ton, EURO4 | Alloc Def, } U\end{array}$ \\
\hline Corte en planta & $\begin{array}{l}\text { Cortadora } \\
\text { eléctrica }\end{array}$ & $10,9 \mathrm{kWh}$ & 0,20 bales/GJ & Chipper, stationary, electric $\{R E R\} \mid$ production | Alloc Def, $U$ \\
\hline
\end{tabular}


Tabla 128 Inventario para el cosechado de astillas del chopo, por GJ cosechado

\begin{tabular}{|c|c|c|c|c|}
\hline & Tool & $\begin{array}{l}\text { Energy } \\
\text { consumptio } \\
\mathrm{n}\end{array}$ & Input values & Ecoinvent process \\
\hline Cosechadora & Claas Jaguar & $97,77 \mathrm{~kg} / \mathrm{ha}$ & $0,0949 \mathrm{ha} / \mathrm{GJ}$ & $\begin{array}{l}\text { Combine harvesting }\{R E R\} \mid \text { processing | Alloc Def, } U \text {-adapted for chip harvesting with Claas } \\
\text { Jaguar }\end{array}$ \\
\hline Tractor auxiliar & $\begin{array}{l}\text { Agricultural } \\
\text { tractor and } \\
\text { trailer }\end{array}$ & $32,6 \mathrm{~kg} / \mathrm{ha}$ & $0,0316 \mathrm{tkm} / \mathrm{GJ}$ & Transport, tractor and trailer, agricultural $\{$ RoW $\} \mid$ processing | Alloc Def, $U$ \\
\hline Transporte de astillas & Lorry, $40 \mathrm{t}, 90 \mathrm{~m} 3$ & & $1,141 \mathrm{tkm} / \mathrm{GJ}$ & $\begin{array}{l}\text { Transport, freight, lorry }>32 \text { metric ton, EURO4 }\{\text { RoW }\} \mid \text { transport, freight, lorry }>32 \text { metric } \\
\text { ton, EURO4 | Alloc Def, } U\end{array}$ \\
\hline
\end{tabular}




\section{ANEXO II: TABLAS DE INVENTARIO ECONÓMICO}

Este anexo incluye en primer lugar las tablas de inventario del análisis Input Output. En segundo lugar incluye las tablas de información para la monetización de externalidades relacionadas con emisiones de contaminantes.

Tabla 129 Inventario económico de la fase de inversión inicial de la planta HYSOL (descontado al año de comienzo del proyecto)

\begin{tabular}{|c|c|c|c|c|c|}
\hline \multirow[b]{2}{*}{ Inventario para la fase inversión inicial } & \multirow{2}{*}{$\begin{array}{l}\mathrm{M}_{2011} \\
\text { (Producción) }\end{array}$} & \multirow{2}{*}{ Sector económico } & \multicolumn{3}{|c|}{ MÁRGENES (M€ $\left.€_{2011}\right)$} \\
\hline & & & $\begin{array}{l}\text { Transporte } \\
\text { (c23) }\end{array}$ & \begin{tabular}{|l} 
Comercial \\
(c21)
\end{tabular} & $\begin{array}{l}\text { Impuestos } \\
\text { (c31) }\end{array}$ \\
\hline INVERSIÓN INMATERIAL & 138,67 & & 0 & $3,64 \mathrm{E}-02$ & $5,38 \mathrm{E}+00$ \\
\hline Desarrollo de proyecto (servicio consultoría, ingeniería) & 62,55 & Renting of M\&Eq and Other Business Activities & 0 & $2,20 \mathrm{E}-02$ & $2,58 \mathrm{E}+00$ \\
\hline Gestión del EPC & 0,00 & Renting of M\&Eq and Other Business Activities & 0 & 0 & 0 \\
\hline Contingencias & 40,94 & Renting of M\&Eq and Other Business Activities & 0 & $1,44 \mathrm{E}-02$ & $1,69 \mathrm{E}+00$ \\
\hline Intereses & 35,19 & Financial Intermediation & 0 & 0 & $1,11 \mathrm{E}+00$ \\
\hline URBANIZACIÓN Y CONSTRUCCIÓN & 136,90 & & $-6,65 \mathrm{E}-01$ & $2,91 \mathrm{E}+00$ & $1,72 \mathrm{E}+00$ \\
\hline Cimientos ( $12 \%$ de constr) & 14,08 & Other Non-Metallic Mineral & $5,42 \mathrm{E}-01$ & $2,34 \mathrm{E}+00$ & $1,12 \mathrm{E}-01$ \\
\hline $\begin{array}{l}\text { Construcción estructuras y caminos/carreteras ( } 4 \text { \% de } \\
\text { constr) }\end{array}$ & 5,06 & Basic Metals and Fabricated Metal & $3,05 E-02$ & $5,73 \mathrm{E}-01$ & $2,93 \mathrm{E}-02$ \\
\hline Construcción planta (personal y maquinaria) (75 \%) & 103,50 & Construction & 0 & 0 & $3,21 \mathrm{E}+00$ \\
\hline Transporte de componentes planta (8\%) & 14,25 & Inland Transport & $-1,24 \mathrm{E}+00$ & 0 & $-1,63 E+00$ \\
\hline COMPRA DE COMPONENTES: Campo solar & 128,79 & & $1,84 \mathrm{E}+00$ & $1,49 \mathrm{E}+01$ & $1,61 \mathrm{E}+00$ \\
\hline Espejos & 31,56 & Other Non-Metallic Mineral & $1,22 \mathrm{E}+00$ & $5,24 \mathrm{E}+00$ & $2,50 \mathrm{E}-01$ \\
\hline Seguidores solares & 4,10 & Electrical and Optical Equipment & $9,48 \mathrm{E}-03$ & $1,58 \mathrm{E}+00$ & 1,97E-01 \\
\hline Estructura metálica del pedestal & 62,79 & Basic Metals and Fabricated Metal & $3,79 \mathrm{E}-01$ & $7,11 \mathrm{E}+00$ & $3,64 \mathrm{E}-01$ \\
\hline Cimientos & 6,07 & Other Non-Metallic Mineral & 2,34E-01 & $1,01 \mathrm{E}+00$ & $4,81 \mathrm{E}-02$ \\
\hline Mejoras del terreno & 24,27 & Construction & 0 & 0 & $7,54 \mathrm{E}-01$ \\
\hline COMPRA DE COMPONTENTES: Torre y receptor & 48,43 & & $1,19 \mathrm{E}+00$ & $6,94 \mathrm{E}+00$ & 3,39E-01 \\
\hline
\end{tabular}




\begin{tabular}{|c|c|c|c|c|c|}
\hline Hormigón torre & 9,53 & Other Non-Metallic Mineral & 3,67E-01 & $1,58 \mathrm{E}+00$ & $7,55 \mathrm{E}-02$ \\
\hline Acero torre & 4,83 & Basic Metals and Fabricated Metal & $2,92 \mathrm{E}-02$ & $5,47 E-01$ & $2,80 \mathrm{E}-02$ \\
\hline Cuarzo del receptor & 18,11 & Other Non-Metallic Mineral & 6,97E-01 & $3,00 E+00$ & $1,43 \mathrm{E}-01$ \\
\hline Acero del receptor & 12,42 & Basic Metals and Fabricated Metal & 7,49E-02 & $1,41 E+00$ & 7,19E-02 \\
\hline Tuberías del receptor & 3,55 & Basic Metals and Fabricated Metal & $2,14 \mathrm{E}-02$ & $4,02 \mathrm{E}-01$ & $2,06 \mathrm{E}-02$ \\
\hline COMPRA DE COMPONENTES: ALMACENAMIENTO & 52,80 & & $3,83 \mathrm{E}-02$ & $1,65 \mathrm{E}-01$ & $7,32 E+00$ \\
\hline Sales fundidas & 26,87 & Mining and Quarrying & & & \\
\hline Tanques de almacenamiento & 9,33 & Machinery, Nec & 0 & 0 & $2,74 \mathrm{E}+00$ \\
\hline Válvulas y tuberías & 13,74 & Machinery, Nec & 0 & 0 & $4,03 E+00$ \\
\hline Bombas & 1,87 & Machinery, Nec & 0 & 0 & $5,47 E-01$ \\
\hline Materiales de aislamiento & 1,00 & Other Non-Metallic Mineral & 3,83E-02 & $1,65 \mathrm{E}-01$ & $7,88 \mathrm{E}-03$ \\
\hline COMPRA DE COMPONENTES: BLOQUE DE POTENCIA & 98,51 & & 0 & 0 & $1,08 \mathrm{E}+01$ \\
\hline Elementos bloque de potencia & 36,69 & Machinery, Nec & 0 & 0 & $1,08 \mathrm{E}+01$ \\
\hline Turbinas, generadores y condensadores & 61,82 & Machinery, Nec & 0 & 0 & 0 \\
\hline COMPRA DE COMPONENTES: Otras INSTALACIONES & 47,55 & & 3,54E-02 & $5,92 \mathrm{E}+00$ & $1,91 \mathrm{E}+00$ \\
\hline Sistema eléctrico & 15,30 & Electrical and Optical Equipment & 3,54E-02 & $5,92 \mathrm{E}+00$ & 7,34E-01 \\
\hline Bombas de captación de agua & 0,68 & Machinery, Nec & 0 & 0 & $1,99 \mathrm{E}-01$ \\
\hline $\begin{array}{l}\text { Edificio de oficinas y otros (dosificación química y } \\
\text { muestreo, } \mathrm{PCl} \text { y aire comprimido) }\end{array}$ & 31,57 & Construction & 0 & 0 & $9,80 \mathrm{E}-01$ \\
\hline TOTAL & 651,65 & & $2,44 \mathrm{E}+00$ & $3,09 E+01$ & $2,90 \mathrm{E}+01$ \\
\hline
\end{tabular}

Sector c21= Retail Trade, Except of Motor Vehicles and Motorcycles; Repair of Household Goods

Sector c23= Inland Transport

Sector c31= Public Admin and Defence; Compulsory Social Security 
Tabla 130 Inventario económico de la fase de operación y mantenimiento de la planta HYSOL (descontado al año de comienzo del proyecto)

\begin{tabular}{|c|c|c|c|c|c|}
\hline \multirow{2}{*}{$\begin{array}{l}\text { Inventario para la fase de operación y } \\
\text { mantenimiento }\end{array}$} & \multirow{2}{*}{$\begin{array}{l}\text { M€2011 } \\
\text { (Producción) }\end{array}$} & \multirow{2}{*}{ Sector económico } & \multicolumn{3}{|c|}{ MÁRGENES (M€ $\left.€_{2011}\right)$} \\
\hline & & & $\begin{array}{l}\text { Transporte } \\
\text { (c23) }\end{array}$ & $\begin{array}{l}\text { Comercial } \\
\text { (c21) }\end{array}$ & $\begin{array}{l}\text { Impuestos } \\
\text { ( c31) }\end{array}$ \\
\hline CONSUMO DE MATERIAS & 0,210 & & 0 & $3,69 \mathrm{E}-06$ & $8,52 \mathrm{E}-03$ \\
\hline Agua & 0,210 & Electricity, Gas and Water Supply & 0 & $3,69 E-06$ & $8,52 \mathrm{E}-03$ \\
\hline CONSUMOS ENERGÉTICOS & 14,069 & & 0 & 0 & 0 \\
\hline Gas Natural & 14,069 & Electricity, Gas and Water Supply & 0 & 0 & 0 \\
\hline OTROS COSTES DE EXPLOTACIÓN & 8,915 & & $3,37 \mathrm{E}-02$ & $1,45 \mathrm{E}-01$ & $2,88 \mathrm{E}-01$ \\
\hline \multirow[b]{2}{*}{ Personal } & 0,503 & Efectos inducidos & 0 & 0 & $9,96 \mathrm{E}-05$ \\
\hline & 0,446 & $\begin{array}{l}\text { Public Admin and Defence; Compulsory Social } \\
\text { Security }\end{array}$ & 0 & 0 & $5,74 \mathrm{E}-02$ \\
\hline Alquiler de terreno & 0,036 & Real Estate Activities & 0 & 0 & $9,96 \mathrm{E}-05$ \\
\hline Spare partes: Rankine + Bryton & 0,196 & Machinery, Nec & 0 & 0 & $5,74 \mathrm{E}-02$ \\
\hline Spare plants: Solar field & 0,874 & Other Non-Metallic Mineral & $3,37 \mathrm{E}-02$ & $1,45 \mathrm{E}-01$ & $6,93 \mathrm{E}-03$ \\
\hline Consumibles y reparación de componentes & 0,696 & Renting of M\&Eq and Other Business Activities & 0 & $2,45 \mathrm{E}-04$ & $2,87 \mathrm{E}-02$ \\
\hline Intereses & 5,872 & Financial Intermediation & 0 & 0 & $1,85 \mathrm{E}-01$ \\
\hline Seguros & 0,292 & Financial Intermediation & 0 & 0 & $9,23 \mathrm{E}-03$ \\
\hline TOTAL & 23,19 & & $3,37 \mathrm{E}-02$ & $1,45 \mathrm{E}-01$ & $2,96 \mathrm{E}-01$ \\
\hline
\end{tabular}

Sector c21= Retail Trade, Except of Motor Vehicles and Motorcycles; Repair of Household Goods

Sector c23= Inland Transport

Sector c31= Public Admin and Defence; Compulsory Social Security 
Tabla 131 Inventario económico de la fase de desmantelamiento y disposición de residuos de la planta HYSOL (descontado al año de comienzo del proyecto)

\begin{tabular}{|c|c|c|c|c|c|}
\hline \multirow{2}{*}{$\begin{array}{l}\text { Inventario para la fase de operación y } \\
\text { mantenimiento }\end{array}$} & \multirow{2}{*}{$\begin{array}{l}\text { M€2011 } \\
\text { (Producción) }\end{array}$} & \multirow{2}{*}{ Sector económico } & \multicolumn{3}{|c|}{ MÁRGENES $\left(\mathrm{M}_{2011}\right)$} \\
\hline & & & $\begin{array}{l}\text { Transporte } \\
\text { (c23) }\end{array}$ & $\begin{array}{l}\text { Comercial } \\
\text { (c21) }\end{array}$ & $\begin{array}{l}\text { Impuestos } \\
\text { (c31) }\end{array}$ \\
\hline $\begin{array}{l}\text { Desmantelamiento del campo solar y bloque de } \\
\text { potencia }\end{array}$ & 1,976 & Construction & 0 & 0 & $6,13 \mathrm{E}-02$ \\
\hline Transplante y reforestación & 0,0032 & Agriculture, Hunting, Forestry and Fishing & $5,00 \mathrm{E}-05$ & $6,70 \mathrm{E}-04$ & $-3,87 \mathrm{E}-05$ \\
\hline Vertido a vertederos y plantas de tratamiento & 0,187 & Other Community, Social and Personal Services & $1,77 \mathrm{E}-04$ & $1,00 \mathrm{E}-02$ & $5,11 \mathrm{E}-03$ \\
\hline TOTAL & 2,166 & & $2,27 \mathrm{E}-04$ & $1,07 E-02$ & $6,64 \mathrm{E}-02$ \\
\hline
\end{tabular}

Sector c21= Retail Trade, Except of Motor Vehicles and Motorcycles; Repair of Household Goods

Sector c23= Inland Transport

Sector c31= Public Admin and Defence; Compulsory Social Security

Tabla 132 Inventario económico de la fase de inversión inicial de la planta TERMOSOLAR CCP descontado al año de comienzo del proyecto)

\begin{tabular}{|c|c|c|c|c|c|}
\hline \multirow[b]{2}{*}{ Inventario para la fase inversión inicial } & \multirow{2}{*}{$\begin{array}{l}M €_{2011} \\
\text { (Producción) }\end{array}$} & \multirow[b]{2}{*}{ Sector económico } & \multicolumn{3}{|c|}{ MÁRGENES (M€ $\left.€_{2011}\right)$} \\
\hline & & & $\begin{array}{l}\text { Transporte } \\
\text { (c23) }\end{array}$ & $\begin{array}{l}\text { Comercial } \\
\text { (c21) }\end{array}$ & $\begin{array}{l}\text { Impuestos } \\
\text { (c31) }\end{array}$ \\
\hline INVERSIÓN INMATERIAL & 47,72 & & 0 & $1,26 \mathrm{E}-02$ & $1,85 \mathrm{E}+00$ \\
\hline Desarrollo de proyecto (servicio consultoría, ingeniería) & 8,04 & $\begin{array}{l}\text { Renting of M\&Eq and Other Business } \\
\text { Activities }\end{array}$ & 0 & $2,83 \mathrm{E}-03$ & $3,31 \mathrm{E}-01$ \\
\hline Gestión del EPC & 18,49 & $\begin{array}{l}\text { Renting of M\&Eq and Other Business } \\
\text { Activities }\end{array}$ & 0 & $6,50 \mathrm{E}-03$ & $7,62 \mathrm{E}-01$ \\
\hline Contingencias & 9,24 & $\begin{array}{l}\text { Renting of M\&Eq and Other Business } \\
\text { Activities }\end{array}$ & 0 & $3,25 \mathrm{E}-03$ & $3,81 \mathrm{E}-01$ \\
\hline Intereses & 11,95 & Financial Intermediation & 0 & 0 & $3,77 \mathrm{E}-01$ \\
\hline URBANIZACIÓN Y CONSTRUCCIÓN & 53,90 & & $-2,74 \mathrm{E}-01$ & $1,17 \mathrm{E}+00$ & $6,56 \mathrm{E}-01$ \\
\hline Cimientos & 5,62 & Other Non-Metallic Mineral & $2,16 \mathrm{E}-01$ & $9,33 \mathrm{E}-01$ & $4,45 \mathrm{E}-02$ \\
\hline Construcción estructuras y caminos/carreteras & 2,10 & Basic Metals and Fabricated Metal & $1,27 \mathrm{E}-02$ & $2,37 \mathrm{E}-01$ & $1,22 \mathrm{E}-02$ \\
\hline
\end{tabular}




\begin{tabular}{|c|c|c|c|c|c|}
\hline Construcción planta (personal y maquinaria) & 40,69 & Construction & 0 & 0 & $1,26 \mathrm{E}+00$ \\
\hline Transporte de componentes planta & 5,80 & Inland Transport & $-5,03 E-01$ & 0 & $-6,64 \mathrm{E}-01$ \\
\hline COMPRA DE COMPONENTES: CIRCUITO HTF & 17,76 & & $2,92 \mathrm{E}-02$ & $5,49 E-01$ & $1,25 \mathrm{E}+00$ \\
\hline Fluido de transmisión térmica & 8,74 & Chemicals and Chemical Products & & & \\
\hline Tuberías & 4,85 & Basic Metals and Fabricated Metal & $2,92 \mathrm{E}-02$ & $5,49 \mathrm{E}-01$ & $2,81 \mathrm{E}-02$ \\
\hline Bombas de circulación & 1,23 & Machinery, Nec & 0 & 0 & $3,61 \mathrm{E}-01$ \\
\hline Depósitos de expansión, gas natural y rebose & 2,95 & Machinery, Nec & 0 & 0 & $8,64 \mathrm{E}-01$ \\
\hline COMPRA DE COMPONENTES:CAMPO SOLAR & 48,30 & & $5,15 \mathrm{E}-01$ & $5,42 E+00$ & $6,88 \mathrm{E}-01$ \\
\hline Espejos & 10,02 & Other Non-Metallic Mineral & 3,86E-01 & $1,66 \mathrm{E}+00$ & $7,94 \mathrm{E}-02$ \\
\hline Tubos absorbedores & 13,46 & Machinery, Nec & & & \\
\hline Pilones y estructura del colector solar & 19,89 & Basic Metals and Fabricated Metal & $1,20 \mathrm{E}-01$ & $2,25 E+00$ & 1,15E-01 \\
\hline Sistema de seguimiento solar & 0,59 & Electrical and Optical Equipment & $1,36 \mathrm{E}-03$ & $2,28 \mathrm{E}-01$ & $2,83 E-02$ \\
\hline Sistema eléctrico y electrónico & 3,30 & Electrical and Optical Equipment & 7,64E-03 & $1,28 \mathrm{E}+00$ & $1,58 \mathrm{E}-01$ \\
\hline Juntas rotatorias & 1,05 & Machinery, Nec & 0 & 0 & $3,07 E-01$ \\
\hline COMPRA DE COMPONENTES: ALMACENAMIENTO & 22,83 & & $2,30 \mathrm{E}-02$ & $9,74 \mathrm{E}-01$ & 7,53E-01 \\
\hline Sales fundidas & 17,87 & Mining and Quarrying & & & \\
\hline Tanques de almacenamiento & 0,99 & Machinery, Nec & 0 & 0 & $2,89 \mathrm{E}-01$ \\
\hline Valves and piping & 0,34 & Machinery, Nec & 0 & 0 & 9,99E-02 \\
\hline Bombas & 0,31 & Machinery, Nec & 0 & 0 & $9,00 E-02$ \\
\hline Materiales de aislamiento & 0,46 & Other Non-Metallic Mineral & $1,76 \mathrm{E}-02$ & $7,58 \mathrm{E}-02$ & $3,62 \mathrm{E}-03$ \\
\hline Intercambiadores de calor aceite-sales & 0,54 & Machinery, Nec & 0 & 0 & 1,59E-01 \\
\hline Balance of System & 2,32 & Electrical and Optical Equipment & $5,37 \mathrm{E}-03$ & $8,98 \mathrm{E}-01$ & $1,11 \mathrm{E}-01$ \\
\hline COMPRA DE COMPONENTES: BLOQUE DE POTENCIA & 29,91 & & $1,36 \mathrm{E}-02$ & $2,28 \mathrm{E}+00$ & $2,97 E+00$ \\
\hline Sistema eléctrico & 5,90 & Electrical and Optical Equipment & $1,36 \mathrm{E}-02$ & $2,28 \mathrm{E}+00$ & $2,83 \mathrm{E}-01$ \\
\hline Tren generación de vapor & 3,28 & Machinery, Nec & 0 & 0 & $9,61 \mathrm{E}-01$ \\
\hline $\begin{array}{l}\text { Bombas de refrigeración, agua de alimentación, condensados } \\
\text { y equipos. }\end{array}$ & 3,28 & Machinery, Nec & 0 & 0 & $9,61 \mathrm{E}-01$ \\
\hline Válvulas & 0,66 & Machinery, Nec & 0 & 0 & 1,92E-01 \\
\hline
\end{tabular}




\begin{tabular}{|l|l|l|l|}
\hline Turbina, generador y condensador & 14,83 & Machinery, Nec & \\
\hline Desgasificador & 0,66 & Machinery, Nec & 0 \\
\hline Torres de refrigeración & 1,31 & Machinery, Nec & 0 \\
\hline COMPRA DE COMPONENTES: Otras INSTALACIONES & 3,52 & & 0 \\
\hline $\begin{array}{l}\text { Bombas de captación de agua } \\
\text { Edificio de oficinas y otros (dosificación química y muestreo, } \\
\text { PCl y aire comprimido) }\end{array}$ & 0,82 & Machinery, Nec & 0 \\
\hline Planta de tratamiento de aguas & Construction & 0 \\
\hline TOTAL & 2,04 & Construction & 0 \\
\hline
\end{tabular}

Sector c21= Retail Trade, Except of Motor Vehicles and Motorcycles; Repair of Household Goods

Sector $\mathrm{c} 23=$ Inland Transport

Sector c31= Public Admin and Defence; Compulsory Social Security

Tabla 133 Inventario económico de la fase de operación y mantenimiento de la planta TERMOSOLAR CCP (descontado al año de comienzo del proyecto)

\begin{tabular}{|c|c|c|c|c|c|}
\hline \multirow{2}{*}{$\begin{array}{l}\text { Inventario para la fase de operación y } \\
\text { mantenimiento }\end{array}$} & \multirow{2}{*}{$\begin{array}{l}\text { M€2011 } \\
\text { (Producción) }\end{array}$} & \multirow{2}{*}{ Sector económico } & \multicolumn{3}{|c|}{ MÁRGENES (M€ $\left.€_{2011}\right)$} \\
\hline & & & $\begin{array}{l}\text { Transporte } \\
\text { (c23) }\end{array}$ & $\begin{array}{l}\text { Comercial } \\
\text { (c21) }\end{array}$ & $\begin{array}{l}\text { Impuestos } \\
\text { (c31) }\end{array}$ \\
\hline CONSUMO DE MATERIAS & 0,368 & & \multicolumn{3}{|c|}{$6,22 \mathrm{E}-06$} \\
\hline Agua & 0,368 & Electricity, Gas and Water Supply & 0 & $6,22-06$ & $1,43 \mathrm{E}-02$ \\
\hline CONSUMOS ENERGÉTICOS & 2,110 & & & 0 & 0 \\
\hline Gas Natural & 2,110 & Electricity, Gas and Water Supply & 0 & 0 & 0 \\
\hline OTROS COSTES DE EXPLOTACIÓN & 4,622 & & & $3,56 \mathrm{E}-04$ & $1,24 \mathrm{E}-01$ \\
\hline \multirow[b]{2}{*}{ Personal } & 0,414 & Efectos inducidos & 0 & 0 & 0 \\
\hline & 0,364 & $\begin{array}{l}\text { Public Admin and Defence; Compulsory Social } \\
\text { Security }\end{array}$ & 0 & 0 & 0 \\
\hline Alquiler de terreno & 0,126 & Real Estate Activities & 0 & 0 & $3,47 E-04$ \\
\hline Administración y gestión & 0,203 & Renting of M\&Eq and Other Business Activities & 0 & $6,84 \mathrm{E}-05$ & $8,01 \mathrm{E}-03$ \\
\hline Intereses & 2,057 & Financial Intermediation & 0 & 0 & $6,29 \mathrm{E}-02$ \\
\hline
\end{tabular}


Consumibles y reparación de componentes

Transacción comercial (venta electricidad)

Seguros

TOTAL

Sector $21=$ Retail Trade, Except

Sector c23= Inland Transport

Sector c31= Public Admin and Defence; Compulsory Social Security

Tabla 134 Inventario económico de la fase de desmantelamiento y disposición de residuos de la planta TERMOSOLAR CCP (descontado al año de comienzo del proyecto)

\begin{tabular}{|c|c|c|c|c|c|}
\hline \multirow{2}{*}{$\begin{array}{l}\text { Inventario para la fase de operación y } \\
\text { mantenimiento }\end{array}$} & \multirow{2}{*}{$\begin{array}{l}\text { M€2011 } \\
\text { (Producción) }\end{array}$} & \multirow[b]{2}{*}{ Sector económico } & \multicolumn{3}{|c|}{ MÁRGENES (M€ 2011$)$} \\
\hline & & & $\begin{array}{l}\text { Transporte } \\
\text { (c23) }\end{array}$ & $\begin{array}{l}\text { Comercial } \\
\text { (c21) }\end{array}$ & $\begin{array}{l}\text { Impuestos } \\
\text { (c31) }\end{array}$ \\
\hline $\begin{array}{l}\text { Desmantelamiento del campo solar y bloque de } \\
\text { potencia }\end{array}$ & 0,673 & Construction & 0 & 0 & $2,09 \mathrm{E}-02$ \\
\hline Transplante y reforestación & 0,00111 & Agriculture, Hunting, Forestry and Fishing & $1,72 \mathrm{E}-05$ & $2,30 \mathrm{E}-04$ & $-1,33 \mathrm{E}-05$ \\
\hline Vertido a vertederos y plantas de tratamiento & 0,0627 & Other Community, Social and Personal Services & $5,93 \mathrm{E}-05$ & $3,37 \mathrm{E}-03$ & 1,71E-03 \\
\hline TOTAL & 0,736 & & $7,65 \mathrm{E}-05$ & $3,60 \mathrm{E}-03$ & $2,26 \mathrm{E}-02$ \\
\hline
\end{tabular}

Sector c21= Retail Trade, Except of Motor Vehicles and Motorcycles; Repair of Household Goods

Sector c23= Inland Transport

Sector c31= Public Admin and Defence; Compulsory Social Security

Renting of M\&Eq and Other Business Activities

Renting of M\&Eq and Other Business Activities

Financial Intermediation

\begin{tabular}{|lll|}
\hline 0 & $2,32 \mathrm{E}-04$ & $2,72 \mathrm{E}-02$ \\
\hline 0 & $5,47 \mathrm{E}-05$ & $6,41 \mathrm{E}-03$ \\
0 & 0 & $1,86 \mathrm{E}-02$ \\
\hline & $3,62 \mathrm{E}-04$ & $1,38 \mathrm{E}-01$ \\
\hline
\end{tabular}

Repair of Household Goods

\begin{tabular}{l|l}
0,689 & Renting of M\&Eq and Other Business Activities \\
\hline 0,162 & Renting of M\&Eq and Other Business Activities \\
\hline 0,608 & Financial Intermediation \\
\hline 9,211 &
\end{tabular}

(n)


Tabla 135 Euros por kilogramo de emisión al aire en España, según lo calculado por el proyecto CASES para una altura de emisión desconocida (CASES project 2008)

\begin{tabular}{|c|c|c|}
\hline Emisiones al aire & $€ 2000 / \mathrm{kg}$ & $€ 2013 / \mathrm{kg}$ \\
\hline \multicolumn{3}{|l|}{ Salud humana } \\
\hline $\mathrm{NH}_{3}$ & 3,0463 & 4,3145 \\
\hline NMVOC & 0,5791 & 0,8200 \\
\hline $\mathrm{NO}$ & 2,0610 & 2,9190 \\
\hline PPM $_{\mathrm{co}}$ & 0,6688 & 0,9472 \\
\hline $\mathrm{PPM}_{25}$ & 11,8287 & 16,7530 \\
\hline $\mathrm{SO}_{2}$ & 3,7428 & 5,3008 \\
\hline $\mathrm{Cd}$ & 66,865 & 94,7016 \\
\hline As & 422,043 & 597,7441 \\
\hline $\mathrm{Ni}$ & 0,942 & 1,3342 \\
\hline $\mathrm{Pb}$ & 223,636 & 316,7381 \\
\hline $\mathrm{Hg}$ & 6782,323 & 9605,8780 \\
\hline $\mathrm{Cr}$ & 5,631 & 7,9752 \\
\hline $\mathrm{Cr}-\mathrm{VI}$ & 28,155 & 39,8762 \\
\hline Formaldehyde & 0,17 & 0,2408 \\
\hline Dioxin & 31368242,8 & 44427184,0234 \\
\hline \multicolumn{3}{|c|}{ Pérdida de biodiversidad } \\
\hline $\mathrm{NH}_{3}$ & 1,367 & 1,9354 \\
\hline NMVOC & $-0,022$ & $-0,0311$ \\
\hline NOx & 0,408 & 0,5776 \\
\hline $\mathrm{SO}_{2}$ & 0,084 & 0,1189 \\
\hline \multicolumn{3}{|l|}{ Daño a cultivos } \\
\hline $\mathrm{SO}_{2}$ & $-0,004$ & $-0,0057$ \\
\hline \multicolumn{3}{|l|}{ Daño a materiales } \\
\hline $\mathrm{NO}$ & 0,012 & 0,0170 \\
\hline $\mathrm{SO}_{2}$ & 0,03 & 0,0425 \\
\hline
\end{tabular}


Tabla 136 Euros por kilogramo de radionucleótidos emitidos al aire y agua, según lo calculado por el proyecto CASES (CASES project 2008)

\begin{tabular}{|c|c|c|}
\hline Emisión de radionucleótidos & Compartimento & $€ 2013 / \mathrm{kBq}$ \\
\hline Aerosols, radioactive, unspecified & al aire & $3,09 E-04$ \\
\hline Carbon-14 & al aire & $1,68 \mathrm{E}-03$ \\
\hline Carbon-14 & al agua & $1,13 E-05$ \\
\hline Cesium-137 & al aire & $1,14 \mathrm{E}-03$ \\
\hline Cesium-137 & al agua & $1,51 \mathrm{E}-05$ \\
\hline Hydrogen-3, Tritium & al aire & $6,13 \mathrm{E}-07$ \\
\hline Hydrogen-3, Tritium & al agua & $1,31 \mathrm{E}-07$ \\
\hline lodine-129 & al aire & $9,89 \mathrm{E}-03$ \\
\hline lodine-131 & al aire & $3,14 \mathrm{E}-03$ \\
\hline lodine-131 & al agua & $9,80 \mathrm{E}-03$ \\
\hline lodine-133 & al aire & $4,51 \mathrm{E}-07$ \\
\hline lodine-133 & al agua & $0,00 \mathrm{E}+00$ \\
\hline lodine-135 & al aire & $0,00 E+00$ \\
\hline Krypton-85 & al aire & $3,31 \mathrm{E}-08$ \\
\hline Krypton-85 & al agua & $0,00 \mathrm{E}+00$ \\
\hline Krypton-85m & al aire & $0,00 E+00$ \\
\hline $\begin{array}{l}\text { Noble gases, radioactive, } \\
\text { unspecified }\end{array}$ & al aire & $6,65 \mathrm{E}-08$ \\
\hline Radon-222 & al aire & $1,74 \mathrm{E}-08$ \\
\hline Thorium-230 & al aire & 4,64E-03 \\
\hline Thorium-230 & al agua & $0,00 E+00$ \\
\hline Uranium-234 & al aire & $1,24 \mathrm{E}-03$ \\
\hline Uranium-234 & al agua & $3,06 \mathrm{E}-05$ \\
\hline Uranium-235 & al aire & $1,01 \mathrm{E}-03$ \\
\hline Uranium-235 & al agua & $1,10 E-04$ \\
\hline Uranium-238 & al aire & $1,08 \mathrm{E}-03$ \\
\hline Uranium-238 & al agua & $3,03 \mathrm{E}-04$ \\
\hline Strontium-90 & al agua & $7,26 \mathrm{E}-07$ \\
\hline Rubidium-106 & al agua & $5,10 \mathrm{E}-07$ \\
\hline Lead-210 & al aire & $1,55 \mathrm{E}-04$ \\
\hline Polonium-210 & al aire & $1,55 \mathrm{E}-04$ \\
\hline Radium-226 & al aire & $9,27 E-05$ \\
\hline
\end{tabular}




\section{ANEXO III: TABLAS DE INVENTARIO Y CARACTERIZACIÓN PARA EL ACV-S}

Este anexo incluye en primer lugar el inventario para el análisis de riesgos sociales con la Social Hotspots Database. En segundo lugar incluye el inventario social e información de caracterización para el análisis social específico.

\section{Inventario social para el análisis de riesgos sociales con la SHDB de la planta HYSOL}

Tabla 137 Inventario para el análisis de hotspots sociales de la fase E\&F de la planta HYSOL

\begin{tabular}{llcc} 
Receptor central & & M\$ 2015 & $\mathbf{\$ 2 0 0 2}$ \\
\hline Hormigón torre & Mineral products nec/ES & 12,1 & 9.214 .200 \\
\hline Acero torre & Metal products/ES & 6,2 & 4.721 .300 \\
\hline Cuarzo receptor & Mineral products nec/ES & 25 & 19.037 .600 \\
\hline Acero receptor & Metal products/ES & 15,9 & 12.107 .900 \\
\hline Tuberías receptor & Metal products/ES & 4,5 & 3.426 .800 \\
\hline
\end{tabular}

\begin{tabular}{llcc} 
Campo solar & & & \\
\hline Espejos & Mineral products nec/ES & 13,5 & 10.280 .300 \\
\hline Cimientos & Mineral products nec/ES & 8,4 & 6.396 .600 \\
\hline Pedestal y estructura del heliostato & Metal products/ES & 80,3 & 61.148 .600 \\
\hline Sist. de seguimiento solar & Electronic equipment/ES & 6,69 & 5.094 .500 \\
\hline
\end{tabular}

\begin{tabular}{llcc} 
Almacenamiento térmico & & & \\
\hline Sales fundidas & Minerals nec/CL & 30,6 & 23.302 .000 \\
\hline Tanques de almacenamiento & Machinery and equipment nec/ES & 13,7 & 10.432 .600 \\
\hline Valves and piping & Metal products/ES & 20,2 & 15.382 .300 \\
\hline Bombas & Machinery and equipment nec/ES & 2,7 & 2.056 .100 \\
\hline Materiales de aislamiento & Mineral products nec/ES & 1,4 & 1.066 .100 \\
\hline Bloque de potencia & & & \\
\hline Tren generación de vapor & Machinery and equipment nec/ES & 24,5 & 18.656 .800 \\
\hline Turbina de gas italia & Machinery and equipment nec/ES & 34,3 & 26.119 .500 \\
\hline Turbina vapor alemania & Machinery and equipment nec/ES & 36 & 27.414 .100 \\
\hline Elementos bryton yHYSOL & Machinery and equipment nec/DE & 29,4 & 22.388 .200 \\
\hline $\begin{array}{l}\text { Instalaciones } \\
\text { Bombas de captación de agua }\end{array}$ & Machinery and equipment nec/ES & 1 & \\
\hline $\begin{array}{l}\text { Edificio de oficinas y otros } \\
\text { (dosificación química y muestreo, } \\
\text { PCl y aire comprimido) }\end{array}$ & Construction/ES & 37 & 28.175 .600 \\
\hline Sistema eléctrico & Electronic equipment/ES & 25 & 19.037 .600 \\
\hline
\end{tabular}


Tabla 138 Inventario para el análisis de hotspots sociales de la fase de Construcción de la planta HYSOL

\begin{tabular}{llcc} 
& & M\$ 2015 & $\mathbf{\$ 2 0 0 2}$ \\
\hline Cimientos & Mineral products nec/ES & 19,4 & 14.773 .100 \\
\hline $\begin{array}{l}\text { Construcción estructuras y } \\
\text { caminos/carreteras }\end{array}$ & Metal products/ES & 6,5 & 4.634 .700 \\
\hline Construcción planta (personal) & Construction/ES & 149,7 & 113.996 .900 \\
\hline Construcción planta (maquinaria) & Business services nec/ES & 0 & 0 \\
\hline Alquiler de terreno & Electricity/ES & 44 & 33.506 .100 \\
\hline Contingencias & Electricity/ES & 67,2 & 51.173 .000 \\
\hline Ingeniería de proyecto & Electricity/ES & 0 & 0 \\
\hline Gestión de proyecto (del EPC) & Transport nec/ES & 12,90 & 9.823 .400 \\
\hline $\begin{array}{l}\text { Transporte de materiales } \\
\text { construcción }\end{array}$ & Financial services nec/ES & 41,3 & 31.450 .000 \\
\hline Intereses bancarios & & & \\
\hline
\end{tabular}

Tabla 139 Inventario para el análisis de hotspots sociales de la fase de Operación y Mantenimiento de la planta HYSOL

\begin{tabular}{|c|c|c|c|}
\hline & & M\$2015/yr & $\$ 2002 / y r$ \\
\hline Personal & NO INCLUIDO & 2,327 & 1.772 .000 \\
\hline Agua & Water/ES & 0,536 & 408.200 \\
\hline Gas Natural & Natural gas, Spain (07/2015) & 34,5 & 26.271 .800 \\
\hline Alquiler terreno & Business services nec/ES & 0,0889 & 67.700 \\
\hline Recambios componentes & Machinery and equipment nec/ES & 0,62105 & 472.900 \\
\hline Recambios componentes & Mineral products nec/ES & 2,6 & 1.979 .900 \\
\hline Seguros & Insurance/ES & 0,739 & 562.800 \\
\hline Intereses bancarios & Financial services nec/ES & 14,854 & 11.311 .400 \\
\hline Consumibles y reparación & Electricity/ES & 1,7765 & 1.352 .800 \\
\hline
\end{tabular}

Tabla 140 Inventario para el análisis de hotspots sociales de la fase de Desmantelamiento y Disposición de residuos de la planta HYSOL

M\$ 2015

$\$ 2002$

Desmantelamiento del

\begin{tabular}{llcc}
$\begin{array}{l}\text { campo solar y bloque de } \\
\text { potencia }\end{array}$ & Construction/ES & 12,910 & 9.831 .000 \\
\hline Transplante y reforestación & Forestry/ES & 0,025 & 19.000 \\
\hline $\begin{array}{l}\text { Vertido a vertederos y } \\
\text { plantas de tratamiento }\end{array}$ & $\begin{array}{l}\text { Public Administration, Defense, } \\
\text { Education, Health/ES }\end{array}$ & 1,2832 & 977.200
\end{tabular}




\section{Inventario social para el análisis de riesgos sociales con la SHDB de la planta termosolar convencional}

Tabla 141 Inventario para el análisis de hotspots sociales de la fase E\&F de la planta TERMOSOLAR CCP

Circuito HTF

M€ 2013

$\$ 2002$

\begin{tabular}{llcc}
\hline Fluido de transmisión térmica & Chemical, rubber, plastic products/BE & 9,98906 & 7.122 .500 \\
\hline Tuberías & Metal products/ES & 6,24292 & 4.451 .400 \\
\hline Bombas de circulación & Machinery and equipment nec/ES & 1,81972 & 1.297 .500 \\
\hline $\begin{array}{l}\text { Depósitos de expansión, gas natural } \\
\text { y rebose }\end{array}$ & Machinery and equipment nec/ES & 4,365 & 3.112 .400 \\
\hline Transporte componentes (3\%) & Transport nec/ES & 0,6933 & 494.300
\end{tabular}

\section{Campo solar}

\begin{tabular}{llcc} 
Espejos & Mineral products nec/ES & 13,9 & 9.911 .200 \\
\hline Tubos absorbedores & Machinery and equipment nec/DE & 15,4 & 10.980 .700 \\
\hline $\begin{array}{l}\text { Pilones y estructura del colector } \\
\text { solar }\end{array}$ & Metal products/ES & 25,6 & 18.253 .700 \\
\hline Sistema de seguimiento solar & Electronic equipment/ES & 0,97 & 691.600 \\
\hline Sistema eléctrico y electrónico & Electronic equipment/ES & 5,43 & 3.871 .800 \\
\hline Juntas rotatorias & Machinery and equipment nec/ES & 1,55 & 1.105 .200 \\
\hline Transporte componentes & Transport nec/ES & 1,94 & 1.386 .000 \\
\hline
\end{tabular}

\begin{tabular}{|c|c|c|c|}
\hline \multicolumn{4}{|l|}{ Almacenamiento térmico } \\
\hline Sales fundidas & Minerals nec/CL & 20,45148 & 14.582 .600 \\
\hline Tanques de almacenamiento & Machinery and equipment nec/ES & 1,46179 & 1.042 .300 \\
\hline Valves and piping & Machinery and equipment nec/ES & 0,503721 & 359.200 \\
\hline Bombas & Machinery and equipment nec/ES & 0,454154 & 323.800 \\
\hline Materiales de aislamiento & Mineral products nec/ES & 0,633798 & 451.900 \\
\hline $\begin{array}{l}\text { Intercambiadores de calor aceite- } \\
\text { sales }\end{array}$ & Machinery and equipment nec/ES & 0,802869 & 572.500 \\
\hline $\begin{array}{l}\text { Balance of System (electrical } \\
\text { equipment and others) }\end{array}$ & Electronic equipment/ES & 3,81889 & 2.723 .000 \\
\hline Transporte componentes & Transport nec/ES & 0,869898 & 620.300 \\
\hline \multicolumn{4}{|l|}{ Bloque de potencia } \\
\hline Sistema eléctrico & Electronic equipment/ES & 9,7 & 6.916 .400 \\
\hline Tren generación de vapor & Machinery and equipment nec/ES & 4,85 & 3.458 .200 \\
\hline $\begin{array}{l}\text { Bombas de refrigeración, agua de } \\
\text { alimentación, condensados y } \\
\text { equipos. }\end{array}$ & Machinery and equipment nec/ES & 4,85 & 3.458 .200 \\
\hline Válvulas & Machinery and equipment nec/ES & 0,97 & 691.600 \\
\hline Turbina, generador y condensador & Machinery and equipment nec/DE & 16,975 & 12.103 .800 \\
\hline Desgasificador & Machinery and equipment nec/ES & 0,97 & 691.600 \\
\hline Torres de refrigeración & Machinery and equipment nec/ES & 1,94 & 1.383 .300 \\
\hline Transporte componentes & Transport nec/ES & 1,245 & 887.700 \\
\hline \multicolumn{4}{|l|}{ Instalaciones } \\
\hline Bombas de captación de agua & Machinery and equipment nec/ES & 1 & 761.500 \\
\hline $\begin{array}{l}\text { Edificio de oficinas y otros } \\
\text { (dosificación química y muestreo, } \mathrm{PCl} \\
\text { y aire comprimido) }\end{array}$ & Construction/ES & 37 & 28.175 .600 \\
\hline Planta de tratamiento de aguas & Construction/ES & 25 & 19.037 .600 \\
\hline Transporte componentes & Transport nec/ES & 0,135 & 96.400 \\
\hline
\end{tabular}


Tabla 142 Inventario para el análisis de hotspots sociales de la fase de Construcción de la planta TERMOSOLAR CCP

\begin{tabular}{llcc} 
& & M€2013 & $\mathbf{\$ 2 0 0 2}$ \\
\hline Cimientos & Mineral products nec/ES & 7,566 & 5.394 .800 \\
\hline $\begin{array}{l}\text { Construcción estructuras y } \\
\text { caminos/carreteras }\end{array}$ & Metal products/ES & 2,425 & 1.729 .100 \\
\hline Construcción planta (personal) & Construction/ES & 48 & 34.225 .700 \\
\hline Construcción planta (maquinaria) & Business services nec/ES & & \\
\hline Alquiler de terreno & Electricity/ES & 10 & 7.130 .300 \\
\hline Contingencias & Electricity/ES & 8,66 & 6.174 .900 \\
\hline Ingeniería de proyecto & Electricity/ES & 20 & 14.260 .700 \\
\hline Gestión de proyecto (del EPC) & Transport nec/ES & 0,31 & 220.300 \\
\hline Transporte de materiales construcción & Financial services nec/ES & 7,566 & 5.394 .800 \\
\hline Intereses bancarios & & &
\end{tabular}

Tabla 143 Inventario para el análisis de hotspots sociales de la fase de Operación y Mantenimiento de la planta TERMOSOLAR CCP

\begin{tabular}{llcc} 
& & $\mathbf{M € 2 0 1 3 / y r}$ & $\mathbf{\$ 2 0 0 2 / y r}$ \\
\hline Personal & NO INCLUIDO & 1,92 & 1.369 .000 \\
\hline Agua & Water/ES & 0,692 & 493.400 \\
\hline Gas Natural & Natural gas, Spain (07/2015) & 5,042386 & 3.595 .400 \\
\hline Alquiler terreno & Business services nec/ES & 0,312 & 222.500 \\
\hline Recambios componentes & Machinery and equipment nec/ES & 0,5 & 356.500 \\
\hline Recambios componentes & Mineral products nec/ES & 0,4 & 285.200 \\
\hline Seguros & Insurance/ES & 1,5 & 1.069 .600 \\
\hline Intereses bancarios & Financial services nec/ES & 5,07672 & 3.619 .900 \\
\hline Consumibles y reparación & Electricity/ES & 1,7 & 1.212 .200 \\
\hline
\end{tabular}

Tabla 144 Inventario para el análisis de hotspots sociales de la fase de Desmantelamiento y Disposición de residuos de la planta TERMOSOLAR CCP

\begin{tabular}{llcc} 
& & M€2013 & $\mathbf{\$ 2 0 0 2}$ \\
\hline $\begin{array}{l}\text { Desmantelamiento del campo } \\
\text { solar y bloque de potencia }\end{array}$ & Construction/ES & 4,425 & 3.155 .200 \\
\hline Transplante y reforestación & Forestry/ES & 0,0086 & 6.132 \\
\hline $\begin{array}{l}\text { Vertido a vertederos y plantas de } \\
\text { tratamiento }\end{array}$ & $\begin{array}{l}\text { Public Administration, Defense, } \\
\text { Education, Health/ES }\end{array}$ & 0,4331 & 308.803 \\
\hline
\end{tabular}




\section{Inventario social y caracterización del análisis específico.}

A continuación se describe el proceso de caracterización seguido para cada indicador y subcategoría del ciclo de vida de las plantas HYSOL y termosolar convencional (se asume que ambas están construidas, operadas y desmanteladas por la misma empresa). Se han analizado de forma conjunta las fases de construcción y desmantelamiento, ya que ambas las realiza la misma empresa y corresponden al mismo sector económico (construcción). En la Tabla 145 y la Tabla 146 se describen los indicadores escogidos para cada subcategoría, los valores obtenidos para la empresa en cuestión, los obtenidos para la media española (con sus fuentes), y el valor/color de escala que se le ha asignado a cada indicador. El verde claro y oscuro corresponde a indicadores mejores y mucho mejores, mientras que el naranja claro y oscuro a indicadores peores o mucho peores. El gris se ha escogido para resultados similares o desconocidos.

Las subcategorías clasificadas en las categorías de actor comunidad local, sociedad y actores de la cadena de valor coinciden para todas fases, por lo que sólo se muestran en la Tabla 145.

Tabla 145 Inventario y caracterización para las fases de Construcción y Desmantelamiento de la planta HYSOL

\begin{tabular}{|c|c|c|c|c|c|c|}
\hline \multirow[b]{2}{*}{ Categoría de actor } & \multirow[b]{2}{*}{ Indicadores } & \multicolumn{2}{|l|}{ España } & \multicolumn{2}{|c|}{ Empresa } & \multirow{2}{*}{$\begin{array}{l}\text { Carac- } \\
\text { teriza- } \\
\text { ción }\end{array}$} \\
\hline & & Valor & $\begin{array}{l}\text { Año del dato } \\
\text { y fuente }\end{array}$ & Valor & $\begin{array}{l}\text { Año del dato y } \\
\text { fuente }\end{array}$ & \\
\hline
\end{tabular}

\begin{tabular}{|c|c|c|c|c|c|c|}
\hline \multicolumn{7}{|l|}{ Trabajadores } \\
\hline \multirow{2}{*}{$\begin{array}{l}\text { Libertad de } \\
\text { asociación y } \\
\text { negociación } \\
\text { colectiva }\end{array}$} & \multicolumn{5}{|c|}{$\begin{array}{l}\text { Se apoya adecuadamente la presencia de sindicatos dentro de la organización se y los trabajadores son libres de afiliarse a sindicatos de su } \\
\text { elección. }\end{array}$} & \multirow{2}{*}{$\begin{array}{l}\text { Similar } \\
\text { mucho } \\
\text { mejor }\end{array}$} \\
\hline & $\begin{array}{l}\text { \% de afiliados sobre el total de } \\
\text { personas empleadas }\end{array}$ & Construction sector: $10,5 \%$. & $\begin{array}{l}\text { 2009,(Beneyto } \\
\text { 2010) }\end{array}$ & $27,70 \%$ & $\begin{array}{l}\text { 2014, Informe } \\
\text { RSC }\end{array}$ & \\
\hline Trabajo infantil & \multicolumn{5}{|c|}{$\begin{array}{l}\text { Aunque se han encontrado pocos indicios de trabajo infantil, no hay información precisay oficial sobre e } \\
\text { ste indicador. Sin embargo, según la SHDB, el riesgo en el país es bajo y no hay evidencias de trabajo infantil en los sectores de interés. }\end{array}$} & Similar \\
\hline Salario justo & $\begin{array}{l}\text { Desigualdad salarial (salario } \\
\text { medio en comparación con el } \\
\text { salario de ejecutivos) }\end{array}$ & $\begin{array}{l}\text { El salario medio de los directivos es } 133,9 \% \\
\text { mayor que el salario medio }\end{array}$ & $\begin{array}{l}\text { 2012, (INE } \\
2014)\end{array}$ & $\begin{array}{l}\text { El salario de los ejecutivos es } 771 \% \\
\text { que la media de los empleados }\end{array}$ & $\begin{array}{l}2013, \text { Informe } \\
\text { corporativo } \\
\text { anual }\end{array}$ & $\begin{array}{l}\text { mucho } \\
\text { peor }\end{array}$ \\
\hline
\end{tabular}




\begin{tabular}{|c|c|c|c|c|c|c|}
\hline & Salario medio anual & $23454 €$ (sector construcción) & \begin{tabular}{|l}
$2012,($ INE \\
$2014)$
\end{tabular} & $23.283 €$ & \begin{tabular}{|l|}
2013, Informe \\
corporativo
\end{tabular} & similar \\
\hline & Salario mínimo en la empresa & $9.080 €$ & $\begin{array}{l}\text { 2015,(Real } \\
\text { Decreto } \\
1106 / 2014 \\
2014)\end{array}$ & $10.254 €$ & $\begin{array}{l}\text { 2010, Convenio } \\
\text { colectivo }\end{array}$ & mejor \\
\hline Horario laboral & Horas de trabajo anuales & $\begin{array}{l}2064,4 \text { (sector construcción, } 39.7 \text { por } \\
\text { semana) }\end{array}$ & $\begin{array}{l}\text { 2010, (ILO } \\
\text { 2010) }\end{array}$ & 1800 horas & $\begin{array}{l}\text { 2010, Convenio } \\
\text { colectivo }\end{array}$ & mejor \\
\hline Trabajo forzado & $\begin{array}{l}\text { Medidas contra el trabajo } \\
\text { forzado }\end{array}$ & \begin{tabular}{|l|} 
En España, un gran número de centros de \\
información para in migrantes están a cargo \\
de las comisiones de los trabajadores y \\
sindicatos, asesorando a los migrantes \\
sobre el trabajo, las regulaciones de empleo \\
y los procedimientos, proporcionando \\
también idioma y otros conocimientos \\
prácicos para inmigrantes.
\end{tabular} & $\begin{array}{l}\text { 2009, (ILO } \\
\text { 2009) }\end{array}$ & $\begin{array}{l}\text { Empresas que presentan el } 83 \% \text { de } \\
\text { los empleados han desarrollado } \\
\text { protocolos o políticas para } \\
\text { minimizar este riesgo }\end{array}$ & $\begin{array}{l}\text { 2014, Informe } \\
\text { RSC }\end{array}$ & similar \\
\hline \multirow{3}{*}{$\begin{array}{l}\text { Igualdad de } \\
\text { oportunidades/Disc } \\
\text { riminación }\end{array}$} & $\begin{array}{l}\text { Tasas de empleo de personas } \\
\text { con necesidades especiales en } \\
\text { relación con el total de } \\
\text { personas empleadas }\end{array}$ & $\begin{array}{l}1.69 \% \text { de empleados con necesidades } \\
\text { especiales en los sectores de la industria y } \\
\text { la construcción. }\end{array}$ & $\begin{array}{l}\text { 2013, (INE } \\
2015)\end{array}$ & $\begin{array}{l}2,3 \% \text { de empleados con } \\
\text { necesidades especiales }\end{array}$ & $\begin{array}{l}2013, \text { Informe } \\
\text { corporativo } \\
\text { anual }\end{array}$ & mejor \\
\hline & $\begin{array}{l}\text { Relación de hombres y mujeres } \\
\text { en los trabajadores de la } \\
\text { empresa }\end{array}$ & $\begin{array}{l}\text { Ratio de } 6.34 \text { en los sectores de la } \\
\text { construcción y suministro de electricidad }\end{array}$ & $\begin{array}{l}\text { 2013, (INE } \\
2015)\end{array}$ & Ratio de 7.92 & $\begin{array}{l}\text { 2013, Informe } \\
\text { corporativo } \\
\text { anual }\end{array}$ & peor \\
\hline & $\begin{array}{l}\text { Relación de hombres y mujeres } \\
\text { en los puestos directivos de la } \\
\text { empresa }\end{array}$ & Ratio de 2.75 & $\begin{array}{l}\text { 2013, (INE } \\
2015)\end{array}$ & Ratio de 22 & $\begin{array}{l}2013, \text { Informe } \\
\text { corporativo } \\
\text { anual }\end{array}$ & $\begin{array}{l}\text { mucho } \\
\text { peor }\end{array}$ \\
\hline Salud y seguridad & $\begin{array}{l}\text { Programas de educación, } \\
\text { formación, asesoramiento, } \\
\text { prevención de riesgos para } \\
\text { ayudar a los trabajadores }\end{array}$ & \multicolumn{2}{|c|}{$\begin{array}{l}\text { Según el SHDB, existe alto riesgo de pérdida de años de } \\
\text { vida y muerte por exposición a carcinógenos y } \\
\text { macropartículas aerotransportadas, así como riesgo muy } \\
\text { alto de lesiones no fatales por país (también en los } \\
\text { sectores construcción y electricidad). Muy alto riesgo de } \\
\text { lesiones fatales en el sector de la construcción. }\end{array}$} & $\begin{array}{l}\text { El grupo empresarial ha } \\
\text { introducido programas de } \\
\text { educación, formación, } \\
\text { asesoramiento, y prevención y } \\
\text { control de riesgos en el lugar de } \\
\text { trabajo en el } 96,6 \% \text { de las } \\
\text { empresas integrantes. }\end{array}$ & $\begin{array}{l}\text { 2014, Informe } \\
\text { corporativo } \\
\text { anual }\end{array}$ & mejor \\
\hline
\end{tabular}




\begin{tabular}{|c|c|c|c|c|c|c|}
\hline & $\begin{array}{l}\text { Presencia de una política } \\
\text { formal sobre salud y seguridad }\end{array}$ & \multicolumn{2}{|c|}{$\begin{array}{l}\text { Según la SHDB existe riesgo de problemas de salud. La } \\
\text { normativa española requiere que haya comités de Salud y } \\
\text { seguridad dentro de este tipo de empresas. }\end{array}$} & $\begin{array}{l}\text { La empresa tiene comités de Salud } \\
\text { y seguridad. Está formado por los } \\
\text { delegados y representantes de la } \\
\text { empresa. Tienen reuniones } \\
\text { regulares (una por trimestre) }\end{array}$ & $\begin{array}{l}\text { 2014, Informe } \\
\text { RSC }\end{array}$ & similar \\
\hline & $\begin{array}{l}\text { Ratio de accidentes por } \\
\text { empleado }\end{array}$ & $\begin{array}{l}6011 \text { accidentes por cada millón de horas } \\
\text { trabajadas }\end{array}$ & $\begin{array}{l}\text { 2013, (ILO } \\
2013)\end{array}$ & $\begin{array}{l}\text { 4,22 accidentes por cada millón de } \\
\text { horas trabajadas }\end{array}$ & $\begin{array}{l}2013, \text { CSR } \\
\text { report }\end{array}$ & $\begin{array}{l}\text { mucho } \\
\text { mejor }\end{array}$ \\
\hline Seguridad social & Se provee de seguridad social & \multicolumn{2}{|c|}{$\begin{array}{l}\text { La ley obliga a proveer de seguridad social a todos los } \\
\text { trabajadores. }\end{array}$} & \multicolumn{2}{|c|}{$\begin{array}{l}\text { La ley obliga a proveer de seguridad social a todos } \\
\text { los trabajadores. }\end{array}$} & similar \\
\hline
\end{tabular}

Comunidad local

\begin{tabular}{|c|c|c|}
\hline Empleo local & $\begin{array}{l}\text { Se prevé la creación de empleo local en el informe de impacto ambiental del proyecto y también en los } \\
\text { periódicos locales. (ABC 2011) }\end{array}$ & mejor \\
\hline Acceso a recursos materiales & $\begin{array}{l}\text { El agua es el único recurso material que puede ser afectado significativamente debido a las necesidades de la } \\
\text { planta. Sin embargo, este riesgo se contempla en el informe de impacto ambiental del proyecto y no se } \\
\text { encontró riesgos significativos. }\end{array}$ & similar \\
\hline Acceso a recursos inmateriales & \multirow{7}{*}{$\begin{array}{l}\text { La planta no afecta a estas cuestiones ya que se encuentra lejos de la población y no interactúa con personas } \\
\text { locales. }\end{array}$} & similar \\
\hline Reubicación y migración & & similar \\
\hline Patrimonio cultural & & similar \\
\hline Condiciones de vida seguras y salubres & & similar \\
\hline Respeto a los derechos indígenas & & similar \\
\hline Community engagement & & similar \\
\hline Condiciones de vivienda segura & & similar \\
\hline
\end{tabular}

Sociedad

Sociedad

Goldemberg et al (Goldemberg et al. 1985) afirmó lo siguiente: "Las mejoras importantes en bienestar humano requieren incrementos considerables del nivel de uso de la energía", "El aumento del uso de la energía es valioso en tanto que mejora la calidad de vida mediante la provisión de servicios energéticos como cocinar,

Utilidad del producto iluminar, calentar el agua, calentar o enfriar el ambiente, transporte personal o de mercancías, calor para procesos industriales, energía motriz, etc.", "una manera más efectiva de lidiar con la pobreza es asignar recursos directamente a la satisfacción de las necesidades básicas de los más pobres, asegurando de esta 


\begin{tabular}{|c|c|c|c|c|c|}
\hline & & \multicolumn{3}{|c|}{$\begin{array}{l}\text { en la sociedad internacional que enlazan la energía con la satisfacción de necesidades básicas, como en "El } \\
\text { programa de reconstrucción y desarrollo de Sudáfrica" (African National Context 1994). Por lo tanto, aunque la } \\
\text { electricidad en sí no es una necesidad básica, actualmente es una herramienta necesaria para proveer de } \\
\text { recursos y estándares básicos destinados a satisfacer necesidades básicas. Por estos argumentos, este indicador } \\
\text { se ha calificado como mucho mejor, ya que se ha considerado que la provisión de electricidad juega un papel } \\
\text { esencial en el desarrollo humano actual. }\end{array}$} & \\
\hline \multicolumn{2}{|c|}{ Compromiso público con la sostenibilidad } & \multicolumn{3}{|c|}{$\begin{array}{l}\text { La construcción y operación de las centrales de electricidad proveniente de energía solar está bien aceptada } \\
\text { dentro de la sociedad, especialmente cuando se comparan con otras tecnologías. Además, la compañía ha } \\
\text { alcanzado una certificación GRI y tiene una memoria de RSC, siendo que informar sobre la sostenibilidad de la } \\
\text { empresa no es obligatorio en España. }\end{array}$} & $\begin{array}{l}\text { mucho } \\
\text { mejor }\end{array}$ \\
\hline \multirow{2}{*}{$\begin{array}{l}\text { Desarrollo } \\
\text { tecnológico }\end{array}$} & Desarrollo tecnológico & \multicolumn{3}{|c|}{$\begin{array}{l}\text { La compañía está implicada en al menos un proyecto de I+D dentro del séptimo programa marco de la Unión } \\
\text { Europea. }\end{array}$} & $\begin{array}{l}\text { mucho } \\
\text { mejor }\end{array}$ \\
\hline & $\begin{array}{l}\text { Porcentaje de gastos en I+D por } \\
\text { ingresos }\end{array}$ & $\begin{array}{l}\text { Valor promedio en la industria (gasto en i+d menos gasto } \\
\text { laboral por ingresos): } 0,282 \%\end{array}$ & $0,157 \%$ & 2014, Informe RSC & peor \\
\hline $\begin{array}{l}\text { Contribución al } \\
\text { desarrollo económico }\end{array}$ & Efecto multiplicador & \multicolumn{3}{|c|}{ Efecto multiplicador derivado del análisis Input Output de la planta. C phase: 2,14; D\&D: 2.29} & $\begin{array}{l}\text { Mucho } \\
\text { mejor }\end{array}$ \\
\hline
\end{tabular}

Actores de la cadena de valor

\begin{tabular}{|l|l|l|l|l|l|}
\hline Competencia leal & $\begin{array}{l}\text { Acciones legales durante el } \\
\text { período (como empresa } \\
\text { miembro de una alizanza } \\
\text { comportándose de forma } \\
\text { desleal). }\end{array}$ & $\begin{array}{l}\text { España ha puesto en marcha reglas fuertes que } \\
\text { aseguran que las empresas del estado no están } \\
\text { aisladas de las fuerzas del mercado y que } \\
\text { minimizan la interferencia política en su } \\
\text { gestión. Junto con Eslovenia, tiene los puntajes }\end{array}$ & $\begin{array}{l}2013, \\
\text { (OECD }\end{array}$ & $\begin{array}{l}\text { Dos acciones legales completadas y } \\
\text { rechazadas por la Comisión } \\
\text { Nacional de los mercados y la } \\
\text { competencia que implican } \\
\text { actividades de la empresa. Una }\end{array}$ & $\begin{array}{l}2013 \text { and 2009 } \\
\text { Periódicos y } \\
\text { Comisión } \\
\text { Nacional de los } \\
\text { Mercados y la }\end{array}$ \\
peor \\
\hline
\end{tabular}




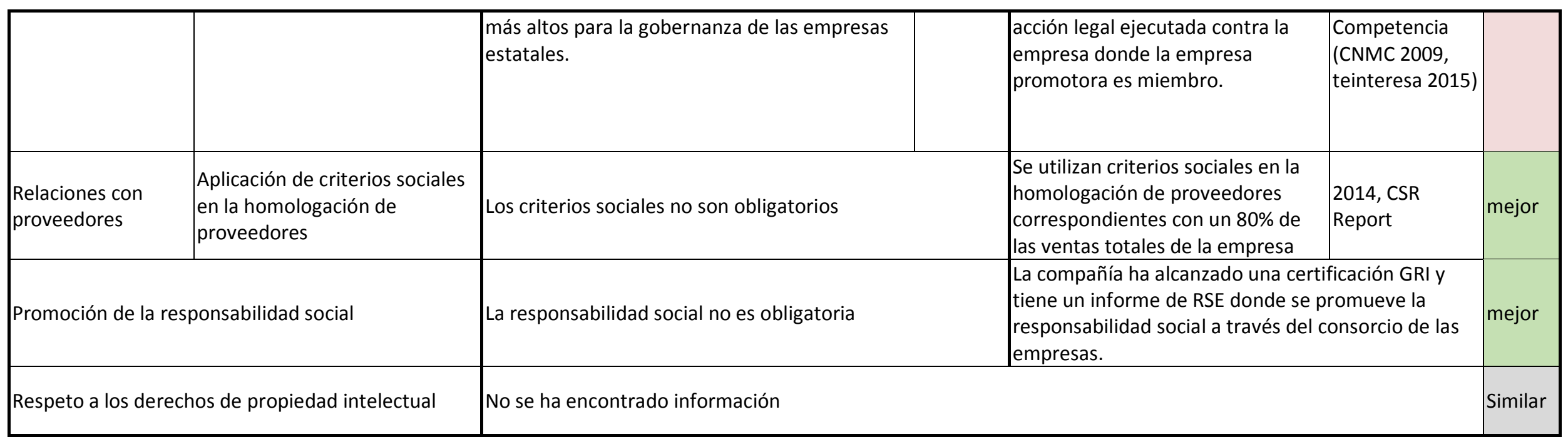


Tabla 146 Inventario y caracterización para la fase de Operación y Mantenimiento de la planta HYSOL

\begin{tabular}{|c|c|c|c|c|c|c|}
\hline \multirow{2}{*}{ Categoría de actor } & \multirow{2}{*}{ Indicadores } & \multicolumn{2}{|l|}{ España } & \multicolumn{2}{|c|}{ Empresa } & \multirow{2}{*}{$\begin{array}{l}\text { Carac- } \\
\text { teriza- } \\
\text { ción }\end{array}$} \\
\hline & & Valor & $\begin{array}{l}\text { Año del } \\
\text { dato y } \\
\text { fuente }\end{array}$ & Valor & $\begin{array}{l}\text { Año del dato y } \\
\text { fuente }\end{array}$ & \\
\hline
\end{tabular}

\section{Trabajadores}

\begin{tabular}{|c|c|c|c|c|c|c|}
\hline \multirow{2}{*}{$\begin{array}{l}\text { Libertad de asociación y } \\
\text { negociación colectiva }\end{array}$} & \multicolumn{5}{|c|}{$\begin{array}{l}\text { Se apoya adecuadamente la presencia de sindicatos dentro de la organización se y los trabajadores son libres de afiliarse a sindicatos de su } \\
\text { elección. }\end{array}$} & \multirow{2}{*}{ similar } \\
\hline & $\begin{array}{l}\text { \% de afiliados sobre el } \\
\text { total de personas } \\
\text { empleadas }\end{array}$ & Sector construcción: 10,5\%. & $\begin{array}{l}\text { 09,(Beneyto } \\
10)\end{array}$ & $27,70 \%$ & $\begin{array}{l}\text { 2014, Informe } \\
\text { RSC }\end{array}$ & \\
\hline Trabajo infantil & \multicolumn{5}{|c|}{$\begin{array}{l}\text { Aunque se han encontrado pocos indicios de trabajo infantil, no hay información precisay oficial sobre este indicador. Sin embargo, según la } \\
\text { SHDB, el riesgo en el país es bajo y no hay evidencias de trabajo infantil en los sectores de interés. }\end{array}$} & similar \\
\hline \multirow{3}{*}{ Salario justo } & \begin{tabular}{|l|} 
Desigualdad salarial \\
(salario medio en \\
comparación con el salario \\
de ejecutivos)
\end{tabular} & $\begin{array}{l}\text { El salario medio de los directivos es } \\
133,9 \% \text { mayor que el salario medio }\end{array}$ & \begin{tabular}{l|}
$2012,($ INE \\
$2014)$
\end{tabular} & $\begin{array}{l}\text { El salario de los ejecutivos es } 771 \% \\
\text { que la media de los empleados }\end{array}$ & $\begin{array}{l}\text { 2013, Informe } \\
\text { corporativo anual }\end{array}$ & $\begin{array}{l}\text { mucho } \\
\text { peor }\end{array}$ \\
\hline & Salario medio anual & $52324,67 €$ (sector provisión de energía) & $\begin{array}{l}\text { 2012,(INE } \\
2014)\end{array}$ & $23.283 €$ & $\begin{array}{l}\text { 2013, Informe } \\
\text { corporativo anual }\end{array}$ & $\begin{array}{l}\text { mucho } \\
\text { peor }\end{array}$ \\
\hline & $\begin{array}{l}\text { alario mínimo en la } \\
\text { empresa }\end{array}$ & $9.080 €$ & \begin{tabular}{|l|}
$2015,($ Real \\
Decreto \\
$1106 / 2014$ \\
$2014)$
\end{tabular} & $10.254 €$ & $\begin{array}{l}\text { 2010, Convenio } \\
\text { colectivo }\end{array}$ & mejor \\
\hline Horario laboral & Horas de trabajo anuales & $\begin{array}{l}2074,8 \text { ( } 39,9 \text { horas por semana, Sector } \\
\text { electricidad, gas y suministro de agua) }\end{array}$ & $\begin{array}{l}\text { 2010, (ILO } \\
2010)\end{array}$ & 1800 horas & $\begin{array}{l}\text { 2010, Convenio } \\
\text { colectivo }\end{array}$ & mejor \\
\hline Trabajo forzado & $\begin{array}{l}\text { Medidas contra el trabajo } \\
\text { forzado }\end{array}$ & $\begin{array}{l}\text { En España, un gran número de centros de } \\
\text { información para in migrantes están a } \\
\text { cargo de las comisiones de los } \\
\text { trabajadores y sindicatos, asesorando a los } \\
\text { migrantes sobre el trabajo, las }\end{array}$ & $\begin{array}{l}2009,(\text { ILO } \\
2009)\end{array}$ & $\begin{array}{l}\text { Empresas que presentan el } 83 \% \text { de } \\
\text { los empleados han desarrollado } \\
\text { protocolos o políticas para minimizar } \\
\text { este riesgo }\end{array}$ & $\begin{array}{l}\text { 2014, Informe } \\
\text { RSC }\end{array}$ & similar \\
\hline
\end{tabular}




\begin{tabular}{|c|c|c|c|c|c|c|}
\hline & & $\begin{array}{l}\text { regulaciones de empleo y los } \\
\text { procedimientos, proporcionando también } \\
\text { idioma y otros conocimientos prácicos } \\
\text { para inmigrantes. }\end{array}$ & & & & \\
\hline \multirow{3}{*}{$\begin{array}{l}\text { Igualdad de } \\
\text { oportunidades/Discrimin } \\
\text { ación }\end{array}$} & $\begin{array}{l}\text { Tasas de empleo de } \\
\text { personas con necesidades } \\
\text { especiales en relación con } \\
\text { el total de empleados }\end{array}$ & $\begin{array}{l}\text { 1.69\% de empleados con necesidades } \\
\text { especiales en los sectores de la industria y } \\
\text { la construcción. }\end{array}$ & $\begin{array}{l}\text { 2013, (INE } \\
\text { 2015) }\end{array}$ & $\begin{array}{l}2,3 \% \text { de empleados con necesidades } \\
\text { especiales }\end{array}$ & $\begin{array}{l}\text { 2013, Informe } \\
\text { corporativo anual }\end{array}$ & mejor \\
\hline & \begin{tabular}{|l|} 
Relación de hombres y \\
mujeres en los \\
trabajadores
\end{tabular} & $\begin{array}{l}\text { Ratio de } 6.34 \text { en los sectores de la } \\
\text { construcción y suministro de electricidad }\end{array}$ & $\begin{array}{l}\text { 2013, (INE } \\
2015)\end{array}$ & Ratio de 7.92 & $\begin{array}{l}\text { 2013, Informe } \\
\text { corporativo anual }\end{array}$ & peor \\
\hline & $\begin{array}{l}\text { Relación de hombres y } \\
\text { mujeres en los puestos } \\
\text { directivos de la empresa }\end{array}$ & Ratio de 2.75 & $\begin{array}{l}\text { 2013, (INE } \\
2015)\end{array}$ & Ratio de 22 & $\begin{array}{l}\text { 2013, Informe } \\
\text { corporativo anual }\end{array}$ & $\begin{array}{l}\text { mucho } \\
\text { peor }\end{array}$ \\
\hline \multirow{3}{*}{ Salud y seguridad } & $\begin{array}{l}\text { Programas de educación, } \\
\text { formación, asesoramiento, } \\
\text { prevención de riesgos para } \\
\text { ayudar a los trabajadores }\end{array}$ & \multicolumn{2}{|c|}{$\begin{array}{l}\text { Según el SHDB, existe alto riesgo de pérdida de años } \\
\text { de vida y muerte por exposición a carcinógenos y } \\
\text { macropartículas aerotransportadas, así como riesgo } \\
\text { muy alto de lesiones no fatales por país (también en } \\
\text { los sectores construcción y electricidad). Muy alto } \\
\text { riesgo de lesiones fatales en el sector de la } \\
\text { construcción. }\end{array}$} & $\begin{array}{l}\text { El grupo empresarial ha introducido } \\
\text { programas de educación, formación, } \\
\text { asesoramiento, y prevención y } \\
\text { control de riesgos en el lugar de } \\
\text { trabajo en el } 96,6 \% \text { de las empresas } \\
\text { integrantes. }\end{array}$ & $\begin{array}{l}\text { 2014, Informe } \\
\text { corporativo anual }\end{array}$ & mejor \\
\hline & $\begin{array}{l}\text { Presencia de una política } \\
\text { formal sobre salud y } \\
\text { seguridad }\end{array}$ & \multicolumn{2}{|c|}{$\begin{array}{l}\text { Según la SHDB existe riesgo de problemas de salud. La } \\
\text { normativa española requiere que haya comités de } \\
\text { Salud y seguridad dentro de este tipo de empresas. }\end{array}$} & $\begin{array}{l}\text { La empresa tiene comités de Salud y } \\
\text { seguridad. Está formado por los } \\
\text { delegados y representantes de la } \\
\text { empresa. Tienen reuniones regulares } \\
\text { (una por trimestre) }\end{array}$ & $\begin{array}{l}\text { 2014, Informe } \\
\text { RSC }\end{array}$ & similar \\
\hline & $\begin{array}{l}\text { Ratio de accidentes por } \\
\text { empleado }\end{array}$ & $\begin{array}{l}6011 \text { accidentes por cada millón de horas } \\
\text { trabajadas }\end{array}$ & $\begin{array}{l}\text { 2013, (ILO } \\
2013)\end{array}$ & $\begin{array}{l}\text { 4,22 accidentes por cada millón de } \\
\text { horas trabajadas }\end{array}$ & 2013, CSR report & $\begin{array}{l}\text { mucho } \\
\text { mejor }\end{array}$ \\
\hline Seguridad social & $\begin{array}{l}\text { Se provee de seguridad } \\
\text { social }\end{array}$ & \multicolumn{2}{|c|}{$\begin{array}{l}\text { La ley obliga a proveer de seguridad social a todos los } \\
\text { trabajadores. }\end{array}$} & \multicolumn{2}{|c|}{$\begin{array}{l}\text { La ley obliga a proveer de seguridad social a todos los } \\
\text { trabajadores. }\end{array}$} & \\
\hline
\end{tabular}


La Tabla 147 describe los resultados del paso de aporte de significado (caracterización y ponderado) para cada subcategoría y categoría de impacto aplicable tanto a la planta HYSOL como a la planta termosolar convencional, ya que se asume que ambas están construidas y operadas por la misma empresa.

Tabla 147 Paso de aporte de significado: Resultados de las categorías de impacto y subcategorías del análisis especifico de la planta HYSOL

\begin{tabular}{|c|c|c|c|c|c|c|}
\hline \multirow{2}{*}{ Categorías } & \multirow{2}{*}{ Subcategorías } & \multirow{2}{*}{$\begin{array}{l}\text { Categoría de actor } \\
\text { correspondiente }\end{array}$} & \multicolumn{2}{|c|}{ Fases C y D } & \multicolumn{2}{|c|}{ Fase O\&M } \\
\hline & & & $\mathrm{Ch}^{*}$ & Media & $\mathrm{Ch}^{*}$ & Media \\
\hline \multirow{7}{*}{$\begin{array}{l}\text { Derechos laborales y } \\
\text { trabajo digno }\end{array}$} & Libertad de asociación y negociación colectiva & Trabajadores & 1 & \multirow{7}{*}{0,21} & 0,50 & \multirow{7}{*}{0,16} \\
\hline & Trabajo infantil & Trabajadores & 0 & & 0 & \\
\hline & Salario justo & Trabajadores & $-0,33$ & & -1 & \\
\hline & Horario laboral & Trabajadores & 1 & & 1 & \\
\hline & Trabajo forzado & Trabajadores & 0 & & 0 & \\
\hline & Igualdad de oportunidades/Discriminación & Trabajadores & $-0,67$ & & $-0,67$ & \\
\hline & Reubicación y migración & Comunidad local & 0 & & 0 & \\
\hline \multirow{4}{*}{ Salud y seguridad } & Salud y seguridad & Trabajadores & 1 & \multirow{4}{*}{0,25} & 1 & \multirow{4}{*}{0,25} \\
\hline & Seguridad social & Trabajadores & 0 & & 0 & \\
\hline & Condiciones de vida seguras y salubres & Comunidad local & 0 & & 0 & \\
\hline & Condiciones de vivienda segura & Comunidad local & 0 & & 0 & \\
\hline \multirow{5}{*}{$\begin{array}{l}\text { Patrimonio cultural y } \\
\text { natural }\end{array}$} & Acceso a recursos materiales & Comunidad local & 0 & \multirow{5}{*}{0} & 0 & \multirow{5}{*}{0} \\
\hline & Patrimonio cultural & Comunidad local & 0 & & 0 & \\
\hline & Respeto a los derechos indígenas & Comunidad local & 0 & & 0 & \\
\hline & Prevención y mitigación de conflictos armados & Sociedad & 0 & & 0 & \\
\hline & Acceso a recursos inmateriales & Comunidad local & 0 & & 0 & \\
\hline \multirow{5}{*}{ Relaciones justas } & Corrupción & Sociedad & -1 & \multirow{5}{*}{0,29} & -1 & \multirow{5}{*}{0,29} \\
\hline & Competencia leal & Actores de la cadena de valor & -1 & & -1 & \\
\hline & Relaciones con proveedores & Actores de la cadena de valor & 1 & & 1 & \\
\hline & Respeto a la propiedad intelectual & Actores de la cadena de valor & 0 & & 0 & \\
\hline & Promoción de la responsabilidad social & Actores de la cadena de valor & 1 & & 1 & \\
\hline
\end{tabular}




\begin{tabular}{|c|c|c|c|c|c|c|}
\hline & Compromiso público con la sostenibilidad & Sociedad & 2 & & 2 & \\
\hline & Compromiso con la comunidad & Comunidad local & 0 & & 0 & \\
\hline \multirow{4}{*}{$\begin{array}{l}\text { Sostenibilidad socio- } \\
\text { económica }\end{array}$} & Empleo local & Comunidad local & 1 & \multirow{4}{*}{1,38} & 1 & \multirow{4}{*}{1,38} \\
\hline & Contribución al desarrollo económico & Sociedad & 2 & & 2 & \\
\hline & Desarrollo tecnológico & Sociedad & 0,5 & & 0,5 & \\
\hline & Utilidad social del producto & Sociedad & 2 & & 2 & \\
\hline
\end{tabular}

${ }^{*} \mathrm{Ch}=$ Caracterización 